Portland State University

PDXScholar

Winter 4-2-2018

\title{
The Preparation of Diaryliodonium Salts for Application in Arylation Chemistry
}

Thomas Ludwig Seidl

Portland State University

Follow this and additional works at: https://pdxscholar.library.pdx.edu/open_access_etds

Part of the Chemistry Commons

Let us know how access to this document benefits you.

\section{Recommended Citation}

Seidl, Thomas Ludwig, "The Preparation of Diaryliodonium Salts for Application in Arylation Chemistry" (2018). Dissertations and Theses. Paper 4238.

https://doi.org/10.15760/etd.6122

This Dissertation is brought to you for free and open access. It has been accepted for inclusion in Dissertations and Theses by an authorized administrator of PDXScholar. Please contact us if we can make this document more accessible: pdxscholar@pdx.edu. 
The Preparation of Diaryliodonium Salts for Application in Arylation Chemistry

by

Thomas Ludwig Seidl

A dissertation submitted in partial fulfillment of the requirements for the degree of

Doctor of Philosophy

in

Chemistry

\author{
Dissertation Committee: \\ David R. Stuart, Chair \\ David Peyton \\ Robert Strongin \\ Erik Sanchez
}

Portland State University

2018 
(C) 2017 Thomas Ludwig Seidl 


\begin{abstract}
Diaryliodonium salts offer potential as novel reagents for arylation chemistry. An overall goal and successful outcome of this work has been to further understanding of diaryliodonium salt chemistry by developing practical methods that enable chemists more convenient access to these reagents, for the purpose of reaction development. To this end a robust and convenient preparation method has been developed and resulted in novel commercially available diaryliodonium salts. The remainder of the work described, has focused on understanding the parameters important to diaryliodonium mediated arylation and has resulted in a solid framework that multiple future development efforts can build upon.
\end{abstract}

A strategy adopted throughout this work was to use multivariate methodologies such as Design of Experiments (DoE). Applicable chapters show the results of optimization studies that were carried out using DoE, during the course of this work. Additionally, the desire to further realize the potential that DoE has to offer inspired of a search for parameters to study fundamental reactivity. Chapter 2 details the development of a practical diaryliodonium salt synthesis that is convenient, facile, and economical. A detailed procedure is also included and was drafted to the requirements for publication in the journal Organic Synthesis. Finally, limitations and future directions of the method are discussed. Chapter 3 describes studies aimed at understanding the role of the counter anion; a very practical counter anion screening method is presented. Future directions are discussed and include detailed characterization of diaryliodonium salts by NMR. Chapter 3 also describes a practical, scalable, and rapid salt exchange method 
developed during this work. Chapter 4 describes the results obtained in studying an azidation reaction via solubility parameters. All Supporting Information, including characterization data and experimental details, are provided in Chapter 5. 


\section{Dedication}

To my wife and parents who have supported me on this exciting and informative path towards a doctorate.

I'm a lucky man... and the more I practice and work at things the luckier I get!

- adapted from Efren Reyes 


\section{Acknowledgments}

My sincere thanks go to Dr. David Stuart for welcoming me into his new group. I am honored to be among his first doctoral students. I will always value Dr. Stuart for being invested in and advocating for his students, for patiently allowing his students to develop as chemists and for maintaining high standards, without apparent judgement of students' mistakes. Thanks also to Dr. McCormick, Dr. Peyton and Dr. Sanchez, who benefited my studies by sharing their knowledge and experience. Special thanks to Dr. Strongin for his openness and kind support throughout my doctoral program.

My special thanks go to:

Dr. Kenneth Ward for his support and encouragement. Thank you Ken, for providing me the unexcpected opportunity to embark on a new adventure in R\&D. I am honored, delighted and eager to find out what lies ahead.

Stephan Kaplan, to whom I am indebted for his mentoring in science, management and life. You have been a tremendous influence on me and I am grateful for all that you have done.

Dr. Dan Kaplan for a decade of friendship, always being available to listen, consult, advise, discuss and proof read.

Dr. Katherine Liebman for her help in testing out the procedure developed in Chapter 2. Dan Kaplan, Capri Price and Dr. Ludwig and Rosemarie Seidl, for your efforts in proofreading this document. Lee and Stacey Gardner for contributing the dictation software that saved me hours while writing this document. 
The senior students and established researchers at PSU. You explained the ins and outs of the program.

My labmates and all friends I have met along the way.

Brennen, Florian and Justin, for being hard working and eager to learn. Thank you for your diligence.

My son and daughter, Quinn and Vida, for brightening my life! Quinn, thank you for providing enough wonderful drawings to help block out glare from the distracting world outside the lab. 
Table of Contents

Abstract

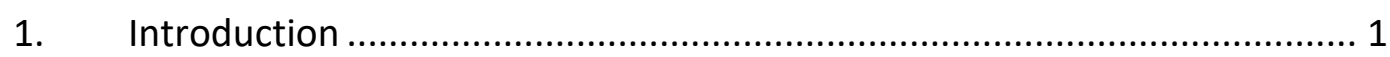

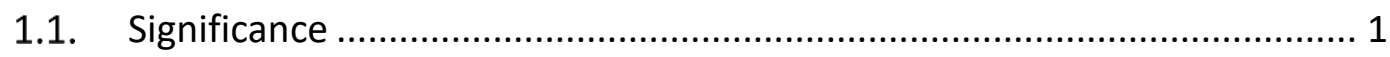

1.2. The status of contemporary arylation ............................................ 3

1.3. Diaryliodonium salts as arylation reagents ...................................... 5

1.4. Historical overview of diaryliodonium salts ..................................... 6

1.5. Overview of diaryliodonium salt structure and reactivity ...................... 7

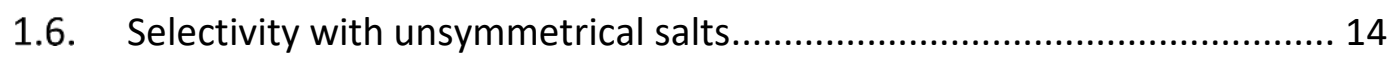

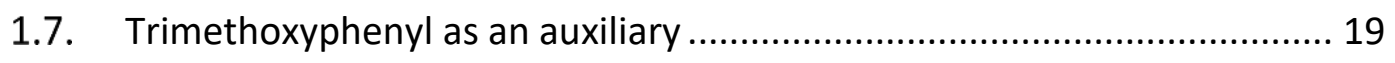

1.8. Overview of the preparation of diaryliodonium salts ........................... 20

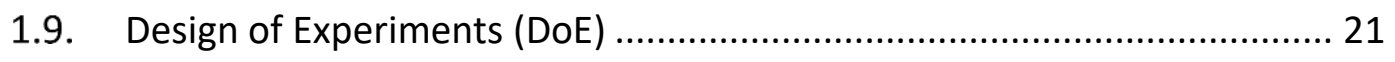

2. Developing the synthesis of aryl(TMP)iodonium tosylate...................... 26

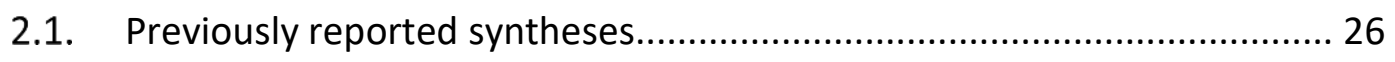

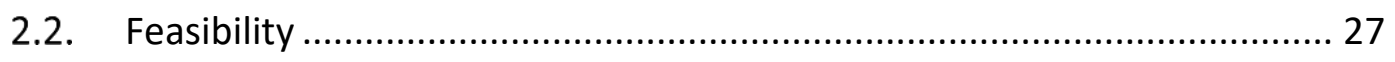


2.3. Optimization Details

2.3.1. Assessment of main effects of 5 factors under study

2.3.2. Full Factorial to assess interaction effects of $A, B, C, D$

2.3.3. Optimization via a Response Surface Model (RSM) 40

2.3.4. Conclusion

2.3.5. Stability Studies

2.4. Applications 46

2.5. Preparation of (4-methylbenzoate) $\left(2^{\prime}, 4^{\prime}, 6^{\prime}\right.$-trimethoxyphenyl)iodonium tosylate. 48

2.6. Future directions: Aryl(TMB)iodonium tosylates ............................... 54

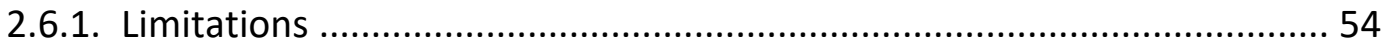

2.6.2. Bronsted acid-free preparation of aryl(TMB)iodonium tosylate.............. 57

3. An admix approach to determine the effect of the counter anion on

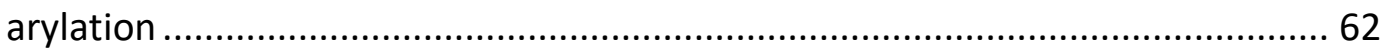

3.1. Introduction to the counter anion and its significance ..........................62 62

3.2. Feasibility of counter anion screening by the admix method ..................6 65

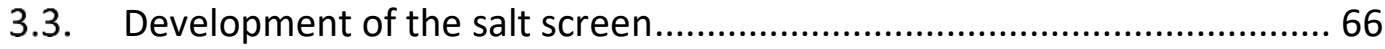

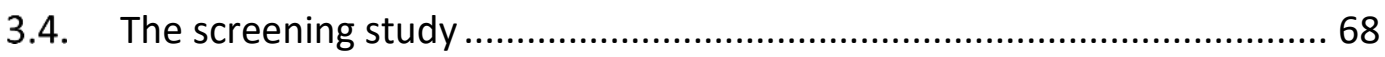

3.5. Comparison of pre-exchanged and admixed azidation ...........................69 
3.6. Scope of the screening method

3.7. Optimization and some azidation examples......................................... 73

3.8. Discussion of unexpected $\mathrm{BF}_{4}$ and OTf doping results.......................... 76

3.9. Spectator salt or in-situ anion exchange?.......................................... 81

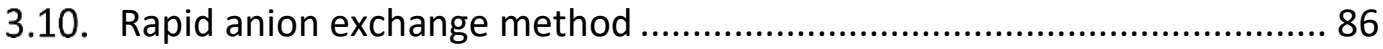

4. Details on solvent selection: use of Hansen Solubility Parameters .......... 90

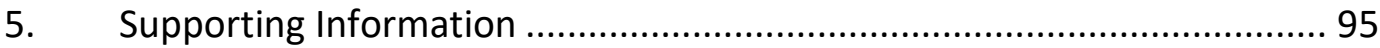

5.1. General information for all Supporting Information herein..................... 95

5.2. Supporting Information for Chapter 2 ............................................... 97

5.2.1. General procedure for the synthesis of aryl(TMB)iodonium tosylates ..... 97

5.2.2. Characterization data for aryl(TMB)Iodonium tosylates ......................... 97

5.2.3. General procedure for anion exchange of aryl(TMB)iodonium tosylates...... 106

5.2.4. Characterization data for anion exchanged aryl(TMB)iodonium salts.... 107

5.2.5. Representative procedure for one-pot preparation of aryl(TMB)iodonium bromides 109

5.2.6. Characterization data of aryl(TMB)iodonium bromides 110

5.2.7. Preparation of compounds in Applications section 110

5.2.8. Qualitative Stability Study 112 
5.2.9. NMR spectra for aryl(TMB)iodonium tosylates

5.3. Supporting Information for Chapter 3

5.3.1. Procedure A: Synthesis of aryl(TMP)iodonium tosylates ${ }^{2}$

5.3.2. Procedure $B$ : Anion exchange of aryl(TMP)iodonium tosylates ${ }^{2}$ 165

5.3.3. Procedure C: Aryl(TMP)iodonium bromides to acetate exchange..... 166

5.3.4. Determination of $G C$ response factors for $2 a$ and $2 b$. 167

5.3.5. Procedure D: Aryl azidation with pre-exchanged diaryliodonium salts .. 168

5.3.6. Procedure E: Aryl azidation of aryl(TMP)iodonium tosylates with a dope salt. 168

5.3.7. Screening Table: Corrected GC-MS yields ( 2 equiv. $\mathrm{NaN}_{3}, 50{ }^{\circ} \mathrm{C}, 2$ hours) .... 169

5.3.8. Raw (uncorrected) GC-MS data for recapitulation of literature screening.... 169

5.3.9. Characterization data. 170

5.3.10. NMR spectra for aryl(TMP)iodonium tosylates 175

5.3.11. References for Chapter 3 193

References 197 


\section{LIST of TABLES}

Table 1. Summary of Placket-Burman design .............................................. 32

Table 2. Contribution of factors, interactions and curvature to yield................. 33

Table 3. Summary of full factorial design ..................................................... 34

Table 4. Regression analysis of factorial study .......................................... 34

Table 5. Evaluation of overall Factorial Model (Design Expert).......................... 35

Table 6. Factors selected as model terms based on ANOVA and corresponding

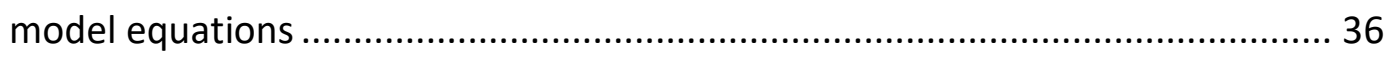

Table 7. Factors selected as RSM model terms ......................................... 40

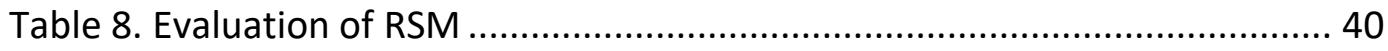

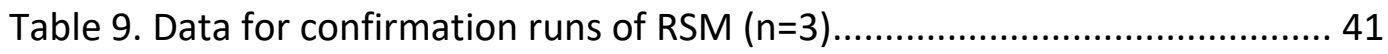

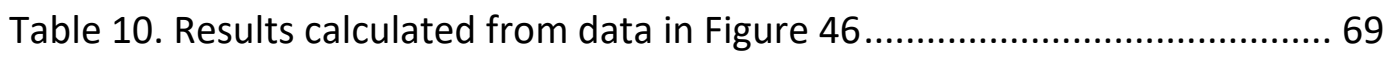

Table 11. Solvent screening for aryl azidation using HSP and fractional HSP ...... 91

Table 12. The coordinates for the vertices of the area of maximum yield .......... 93

Table 13. Determination of GC response factors for $2 \mathrm{a}$ and $2 \mathrm{~b} . \ldots \ldots \ldots \ldots \ldots \ldots \ldots . . . . . . . . . . .167$

Table 14. Screening Table: Corrected GC-MS yields..................................... 169 


\section{LIST of FIGURES}

Figure 1. Applications of molecules containing aromatic moieties

Figure 2. Late stage use of TMC. Metal content is contrasted with regulatory limits

Figure 3. General structures of commonly encountered hypervalent iodine....... 9

Figure 4. The T-Shape structure of crystalline diaryliodonium salt .................... 10

Figure 5. Structural features of the Ar2IX configuration ................................. 11

Figure 6. Ochiai determined that the I-Ph behaved as a hypernucleofuge.......... 12

Figure 7. Three common modes of diaryliodonium salt reactivity.................... 13

Figure 8. The putative mechanism for the ionic, 2-electron coupling pathway... 13

Figure 9. Pseudorotation isomerizes aryl groups between axial and equatorial

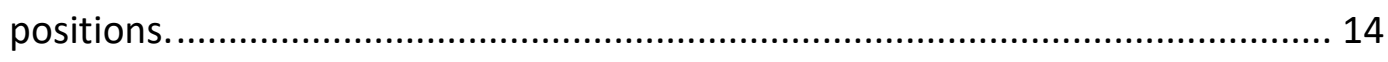

Figure 10. Anatomy of symmetrical and unsymmetrical iodonium salts............ 15

Figure 11. Hypothetical late stage functionalization of Flubendiamide.............. 16

Figure 12. The difference in the transition state of the pseudorotated isomers......

Figure 13. Togni's computational work shows the relative transition state energy is consistent with the criteria for Curtain-Hammet kinetics ............................... 18

Figure 14. Assymmetric diaryliodonium salt configuration .............................. 20

Figure 15. Common routes to prepare diaryliodonium salts ........................... 21

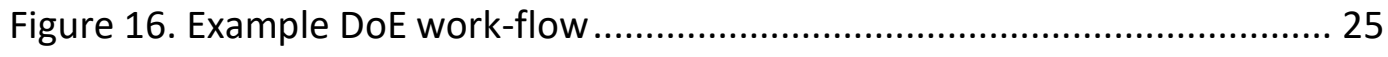


Figure 17. a) Previously reported route to TMP containing diaryliodonium salts; b)

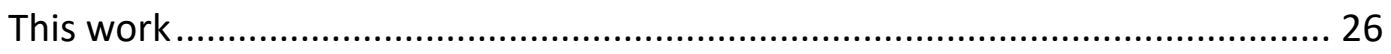

Figure 18. Application of aryl(TMP)iodonium salts ....................................... 27

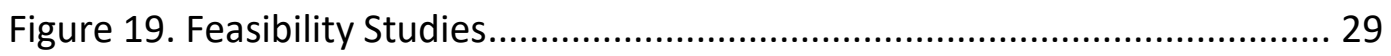

Figure 20. Reaction used for optimization............................................. 30

Figure 21 . Reaction used for optimization............................................. 31

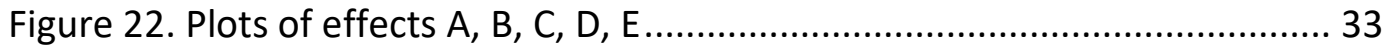

Figure 23. A) 3D-plot of factorial response at $\mathrm{T}=77^{\circ} \mathrm{C}$, Stage $2=5 \mathrm{~min}$, B) illustration of temperature/concentration interaction ............................................ 37

Figure 24. A) 3D-plot of factorial response at Time1 $=30 \mathrm{~min}$, Time2 $=5 \mathrm{~min}, \mathrm{~B}$ ) illustration of concentration/Time 1 interaction .......................................... 38

Figure 25. A) 3D-plot of factorial response at conc. $=1 \mathrm{M}$, Stage $2=5 \mathrm{~min}, \mathrm{~B}$ )

illustration of temperature/Time 1 interaction ........................................... 39

Figure 26. Results of optimization. The model shown has predictive value ........ 41

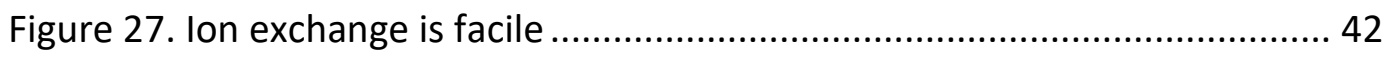

Figure 28. Scope of the preparation of aryl(TMP)iodonium tosylates ................ 43

Figure 29. Light and thermal stability studies........................................... 44

Figure 30 . Shot glass diaryliodonium synthesis .......................................... 46

Figure 31. Internal reaction temperature profiles......................................... 45

Figure 32. Synthetic examples using aryl(TMB)iodonium salts ........................ 46

Figure 33. Synthesis of the title compound ............................................... 48

Figure 34. A) reaction set-up; B) addition of reagents; C) formation of slurry .... 49 
Figure 35. A) reaction color observed after addition of TMB; B) reaction color observed after cooling reaction; C) precipitated product after trituration ......... 50 Figure 36. A) isolation of 1 by suction filtration; B) filter cake after rinsing and resuspending in diethyl ether; C) final product

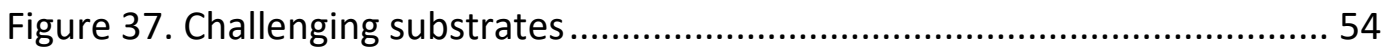

Figure 38. Example of reactive ortho-positioned substrates that give unexpected products 55

Figure 39. a) aryl(TMP)iodonium tosylate under basic conditions. b) feasibility trials 58

Figure 40. Hypothetical catalytic cycle including acid free oxidation of aryliodides. 60

Figure 41. Concept for a catalytic cycle under basic conditions 61 Figure 42. Counter anion use in diaryliodonium mediated arylation according to forty-two reports between 2011 and 2016 63 Figure 43. a) 1,1,3,3-Tetratriflylpropene (TTP) developed by List et al. b) Example of a diaryliodonium salt that is liquid at room temperature. 64 Figure 44. a) traditional salt screening, b) This work: counter anion screening by ad-mixing salt 66 Figure 45. Azide arylation was used to test salt screening.... 67 Figure 46. Salt screening method and results 68 Figure 47. Comparison of azidation yields and pre-exchanged diaryliodonium salts, and pre-exchanged diaryliodonium salts admixed with common anion. 71 
Figure 48. Salt doped reactions recapitulate literature results of pre-exchanged salts

Figure 49. Optimization of the aryl azidation reaction 73

Figure 50. Optimization of azidation. Contour plot with confirmation runs ....... 75

Figure 51. Representative scope of aryl azide compounds synthesized ............. 76

Figure 52. Proposed processes that could limit availability of diaryliodonium salts for reaction even when in solution 78

Figure 53. Azidation yield as a function of the amount of dope salt added ........ 79 Figure 54. Azidation yield as a function of the amount of dope salt added ........ 79 Figure 55. Azidation yield is plotted as a function of the amount of dope salt added 80

Figure 56. Yield is plotted as a function of the ratio tosylate to azide as both are varied 80

Figure 57. Diaryliodonium salts with Mesityl (Mes) and TMP auxiliaries..... 81 Figure 58. A) ${ }^{13} \mathrm{C}$ NMR Peak assignments for TMP salt B) added tetrabutyl ammonium chloride shifts the ipso-carbon peak towards the location of the neat iodonium chloride salt. $(\mathrm{aux}=\mathrm{TMP})$ 82 Figure 59. A) ${ }^{13} \mathrm{C}$ NMR Peak assigments for Mes salt B) added tetrabutyl ammonium chloride shifts the ipso-carbon peak towards the location of the neat iodonium chloride salt. (aux = Mes) 83 Figure 60. Ipso-carbon shift of TMP-I bond. The same trends were observed with the mesityline auxiliary. 85 
Figure 61. Anion exchange from tosylate

Figure 62. Ion exchange columns are fast, scalable and reusable 86

Figure 63. Scope of currently tested salts exchanged using the elution method .....

Figure 64. Feasibility study for re-use of anion exchange cartridge...... 88

Figure 65. Solvent effect on azidation of 4-tertbutyl iodobenzene. Ternary contour plots of yield vs. Hansen Solubility Parameters, using unoptimized reaction conditions 92

Figure 66. Solvent effect on azidation of 4-methyl iodobenzoate. Ternary contour plots of yield vs. Hansen Solubility Parameters, using unoptimized reaction conditions. 93

Figure 67. Qualitative stability study 112

Figure $68 .{ }^{1} \mathrm{H}$ NMR spectrum of 6 at $400 \mathrm{MHz}$ in $\mathrm{CDCl}_{3}$ at $298 \mathrm{~K}$. 113

Figure $69 .{ }^{13} \mathrm{C}$ NMR spectrum of 6 at $101 \mathrm{MHz}$ in $\mathrm{CDCl}_{3}$ at $298 \mathrm{~K}$ 113

Figure $70 .{ }^{1} \mathrm{H}$ NMR spectrum of 11 at $400 \mathrm{MHz}$ in DMSO-d $\mathrm{d}_{6}$ at $298 \mathrm{~K}$ 114

Figure $71 .{ }^{13} \mathrm{C}$ NMR spectrum of 11 at $101 \mathrm{MHz}$ in DMSO-d 6 at $298 \mathrm{~K}$ 114

Figure $72 .{ }^{1} \mathrm{H}$ NMR spectrum of 12 at $400 \mathrm{MHz}$ in DMSO-d 6 at $298 \mathrm{~K}$ 115

Figure $73 .{ }^{13} \mathrm{C}$ NMR spectrum of 12 at $101 \mathrm{MHz}$ in DMSO-d $\mathrm{d}_{6}$ at $298 \mathrm{~K}$ 115

Figure 74. ${ }^{1} \mathrm{H}$ NMR spectrum of 13 at $400 \mathrm{MHz}$ in DMSO-d 6 at $298 \mathrm{~K}$ 116

Figure $75 .{ }^{13} \mathrm{C}$ NMR spectrum of 13 at $101 \mathrm{MHz}$ in DMSO-d 6 at $298 \mathrm{~K}$. 116

Figure 76. ${ }^{1} \mathrm{H}$ NMR spectrum of 14 at $400 \mathrm{MHz}$ in DMSO-d 6 at $298 \mathrm{~K}$. 117

Figure $77 .{ }^{13} \mathrm{C}$ NMR spectrum of 14 at $101 \mathrm{MHz}$ in DMSO-d 6 at $298 \mathrm{~K}$ 117 
Figure 78. ${ }^{1} \mathrm{H}$ NMR spectrum of 15 at $400 \mathrm{MHz}$ in DMSO-d 6 at $298 \mathrm{~K} \ldots \ldots \ldots \ldots . . . . .118$

Figure 79. ${ }^{13} \mathrm{C}$ NMR spectrum of 15 at $101 \mathrm{MHz}$ in DMSO-d 6 at $298 \mathrm{~K} \ldots \ldots \ldots . . . .118$

Figure 80. ${ }^{1} \mathrm{H}$ NMR spectrum of 16 at $400 \mathrm{MHz}$ in DMSO-d 6 at $298 \mathrm{~K} \ldots \ldots \ldots \ldots . . . . .119$

Figure $81 .{ }^{13} \mathrm{C}$ NMR spectrum of 16 at $101 \mathrm{MHz}$ in DMSO-d 6 at $298 \mathrm{~K} \ldots \ldots \ldots . . . .119$

Figure 82. ${ }^{1} \mathrm{H}$ NMR spectrum of 17 at $400 \mathrm{MHz}$ in DMSO-d 6 at $298 \mathrm{~K} \ldots \ldots \ldots \ldots . . . . .120$

Figure $83 .{ }^{13} \mathrm{C}$ NMR spectrum of 17 at $101 \mathrm{MHz}$ in DMSO-d 6 at $298 \mathrm{~K} \ldots \ldots \ldots . . . .120$

Figure 84. ${ }^{1} \mathrm{H}$ NMR spectrum of 18 at $400 \mathrm{MHz}$ in DMSO-d 6 at $298 \mathrm{~K} \ldots \ldots \ldots \ldots . . . . .121$

Figure $85 .{ }^{13} \mathrm{C}$ NMR spectrum of 18 at $101 \mathrm{MHz}$ in DMSO-d 6 at $298 \mathrm{~K} \ldots \ldots \ldots \ldots . . . .121$

Figure 86. ${ }^{1} \mathrm{H}$ NMR spectrum of 19 at $400 \mathrm{MHz}$ in DMSO-d 6 at $298 \mathrm{~K} . . . . . . . . . . . .122$

Figure $87 .{ }^{13} \mathrm{C}$ NMR spectrum of 19 at $101 \mathrm{MHz}$ in DMSO-d 6 at $298 \mathrm{~K} \ldots \ldots \ldots . . . .122$

Figure 88. ${ }^{1} \mathrm{H}$ NMR spectrum of $19-\mathrm{Br}$ at $400 \mathrm{MHz}$ in DMSO-d ${ }_{6}$ at $298 \mathrm{~K} \ldots \ldots . . .123$

Figure 89. ${ }^{13} \mathrm{C}$ NMR spectrum of $19-\mathrm{Br}$ at $101 \mathrm{MHz}$ in $\mathrm{DMSO}-\mathrm{d}_{6}$ at $298 \mathrm{~K} \ldots \ldots . .123$

Figure 90. ${ }^{1} \mathrm{H}$ NMR spectrum of 19-I at $400 \mathrm{MHz}$ in DMSO-d 6 at 298K.......... 124

Figure $91 .{ }^{13} \mathrm{C}$ NMR spectrum of 19-I at $101 \mathrm{MHz}$ in DMSO-d 6 at 298K ........ 124

Figure 92. ${ }^{1} \mathrm{H}$ NMR spectrum of $19-\mathrm{CF}_{3} \mathrm{COO}$ at $400 \mathrm{MHz}$ in DMSO-d $\mathrm{d}_{6}$ at $298 \mathrm{~K} \ldots .$. 125

Figure $93 .{ }^{13} \mathrm{C}$ NMR spectrum of $19-\mathrm{CF}_{3} \mathrm{COO}$ at $101 \mathrm{MHz}$ in DMSO-d 6 at $298 \mathrm{~K} \ldots$ 125

Figure $94 .{ }^{19} \mathrm{~F}$ NMR spectrum of $19-\mathrm{CF}_{3} \mathrm{COO}$ at $376 \mathrm{MHz}$ in DMSO-d 6 at $298 \mathrm{~K} \ldots .$. 126

Figure 95. ${ }^{1} \mathrm{H}$ NMR spectrum of 19-OTf at $400 \mathrm{MHz}$ in DMSO-d 6 at 298K ..... 126

Figure $96 .{ }^{13} \mathrm{C}$ NMR spectrum of $19-\mathrm{OTf}$ at $101 \mathrm{MHz}$ in DMSO-d 6 at $298 \mathrm{~K} \ldots . .127$

xvi 
Figure $97 .{ }^{19} \mathrm{~F}$ NMR spectrum of 19-OTf at $376 \mathrm{MHz}$ in DMSO-d 6 at $298 \mathrm{~K} \ldots . .127$

Figure 98. ${ }^{1} \mathrm{H}$ NMR spectrum of $19-\mathrm{PF}_{6}$ at $400 \mathrm{MHz}$ in DMSO-d 6 at $298 \mathrm{~K} \ldots . . .128$

Figure $99 .{ }^{13} \mathrm{C}$ NMR spectrum of $19-\mathrm{PF}_{6}$ at $101 \mathrm{MHz}$ in $\mathrm{DMSO}-\mathrm{d}_{6}$ at $298 \mathrm{~K} \ldots \ldots . . .128$

Figure 100. ${ }^{19} \mathrm{~F}$ NMR spectrum of $19-\mathrm{PF}_{6}$ at $376 \mathrm{MHz}$ in DMSO-d 6 at $298 \mathrm{~K} \ldots 129$

Figure 101. ${ }^{1} \mathrm{H}$ NMR spectrum of $19-\mathrm{BF}_{4}$ at $400 \mathrm{MHz}$ in DMSO-d 6 at $298 \mathrm{~K} \ldots 129$

Figure $102 .{ }^{13} \mathrm{C}$ NMR spectrum of $19-\mathrm{BF}_{4}$ at $101 \mathrm{MHz}$ in DMSO-d 6 at $298 \mathrm{~K} . . .130$

Figure 103. ${ }^{19} \mathrm{~F}$ NMR spectrum of $19-\mathrm{BF}_{4}$ at $376 \mathrm{MHz}$ in DMSO-d 6 at $298 \mathrm{~K} \ldots 130$

Figure $104 .{ }^{1} \mathrm{H}$ NMR spectrum of 20 at $400 \mathrm{MHz}$ in DMSO-d $\mathrm{d}_{6}$ at $298 \mathrm{~K} \ldots \ldots \ldots . . . . .131$

Figure $105 .{ }^{13} \mathrm{C}$ NMR spectrum of 20 at $101 \mathrm{MHz}$ in DMSO-d 6 at $298 \mathrm{~K} \ldots \ldots \ldots . . .131$

Figure 106. ${ }^{1} \mathrm{H}$ NMR spectrum of 21 at $400 \mathrm{MHz}$ in DMSO-d 6 at $298 \mathrm{~K} \ldots \ldots \ldots . . . . .132$

Figure 107. ${ }^{13} \mathrm{C}$ NMR spectrum of 21 at $101 \mathrm{MHz}$ in DMSO-d 6 at $298 \mathrm{~K} \ldots \ldots \ldots . . .132$

Figure 108. ${ }^{19} \mathrm{~F}$ NMR spectrum of 21 at $376 \mathrm{MHz}$ in DMSO-d 6 at $298 \mathrm{~K} \ldots \ldots \ldots . . . .133$

Figure 109. ${ }^{1} \mathrm{H}$ NMR spectrum of 22 at $400 \mathrm{MHz}$ in DMSO-d 6 at $298 \mathrm{~K} \ldots \ldots \ldots . . . . .133$

Figure $110 .{ }^{13} \mathrm{C}$ NMR spectrum of 22 at $101 \mathrm{MHz}$ in DMSO-d 6 at $298 \mathrm{~K} \ldots \ldots \ldots . . .134$

Figure $111 .{ }^{1} \mathrm{H}$ NMR spectrum of 24 at $400 \mathrm{MHz}$ in DMSO-d $\mathrm{d}_{6}$ at $298 \mathrm{~K} . . . \ldots \ldots \ldots . . . . .134$

Figure $112 .{ }^{13} \mathrm{C}$ NMR spectrum of 24 at $101 \mathrm{MHz}$ in DMSO-d 6 at $298 \mathrm{~K} \ldots \ldots \ldots . . .135$

Figure 113. ${ }^{19} \mathrm{~F}$ NMR spectrum of 24 at $376 \mathrm{MHz}$ in DMSO-d 6 at $298 \mathrm{~K} . . . \ldots \ldots . . . .135$

Figure 114. ${ }^{1} \mathrm{H}$ NMR spectrum of 25 at $400 \mathrm{MHz}$ in DMSO-d 6 at $298 \mathrm{~K} \ldots \ldots \ldots . . . . .136$

Figure $115 .{ }^{13} \mathrm{C}$ NMR spectrum of 25 at $101 \mathrm{MHz}$ in DMSO-d 6 at $298 \mathrm{~K} \ldots \ldots \ldots . . .136$

Figure 116. ${ }^{1} \mathrm{H}$ NMR spectrum of 26 at $400 \mathrm{MHz}$ in DMSO-d $\mathrm{d}_{6}$ at $298 \mathrm{~K} \ldots \ldots \ldots . . . . .137$

Figure $117 .{ }^{13} \mathrm{C}$ NMR spectrum of 26 at $101 \mathrm{MHz}$ in DMSO-d 6 at $298 \mathrm{~K} \ldots \ldots \ldots . . .137$

Figure 118. . ${ }^{1} \mathrm{H}$ NMR spectrum of 27 at $400 \mathrm{MHz}$ in DMSO-d 6 at $298 \mathrm{~K} \ldots \ldots \ldots . . . .138$

xvii 
Figure 119. ${ }^{13} \mathrm{C}$ NMR spectrum of 27 at $101 \mathrm{MHz}$ in DMSO-d 6 at $298 \mathrm{~K} \ldots \ldots \ldots . . .138$

Figure 120. ${ }^{1} \mathrm{H}$ NMR spectrum of 28 at $400 \mathrm{MHz}$ in DMSO-d 6 at $298 \mathrm{~K} \ldots \ldots \ldots . . . . .139$

Figure $121 .{ }^{13} \mathrm{C}$ NMR spectrum of 28 at $101 \mathrm{MHz}$ in $\mathrm{DMSO}_{-} \mathrm{d}_{6}$ at $298 \mathrm{~K} \ldots \ldots \ldots . . .139$

Figure $122 .{ }^{19} \mathrm{~F}$ NMR spectrum of 28 at $376 \mathrm{MHz}$ in DMSO-d 6 at $298 \mathrm{~K} \ldots \ldots \ldots . . . .140$

Figure 123. ${ }^{1} \mathrm{H}$ NMR spectrum of $28-\mathrm{PF}_{6}$ at $600 \mathrm{MHz}$ in DMSO-d 6 at $298 \mathrm{~K} \ldots . .140$

Figure $124 .{ }^{13} \mathrm{C}$ NMR spectrum of $28-\mathrm{PF}_{6}$ at $101 \mathrm{MHz}$ in DMSO-d 6 at 298K ... 141

Figure $125 .{ }^{19} \mathrm{~F}$ NMR spectrum of $28-\mathrm{PF}_{6}$ at $376 \mathrm{MHz}$ in DMSO-d 6 at $298 \mathrm{~K} \ldots . .141$

Figure 126. ${ }^{1} \mathrm{H}$ NMR spectrum of 29 at $400 \mathrm{MHz}$ in DMSO-d $\mathrm{d}_{6}$ at $298 \mathrm{~K} \ldots \ldots \ldots . . . . .142$

Figure $127 .{ }^{13} \mathrm{C}$ NMR spectrum of 29 at $101 \mathrm{MHz}$ in DMSO-d 6 at $298 \mathrm{~K} \ldots \ldots \ldots . . .142$

Figure 128. ${ }^{19} \mathrm{~F}$ NMR spectrum of 29 at $376 \mathrm{MHz}$ in DMSO-d 6 at $298 \mathrm{~K} . . . . . . . . .143$

Figure 129. ${ }^{1} \mathrm{H}$ NMR spectrum of precursor for 29 at $400 \mathrm{MHz}$ in $\mathrm{CDCl}_{3}$ at $298 \mathrm{~K}$..

143

Figure $130 .{ }^{13} \mathrm{C}$ NMR spectrum of precursor for 29 at $101 \mathrm{MHz}$ in $\mathrm{CDCl}_{3}$ at $298 \mathrm{~K}$.

Figure $131 .{ }^{19} \mathrm{~F}$ NMR spectrum of precursor for 29 at $376 \mathrm{MHz}$ in $\mathrm{CDCl}_{3}$ at $298 \mathrm{~K}$. 144

Figure 132. ${ }^{1} \mathrm{H}$ NMR spectrum of 30 at $400 \mathrm{MHz}$ in DMSO-d 6 at $298 \mathrm{~K} \ldots \ldots \ldots . . . . .145$

Figure 133. ${ }^{13} \mathrm{C}$ NMR spectrum of 30 at $101 \mathrm{MHz}$ in DMSO-d 6 at $298 \mathrm{~K} . . . \ldots . . . .145$

Figure 134. ${ }^{1} \mathrm{H}$ NMR spectrum of precursor for 30 at $400 \mathrm{MHz}$ in $\mathrm{CDCl}_{3}$ at $298 \mathrm{~K}$.. 146

Figure $135 .{ }^{13} \mathrm{C}$ NMR spectrum of precursor for 30 at $101 \mathrm{MHz}$ in $\mathrm{CDCl}_{3}$ at $298 \mathrm{~K}$. 
Figure $136 .{ }^{1} \mathrm{H}$ NMR spectrum of 31 at $400 \mathrm{MHz}$ in DMSO-d 6 at $298 \mathrm{~K}$. 147

Figure 137. ${ }^{13} \mathrm{C}$ NMR spectrum of 31 at $101 \mathrm{MHz}$ in DMSO-d 6 at $298 \mathrm{~K}$ 147

Figure 138. ${ }^{19} \mathrm{~F}$ NMR spectrum of 31 at $376 \mathrm{MHz}$ in DMSO-d $\mathrm{d}_{6}$ at $298 \mathrm{~K}$ 148

Figure 139. ${ }^{1} \mathrm{H}$ NMR spectrum of 32 at $400 \mathrm{MHz}$ in DMSO-d 6 at $298 \mathrm{~K}$. 148

Figure 140. ${ }^{13} \mathrm{C}$ NMR spectrum of 32 at $101 \mathrm{MHz}$ in DMSO-d 6 at $298 \mathrm{~K}$. 149

Figure 141. ${ }^{1} \mathrm{H}$ NMR spectrum of $32-\mathrm{Br}$ at $400 \mathrm{MHz}$ in DMSO-d 6 at $298 \mathrm{~K} \ldots . . .149$

Figure $142 .{ }^{13} \mathrm{C}$ NMR spectrum of $32-\mathrm{Br}$ at $101 \mathrm{MHz}$ in DMSO-d 6 at $298 \mathrm{~K} \ldots . .150$

Figure 143. ${ }^{1} \mathrm{H}$ NMR spectrum of 33 at $400 \mathrm{MHz}$ in DMSO-d $\mathrm{d}_{6}$ at $298 \mathrm{~K} \ldots \ldots \ldots . . . . .150$

Figure $144 .{ }^{13} \mathrm{C}$ NMR spectrum of 33 at $101 \mathrm{MHz}$ in DMSO-d 6 at 298K .......... 151

Figure 145. ${ }^{1} \mathrm{H}$ NMR spectrum of 34 at $400 \mathrm{MHz}$ in DMSO-d 6 at 298K............ 151

Figure 146. ${ }^{13} \mathrm{C}$ NMR spectrum of 34 at $101 \mathrm{MHz}$ in DMSO-d 6 at $298 \mathrm{~K} \ldots \ldots . . . .152$

Figure 147. ${ }^{1} \mathrm{H}$ NMR spectrum of $34-\mathrm{Br}$ at $400 \mathrm{MHz}$ in DMSO-d 6 at $298 \mathrm{~K} \ldots . . .152$

Figure 148. ${ }^{13} \mathrm{C}$ NMR spectrum of $34-\mathrm{Br}$ at $101 \mathrm{MHz}$ in DMSO-d 6 at 298K.... 153

Figure 149. ${ }^{1} \mathrm{H}$ NMR spectrum of 35 at $101 \mathrm{MHz}$ in DMSO-d $\mathrm{d}_{6}$ at $298 \mathrm{~K}$........... 153

Figure 150. ${ }^{13} \mathrm{C}$ NMR spectrum of 35 at $101 \mathrm{MHz}$ in DMSO-d 6 at 298K .......... 154

Figure 151. ${ }^{1} \mathrm{H}$ NMR spectrum of $35-\mathrm{Br}$ at $400 \mathrm{MHz}$ in DMSO-d 6 at 298K ...... 154

Figure 152. ${ }^{13} \mathrm{C}$ NMR spectrum of 35-Br at $101 \mathrm{MHz}$ in DMSO-d 6 at 298K.... 155

Figure 153. ${ }^{1} \mathrm{H}$ NMR spectrum of 36 at $400 \mathrm{MHz}$ in DMSO-d 6 at 298K........... 155

Figure $154 .{ }^{13} \mathrm{C}$ NMR spectrum of 36 at $101 \mathrm{MHz}$ in DMSO-d 6 at 298K .......... 156

Figure 155. ${ }^{1} \mathrm{H}$ NMR spectrum of 37 at $400 \mathrm{MHz}$ in DMSO-d ${ }_{6}$ at $298 \mathrm{~K} \ldots \ldots . . . . . .156$

Figure 156. ${ }^{13} \mathrm{C}$ NMR spectrum of 37 at $101 \mathrm{MHz}$ in DMSO-d 6 at $298 \mathrm{~K} \ldots \ldots \ldots . . .157$

Figure 157. ${ }^{19} \mathrm{~F}$ NMR spectrum of 37 at $376 \mathrm{MHz}$ in DMSO-d 6 at $298 \mathrm{~K} \ldots \ldots \ldots . . . .157$

xix 
Figure 158. ${ }^{1} \mathrm{H}$ NMR spectrum of 38 at $400 \mathrm{MHz}$ in DMSO-d 6 at $298 \mathrm{~K} \ldots \ldots \ldots . . . . .158$

Figure 159. ${ }^{13} \mathrm{C}$ NMR spectrum of 38 at $101 \mathrm{MHz}$ in DMSO-d 6 at $298 \mathrm{~K} \ldots \ldots \ldots . . .158$

Figure 160. ${ }^{1} \mathrm{H}$ NMR spectrum of 39 at $400 \mathrm{MHz}$ in DMSO-d $\mathrm{d}_{6}$ at $298 \mathrm{~K} \ldots \ldots \ldots . . . . .159$

Figure $161 .{ }^{13} \mathrm{C}$ NMR spectrum of 39 at $101 \mathrm{MHz}$ in DMSO-d 6 at $298 \mathrm{~K}$.......... 159

Figure 162. ${ }^{1} \mathrm{H}$ NMR spectrum of 40 at $400 \mathrm{MHz}$ in $\mathrm{CDCl}_{3}$ at $298 \mathrm{~K} \ldots \ldots \ldots \ldots \ldots . . . . . .160$

Figure 163. ${ }^{13} \mathrm{C}$ NMR spectrum of 40 at $101 \mathrm{MHz}$ in $\mathrm{CDCl}_{3}$ at $298 \mathrm{~K} \ldots \ldots \ldots \ldots . . . . . .160$

Figure 164. ${ }^{1} \mathrm{H}$ NMR spectrum of 43 at $400 \mathrm{MHz}$ in $\mathrm{CDCl}_{3}$ at $298 \mathrm{~K} . . . . . . . . . . . . . . .161$

Figure $165 .{ }^{13} \mathrm{C}$ NMR spectrum of 43 at $101 \mathrm{MHz}$ in $\mathrm{CDCl}_{3}$ at $298 \mathrm{~K} . . . \ldots \ldots \ldots . . . . . .161$

Figure 166. ${ }^{1} \mathrm{H}$ NMR spectrum of 45 at $400 \mathrm{MHz}$ in $\mathrm{CDCl}_{3}$ at $298 \mathrm{~K} . . . \ldots \ldots \ldots . . . . . .162$

Figure 167. ${ }^{13} \mathrm{C}$ NMR spectrum of 45 at $101 \mathrm{MHz}$ in $\mathrm{CDCl}_{3}$ at $298 \mathrm{~K} \ldots \ldots \ldots \ldots . . . . . .162$

Figure 168. ${ }^{19} \mathrm{~F}$ NMR spectrum of 45 at $376 \mathrm{MHz}$ in $\mathrm{CDCl}_{3}$ at $298 \mathrm{~K} \ldots \ldots \ldots \ldots . . . . . .163$

Figure 169. Synthesis of aryl(TMP)iodonium tosylates ................................. 164

Figure 170. Anion exchange of aryl(TMP)iodonium tosylates ........................ 165

Figure 171. Aryl(TMP)iodonium bromides to acetate exchange ..................... 166

Figure 172. Determination of GC response factors for $2 a$.............................. 167

Figure 173. Determination of GC response factors for 2b........................... 167

Figure 174. Aryl azidation with pre-exchanged diaryliodonium salts................ 168

Figure 175. Aryl azidation of aryl(TMP)iodonium tosylates with a dope salt..... 168

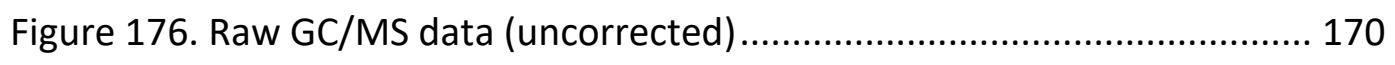

Figure 177. ${ }^{1} \mathrm{H}$ NMR spectrum of $14-\mathrm{Br}$ at $600 \mathrm{MHz}$ in $\mathrm{DMSO}-\mathrm{d}_{6}$ and $\mathrm{CD}_{3} \mathrm{OD}$ at $298 \mathrm{~K}$ 
Figure $178 .{ }^{13} \mathrm{C}$ NMR spectrum of $14-\mathrm{Br}$ at $101 \mathrm{MHz}$ in DMSO-d $\mathrm{d}_{6}$ and $\mathrm{CD}_{3} \mathrm{OD}$ at $298 \mathrm{~K}$ 175

Figure 179. ${ }^{1} \mathrm{H}$ NMR spectrum of $14-\mathrm{Cl}$ at $400 \mathrm{MHz}$ in $\mathrm{DMSO}-\mathrm{d}_{6}$ and $\mathrm{CD}_{3} \mathrm{OD}$ at $298 \mathrm{~K}$ 176

Figure $180 .{ }^{13} \mathrm{C}$ NMR spectrum of $14-\mathrm{Cl}$ at $101 \mathrm{MHz}$ in $\mathrm{DMSO}-\mathrm{d}_{6}$ and $\mathrm{CD}_{3} \mathrm{OD}$ at $298 \mathrm{~K}$ 176

Figure 181. ${ }^{1} \mathrm{H}$ NMR spectrum of $14-\mathrm{OAc}$ at $400 \mathrm{MHz}$ in $\mathrm{CD}_{3} \mathrm{OD}$ at $298 \mathrm{~K}$ 177

Figure $182 .{ }^{13} \mathrm{C}$ NMR spectrum of $14-\mathrm{OAC}$ at $101 \mathrm{MHz}$ in $\mathrm{CD}_{3} \mathrm{OD}$ at $298 \mathrm{~K} \ldots \ldots \ldots . . .177$

Figure 183. ${ }^{1} \mathrm{H}$ NMR spectrum of $14-\mathrm{OTf}$ at $400 \mathrm{MHz}$ in DMSO-d 6 at $298 \mathrm{~K} . . . . . .178$

Figure $184 .{ }^{13} \mathrm{C}$ NMR spectrum of $14-\mathrm{OTf}$ at $101 \mathrm{MHz}$ in DMSO-d 6 at $298 \mathrm{~K} \ldots \ldots .178$

Figure $185 .{ }^{19} \mathrm{~F}$ NMR spectrum of $14-\mathrm{OTf}$ at $376 \mathrm{MHz}$ in DMSO-d 6 at $298 \mathrm{~K}$...... 179

Figure 186. ${ }^{1} \mathrm{H}$ NMR spectrum of $14-\mathrm{BF}_{4}$ at $400 \mathrm{MHz}$ in $\mathrm{DMSO}-\mathrm{d}_{6}$ at $298 \mathrm{~K} \ldots \ldots . . .179$

Figure 187. ${ }^{1} \mathrm{H}$ NMR spectrum of $20-\mathrm{Br}$ at $600 \mathrm{MHz}$ in DMSO-d $\mathrm{d}_{6}$ at $298 \mathrm{~K} . . . . . . . .180$

Figure $188 .{ }^{13} \mathrm{C}$ NMR spectrum of $20-\mathrm{Br}$ at $151 \mathrm{MHz}$ in DMSO- $\mathrm{d}_{6}$ and $\mathrm{CD}_{3} \mathrm{OD}$ at $298 \mathrm{~K}$ 180

Figure 189. ${ }^{1} \mathrm{H}$ NMR spectrum of $20-\mathrm{Cl}$ at $400 \mathrm{MHz}$ in $\mathrm{DMSO}-\mathrm{d}_{6}$ and $\mathrm{CD}_{3} \mathrm{OD}$ at $298 \mathrm{~K}$ 181

Figure 190. ${ }^{13} \mathrm{C}$ NMR spectrum of $20-\mathrm{Cl}$ at $101 \mathrm{MHz}$ in DMSO- $\mathrm{d}_{6}$ and $\mathrm{CD}_{3} \mathrm{OD}$ at $298 \mathrm{~K}$ 181

Figure 191. ${ }^{1} \mathrm{H}$ NMR spectrum of $20-$ TFA at $600 \mathrm{MHz}$ in DMSO-d 6 at $298 \mathrm{~K}$ 182

Figure $192 .{ }^{13} \mathrm{C}$ NMR spectrum of $20-\mathrm{TFA}$ at $151 \mathrm{MHz}$ in DMSO-d 6 298K........... 182

Figure 193. ${ }^{19} \mathrm{~F}$ NMR spectrum of $20-\mathrm{TFA}$ at $376 \mathrm{MHz}$ in DMSO-d 6 298K ........... 183 
Figure 194. ${ }^{1} \mathrm{H}$ NMR spectrum of $20-\mathrm{OAc}$ at $600 \mathrm{MHz}$ in $\mathrm{CD}_{3} \mathrm{OD}$ at $298 \mathrm{~K} \ldots \ldots \ldots . . . .183$

Figure $195 .{ }^{13} \mathrm{C}$ NMR spectrum of $20-\mathrm{OAC}$ at $151 \mathrm{MHz}$ in $\mathrm{CD}_{3} \mathrm{OD}$ at $298 \mathrm{~K} \ldots \ldots \ldots . . . .184$

Figure 196. ${ }^{1} \mathrm{H}$ NMR spectrum of $20-\mathrm{OTf}$ at $400 \mathrm{MHz}$ in DMSO-d 6 at $298 \mathrm{~K} \ldots \ldots . . .184$

Figure 197. ${ }^{13} \mathrm{C}$ NMR spectrum of $20-\mathrm{OTf}$ at $101 \mathrm{MHz}$ in DMSO-d 6 at $298 \mathrm{~K} \ldots \ldots .185$

Figure 198. ${ }^{19} \mathrm{~F}$ NMR spectrum of 20-OTf at $376 \mathrm{MHz}$ in DMSO-d 6 at $298 \mathrm{~K} . . . . .185$

Figure 199. ${ }^{1} \mathrm{H}$ NMR spectrum of $20-\mathrm{BF}_{4}$ at $400 \mathrm{MHz}$ in DMSO-d 6 at $298 \mathrm{~K} \ldots \ldots . . .186$

Figure $200 .{ }^{13} \mathrm{C}$ NMR spectrum of $20-\mathrm{BF}_{4}$ at $101 \mathrm{MHz}$ in DMSO-d 6 at $298 \mathrm{~K} \ldots \ldots 186$

Figure 201. ${ }^{19} \mathrm{~F}$ NMR spectrum of $20-\mathrm{BF}_{4}$ at $376 \mathrm{MHz}$ in DMSO-d 6 at $298 \mathrm{~K} \ldots . . .187$

Figure 202. ${ }^{1} \mathrm{H}$ NMR spectrum of 50 at $400 \mathrm{MHz}$ in $\mathrm{CDCl}_{3}$ at $298 \mathrm{~K} \ldots \ldots \ldots \ldots \ldots \ldots . . . . . . . .187$

Figure 203. ${ }^{13} \mathrm{C}$ NMR spectrum of 50 at $101 \mathrm{MHz}$ in $\mathrm{CDCl}_{3}$ at $298 \mathrm{~K} \ldots \ldots \ldots \ldots \ldots . . . . . . . .188$

Figure 204. ${ }^{1} \mathrm{H}$ NMR spectrum of 51 at $600 \mathrm{MHz}$ in $\mathrm{CDCl}_{3}$ at $298 \mathrm{~K} \ldots \ldots \ldots \ldots \ldots \ldots . . . . . . . . .188$

Figure 205. ${ }^{13} \mathrm{C}$ NMR spectrum of 51 at $151 \mathrm{MHz}$ in $\mathrm{CDCl}_{3}$ at $298 \mathrm{~K} \ldots \ldots \ldots \ldots \ldots . . . . . . .189$

Figure 206. ${ }^{1} \mathrm{H}$ NMR spectrum of 56 at $101 \mathrm{MHz}$ in $\mathrm{CDCl}_{3}$ at $298 \mathrm{~K} . \ldots \ldots \ldots \ldots \ldots . . . . . . .189$

Figure 207. ${ }^{13} \mathrm{C}$ NMR spectrum of 56 at $101 \mathrm{MHz}$ in $\mathrm{CDCl}_{3}$ at $298 \mathrm{~K} \ldots \ldots \ldots \ldots \ldots . . . . . . .190$

Figure 208. ${ }^{1} \mathrm{H}$ NMR spectrum of 57 at $400 \mathrm{MHz}$ in $\mathrm{CDCl}_{3}$ at $298 \mathrm{~K} \ldots \ldots \ldots \ldots \ldots \ldots . . . . . . . . . .190$

Figure 209. ${ }^{13} \mathrm{C}$ NMR spectrum of 57 at $101 \mathrm{MHz}$ in $\mathrm{CDCl}_{3}$ at $298 \mathrm{~K}$................. 191

Figure 210. ${ }^{1} \mathrm{H}$ NMR spectrum of 58 at $400 \mathrm{MHz}$ in $\mathrm{CDCl}_{3}$ at $298 \mathrm{~K} \ldots \ldots \ldots \ldots \ldots \ldots . . . . . . . . .191$

Figure $211 .{ }^{13} \mathrm{C}$ NMR spectrum of 58 at $101 \mathrm{MHz}$ in $\mathrm{CDCl}_{3}$ at $298 \mathrm{~K}$.................. 192

Figure 212. ${ }^{1} \mathrm{H}$ NMR spectrum of 59 at $400 \mathrm{MHz}$ in $\mathrm{CDCl}_{3}$ at $298 \mathrm{~K} \ldots \ldots \ldots \ldots \ldots \ldots . . . . . . . . . .192$

Figure 213. ${ }^{13} \mathrm{C}$ NMR spectrum of 59 at $101 \mathrm{MHz}$ in $\mathrm{CDCl}_{3}$ at $298 \mathrm{~K} . \ldots \ldots \ldots \ldots \ldots . . . . . . .193$ 


\section{Introduction}

\subsection{Significance}

Molecules containing aryl motifs are important to our daily lives and are implicated in pharmaceuticals, agrochemicals, engineering plastics, dyes for textiles and diagnostic sensing, and many other technologies that help to shape the way we live. Figure 1 shows several molecules that have impacted the lives of people globally and demonstrates that substituted aryl groups are a common feature of molecules in diverse and impactful applications. Notably the active pharmaceutical ingredients (APIs) of nonsteroidal anti-inflammatory drugs (NSAID; 1,2,3); fluorescent dyes, such as rhodamine (4); polyethersulfone (PES, 7); and sulfonated PES (8).

Biologically active compounds

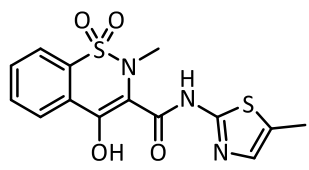

Meloxicam (1) - NSAID

Fluorescent Dyes

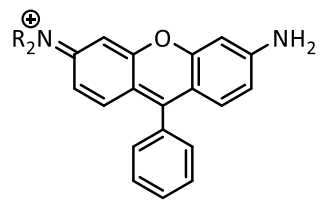

Rhodamine (4) - fluorescent dye<smiles>O=C(O)Cc1ccccc1Nc1c(Cl)cccc1Cl</smiles>

Diclofenac (2) - NSAID

Pigments

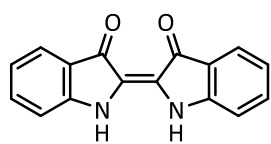

Indigotin (5) - textile pigment

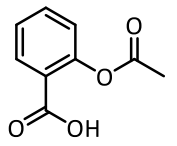

Aspirin (3) - NSAID;

natural product derrivative

Functional Materials Me

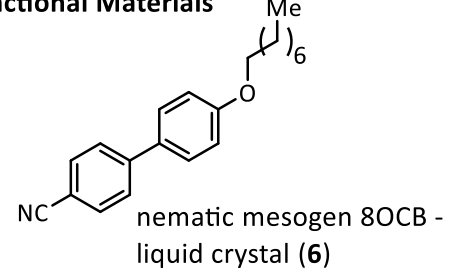

Macromolecules:

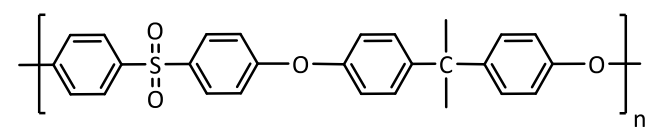

PES (7) - engineering thermoplastic

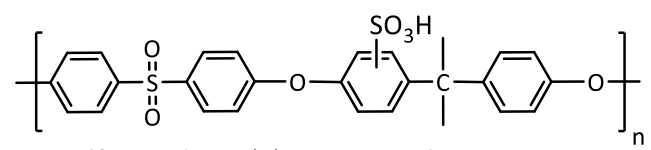

Sulfonated PES (8) - cation exchange resin

Figure 1. Applications of molecules containing aromatic moieties. 
Arguably, the types of substitutions and the substitution pattern of a given arene define its behavior and structure-function relationship (SFR). For example, substituting a single hydrogen for a sulfonate group converts the commodity polymer, PES (7) into sulfonated-PES (8), (Figure 1). Comparison of $\mathbf{7}$ and $\mathbf{8}$ nicely shows how a single substitution sufficiently alters the SFR so that the new material now finds application as a cation exchange resin. Sulfonated-PES is no longer a suitable engineering thermoplastic as is 7 . Figure 2 shows a generalized arylation reaction, wherein a single aryl hydrogen is substituted for another functional group. Broadly defined, arylation is the set of chemical transformations that result in the functionalization of arenes. To this end, the work described here focuses on the discovery and improvement of reagents useful for arylation reactions. Generally applicable reactions lead to simplified synthetic preparations of aromatic compounds, thereby reducing the resource demands of chemical synthesis and also facilitating the creation of novel compounds. Therefore, developing more general arylation chemistry would, in effect, render it more useful to synthetic chemists. Simplified syntheses and preparations of novel chemicals are two key outcomes that justify continued reaction development within this niche. One long term benefit of continued development could be an increased variety of chemicals available to chemists. Greater variety of available chemicals will increase the number of potential applications as well as further understanding of structure-to-function. 


\subsection{The status of contemporary arylation}

Arylation has been the subject of intense research for over two centuries. The current state-of-the-art for arylation is dominated by transition metal catalysis (TMC), which has brought tremendous advances to synthetic chemistry. ${ }^{1}$ Despite its popularity, there are situations which clearly demonstrate the need for alternatives. Specifically, the combination of late-stage synthesis and TMC can be problematic due to the difficulty of removing trace metals from reaction products. ${ }^{2}$ Removal or reclamation/reworking of the metals used in catalysts may serve to reduce manufacturing costs associated with waste. Additionally, products manufactured in regulated industries are required to comply with requirements of the applicable regulatory agency. For example, the FDA has set strict criteria for acceptable trace metal content in APIs. ${ }^{3}$ Trace metal removal is challenging, in part, because the allowable concentration limits for trace metals are very low in comparison to commonly employed catalyst loading used in chemical synthesis. For example, the Losartan synthesis, shown in Figure 3, used a one mole percent loading of palladium acetate, which corresponds to roughly $1600 \mathrm{ppm}$ palladium. ${ }^{4}$ The limit in

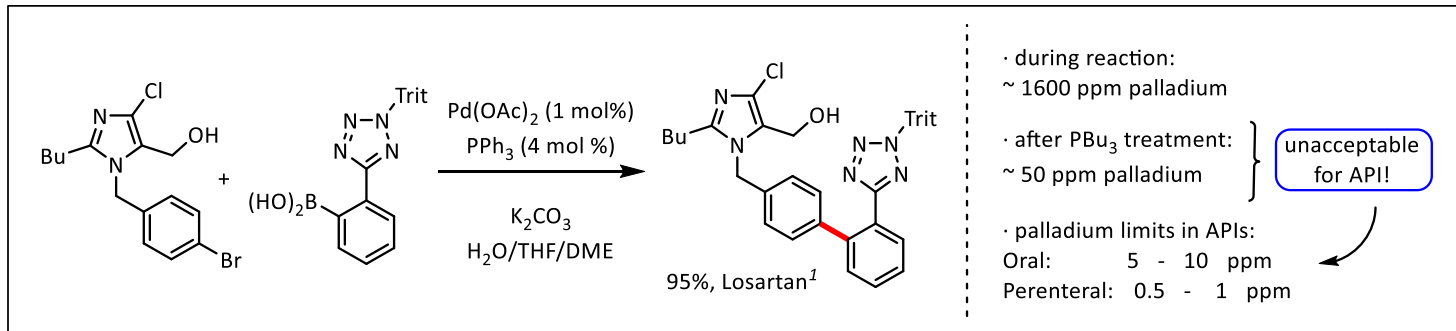

Figure 2. Late stage use of TMC. Metal content is contrasted with regulatory limits for Pd in APIs.

APIs for residual palladium is less than $10 \mathrm{ppm}$ for oral administration and less than 1 ppm for parenteral administration. ${ }^{5}$ As reported by Garrett, even after treatment with 
tributyl phosphine, about 50 ppm palladium remained. ${ }^{6}$ Notably, tributyl phosphine is itself moderately toxic, has a strongly unpleasant smell, and generally must be used in an air free environment.

A metal-free arylation reaction could simplify syntheses in regulated industries by eliminating the need for catalyst removal and associated verification testing. The cost of TMC can also be very high, in particular, when precious metals and custom ligands are required. There are many examples that suggest the cost of designer ligands far outweighs the cost even of the precious metal component. For example, $100 \mathrm{mg}$ of the generation 3, Buchwald Palladacycle, CAS 1536473-72-9, from Strem Chemicals, sold for seventy dollars (December, 2015). Based on the December 28th, 2015 closing price of one troy ounce of palladium (\$554), one hundred milligrams would have cost just shy of two dollars. ${ }^{7}$ Based on the cost of one gram of palladium chloride, roughly sixty dollars, the cost for one hundred miligrams is about six dollars. The significantly higher price of the palladacycle when compared to a precious metal is plausibly indicative of the development cost associated with catalysts bearing designer ligands. An inherent characteristic of TMC with designer ligands is that they catalyze a specific transformation very well, but are not generally applicable to many different transformations. This keeps the likelihood of ligand development high, whenever novel reactivity is considered. Also, TMCs are frequently moisture- and/or air-sensitive and greater availability of bench-stable reagents would lessen the environmental controls and maintenance needed for storage and processing. Finally, an important distinction to remember is that TMC's are catalysts and not reactants. Developing reagents that 
accommodate a broad substrate scope without added catalysts is a useful effort because, it is complementary to current technology. Although the point has been made that reagents capable of metal-free reactivity will avoid the cost of transition metal catalysts and associated ligand development, it is noteworthy that this does not preclude the addition of a TMC if needed. The reagents that will be discussed in this work are not catalysts and are not offered as a competing technology to TMC. A more realistic view would be that efforts to develop reagents capable of metal-free reactivity are complementary and so will hopefully lower dependence on TMC by offering the chemist greater flexibility in chemical synthesis. A particularly attractive scenario would include the discovery of reagents that undergo specific transformations that may be tuned with reaction conditions.

\subsection{Diaryliodonium salts as arylation reagents}

Diaryliodonium salts represent a potential alternative for arylation reagents and have been shown to mitigate several of the gaps in the toolkit currently available to chemists. In his 2016 review, Zhadankin asserts that iodine reagents, in general, are viable as sustainable alternatives to metals, because iodine is itself relatively more environmentally benign, cheap, and sufficiently abundant. ${ }^{8}$ Global crude iodine reserves are primarily found in Chile and Japan and its price is listed as $\$ 23 / \mathrm{kg}$ by the United States Geological Survey (USGS). ${ }^{9}$ In contrast the 2016 prices of platinum and palladium listed by the USGS were $\$ 1000$ per oz. $(\$ 32,151$ per $\mathrm{kg})$ and $\$ 615$ per oz. $(\$ 19,773$ per kg), respectively. Currently, 30,000 metric tons of iodine are harvested 
annually and the estimated worldwide reserves are about 15 million metric tons. ${ }^{10}$

While this is not by any means a rigorous cost analysis, it seems that given the chance to become mainstream reagents, iodine based compounds could be economically competitive to their more expensive transition metal based counterparts.

Diaryliodonium salts enable transfer of aryl groups to heteroatoms as well as carbon atoms and are generally used under mild conditions, do not require inert environments or forcing conditions and may be used alone or with a transition metal. The vast majority are bench stable compounds and require minimal environmental controls to use. Together, the characteristically mild conditions, broad substrate scope, and regiospecificity possible with diaryliodonium salts make them a potentially useful reagent for late stage functionalization of complex arenes. The ability to perform specific and selective late stage transformations with a metal-free reagent is of particular value in the pharmaceutical industry, where strict limits on residual metal content must be met.

\subsection{Historical overview of diaryliodonium salts}

First discovered in the $1890^{\prime}$ s by Wilgerodt, ${ }^{11}$ the potential breadth of arylation reactions with diaryliodonium salts was first demonstrated by Beringer in the 1950 's. ${ }^{12}$ Later, in the 1970's, efforts were made to characterize their structures and to begin understanding basic reactivity of hypervalent iodine compounds including, diaryliodonium salts. Several reviews are available for further reading on the overall class of hypervalent iodine reagents and their application for small molecule synthesis. ${ }^{13}$ 
In the 1970's, Crivello and coworkers reported that diaryliodonium salts may be used as photo-acid-generators (PAGs). ${ }^{14}$ As polymerization initiators in photoresists, diaryliodonium salts have had an enormous impact on the development of modern electronics. ${ }^{15}$ Today, research into hypervalent iodine reagents is gaining popularity as they offer an attractive combination of qualities including generally good stability and versatile chemical reactivity. They offer the potential for tuning reactivity according to reaction conditions, and as nonmetals, may eliminate the need for metal removal. To date, hypervalent iodine reagents, including diaryliodonium salts have become accepted reagents for natural products and pharmaceutical synthesis. ${ }^{16}$ While this work is focused on the development of specific diaryliodonium reagents and some aspects of their behavior in closed-shell arylation reactions, it is warranted to provide a brief discussion of hypervalent iodine as well as some of its history.

\subsection{Overview of diaryliodonium salt structure and reactivity}

Every organic chemistry student is first introduced to organoiodine with iodine existing as an organoiodide. Undergraduate courses rarely, if ever, mention the higher oxidation states, (+III) and (+V), which have found considerable use in small molecule synthesis, functional group transformation and polymer chemistry. Figure 4 shows the general structures of aromatic organoiodine compounds in various commonly encountered configurations. Diaryliodonium salts, less commonly called $\lambda^{3}$-diaryliodanes, are a subclass of hypervalent iodine(III) reagents. The T-shaped structure in Figure 4 and Figure 5 , has been experimentally determined by X-ray crystallography for numerous 
diaryliodonium compounds. ${ }^{17}$ It follows that for crystalline diaryliodonium salts, the Tshape structure has been used to rationalize the thermodynamic stability of diaryliodonium salts. There has been controversy in the literature over whether these compounds are really salts. For clarity, referring to a diaryliodonium compound as a "diaryliodane" suggests that it is not a salt and that the X-group is bound to the iodine via a dative bond. Whether these comounds exist in the diaryliodane form, or in the ionic diaryliodonium form is debated in the literature. This author contends that the structure at any given moment likely depends foremost on the state of solvation as well as the identity of $\mathbf{X}$. Regardless, the T-shape is also important for understanding the outcome of the putative reductive-elimination pathway that has been described for diaryliodonium mediated arylation. ${ }^{12 k}$

Many derivatives of the general structures shown in Figure 3, are bench stable and commercially available from mainstream chemical suppliers. In fact, polycoordinate compounds have been reported for the entire halide family, except fluorine and are collectively referred to as halonium compounds. 


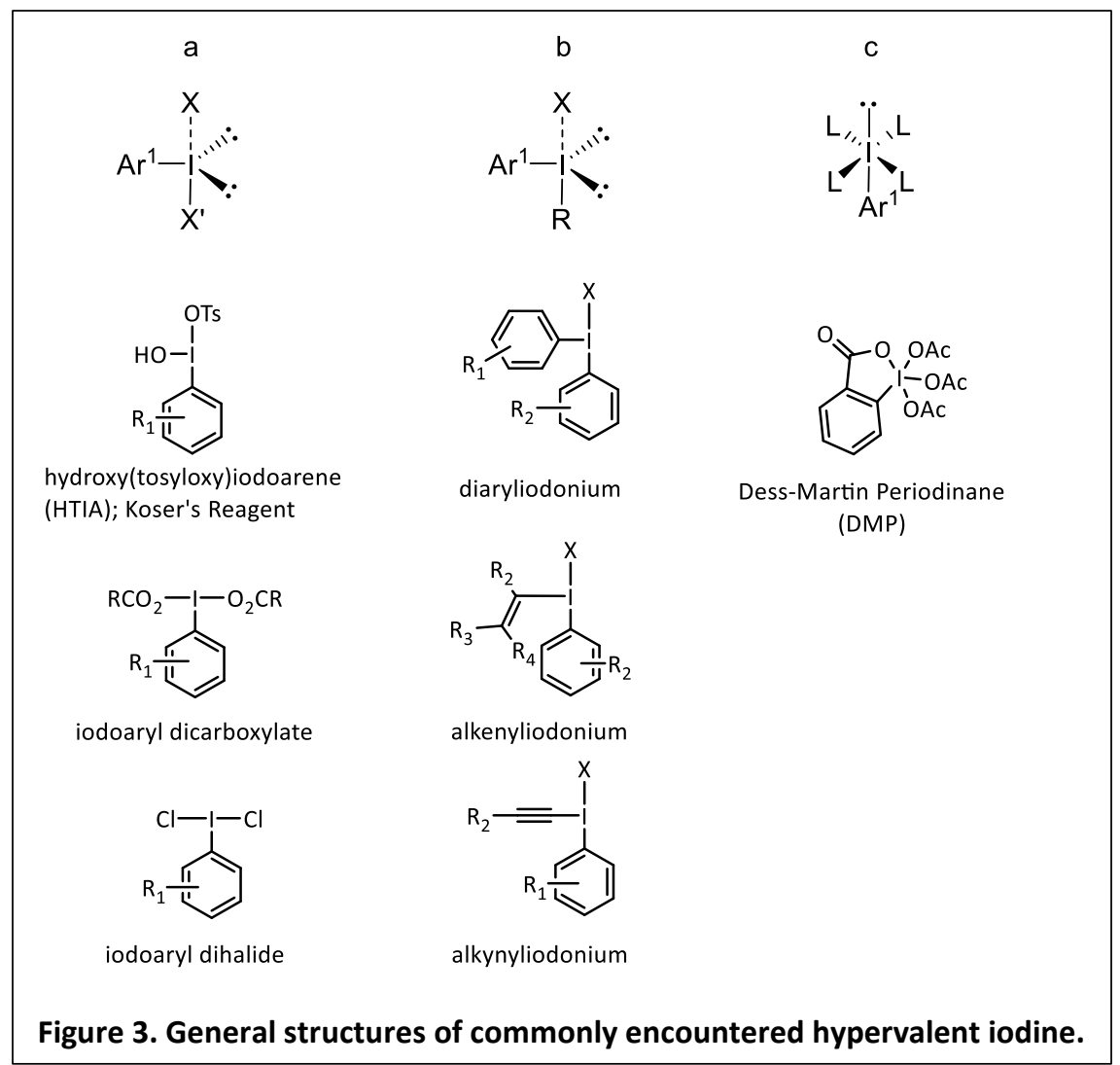

Reagents such as hydroxy(tosyloxy)iodoarenes (HTIA, Figure 4a) and Dess-Martin periodinane (DMP, Figure 4c) act as oxidants and have been widely used. HTIA additionally has been used for ligand transfer of the sulfonate group. Iodoaryl dihalides have been used to access high oxidation states in metal reagents and also may be used as ligand transfer reagents, for example halogenation of an alkene. Both the dihalide and diacetoxy species may be used as chain transfer reagents in radical polymerizations. The diacetoxy species may also be used in oxidative coupling reactions, for example in the homocoupling of n-heterocyclic carbenes (NHCs). Uniquely, diaryl-, alkenyl- and alkynyliodonium salts are carbon transfer reagents. Chapter 2 presents the detailed 
development of a diaryliodonium reagent, which transfers aryl groups to nucleophiles and lies at the heart of the work presented here.
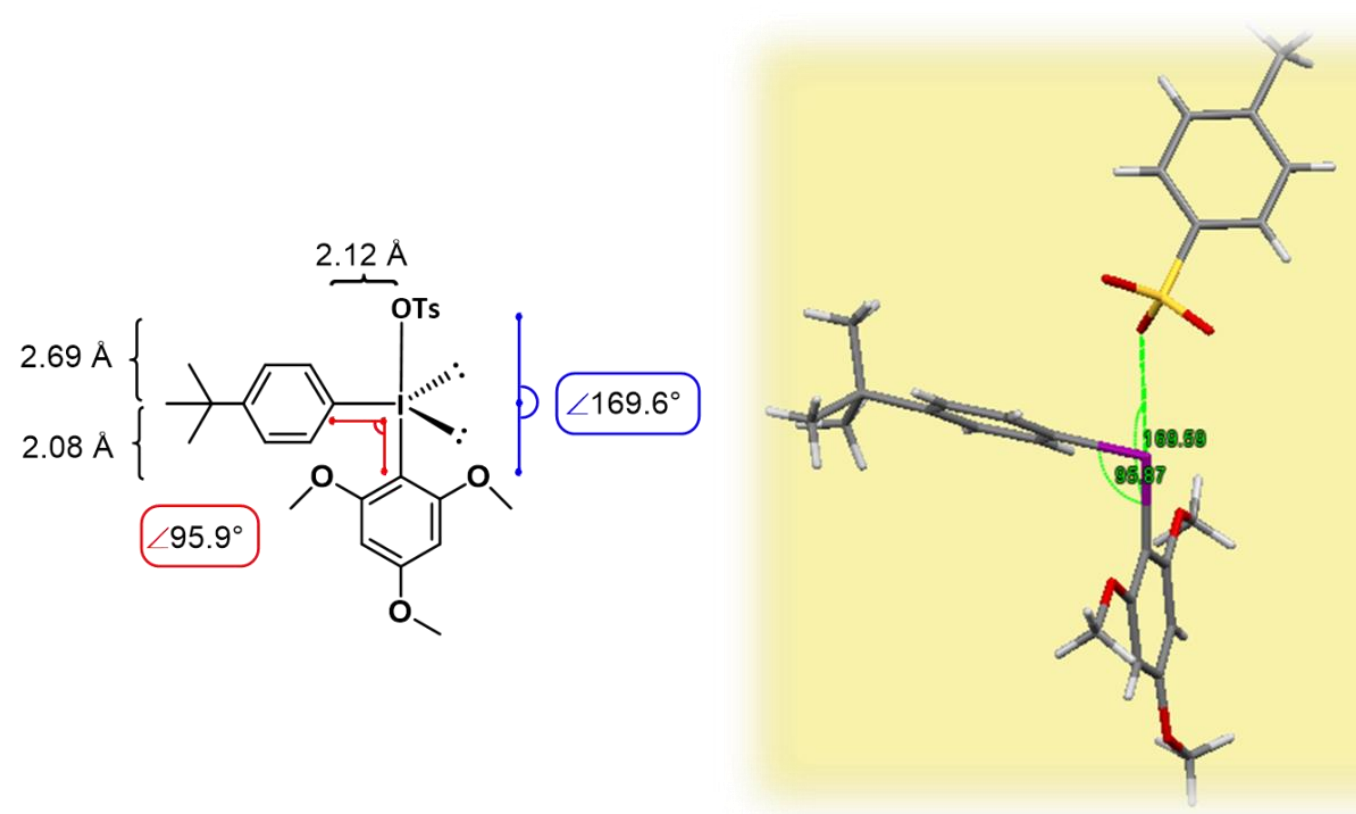

Figure 4. The T-Shape structure of crystalline diaryliodonium salt. Collected with help of Dr. Kuo at Lewis \& Clarke college.

The full scope of described structures is more complicated than might be expected, based on Figure 3. In fact, depending on the R-group and the environment, many of these structures can form dimers and oligomeric networks with potentially significantly different physical and chemical properties relative to the monomeric species. Further discussion of these somewhat esoteric structures is beyond the scope of the material presented here. 
The stability of diaryliodonium salts that have the general, T-shaped, crystal structure shown in Figure 4 is thought to depend on the configuration of ligands around the iodine center. In the 1970's, Shustorovich studied the, axially oriented, three-centerfour-electron (3c-4e) bond and its constituents.

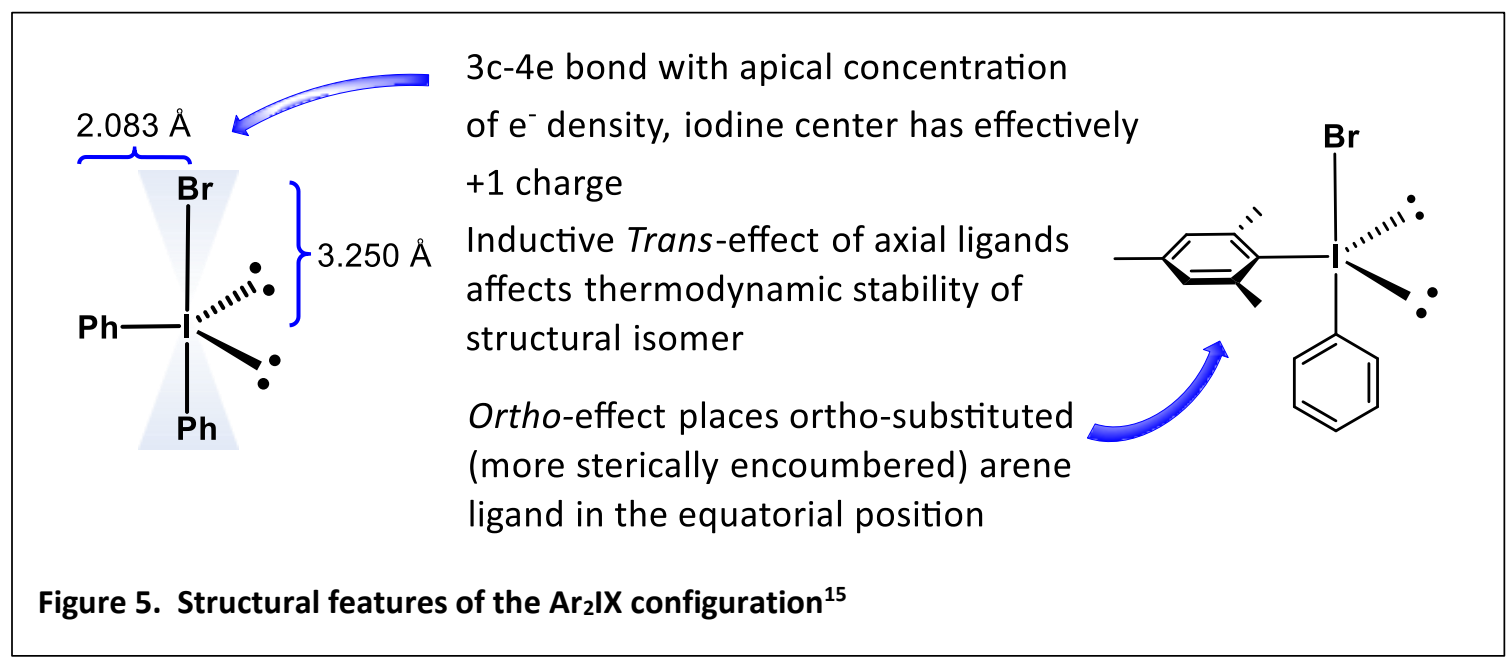

He suggests that both of the apical ligands of the 3c-4e bond of hypervalent iodine (III) compounds exert an inductive trans-influence on the opposite ligand, the strength of which depends on the $\sigma$-donating ability of both ligands. The stronger $\sigma$-donor will have stronger bonding to the iodine center and will simultaneously weaken the opposite iodine-ligand bond. Shustorovich posited that, because of the trans-influence, the combination of one strong and one moderate sigma donating ligand would likely allow the $3 \mathrm{c}-4 \mathrm{e}$ bond the greatest thermodynamic stability. ${ }^{18}$ Accepting this rationale, it becomes clear that in a diaryliodonium salt, the 3c-4e bond will virtually always include one arene and the X-group, but a configuration with two apical arenes is very unlikely to 
occur. Examples of all-carbon ligated iodine species have been reported, however, they were prepared at $-80{ }^{\circ} \mathrm{C}$ and were extremely unstable. ${ }^{19}$

The reactivity of diaryliodonium salts as electrophilic carbon transfer agents is justified by the charge polarization of the $3 c-4 e$ bond. The iodine center effectively carries $a+1$ charge, making it inherently electrophilic and allowing for attack by nucleophiles. A second feature that is often cited is the excellent leaving ability of the aryliodide moiety which has been called a hypernucleofuge. An example of the leaving ability of Ar-I is presented in Figure 6 below. ${ }^{20}$

leaving group
Figure 6. Ochiai determined that the I-Ph behaved as a hypernucleofuge via comparison to the
same reaction with other leaving groups.

There are three main modes of reactivity by which arylation reactions of diaryliodonium salts are thought to proceed. Of the three pathways (Figure 7), the ionic (closed-shell) pathway is most developed, in particular, for arylation with heteroatoms ${ }^{21 a-1}$. The work here is primarily concerned with reagent development and the work presented here on coupling reactions is exclusively using nucleophiles that proceed through the ionic pathway. The radical and benzyne pathways will not be discussed further. 


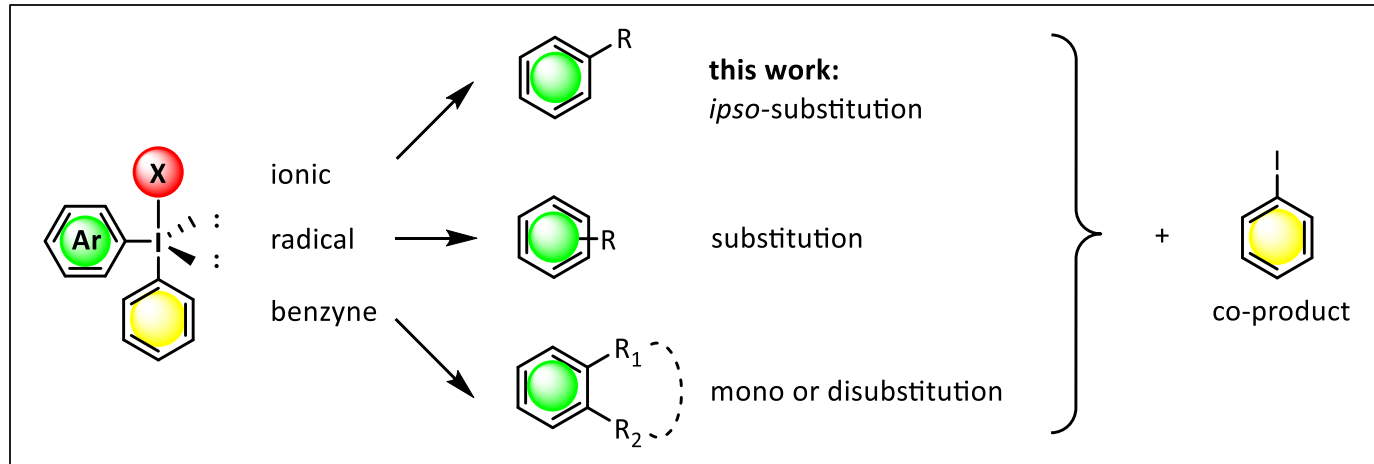

Figure 7. Three common modes of diaryliodonium salt reactivity.

The ionic mechanism is thought to occur according to Figure 8. The nucleophile undergoes metathesis with the $\mathbf{X}$-group, followed by formation of a three membered transition state, wherein the nucleophile is transferred to the equatorial-aryl group by reductive elimination. The reaction results in arylation of the nucleophile and a stoichiometric amount of an aryl iodide co-product.

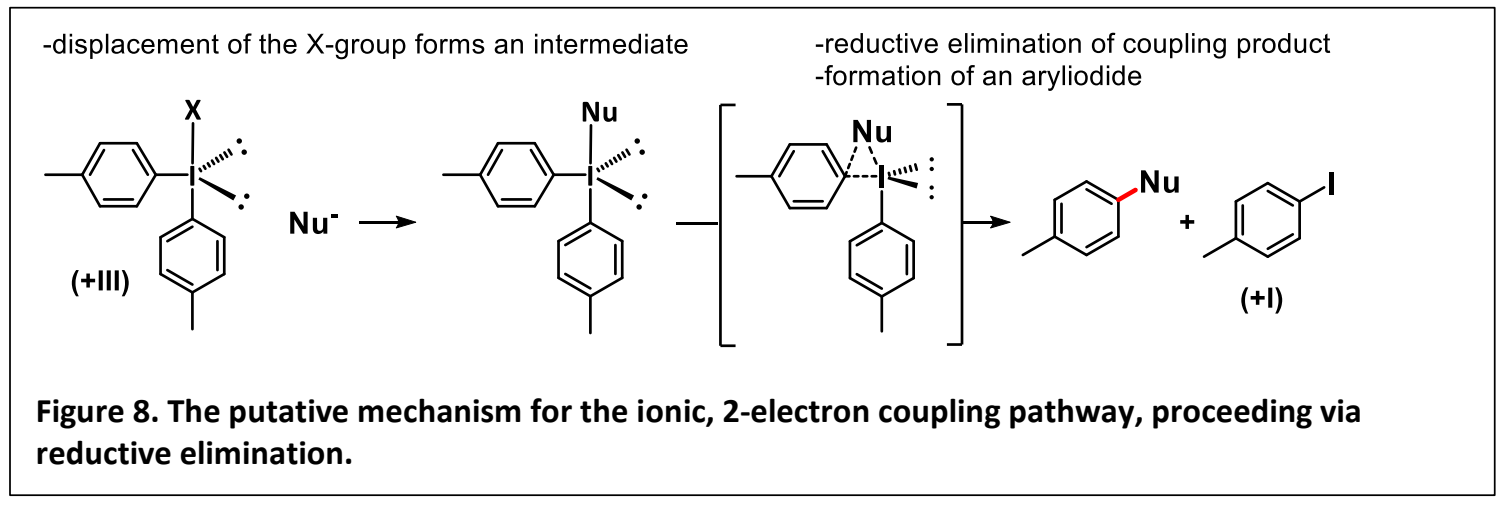

An inherent advantage of diaryliodonium salts, undergoing coupling via reductive

elimination, is that they affect an ipso-substitution and so offer excellent and predictable regiospecificity. It is immediately apparent that chemoselectivity is not an issue for the reaction shown in Figure 8. This is because the diaryliodonium salt shown 
has two identical aryl groups. Such a diaryliodonium salt is termed symmetrical. In contrast, chemoselectivity does become important when considering arylation with unsymmetrical diaryliodonium salts. Figure 10 shows two aspects of unsymmetrical diaryliodonium salts that are needed to understand how chemoselectivity occurs and ultimately how it may be controlled.

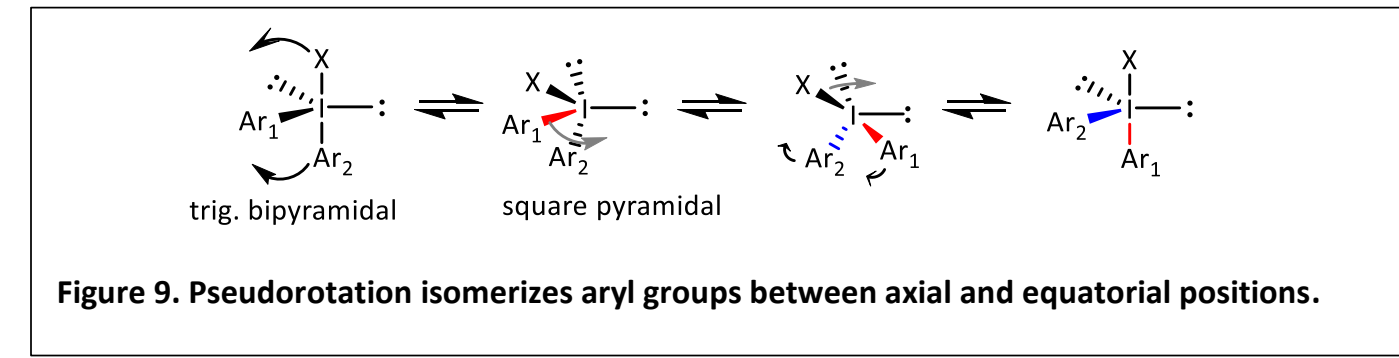

Firstly, the T-shape helps to visualize that once the nucleophile replaces the X-group it can only reductively eliminate with a ligand in the equatorial position. Secondly, isomerization via pseudorotation means that both arenes may occupy the equatorial position. This means that both aryl groups have opportunity to enter the transition state preceding reductive coupling and that the product distribution will be determined by the relative energies of the two possible isomers of the transition state.

\subsection{Selectivity with unsymmetrical salts}

In practice, selectivity of the reaction and the resultant product distribution may be modulated by tuning the physicochemical properties of both arenes. Considering the 
symmetrical diaryliodonium salt

exchangeable X-group

(counteranion)

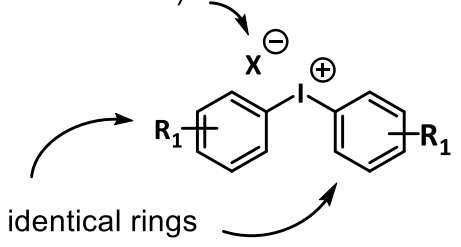

unsymmetrical diaryliodonium salt

exchangeable X-group

(counteranion)

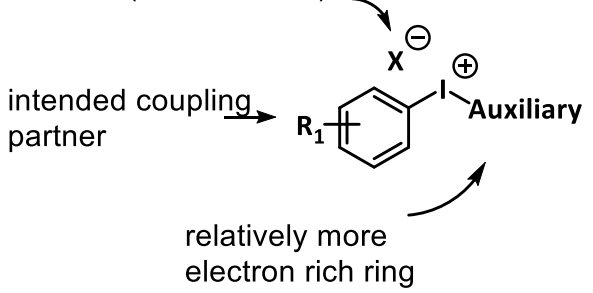

Figure 10. Anatomy of symmetrical and unsymmetrical iodonium salts

case, where one arene always leaves as its iodide, then it becomes reasonable to

label it as an auxiliary group (Aux). Unsymmetrical diaryliodonium salts are contrasted

with their symmetrical counterparts in Figure 10 and may be described as consisting of

four components: the iodine center, the X-group, the Ar group and AuX-group. In a

coupling reaction, the Ar-group is the intended coupling partner and the Aux-group is

intended to leave as its iodide.

The practical result of the distinction between Ar and Aux is that when a symmetrical salt undergoes a coupling reaction an equivalent of Ar is lost. The potential significance of losing an equivalent of $\mathrm{Ar}$ is explained by the hypothetical late stage functionalization of Flubendiamide (Figure 11). 


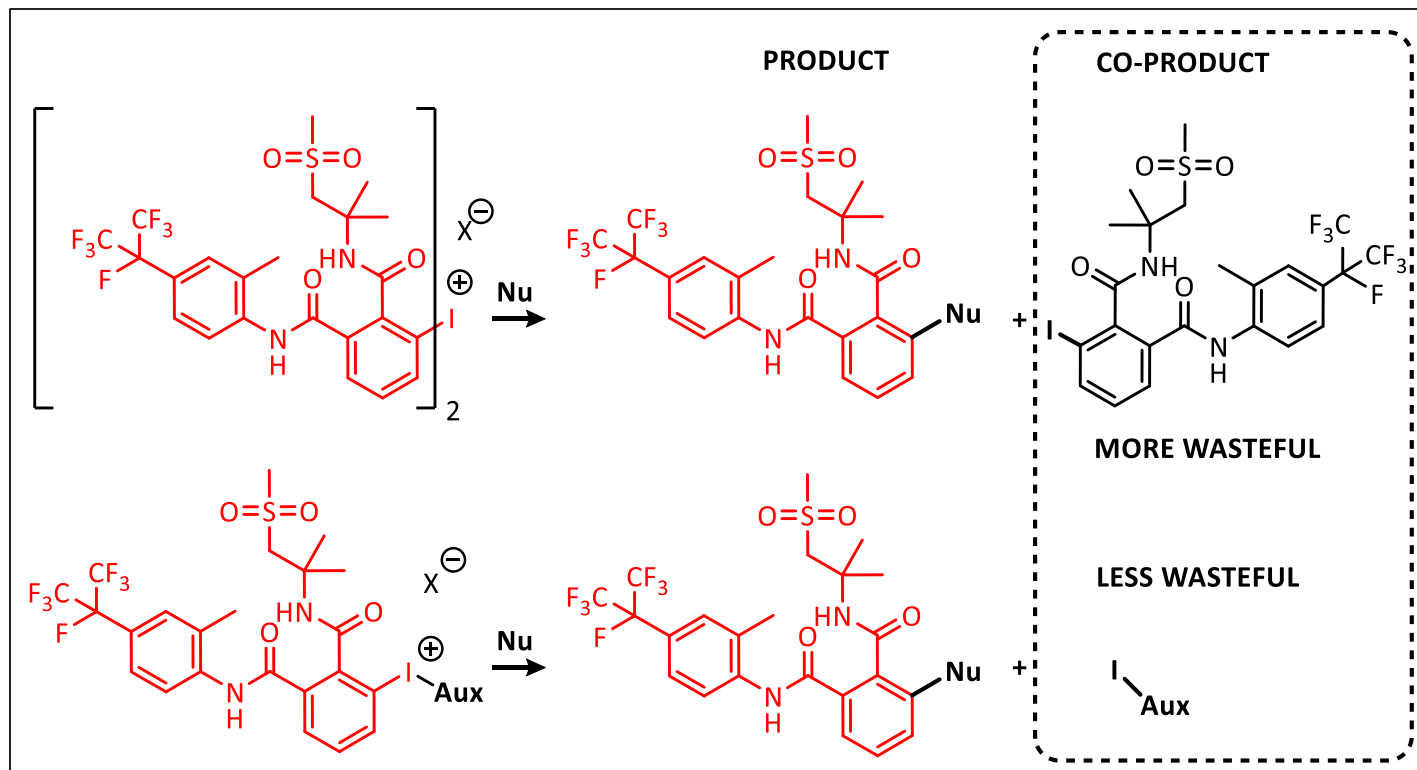

Figure 11. Hypothetical late stage functionalization using a symmetrical iodonium salt of Flubendiamide Bayer CropScience (2006).

While the aryliodide co-product from reaction of the symmetrical salt in Figure 11 can potentially be reworked, such an undertaking would at best be mitigating and cannot be viewed as a solution. This limitation makes symmetrical diaryliodonium mediated arylation of elaborate products untenable. On the other hand, if the leaving moiety can reliably be the iodide of a simple arene, then waste is minimized and a workable situation may be realized.

The source of selectivity was studied in detail by Togni. ${ }^{22}$ He suggests that in the absence of sterics, the $3 \mathrm{c}-4 \mathrm{e}$ bond polarity, and in particular the charge of the ipsocarbon in the 3c-4e bond, determine the selectivity. More specifically, Togni calculates the partial charge on the ipso-carbon of both arenes when they are in the axial position. The difference of partial charges at the ipso-carbon for variously substituted rings is 
shown to correlate well with the activation barrier to reach the transition state (Figure 12).

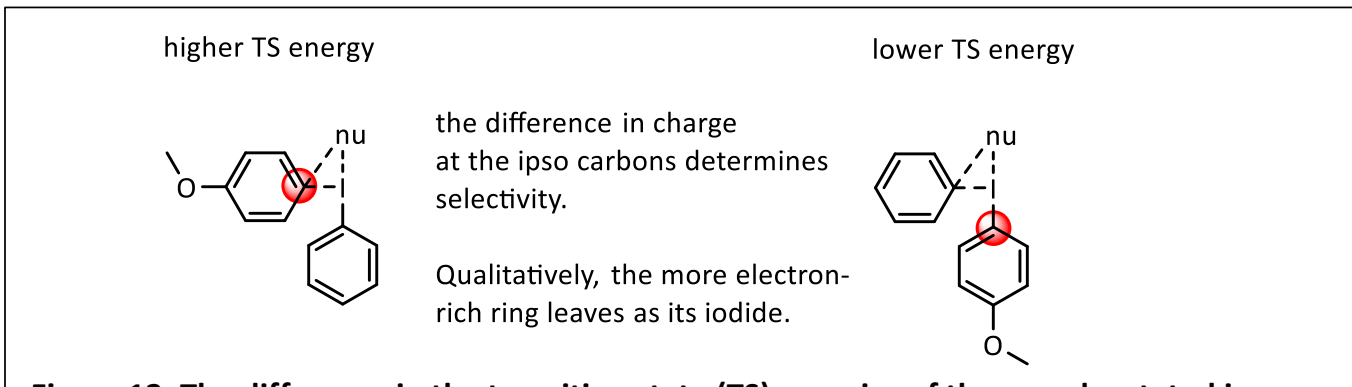

Figure 12. The difference in the transition state (TS) energies of the pseudorotated isomers

There are numerous examples in the literature that corroborate Togni's findings and it generally holds true that the more electron poor ring will couple to a nucleophile. Togni was also able to show that the correlation between ipso-carbon charge and activation barrier does not hold when one of the ligands is stericaly congested. These results support experimental observations that the more electron rich ring, if bulky, can be the favored coupling partner (Figure 13).

Wiegend, who first suggested the ortho-effect, performed pyrolysis experiments with diaryliodonium halides and showed that steric bulk in the ortho-position influences the 


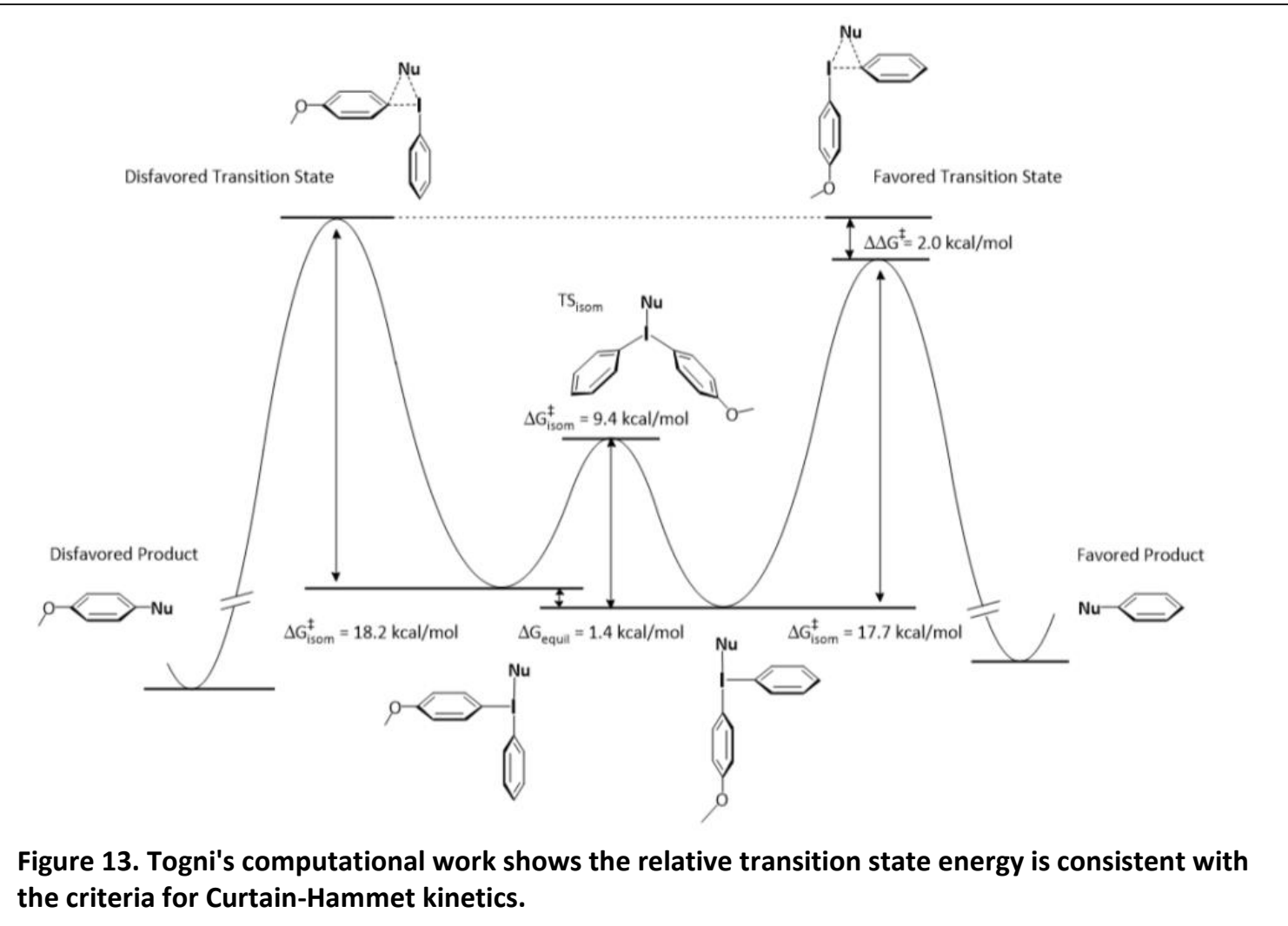

reaction outcome, however, no unambiguous trend was presented. ${ }^{23}$ Consequently, it is assumed that the bulkier group occupies the "roomier" equatorial position in the transition state. The cumulative data from the literature regarding this so-called orthoeffect is not straightforward. For example, Olofsson provides data showing that, in certain cases, steric bulk of the nucleophile may also play a role in determining selectivity of coupling (Figure 5). ${ }^{24}$ Olofsson reported that the bulky nucleophile exerted an "anti-ortho-effect", much to the chagrin of the encumbered ring. Pike and Widdowson additionally have shown evidence of the ortho-effect in fluorination reactions..$^{25}$ As such it is difficult to outline a general trend across all nucleophiles with a single sterically and electronically defined diaryliodonium salt. The observed anti-orthoeffect strongly alludes to the importance of including all components comprising the 
transition state as well as those that are part of intermediate structures leading to the transition state. These components necessarily include the auxiliary, the aryl group, the $\mathbf{X}$-group and the nucleophile. The $\mathbf{X}$-group and the nucleophile have received very little attention to date. Even empirical studies of the $\mathbf{X}$-group are rare and not comprehensive to the point that no parameter with which to evaluate the counteranion has been proposed. Most often, authors have simply stated that "non-coordinating" anions are preferable, such as triflate or tetrafluoroborate. ${ }^{26}$ An interesting consideration to include would be solvent identity, simply because salts or salt-like species are directly involved in the reaction until reductive elimination occurs. In particular with salts, the coordinating effect of certain solvents could play a role. It is conceivable that a certain coordinating solvent would increase solvation and drive apart the $\mathbf{X}$-group and leave the iodonium center available for attack. It is also conceivable that a solvent could coordinate too effectively, replace the $\mathbf{X}$-group, but also hamper approach of the nucleophile.

\subsection{Trimethoxyphenyl as an auxiliary}

The value of the computational work by Togni is that it helps to rationalize a conceptual framework that corroborates empirical observations that sterically unhindered, electron rich, arenes preferentially leave the coupling reaction as their iodide. Diaryliodonium salts bearing a 2,4,6-trimethoxyphenyl (TMP) group have been demonstrated by several authors, notably Olofsson and Pike, to provide excellent selectivity across several nucleophiles (Figure 14). ${ }^{27}$ 
The realization of a diaryliodonium salt with generally excellent selectivity completes a paradigm shift away from the symmetrical diaryliodonium salt. Despite the advantages

Figure 14. Assymmetric diaryliodonium salt configuration
of the trimethoxyphenyl auxiliary being reported already a decade ago, no convenient preparation of these reagents was described. As a result, reaction development efforts have rarely focused on TMP containing diaryliodonium salts and selectivity remained an issue. Previously reported syntheses of TMP containing diaryliodonium salts required an I(III) starting material and took multiple steps with overall moderate yield. The work described in Chapter 2 shows that aryl(TMP)iodonium salts are now readily prepared in under an hour, greatly facilitating reaction development with these promising reagents.

\subsection{Overview of the preparation of diaryliodonium salts}

Most often, the route to build diaryliodonium salts involves first oxidation of an iodoarene to the +3 oxidation state, followed by installation of the second arene via electrophilic aromatic substitution. Figure 15 shows four distinct methods to build diaryliodonium salts. Of these methods, the simplest in practice are those using an oxidant in conjunction with a Bronsted acid as cooling below zero centigrade is rarely required. The reaction using molecular iodine is useful for symmetrical salts and when more than one arene is present a statistical product mixture will result. Reactions employing boron trifluoride etherate tend to require lower temperatures often and moisture can be an issue. The reaction using boronic acids has the benefit of good 
tolerance for electron rich iodoarenes, which have been problematic in reactions employing Bronsted acids.

$$
\text { (colvent }
$$

Figure 15. Common routes to prepare diaryliodonium salts.

\subsection{Design of Experiments (DoE)}

Design of Experiments (DoE) is a methodology that employs multivariate analysis to test a given hypothesis. It originated from the work of William Gosset, who was working to improve batch consistency at the Guinness Brewing Company and so was concerned over statistics with small sample sizes. Gosset's work was published under the pseudonym, Student, and his ideas on "designed experiments" were later developed by scientists like Fisher and Taguchi. Today, industry commonly employs DoE during the development phases of R\&D projects and heavily relies upon DoE for the creation of 
robust manufacturing processes. DoE is rare in academic organic chemistry laboratories in North America and formal training is hard to find. It was successfully implemented for the optimization of a diaryliodonium salt preparation (Chapter 2) as well as for an azidation reaction (Chapter 3). The workflow in Figure 16 describes one, albeit simple, implementation of DoE. Importantly, optimization may be considered complete when the results of confirmation runs are in sufficient agreement with results predicted by the model.

An initial, 2-level fractional factorial design allows the relative contributions of many factors to be efficiently assessed and unimportant factors need not be studied further (Figure 16, Phase 0). Because the designs in Phases 0 and 1 vary factors over 2-levels, data is necessarily fit to a linear model. Despite the linear model, the use of center points in the initial 2-level design allows deviations from the linear fit to be detected. That is, if center point runs are statistically significant and do not fit to the linear model, curvature is indicated. After culling unimportant factors the remaining ones can then be studied in enough detail to quantify interaction effects between them (Figure 16, Phase 1). An interaction occurs when the contribution of one factor on a chosen output depends on the level of at least one other factor. Without simultaneously varying the levels of factors, the interaction effects may be overlooked and the importance of a factor may be overlooked. The ability to assess interaction effects makes DoE inherently more accurate than the traditional One Variable At A Time (OVAT) method. Using OVAT relies on luck to stumble upon the optimal conditions. 
Not immediately obvious from the workflow is that data from successive experiment designs may be combined. The ability to grow the relevant pool of data by accretion is one way that using DoE can make optimization more efficient. Curvature detected in Phase 0 or 1 may be characterized by augmenting the data set obtained from the 2-level factorial with the additional data points (levels) needed to apply a higher order model (Figure 16, Phase 2). At this point the designs are often termed response surface analyses (RSA). Finally, regression analysis like ANOVA, various statistical tests and confirmation runs, are tools for objective evaluation of design models as well as, troubleshooting, and evaluation of design matrixes as well as results.

A final comments regarding the usefulness of DoE for research in chemistry, is that the work presented here is only the tip of the iceberg. This work only has dealt with the optimization of reaction environment and other variables that are easily controlled and continuous. In other words, only conditions were studied. Consider, however, the case where physicochemical parameters are used as inputs to experiment designs. Then, conceptually, it becomes possible to use DoE and its advantages to study fundamental aspects of reactivity. Here, useful physicochemical parameters include any quantifiable value that is directly or indirectly related to the fundamental properties of a molecule. For example, Hammet constants, peak locations of various substrates on a given type of spectrum, redox potentials, solubility parameters and even results from DFT calculations are all of potential use. In chapter 3 , the beginning of such work is presented by the study of yield as a function Hansen Solubility Parameters (HSP). A difficulty that is not 
immediately obvious is that it can be difficult to design symmetrical matrixes when using physicochemical parameters. For example, the DoEs shown above use symmetrical ranges of input variables and this is possible, because the variables are continuous. Here, physicochemical parameters are discussed as discrete variables with values that describe an inherent characteristic of a molecule. The nature of DoE is that results are most reliable when the levels of input variables can be set over regular intervals. As a result, when dealing with physicochemical parameters of molecules, DoE matrices will not be perfect arrays of orthogonal factors and the methods to adjust both the designs and their analysis are beyond the scope of this work. 


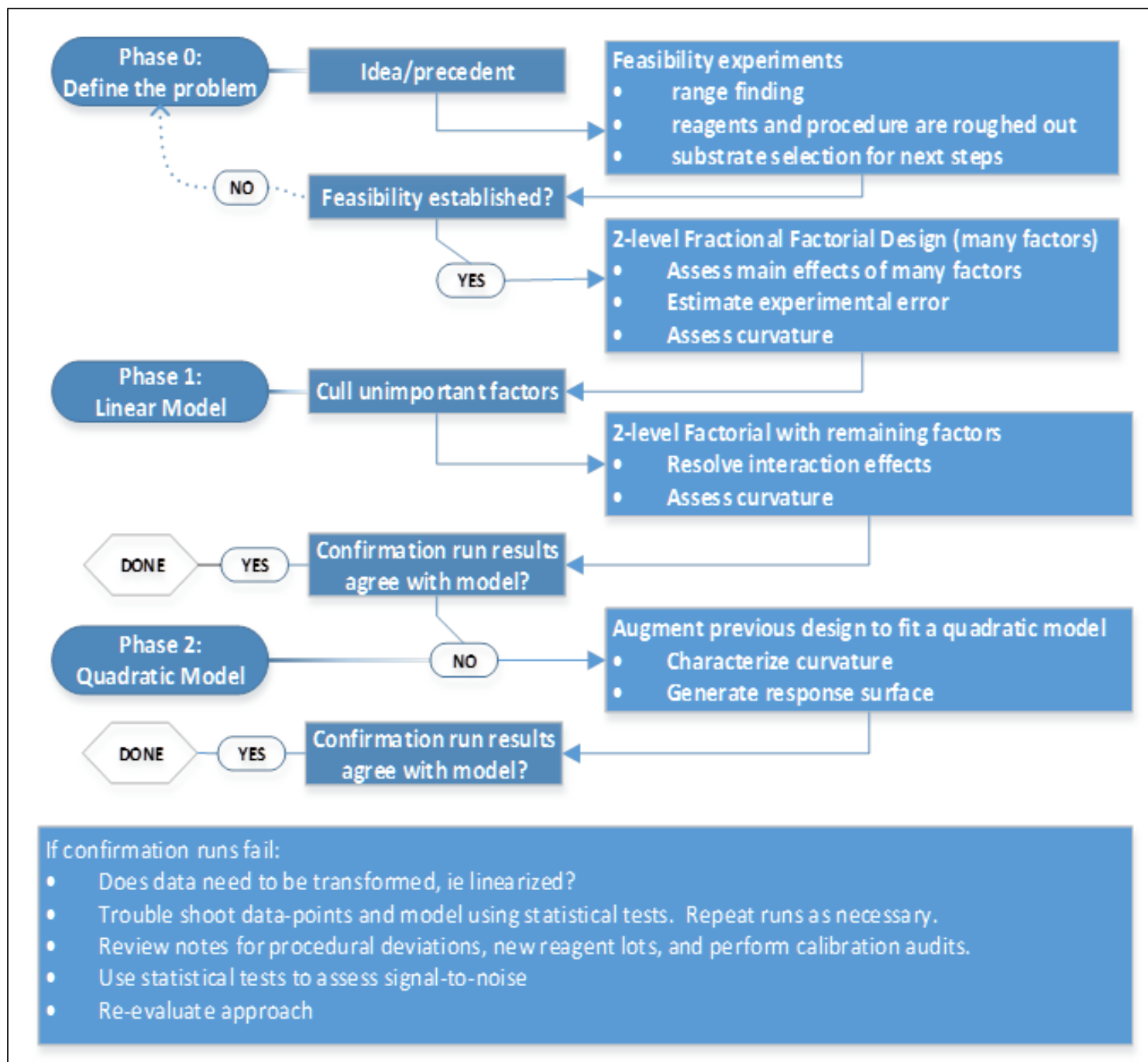

Figure 16. Example DoE work-flow. 


\section{Developing the synthesis of aryl(TMP)iodonium tosylate}

\subsection{Previously reported syntheses}

With the belief that diaryliodonium salts will only gain traction as mainstream arylation reagents after the described issues relating to selectivity have been overcome, the development of a practical synthesis of a selective diaryliodonium salt reagent became a priority. In particular for functionalization of elaborate molecules, it is necessary to move away from symmetrical salts in order to overcome an inherent limitation.

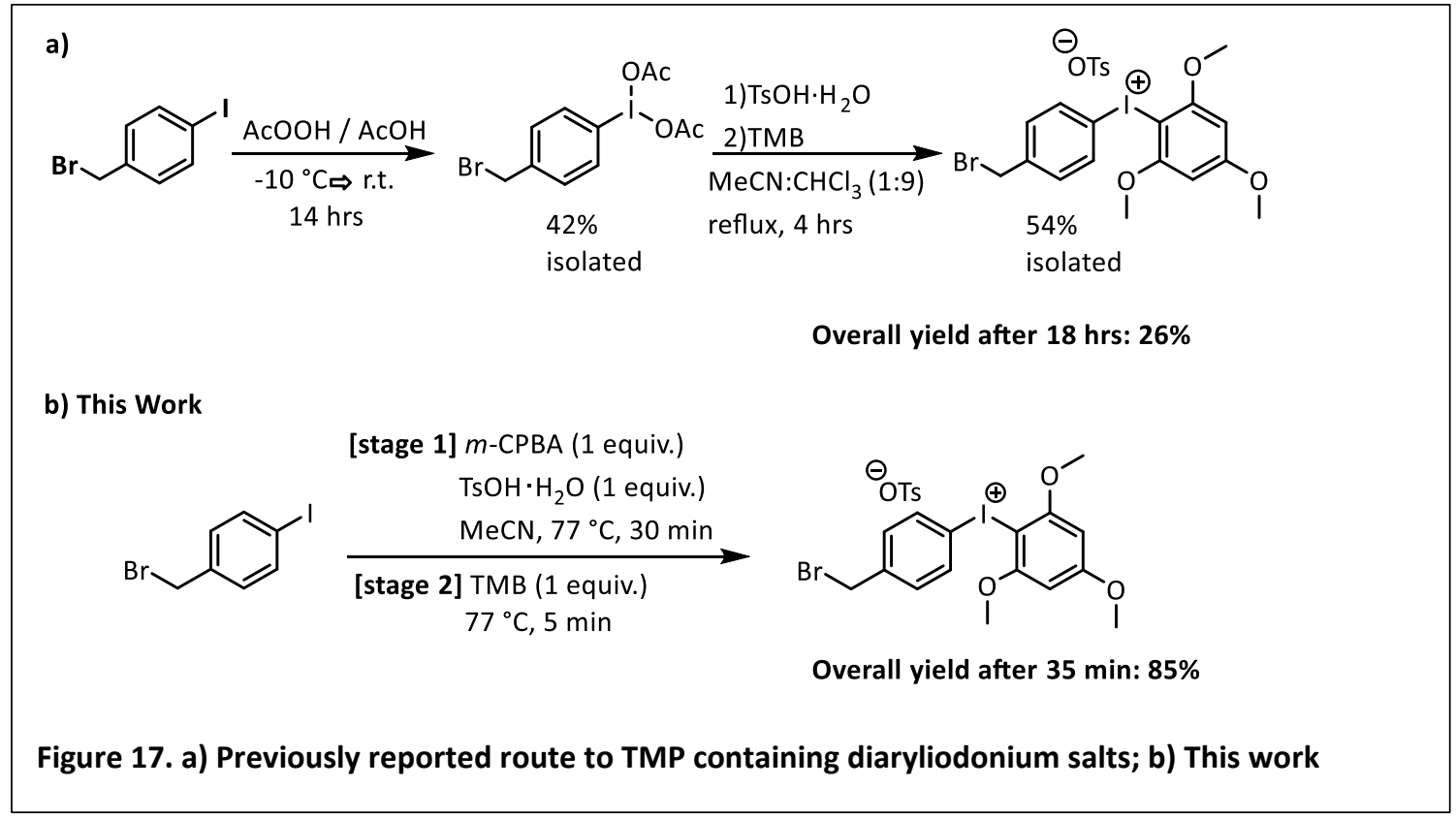

Arylation with diaryliodonium salts has excellent precedent. Still, current knowledge falls short when it comes to understanding exactly what reaction conditions, which combinations of reagents, and how the specific configuration of the diaryliodonium salt results in preference of one mechanism (ionic vs. radical vs. benzyne) over another and transfer of one aryl group over another. Critics have alleged that these reagents are 
difficult to prepare and that they are not practical for use in modification of elaborate molecules, as encountered in late-stage synthesis of pharmaceuticals or in the postmodification of polymers. Our work, to date, has resulted in the development of a significantly improved method for the preparation of a variety of diaryliodonium salts and demonstrates successful coupling to elaborate arenes. Our data shows successful use of Design of Experiment (DoE) approach in order to develop a practical synthesis of diaryliodonium salts. The preparation is shown to be very repeatable and accommodates a broad scope of iodoaryl substrates. The preparation described below has been published and has been adapted into an Org Syn method, which is presented in Chapter 2b. As a final proof of success, several of the reagents have been made commercially available by $\mathrm{TCl}$ and are available in North America, Japan and Europe.

\subsection{Feasibility}

We have developed a robust synthesis of unsymmetrical (Figure 17b), aryl(TMP)iodonium tosylates and used DoE to arrive at optimized conditions with a model substrate. Precedent for diaryliodonium salts and the justification for choosing trimethoxyphenyl based aryliodonium salts are discussed in previous sections.

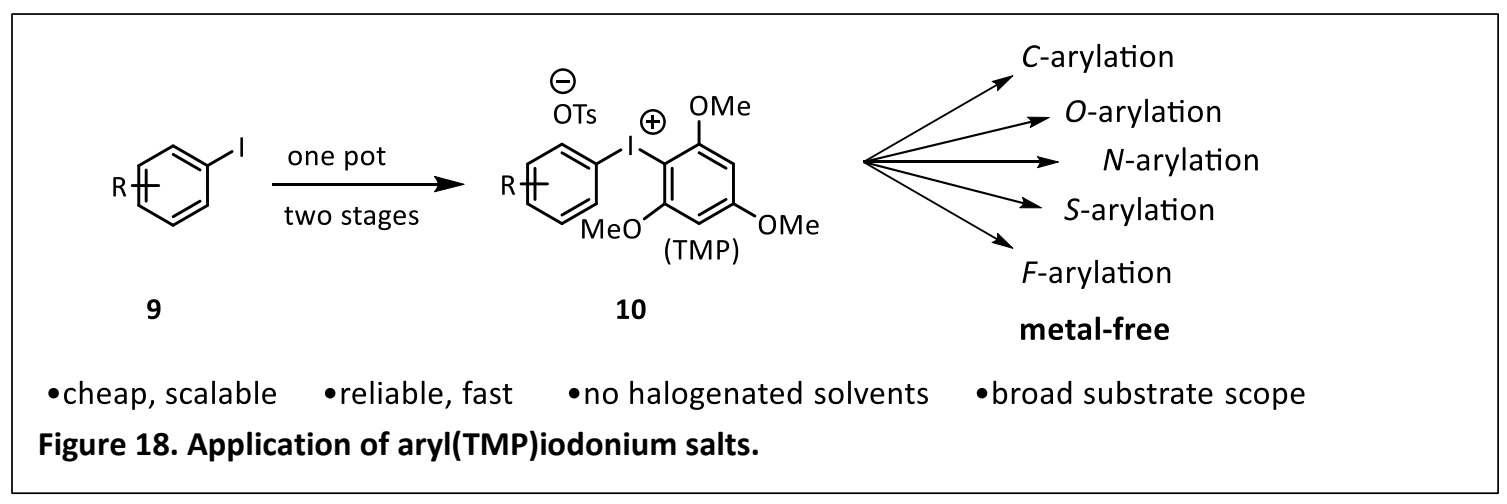


The research groups of Olofsson and Pike previously demonstrated the importance of the trimethoxyphenyl auxiliary in diaryliodonium salts. ${ }^{28,29}$ The three methoxy groups on TMP are stable and sufficiently electron-donating to help to ensure that the auxiliary will be relatively more electron rich than the other arene. The tosylate counteranion was selected according to precedent methods from the chemical literature. Tosic acid is consumed during oxidation of the aryliodide (stage 1 ) and its conjugate base takes on the role of counter anion in the iodonium product. Fortunately, the tosylate anion has proven to be very amenable to exchange by various alkali salts. Counter anion identity has been shown to significantly affect reaction outcomes and is discussed in detail in Chapter 3.

Preparation of $\mathbf{1 0}$ was previously accomplished by first preparing the hydroxy (tosyloxy)iodoarene (HTIA) by Olofsson's method ${ }^{30}$ (Figure 19, Pot 1 ) and then reacting it further with TMB similarly to a method from Pike ${ }^{13}$ (Figure 19, Pot 2). During feasibility experiments, it was observed that the rate of HTIA formation dramatically increased upon raising the concentration from $0.1 \mathrm{M}$ to $1 \mathrm{M}$. It was evident that Olofsson's procedure had unrealized potential. Feasibility tests also showed that it was possible to form the aryl(TMB)iodonium tosylate by adding TMB directly to the crude HTIA intermediate. In order to further simplify and also to make the reaction more environmentally friendly, a single solvent, acetonitrile, was used for both steps of the reaction. Using acetonitrile avoids the use of perfluorinated alcohols, which are costly and hazardous. 
Pot 1: oxidation into hydroxy(tosyloxy)iodoarene or Koser's Reagent (from Olofsson)

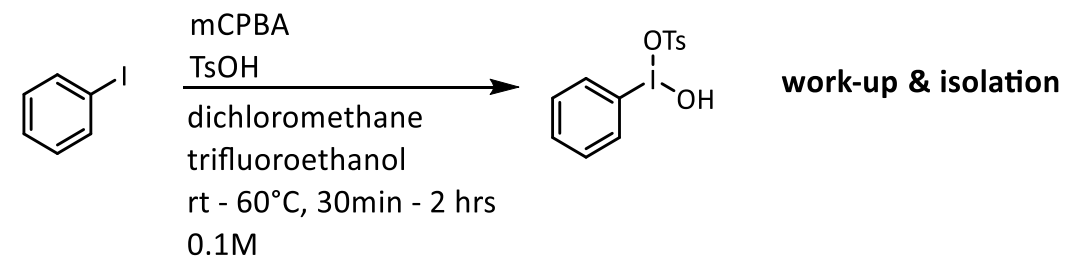

Pot 2: installation of trimethoxyphenyl auxiliary (based on Pike)<smiles>OI(c1ccccc1)c1ccccc1</smiles><smiles>COC(C)=O</smiles>

(1:9); reflux $4 \mathrm{hrs}$<smiles></smiles>

Figure 19. Feasibility Studies. Pot 1: Olofsson's preparation of HTBIA; Pot 2: Modification of Pike's procedure, which first required conversion of a diacetoxyiodoarene into HTBIA.

Upon successful demonstration of feasibility, our one-pot reaction was optimized using

DoE. The optimization substrate chosen was 4-methyl-iodobenzoate. The moderate yields of this substrate under feasibility conditions were thought to be directly related to the electron withdrawing nature of the ester group. Feasibility work, performed with 4trifluoromethyl-iodobenzene and 4-tolyl-iodobenzene followed literature trends for formation of the HTIA intermediate. Consistent with expectations, more electron rich iodoarenes required shorter reaction times to form the HTIA analogue. The literature shows that similar, two-pot, preparations of diaryliodonium tosylates, bearing auxiliaries other than TMP, were most challenging for iodoarenes bearing electron withdrawing substituents. Initial one-pot experiments resulted in encouraging yields between $60 \%$ and $70 \%$, indicating that the iodobenzoate substrate was a useful choice for optimization. 


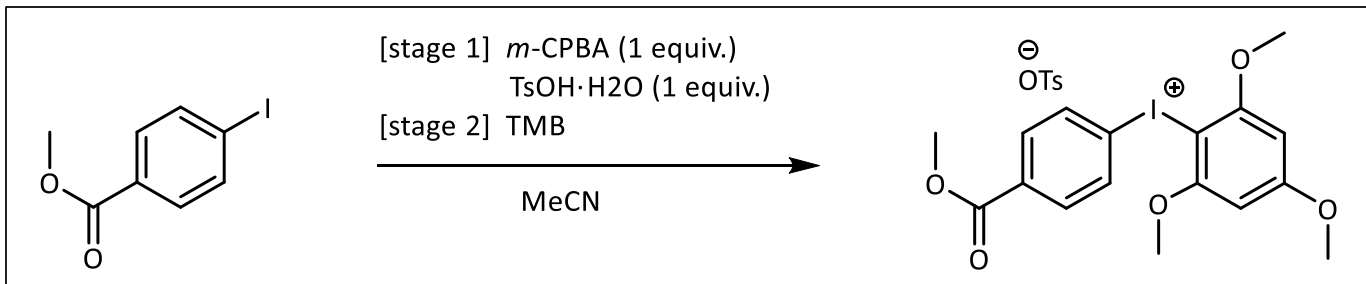

Figure 20. Reaction used for optimization.

Optimization of the reaction shown in Figure 20 followed the work flow presented in Chapter 1, Figure 16, and resulted in model-predicted yields that agreed with experimentally obtained yields. The predictive value of the model is supported by the confirmation run data listed in Table 9 and also plotted on the response surface in Figure 26. The optimization was considered successfully concluded upon observing that the mean and standard deviation of the confirmation runs fell within those predicted by the model. A very interesting result of early DoE runs was the unexpectedly fast reaction to install the TMP auxiliary. As a result, the reaction time of stage 2 was shortened to a practical limit of 5 minutes. A detailed description of the optimization process is provided in the following section. 


\subsection{Optimization Details}

General comments and a brief overview of DoE were given in Section 1.9.

\subsubsection{Assessment of main effects of $\mathbf{5}$ factors under study}

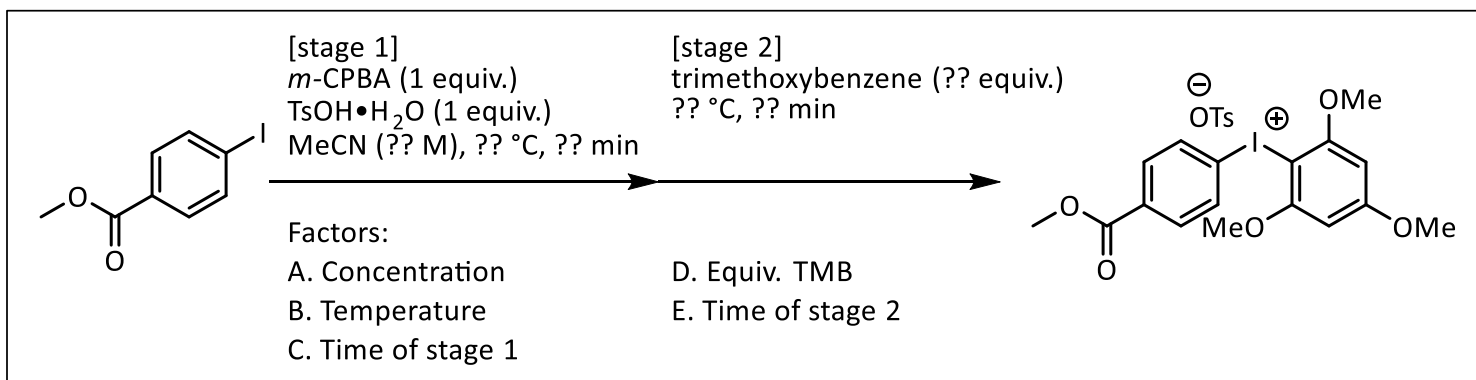

Figure 21. Reaction used for optimization. Factors under study were $A$ through $E$.

thereby reducing the subsequent work-load. As mentioned, factors are studied over two levels and linear models necessarily apply. Nonetheless, the addition of replicate center points serves to: 1) provide an early assessment as to the presence or absence of curvature, and 2) provide an estimate of the experimental error, which here is taken as the standard deviation of the replicate runs. An estimate of the experimental error is important as it determines the signal-to-noise ratio $(\mathrm{S} / \mathrm{N})$ of the results. The $\mathrm{S} / \mathrm{N}$ value is critical to determining the size of an observed change in an output that one may distinguish from noise, at a chosen level of confidence. ${ }^{32}$ Estimating experimental error in this way makes the assumption that error is constant across the design space. This is generally true, provided that whatever mechanism is driving the process under study also remains constant over the design space. 


\begin{tabular}{|c|c|c|c|c|}
\hline Factor & Description $^{b}$ & low level ${ }^{a}$ & $\underline{\text { center level }}^{a}$ & $\underline{\text { high level }}^{a}$ \\
\hline$A$ & Conc. (M) & $0.1(-1)$ & $0.55 \quad(0)$ & $1 \quad(1)$ \\
\hline B & Time 1 (min) & $2 \quad(-1)$ & 16 & $30 \quad(1)$ \\
\hline C & Time 2 ( $\min )$ & $2 \quad(-1)$ & (0) & $30 \quad(1)$ \\
\hline D & Temp. $\left({ }^{\circ} \mathrm{C}\right)$ & $25 \quad(-1)$ & (0) & $80 \quad(1)$ \\
\hline$E$ & TMB (equiv) & $1 \quad(-1)$ & 2.0 & $3 \quad(1)$ \\
\hline
\end{tabular}

In this case, twelve experiments were required to study five factors and five center points were added (Table 1). For perspective, up to 28 experiments could be run in one regular work day. Additionally, the use of coded and actual values to describe the levels factors are set at (Table 1) is discussed in Section 2.3.2.

The Results of the Placket-Burman design are shown in Table 2 and Figure 22. Factors considered significant effects (A, B, D) are bolded in Table 2 and account for $\sim 90 \%$ of the contribution to the measured response. The "equivalents of TMB" factor was rejected from subsequent work because its effect was inversely proportional to yield. Despite the low effect on yield, the reaction time of Stage 2 was included in subsequent experiment designs simply to satisfy the author's curiosity. However, it would have been justifiable to exclude Time 2 from further study. 


\begin{tabular}{|c|c|c|}
\hline Factor & Description & \%contribution \\
\hline A & Conc. (M) & 7.71 \\
\hline B & $\begin{array}{l}\text { Time } 1 \\
\text { (min) }\end{array}$ & 19.35 \\
\hline C & $\begin{array}{l}\text { Time } 2 \\
\text { (min) }\end{array}$ & 0.12 \\
\hline D & Temp. $\left({ }^{\circ} \mathrm{C}\right)$ & 30.35 \\
\hline curvature & - & 31.94 \\
\hline E & TMB (equiv) & 2.77 \\
\hline$A B$ & \multirow{6}{*}{$\begin{array}{l}\text { Interaction } \\
\text { Terms }\end{array}$} & 1.85 \\
\hline$A C$ & & 1.09 \\
\hline$A D$ & & 3.81 \\
\hline$A E$ & & 0.12 \\
\hline BC & & 0.03 \\
\hline $\mathrm{BE}$ & & 0.82 \\
\hline Pure error & - & 0.033 \\
\hline $\begin{array}{l}\text { Table 2. Co } \\
\text { interaction } \\
\text { shown (cal } \\
\text { software). }\end{array}$ & $\begin{array}{l}\text { ntribution of } \\
\text { is and curvatu } \\
\text { culated with }\end{array}$ & $\begin{array}{l}\text { Sum = 100\% } \\
\text { factors, } \\
\text { re to yield are } \\
\text { Pesign Expert }\end{array}$ \\
\hline
\end{tabular}
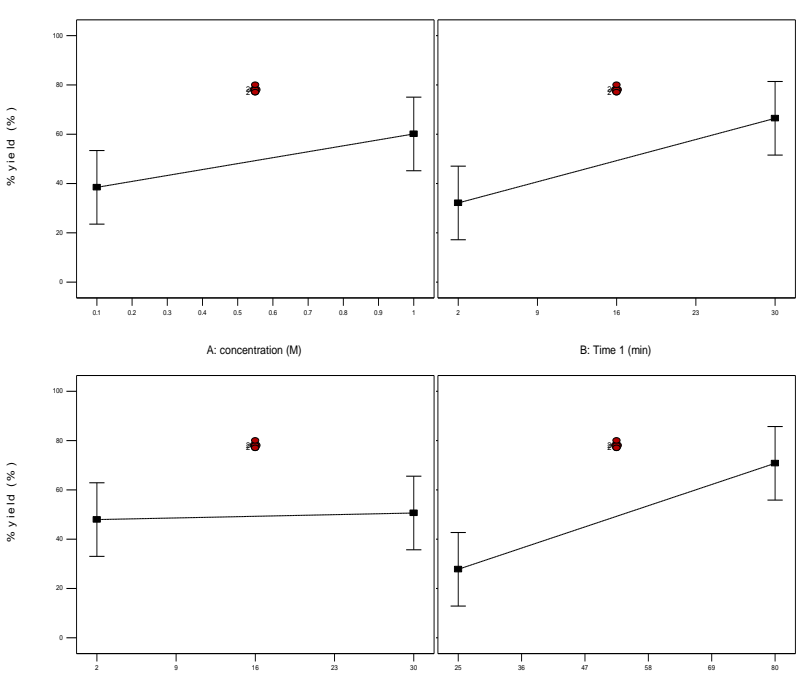

Figure 22. Plots of effects $A, B, C, D, E$. Five center point runs are also shown in each plot. In each plot, the $x$-axis runs from the low to the high value and the $y$-axis from $0 \%$ to $100 \%$.

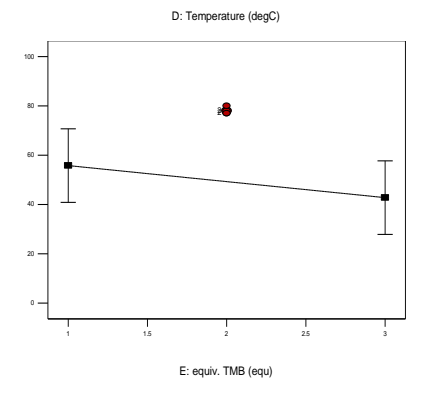

\subsubsection{Full Factorial to assess interaction effects of A, B, C, D}

The full factorial design allows identification of interactions between factors (Figure 16,

Phase 1). This design, with the four factors selected in the previous design, required sixteen experiments. It would be possible to have first run the full-factorial and skipped the fractional factorial design altogether. However, the total number of runs is equal to the number of levels raised to number of factors under study. This optimization was started with five factors, studied at two levels. Starting with a full factorial in lieu of the fractional factorial design would have required 25 , or 32 , experiments. Some replicate points would still be needed to estimate experimental error. If Time 2 had been 
omitted from further study then the total number of experiments at this point would have been twenty-five: seventeen from the Placket Burman plus another eight for the full factorial with factors A, B, D. Hence, the stepwise approach to the methodology in Figure 16 is aimed at increasing efficiency of the overall process and this benefit should increase with the number of factors initially selected for study.

\begin{tabular}{|llll|}
\hline Factor & Description $^{b}$ & low level & high level $^{a}$ \\
A & Conc. (M) & $0.1(-1)$ & $1 \quad(1)$ \\
B & Time 2 (min) & $2(-1)$ & $30(1)$ \\
C & Time $1(\min )$ & $2(-1)$ & $30(1)$ \\
D & Temp. $\left({ }^{\circ} \mathrm{C}\right)$ & $25(-1)$ & $80(1)$ \\
Table 3. Summary of full factorial design. & & \\
\hline
\end{tabular}

\begin{tabular}{|c|c|c|c|c|}
\hline Factor & Description & $\begin{array}{l}\text { Standardized } \\
\text { Effect }\end{array}$ & $\begin{array}{l}\text { Sum of } \\
\text { Squares }\end{array}$ & $\%$ Contribution \\
\hline A-Conc & Temp. $\left({ }^{\circ} \mathrm{C}\right)$ & 20.27 & 1642.37 & 10.93 \\
\hline B-Time 1 & Time 1 (min) & 21.32 & 1817.60 & 12.09 \\
\hline C-Time 2 & Time 2 (min) & -1.41 & 8.42 & 0.056 \\
\hline D-temperature & Conc. (M) & 52.25 & 10918.68 & 72.65 \\
\hline$A B$ & \multirow{11}{*}{$\begin{array}{l}\text { Interaction } \\
\text { Terms }\end{array}$} & 3.37 & 45.39 & 0.30 \\
\hline$A C$ & & -0.55 & 1.18 & 7.87E-003 \\
\hline$A D$ & & 6.04 & 145.87 & 0.97 \\
\hline $\mathrm{BC}$ & & 1.4 & 7.97 & 0.053 \\
\hline BD & & 0.059 & 0.014 & 9.19E-005 \\
\hline$C D$ & & -2.01 & 16.64 & 0.11 \\
\hline$A B C$ & & 1.38 & 7.71 & 0.051 \\
\hline ABD & & -10.19 & 415.24 & 2.76 \\
\hline$A C D$ & & 0.50 & 0.98 & $6.49 \mathrm{E}-003$ \\
\hline$B C D$ & & 0.52 & 1.21 & 8.03E-003 \\
\hline$A B C D$ & & 0.34 & 0.54 & $3.57 \mathrm{E}-003$ \\
\hline
\end{tabular}




\begin{tabular}{|c|c|c|c|c|}
\hline & & Results & & Conclusion \\
\hline F-value & 388.83 & $\begin{array}{l}\text { p-value } \\
(\text { Prob }>F)\end{array}$ & $<0.0001$ & $\begin{array}{l}\text { The model is significant and there a } \\
0.01 \% \text { chance this F-value could be } \\
\text { due to noise }\end{array}$ \\
\hline Std. Dev. & 2.35 & R-Squared & 0.9971 & Predicted and Adjusted R-Squared \\
\hline Mean & 45.69 & Adj. R-Squared & 0.9945 & $\begin{array}{l}\text { values are }<0.2 \text { apart, indicating the } \\
\text { model is appropriate for the data }\end{array}$ \\
\hline CV\% & 5.14 & Pred R-Squared & 0.9883 & collected \\
\hline PRESS & 176.35 & Adeq Precision & 50.456 & $\begin{array}{l}\text { This model can be used to navigate } \\
\text { the design space due to sufficient } \\
\text { signal-to-noise ratio. }\end{array}$ \\
\hline
\end{tabular}

The model at this point linear and already has good value for prediction. The linear equations including main effects and interaction effects are shown below. Readers are encouraged to pay particular attention to Figures 23,24 and 25 as they graphically show the importance of interaction effects. Note that because each factor is varied over two levels, it is possible to code the lower level as (-1) and the higher level as (1). The coded factors are each varied over the same range and so their contribution to the output may be directly compared and their relative importance assessed. The relative contribution of factors $A, B, D$ and their interaction effects, $A B, A D, B D$ and $A B D$ can be seen Table 5 . The equation using the actual levels is predictive within the tested design space. That is, the equation in terms of actual factors may be used to navigate the design space, but should not be used to extrapolate beyond the tested design. 

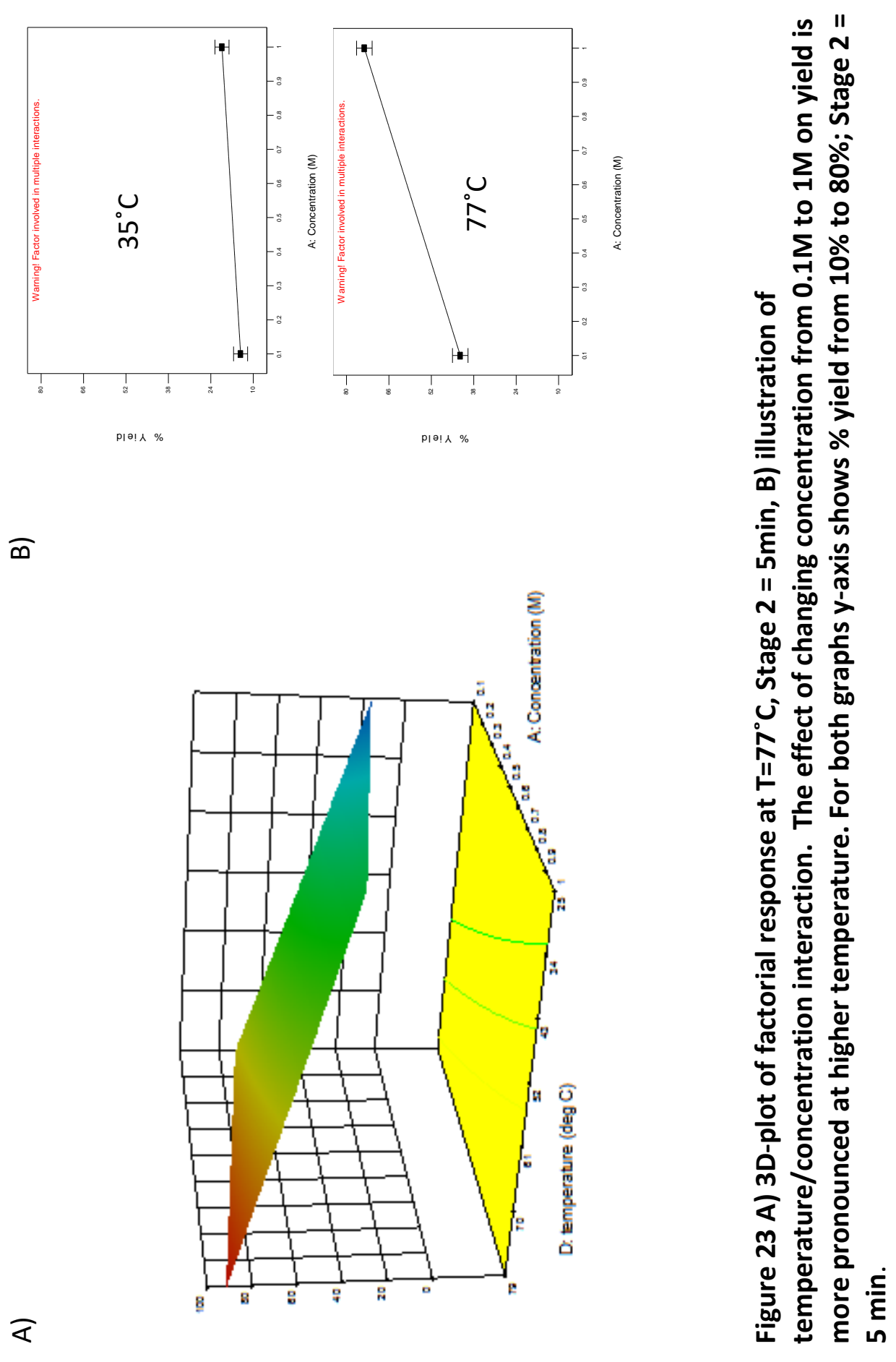

руәщᄊ ж 


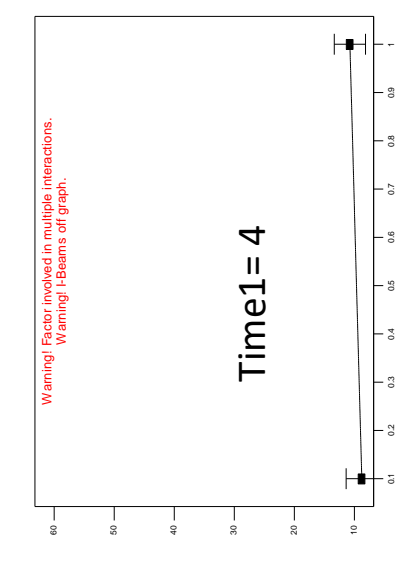

p|ә!ᄉ \%

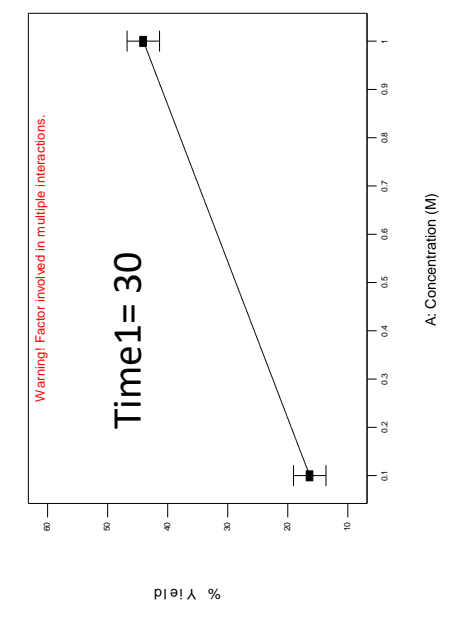

$\widetilde{\infty}$

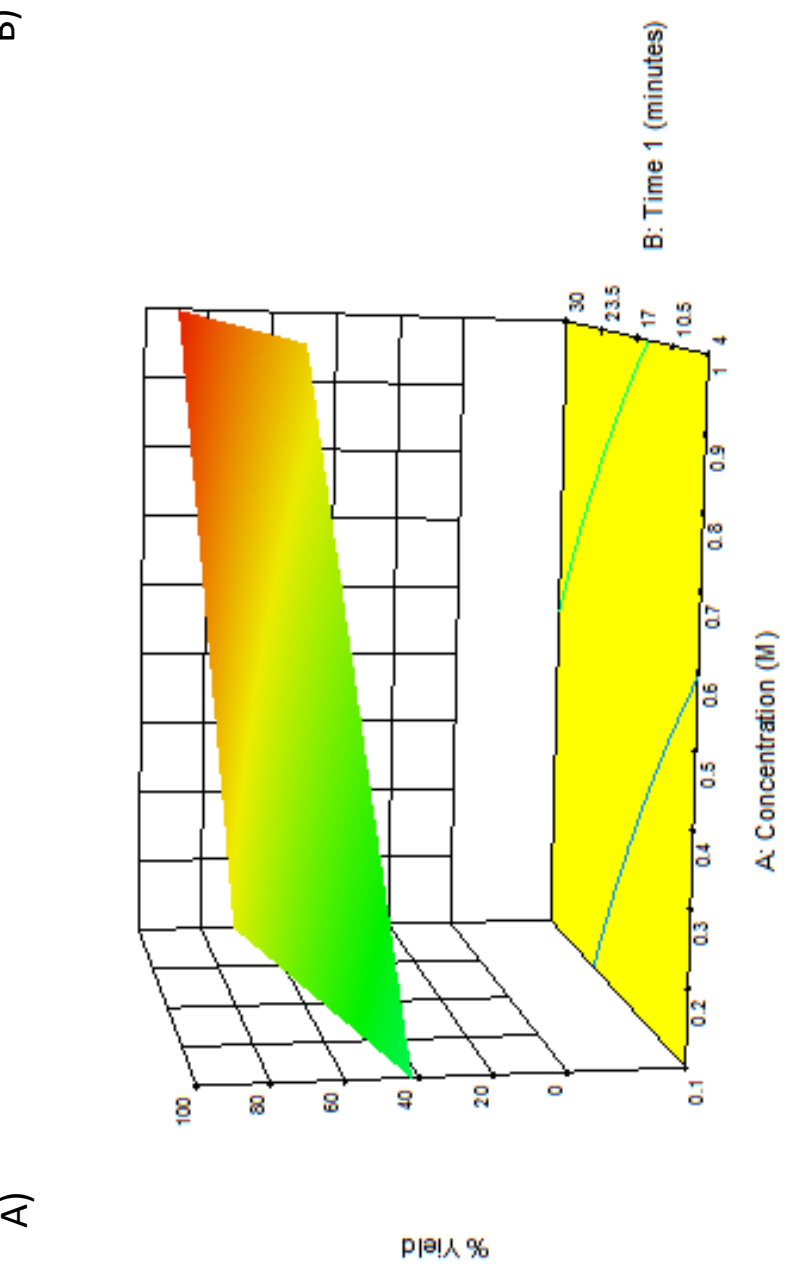

미리 \%

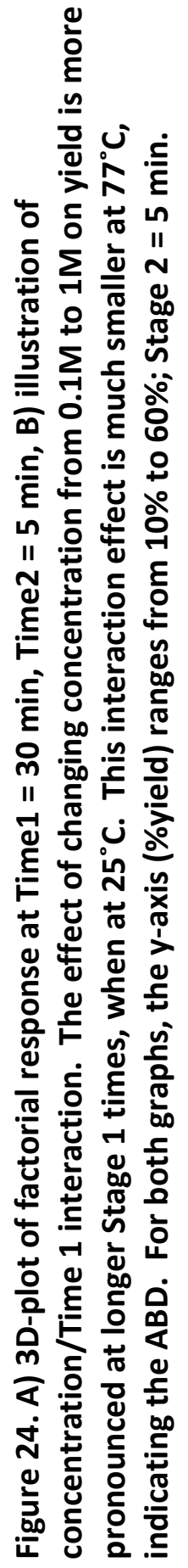




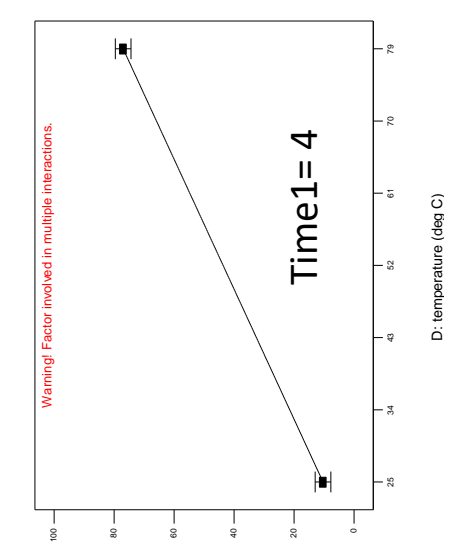

미키 $\%$

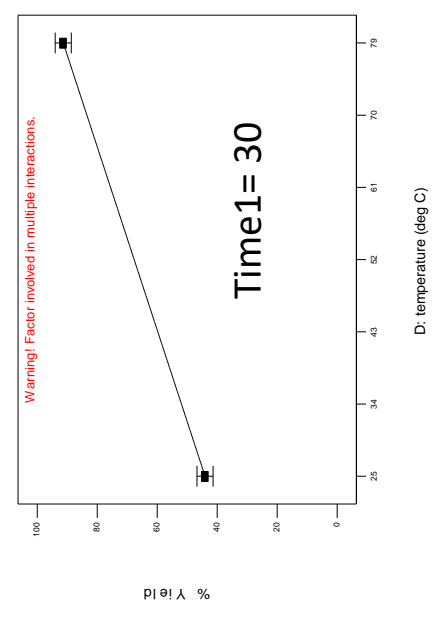

$\widehat{\infty}$

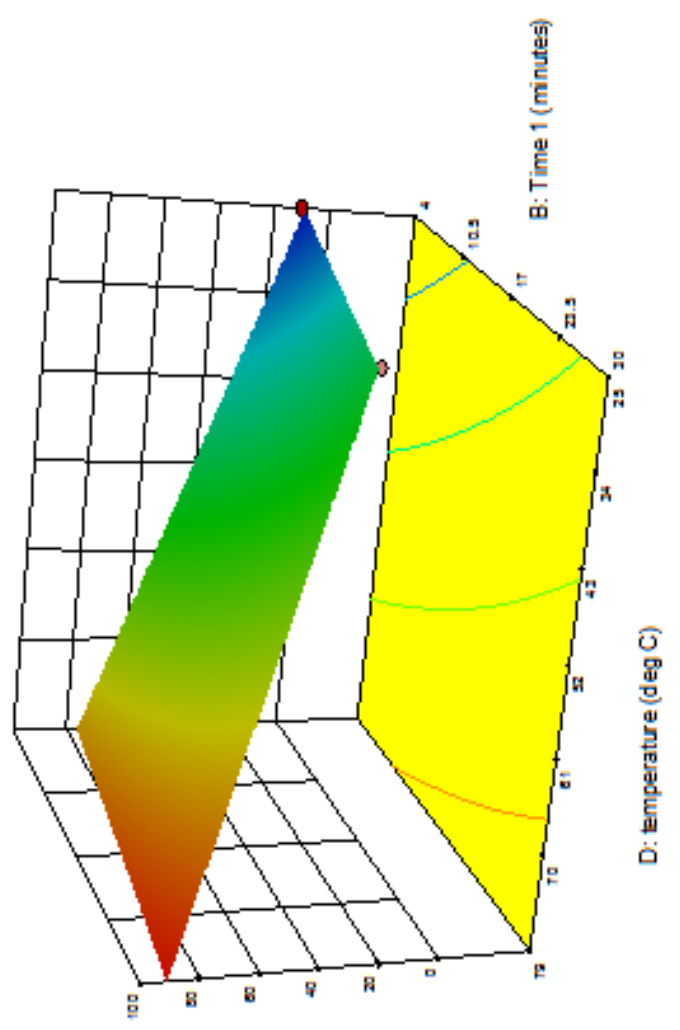

๔

ріәپ ж

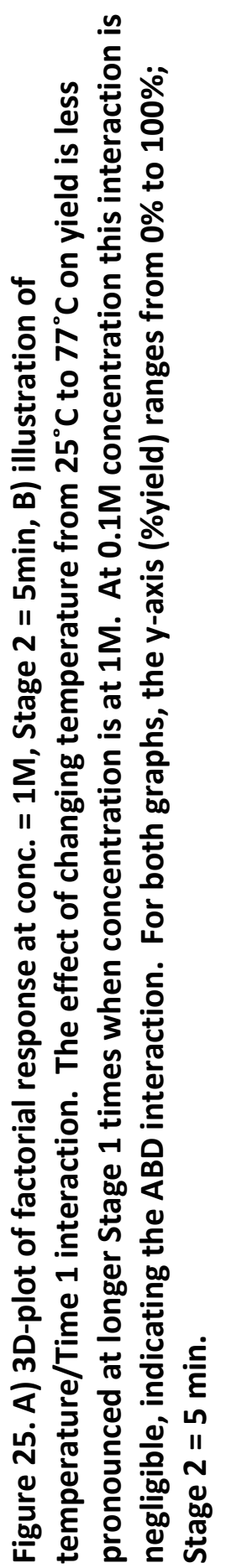




\subsubsection{Optimization via a Response Surface Model (RSM)}

Results from the factorial design above are augmented with additional points necessary to apply a quadratic model. Ten additional points were needed to achieve the response surface in Figure 26 . The additional points were applied in a face-centered design with respect to the factorial model discussed above. Additional points were then taken to confirm the model. Confirmation runs were performed in triplicate (Table 9). The results and model equation based on actual factors are given in Table 7 . The evaluation of the results, as calculated by Design Expert, is given in Table 7.

\begin{tabular}{|c|c|c|c|c|c|c|}
\hline \multicolumn{2}{|c|}{ Factor } & \multicolumn{2}{|c|}{ Description } & Sum of Squares & F-value & $\begin{array}{l}\text { p-value } \\
\text { Prob > F }\end{array}$ \\
\hline \multicolumn{2}{|c|}{ A-Concentration } & & 2067.46 & 37.36 & $<0.0001$ \\
\hline \multicolumn{2}{|c|}{ B-Time 1} & \multicolumn{2}{|l|}{ Time 1 ( $\min )$} & 1559.98 & 19.64 & 0.0002 \\
\hline \multicolumn{2}{|c|}{ D-temperature } & \multicolumn{2}{|l|}{ Conc. (M) } & 13732.11 & 14.82 & 0.0009 \\
\hline \multicolumn{2}{|c|}{$A^{2}$} & \multirow{2}{*}{\multicolumn{2}{|c|}{ Quadratic terms }} & 291.92 & 130.47 & $<0.0001$ \\
\hline \multicolumn{2}{|l|}{$D^{2}$} & & & 1152.60 & 2.77 & 0.1107 \\
\hline \multicolumn{7}{|c|}{$\begin{array}{l}\text { Equation based on actual factors: } \\
\% \text { yield }=73.8+10.7 A+9.3 B+27.6 D-10.2 A^{2}-20.2 D^{2}\end{array}$} \\
\hline & & Results & & & clusion & \\
\hline F-value & 37.36 & $\begin{array}{l}\text { p-value } \\
\text { (Prob > F) }\end{array}$ & $<0.0001$ & $\begin{array}{l}\text { The model is } \mathrm{S} \\
\text { chance this F-l }\end{array}$ & $\begin{array}{l}\text { ant and } t \\
\text { ould be }\end{array}$ & $\begin{array}{l}.01 \% \\
\text { toise }\end{array}$ \\
\hline $\begin{array}{l}\text { Std. } \\
\text { Dev. }\end{array}$ & 10.26 & R-Squared & & Predicted and & ted R-Squ & alues are \\
\hline Mean & 54.85 & Adj. R-Squared & 0.8749 & $\begin{array}{l}<0.2 \text { apart, ind } \\
\text { for the data co }\end{array}$ & $\begin{array}{l}g \text { the mo } \\
d\end{array}$ & propriate \\
\hline CV\% & 18.7 & Pred R-Squared & 0.8247 & & & \\
\hline PRESS & 3833.68 & Adeq Precision & 18.578 & $\begin{array}{l}\text { This model car } \\
\text { space due to s }\end{array}$ & $\begin{array}{l}\text { sed to na } \\
\text { nt signal }\end{array}$ & $\begin{array}{l}\text { he design } \\
\text { e ratio. }\end{array}$ \\
\hline
\end{tabular}




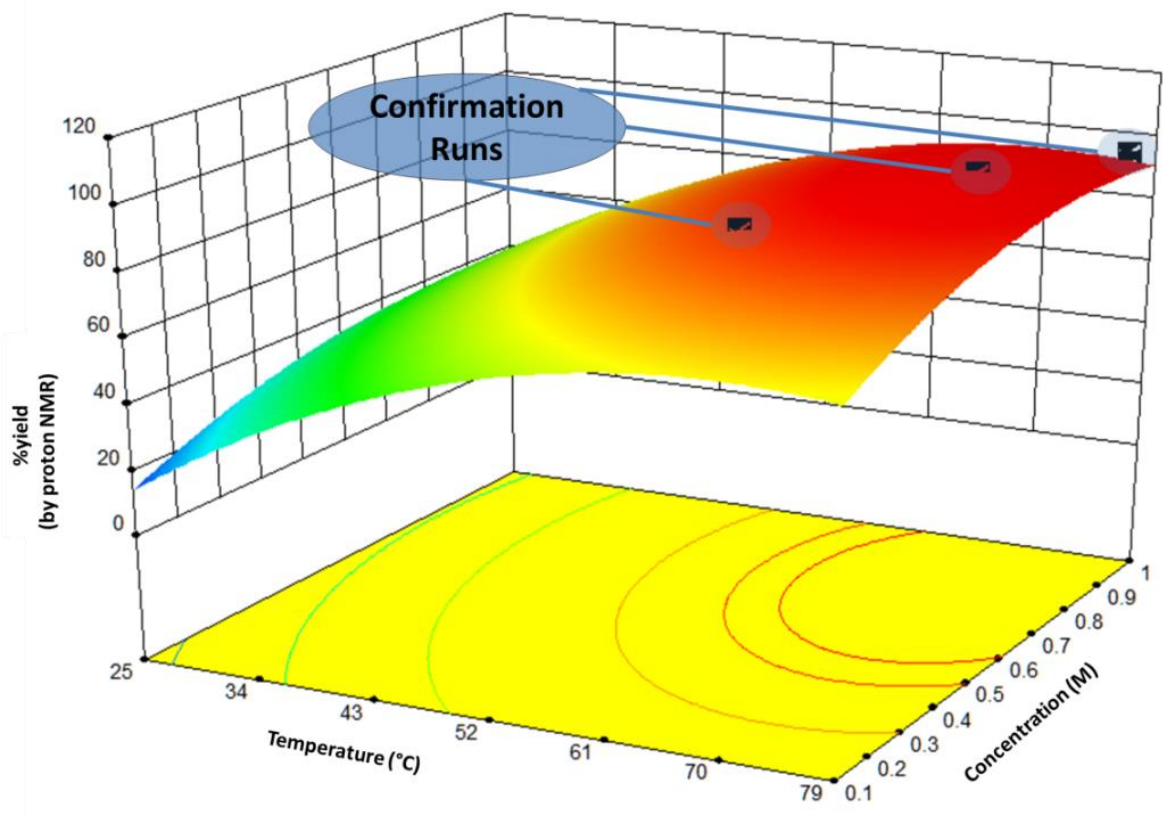

Figure 26. Results of optimization. The model shown has predictive value. Triplicate $0.2 \mathrm{mmol}$ scale confirmation runs are shown.

$\begin{array}{lllllll}\text { Conc. }(\mathrm{M}) & \text { Time1 }(\mathrm{min}) & \text { Time2 }(\mathrm{min}) & \text { Temp }(\mathrm{C}) & \text { Yield }(\%) & \text { Predicted }(\%) & \text { Scale }(\mathrm{mmol}) \\ 1.0 & 30 & 5 & 77 & 94+/-1.7 & 92+/-10 & 5 \\ 0.8 & 30 & 5 & 70 & 93+/-3.3 & 95+/-10 & 5 \\ 0.5 & 30 & 5 & 60 & 89+/-0.3 & 88+/-10 & 5\end{array}$

Table 9. Data for confirmation runs of RSM ( $n=3)$

\subsubsection{Conclusion}

Figure 28 shows the published scope of materials prepared to our procedure. Some examples of diaryliodonium salts that were challenging to make are presented at the end of this chapter and feasibility is demonstrated for a modified procedure that may enable access to challenging diaryliodonium salts. 
The aryl(TMP)iodonium tosylates we have encountered have good bench stability and may be stored indefinitely at $4{ }^{\circ} \mathrm{C}$ or colder. Compared to existing procedures, our method has a broader substrate scope, as good or better functional group tolerance and works well with elaborate iodoarenes (Figure 24: 27, 29, 30). An unforeseen benefit of the tosylate group is that it readily lends itself to anion exchange (Figure 27).

$\mathbf{X}=\mathbf{C F}_{\mathbf{3}} \mathbf{C O O}, 86 \%$
$\mathbf{X}=\mathbf{I}, 94 \%$ (from KI)
$\mathbf{X}=\mathbf{O T f}, 90 \%$
$\mathbf{X}=\mathbf{P F}_{6}, 90 \%$ (from $\left.\mathrm{KPF}_{6}\right)$
$\mathbf{X}=\mathbf{B F}, 96 \%$
$\mathbf{X}=\mathbf{B r}, 96 \%$

Figure 27. Ion exchange is facile as demonstrated here with biphenyl(TMP)iodonium tosylate.

The procedure is scalable and has been run between $0.2 \mathrm{mmol}$ and $50 \mathrm{mmol}$ scale without noticeable effect on yield. Starting materials that feed the development of diaryliodonium mediated chemistry are now more readily available and preparation time has been reduced from two days to less than 2 hours. This contribution was recognized as a key factor in the expedient development of novel benzyne reactivity that was recently published by the Stuart Research Group. Additionally, the broadened substrate scope of accessible diaryliodonium starting materials has enabled access to etherification of electron rich and elaborate arenes. Both of these advancements are examples of limitations in arylation chemistry with diaryliodonium salts that are precedented in the literature and have now been significantly improved. 


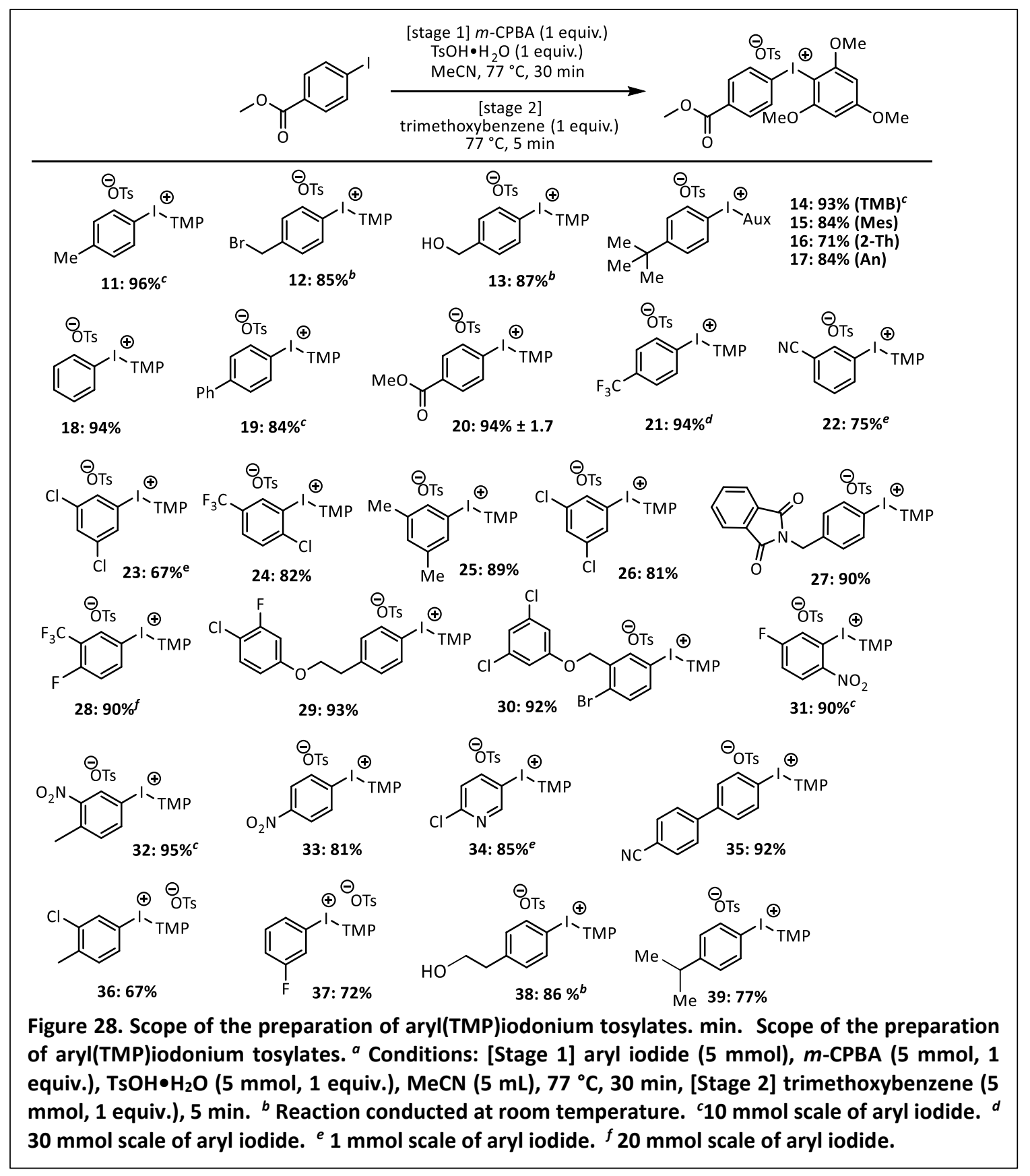

\subsubsection{Stability Studies}

As previously mentioned, diaryliodonium salts are used as photo-acid generators and will degrade rapidly upon exposure to UV light. Direct exposure to UV, including direct sunlight through a window will degrade many diaryliodonium salts in less than one day. 
In order to gauge their bench stability in the laboratory, a qualitative stability study was performed. Samples in clear/transparent scintillation vials were placed on a window sill. Control samples, wrapped in aluminum foil, were placed near the window as well. The control samples did not appear to be degraded upon visual inspection at any point during the study. Figure 29 shows results for two aryl(TMP)liodonium salts, one with an electron poor arene and one electron rich. The tosylate salts appear to be generally more stable than the hexafluorophosphate salts. Thermal stability was tested using DSC and results are also shown in Figure 29.

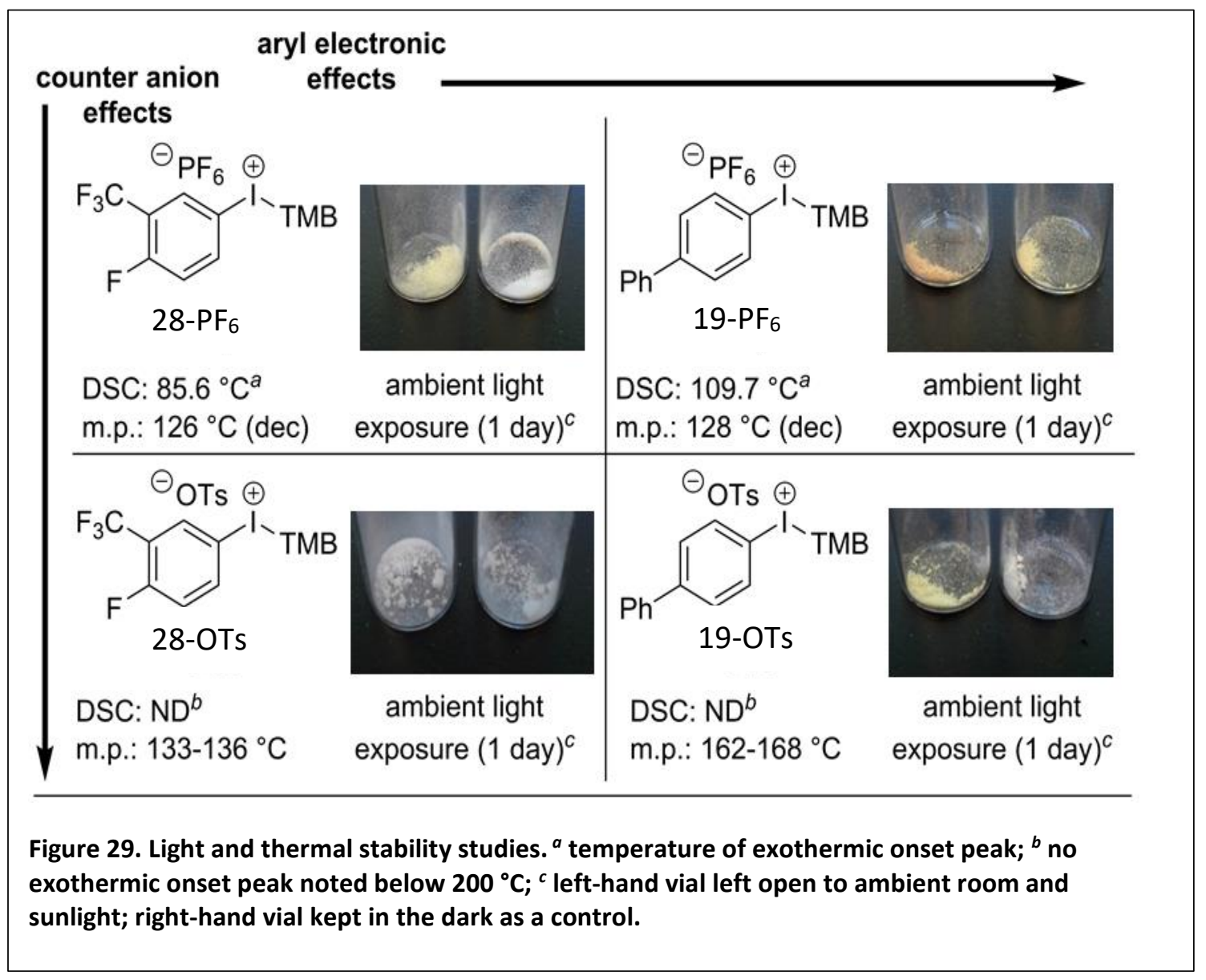


The internal reaction temperature was also monitored in order to be aware of potential exothermic events, since even the possibility of a run-away reaction must be taken seriously. This data was collected with an in-situ temperature probe and readings were manually recorded from a digital readout. Two trials were performed, one at ambient temperature with no heat bath and the other in a $77^{\circ} \mathrm{C}$ silicone oil bath.

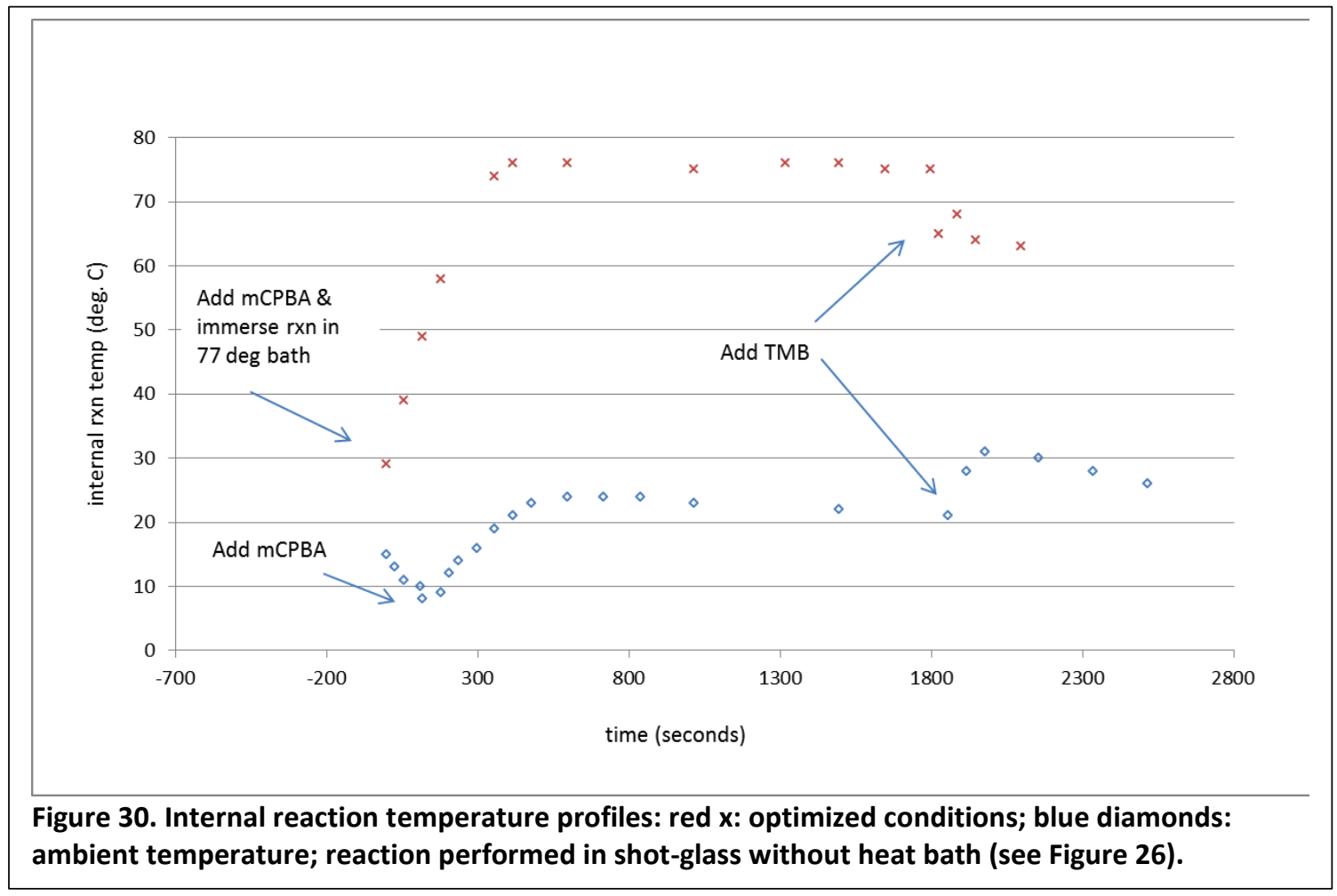




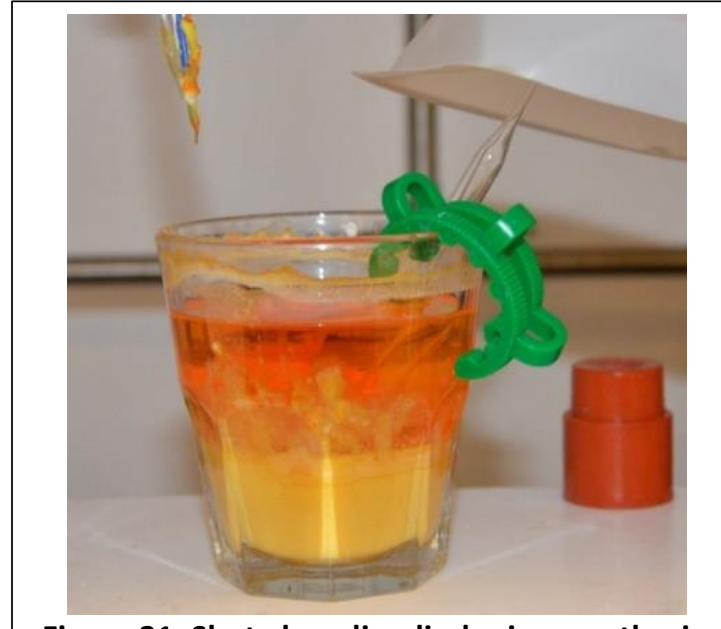

Figure 31. Shot glass diaryliodonium synthesis.
The results are shown in Figure 30. Note that the ambient temperature trial exhibits exothermic and endothermic events that are attributed to the reaction progressing as well as dissolution of freshly added reagent. The apparatus for the ambient temperature reaction is shown in Figure

31. The $77^{\circ} \mathrm{C}$ reaction has an uneventful temperature profile and was removed from the heat bath at about $35 \mathrm{~min}$ ( $2100 \mathrm{sec}$.$) . This indicates that a standard silicone oil bath$ without agitation provides sufficient heat exchange to control the reaction temperature.

\subsection{Applications}

a) with $C_{-}, N_{-}, O_{-}, S$-nucleophiles<smiles>CCOC(=O)C1(c2ccc(-c3ccccc3)cc2)CCCCC1=O</smiles>

40: $55 \%$

43: $78 \%$

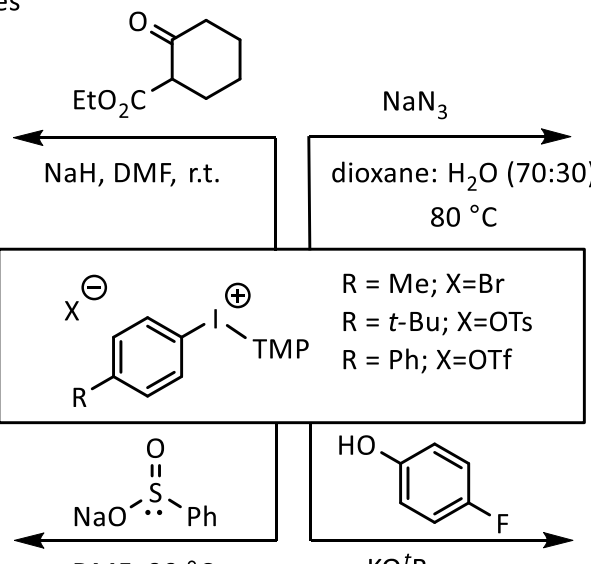

$\mathrm{KO}^{t} \mathrm{Bu}$,<smiles>[R]c1ccc([N])cc1</smiles>

41: $\mathrm{R}=t-\mathrm{Bu}, 63 \%$

42: $\mathrm{R}=\mathrm{Ph}, 72 \%$ toluene, $40^{\circ} \mathrm{C}$

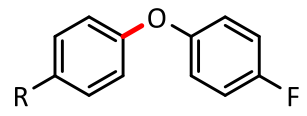

44: $R=M e, 85 \%$

45: $\mathrm{R}=\mathrm{Ph}, 80 \%$

b) in a liquid-crystal synthesis<smiles>CCCCCCCCO</smiles><smiles>CCCCCCCOc1ccc(-c2ccc(C#N)cc2)cc1</smiles>

Figure 32. Synthetic examples using aryl(TMB)iodonium salts. Reactions were not optimized. 
Figure 32 shows several application examples of the aryl(TMP)iodonium salts. The examples underscore the wide substrate scope that diaryliodonium salts can accommodate. Good to excellent yields were achieved with $C_{-}, N_{-}, \mathrm{O}-$, $S$-nucleophiles. None of the reactions shown in Figure 32 were optimized. 


\subsection{Preparation of (4-methylbenzoate) $\left(2^{\prime}, 4^{\prime}, 6^{\prime}\right.$-trimethoxyphenyl)iodonium tosylate}

With the intention of increasing awareness of diaryliodonium salts worldwide, the synthesis developed in Chapter 2 has been submitted to the journal Organic Synthesis. The purpose of this journal is to provide organic chemists with a source of experimentally checked procedures. At the time of this writing, the checking process at Org Syn is in progress. Dr. Katherine Liebman, an experienced researcher and synthetic organic chemist at Portland State University, kindly volunteered to perform the procedure stated below. Both the author and Dr. Liebman carried out the procedure on different days, using the same equipment, and obtained pure product in $91 \%$ yield on 50 mmol scale. Dr. Liebman carried out this synthesis for the first time without input beyond the written procedure.

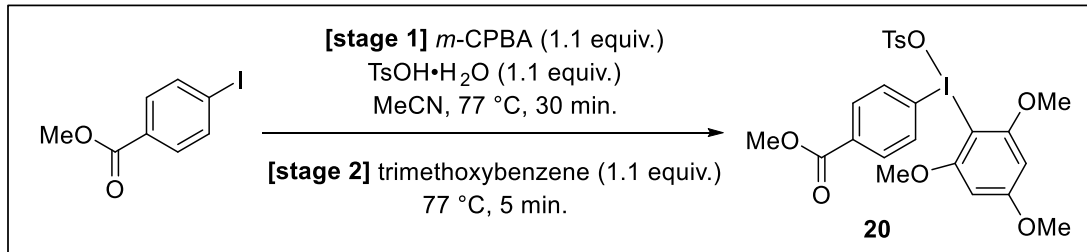

Figure 33. Synthesis of the title compound

An oil bath (Note 1 ) is heated to $77^{\circ} \mathrm{C}$ with a digitally controlled hot-plate/stirrer, which is on a lab jack. A 500-mL two-neck (24/40) round-bottom flask equipped with a Tefloncoated magnetic stir bar ( $25 \mathrm{~mm} \times 15 \mathrm{~mm}$, elliptical) is clamped above the oil bath (Note 2). A jacketed, water-cooled, reflux condenser (24/40) and a powder funnel (24/40, glass or polypropylene) are placed on each neck of the round bottom flask as shown in 
Figure 34A. Methyl-4-iodobenzoate (Note 3) (13.1 g, $50.0 \mathrm{mmol}, 1$ equiv.) and $p$ toluenesulfonic acid monohydrate (Note 4) (9.5 g, $50.0 \mathrm{mmol}, 1$ equiv.) are weighed out and transferred sequentially into the round bottom flask via the powder funnel. Acetonitrile (Note 5) $(40 \mathrm{~mL})$ is added to the round bottom flask through the powder funnel. The reagents are vigorously stirred (Note 6) while still outside the oil bath (Figure 34B). m-Chloroperoxybenzoic acid (Note 7) (10.7 g, $50.0 \mathrm{mmol}, 1$ equiv.) is weighed out and added to the round bottom flask through the powder funnel. An additional $10 \mathrm{~mL}$ of acetonitrile is used to wash residual powder on the funnel into the flask. The powder funnel is replaced with a stopper (24/40; ground glass or Teflon), which is secured with a Keck clip. The lab jack is raised until the solvent line of the reaction is below the surface of the pre-heated oil bath (Figure 34C). The reaction mixture is stirred at $77^{\circ} \mathrm{C}$ (bath temperature) for 30 minutes. A fleeting yellow color may develop, followed by formation of thick slurry (Figure 34C) (Note 8).

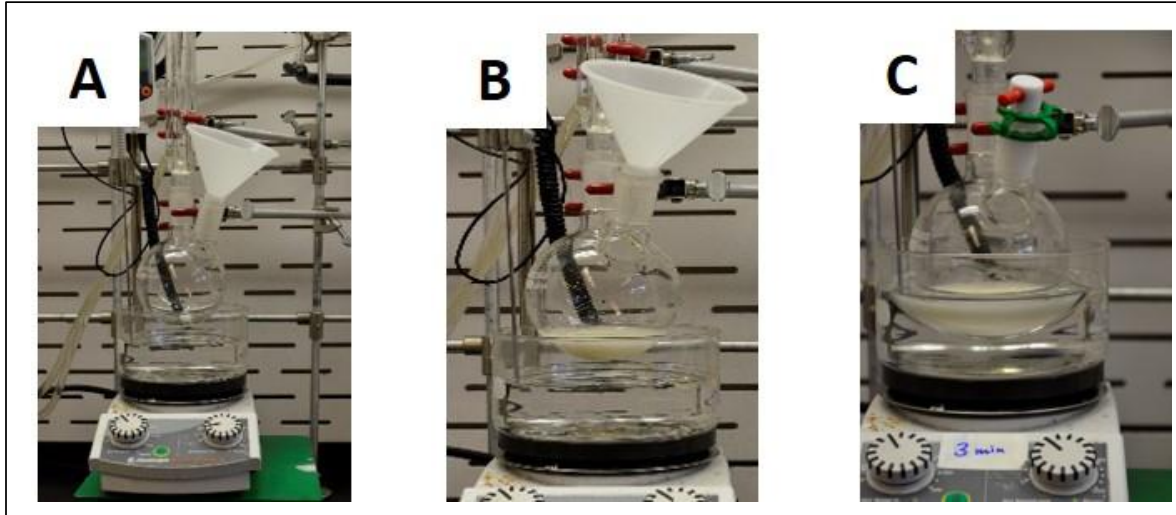

Figure 34. A) reaction set-up; B) addition of reagents and solvent outside the oil bath; C) thick slurry formed after 3 minutes at $77^{\circ} \mathrm{C}$. 
The stopper is removed and 1,3,5-trimethoxybenzene (Note 9) (8.4 g, $50.0 \mathrm{mmol}, 1$ equiv.) is added to the reaction via the powder funnel (Note 10). The stopper is replaced on the round bottom flask, secured with a Keck clip, and the reaction is stirred at $77^{\circ} \mathrm{C}$ for 5 minutes. Upon addition of trimethoxybenzene, the slurry (Figure 34C) dissolves immediately and the homogeneous solution becomes a deep amber color (Figure 35A). The lab jack is lowered and the reaction mixture is allowed to air-cool for 5 minutes with continued stirring. The reaction color lightens to an opaque orange upon cooling (Figure 35B).

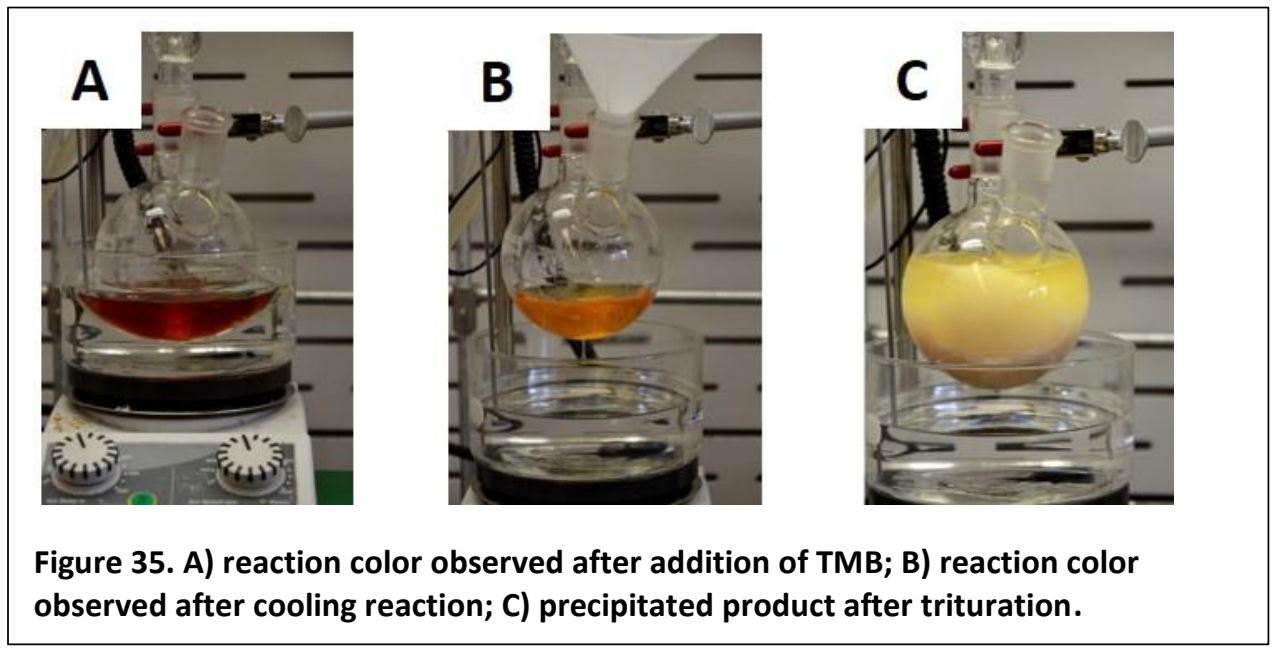

The reaction product, $\mathbf{2 0}$, is triturated from the reaction mixture by addition of diethyl ether (Note 11) (300 mL) and the mixture is stirred at room temperature for 15 minutes, during which time, an off-white precipitate forms in a light yellow mother liquor (Figure 35C). Product, 20, is isolated by suction filtration of the reaction mixture using a 150$\mathrm{mL}$, medium porosity, fritted-glass funnel. The precipitate is rinsed with diethyl ether (3 $\times 40 \mathrm{~mL}$ ) (Figure 36A). During each rinse cycle, suction is interrupted suction, the filter 
cake re-suspended in diethyl ether, and any clumps are broken up with a spatula before suction is resumed in order to remove the rinse solution (Note 12) (Figure 36B). The filtrate discarded. The product is left under suction for 5 minutes, the filter cake is broken up into a powder using a spatula that is left under suction for an additional 15 minutes. The product, $\mathbf{2 0}$, is obtained as a free-flowing, off-white to pale pink powder (27.3 g, $45.5 \mathrm{mmol}, 91 \%$ ) (Figure 36C). The product was determined to be $97.9 \mathrm{wt} \%$ pure by qNMR (Note 13, 14, and 15).

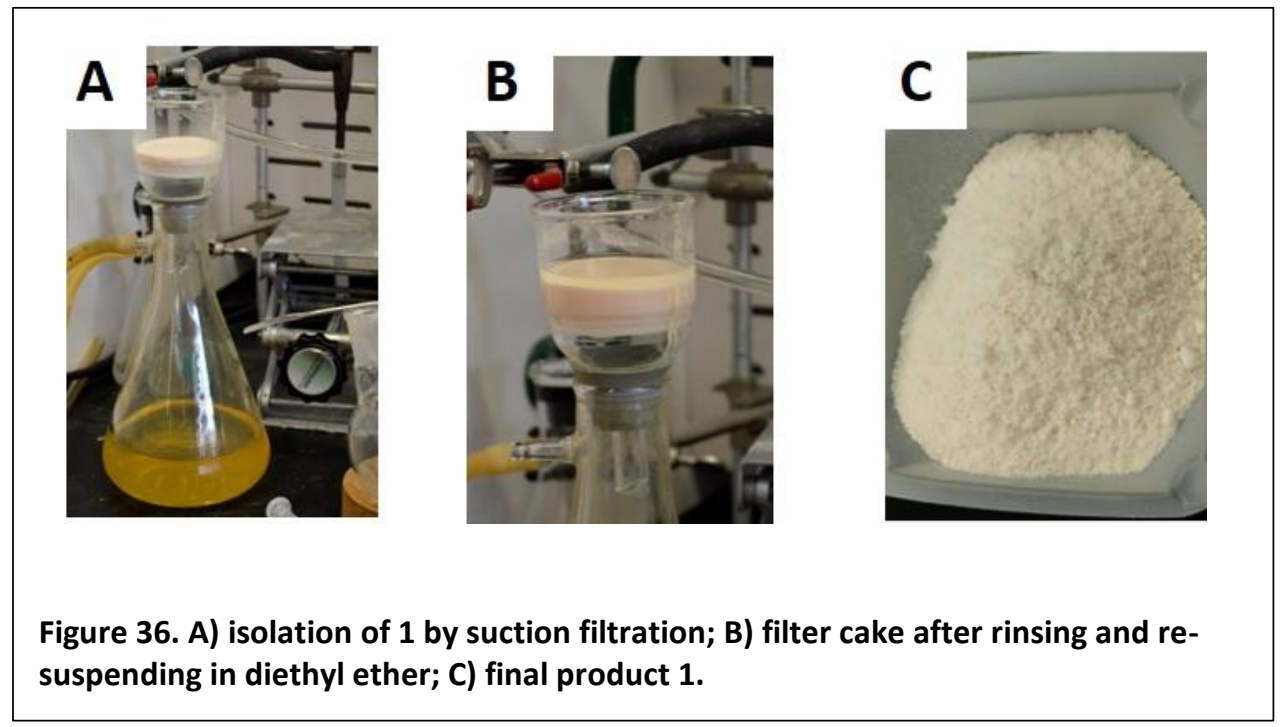

Notes \& Safety:

1. The oil bath is prepared in a crystallization dish $(8 \mathrm{~cm} \times 15 \mathrm{~cm})$ half-filled with silicon oil.

2. The round bottom flask should not be immersed in the oil bath, until indicated in the instructions.

3. Methyl-4-iodobenzoate was purchased from (Oakwood, 079685, 99\% used as received. 
4. -Toluenesulfonic acid monohydrate was purchased from (Sigma Aldrich, T35920, Reagent Plus $\geq 98 \%$, used as received.

5. Acetonitrile was purchased from VWR

6. $m$-Chloroperoxybenzoic acid was purchased from (Aldrich, $273031, \leq 77 \%$ ) and dried under vacuum until the flask was no longer cool to touch.

7. The stir bar will continue to agitate the reaction, no additional solvent is necessary.

8. 1,3,5-Trimethoxybenzene was purchased from (Aldrich, 138827, $\geq 99 \%$ ), used as received.

9. The round bottom flask is not removed from the oil bath during addition of 1,3,5trimethoxybenzene. Additional acetonitrile (up to $10 \mathrm{~mL}$ ) may be used to wash any precipitate stuck to the side walls of the round bottom flask.

10. Diethyl ether was purchased from (Fisher, ACS grade and as used as received)

11. The diethyl ether rinse solvent can also be used to wash out the $500 \mathrm{~mL}$ round bottom flask into the filter funnel.

12. The purity of $\mathbf{2 0}$ (MW 600.4; $57.8 \mathrm{mg}$ ) was determined by qNMR in DMSO- $d_{6}$ as solvent and 4,4'-dihydroxybiphenyl (> 99 wt\% purity; MW 186.2; $15.2 \mathrm{mg}$ ) as internal standard; the relaxation time (D1) set to 30 seconds.

13. The remaining $\sim 2 \mathrm{wt} \%$ was residual solvent (acetonitrile and diethyl ether) which we were unable to remove even when the sample was placed under reduced pressure.

14. Characterization of 20: ${ }^{1} \mathrm{H}$ NMR (400 MHz, DMSO- $\left.d_{6}\right) \delta 8.06$ (d, $\left.J=8.4 \mathrm{~Hz}, 2 \mathrm{H}\right), 7.96$ (d, $J=8.5 \mathrm{~Hz}, 2 \mathrm{H}), 7.49$ (d, $J=7.9 \mathrm{~Hz}, 2 \mathrm{H}), 7.11(\mathrm{~d}, J=7.8 \mathrm{~Hz}, 2 \mathrm{H}), 6.49(\mathrm{~s}, 2 \mathrm{H}), 3.95(\mathrm{~s}, 6 \mathrm{H})$, $3.88(\mathrm{~s}, 3 \mathrm{H}), 3.86(\mathrm{~s}, 3 \mathrm{H}), 2.28(\mathrm{~s}, 3 \mathrm{H}) .{ }^{13} \mathrm{C} \mathrm{NMR}\left(101 \mathrm{MHz}, \mathrm{DMSO}-d_{6}\right) \delta 166.3,165.1$, $159.4,145.5,137.6,134.5,132.0,131.7,128.0,125.4,121.0,92.1,86.7,57.3,56.1$, 52.6, 20.7. FT-IR: 3041, 2949, 2842, 1721, 1646, 1582, 1457, 1343, 1282, 1186, 1034, 
$816 \mathrm{~cm}^{-1}$. HRMS $\left(\mathrm{ESI}^{+}\right)$: Calculated for $\mathrm{C}_{17} \mathrm{H}_{18} \mathrm{IO}_{5}{ }^{+}$[M - OTs $]^{+}$: 429.0193; Observed 429.0167. Melting point: $169-175{ }^{\circ} \mathrm{C}$. 


\subsection{Future directions: $A r y l(T M B)$ iodonium tosylates}

\subsubsection{Limitations}

During the development efforts described in section 2.1 it became clear that some limitations exist. Figure 37 shows various diaryliodonium salts that proved to be challenging to make, as they failed to produce diaryliodonium salts in synthetically useful yield and purity. Depending on the substrate, the failure appeared to occur during the initial oxidation step or during installation of the auxiliary.

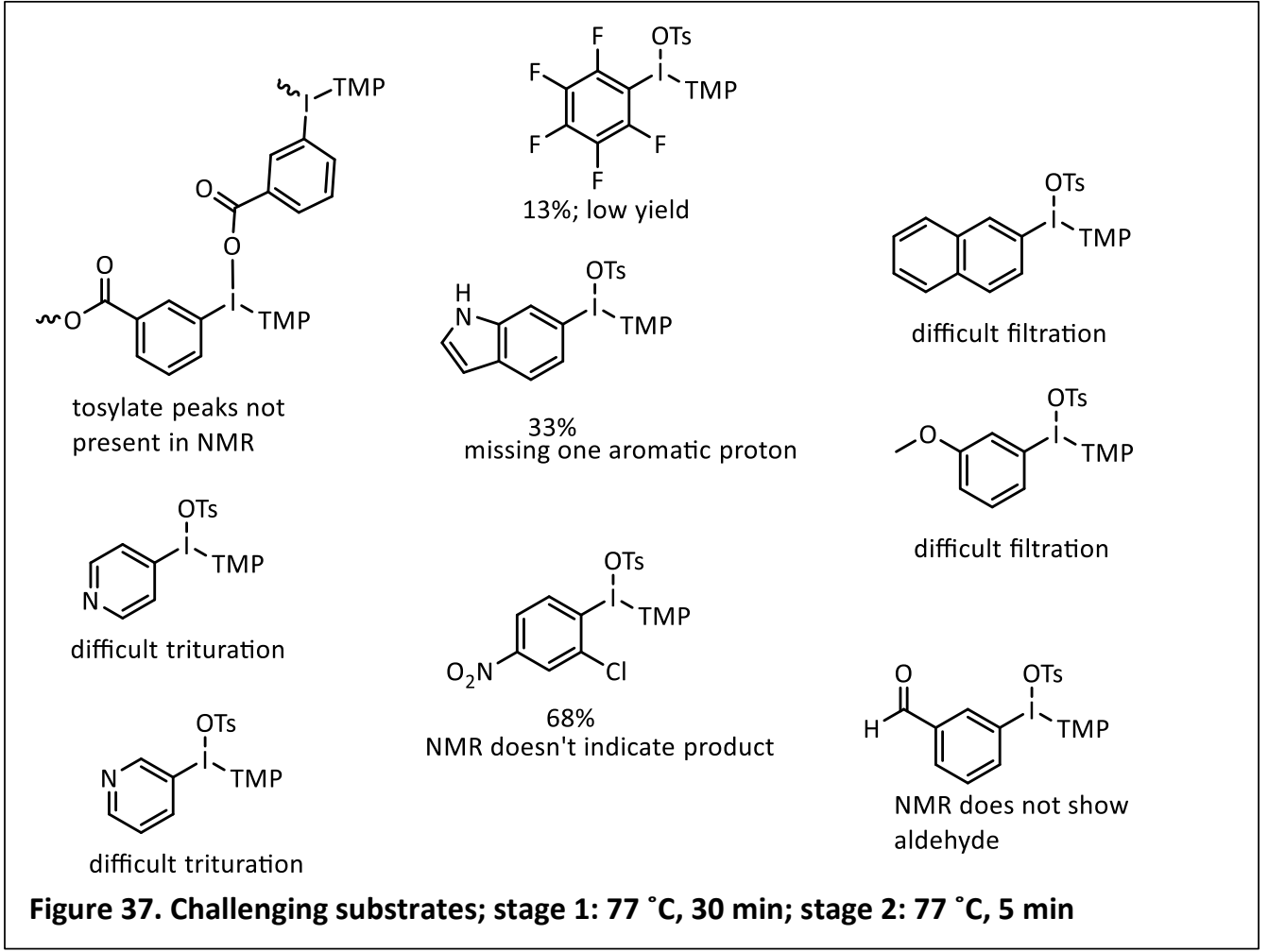

An interesting and fortunate feature of the response surface generated during optimization (Figure 26) is its gentle curvature, which is taken as an indication that acceptable yields may be obtained even when running the reaction of lower temperature. For example, Figure 28 shows several examples where reaction 
temperature had to be lowered in order to be successful. As such, when a challenging substrate is encountered it is recommended that the first measure taken is to lower the temperature at Stage I, optionally increasing the reaction time. It was noted that challenging aryl substrates included functional groups prone to oxidation, like aldehydes and ketones. Nitrogen containing substrates are generally challenging, regardless whether aliphatic or aromatic, and relatively few examples exist in the literature. Diaryliodonium salts have been built from a few pyridyl, protected primary and secondary aliphatic amines as well as anilines. Another grouping of challenging substrates includes those that furnish a clean material in good yield with unexpected structure. An interesting example was observed with the ortho-nitrile, which was

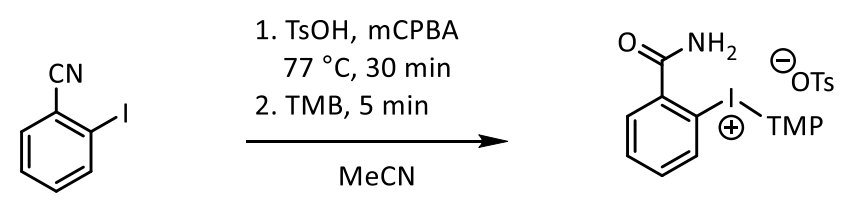

46: $93 \%$

Figure 38. Example of reactive ortho-positioned substrates that give unexpected products.

converted into a primary amide upon analysis of the diaryliodonium salt product. Proton NMR and high-resolution mass spectrometry supported this finding. Similarly, iodoindole was not converted into the expected product. Interestingly, a good yield was achieved of a clean material with a ${ }^{1} \mathrm{H} N M R$ spectrum that is consistent with a diaryliodonium salt, but not the expected product. This author expects the difficulties with nitrogen containing substrates are in part due to the nucleophilicity of the nitrogen and its state of protonation. Examples of hypervalent iodine compounds in which 
ligands are bonded to the iodine via nitrogen are well known in the literature, for example, Barluenga's Reagent. However, it seems mostly relevant that the initial oxidation occurs in the presence of a Bronsted acid. It is very likely that protonation of a nitrogen, thus changing the ionization state to +1 , will have a significant effect on chemical and physical properties. For example, in the case of a pyridyl or aniline substrate, conversion of the nitrogen into the ammonium form will inductively cause the substrate to become more electron deficient and potentially slow the rate of the oxidation step. The oxidized substrate would essentially be a dication and require two equivalents of the X-group. From a practical standpoint it seems very plausible that understanding the ionization state of nitrogen functionalities throughout the procedure will increase likelihood of successful workup and isolation of the target product. Of course, the first step would include simply adding a second equivalent of the Bronsted acid. Removal of the Bronsted acid from the procedure and the feasibility of acid-free preparation of diaryliodonium salt will be discussed in the next section.

Finally, certain substrates undergo reactions that seem to fail upon addition of the auxiliary. A control experiment showed that $\mathrm{mCPBA}$ and TMB react quickly and with release of heat. Based on this result, it is assumed that when a diaryliodonium salt synthesis fails upon addition of the auxiliary, it is likely due to unexpectedly slow progress of the oxidation step. If the oxidation step is slow, then significant mCPBA will remain available to react and consume the auxiliary when it is added to the drink. From experience, the resulting product mixture will very likely not triturate. 


\subsubsection{Bronsted acid-free preparation of aryl(TMB)iodonium tosylate}

At some point upon entering a laboratory focused on diaryliodonium salts it is likely that any person will question the need for the additional protic acid during the oxidation step. In the academic research lab a viable work-around could be to perform slow addition of the oxidant and/or the auxiliary. At the expense of increased time to install the auxiliary, it may also help to introduce the auxiliary in an ethyl ether solution, as the ethyl ether will adjust the solubility properties of the reaction and encourage any diaryliodonium salt to precipitate as it forms.

In an attempt to overcome the limitations discussed in the previous section, the reaction was attempted using sodium tosylate in place of tosic acid. In this formulation, mCPBA is initially the strongest acid with a pKa of 7.48 , which is about 1 million times weaker then tosic acid. The rationale for this formulation was that the oxidant properties of mCPBA would be attenuated. Importantly, the reaction is not free of protic acid as the mCPBA is converted to its benzoic acid derivative with a pKa of about 3.5. The first substrate tested was 4-methyl iodobenzoate and analysis of its oxidation product has not been possible due to its insolubility in any solvent tested. On visual inspection, the oxidation reaction appeared to progress as expected and a thixotropic paste was formed. The intermediate nonetheless reacted with TMB in acetonitrile. Because the diaryliodonium salt of this substrate is known to be soluble at $77^{\circ} \mathrm{C}$, it was expected that reacting the intermediate with TMB would result in at least part of the reaction going into solution. The reaction proceeded at a sluggish pace and was left to 
reflux for one week. Upon removal of insoluble material, evaporation of the solvent, and trituration with ethyl ether, the diaryliodonium salt was realized at $39 \%$ yield. Based on this initial result, the 3 - and 4-iodoanisole substrates were reacted as shown in Figure 39.

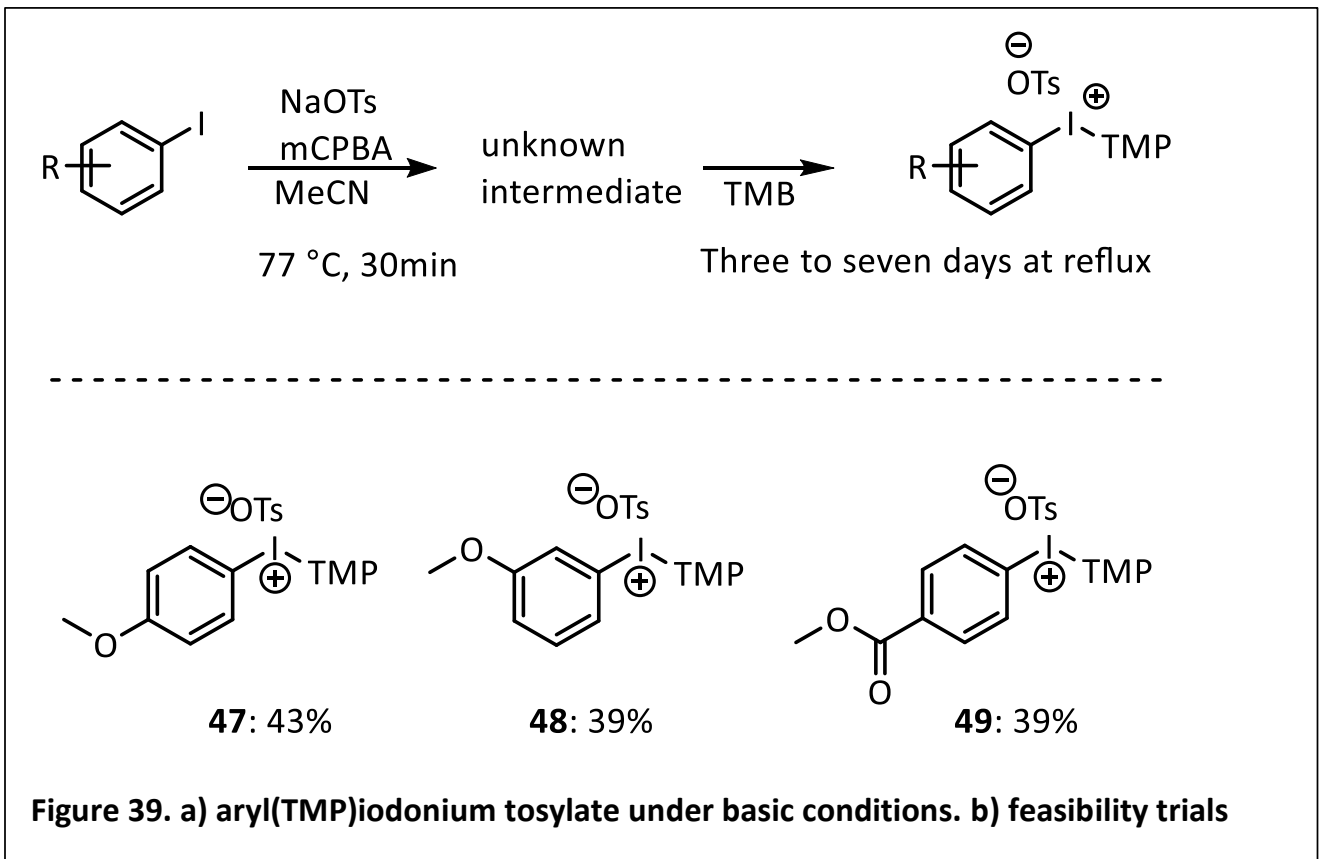

The results in Figure 39 are encouraging because the reaction at $77^{\circ} \mathrm{C}$ did not work with the iodoanisole starting substrates. The reaction conditions have been made milder using the conjugate base of the Bronsted acid.

Initial attempts to prepare diaryliodonium salts from iodoaniline were not successful, however, formation of the product was not rigorously ruled out. That is, the product was not worked up with the ionization state of the aniline moiety in mind. In such cases, failure of the product to triturate in ethyl ether should not be used as a conclusive assessment whether an iodonium salt has formed. While feasibility of the 
method has been shown in terms of the chemistry, it is not overwhelmingly obvious whether the acid-free synthesis may be developed into a practicable method. Recommendations for future work are listed below.

- Can product be formed without even the addition of an X-group salt?

- How does varying the X-group salt affect the reaction and solubility of the intermediate?

- What is the intermediate?

- What is the effect of adding a Lewis acid to the oxidation product?

The significance of the acid-free diaryliodonium synthesis could potentially go beyond simply expanding the substrate scope of current diaryliodonium salt preparations. Without Bronsted acid it is possible to envision a reaction cycle whereby a chemical transformation is accomplished and catalyzed by a polyvalent organoiodine reagent that cycles between diaryl and monoaryl species. From the hypothetical catalytic cycle shown in Figure 40, it is clear that nucleophiles are required for two steps. One of these serves to generate the diaryliodonium salt from the oxidized iodoarene. The second nucleophile is the intended coupling partner in arylation. Because two nucleophiles are present in one pot, it will be necessary for them to be orthogonal reagents. The absence of acid would potentially allow the use of reagents such as the readily prepared aryl-boronates and aryl-silicates that have been demonstrated to impart nucleophilic character on the carbon atom ipso to boron or silicon. Both of these reagents are acid sensitive. Although not for arylation, Wirth has also used in-situ generation of the 
hypervalent iodine species, using sodium perborate or a 1:1 admixture of boron trifluoride etherate and trimethylsilyl triflate. ${ }^{33}$

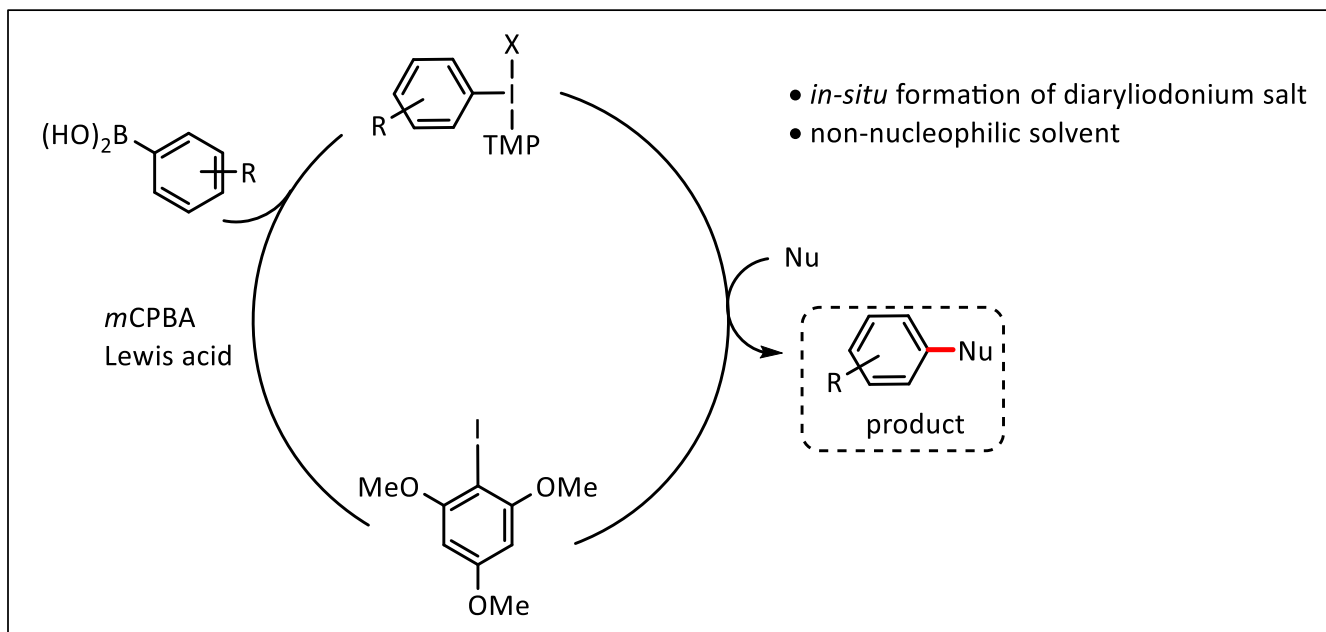

Figure 40. Hypothetical catalytic cycle including acid free oxidation of aryliodides

One interesting alternative would be to devise a method that electrochemically generates the hypervalent iodine species. The schematic in Figure 41 depicts the concept-design of such a process. ${ }^{34}$ The electrolyte would be comprised of the X-group salt as the anode of a platinum wire. As diaryliodonium salts are known to react nonreversibly react at electrodes, the voltage would need to be carefully poised. Additionally, considerations such as pulsed current and/or switching between multiple working electrodes may benefit the reaction by limiting the amount of reactive intermediate and avoiding poisoning of the electrode surface. 


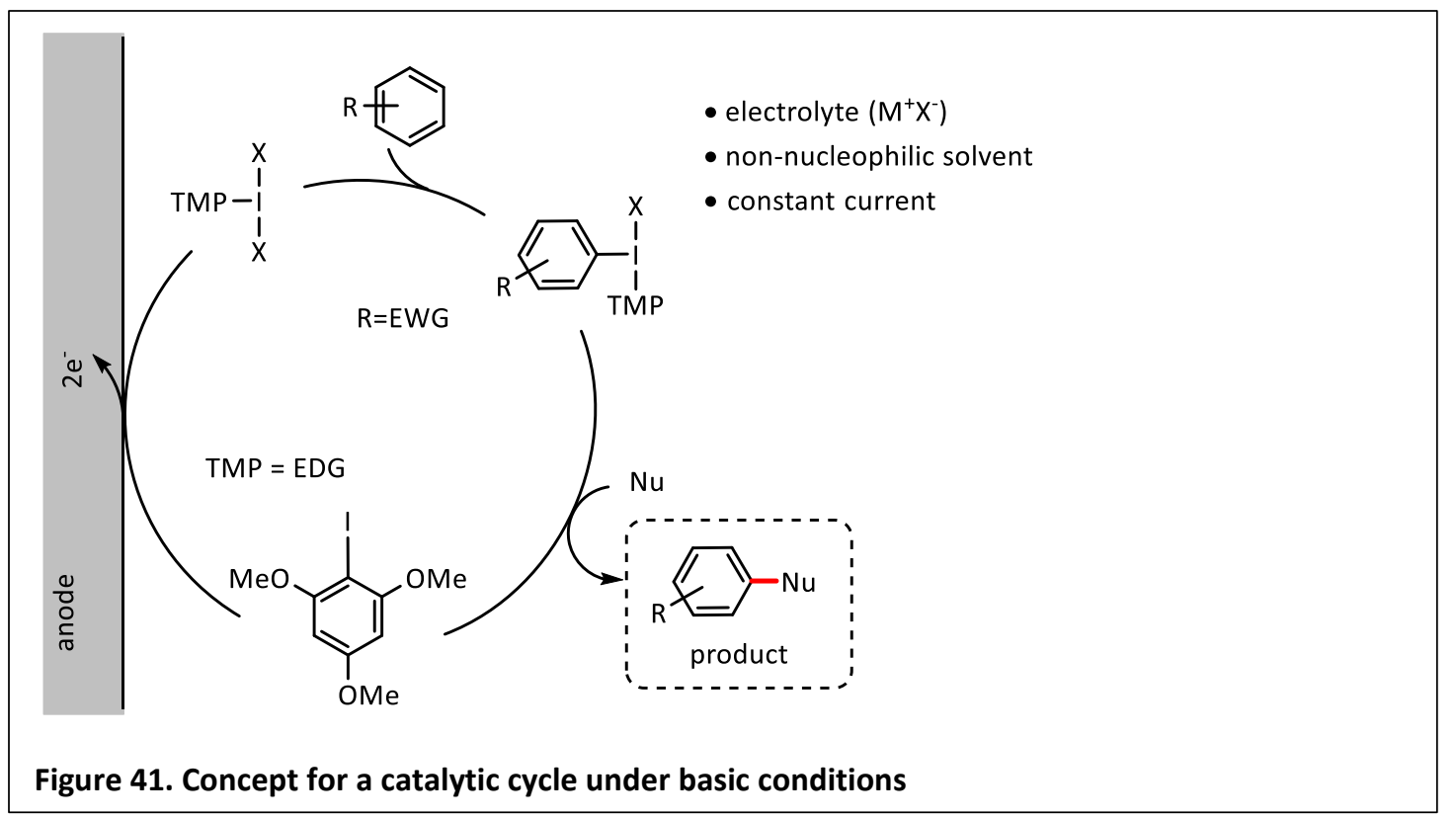

Anodic oxidation of iodobenzene to phenyliodine(III)bis(trifluoroethoxide)], (PIFE) has been reported and the oxidant solution is stable in a refrigerator for one week. ${ }^{35}$ The difficulty with electrochemical methods is the reoxidation, given that the reduction potential of iodobenzene is $1.9 \mathrm{~V}$, versus $\mathrm{Ag} / \mathrm{AgCl}$ electrode. Still, this does not conclusively demonstrate lack of potential to use electrochemistry for the in-situ generation of reactive intermediates in hypervalent iodine chemistry. Very few reports exist on the electrochemical preparation of hypervalent organoiodine compounds and this area seems to be largely undiscovered. Furthermore, it is known that reduction potentials may be significantly modulated depending on conditions in the electrochemical cell as well as by functional groups on the ring. Electrochemical reactions are attractive because of the possibility to generate reactive intermediates that may otherwise not be possible. 


\section{An admix approach to determine the effect of the counter anion on arylation}

\subsection{Introduction to the counter anion and its significance}

Diaryliodonium salts are increasingly studied for arylation of nucleophiles and the counter anion $(\mathrm{X})$ is an important lever for reactivity. Of the three ligands, Ar and Aux have been discussed in both experimental and computational reports. Chapter 1 and Chapter 2 also discussed aspects of how Ar and Aux affect diaryliodonium mediated arylation. However, within the context of arylation, there is little information regarding the influence $X$ has on the reactivity of diaryliodonium salts. Most importantly, no convenient method to select a counteranion has been proposed. It follows that this component of diaryliodonium salts is understudied and little information exists on how $X$ potentially could interact with other reaction parameters. It is clear from Figure 42 that the three most commonly used X-groups including OTf, BF4 and OTs are the conjugate bases of the Bronsted acids called out by the three most popular diaryliodonium salt syntheses (see Figure 42).

Within the context of arylation of nucleophiles proceeding through the ionic pathway, many reports on diaryliodonium salts include a counteranion screening study. However about $25 \%$ of recent reports (2011 to 2016 ) we reviewed did not test more than one counter anion (see Figure 42, green). ${ }^{36}$ This is surprising given the potentially large influence counteranion identity can have on reactivity. The data in Figure 42 give insight into the recent use of counteranions in diaryliodonium research. Perhaps most striking is that there is no clear "best" counter anion. This supports the notion that contribution 
of the counter anion to the progression of arylation reactions is not well enough

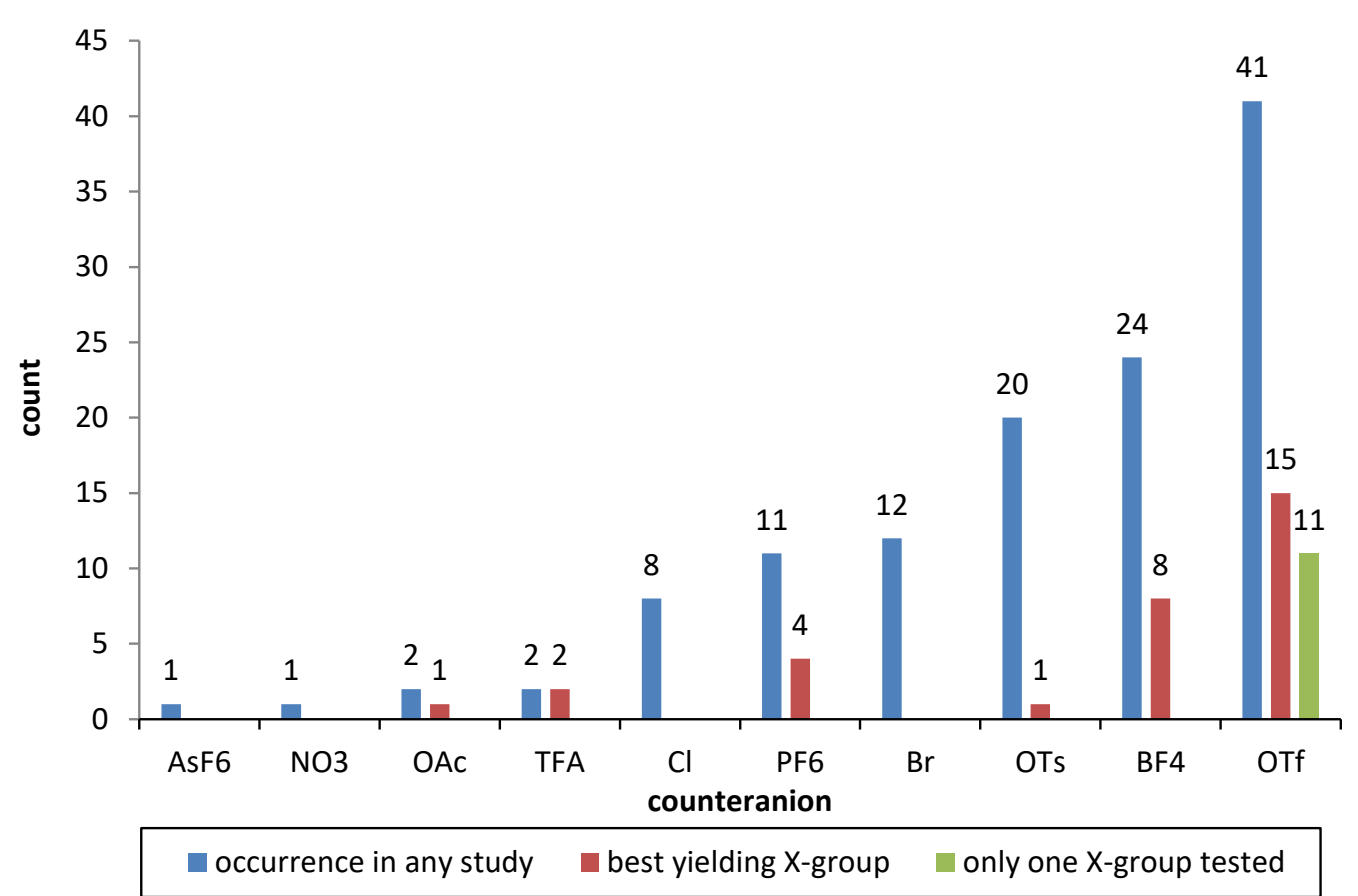

Figure 42. Counter anion use in diaryliodonium mediated arylation according to forty-two reports between 2011 and 2016.

understood to allow rational selection of a counter anion for a given set of reaction conditions. An obvious and undesirable result of the current level of understanding of the X-group is that efforts to study it have been heuristic. A further complication is that varying the X-group for a single salt may necessitate additional development. More often than not, varying the X-group is more easily accomplished by anion exchange rather than by varying the type of Bronsted acid used in the diaryliodonium synthesis. While anion exchange tends to be a simple procedure, it is sensitive to the composition and structure of the aryl ligands. A particularly challenging anion exchange, for example, is the conversion of tosylate to acetate. In fact, the reaction does not proceed without resorting to forcing conditions. Interestingly, the exchange of tosylate into 
trifluoroacetate could be readily accomplished, while trichloroacetate required further method development, which is described in Section 3.10. Importantly, development of a counter anion screening method will potentially improve the odds of successful reaction development and help diaryliodonium salts gain traction as mainstream arylation reagents. If the method is also facile and practicable with small amounts of reagents, it would also enable study of novel, hard to access counteranions, such as the conjugate base of the allylic Bronsted acid, 1,1,3,3-tetratriflylpropene (TTP). TTP was very recently developed by List et al and shown in Figure 43a. ${ }^{37}$ Another recent report studied the effect of the counter anion on reactivity and solubility on diaryliodonium salts as photoinitiators of polymerization reactions. They found one example of a diaryliodonium salt that exists as an oil at room temperature and therefore would qualify as an ionic liquid. This diaryliodonium salt was soluble even in nonpolar solvents,

a)

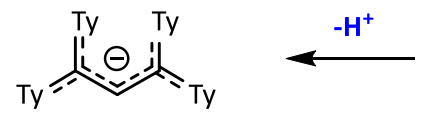

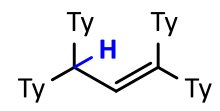

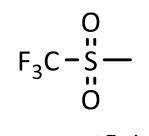

b)

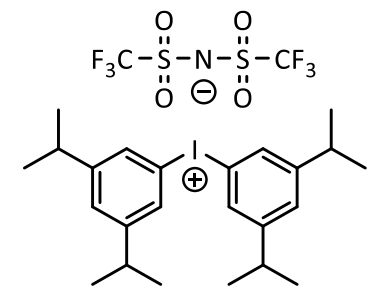

Figure 43. a) 1,1,3,3-Tetratriflylpropene (TTP) developed by List et al. b) Example of a diaryliodonium salt that is liquid at room temperature.

such as diethyl ether, but only when paired with the bistriflimide counter anion shown (Figure 43b). Importantly, almost every reported synthesis of diaryliodonium salts prescribes diethyl ether for trituration and washing of the product. This result is also intriguing simply because hypervalent iodine compounds often exhibit poor solubility in 
many solvents. Diaryliodonium electrophiles often perform well in inhomogenous reactions, however, characterization methods that require dissolved analytes would certainly benefit from better solubility. In summary, the most important requirements for this screening method is to overcome the need for laborious anion exchanges and to provide reliable results when performed on very small scale reactions.

\subsection{Feasibility of counter anion screening by the admix method}

We set out to develop a screening method and started with the literature survey shown in Figure 42. According to the forty-two articles surveyed, the contribution to yield due to counter anion identity spans a large range. Reactions have been reported that seem insensitive to X-group identity. ${ }^{38}$ On the other hand, one reaction exclusively worked in the presence of the acetate anion, which is one of the least often used X-groups. ${ }^{39}$ Reported counteranion screening studies tested between 2 and 5 counteranions and on average the best counteranion gave a $29 \%$ higher yield than the worst, when other conditions were held constant. While iodonium triflates could be seen as a frontrunner, there are frequent examples of other counteranions that give equivalent or better results. This underscores both the potential importance of counteranion identity as well as the necessity for a practicable screening method. 


\subsection{Development of the salt screen}

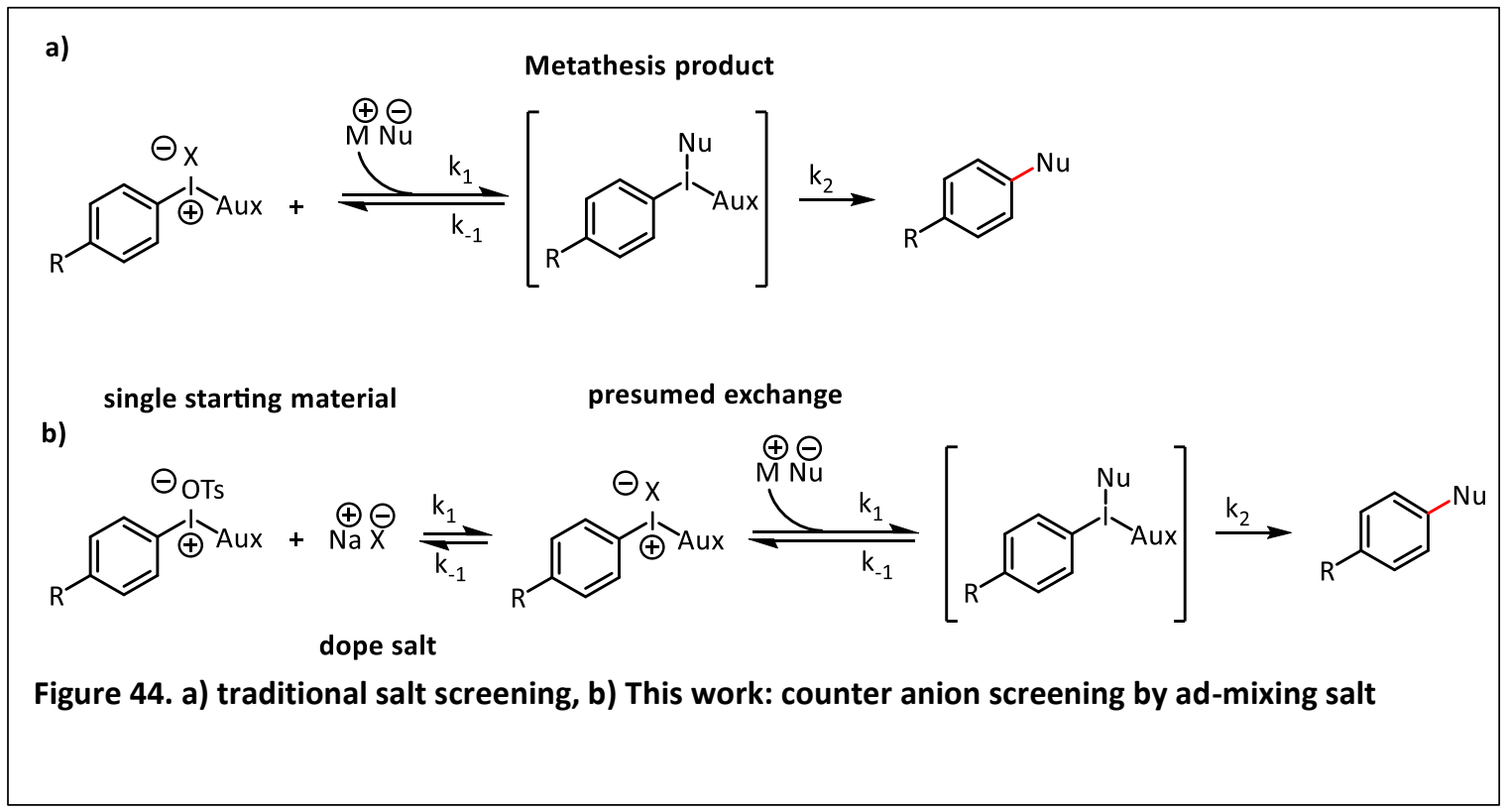

The envisioned method was conceptualized according to the scheme shown in Figure

44b. It was envisioned that an admixed salt would insert itself into the putative

mechanism in Figure 44b. In theory, if in-situ anion exchange occurs and the product of this exchange more readily undergoes metathesis with the nucleophile, then the measured yield would increase relative to the reaction with no additive. On the other hand, if metathesis with the nucleophile is fastest with the initial diaryliodonium ion pair, then the yield will either be slowed or remain unaffected. Testing feasibility of implementation required a selection of a model reaction (Figure 45), for which we chose the well precedented diaryliodonium mediated azide arylation reaction. ${ }^{40,41}$ Sodium azide was selected as the azide source in order to avoid further complication of the system with additional cations. We chose to use unsymmetrical diaryliodonium salts bearing a trimethoxyphenyl (TMP) auxiliary for reasons discussed in Chapter 2. A 
convenient and economical method of screening for diaryliodonium counteranions as a tool for reaction and process development is presented below.

\section{Testing other $\mathrm{X}$-groups requires multiple starting material preparations}

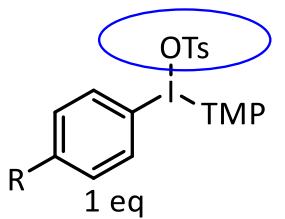

2. $\mathrm{NaN}_{3}, 2 \mathrm{eq}, 50^{\circ} \mathrm{C}, 2 \mathrm{hr}$
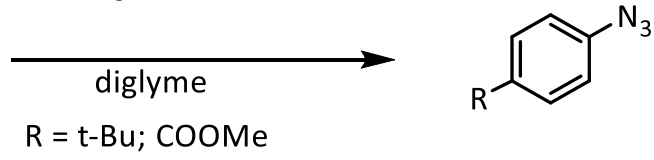

Figure 45. Azide arylation was used to test salt screening

Feasibility reactions were carried out similarly to the reaction in Figure 46, albeit using a stoichiometric amount of a sodium salt rather than an excess. The results of these reactions clearly demonstrated that ad-mixing the electrophile with various sodium salts had a significant effect on yield. Next, a solvent study was performed based on the expectation that solvent identity would affect the behavior of any salts in the reaction mixture. It is well known that, depending on the solvent, the ions in solution may be differently stabilized, potentially impacting the reaction at hand. A rational approach was used for the solvent selection process and is detailed in Chapter 4. The remaining azidation studies included an electron-rich and an electron-poor aromatic substrate reacting in nine different solvents. It was found that that acetonitrile and diglyme were good solvents, in that synthetically useful yields were obtained without having performed any optimization. The electronically distinct substrates were also not sterically hindered and were included in order to observe potential interaction of ring electronics and the identity of the dope salt. 


\subsection{The screening study}

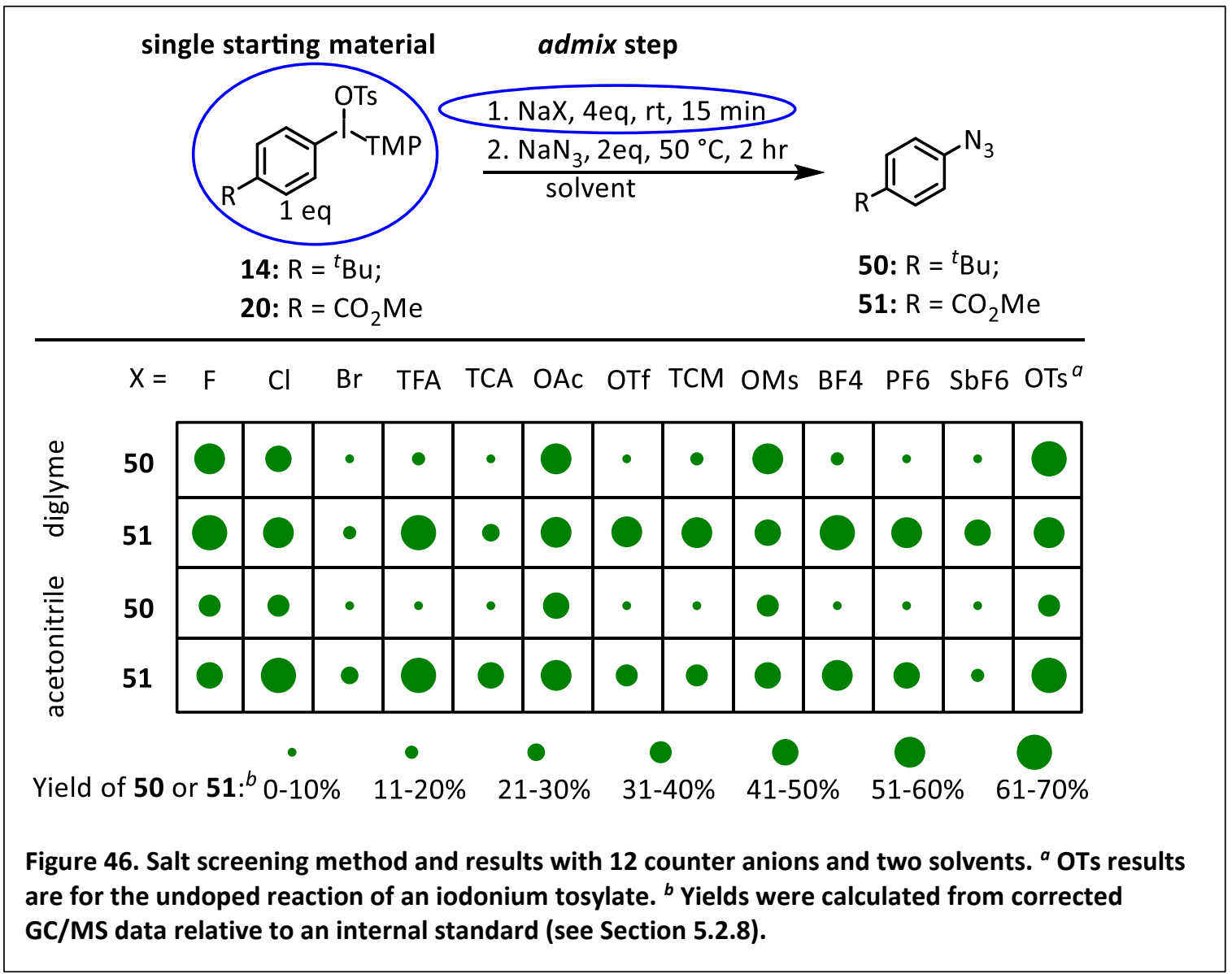

A screening study was performed with four equivalents of dope salt and two equivalents

of sodium azide as shown in Figure 46. The layout of the study is conceptually simple and is shown along with screening results. Four groupings of sodium salts were tested, including those based on halides, acetates, and mesylates as counteranions. The fourth group can loosely be described as containing conjugate bases of fluorinated super acids. The data clearly showed that salt doping has an effect on azidation yield and Table 10 highlights important results from the screening experiment. The data used to build Figure 46 is available in the Supporting Information for Chapter 3. 


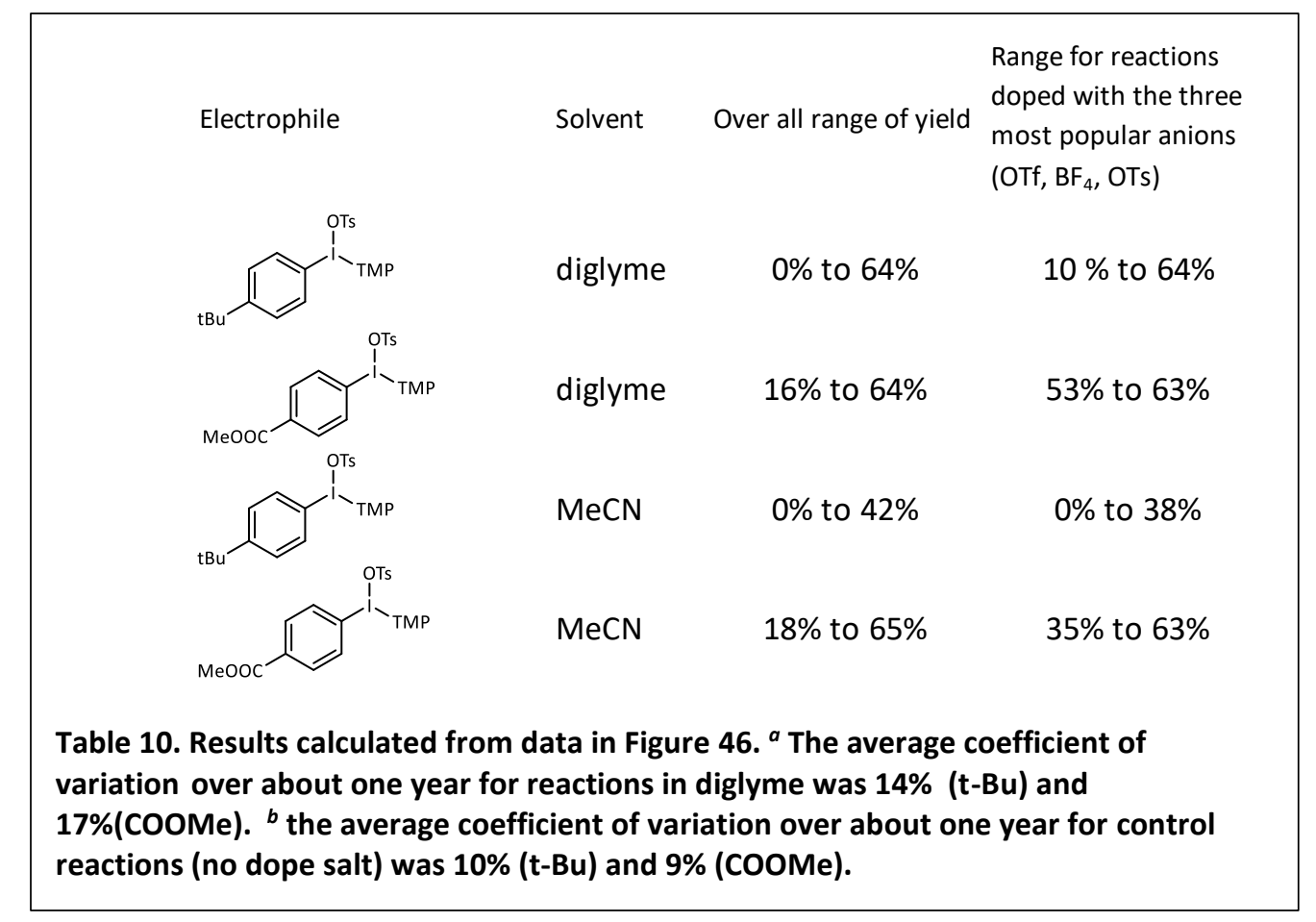

\subsection{Comparison of pre-exchanged and admixed azidation}

For this to be a viable counter anion screening method, it was also necessary to compare the results of doped reactions with those of pre-exchanged salts bearing the analogous X-group. The results of side-by-side experiments, comparing salt-doped azidation reactions of diaryliodonium tosylates to those of pre-exchanged diaryliodonium salts, are shown in Figure 47. The results indicate sufficient correlation between doped and pre-exchanged reactions and further support the use of salt additives as a screening method. The reactions to which $\mathrm{BF}_{4}$ and OTf were added did not track well in comparison to the remaining trials. In order to better understand these results, the azidation reactions were repeated with diaryliodonium tetrafluoroborate and diaryliodonium triflate starting materials. In both cases, four equivalents of 
common anion were added as sodium salts and the yields converged with those of the screening results.

One of the more intriguing results had been increased yield obtained when sodium acetate was the additive in the azidation of $\mathbf{1 4}$. The data for triplicate runs of the control reaction (yield $=66.5 \% \pm 0.8$ ) and the sodium acetate doped reaction (yield $=$ $76 \% \pm 1.2$ ) suggests that the means are significantly different. This result was unexpected as, in our hands, exchanging tosylate for acetate has not been possible without first converting to a halide and then forcing the exchange with silver acetate. Unfortunately, the beneficial effect of adding acetate was not repeated during optimization. During optimization it was observed that addition of acetate had no statistically significant effect on yield. The conflicting results observed with acetate doping were taken as a welcome reminder that when assessing replicate results, day-today variation must be considered. As previously mentioned, the $\mathrm{S} / \mathrm{N}$ value is key in objectively assigning a change in output to any effect. Interestingly, Table 10 points out that the coefficient of variation calculated from about one year's worth of the control reaction with 14 was $10 \%$. Because of this variation in the longer term data, a more rigorous assessment would be needed in order to more confidently make any conclusions regarding the effect of acetate anion on azidation of $\mathbf{1 4}$. Nonetheless, the often close correlation of doped to pre-exchanged yield results, points to the possibility that anion-exchange may not always be necessary in a process. 

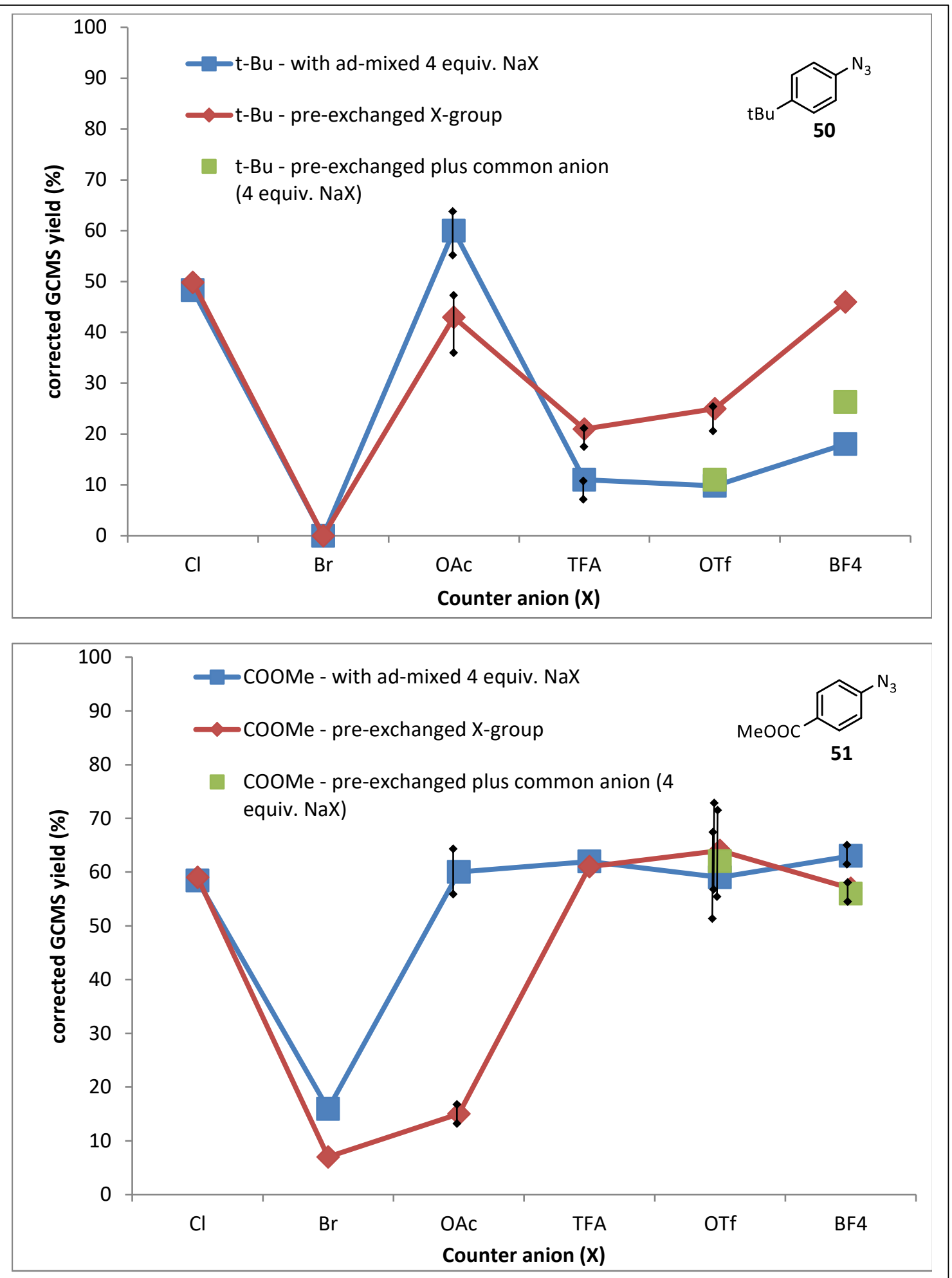

Figure 47. Comparison of azidation yields for iodonium tosylate doped with $\mathrm{NaX}$, pre-exchanged diaryliodonium salts, and pre-exchanged diaryliodonium salts admixed with 4 equiv. of common anion. When available, error bars are given as standard deviations. 


\subsection{Scope of the screening method}

We then moved on to test the general applicability of salt doping as a primary screen by adapting reported reactions to be compatible with salt doping. Care was taken to follow the literature procedures as closely as possible. ${ }^{42}$ Figure 48 shows that upon normalizing results to $100 \%$, we observed significant correlation between our results. These results not only demonstrated the applicability of salt-doping as primary screen, but also demonstrate its practicality by using only one diaryliodonium starting material (see Figure 46). 


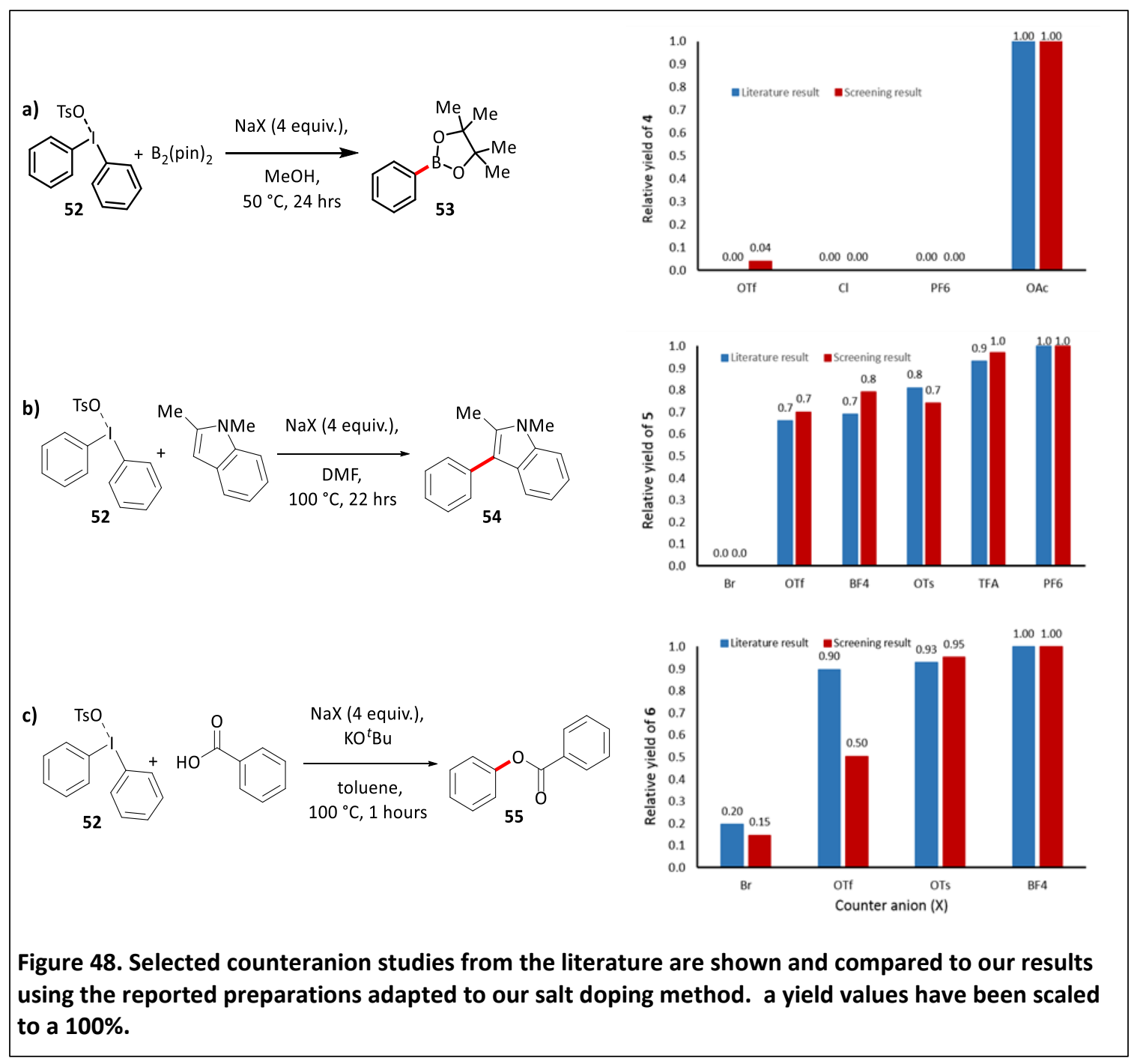

\subsection{Optimization and some azidation examples}

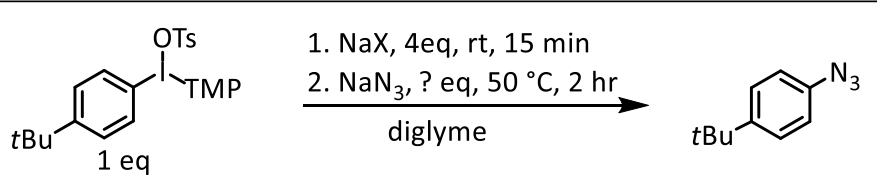

Factors:

1) presence of 4 equ sodium acetate

2) equivalents of sodium azide

3) temperature

Figure 49. Optimization of the aryl azidation reaction. 
Optimization was performed with the more electron rich substrate as shown in Figure 48. The tosylate was selected as the best X-group for the azidation reaction and the reaction was optimized. The DoE workflow, presented in Figure 16, was again followed. A full factorial design was performed to study the effect on azidation yield of temperature, equivalents of sodium azide, and the presence or absence of sodium acetate in the reaction. There was no statistically significant difference in reaction yield whether or not sodium acetate was included. The optimization was continued with two factors, temperature and azide-stoichiometry, in order to generate the quadratic model described by the contour plot below (Figure 50). The graph below nicely shows the importance of interaction effects, which are clearly present between the factors, temperature and azide concentration. A chemist using the OVAT method may reasonably decide to study the effect of azide concentration. The importance of azide concentration may be overlooked if the reaction were to be run below around $40{ }^{\circ} \mathrm{C}$, because the contour lines are nearly parallel to the ordinate. If azide concentration is deemed to have little effect, then temperature would likely be studied next. However, the two hour reaction using 2 equivalents of sodium azide will reach its maximum yield of about $70 \%$ at $64{ }^{\circ} \mathrm{C}$. The take home message is that DoE can provide high quality data in relatively few experiments as compared to the OVAT method. 


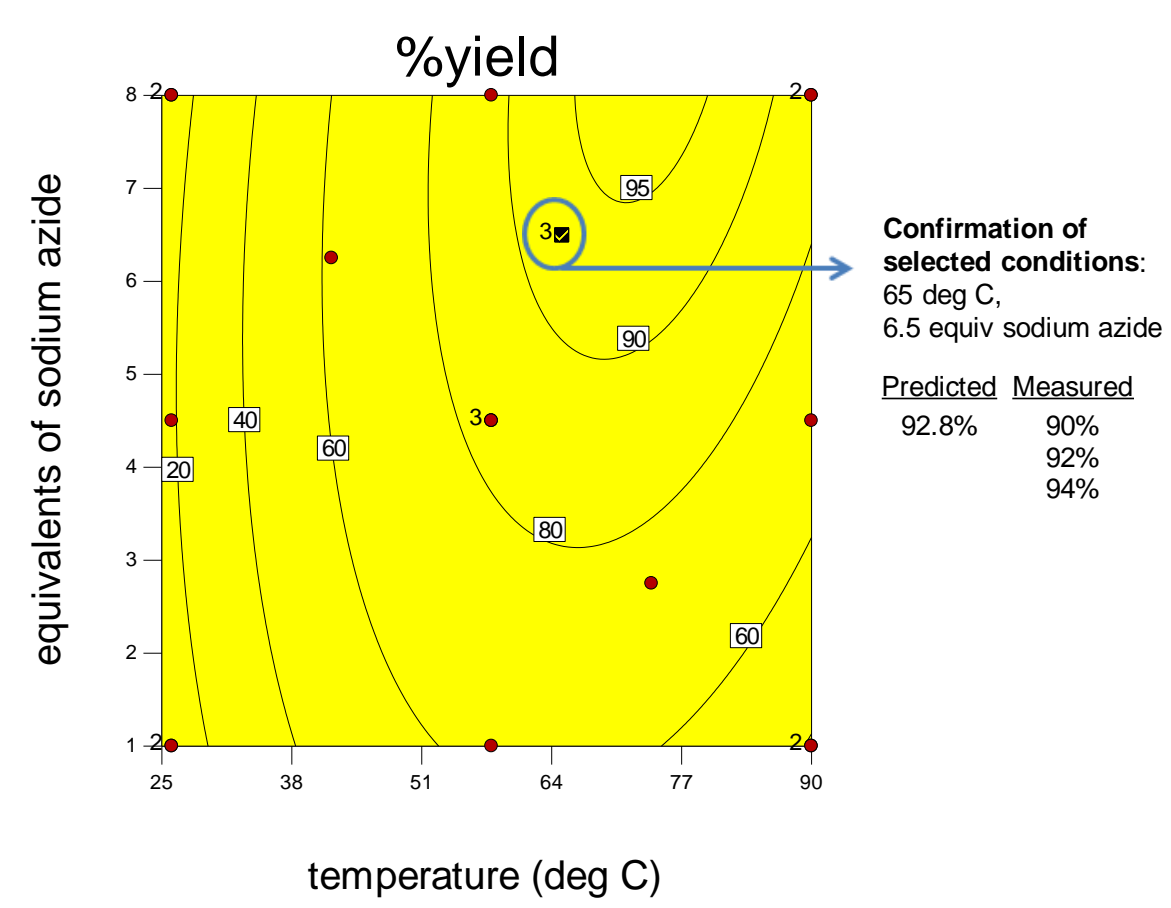

Figure 50. Optimization of azidation. Contour plot with confirmation runs. Note that varying either factor independently would not have allowed the maximum yield conditions to be located

With optimization complete, several azidations were performed in order to demonstrate the substrate scope of the reaction with aryl(TMP)iodonium tosylates. A variety of functional groups were tolerated, including a pyridyl, a phenethyl alcohol and one elaborate arene (Figure 51). The experimental details may be found in the Supporting Information for Chapter 3. 


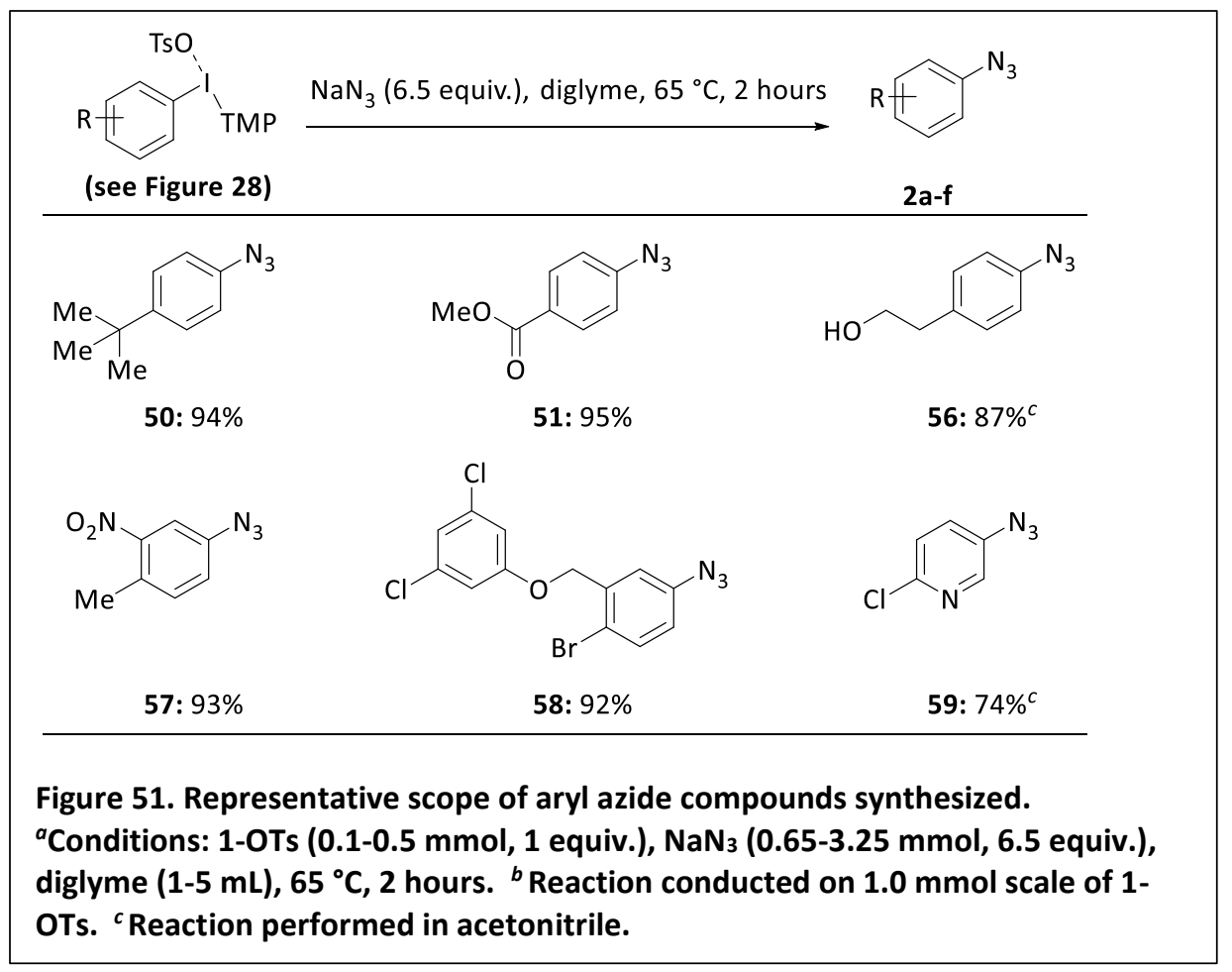

\subsection{Discussion of unexpected $\mathrm{BF}_{4}$ and OTf doping results}

According to the putative mechanism shown in Figure 8, it is generally assumed that formation of the transition state immediately preceding reductive elimination comprises the rate limiting step. More specifically, displacement of the counteranion by a nucleophile is not commonly considered as influential over the reaction yield and the product distribution. However, this is not entirely consistent with our observations, that upon adding excess common anion, as in the case of $\mathrm{BF}_{4}$ and OTf salts, the yield of aryl azide was reduced. The reduced yield was clearly related to addition of excess common anion and GC/MS data did not indicate any appreciable change in chemoselectivity and no unexpected products were observed. A series of experiments was performed in order to collect more complete data regarding the effect of the added 
common anion on reaction yield. A common characteristic of diaryliodonium salts is their poor solubility, which often results in inhomogenous reaction mixtures. Addition of an excess of the common anion should force precipitation of the diaryliodonium salt according to its solubility product. It was assumed that metathesis between the nucleophile and the counter anion could not occur while the diaryliodonium salt is precipitated. However, while working on a related project, to develop a rapid and scalable counter anion exchange method (Section 3.10), it seemed that anion exchange is possible so long as one of reactants is soluble. It was observed that if a diaryliodonium tosylate is eluted through a plug of granulated salt $(\mathrm{NaX})$, then ion exchange occurs during the course of elution and solid sodium tosylate is presumably left behind. It seems reasonable that this would likely also apply to ionic nucleophiles participating in inhomogeneous reactions. Furthermore, the data shown in Figures 53, 54 and 55 show an unexpected increase in yield when roughly one equivalent or less of the dope salt is added. Based on these observations, two additional considerations potentially become relevant. Firstly, a change in ionic strength of the reaction medium due to addition of some amount of salt is a reasonable possibility. Secondly, aside from simply precipitating, the common ion effect could also influence unknown equilibria that exist due to secondary interactions between dissolved diaryliodonium salts. This concept was also suggested by a group studying polymerization reactions using diaryliodonium salt initiators (Figure 52). They found that conductivity correlated with polymerization rate, which should be proportional to the rate at which the diaryliodonium salt transforms into an active initiator. Of particular note, the 
polymerization rate and the conductivity did not correlate with the solubility of the iodonium salts under study.

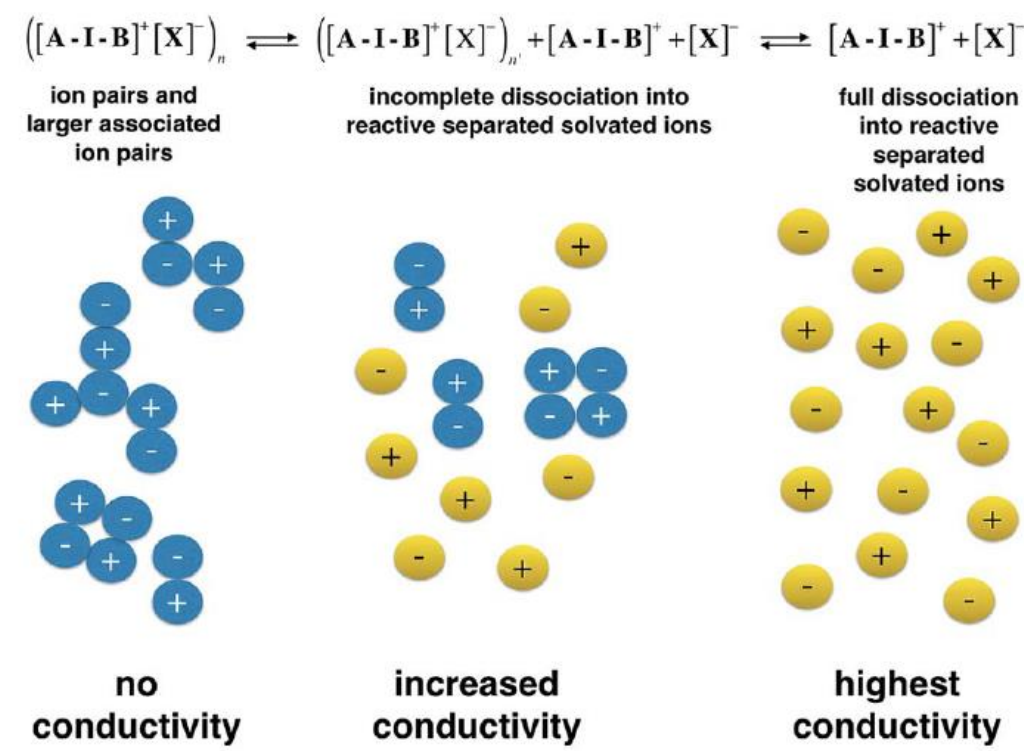

Figure 52. Proposed processes that could limit availability of diaryliodonium salts for reaction even when in solution. ${ }^{26}$

Reaction stoichiometries were studied in more detail and some noteworthy results were obtained. The importance of these experiments is that they directly study the possible effect of salt equilibria on the azidation reaction. While further study beyond the figures below has not been possible, the data does seem to be consistent with the notion that more than one mechanism is influencing the azidation reaction. Without replicating these results and further study, it is difficult to say more. The data is quite compelling in that it could indicate that the metathesis step is a stronger lever for reaction yield that is traditionally believed. 


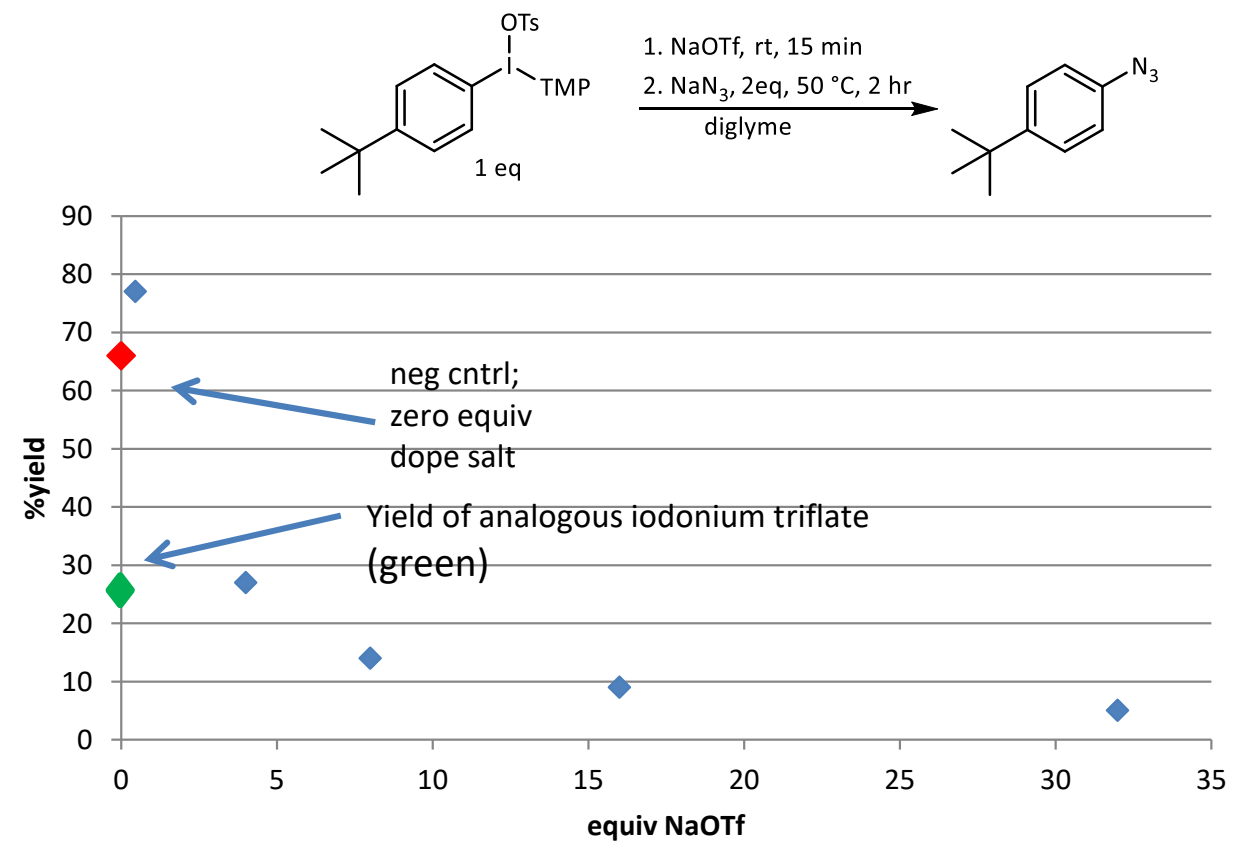

Figure 53. Azidation yield is plotted as a function of the amount of dope salt added.

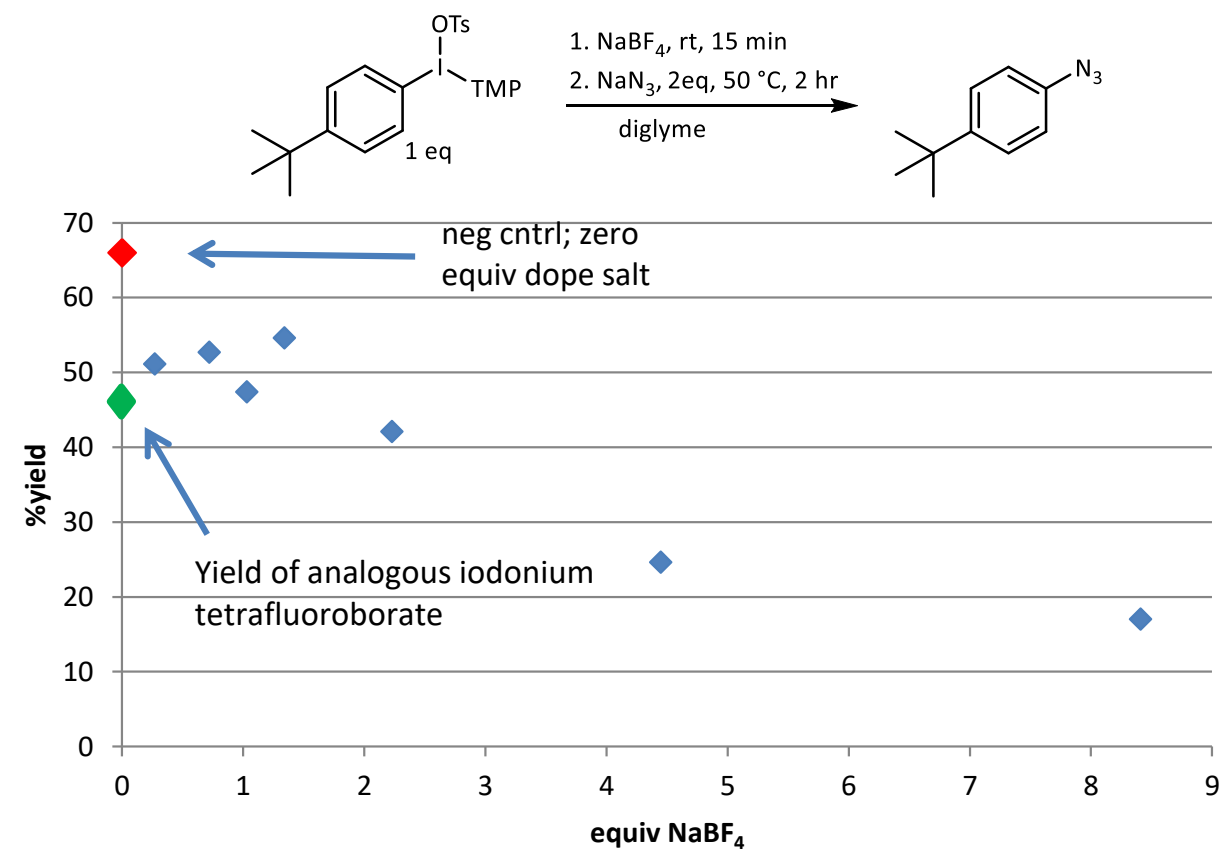

Figure 54. Azidation yield is plotted as a function of the amount of dope salt added. 


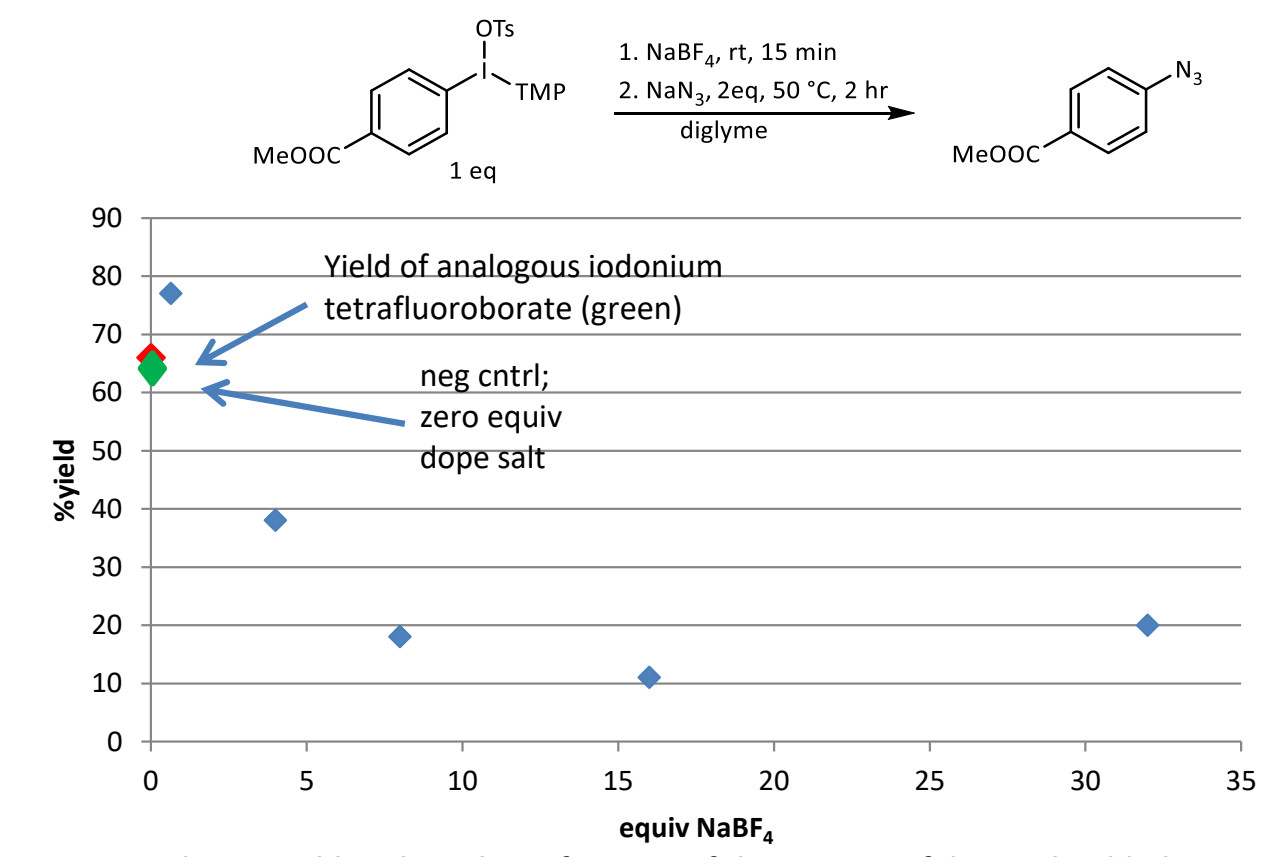

Figure 55. Azidation yield is plotted as a function of the amount of dope salt added

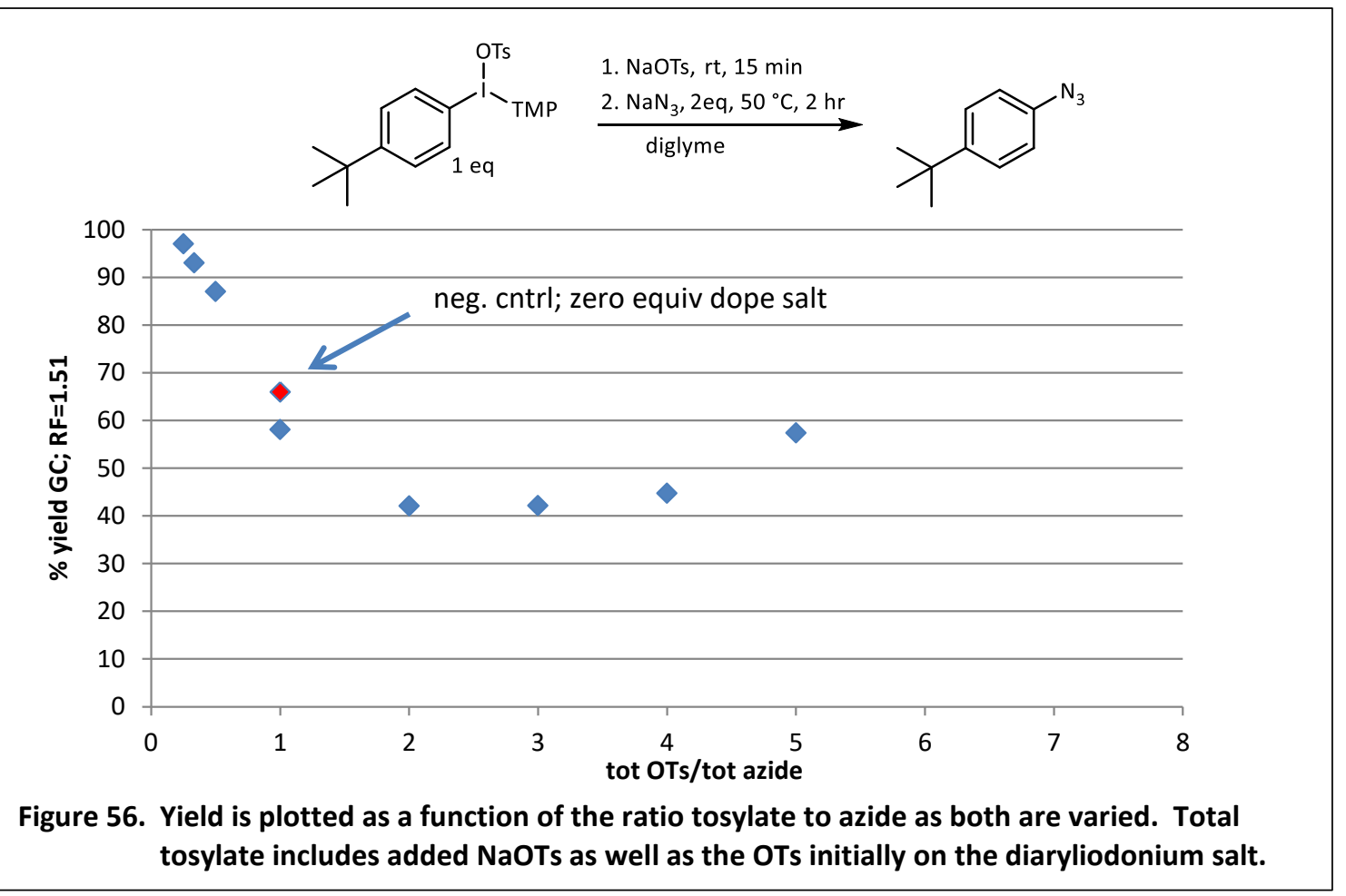




\subsection{Spectator salt or in-situ anion exchange?}

NMR studies were conducted in an attempt to better understand the chemical processes that are affected by changes in counter anion identity. Because of the limited solubility of diaryliodonium salts, solvents could not be varied and DMSO- $d_{6}$ was used for the majority of NMR experiments.

After rigorous assignment of chemical shifts for proton and carbon NMR spectra, peak shifts were analyzed for changes that could be correlated to counter anion identity (see Supporting Information). As expected, the ipso-carbon signals corresponding to both iodine-arene bonds are affected by counter anion identity. The greatest differences were noted among the halide anions (Figure 59). Also, exchanging trifluoroacetate for acetate resulted in a significant deshielding of the ipso-carbons in a diaryliodonium salt with a TMP auxiliary (Figure 59).

An interesting, observation occurred when tetrabutylammonium chloride was added to the NMR solution of diaryliodonium salts with either the TMP or the Mes auxiliary. The
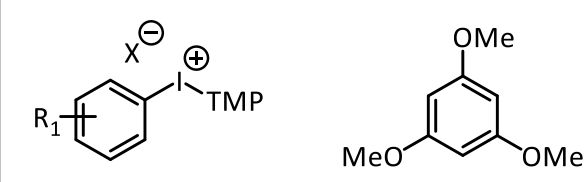

Aux $=\mathrm{TMP}$
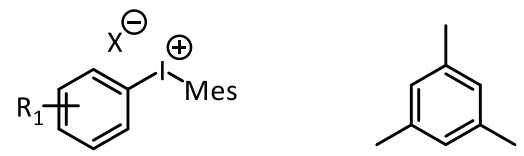

Aux $=$ Mes

Figure 57. Diaryliodonium salts with Mesityl (Mes) and TMP auxiliaries.
Mes salt is significantly more sterically

encumbered than TMP. Further, being alkyl

substituted, Mes is electron rich, however, not

to the same extent as TMP (Figure 57).

Considering the trans-influence, TMP would be the more $\sigma$-donating of the two auxiliaries and 


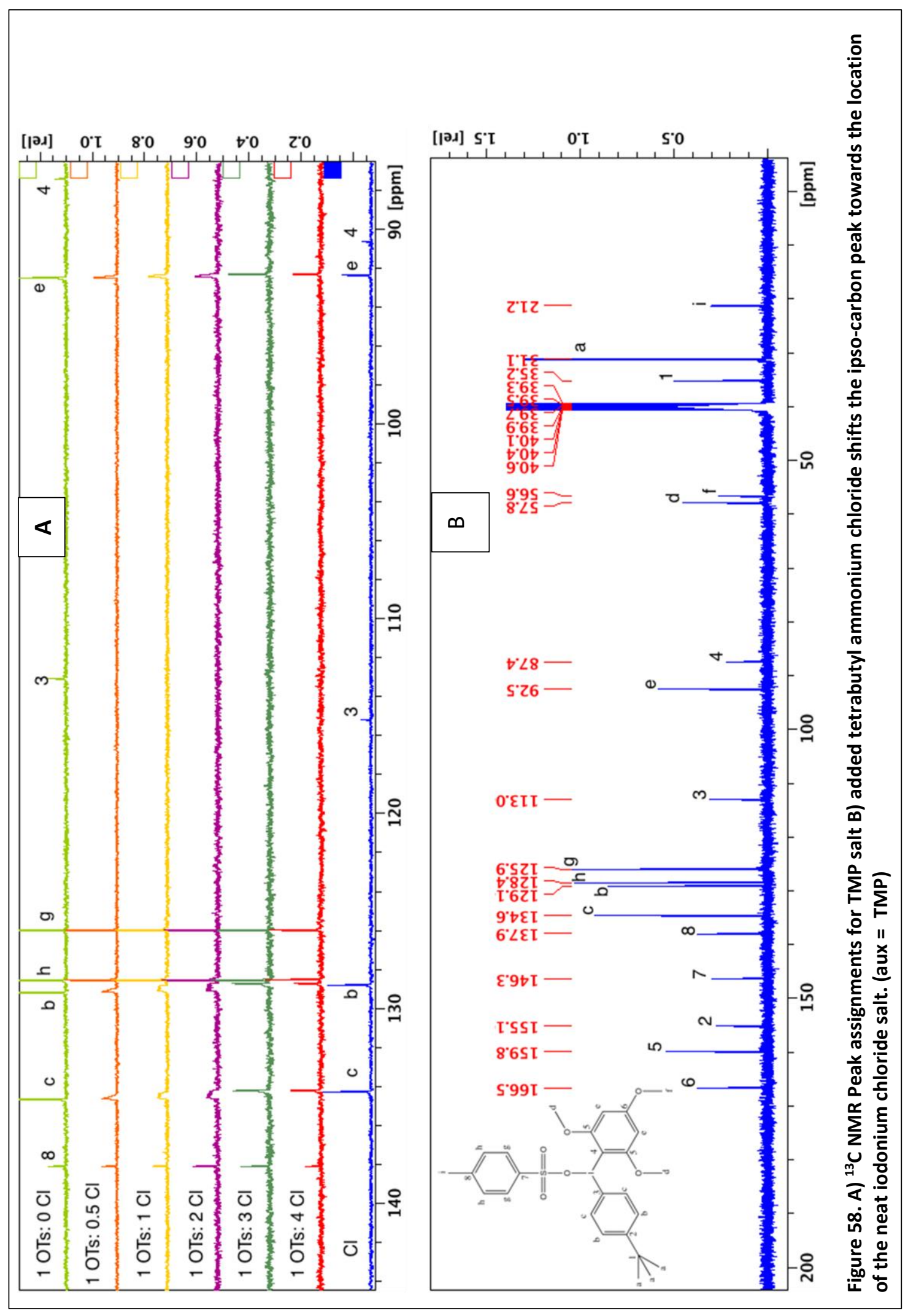




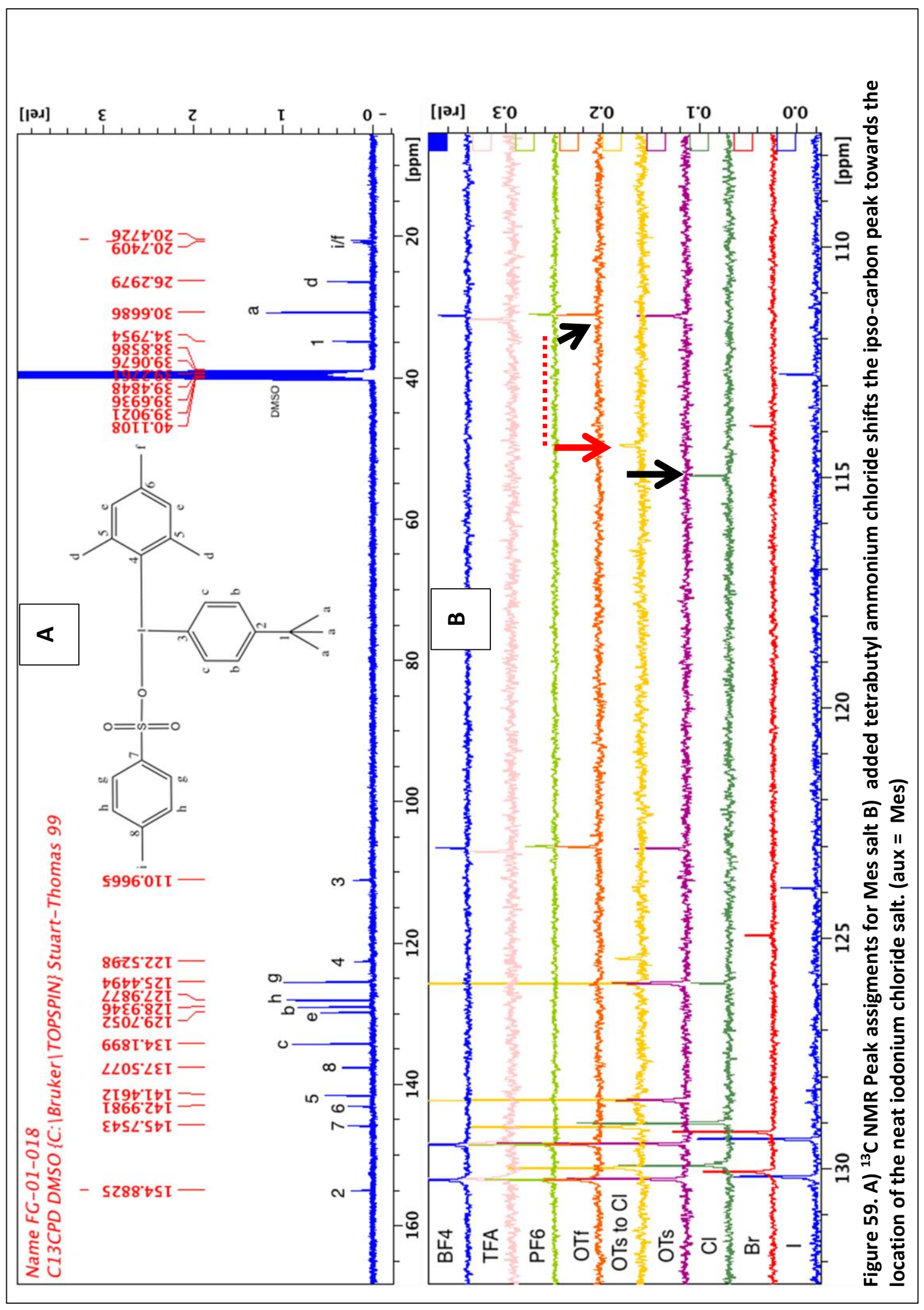


so more destabilizing to the X-group, which is the assumed trans-ligand. The hypothesis was that adding chloride anion to an NMR so lution of diaryliodonium tosylate would effect a counter anion exchange and that depending on the chloride concentration the ipso-carbon peaks in the ${ }^{13} \mathrm{C}$ NMR spectrum should converge on the shift of the neat diaryliodonium chloride. In fact, this was observed when an NMR solution of aryl(mesityl)iodonium tosylate was exposed to chloride anion (Figure 59). However, when the same experiment was performed with an aryl(TMP)iodonium tosylate, the expected shift did not occur and instead the ipso-carbon peaks in the ${ }^{13} \mathrm{C}$ NMR spectrum became increasingly broadened with increasing chloride concentration (Figure 58a). Upon adding up to a four-fold excess of chloride anion, the peaks do clearly indicate conversion to the chloride salt. However, a puzzling feature of the ${ }^{13} \mathrm{C}$ NMR scans of the aryl(TMP)iodonium tosylate is that even at half an equivalent added chloride, the ipsocarbon peaks are no longer appreciable. The peaks that are visibly affected with increasing chloride concentration were assigned to the Ar-group and not the Aux-group (see Figure 58b).

These recent findings could potentially be explained by a difference in the ground-state stability when using either a TMP or Mes auxiliary. More specifically, the TMP auxiliary is by far the most electron-rich of any of the arenes that were part of this experiment and so should exert the largest trans-influence on the trans-ligand bound to iodine. It is conceivable that the larger trans-influence of TMP and its lack of steric bulk allow it to spend more time in the axial position. If this is the case, then association of any Xgroup in solution with the iodine may be destabilized and the result could be a rapid 
equilibrium between associated and dissociated states. Additionally, the shifting peaks, " $\mathrm{c}$ " and " $\mathrm{d}$ " are assigned to the Ar-group and the peaks, " $\mathrm{h}$ " and " $\mathrm{g}$ " are unchanged and assigned to the tosylate group. This indicates that whatever change is occurring is due to the manner in which the chloride anion is interacting with the iodine center.

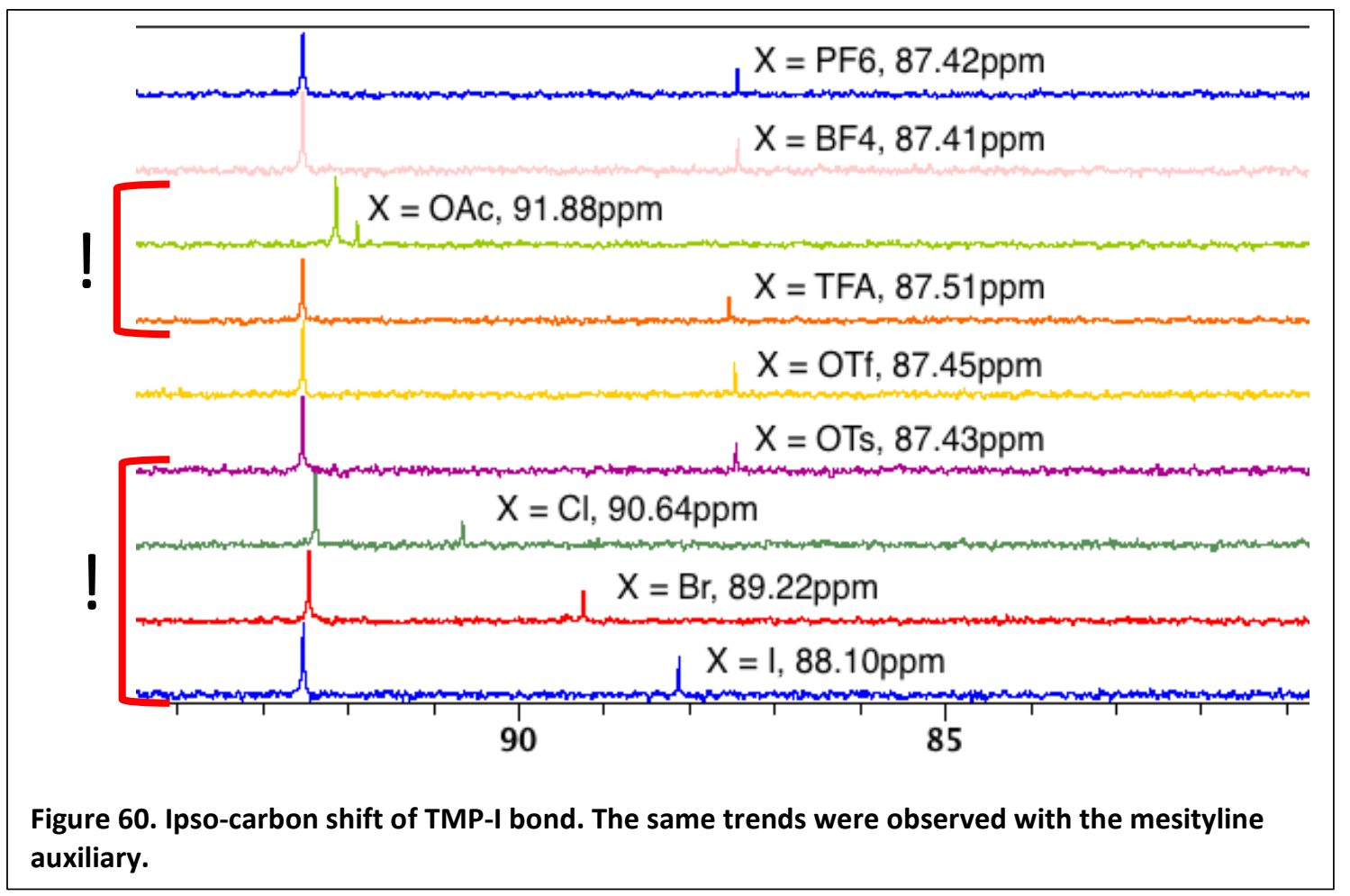




\subsection{Rapid anion exchange method}

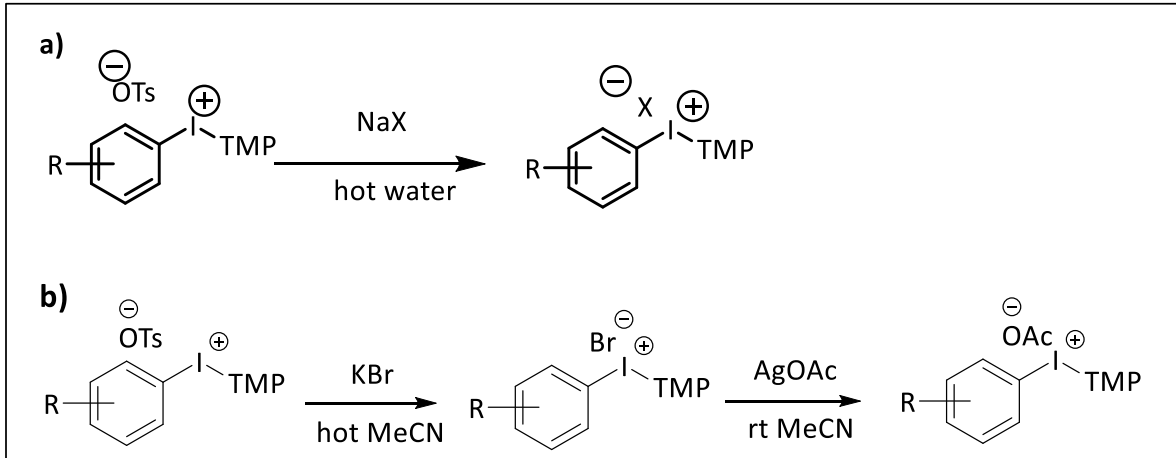

Figure 61. Anion exchange from tosylate a) basic aqueous salt exchange process; b)formation of acetates requires a two step process

Several anion exchange methods exist for diaryliodonium salts. Figure 61a shows the anion exchange method preferred in this document as it usually avoids extractions, is facile and often removes trace impurities. Several authors report anion exchanges by

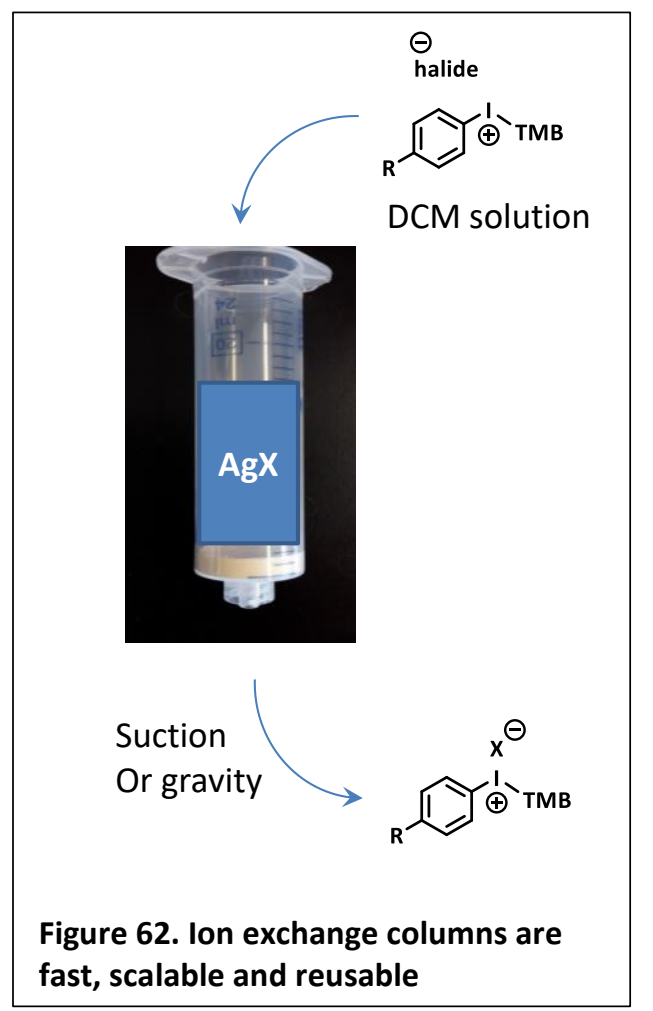

first dissolving the diaryliodonium salt into

dichloromethane or chloroform and then

vigorously mixing the solution with a saturated

solution aqueous solution bearing the target

anion. This, DCM-extraction method, often

results in emulsions and messy extractions and is

poorly suited for scale-up. The method in Figure

$61 \mathrm{a}$ is superior because extractions are usually

not needed. Nonetheless a more rapid method is

desirable if preparing many different types of 
salts. Based on observations of the anion exchange process, it was noticed that both components may not necessarily need to be substantially in solution in order to undergo anion exchange. In fact, precedent for this exists with ion exchange resins that undergo metathesis with an eluent.

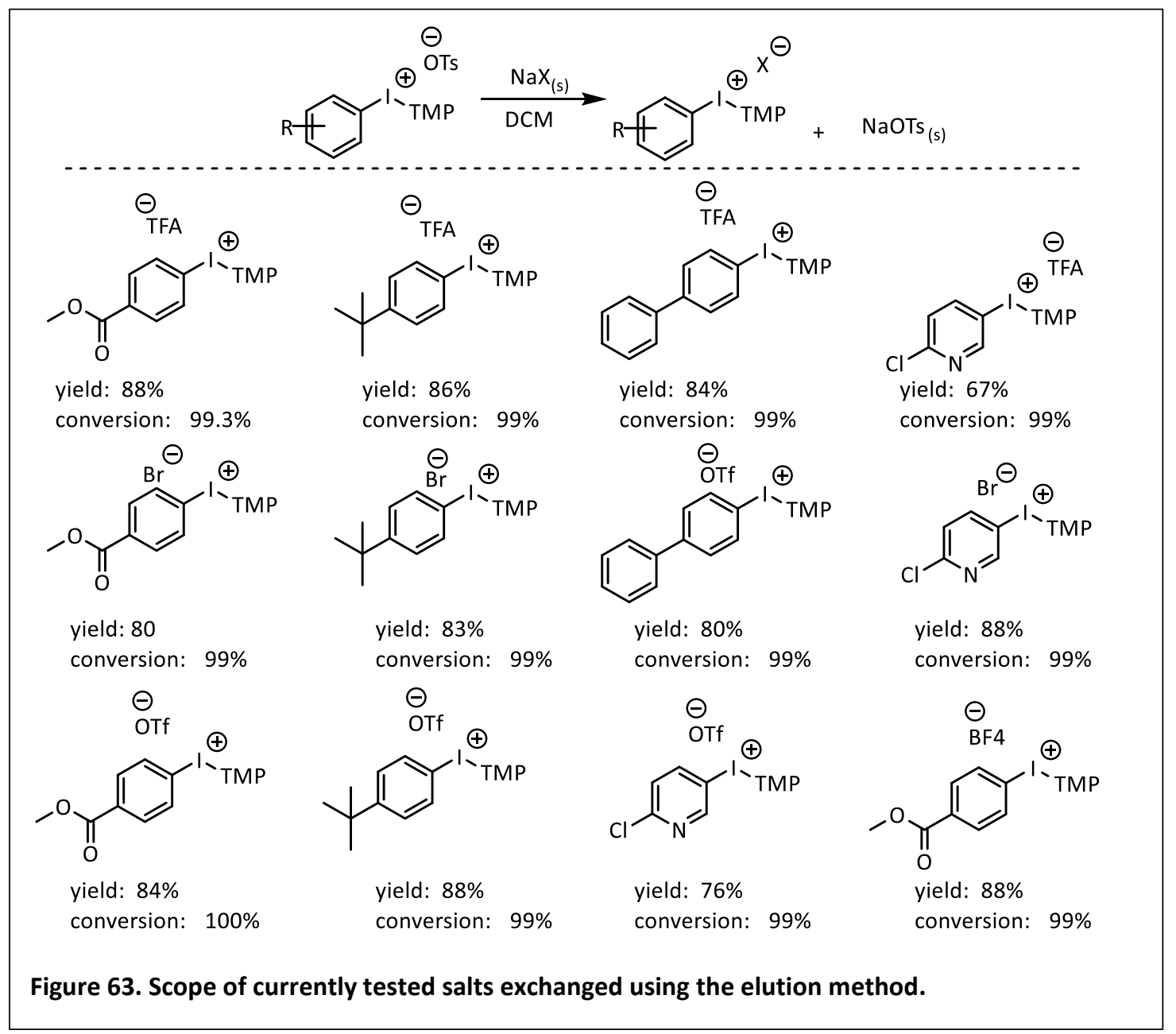

The work in this section simply describes the feasibility demonstration of an anion exchange method that functions by elution of a dissolved diaryliodonium salt through a column packed with a sodium salt comprised of the target anion. Immediately, it became clear that each different substrate will require some amount of development as 
the method is somewhat finicky. For example, while exchanging tosylate for TFA, the rate of elution of a diaryliodonium-methanol solution was found to quickly diminish to the point that the liquid could not be eluted with pressure nor with suction. This clogging was assumed to occur as sodium tosylate fines precipitated within the column. The solution was to include a filter-aid in the column packing. Celite and coral sand both worked as filter aids, with coral sand being superior. In this way, some mindfulness and attention to engineering solutions may be necessary for certain salts to be anion exchanged by this method. When the method works, however, several milimol of diaryliodonium salt may be exchanged within minutes, plus the time to remove the solvent. Figure 63 shows that excellent conversion was achieved for several different starting diaryliodonium tosylate salts. These salts could be anion exchanged in moderate

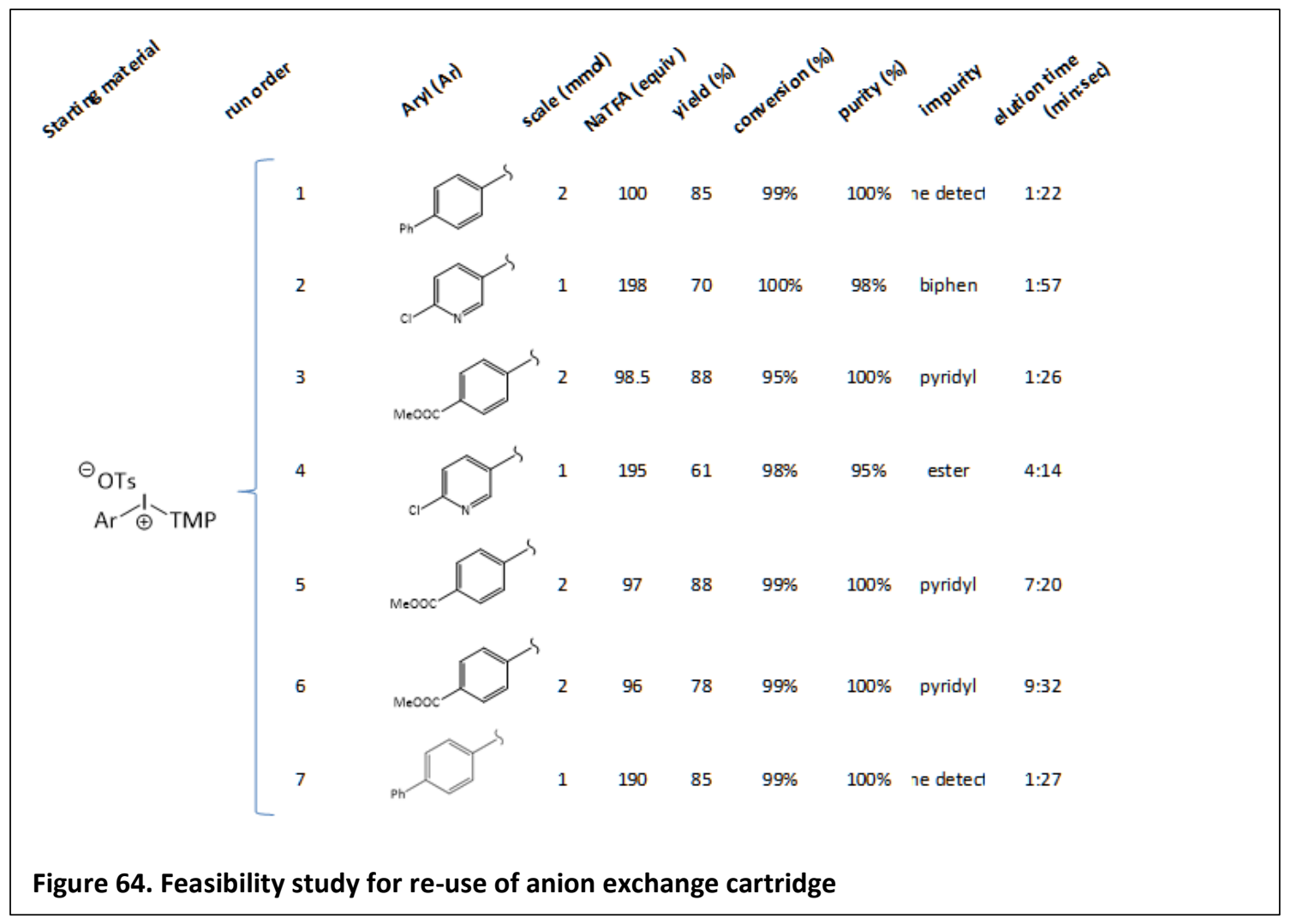


to excellent yield, using a scalable process, in less than 10 minutes, which would previously take at least 2 hours. Finally, the columns were fabricated from plastic syringes and based on feasibility experiments in Figure 64 they are reusable. Based on the reusability and scalability of this method it is likely that one such cartridge, or column would last a research laboratory months. A particularly time saving experiment was realized when diaryliodonium tosylate was eluted through a layer of bromide salt followed by a layer of a silver acetate or silver tetrafluoroborate salt. By using layers of solid salts it was possible to exchange tosylate into acetate, which normally takes several steps and is laborious. As such this was a successful side project. 


\section{Details on solvent selection: use of Hansen Solubility Parameters}

Solvents for the azidation reactions presented in Chapter 3 were selected based on their Hansen Solubility Parameters (HSP). Briefly, HSP are an improvement on the Hildebrandt solubility parameter, which was based on the idea that the enthalpy of vaporization of a solvent is a function of the affinity between solvent molecules. Dr. Charles Hansen further developed the Hildebrand parameter by suggesting that the affinity between solvent molecules is the combination of dispersion, polar, and hydrogen bonding forces. Using these three parameters Hansen empirically determined and published the HSP values for thousands of small molecules and polymers. The concept and practical utility of HSP is easily visualized if the three parameters are used as the axes on a 3D graph. By empirically determining the limit of solubility of an analyte on each axes one can estimate its HSP values. A molecule will be readily soluble when mixed in a solvent with similar HSP.

In this case, HSP were used to select solvents with the intention of adequately representing the possible solvent space. Ideally, nine readily available solvents would be selected so that their HSP would form a cube with a center point in HSP space. It was quickly obvious that at best the solvents selected would resemble some very distorted polyhedron comprised of 8 vertices and a point somewhere within its volume. The solvents were additionally cross-referenced against principal component analysis values (PCA) reported by Rolph Carlson. ${ }^{43}$ The PCA analysis is not trivial and includes 
numerous parameters. The solvents selected for our study were found to adequately represent the solvent space according to both HSP and Carlson's PCA analysis.

The azidation reactions in Figure 45 were performed using one electron rich and one electron poor aryl(TMP)iodonium tosylate. Table 12 shows the azidation yield for each solvent as well as the HSP values and fractional HSP values.

\begin{tabular}{|l|cll|lll||cc||}
\hline solvent & Disp & Polar & H-bond & D\% & P\% & H\% & tBu \%yield & $\begin{array}{c}\text { COOMe } \\
\text { \%yield }\end{array}$ \\
\hline pentane & 14.5 & 0.0 & 0.0 & $100 \%$ & $0 \%$ & $0 \%$ & 0 & 0 \\
water & 15.6 & 16.0 & 42 & $21 \%$ & $22 \%$ & $57 \%$ & 2 & 1 \\
toluene & 18.0 & 1.4 & 2.0 & $84 \%$ & $7 \%$ & $9 \%$ & 12 & 7 \\
Ethylene Glycol & 16.0 & 12.0 & 20.0 & $33 \%$ & $25 \%$ & $42 \%$ & 20 & 29 \\
1,4 dioxane & 19.0 & 1.8 & 7.4 & $67 \%$ & $6 \%$ & $26 \%$ & 39 & 24 \\
Dichloroethane & 19.0 & 7.4 & 4.1 & $62 \%$ & $24 \%$ & $13 \%$ & 37 & 28 \\
Ethanol & 15.8 & 8.8 & 19.4 & $36 \%$ & $20 \%$ & $44 \%$ & 42 & 25 \\
Acetonitrile & 15.3 & 18.0 & 6.1 & $39 \%$ & $46 \%$ & $15 \%$ & 30 & 41 \\
propylene & 21.0 & 18.0 & 6.1 & $47 \%$ & $40 \%$ & $14 \%$ & 32 & 41 \\
carbonate & & & & & & & & \\
diglyme & 16.2 & 7.8 & 12.6 & $44 \%$ & $21 \%$ & $34 \%$ & 45 & 41 \\
\hline
\end{tabular}

Table 11. Solvent screening for aryl azidation using HSP and fractional HSP. Unoptimized conditions were used.

Fractional HSP values simply are the geometric average of the standard HSP values. For example, the fractional dispersion parameter of pentane is found by taking the ratio of the regular dispersion HSP value and sum of all three regular HSP values. The fractional polar and hydrogen bonding parameters may be calculated the same way. The fractional values allow the reaction yields from Table 12 to be shown as contour lines on the ternary diagrams in Figure 65 and Figure 66. 


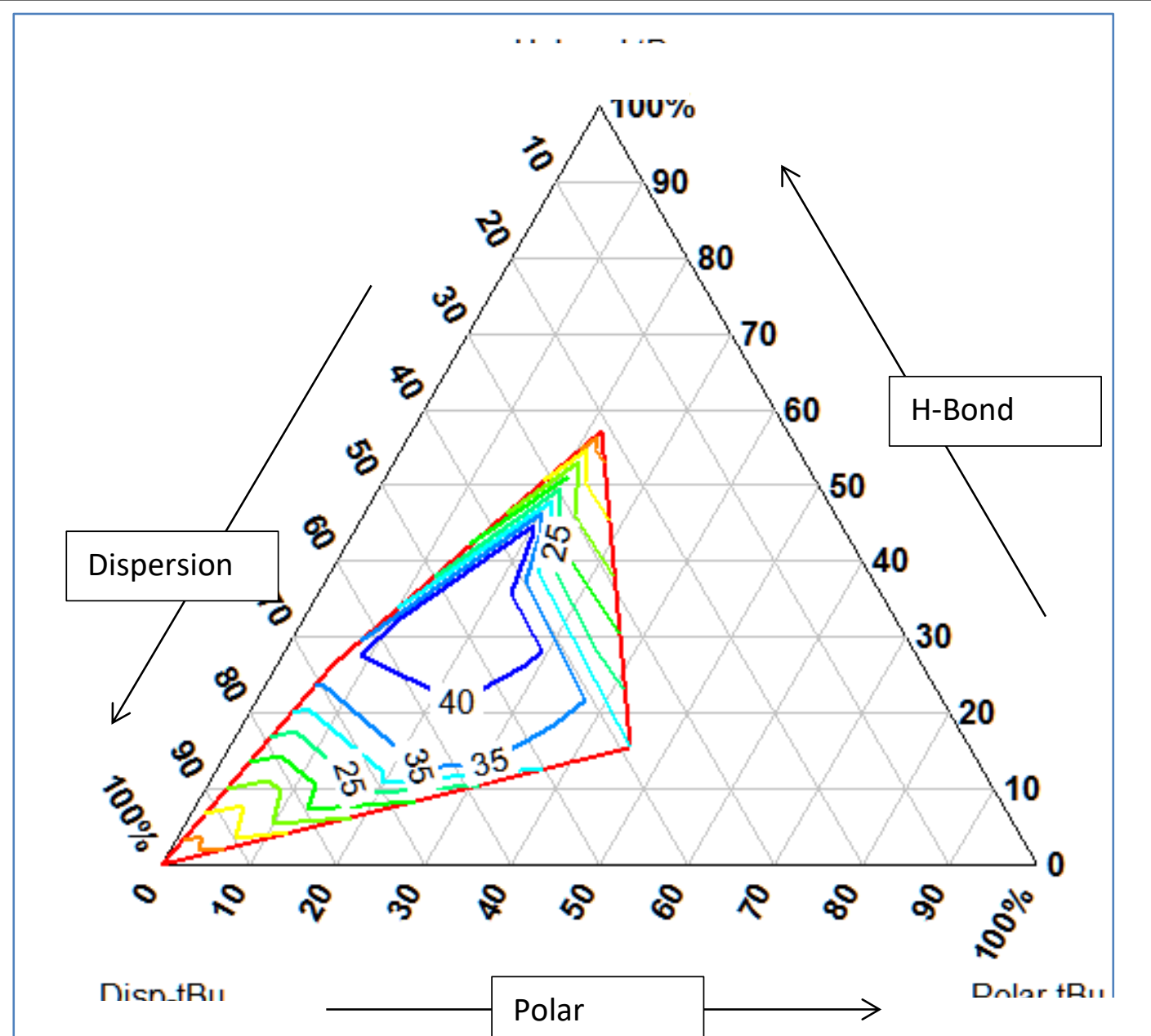

Figure 65. Solvent effect on azidation of 4-tertbutyl iodobenzene. Ternary contour plots of yield vs. Hansen Solubility Parameters, using unoptimized reaction conditions. 


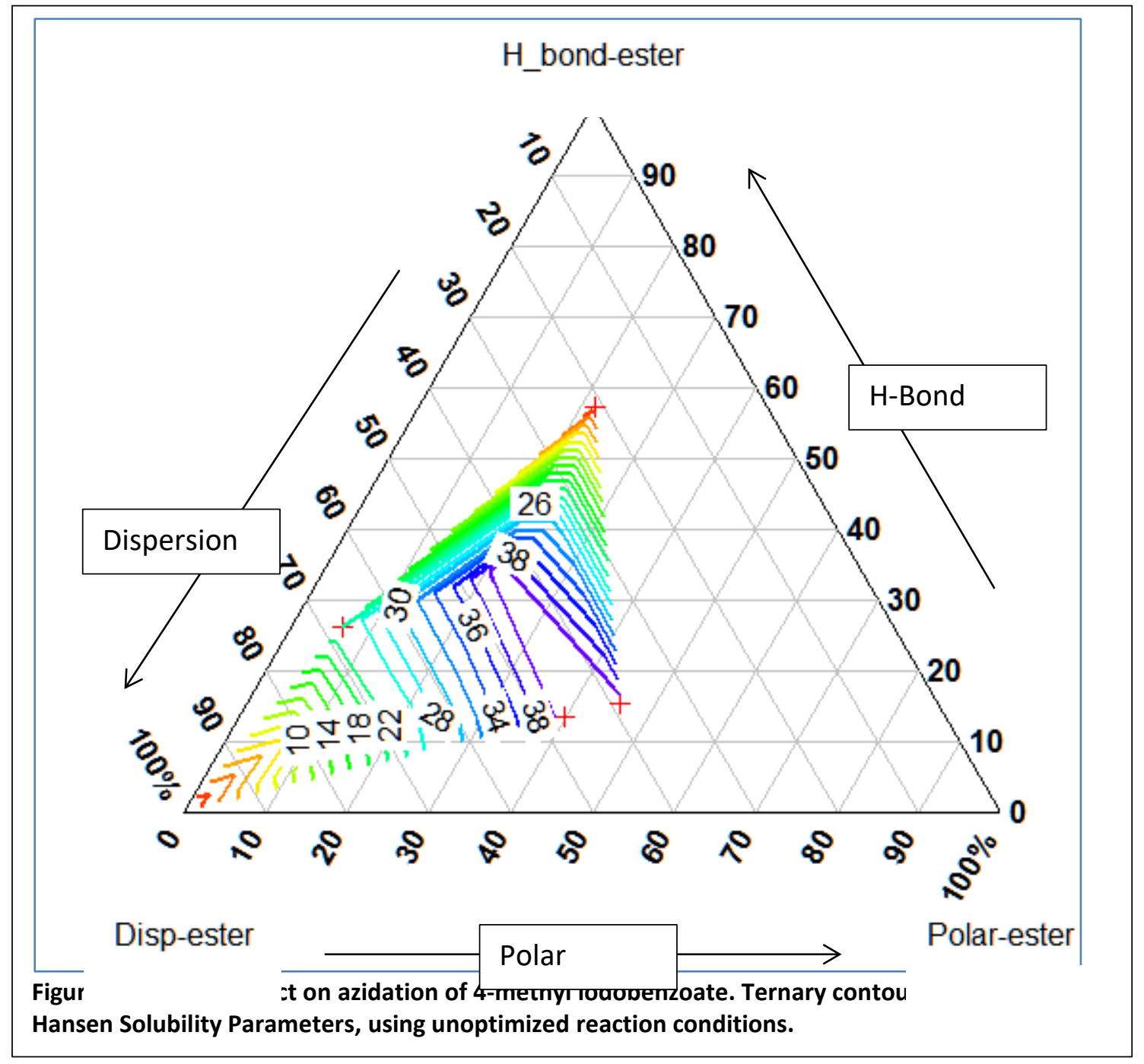

\begin{tabular}{|cccc|}
\hline index & D\% & P\% & H\% \\
a & 46 & 20 & 34 \\
b & 43 & 22 & 35 \\
c & 47.5 & 26.5 & 26 \\
d & 44 & 28 & 28 \\
average & 45 & 24 & 31 \\
Table 12. The coordinates for the vertices of the area of maximum yield on both Figure 65 and \\
Figure 66.
\end{tabular}


The area of maximum yield shared by the ternary plots in Figure 65 and Figure 66 is bounded by the coordinates that correspond to the fractional HSP listed in Table 13. A particularly useful aspect of HSP is that they are additive according to mole fraction. That is, if two or more hypothetical, miscible, solvents are mixed then the HSP of the mixture may be calculated according to the new solvent systems composition. Similarly, Table 12 shows the average fractional HSP that correspond to maximum yield can be used to look up a solvent with the closest matching HSP. Based on the results shown in the two ternary diagrams, it is clear that parameters such as HSP have potential for use as inputs to experiment designs. This sets the framework for future studies that use physicochemical properties as inputs to experiment designs, thus studying the chemistry directly and not just the effect of reaction conditions. 


\section{Supporting Information}

\subsection{General information for all Supporting Information herein.}

Materials. Commercially available reagents and solvents were used without further purification unless otherwise stated. m-CPBA was purchased from Sigma-Aldrich, dried, and assayed by iodometric titration before use according to literature procedures. ${ }^{44}$ Starting materials for Figure $51{ }^{45}, \mathbf{1 4 - T F A}{ }^{46}, \mathbf{5 2}^{47}$ were prepared to previously reported procedures.4'-iodo-[1,1'-biphenyl]-4-carbonitrile ${ }^{48}$ and 2-(4-iodobenzyl)isoindoline-1,3dione $^{49}$ was prepared according to literature procedure. All other materials were prepared as described in detail below.

Methods. Reactions were performed in borosilicate, Teflon-lined, screw-cap vials or round bottom flasks without exclusion of ambient air or moisture, unless otherwise stated. Reactions heated above room temperature were done in an aluminum block or oil bath, heated externally by a digitally controlled hotplate/stirrer. Solvents were removed by rotary evaporation.

Proton $\left({ }^{1} \mathrm{H}\right)$, carbon $\left({ }^{13} \mathrm{C}\right)$ and fluorine $\left({ }^{19} \mathrm{~F}\right)$ nuclear magnetic resonance (NMR) spectra were recorded using a Bruker AVANCE III spectrometer with a 9.4 T magnet, $5 \mathrm{~mm}$ BBO probe and operating at $400.13 \mathrm{MHz}$. If indicated, a Bruker Avance III with $5 \mathrm{~mm}$ PATXI probe, operating at $599.88 \mathrm{MHz}$, was used. Each spectrum shown below was recorded at $298 \mathrm{~K}$ in DMSO- $d_{6}$ or $\mathrm{CDCl}_{3}$. Chemical shifts in proton and carbon spectra are referenced to the tetramethylsilane (TMS) signal. Multiplicity is given as follows: $s=$ singlet, $d=$ doublet, $\mathrm{t}=$ triplet, $\mathrm{q}=$ quartet, $\mathrm{dq}=$ doublet of quartets, $\mathrm{m}=$ multiplet. NMR yields were 
determined from ${ }^{1} \mathrm{H}$ NMR spectra of crude reaction products using anhydrous dimethylformamide (ACROS, 99.8\%) as an internal standard.

Thin layer chromatography (TLC) was performed using plastic-backed silica gel plates (Silicagel $60 \AA$ A F-254) and visualization was accomplished using ultraviolet light (254 nm). Flash column chromatography was performed on SiliCycle silica gel, (SiliaFlash, P60, 40$63 \mu \mathrm{m}, 60 \AA ̊)$.

FT-IR spectroscopy was performed on a ThermoScientific, Nicolet iS5 spectrometer in transmission mode, using OMNIC software, version 9.2.98. Samples were dissolved in dichloromethane, applied to a salt plate and the solvent allowed to evaporate.

Molecular weight determinations were made on a ThermoElectron, LTQ-Orbitrap, high resolution mass spectrometer with dedicated Accela HPLC system and electrospray ionization (ESI). High resolution MS of compound $\mathbf{S} 1$ was obtained from the Oregon State University, Mass Spectrometry Facility and used a Water Synapt G2 coupled to Agilent APGC. Low resolution molecular weight determinations were made using an Agilent 5973 GC-MS system, using El.

Melting point (mp) measurements were recorded using Mel-Temp instruments and reported as uncorrected values. Melting point samples were taken from the product produced to the following procedures without further purification. 


\subsection{Supporting Information for Chapter 2}

\subsubsection{General procedure for the synthesis of aryl(TMB)iodonium tosylates}

Aryl iodide ( $5 \mathrm{mmol}, 1$ equiv.) and acetonitrile $(5 \mathrm{~mL}$ ) were added to a $50 \mathrm{~mL}$ roundbottom flask, equipped with a magnetic stir bar. Toluenesulfonic acid (5.05 mmol, 1.01 equiv.) was added in one portion, followed by one portion of $m$-CPBA (5.05 mmol, 1.01 equiv.). After attaching a reflux condenser, the reaction was lowered into an oil bath set to $77^{\circ} \mathrm{C}$ and stirred vigorously. After 30 minutes, the reflux condenser is removed in order to add (5.05 mmol, 1.01 equiv) 1,3,5-trimethoxybenzene (TMB) in one portion and stirring was continued at $77^{\circ} \mathrm{C}$ for 5 minutes. The reaction was removed from heat and concentrated under reduced pressure. The crude residue was triturated with diethyl ether. The precipitate was isolated by vacuum filtration and washed by slurry filtration with diethyl ether $(3 \times 20 \mathrm{~mL})$. After drying under high vacuum the diaryliodonium salt was obtained in analytically pure form.

\subsubsection{Characterization data for aryl(TMB)lodonium tosylates}

Compound 11 - Prepared according to the general procedure above on $10 \mathrm{mmol}$ scale $\Theta_{\mathrm{OTS}}^{\oplus}$ and obtained in $96 \%$ yield (5.353 g) as an off-white powder. ${ }^{1} \mathrm{H}$ NMR $\left(400 \mathrm{MHz}, \mathrm{DMSO}-d_{6}\right) \delta 7.83-7.75(\mathrm{~m}, 2 \mathrm{H}), 7.52-7.45(\mathrm{~m}, 2 \mathrm{H}), 7.25$ (d, $J=8.1 \mathrm{~Hz}, 2 \mathrm{H}), 7.11(\mathrm{~d}, J=7.8 \mathrm{~Hz}, 2 \mathrm{H}), 6.45(\mathrm{~s}, 2 \mathrm{H}), 3.94(\mathrm{~s}, 6 \mathrm{H})$, $3.86(\mathrm{~s}, 3 \mathrm{H}), 2.30(\mathrm{~s}, 3 \mathrm{H}), 2.28(\mathrm{~s}, 3 \mathrm{H}) .{ }^{13} \mathrm{C}$ NMR $\left(101 \mathrm{MHz}, \mathrm{DMSO}-d_{6}\right)$ $\delta 166.0,159.3,145.5,141.8,137.6,134.3,132.0,128.0,125.4,112.4,91.9,87.2$, 57.2, $56.1,20.7$ (one carbon signal unaccounted for due to overlapping methyl signals). FT-IR: 3023, 1642, 1585, 1458, 1414, 1207, 1185, 1035, $816 \mathrm{~cm}^{-1}$. HRMS (ESI $\left.{ }^{+}\right)$: Calculated for $\mathrm{C}_{18} \mathrm{H}_{18} \mathrm{IO}_{3}{ }^{+}$[M - OTs] : 385.0295; Observed 385.0265. Mp decomposed $168 \mathrm{C}$. 
Compound 12 - Prepared according to the general procedure above with the exception

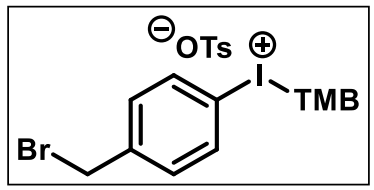
of running both stages at room temperature. The $5 \mathrm{mmol}$ scale reaction yielded $85 \%(2.621 \mathrm{~g})$ as a white powder. ${ }^{1} \mathrm{H}$ NMR (400 MHz, DMSO- $\left.d_{6}\right) \delta 7.92-7.87(\mathrm{~m}, 2 \mathrm{H}), 7.54-7.44(\mathrm{~m}, 4 \mathrm{H}), 7.10(\mathrm{~d}$, $J=7.8 \mathrm{~Hz}, 2 \mathrm{H}), 6.45(\mathrm{~s}, 2 \mathrm{H}), 4.70(\mathrm{~s}, 2 \mathrm{H}), 3.94(\mathrm{~s}, 6 \mathrm{H}), 3.86(\mathrm{~s}, 3 \mathrm{H})$, $2.28(\mathrm{~s}, 3 \mathrm{H}) .{ }^{13} \mathrm{C}$ NMR $\left(101 \mathrm{MHz}, \mathrm{DMSO}-d_{6}\right) \delta 166.0,159.2,145.4,141.5,137.6,134.6$, 132.0, 128.0, 125.4, 115.8, 91.9, 87.7, 57.2, 56.1, 32.7, 20.7. FT-IR: 3090, 3033, 2978, 2945, 2844, 1643, 1583, 1413, 1186, 815, 682, $565 \mathrm{~cm}^{-1}$. HRMS $\left(\mathrm{ESI}^{+}\right)$: Calculated for $\mathrm{C}_{16} \mathrm{H}_{17} \mathrm{BrIO}_{3}^{+}[\mathrm{M}-\mathrm{OTs}]^{+}: 462.9400$ Observed 462.9383. Mp decomposed $157 \mathrm{C}$

Compound 13 - Prepared according to the general procedure above on $5 \mathrm{mmol}$ scale with $\Theta_{\mathrm{OTS}} \oplus_{\mathrm{TMB}}$ the following deviations: i) Stage 1 was run at ambient temperature, ii) stage 2 was run at ambient temperature, iii) Stage 2 reaction progress was assessed by TLC and Stage 2 reaction time was one hour. The product was isolated in $87 \%$ yield $(2.49 \mathrm{~g})$ as a white powder. ${ }^{1} \mathrm{H}$ NMR $\left(400 \mathrm{MHz}\right.$, DMSO- $\left.d_{6}\right) \delta 7.87(\mathrm{~d}, J=8.4 \mathrm{~Hz}, 2 \mathrm{H}), 7.48(\mathrm{~d}, J=8.1 \mathrm{~Hz}$, $2 \mathrm{H}), 7.38(\mathrm{~d}, J=8.4 \mathrm{~Hz}, 2 \mathrm{H}), 7.10(\mathrm{~d}, J=7.9 \mathrm{~Hz}, 2 \mathrm{H}), 6.45(\mathrm{~s}, 2 \mathrm{H}), 5.50-5.25$ (br. $\mathrm{s}, 1 \mathrm{H})$, $4.52(\mathrm{~s}, 2 \mathrm{H}), 3.94(\mathrm{~s}, 6 \mathrm{H}), 3.85(\mathrm{~s}, 3 \mathrm{H}), 2.27(\mathrm{~s}, 3 \mathrm{H}) .{ }^{13} \mathrm{C}$ NMR (101 MHz, DMSO-d 6 ) $\delta$ 166.0, 159.2, 146.5, 145.4, 137.6, 134.1, 129.1, 128.0, 125.4, 113.6, 91.9, 87.2, 61.9, 57.2, 56.0, 20.7. FT-IR: 3410, 3080, 3033, 2995, 2918, 2852, 1644, 1572, 1443, 1412, 1340, 1040, 821 $\mathrm{cm}^{-1}$. HRMS $\left(\mathrm{ESI}^{+}\right)$: Calculated for $\mathrm{C}_{16} \mathrm{H}_{18} \mathrm{IO}_{4}{ }^{+}[\mathrm{M}-\mathrm{OTs}]^{+}:$:01.0244; Observed 401.0219. Mp $184-186^{\circ} \mathrm{C}$

Compound 14 - Prepared according to the general procedure above on $10 \mathrm{mmol}$ scale

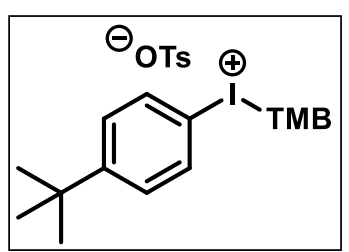
and obtained in $93 \%$ yield $(5.570 \mathrm{~g})$ as a white powder. ${ }^{1} \mathrm{H}$ NMR (400 $\left.\mathrm{MHz}, \mathrm{DMSO}-\mathrm{d}_{6}\right) \delta 7.87-7.80(\mathrm{~m}, 2 \mathrm{H}), 7.53-7.44(\mathrm{~m}, 4 \mathrm{H}), 7.10(\mathrm{~d}, \mathrm{~J}$ $=7.8 \mathrm{~Hz}, 2 \mathrm{H}), 6.47(\mathrm{~s}, 2 \mathrm{H}), 3.96(\mathrm{~s}, 6 \mathrm{H}), 3.87(\mathrm{~s}, 3 \mathrm{H}), 2.28(\mathrm{~s}, 3 \mathrm{H}), 1.23$ (s, 9H). ${ }^{13} \mathrm{C}$ NMR (101 MHz, DMSO) $\delta$ 166.0, 159.3, 154.5, 145.6, $137.5,134.1,128.5,128.0,125.4,112.6,91.9,87.0,57.3,56.1,34.7$, 30.6, 20.7. FT-IR: 3071, 2953, 2867, 2840, 1036, 1634, 1583, 1467, 1412, 1208, 1125, $815 \mathrm{~cm}^{-1}$. HRMS $\left(\mathrm{ESI}^{+}\right)$: Calculated for $\mathrm{C}_{19} \mathrm{H}_{24} \mathrm{IO}_{3}{ }^{+}[\mathrm{M}-\mathrm{OTs}]^{+}:$427.0765; Observed 427.0746. Mp 190-192 ${ }^{\circ} \mathrm{C}$

Compound 15 - Prepared according to the general procedure above on $5 \mathrm{mmol}$ scale with

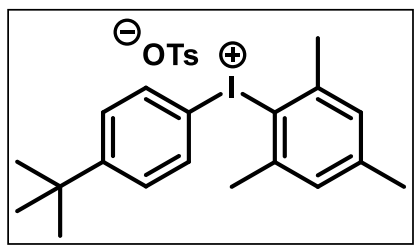
the following deviations: i)in Stage 2, mesitylene was added in place of TMB, ii) Stage 2 reaction time was six hours and reaction progress was monitored by TLC. The product was obtained in $84 \%$ yield $(2.303 \mathrm{~g})$ as a white powder. ${ }^{1} \mathrm{H}$ NMR (400 $\left.\mathrm{MHz}, \mathrm{DMSO}-\mathrm{d}_{6}\right) \delta 7.88(\mathrm{~d}, J=8.7 \mathrm{~Hz}, 2 \mathrm{H}), 7.49(\mathrm{~d}, J=8.7 \mathrm{~Hz}, 2 \mathrm{H})$, $7.46(\mathrm{~d}, J=8.1 \mathrm{~Hz}, 2 \mathrm{H}), 7.19(\mathrm{~s}, 2 \mathrm{H}), 7.09(\mathrm{~d}, J=7.9 \mathrm{~Hz}, 2 \mathrm{H}), 2.60$ (s, 6H), $2.28(\mathrm{~s}, 6 \mathrm{H}), 1.23$ (s, 9H). ${ }^{13} \mathrm{C}$ NMR (101 MHz, DMSO-d 6 ) $\delta 154.6,145.4,142.8$, 141.4, 137.5, 134.1, 129.6, 128.8, 127.9, 125.4, 122.6, 111.0, 34.7, 30.6, 26.2, 20.7, 20.4. FT-IR: 3090, 3062, 3039, 2965, 2871, 2843, 1640, 1393, 1214, 1187, $816 \mathrm{~cm}^{-1}$. HRMS (ESI ${ }^{+}$: Calculated for $\left.\mathrm{C}_{19} \mathrm{H}_{24}\right|^{+}[\mathrm{M} \text { - OTs] }]^{+}: 379.0917$; Observed 379.0895. Mp decomposed $175{ }^{\circ} \mathrm{C}$ 
Compound 16 - Prepared according to the general procedure above on $5 \mathrm{mmol}$ scale with

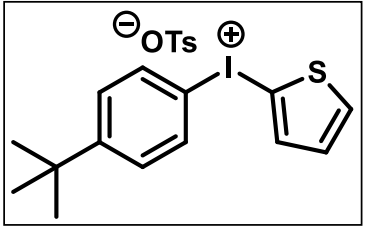
the following deviation: i) in Stage 2, thiophene was used in place of TMB. The product was obtained in $71 \%$ yield $(1.186 \mathrm{~g})$ as a white powder. ${ }^{1} \mathrm{H}$ NMR $\left(400 \mathrm{MHz}, \mathrm{DMSO}-d_{6}\right) \delta 8.20-8.13(\mathrm{~m}, 2 \mathrm{H}), 8.11$ $-8.05(\mathrm{~m}, 1 \mathrm{H}), 7.99-7.92(\mathrm{~m}, 1 \mathrm{H}), 7.57-7.44(\mathrm{~m}, 4 \mathrm{H}), 7.17-7.07$ $(\mathrm{m}, 3 \mathrm{H}), 2.28(\mathrm{~s}, 3 \mathrm{H}), 1.23(\mathrm{~s}, 9 \mathrm{H}) .{ }^{13} \mathrm{C}$ NMR $\left(101 \mathrm{MHz}, \mathrm{DMSO}-d_{6}\right) \delta$ $154.9,145.1,140.2$, 137.8, 137.0, 134.3, 129.4, 128.6, 128.0, 125.4, 115.8, 100.7, 34.7, 30.6, 20.7. FT-IR: 3094, 3059, 2962, 2927, 2867, 1652, 1392, 1214, 1188, 1032, $816 \mathrm{~cm}^{-1}$. HRMS $\left(\mathrm{ESI}^{+}\right)$: Calculated for $\mathrm{C}_{14} \mathrm{H}_{16} \mathrm{IS}^{+}[\mathrm{M}-\mathrm{OTs}]^{+}$: 343.0012; Observed 342.9998. Mp 125$136{ }^{\circ} \mathrm{C}$

Compound 17 - Prepared according to the general procedure above on $5 \mathrm{mmol}$ scale with

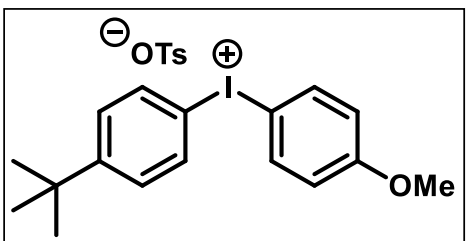
the following three deviations: i) in Stage 2, anisole was used in place of TMB, ii) Stage 2 reaction time was one hour and reaction progress was assessed by TLC; iii) the solvent was not removed from the crude reaction and instead immediately triturated with ethyl ether. The product was filtered and washed according to the general procedure and obtained in $84 \%$ yield $(2.250 \mathrm{~g})$ as a white powder ${ }^{1} \mathrm{H}$ NMR $\left(400 \mathrm{MHz}\right.$, DMSO- $\left.d_{6}\right) \delta 8.24-$ $8.17(\mathrm{~m}, 2 \mathrm{H}), 8.16-8.10(\mathrm{~m}, 2 \mathrm{H}), 7.56-7.51(\mathrm{~m}, 2 \mathrm{H}), 7.50-7.45(\mathrm{~m}, 2 \mathrm{H}), 7.12(\mathrm{~d}, J=7.9$ $\mathrm{Hz}, 2 \mathrm{H}), 7.06-7.01(\mathrm{~m}, 2 \mathrm{H}), 3.77(\mathrm{~s}, 3 \mathrm{H}), 2.28(\mathrm{~s}, 3 \mathrm{H}), 1.23(\mathrm{~s}, 9 \mathrm{H}) .{ }^{13} \mathrm{C} N M R(101 \mathrm{MHz}$, DMSO- $\left.d_{6}\right) \delta 161.7,154.7,145.5,137.6,137.2,134.6,128.5,128.0,125.5,117.2,113.5$, 105.4, 55.6, 34.7, 30.6, 20.7. FT-IR: 3091, 3061, 3050, 2963, 2902, 2869, 2840, 1395, 1254, 1184, $817 \mathrm{~cm}^{-1}$. HRMS $\left(E S I^{+}\right)$: Calculated for $\mathrm{C}_{17} \mathrm{H}_{20} \mathrm{IO}^{+}[\mathrm{M}-\mathrm{OTs}]^{+}:$367.0553; Observed 367.0528 Mp $177-180{ }^{\circ} \mathrm{C}$

Compound 18 - Prepared according to the general procedure above on $5 \mathrm{mmol}$ scale and

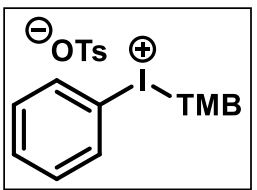
obtained in $93 \%$ yield $(2.520 \mathrm{~g})$ as a white powder. ${ }^{1} \mathrm{H} \mathrm{NMR}(400 \mathrm{MHz}$, DMSO-d $)_{6} \delta 7.92(\mathrm{~d}, J=7.5 \mathrm{~Hz}, 2 \mathrm{H}), 7.64-7.38(\mathrm{~m}, 5 \mathrm{H}), 7.10(\mathrm{~d}, J=7.5$ $\mathrm{Hz}, 2 \mathrm{H}), 6.47(\mathrm{~s}, 2 \mathrm{H}), 3.94(\mathrm{~s}, 6 \mathrm{H}), 3.86(\mathrm{~s}, 3 \mathrm{H}), 2.27(\mathrm{~s}, 3 \mathrm{H}) .{ }^{13} \mathrm{C}$ NMR (101 $\left.\mathrm{MHz}, \mathrm{DMSO}-d_{6}\right) \delta 166.1,159.3,145.5,137.6,134.2,131.4(2), 131.3(6)$, 128.0, 125.4, 116.0, 92.0, 87.0, 57.2, 56.1, 20.7. FT-IR: 3041, 2949, 2842, 2842, 1721, 1646, 1582, 1457, 1343, 1282, 1186, 1034, $816 \mathrm{~cm}^{-1}$. HRMS $\left(\mathrm{ESI}^{+}\right)$: Calculated for $\mathrm{C}_{15} \mathrm{H}_{16} \mathrm{IO}_{3}^{+}[\mathrm{M} \text { - OTs }]^{+}:$371.0139; Observed 371.0121. Mp decomposed $167 \mathrm{C}$.

Compound 19 - Prepared according to the general procedure above on $10 \mathrm{mmol}$ scale

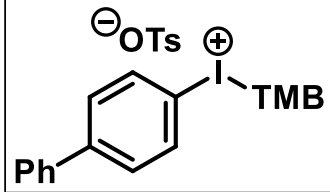
and obtained in $90 \%$ yield $(5.533 \mathrm{~g})$ as an off-white powder. ${ }^{1} \mathrm{H}$ NMR (400 MHz, DMSO-d $) \delta 7.99(\mathrm{~d}, J=8.6 \mathrm{~Hz}, 2 \mathrm{H}), 7.74(\mathrm{~d}, J=8.6$ $\mathrm{Hz}, 2 \mathrm{H}), 7.70-7.62(\mathrm{~m}, 2 \mathrm{H}), 7.56-7.32(\mathrm{~m}, 5 \mathrm{H}), 7.10(\mathrm{~d}, J=7.9 \mathrm{~Hz}$, $2 \mathrm{H}), 6.49(\mathrm{~s}, 2 \mathrm{H}), 3.97(\mathrm{~s}, 6 \mathrm{H}), 3.88(\mathrm{~s}, 3 \mathrm{H}), 2.27(\mathrm{~s}, 3 \mathrm{H}) .{ }^{13} \mathrm{C} N M R$ $\left(101 \mathrm{MHz}\right.$, DMSO-d $\left.d_{6}\right) \delta 166.1,159.3,145.6,143.1,138.1,137.5$, $134.8,129.5,129.0,128.5,128.0,126.9,125.4,114.5,92.0,87.0,57.3,56.1,20.7$. FT-IR: $3089,3068,2967,2943,2878,2839,1646,1586,1468,1339,1209,1033,816,765,684$ 
$\mathrm{cm}^{-1}$. HRMS $\left(\mathrm{ESI}^{+}\right)$: Calculated for $\mathrm{C}_{21} \mathrm{H}_{20} \mathrm{IO}_{3}{ }^{+}[\mathrm{M}-\mathrm{OTs}]^{+}:$447.0452; Observed 447.0431.

$\mathrm{Mp} 162-164{ }^{\circ} \mathrm{C}$

Compound 20 - Prepared according to the general procedure above on $5 \mathrm{mmol}$ scale and<smiles>COC(=O)c1ccc(P(C)O[Na])cc1</smiles>
obtained in $93 \%$ yield $(2.52 \mathrm{~g})$ as a pale yellow powder. ${ }^{1} \mathrm{H}$ NMR (400 MHz, DMSO) $\delta 8.06(\mathrm{~d}, J=8.4 \mathrm{~Hz}, 2 \mathrm{H}), 7.96(\mathrm{~d}, J=8.5 \mathrm{~Hz}$, $2 \mathrm{H}), 7.49$ (d, $J=7.9 \mathrm{~Hz}, 2 \mathrm{H}), 7.11(\mathrm{~d}, J=7.8 \mathrm{~Hz}, 2 \mathrm{H}), 6.49(\mathrm{~s}, 2 \mathrm{H})$, $3.95(\mathrm{~s}, 6 \mathrm{H}), 3.88(\mathrm{~s}, 3 \mathrm{H}), 3.86(\mathrm{~s}, 3 \mathrm{H}), 2.28(\mathrm{~s}, 3 \mathrm{H}) .{ }^{13} \mathrm{C}$ NMR $(101$ $\mathrm{MHz}, \mathrm{DMSO}) \delta 166.3,165.1,159.4,145.5,137.6,134.5,132.0$, 131.7, 128.0, 125.4, 121.0, 92.1, 86.7, 57.3, 56.1, 52.6, 20.7. FTIR: $3041,2949,2842,1721,1646,1582,1457,1343,1282,1186,1034,816 \mathrm{~cm}^{-1}$. HRMS $\left(\mathrm{ESI}^{+}\right)$: Calculated for $\mathrm{C}_{17} \mathrm{H}_{18} \mathrm{IO}_{5}{ }^{+}[\mathrm{M}-\mathrm{OTs}]^{+}$: 429.0193; Observed 429.0167. Mp 169-175 C.

Compound $\mathbf{2 1}$ - Prepared according to the general procedure above on $30 \mathrm{mmol}$ scale

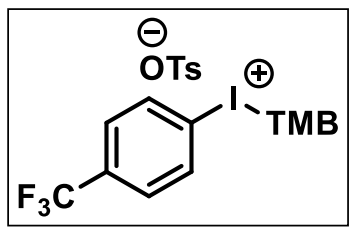
and obtained in $90 \%$ yield (16.527 g) as a white powder. ${ }^{1} \mathrm{H}$ NMR $\left(400 \mathrm{MHz}, \mathrm{DMSO}-d_{6}\right) \delta 8.13(\mathrm{~d}, J=8.2 \mathrm{~Hz}, 2 \mathrm{H}), 7.82(\mathrm{~d}, J=8.4 \mathrm{~Hz}$, $2 \mathrm{H}), 7.52-7.43(\mathrm{~m}, 2 \mathrm{H}), 7.11(\mathrm{~d}, J=7.8 \mathrm{~Hz}, 2 \mathrm{H}), 6.50(\mathrm{~s}, 2 \mathrm{H}), 3.96$ $(\mathrm{s}, 6 \mathrm{H}), 3.89(\mathrm{~s}, 3 \mathrm{H}), 2.29(\mathrm{~s}, 3 \mathrm{H}) .{ }^{13} \mathrm{C}$ NMR $\left(101 \mathrm{MHz}, \mathrm{DMSO}-d_{6}\right) \delta$ $166.4,159.4,145.5,137.6,135.0,131.3\left(q, J_{C-F}=32.4 \mathrm{~Hz}\right), 128.1(q$, $J_{C-F}=3.5 \mathrm{~Hz}$ ), 128.0, 125.4, 123.4 (q, $J_{\mathrm{C}-\mathrm{F}}=272.8 \mathrm{~Hz}$ ), 120.3 (br. s), 92.1, 87.0, 57.3, 56.2, 20.7. ${ }^{19} \mathrm{~F} \mathrm{NMR}\left(376 \mathrm{MHz}, \mathrm{DMSO}-d_{6}\right) \delta$-61.6. FT-IR: 3090, 2979, 2847, 1467, 1644, 1584, $2949,1414,1210,1182,1034,816 \mathrm{~cm}^{-1}$. HRMS $\left(E S{ }^{+}\right)$: Calculated for $\mathrm{C}_{16} \mathrm{H}_{15} \mathrm{~F}_{3} \mathrm{IO}_{3}{ }^{+}[\mathrm{M}-$ OTs $]^{+}$: 439.0013; Observed 438.9989. Mp 167-170 ${ }^{\circ} \mathrm{C}$.

Compound 22 - Prepared according to the general procedure above on $1 \mathrm{mmol}$ scale and $\Theta_{\text {CN }}^{\Theta_{\text {OTS }} \oplus}$ obtained in $75 \%$ yield $(0.428 \mathrm{~g})$ as a pink powder. ${ }^{1} \mathrm{H} \mathrm{NMR}(400 \mathrm{MHz}$, DMSO- $d_{6}$ ) $\delta 8.45$ (dd (appears as triplet), $J=1.5 \mathrm{~Hz}, 1 \mathrm{H}$ ), $8.22-8.17(\mathrm{~m}$, $1 \mathrm{H}), 8.10-8.03(\mathrm{~m}, 1 \mathrm{H}), 7.65$ (dd (appears as triplet), $J=8.0 \mathrm{~Hz}, 1 \mathrm{H}$ ), 7.47 $(\mathrm{d}, J=8.1 \mathrm{~Hz}, 2 \mathrm{H}), 7.11(\mathrm{~d}, J=7.9 \mathrm{~Hz}, 2 \mathrm{H}), 6.48(\mathrm{~s}, 2 \mathrm{H}), 3.95(\mathrm{~s}, 6 \mathrm{H}), 3.88$ $(s, 3 H), 2.29(s, 3 H) .{ }^{13} \mathrm{C}$ NMR (101 MHz, DMSO-d 6$) \delta 166.3,159.3,145.4$, $138.8,137.6,137.3,135.2,132.2,128.0,125.4,116.9,116.1,113.6,92.0$, 87.1, 57.3, 56.1, 20.7. FT-IR: 3088, 2946, 2846, 2232, 1647, 1583, 1468, 1413, 1229, 1187, 1035, $785 \mathrm{~cm}^{-1}$. HRMS $\left(E S I^{+}\right)$: Calculated for $\mathrm{C}_{15} \mathrm{H}_{15} \mathrm{INO}_{3}{ }^{+}$[M - OTs] $]^{+}: 396.0091$; Observed 396.0076. Mp $175-178{ }^{\circ} \mathrm{C}$.

Compound 23 - Prepared according to the general procedure above on $5 \mathrm{mmol}$ scale with $\Theta_{\mathrm{Cl}}^{\Theta_{\mathrm{OTs}}} \oplus_{\mathrm{TMB}}^{\mathrm{Cl}}$ the following exceptions: i) the reaction was removed from the heat bath for 10 minutes before starting Stage 2, ii) Stage 2 was run for 10 minutes at room temperature. The product was obtained in $81 \%$ yield $(2.478 \mathrm{~g})$ as a light pink powder. ${ }^{1} \mathrm{H}$ NMR $\left(400 \mathrm{MHz}, \mathrm{DMSO}-d_{6}\right)$ $\delta 7.95(\mathrm{~d}, J=1.8 \mathrm{~Hz}, 2 \mathrm{H}), 7.83(\mathrm{~s}, 1 \mathrm{H}), 7.48(\mathrm{~d}, J=8.0 \mathrm{~Hz}, 2 \mathrm{H}), 7.11(\mathrm{~d}$, $J=7.9 \mathrm{~Hz}, 2 \mathrm{H}), 6.50(\mathrm{~s}, 2 \mathrm{H}), 3.97(\mathrm{~s}, 6 \mathrm{H}), 3.89(\mathrm{~s}, 3 \mathrm{H}), 2.29(\mathrm{~s}, 3 \mathrm{H}) \cdot{ }^{13} \mathrm{C}$ NMR (101 MHz, DMSO-d $)$ ) $\delta$ 166.5, 159.4, 145.3, 137.7, 135.5, 132.1, 131.4, 128.0, 125.4, 116.6, 92.1, 87.3, 57.3, 56.2, 20.7. FT-IR: 3067, 3037, 2980, 2959, 2939, 2839, 1646, 1587, 
1409, 1211, 1188, 816, 795, 657, $563 \mathrm{~cm}^{-1}$. HRMS (ESI $)$ Calculated for $\mathrm{C}_{15} \mathrm{H}_{14} \mathrm{Cl}_{2} \mathrm{IO}_{3}{ }^{+}[\mathrm{M}$ OTs] $]^{+}$: 438.9359; Observed 438.9342. Mp 193-196 ${ }^{\circ} \mathrm{C}$.

Compound $\mathbf{2 4}$ - Prepared according to the general procedure above on $5 \mathrm{mmol}$ scale and<smiles>O=[N+]([O-])Oc1cc(C(F)(F)F)ccc1Cl</smiles>
obtained in $85 \%$ yield $(2.750 \mathrm{~g})$ as a white powder. ${ }^{1} \mathrm{H}$ NMR $(400$ $\left.\mathrm{MHz}, \mathrm{DMSO}-\mathrm{d}_{6}\right) \delta 8.58(\mathrm{~s}, 1 \mathrm{H}), 7.95(\mathrm{~s}, 2 \mathrm{H}), 7.49(\mathrm{~d}, J=7.6 \mathrm{~Hz}, 2 \mathrm{H})$, $7.10(\mathrm{~d}, J=7.6 \mathrm{~Hz}, 2 \mathrm{H}), 6.47(\mathrm{~s}, 2 \mathrm{H}), 3.95(\mathrm{~s}, 6 \mathrm{H}), 3.86(\mathrm{~s}, 3 \mathrm{H}), 2.27$ (s, 3H). ${ }^{13} \mathrm{C}$ NMR (101 MHz, DMSO) $\delta 166.4,159.5,145.2,140.4$, $138.0,135.9-135.5(\mathrm{~m}), 131.1,130.6-130.3(\mathrm{~m}), 129.1\left(\mathrm{q}, J_{C-F}=\right.$ $33.1 \mathrm{~Hz}$ ), 128.2, 125.5, 122.7 (q, $J_{C-F}=273.1 \mathrm{~Hz}$ ), 120.1, 92.2, 87.6, 57.1, 56.2, 20.8. ${ }^{19} \mathrm{~F}$ NMR (376 MHz, DMSO- $\left.d_{6}\right) \delta$-61.4. FT-IR: 3032, 2942, 2847, 1643, 1590, 1457, 1407, 1212, $1072,1037 \mathrm{~cm}^{-1}$. HRMS (ESI $)$ Calculated for $\mathrm{C}_{16} \mathrm{H}_{14} \mathrm{ClF}_{3} \mathrm{IO}_{3}{ }^{+}[\mathrm{M}-\mathrm{OTs}]^{+}: 472.9623 ;$ Observed 472.9594. Mp $168-170{ }^{\circ} \mathrm{C}$.

Compound 25 - Prepared according to the general procedure above on $5 \mathrm{mmol}$ scale and

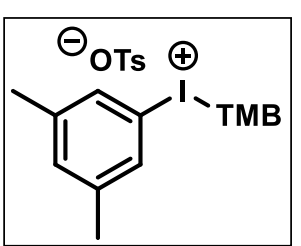
obtained in $89 \%$ yield $(2.532 \mathrm{~g})$ as a white powder. ${ }^{1} \mathrm{H} \mathrm{NMR}(400 \mathrm{MHz}$, DMSO- $\left.d_{6}\right) \delta 7.55(\mathrm{~s}, 2 \mathrm{H}), 7.47(\mathrm{~d}, J=8.0 \mathrm{~Hz}, 2 \mathrm{H}), 7.21(\mathrm{~s}, 1 \mathrm{H}), 7.10(\mathrm{~d}, J$ $=7.9 \mathrm{~Hz}, 2 \mathrm{H}), 6.46(\mathrm{~s}, 2 \mathrm{H}), 3.95(\mathrm{~s}, 6 \mathrm{H}), 3.86(\mathrm{~s}, 3 \mathrm{H}), 2.32-2.22(\mathrm{~m}, 9 \mathrm{H})$. ${ }^{13} \mathrm{C}$ NMR $\left(101 \mathrm{MHz}, \mathrm{DMSO}-d_{6}\right) \delta 166.0,159.3,145.6,141.0,137.5$, $132.9,131.6,128.0,125.4,115.6,92.0,86.7,57.2,56.1,20.7,20.5$. FTIR: 3086, 3054, 3010, 2976, 2945, 2916, 2840, 1582, 1413, 1207, 1189, 1034, $815 \mathrm{~cm}^{-1}$. HRMS (ESI ${ }^{+}$) Calculated for $\mathrm{C}_{17} \mathrm{H}_{20} \mathrm{OO}_{3}{ }^{+}$[M - OTs] ${ }^{+}:$399.0452; Observed 399.0434. Mp 166$168^{\circ} \mathrm{C}$.

Compound 27 - Prepared according to the general procedure above on $5 \mathrm{mmol}$ scale and

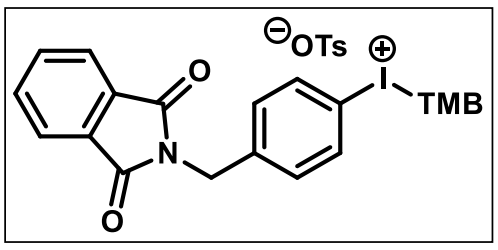
obtained in $90 \%$ yield ( $3.164 \mathrm{~g}$ ) as a white powder. ${ }^{1} \mathrm{H} \mathrm{NMR}$ $\left(400 \mathrm{MHz}, \mathrm{DMSO}-d_{6}\right) \delta 7.95-7.79(\mathrm{~m}, 6 \mathrm{H}), 7.49(\mathrm{~d}, J=8.0$ $\mathrm{Hz}, 2 \mathrm{H}), 7.41(\mathrm{~d}, J=8.4 \mathrm{~Hz}, 2 \mathrm{H}), 7.10(\mathrm{~d}, J=7.9 \mathrm{~Hz}, 2 \mathrm{H}), 6.44$ $(\mathrm{s}, 2 \mathrm{H}), 4.81(\mathrm{~s}, 2 \mathrm{H}), 3.94(\mathrm{~s}, 6 \mathrm{H}), 3.85(\mathrm{~s}, 3 \mathrm{H}), 2.27(\mathrm{~s}, 3 \mathrm{H})$. ${ }^{13} \mathrm{C}$ NMR $\left(101 \mathrm{MHz}\right.$, DMSO- $\left.d_{6}\right) \delta$ 167.6, 166.1, 159.3, 145.5, 140.3, 137.6, 134.5, 131.4, 130.2, 129.1, 128.0, 125.4, 123.2, 114.6, 91.9, 87.1, 57.2, 56.0, 40.2, 20.7. FT-IR: $3021,2968,2842,1700,1643,1392,1229,1184,788,729 \mathrm{~cm}^{-1}$. HRMS $\left(\mathrm{ESI}^{+} \text {): Calculated for } \mathrm{C}_{24} \mathrm{H}_{21} \mathrm{INO}_{5}{ }^{+} \text {[M - OTs }\right]^{+}$: 530.0459; Observed 530.0438. Mp decomposed $172^{\circ} \mathrm{C}$. 
Compound precursor for $\mathbf{2 7}$ - Prepared according to the literature procedure ${ }^{50}$ on 10

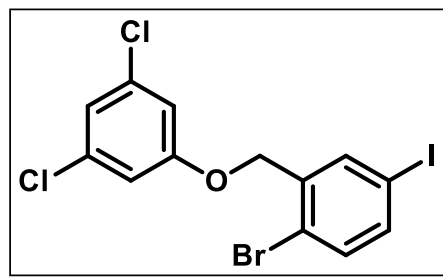
$\mathrm{mmol}$ scale and obtained in $51 \%$ yield $(2.349 \mathrm{~g})$ as a white powder. ${ }^{1} \mathrm{H}$ NMR $\left(400 \mathrm{MHz}, \mathrm{CDCl}_{3}\right) \delta 7.83(\mathrm{~d}, J=2.2 \mathrm{~Hz}, 1 \mathrm{H})$, 7.52 (dd, $J=17.0,2.3 \mathrm{~Hz}, 1 \mathrm{H}), 7.31(\mathrm{~d}, J=8.4 \mathrm{~Hz}, 1 \mathrm{H}), 7.02$ (d (appears as a triplet), $J=1.8 \mathrm{~Hz}, 1 \mathrm{H}), 6.90(\mathrm{~d}, J=1.8 \mathrm{~Hz}, 2 \mathrm{H})$, $5.01(\mathrm{~s}, 2 \mathrm{H}) .{ }^{13} \mathrm{C} \mathrm{NMR}\left(101 \mathrm{MHz}, \mathrm{CDCl}_{3}\right) \delta 159.1,138.5,137.5$, 137.3, 135.5, 134.2, 121.9, 121.9, 113.9, 92.7, 69.0. FTIR: $3053,1573,1265 \mathrm{~cm}^{-1}$. HRMS $\left(\mathrm{AP}^{+}\right)$Calculated for $\left[\mathrm{C}_{13} \mathrm{H}_{8} \mathrm{BrCl}_{2} \mathrm{IO}\right]^{+}: 455.8180$; Observed: 455.8203; $R_{f}: 0.20$ in $100 \%$ hexane.

Compound 28 - Prepared according to the general procedure above on $20 \mathrm{mmol}$ scale

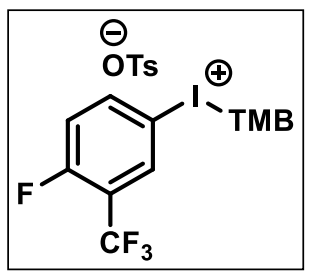
and obtained in $90 \%$ yield (11.258 g) as a white powder. ${ }^{1} \mathrm{H}$ NMR (400 $\mathrm{MHz}, \mathrm{DMSO}) \delta 8.36(\mathrm{dd}, J=6.6,1.8 \mathrm{~Hz}, 1 \mathrm{H}), 8.27-8.18(\mathrm{~m}, 1 \mathrm{H}), 7.66$ $-7.56(\mathrm{~m}, 1 \mathrm{H}), 7.47(\mathrm{~d}, J=8.1 \mathrm{~Hz}, 2 \mathrm{H}), 7.11(\mathrm{~d}, J=7.9 \mathrm{~Hz}, 2 \mathrm{H}), 6.50(\mathrm{~s}$, $2 \mathrm{H}), 3.96(\mathrm{~s}, 6 \mathrm{H}), 3.89(\mathrm{~s}, 3 \mathrm{H}), 2.29(\mathrm{~s}, 3 \mathrm{H}) .{ }^{13} \mathrm{C}$ NMR (101 MHz, DMSO$\left.d_{6}\right) \delta 166.4,160.3\left(\mathrm{~d}, J_{C-F}=259.6 \mathrm{~Hz}\right), 159.3,145.4,141.5\left(\mathrm{~d}, J_{C-F}=9.9\right.$ $\mathrm{Hz}), 137.7,133.3\left(\mathrm{~d}, J_{C-F}=4.6 \mathrm{~Hz}\right), 128.0,125.4,121.3(5)\left(\mathrm{q}, J_{C-F}=\right.$ 540.4, 267.6 Hz), $120.7\left(\mathrm{~d}, J_{C-F}=21.8 \mathrm{~Hz}\right), 118.8\left(\mathrm{dq}, J_{C-F}=33.3,13.3 \mathrm{~Hz}\right), 110.5\left(\mathrm{~d}, J_{C-F}=\right.$ 3.7 Hz), 92.1, 87.5, 57.3, 56.2, 20.7. $\left.{ }^{19} \mathrm{~F} \mathrm{NMR} \mathrm{(376} \mathrm{MHz,} \mathrm{DMSO-} d_{6}\right) \delta-60.4(\mathrm{~d}, J=12.5 \mathrm{~Hz})$, -110.5 (q, J = 12.5 Hz). FT-IR: 3091, 3063, 3034, 2947, 2886, 2886, 2846, 1469, 1345, 1229, $1210,1033,816,682,665,566 \mathrm{~cm}^{-1}$. HRMS $\left(\mathrm{ESI}^{+}\right)$Calculated for $\mathrm{C}_{16} \mathrm{H}_{14} \mathrm{~F}_{4} \mathrm{IO}_{3}{ }^{+}[\mathrm{M}-\mathrm{OTs}]^{+}$: 456.9918; Observed 456.9895. Mp $133-136^{\circ} \mathrm{C}$.

Compound 29 - Prepared according to the general procedure above on $5 \mathrm{mmol}$ scale and (l) obtained in $93 \%$ yield $(2.586 \mathrm{~g})$ as a white powder. ${ }^{1} \mathrm{H}$ NMR (400 MHz, DMSO) $\delta 7.86$ (d, $J=8.4 \mathrm{~Hz}, 2 \mathrm{H}), 7.49$ (d, $J=8.1 \mathrm{~Hz}, 2 \mathrm{H}), 7.41(\mathrm{~d}, J=8.4 \mathrm{~Hz}, 2 \mathrm{H}), 7.28(\mathrm{t}, J=$ $9.1 \mathrm{~Hz}, 1 \mathrm{H}), 7.15-7.06(\mathrm{~m}, 3 \mathrm{H}), 6.93-6.85(\mathrm{~m}, 1 \mathrm{H})$, $6.46(\mathrm{~s}, 2 \mathrm{H}), 4.18(\mathrm{t}, J=6.5 \mathrm{~Hz}, 2 \mathrm{H}), 3.95(\mathrm{~s}, 6 \mathrm{H}), 3.86$ $(\mathrm{s}, 3 \mathrm{H}), 3.04(\mathrm{t}, J=6.4 \mathrm{~Hz}, 2 \mathrm{H}), 2.28(\mathrm{~s}, 3 \mathrm{H}) .{ }^{13} \mathrm{C}$ NMR $\left(101 \mathrm{MHz}, \mathrm{DMSO}-d_{6}\right) \delta$ 166.0, 159.3, $154.8(\mathrm{~d}, J=2.1 \mathrm{~Hz}), 151.7(\mathrm{~d}, J=238.8 \mathrm{~Hz}), 145.6,142.4,137.5,134.3,132.1,128.0,125.4$, 119.6 (d, $J=19.0 \mathrm{~Hz}$ ), 117.1 (d, $J=22.3 \mathrm{~Hz}$ ), 115.8, 114.9 (d, $J=6.9 \mathrm{~Hz}), 113.5,92.0,87.0$, 68.3, 57.2, 56.1, 34.19, 20.7. ${ }^{19} \mathrm{~F}$ NMR (376 MHz, DMSO) $\delta$-127.1. FT-IR: 3092, 3059, 2960, 2927, 2867, 1657, 1394, 1214, 1187, $816 \mathrm{~cm}^{-1}$. HRMS $\left(\mathrm{ESI}^{+}\right)$Calculated for $\mathrm{C}_{23} \mathrm{H}_{22} \mathrm{ClFIO}_{4}{ }^{+}[\mathrm{M}-\mathrm{OTs}]^{+}:$543.0230; Observed 543.0206. Mp $128-130{ }^{\circ} \mathrm{C}$.

Compound precursor for $\mathbf{2 9}$ - Prepared according to the literature procedure ${ }^{50}$ on 10 (l) $\mathrm{mmol}$ scale and obtained in $77 \%$ yield $(2.915 \mathrm{~g})$ as a colorless liquid. ${ }^{1} \mathrm{H}$ NMR $\left(400 \mathrm{MHz}, \mathrm{CDCl}_{3}\right) \delta 7.64-7.56$ $(\mathrm{m}, 2 \mathrm{H}), 7.04-7.02(\mathrm{~m}, 3 \mathrm{H}), 6.91-6.89(\mathrm{~m}, 1 \mathrm{H}), 6.74-6.70$ $(\mathrm{m}, 1 \mathrm{H}), 4.09(\mathrm{t}, J=6.7 \mathrm{~Hz}, 2 \mathrm{H}), 3.02(\mathrm{t}, J=6.7 \mathrm{~Hz}, 2 \mathrm{H}) .{ }^{13} \mathrm{C}$ $\operatorname{NMR}\left(101 \mathrm{MHz}, \mathrm{CDCl}_{3}\right) \delta 154.9\left(\mathrm{~d}, J_{C-F}=2.4 \mathrm{~Hz}\right), 152.7\left(\mathrm{~d}, J_{C-F}=241.3 \mathrm{~Hz}\right), 137.6,137.5$, 131.0, $121.0\left(\mathrm{~d}, J_{C-F}=19.1 \mathrm{~Hz}\right), 116.7\left(\mathrm{~d}, J_{C-F}=22.5 \mathrm{~Hz}\right), 116.2,114.0\left(\mathrm{~d}, J_{C-F}=6.7 \mathrm{~Hz}\right)$, 91.9, 69.0, 35.1. ${ }^{19} \mathrm{~F} \mathrm{NMR}\left(376 \mathrm{MHz}^{\mathrm{CDCl}} \mathrm{CD}_{3}\right) \delta$-126.1. FTIR: 3024, 2253, 1499, 1202, 909 
$\mathrm{cm}^{-1}$. HRMS (EI) Calculated for $\mathrm{C}_{14} \mathrm{H}_{11} \mathrm{ClFIO}$ : 375.9527; Observed: 375.9516 . Rf: 0.26 in $100 \%$ hexane.

Compound 30 - Prepared according to the general procedure above on $5 \mathrm{mmol}$ scale and

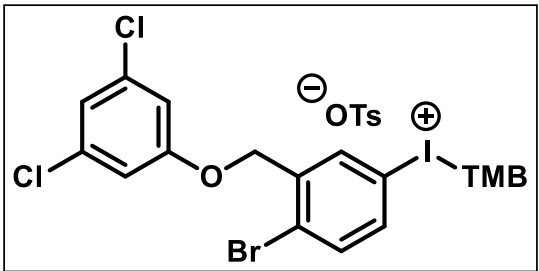
obtained in $92 \%$ yield $(2.871 \mathrm{~g})$ as a white powder. ${ }^{1} \mathrm{H}$ NMR (400 MHz, DMSO) $\delta 7.98(\mathrm{~d}, J=2.1 \mathrm{~Hz}, 1 \mathrm{H}), 7.86-$ $7.74(\mathrm{~m}, 2 \mathrm{H}), 7.48(\mathrm{~d}, J=8.0 \mathrm{~Hz}, 2 \mathrm{H}), 7.20(\mathrm{t}, J=1.7 \mathrm{~Hz}$, $1 \mathrm{H}), 7.14-7.06(\mathrm{~m}, 4 \mathrm{H}), 6.45(\mathrm{~s}, 2 \mathrm{H}), 5.19(\mathrm{~s}, 2 \mathrm{H}), 3.92$ $(\mathrm{s}, 6 \mathrm{H}), 3.88(\mathrm{~s}, 3 \mathrm{H}), 2.28(\mathrm{~s}, 3 \mathrm{H}) .{ }^{13} \mathrm{C}$ NMR $(101 \mathrm{MHz}$, DMSO- $\left.d_{6}\right) \delta 166.2,159.2,159.1,145.5,138.4,137.6$, $135.5,135.4,134.6,134.4,128.0,126.1,125.4,121.0,114.7,114.0,91.9,87.1,69.0,57.2$, 56.1, 20.7. FT-IR: 3033, 2945, 2845, 1640, 1580, 1413, 1212, 1186, 815, $680 \mathrm{~cm}^{-1}$. HRMS $\left(\mathrm{ESI}^{+}\right)$Calculated for $\mathrm{C}_{22} \mathrm{H}_{19} \mathrm{BrCl}_{2} \mathrm{IO}_{4}^{+}[\mathrm{M}-\mathrm{OTs}]^{+}$: 622.8883; Observed 622.8856. Mp decomposed $180^{\circ} \mathrm{C}$.

Compound 31 - Prepared according to the general procedure above on $10 \mathrm{mmol}$ scale ${ }_{\mathrm{TMB}}^{\Theta_{\mathrm{OTS}}}$ and obtained in $95 \%$ yield (5.715 g) as a pale yellow powder. ${ }^{1} \mathrm{H}$ NMR (400 MHz, DMSO) $\delta 8.58(\mathrm{dd}, J=9.1,4.7 \mathrm{~Hz}, 1 \mathrm{H}), 7.83-7.71(\mathrm{~m}, 1 \mathrm{H})$, $7.47(\mathrm{~d}, J=8.0 \mathrm{~Hz}, 2 \mathrm{H}), 7.15-7.06(\mathrm{~m}, 3 \mathrm{H}), 6.62(\mathrm{~s}, 2 \mathrm{H}), 3.97(\mathrm{~s}, 3 \mathrm{H})$, $3.93(\mathrm{~s}, 6 \mathrm{H}), 2.29(\mathrm{~s}, 3 \mathrm{H}) .{ }^{13} \mathrm{C}$ NMR $\left(101 \mathrm{MHz}, \mathrm{DMSO}-d_{6}\right) \delta 167.8,165.7$ $\left(d, J_{C-F}=262.8 \mathrm{~Hz}\right), 160.3,145.4,143.0\left(\mathrm{~d}, J_{C-F}=2.9 \mathrm{~Hz}\right), 137.7,130.2$ $\left(d, J_{C-F}=10.2 \mathrm{~Hz}\right), 128.0,125.4,119.5\left(d, J_{C-F}=23.6 \mathrm{~Hz}\right), 118.9$ (d, $J_{C-F}$ $=27.7 \mathrm{~Hz}), 110.8\left(\mathrm{~d}, J_{C-F}=7.8 \mathrm{~Hz}\right), 92.5,84.6,57.5,56.4,20.7 .{ }^{19} \mathrm{~F}$ NMR $(376 \mathrm{MHz}, \mathrm{DMSO}-$ $\left.d_{6}\right) \delta$-98.1. FT-IR: 3090, 2949, 2847, 2847, 1643, 1582, 1525, 1460, 1347, 1347, 1212, 1187, 1034, $869 \mathrm{~cm}^{-1}$. HRMS $\left(\mathrm{ESI}^{+}\right)$Calculated for $\mathrm{C}_{15} \mathrm{H}_{14} \mathrm{FINO}_{5}{ }^{+}$[M - OTs] $]^{+}: 433.9895$; Observed 433.9876. Mp $173-174{ }^{\circ} \mathrm{C}$.

Compound 32 - Prepared according to the general procedure above on $10 \mathrm{mmol}$ scale<smiles>Cc1ccc([O-])cc1[N+](=O)[O-]</smiles>
and obtained in $95 \%$ yield (5.715 g) as a white powder. ${ }^{1} \mathrm{H} \mathrm{NMR} \mathrm{(400}$ $\mathrm{MHz}, \mathrm{DMSO}) \delta 8.50(\mathrm{~d}, J=1.8 \mathrm{~Hz}, 1 \mathrm{H}), 8.06(\mathrm{dd}, J=8.2,1.9 \mathrm{~Hz}, 1 \mathrm{H})$, $7.60-7.53(\mathrm{~m}, 1 \mathrm{H}), 7.49-7.41(\mathrm{~m}, 2 \mathrm{H}), 7.10(\mathrm{~d}, J=7.8 \mathrm{~Hz}, 2 \mathrm{H}), 6.48$ $(\mathrm{s}, 2 \mathrm{H}), 3.96(\mathrm{~s}, 6 \mathrm{H}), 3.88(\mathrm{~s}, 3 \mathrm{H}), 2.51(\mathrm{~s}, 3), 2.28(\mathrm{~s}, 3 \mathrm{H}) .{ }^{13} \mathrm{C}$ NMR (101 $\left.\mathrm{MHz}, \mathrm{DMSO}-d_{6}\right) \delta 166.3,159.3,149.3,145.5,138.1,137.6,136.5$, $135.4,129.7,128.0,125.4,112.5,92.1,87.3,57.3,56.1,20.7,19.3$. FTIR: 3079, 2975, 2942, 2841, 1581, 1455, 1411, 1272, 1161, $1024 \mathrm{~cm}^{1}$. HRMS (ESI $)$ Calculated for $\mathrm{C}_{16} \mathrm{H}_{17} \mathrm{INO}_{5}{ }^{+}$[M - OTs] ${ }^{+}$: 430.0146; Observed 430.0116. Mp decomposed 113 C.

Compound 33 - Prepared according to the general procedure above on $5 \mathrm{mmol}$ scale and (1) obtained in $90 \%$ yield $(2.656 \mathrm{~g})$ as a pale yellow powder. ${ }^{1} \mathrm{H}$ NMR $\left(400 \mathrm{MHz}, \mathrm{DMSO}-d_{6}\right) \delta 8.27-8.11(\mathrm{~m}, 4 \mathrm{H}), 7.50-7.43(\mathrm{~m}, 2 \mathrm{H}), 7.14$ $-7.05(\mathrm{~m}, 2 \mathrm{H}), 6.50(\mathrm{~s}, 2 \mathrm{H}), 3.95(\mathrm{~s}, 6 \mathrm{H}), 3.88(\mathrm{~s}, 3 \mathrm{H}), 2.28(\mathrm{~s}, 3 \mathrm{H})$. ${ }^{13} \mathrm{C}$ NMR $\left(101 \mathrm{MHz}, \mathrm{DMSO}-d_{6}\right) \delta 166.4,159.4,149.0,145.5,137.6$, $135.4,128.0,125.9,125.4,122.3,92.1,87.1,57.3,56.2$, 20.7. FT- 
IR: 3094, 3058, 3017, 2981, 2946, 2846, 1643, 1583, 1527, 1468, 1346, 1346, 1210, 1034, $848,816 \mathrm{~cm}^{-1}$. HRMS $\left(\mathrm{ESI}^{+}\right)$: Calculated for $\mathrm{C}_{15} \mathrm{H}_{15} \mathrm{INO}_{3}{ }^{+}[\mathrm{M}-\mathrm{OTs}]^{+}:$415.9989; Observed 415.9963. Mp $158-165^{\circ} \mathrm{C}$.

Compound 34 - Prepared according to the general procedure above on $1 \mathrm{mmol}$ scale and $\Theta_{\mathrm{OTS}}^{\oplus}$ obtained in $85 \%$ yield $(0.4933 \mathrm{~g})$ as a white powder. ${ }^{1} \mathrm{H}$ NMR (400 MHz, DMSO- $\left.d_{6}\right) \delta 8.86(\mathrm{~d}, J=2.2 \mathrm{~Hz}, 1 \mathrm{H}), 8.38(\mathrm{dd}, J=8.5,2.3 \mathrm{~Hz}$, $1 \mathrm{H}), 7.62(\mathrm{~d}, J=8.5 \mathrm{~Hz}, 1 \mathrm{H}), 7.47(\mathrm{~d}, J=8.0 \mathrm{~Hz}, 2 \mathrm{H}), 7.11(\mathrm{~d}, J=7.9$ $\mathrm{Hz}, 2 \mathrm{H}), 6.47(\mathrm{~s}, 2 \mathrm{H}), 3.96(\mathrm{~s}, 6 \mathrm{H}), 3.88(\mathrm{~s}, 3 \mathrm{H}), 2.29(\mathrm{~s}, 3 \mathrm{H}) .{ }^{13} \mathrm{C} N M R$ $\left(101 \mathrm{MHz}, \mathrm{DMSO}-d_{6}\right) \delta 166.3,159.2,153.5,152.6,145.3,145.1$, 137.7, 128.0, 127.4, 125.4, 113.8, 92.0, 87.2, 57.3, 56.1, 20.7. FT-IR: 3035, 2943, 2847, 1581, 1455, 1413, 1301, 1210, 1186, 1031, $815 \mathrm{~cm}^{-1}$. HRMS (ESI) Calculated for $\mathrm{C}_{14} \mathrm{H}_{14} \mathrm{ClINO}_{3}{ }^{+}[\mathrm{M}-\mathrm{OTs}]^{+}:$405.9701; Observed 405.9684. Mp decomposed $165^{\circ} \mathrm{C}$

Compound 35 - Prepared according to the general procedure above on $5 \mathrm{mmol}$ scale and

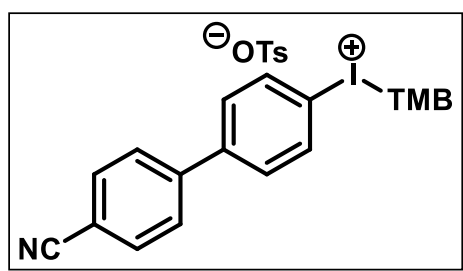
obtained in $92 \%$ yield $(2.931 \mathrm{~g})$ as a white powder. ${ }^{1} \mathrm{H}$ NMR $\left(400 \mathrm{MHz}, \mathrm{DMSO}-\mathrm{d}_{6}\right) \delta 8.06-7.78(\mathrm{~m}, 8 \mathrm{H}), 7.47(\mathrm{~d}, J=8.1$ $\mathrm{Hz}, 2 \mathrm{H}), 7.10(\mathrm{~d}, J=7.8 \mathrm{~Hz}, 2 \mathrm{H}), 6.49(\mathrm{~s}, 2 \mathrm{H}), 3.97(\mathrm{~s}, 6 \mathrm{H}), 3.88$ $(\mathrm{s}, 3 \mathrm{H}), 2.28(\mathrm{~s}, 3 \mathrm{H}) .{ }^{13} \mathrm{C}$ NMR $\left(101 \mathrm{MHz}, \mathrm{DMSO}-d_{6}\right) \delta$ 167.6, 166.1, 159.2, 145.6, 140.3, 137.5, 134.5(3), 134.5(0), 134.2, $131.4,130.1,127.9,125.4,123.2,114.4,91.9,87.0,57.2$, 56.0, 20.7. FT-IR: 3089, 3056, 2980, 2946, 2839, 2227, 1645, 1582, 1413, 1164, 815. HRMS $\left(\mathrm{ESI}^{+}\right)$: Calculated for $\mathrm{C}_{22} \mathrm{H}_{19} \mathrm{INO}_{3}{ }^{+}[\mathrm{M}-\mathrm{OTs}]^{+}$: 472.0404; Observed 472.0375. Mp $174-179{ }^{\circ} \mathrm{C}$.

Compound 36 - Prepared according to the general procedure above on $1 \mathrm{mmol}$ scale and $\Theta_{\mathrm{Cl}}^{\Theta}$ obtained in $67 \%$ yield $(0.397 \mathrm{~g})$ as a white powder. ${ }^{1} \mathrm{H}$ NMR $(400 \mathrm{MHz}$, DMSO) $\delta 7.98-7.96(\mathrm{~m}, 1 \mathrm{H}), 7.76-7.72(\mathrm{~m}, 1 \mathrm{H}), 7.50-7.39(\mathrm{~m}, 3 \mathrm{H})$, $7.10(\mathrm{~d}, J=7.8 \mathrm{~Hz}, 2 \mathrm{H}), 6.47(\mathrm{~s}, 2 \mathrm{H}), 3.95(\mathrm{~s}, 6 \mathrm{H}), 3.87(\mathrm{~s}, 3 \mathrm{H}), 2.33(\mathrm{~s}$, $3 \mathrm{H}), 2.28(\mathrm{~s}, 3 \mathrm{H}) .{ }^{13} \mathrm{C}$ NMR $\left(101 \mathrm{MHz}, \mathrm{DMSO}-d_{6}\right) \delta 166.2,159.3,145.5$, $139.7,137.6,134.8,133.7,133.6,132.8,128.0,125.4,112.8,92.0$, 87.2, 57.3, 56.1, 20.7, 19.4. FT-IR: 3093, 2945, 2845, 1649, 1582, 1467, $1414,1186,1211,1033 \mathrm{~cm}^{1}$. HRMS $\left(\mathrm{ESI}^{+}\right)$Calculated for $\mathrm{C}_{16} \mathrm{H}_{17} \mathrm{ClIO}_{3}{ }^{+}[\mathrm{M}-\mathrm{OTs}]^{+}: 418.9905$; Observed 418.9877. Mp $176-178^{\circ} \mathrm{C}$.

Compound 37 - Prepared according to the general procedure above on $5 \mathrm{mmol}$ scale and $\Theta_{\text {OTs }} \oplus$ obtained in $86 \%$ yield $(2.395 \mathrm{~g})$ a white powder. ${ }^{1} \mathrm{H}$ NMR $(400 \mathrm{MHz}$, DMSO- $\left.d_{6}\right) \delta 7.88-7.82(\mathrm{~m}, 1 \mathrm{H}), 7.72(\mathrm{~d}, J=7.9 \mathrm{~Hz}, 1 \mathrm{H}), 7.55-7.40(\mathrm{~m}$, $4 \mathrm{H}), 7.11(\mathrm{~d}, J=7.9 \mathrm{~Hz}, 2 \mathrm{H}), 6.48(\mathrm{~s}, 2 \mathrm{H}), 3.95(\mathrm{~s}, 6 \mathrm{H}), 3.88(\mathrm{~s}, 3 \mathrm{H}), 2.28(\mathrm{~s}$, $3 \mathrm{H}) .{ }^{13} \mathrm{C}$ NMR (101 MHz, DMSO- $\left.d_{6}\right) \delta 166.3,161.7\left(\mathrm{~d}, J_{C-F}=251.9 \mathrm{~Hz}\right)$, $159.4,145.5,137.7,133.2\left(d, J_{C-F}=7.8 \mathrm{~Hz}\right), 130.3\left(\mathrm{~d}, J_{C-F}=3.2 \mathrm{~Hz}\right), 128.0$, $125.4121 .2\left(\mathrm{~d}, J_{C-F}=24.6 \mathrm{~Hz}\right), 118.7\left(\mathrm{~d}, J_{C-F}=20.8 \mathrm{~Hz}\right), 115.6\left(\mathrm{~d}, J_{C-F}=\right.$ 7.4 Hz), 92.0, 87.2, 57.3, 56.1, 20.7. ${ }^{19} \mathrm{~F} \mathrm{NMR}\left(376 \mathrm{MHz}\right.$, DMSO- $\left.d_{6}\right) \delta$-108.1. FT-IR: 3086, 
2945, 2845, 1650, 1581, 1468, 1414, 1344, 1209, $1035 \mathrm{~cm}^{-1}$. HRMS (ESI ${ }^{+}$) Calculated for $\mathrm{C}_{15} \mathrm{H}_{15} \mathrm{FIO}_{3}{ }^{+}[\mathrm{M}-\mathrm{OTs}]^{+}: 389.0044 ;$ Observed 389.0021. Mp 181-182 ${ }^{\circ} \mathrm{C}$.

Compound 38 - Prepared according to the general procedure above on $5 \mathrm{mmol}$ scale with $\underbrace{\Theta_{\mathrm{OTS}}}_{\mathrm{TMB}}$ the following deviations: i) Stage 1 was run at ambient temperature, ii) stage 2 was run at ambient temperature, iii) Stage 2 reaction progress was assessed by TLC and Stage 2 reaction time was thirtyfive minutes. The product was obtained in $86 \%$ yield (2.504 g) as a white powder. ${ }^{1} \mathrm{H}$ NMR $\left(400 \mathrm{MHz}\right.$, DMSO- $\left.d_{6}\right) \delta 7.82(\mathrm{~d}, J=8.3 \mathrm{~Hz}, 2 \mathrm{H}), 7.49$ (d, J=8.0 Hz, 2H), 7.29 (d, J = 8.3 Hz, 2H), $7.11(\mathrm{~d}, J=7.9 \mathrm{~Hz}, 2 \mathrm{H}), 6.45(\mathrm{~s}, 2 \mathrm{H}), 4.68(\mathrm{~s}, 1 \mathrm{H})$, $3.94(\mathrm{~s}, 6 \mathrm{H}), 3.85(\mathrm{~s}, 3 \mathrm{H}), 3.58(\mathrm{t}, J=6.6 \mathrm{~Hz}, 2 \mathrm{H}), 2.72(\mathrm{t}, J=6.6 \mathrm{~Hz}, 2 \mathrm{H}), 2.27(\mathrm{~s}, 3 \mathrm{H}) .{ }^{13} \mathrm{C}$ NMR $\left(101 \mathrm{MHz}\right.$, DMSO- $\left.d_{6}\right) \delta 166.0,159.3,145.4,143.9,137.7,134.1,132.0,128.0,125.4$, 112.9, 91.9, 87.1, 61.4, 57.2, 56.1, 38.8, 20.7. FT-IR: 3424, 3083, 3030, 2948, 2906, 1640, $1577,1339,1218,1177,1033,562 \mathrm{~cm}^{-1}$. HRMS $\left(E S I^{+}\right)$: Calculated for $\mathrm{C}_{17} \mathrm{H}_{20} \mathrm{OO}_{4}{ }^{+}[\mathrm{M}-\mathrm{OTs}]^{+}$: 415.0401; Observed 415.0382. Mp 181-184 ${ }^{\circ} \mathrm{C}$

Compound 39 - Prepared according to the general procedure above on $5 \mathrm{mmol}$ scale and

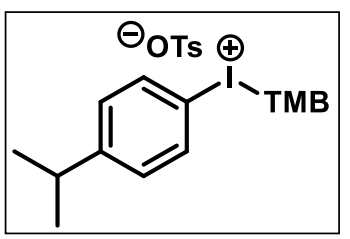
obtained in $77 \%$ yield $(2.251 \mathrm{~g})$ as a white powder. ${ }^{1} \mathrm{H}$ NMR (400 $\left.\mathrm{MHz}, \mathrm{DMSO}-\mathrm{d}_{6}\right) \delta 7.83(\mathrm{~d}, J=8.4 \mathrm{~Hz}, 2 \mathrm{H}), 7.47(\mathrm{~d}, J=8.1 \mathrm{~Hz}, 2 \mathrm{H})$, $7.34(\mathrm{~d}, J=8.5 \mathrm{~Hz}, 2 \mathrm{H}), 7.10(\mathrm{~d}, J=7.8 \mathrm{~Hz}, 2 \mathrm{H}), 6.46(\mathrm{~s}, 2 \mathrm{H}), 3.95$ (s, $6 \mathrm{H}), 3.86(\mathrm{~s}, 3 \mathrm{H}), 2.90$ (septet, $J=6.8 \mathrm{~Hz}, 1 \mathrm{H}), 2.28(\mathrm{~s}, 3 \mathrm{H}), 1.16(\mathrm{~d}, J$ $=6.9 \mathrm{~Hz}, 6 \mathrm{H}) .{ }^{13} \mathrm{C}$ NMR $\left(101 \mathrm{MHz}, \mathrm{DMSO}-d_{6}\right): \delta 166.0,159.3,152.3$, $145.7,137.5,134.4,129.6,127.9,125.4,112.6,91.9,87.0,57.2,56.1,33.1,23.4,20.7$. FTIR: 3090, 3059, 3032, 2961, 2867, 2840, 1651, 1583, 1412, 1213, 1186, $815 \mathrm{~cm}^{-1}$. HRMS $\left(\mathrm{ESI}^{+}\right)$: Calculated for $\mathrm{C}_{18} \mathrm{H}_{22} \mathrm{IO}_{3}{ }^{+}[\mathrm{M}-\mathrm{OTs}]^{+}:$: 413.0608; Observed 413.0587. Mp 149-152 ${ }^{\circ} \mathrm{C}$ 


\subsubsection{General procedure for anion exchange of aryl(TMB)iodonium tosylates}

Aryl(TMB)iodonium tosylate ( $1 \mathrm{~g}, 1$ equiv) is added to $50 \mathrm{~mL}$ boiling water. If the iodonium salt does not dissolve after boiling for 1-2 minutes, then methanol is added portion wise until the material is dissolved or the solution has homogenous appearance. While still hot, a salt containing the target anion is added in excess. The exact amount required depends on the exchange salt and the iodonium salt and an excess of 10 or more equivalents is recommended. The resulting solution is allowed to naturally cool to ambient temperature, before chilling further in an ice-bath. The mixture is suction filtered and the filter cake washed by slurry filtration with water $(3 \times 30 \mathrm{~mL})$. The cake is dried under suction for $10-20$ min and then washed by slurry filtration with ethyl ether $(3 \times 30 \mathrm{~mL})$. The sample is finally dried under high vacuum to remove residual solvent. If iodonium salt is suspected to remain in the aqueous filtrate then it may be extracted with a suitable solvent such as dichloromethane or ethyl acetate. 


\subsubsection{Characterization data for anion exchanged aryl(TMB)iodonium salts}

Compound 19-Br - Prepared according to the general anion exchange procedure above

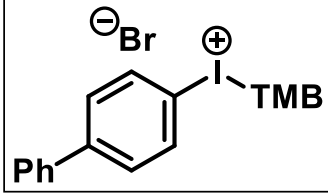
on $2.5 \mathrm{mmol}$ scale, using potassium bromide (20 equiv., $50 \mathrm{mmol}$, $6.00 \mathrm{~g})$ and obtained in $96 \%$ yield (1.28 g) as an off-off-white to light brown powder. ${ }^{1} \mathrm{H}$ NMR (400 MHz, DMSO- $\left.d_{6}\right) \delta 8.00-7.95(\mathrm{~m}, 2 \mathrm{H})$, $7.71(\mathrm{~d}, J=8.6 \mathrm{~Hz}, 2 \mathrm{H}), 7.68-7.63(\mathrm{~m}, 2 \mathrm{H}), 7.53-7.37(\mathrm{~m}, 3 \mathrm{H}), 6.45$ $(\mathrm{s}, 2 \mathrm{H}), 3.95(\mathrm{~s}, 6 \mathrm{H}), 3.87(\mathrm{~s}, 3 \mathrm{H}) .{ }^{13} \mathrm{C}$ NMR $\left(101 \mathrm{MHz}, \mathrm{DMSO}-d_{6}\right) \delta$ 165.6, 159.2, 142.6, 138.3, 134.6, 129.3, 129.0, 128.3, 126.8, 116.5, 91.9, 89.9, 57.2, 56.0. FT-IR: 3072, 2944, 2836, 1636, 1587, 1467, 1338, 1232, 1158, 1033, $824 \mathrm{~cm}^{-1}$. HRMS $\left(E S{ }^{+}\right)$: Calculated for $\mathrm{C}_{21} \mathrm{H}_{20} \mathrm{IO}_{3}{ }^{+}[\mathrm{M}-\mathrm{Br}]^{+}$: 447.0452; Observed 447.0423. Mp 193-195 ${ }^{\circ} \mathrm{C}$.

Compound 19-I - Prepared according to the general anion exchange procedure above on<smiles>COc1ccc(C2CC3CCCC32)cc1</smiles>
$1 \mathrm{mmol}$ scale, using potassium iodide (11 equiv., $10.6 \mathrm{mmol}, 1.765$ g) and obtained in $95 \%$ yield $(0.544 \mathrm{~g}$ ) as a off-white to light brown powder. ${ }^{1} \mathrm{H}$ NMR $\left(400 \mathrm{MHz}\right.$, DMSO- $\left.d_{6}\right) \delta 8.03-7.95(\mathrm{~m}, 2 \mathrm{H}), 7.77-$ $7.70(\mathrm{~m}, 2 \mathrm{H}), 7.70-7.62(\mathrm{~m}, 2 \mathrm{H}), 7.54-7.39(\mathrm{~m}, 3 \mathrm{H}), 6.47(\mathrm{~s}, 2 \mathrm{H})$, $3.97(\mathrm{~s}, 6 \mathrm{H}), 3.88(\mathrm{~s}, 3 \mathrm{H}) .{ }^{13} \mathrm{C}$ NMR $\left(101 \mathrm{MHz}, \mathrm{DMSO}-d_{6}\right) \delta 165.8$, 159.2, 142.8, 138.2, 134.8, 129.4, 129.0, 128.4, 126.8, 115.6, 92.0, 88.6, 57.3, 56.1. FT-IR: $3055,3036,2970,2833,1645,1585,1468,1229,1162,1030,808 \mathrm{~cm}^{-1}$. HRMS $\left(\mathrm{ESI}^{+}\right)$: Calculated for $\mathrm{C}_{21} \mathrm{H}_{20} \mathrm{IO}_{3}{ }^{+}[\mathrm{M}-\mathrm{I}]^{+}$: 447.0452; Observed 447.0422. Mp 164-165 ${ }^{\circ} \mathrm{C}$.

Compound $19-\mathrm{CF}_{3} \mathrm{COO}$ - Prepared according to the general anion exchange procedure $\mathrm{CF}_{3} \mathrm{CoO}_{\mathrm{TMB}}^{\ominus}$ above on $1 \mathrm{mmol}$ scale, using sodium trifluoroacetate (20 equiv., $20.2 \mathrm{mmol}, 2.758 \mathrm{~g})$ and obtained in $86 \%$ yield $(0.481 \mathrm{~g})$ as a offwhite to light brown powder. ${ }^{1} \mathrm{H}$ NMR $\left(400 \mathrm{MHz}, \mathrm{DMSO}-d_{6}\right) \delta 7.99$ $(\mathrm{d}, J=8.1 \mathrm{~Hz}, 2 \mathrm{H}), 7.73(\mathrm{~d}, J=8.1 \mathrm{~Hz}, 2 \mathrm{H}), 7.67(\mathrm{~d}, J=7.4 \mathrm{~Hz}, 2 \mathrm{H})$, $7.53-7.35(\mathrm{~m}, 3 \mathrm{H}), 6.47(\mathrm{~s}, 2 \mathrm{H}), 3.97(\mathrm{~s}, 6 \mathrm{H}), 3.87(\mathrm{~s}, 3 \mathrm{H}) .{ }^{13} \mathrm{C}$ NMR (101 MHz, DMSO- $\left.d_{6}\right)$ $\delta 166.1,159.5,158.1\left(q, J_{C-F}=30.9 \mathrm{~Hz}\right), 143.1,138.2,134.8,129.5,129.1,128.5,126.9$, $117.2\left(q, J_{C-F}=300.4 \mathrm{~Hz}\right), 114.9,92.0,87.4,57.2,56.0 .{ }^{19} \mathrm{~F} \mathrm{NMR}\left(376 \mathrm{MHz}, \mathrm{DMSO}-d_{6}\right) \delta-$ 73.4. FT-IR: $3061,2946,2843,1681,1583,1414,1230,1160,1026,803 \mathrm{~cm}^{-1}$. HRMS (ESI ${ }^{+}$): Calculated for $\mathrm{C}_{21} \mathrm{H}_{20} \mathrm{IO}_{3}{ }^{+}\left[\mathrm{M}-\mathrm{CF}_{3} \mathrm{COO}\right]^{+}:$447.0452; Observed 447.0431. Mp 175-177 ${ }^{\circ} \mathrm{C}$.

Compound 19-OTf - Prepared according to the general anion exchange procedure above<smiles>COc1ccc(-c2ccccc2)cc1</smiles>
on $2 \mathrm{mmol}$ scale with sodium triflate (20 equiv., $40.6 \mathrm{mmol}, 6.99 \mathrm{~g}$ ) and obtained in $90 \%$ yield $(1.094 \mathrm{~g})$ as a off-white to light brown powder. ${ }^{1} \mathrm{H}$ NMR (400 MHz, DMSO- $\left.d_{6}\right) 8.01(\mathrm{~d}, J=8.4 \mathrm{~Hz}, 2 \mathrm{H}), 7.76$ $(\mathrm{d}, J=8.5 \mathrm{~Hz}, 2 \mathrm{H}), 7.68(\mathrm{~d}, J=7.4 \mathrm{~Hz}, 2 \mathrm{H}), 7.59-7.38(\mathrm{~m}, 3 \mathrm{H}), 6.50$ $(\mathrm{s}, 2 \mathrm{H}), 3.99(\mathrm{~s}, 6 \mathrm{H}), 3.89(\mathrm{~s}, 3 \mathrm{H}) .{ }^{13} \mathrm{C}$ NMR $\left(101 \mathrm{MHz}, \mathrm{DMSO}-d_{6}\right) \delta$ $166.2,159.4,143.2,138.1,134.9,129.6,129.1,128.5,126.9,120.7$ (q, J = 322.3 Hz), 114.5, 92.0, 87.0, 57.3, 56.1. ${ }^{19} \mathrm{~F}$ NMR (376 MHz, DMSO) $\delta$-77.7. FT-IR: 3090, 3063, 2944, 2883, 2846, 1578, 1457, 1415, 1259, 1162, 1027, $815 \mathrm{~cm}^{-1}$. HRMS $\left(E S I^{+}\right)$: Calculated for $\mathrm{C}_{21} \mathrm{H}_{20} \mathrm{IO}_{3}{ }^{+}[\mathrm{M}-\mathrm{OTf}]^{+}:$447.0452; Observed 447.0471. Mp decomposed $93^{\circ} \mathrm{C}$. 
Compound 19- $\mathrm{PF}_{6}-$ Prepared according to the general anion exchange procedure above<smiles>CCCc1ccc(-c2ccccc2)cc1</smiles>
on $1 \mathrm{mmol}$ scale with potassium hexafluorophosphate $(20.8$ equiv., $20.8 \mathrm{mmol}, 3.821 \mathrm{~g})$ and obtained in $90 \%$ yield $(0.556 \mathrm{~g})$ as a off-white to light brown powder. ${ }^{1} \mathrm{H}$ NMR $\left(400 \mathrm{MHz}, \mathrm{DMSO}-d_{6}\right) \delta$ $8.04(\mathrm{~d}, J=7.9 \mathrm{~Hz}, 2 \mathrm{H}), 7.76(\mathrm{~d}, J=7.9 \mathrm{~Hz}, 2 \mathrm{H}), 7.67(\mathrm{~d}, J=7.1 \mathrm{~Hz}$, $2 \mathrm{H}), 7.59-7.36(\mathrm{~m}, 3 \mathrm{H}), 6.51(\mathrm{~s}, 2 \mathrm{H}), 4.00(\mathrm{~s}, 6 \mathrm{H}), 3.90(\mathrm{~s}, 3 \mathrm{H}) .{ }^{13} \mathrm{C}$ NMR $\left(101 \mathrm{MHz}, \mathrm{DMSO}-d_{6}\right) \delta 166.2,159.4,143.2,138.2,134.9,129.6,129.1,128.5$, $126.9,114.5,92.0,87.0,57.3,56.1 .{ }^{19} \mathrm{~F} \mathrm{NMR}\left(376 \mathrm{MHz}, \mathrm{DMSO}-d_{6}\right) \delta-70.1\left(\mathrm{~d}, J_{F-p}=\right.$ $711.5 \mathrm{~Hz}$ ). FT-IR: 3109, 1636, 2949, 1583, 2848, 3065, 1473, 1415, 1231, 1163, 1065, $843 \mathrm{~cm}^{-1}$. HRMS $\left(\mathrm{ESI}^{+}\right)$: Calculated for $\mathrm{C}_{21} \mathrm{H}_{20} \mathrm{IO}_{3}{ }^{+}\left[\mathrm{M}-\mathrm{PF}_{6}\right]^{+}:$447.0452; Observed 447.0425. Mp decomposed $127^{\circ} \mathrm{C}$.

Compound 19-BF $-\mathrm{BF}_{4}$ - Prepared according to the general anion exchange procedure above

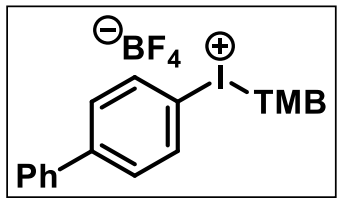
on $1 \mathrm{mmol}$ scale, using sodium tetrafluoroborate (104 equiv, 104 $\mathrm{mmol}, 11.438 \mathrm{~g})$ and obtained in $96 \%$ yield $(0.532 \mathrm{~g})$ as a off-white to light brown powder. ${ }^{1} \mathrm{H} \mathrm{NMR}\left(400 \mathrm{MHz}, \mathrm{DMSO}-\mathrm{d}_{6}\right) \delta 7.99(\mathrm{~d}, J=$ $8.3 \mathrm{~Hz}, 2 \mathrm{H}), 7.75(\mathrm{~d}, J=8.4 \mathrm{~Hz}, 2 \mathrm{H}), 7.67(\mathrm{~d}, J=7.5 \mathrm{~Hz}, 2 \mathrm{H}), 7.53-$ $7.38(\mathrm{~m}, 3 \mathrm{H}), 6.49(\mathrm{~s}, 2 \mathrm{H}), 3.97(\mathrm{~s}, 6 \mathrm{H}), 3.88(\mathrm{~s}, 3 \mathrm{H}) .{ }^{13} \mathrm{C}$ NMR (101 MHz, DMSO-d $)$ ) 166.2, $159.4,143.2,138.1,134.9,129.6,129.1,128.6,126.9,114.5,92.0,87.0,57.3,56.1 .{ }^{19} \mathrm{~F}$ NMR $(376 \mathrm{MHz}$, DMSO-d $) \delta$-148.3. FT-IR: 3088, 3061, 2945, 2845, 1625, 1582, 1472, $1413,1230,1034,817 \mathrm{~cm}^{-1}$. HRMS $\left(\mathrm{ESI}^{+}\right)$: Calculated for $\mathrm{C}_{21} \mathrm{H}_{20} \mathrm{IO}_{3}{ }^{+}\left[\mathrm{M}-\mathrm{BF}_{4}\right]^{+}: 447.0452$; Observed 447.0427. Mp $160-162^{\circ} \mathrm{C}$.

Compound 28- $\mathbf{P F}_{6}$ - Prepared according to the general procedure above on $1 \mathrm{mmol}$ scale (-) and obtained in $61 \%$ yield $(0.365 \mathrm{~g})$ as a white powder. ${ }^{1} \mathrm{H}$ NMR (600 $\mathrm{MHz}, \mathrm{DMSO}) \delta 8.39-8.35(\mathrm{~m}, 1 \mathrm{H}), 8.26-8.18(\mathrm{~m}, 1 \mathrm{H}), 7.68-7.54$ $(\mathrm{m}, 1 \mathrm{H}), 6.49(\mathrm{~s}, 2 \mathrm{H}), 3.96(\mathrm{~s}, 6 \mathrm{H}), 3.88(\mathrm{~s}, 3 \mathrm{H}) .{ }^{13} \mathrm{C}$ NMR $(101 \mathrm{MHz}$, DMSO) $\delta 166.7,160.6(\mathrm{dd}, J=260.1,1.8 \mathrm{~Hz}), 159.6,141.7$ (d, $J_{C-F}=9.6$ $\mathrm{Hz}), 133.6,\left(\mathrm{~d}, J_{C-F}=3.9 \mathrm{~Hz}\right), 121.54(\mathrm{q}, J=273.1 \mathrm{~Hz}), 120.9(\mathrm{~d}, J=21.8$ $\mathrm{Hz}), 119.2(\mathrm{dq}, J=33.2,13.2 \mathrm{~Hz}), 110.5(\mathrm{~d}, J=3.7 \mathrm{~Hz}), 92.2,87.5,57.4$, $56.2{ }^{19} \mathrm{~F}$ NMR (376 MHz, DMSO) $\delta-60.6(\mathrm{~d}, J=12.5 \mathrm{~Hz}),-70.2\left(\mathrm{~d}, J_{P-F}=711.3 \mathrm{~Hz}\right),-110.3$ (q, $J=12.5 \mathrm{~Hz}$ ). FT-IR: 3116, 3064, 2952, 2952, 2848, 1414, 1311, 1163, $845 \mathrm{~cm}^{1}$. HRMS $\left(\mathrm{ESI}^{+}\right.$) Calculated for $\mathrm{C}_{16} \mathrm{H}_{14} \mathrm{~F}_{4} \mathrm{IO}_{3}{ }^{+}\left[\mathrm{M}-\mathrm{PF}_{6}\right]^{+}$: 456.9889; Observed 456.9895. Mp decomposed $126^{\circ} \mathrm{C}$.

Compound 35- $\mathrm{Br}$ - Prepared according to the general anion exchange procedure above

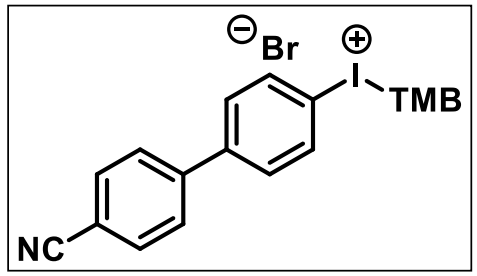
on $1.9 \mathrm{mmol}$ scale, using (19 equiv., $36 \mathrm{mmol}, 4.5 \mathrm{~g}$ ) and obtained in $91 \%$ yield $(1.733 \mathrm{~g})$ as a white powder. ${ }^{1} \mathrm{H}$ NMR $\left(400 \mathrm{MHz}, \mathrm{DMSO}-d_{6}\right) \delta 8.11-7.69(\mathrm{~m}, 8 \mathrm{H}), 6.45(\mathrm{~s}, 2 \mathrm{H})$, $3.96(\mathrm{~s}, 6 \mathrm{H}), 3.87(\mathrm{~s}, 3 \mathrm{H}) .{ }^{13} \mathrm{C}$ NMR $\left(101 \mathrm{MHz}, \mathrm{DMSO}-d_{6}\right) \delta$ $165.6,159.2,142.8,140.4,134.6,132.9,129.6,127.8$, 118.7, 118.6, 110.9, 91.9, 90.9, 57.2, 56.0. FT-IR: 3089, 3056, 2980, 2946, 2839, 2227, 1645, 1582, 1413, 1164, $815 \mathrm{~cm}^{-1}$. HRMS (ESI $)$ Calculated for $\mathrm{C}_{22} \mathrm{H}_{19} \mathrm{INO}_{3}{ }^{+}[\mathrm{M}-\mathrm{Br}]^{+}:$472.0404; Observed 472.0375. Mp 175-176 ${ }^{\circ} \mathrm{C}$. 


\subsubsection{Representative procedure for one-pot preparation of aryl(TMB)iodonium bromides}

4-methyl-3-nitro iodobenzene $(1.33 \mathrm{~g}, 5.1 \mathrm{mmol})$ and acetonitrile $(5 \mathrm{~mL})$ are added to a $250 \mathrm{~mL}$ round-bottom flask, equipped with a stir bar. Toluenesulfonic acid monohydrate ( $0.965 \mathrm{~g}, 5.1 \mathrm{mmol}, 1.0$ equiv.) is added in one portion, followed by one portion of predried $m$-CPBA (1.09 g, $5.1 \mathrm{mmol}, 1.0$ equiv.). After attaching a reflux condenser, the reaction is lowered into a heat bath set to $77^{\circ} \mathrm{C}$ and stirred vigorously. After 30 minutes, the reflux condenser is removed in order to add 1,3,5-trimethoxybenzene $(0.858 \mathrm{~g}, 5.1$ mmol, 1.0 equiv.) in one portion and stirring is continued at $77^{\circ} \mathrm{C}$ for 5 minutes. The reaction is removed from heat and $100 \mathrm{~mL}$ of water are added. The mixture is brought to near boiling until dissolved and $6.0 \mathrm{~g}$ of $\mathrm{KBr}$ are added. After stirring for 2 minutes the solution is removed from heat and allowed to cool naturally, before chilling further by briefly swirling in an ice-water bath. The mixture is suction filtered and the filter cake washed by slurry filtration with water $(3 \times 30 \mathrm{~mL})$. The cake is dried under suction for 10 $-20 \mathrm{~min}$ and then washed by slurry filtration with ethyl ether $(3 \times 30 \mathrm{~mL})$. The sample is finally dried under high vacuum to remove trace solvent. If iodonium salt is suspected to remain in the aqueous filtrate then it may be extracted with a suitable solvent such as dichloromethane or ethyl acetate. After drying under high vacuum, the diaryliodonium salt 23-Br was obtained in $83 \%$ yield $(2.15 \mathrm{~g}, 4.2 \mathrm{mmol})$ as a white powder. 


\subsubsection{Characterization data of aryl(TMB)iodonium bromides}

Compound 32-Br - Prepared according to the representative one-pot preparation of iodonium bromides above on $5 \mathrm{mmol}$ scale in $82 \%$ yield $(2.112 \mathrm{~g})$, as a<smiles></smiles>
pale yellow powder. ${ }^{1} \mathrm{H} N M R\left(400 \mathrm{MHz}, \mathrm{DMSO}-d_{6}\right) \delta 8.51(\mathrm{~d}, J=1.7$ $\mathrm{Hz}, 1 \mathrm{H}), 8.06(\mathrm{dd}, J=8.2,1.8 \mathrm{~Hz}, 1 \mathrm{H}), 7.54(\mathrm{~d}, J=8.4 \mathrm{~Hz}, 1 \mathrm{H}), 6.44(\mathrm{~s}$, $2 \mathrm{H}), 3.95(\mathrm{~s}, 6 \mathrm{H}), 3.87(\mathrm{~s}, 3 \mathrm{H}), 2.51(\mathrm{~d}, J=6.7 \mathrm{~Hz}, 3 \mathrm{H}) .{ }^{13} \mathrm{C}$ NMR (101 $\left.\mathrm{MHz}, \mathrm{DMSO}-d_{6}\right) \delta 165.7,159.1,149.1,138.0,135.8,135.0,129.4$, 116.2, 91.9, 91.8, 57.2, 56.0, 19.3. FT-IR: 3079, 2975, 2942, 2841, 1581, 1524, 1455, 1411, 1342, 1272, 1161, 1024, $815 \mathrm{~cm}^{-1}$. HRMS (ESI ${ }^{+}$) Calculated for $\mathrm{C}_{16} \mathrm{H}_{17} \mathrm{INO}_{5}{ }^{+}[\mathrm{M}-\mathrm{Br}]^{+}:$430.0146; Observed 430.0125. Mp $166-167^{\circ} \mathrm{C}$.

Compound 32-Br - Prepared according to the representative one-pot procedure for preparation of iodonium bromides above on $5 \mathrm{mmol}$ scale in $74 \%$ yield $(2.298 \mathrm{~g})$, as an off-white powder. Ten equivalents, $7.497 \mathrm{~g} \mathrm{KBr}$ were used for the exchange. ${ }^{1} \mathrm{H}$ NMR $\left(400 \mathrm{MHz}, \mathrm{DMSO}-d_{6}\right) \delta 8.83$ $(\mathrm{d}, J=2.2 \mathrm{~Hz}, 1 \mathrm{H}), 8.36(\mathrm{dd}, J=8.5,2.4 \mathrm{~Hz}, 1 \mathrm{H}), 7.60(\mathrm{~d}, J=8.5 \mathrm{~Hz}$, $1 \mathrm{H}), 6.44(\mathrm{~s}, 2 \mathrm{H}), 3.96(\mathrm{~s}, 6 \mathrm{H}), 3.88(\mathrm{~s}, 3 \mathrm{H}) .{ }^{13} \mathrm{C} \mathrm{NMR}(101 \mathrm{MHz}$, DMSO- $\left.d_{6}\right) \delta 165.6,159.0,153.2,151.8,144.7,127.0,117.7,92.1,91.9,57.2$, 56.1. FT-IR: $3075,3039,2971,2942,2842,1582,1454,1412,1342,1161,817,731 \mathrm{~cm}^{-1}$. HRMS (ESI $\left.{ }^{+}\right)$ Calculated for $\mathrm{C}_{14} \mathrm{H}_{14} \mathrm{ClINO}_{3}{ }^{+}[\mathrm{M}-\mathrm{Br}]^{+}:$405.9701; Observed 405.9684. Mp 161-163 ${ }^{\circ} \mathrm{C}$.

\subsubsection{Preparation of compounds in Applications section}

Compound 6 -Prepared according to literature procedure ${ }^{50}$ on $1 \mathrm{mmol}$ scale and obtained $\overbrace{}^{C}$ in $70 \%$ yield after purification $(0.215 \mathrm{~g})$ as a white powder. The crude product was purified by column chromatography with silica gel and gradient elution (hexane, $1 \%$ ethyl ether, $2 \%$ ethyl ether). Mixed fractions were again chromatographed by the same procedure for a combined $70 \%$ of $33 .{ }^{1} \mathrm{H}$ NMR $(400 \mathrm{MHz}$, $\left.\mathrm{CDCl}_{3}\right) \delta 7.68-7.55(\mathrm{~m}, 4 \mathrm{H}), 7.53-7.43(\mathrm{~m}, 2 \mathrm{H}), 7.02-6.91(\mathrm{~m}$, $2 \mathrm{H}), 3.98(\mathrm{t}, J=6.6 \mathrm{~Hz}, 2 \mathrm{H}), 1.88-1.70(\mathrm{~m}, 2 \mathrm{H}), 1.52-1.21(\mathrm{~m}, 10 \mathrm{H}), 0.89(\mathrm{t}, J=6.9 \mathrm{~Hz}$, $3 \mathrm{H}) .{ }^{13} \mathrm{C} \mathrm{NMR}\left(101 \mathrm{MHz}, \mathrm{CDCl}_{3}\right) \delta 159.9,145.2,132.6,131.2,128.3,127.0,119.1,115.1$, $110.0,68.2,31.9,29.4,29.2(9), 29.2(8), 26.1,22.7,14.2$. The spectral data were consistent with that previously reported. ${ }^{51}$ 
Compound 40 - Prepared according to the literature procedure ${ }^{52}$ on $0.4 \mathrm{mmol}$ scale and

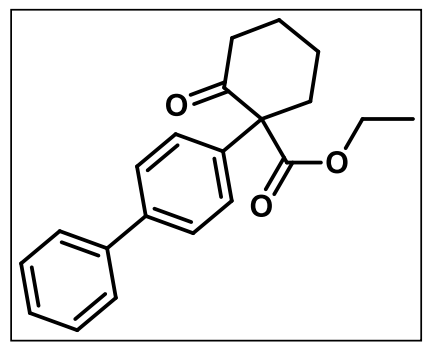
obtained in $55 \%$ yield $(0.070 \mathrm{~g})$ as white powder. ${ }^{1} \mathrm{H}$ NMR (400 $\left.\mathrm{MHz}, \mathrm{CDCl}_{3}\right) \delta 7.59(\mathrm{dt}, J=8.9,2.0 \mathrm{~Hz}, 4 \mathrm{H}), 7.46-7.39(\mathrm{~m}, 2 \mathrm{H})$, $7.37-7.28(\mathrm{~m}, 3 \mathrm{H}), 4.31-4.19(\mathrm{~m}, 2 \mathrm{H}), 2.88-2.76(\mathrm{~m}, 1 \mathrm{H})$, $2.66-2.54(\mathrm{~m}, 2 \mathrm{H}), 2.37(\mathrm{ddd}, J=10.5,6.9,3.1 \mathrm{~Hz}, 1 \mathrm{H}), 2.09-$ $1.94(\mathrm{~m}, 1 \mathrm{H}), 1.93-1.72(\mathrm{~m}, 3 \mathrm{H}), 1.26(\mathrm{t}, J=7.1 \mathrm{~Hz}, 3 \mathrm{H}) .{ }^{13} \mathrm{C}$ NMR $\left(101 \mathrm{MHz}, \mathrm{CDCl}_{3}\right) \delta 206.6,171.2,140.6,140.4,135.8$, 128.8, 128.2, 127.4, 127.1, 127.1, 66.2, 61.8, 40.9, 35.4, 27.7, 22.3, 14.0. FT-IR: 3054, 2985, 1713, 1265, $1133 \mathrm{~cm}^{-1}$. HRMS $\left(\mathrm{ESI}^{+}\right)$Calculated for $\mathrm{C}_{21} \mathrm{H}_{23} \mathrm{O}_{3}{ }^{+}[\mathrm{M}+\mathrm{H}]^{+}:$323.1647; Observed: 323.1619 . Mp 130.8-132.3 ${ }^{\circ} \mathrm{C}$. $\mathrm{R}_{\mathrm{f}}: 0.22$ in $15 \%$ diethyl ether/hexane.

Compound 43 - Prepared according to the literature procedure $\mathrm{s}^{53}$ on $1.0 \mathrm{mmol}$ scale and<smiles>O=S(=O)(c1ccccc1)c1ccc(-c2ccccc2)cc1</smiles>
obtained in $78 \%(0.235 \mathrm{~g})$ as white powder white powder. ${ }^{1} \mathrm{H}$ NMR $\left(400 \mathrm{MHz}, \mathrm{CDCl}_{3}\right) \delta 8.03-7.95(\mathrm{~m}, 4 \mathrm{H}), 7.73-7.67(\mathrm{~m}$, $2 \mathrm{H}), 7.60-7.36(\mathrm{~m}, 8 \mathrm{H}) .{ }^{13} \mathrm{C} \mathrm{NMR}\left(101 \mathrm{MHz}^{\mathrm{C}} \mathrm{CDCl}_{3}\right) \delta 146.2$, $141.8,140.1,139.2,133.2,129.3,129.1,128.6,128.2,127.9$, 127.6, 127.3. FT-IR: 1637, 1265, $1158 \mathrm{~cm}^{-1}$. HRMS (ESI $\left.{ }^{+}\right)$ Calculated for $\mathrm{C}_{18} \mathrm{H}_{15} \mathrm{O}_{2} \mathrm{~S}^{+}[\mathrm{M}+\mathrm{H}]^{+}$: 295.0793; Observed 295.0763; Mp $142.8-147^{\circ} \mathrm{C}$. Rf: 0.20 in $20 \%$ diethyl ether/hexane.

Compound 45 - Prepared according to the literature procedure ${ }^{54}$ on $1.0 \mathrm{mmol}$ scale and

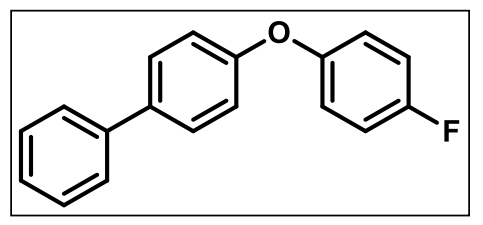
obtained in $80 \%(0.213 \mathrm{~g})$ as white powder. ${ }^{1} \mathrm{H}$ NMR (400 $\mathrm{MHz}, \mathrm{CDCl} 3) \delta 7.58-7.52(\mathrm{~m}, 4 \mathrm{H}), 7.45-7.39(\mathrm{~m}, 2 \mathrm{H}), 7.35$ - $7.30(\mathrm{~m}, \mathrm{~J}=5.9,4.7,2.3 \mathrm{~Hz}, 1 \mathrm{H}), 7.09-6.99(\mathrm{~m}, 6 \mathrm{H}) .{ }^{13} \mathrm{C}$ NMR $(101 \mathrm{MHz}, \mathrm{CDCl} 3) \delta 160.1,157.7,157.3,152.8,140.5$, $136.2,128.6\left(d, J_{C^{-}}=33.3 \mathrm{~Hz}\right), 127.0,126.8,120.6\left(d, J_{C^{-}} \mathrm{F}\right.$ $=8.2 \mathrm{~Hz}), 118.4,116.3\left(\mathrm{~d}, J_{C}-\mathrm{F}=23.2 \mathrm{~Hz}\right) .{ }^{19} \mathrm{~F} \mathrm{NMR}(376 \mathrm{MHz}, \mathrm{CDCl} 3) \delta$-119.9. FT-IR: 1500, 1265, $1214 \mathrm{~cm}^{-1}$. HRMS (EI+) Calculated for $\mathrm{C}_{18} \mathrm{H}_{13} \mathrm{FO}$ : 264.0950; Observed: 264.0942; $\mathrm{Mp} 76.2-78.2^{\circ} \mathrm{C}$. $\mathrm{R}_{\mathrm{f}}$ : 0.6 in $100 \%$ hexane. 


\subsubsection{Qualitative Stability Study}

Small samples of powdered iodonium salts were placed into scintillation vials and left adjacent to a window, exposed to ambient sunlight. A second sample of each salt was placed into a scintillation vial and wrapped with aluminum foil. The samples were periodically photographed. Any discoloration or change in consistency, appreciable upon visual inspection, was taken as evidence for decomposition. The photographs below are selected in order to illustrate the range of decomposition observed. See Figure below for a summary of results. Decomposition has not been observed when these compounds are stored in a freezer.

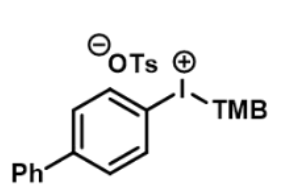
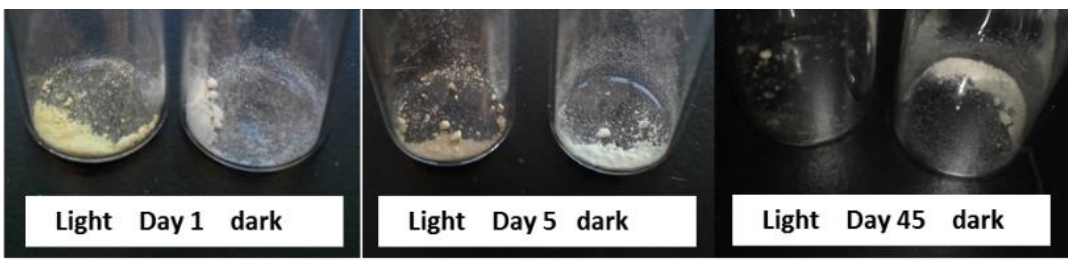<smiles>[13CH3]I([14CH3])c1ccc(-c2ccccc2)cc1</smiles>

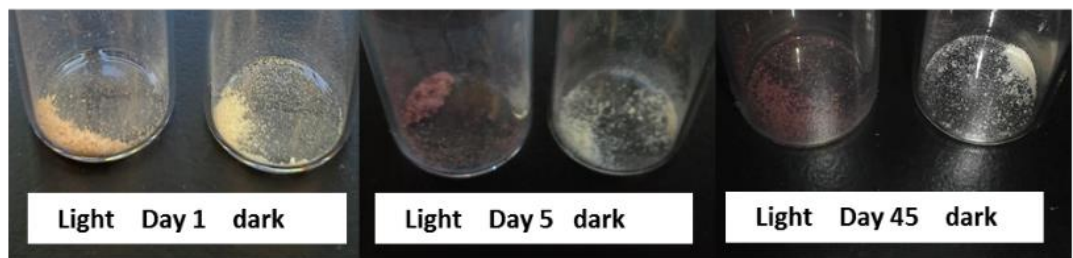<smiles>CCC(C)I(C)c1cc(F)c(C(F)(F)F)cc1F</smiles>

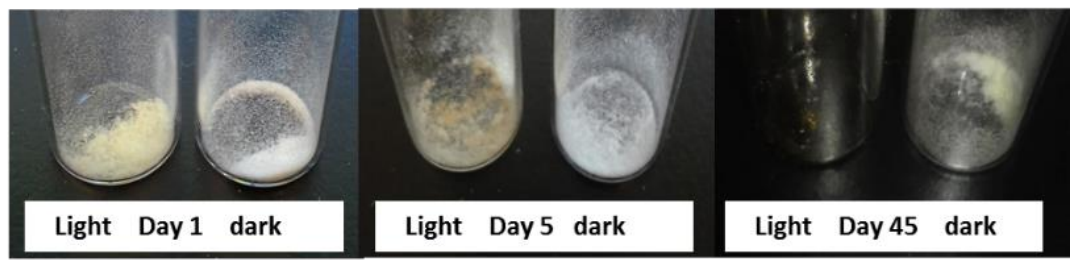

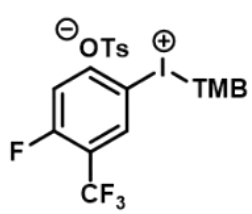

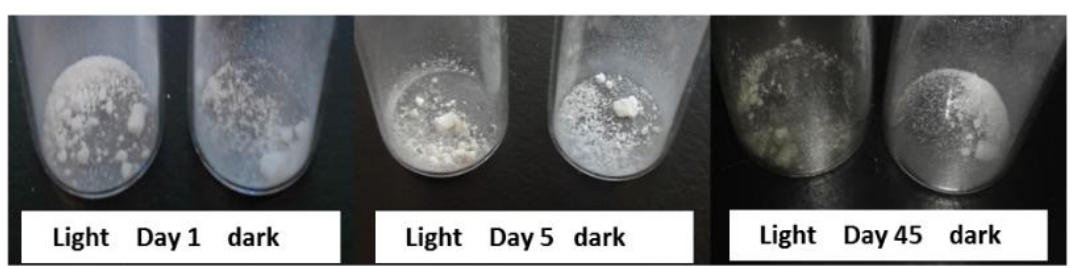

Figure 67. Qualitative stability study, light samples were exposed to ambient sunlight, dark samples were covered with aluminium foil. 


\subsubsection{NMR spectra for aryl(TMB)iodonium tosylates}

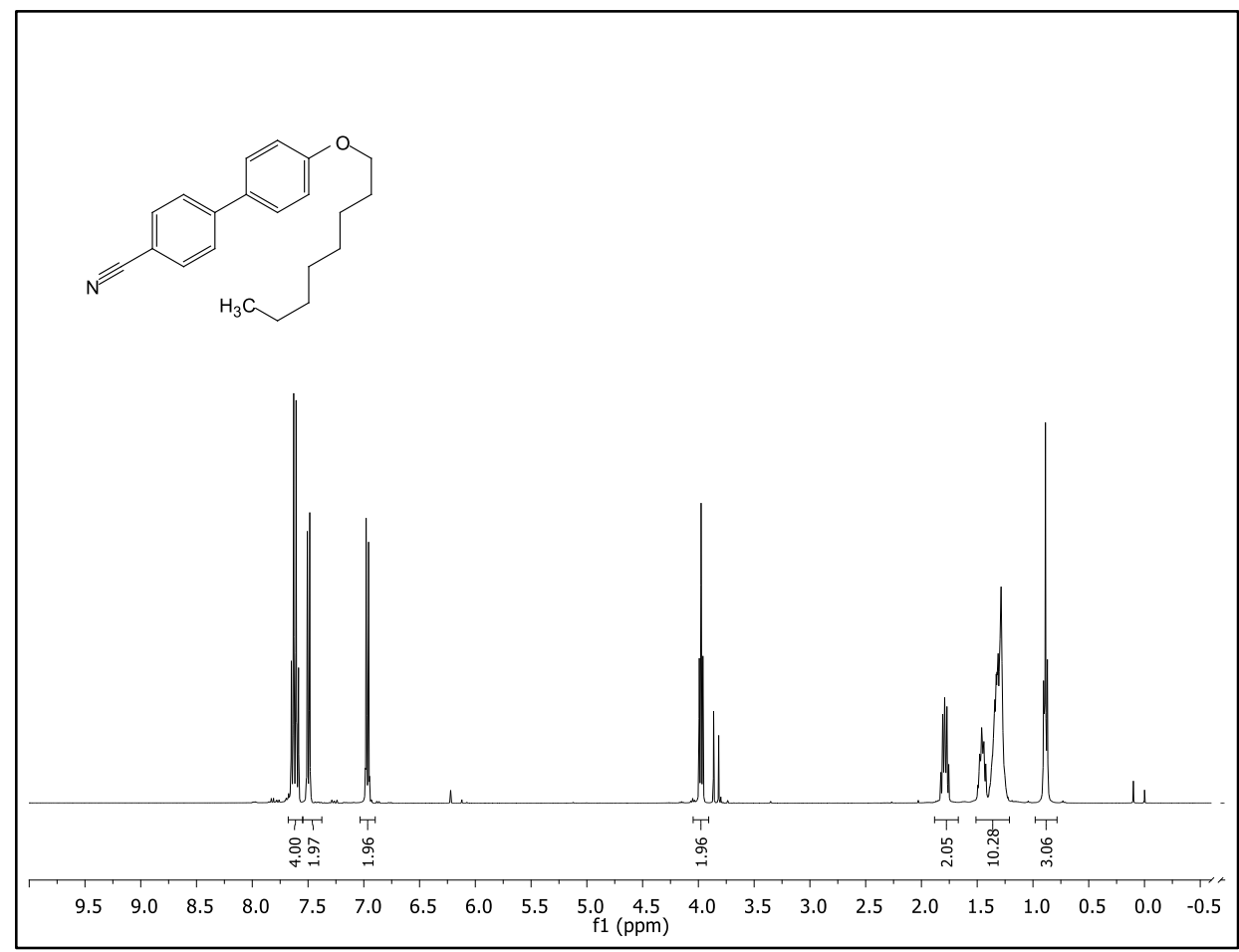

Figure 68. ${ }^{1} \mathrm{H}$ NMR spectrum of 6 at $400 \mathrm{MHz}$ in $\mathrm{CDCl}_{3}$ at $298 \mathrm{~K}$

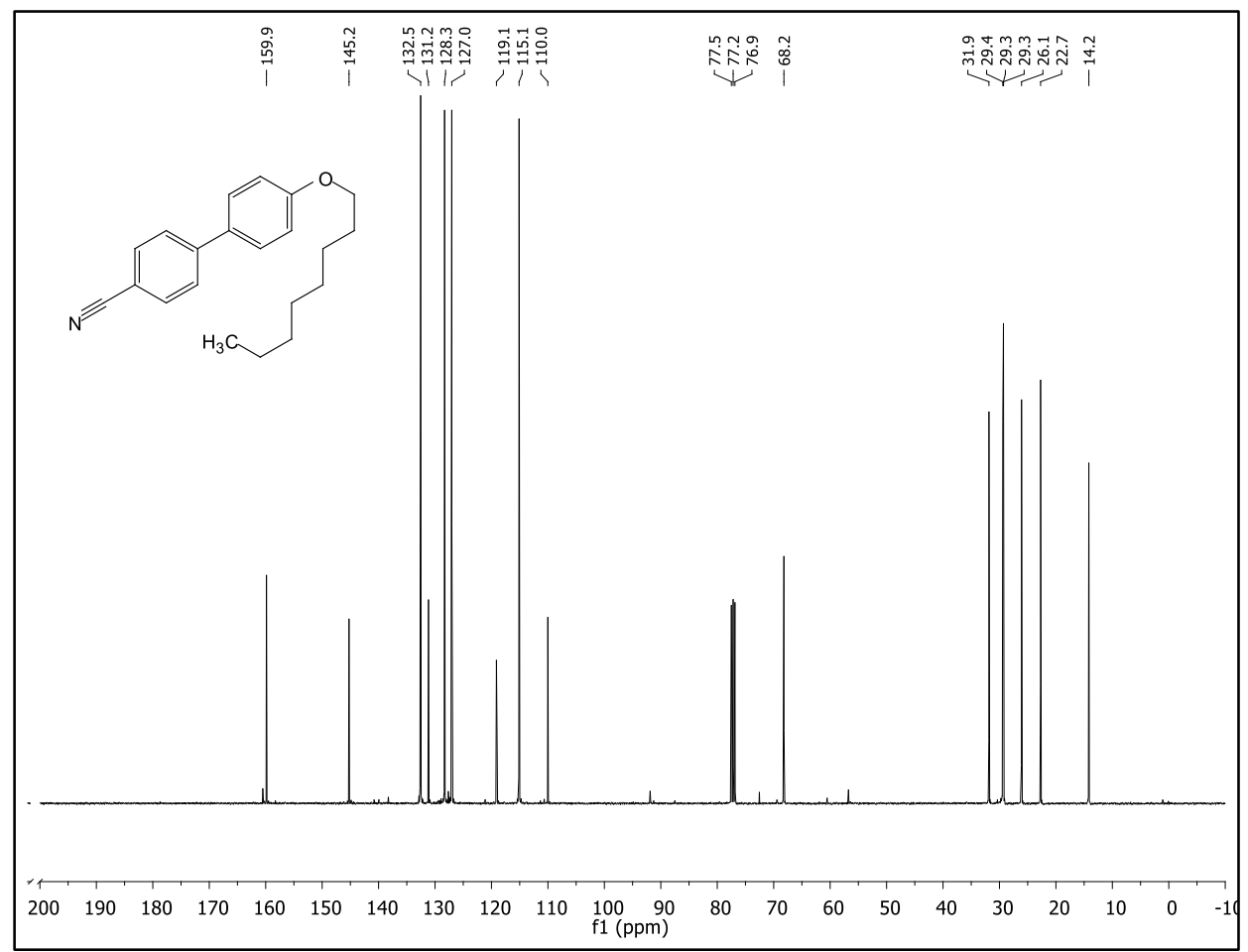

Figure 69. ${ }^{13} \mathrm{C}$ NMR spectrum of 6 at $101 \mathrm{MHz}$ in $\mathrm{CDCl}_{3}$ at $298 \mathrm{~K}$. 


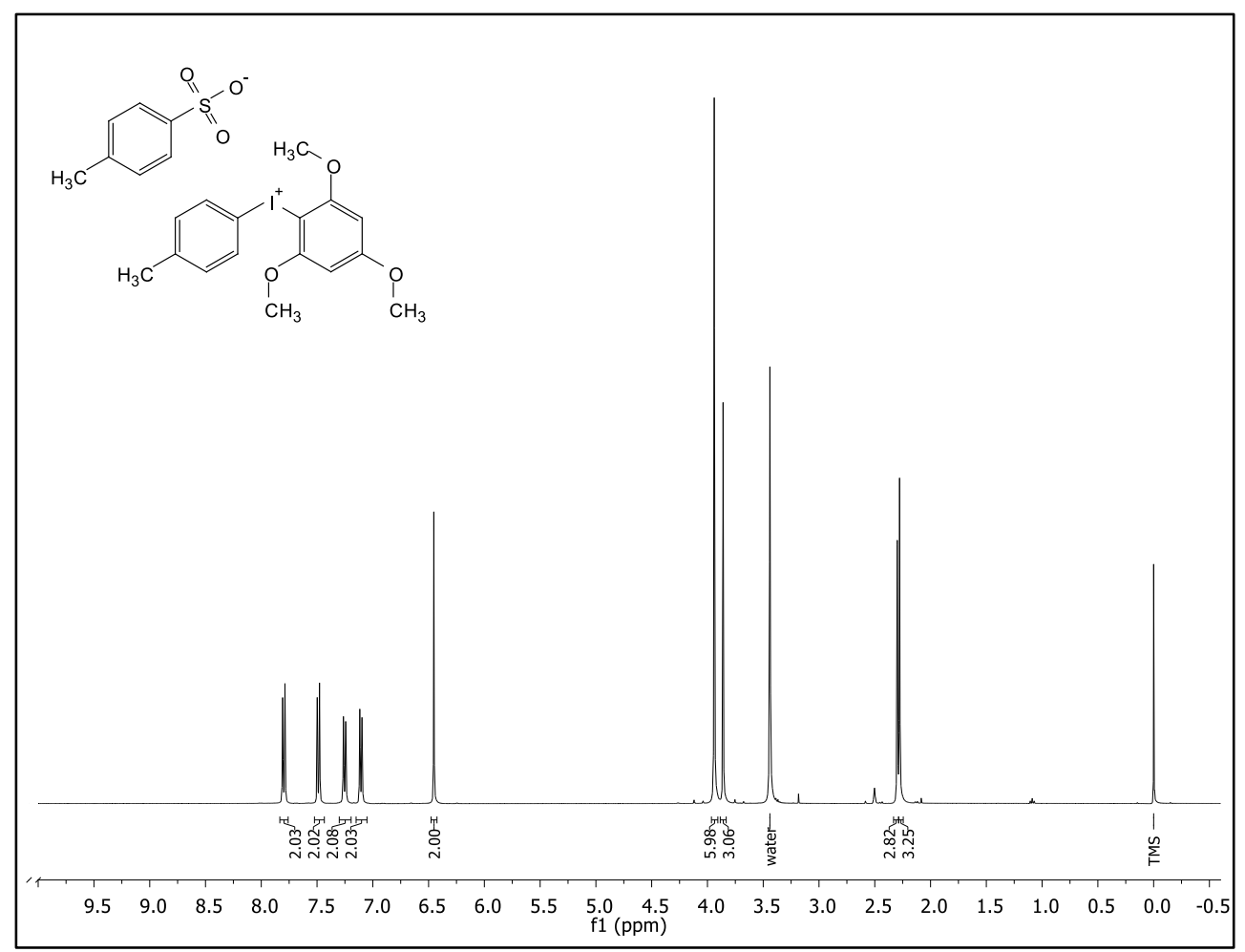

Figure $70 .{ }^{1} \mathrm{H}$ NMR spectrum of 11 at $400 \mathrm{MHz}$ in DMSO- $d_{6}$ at $298 \mathrm{~K}$

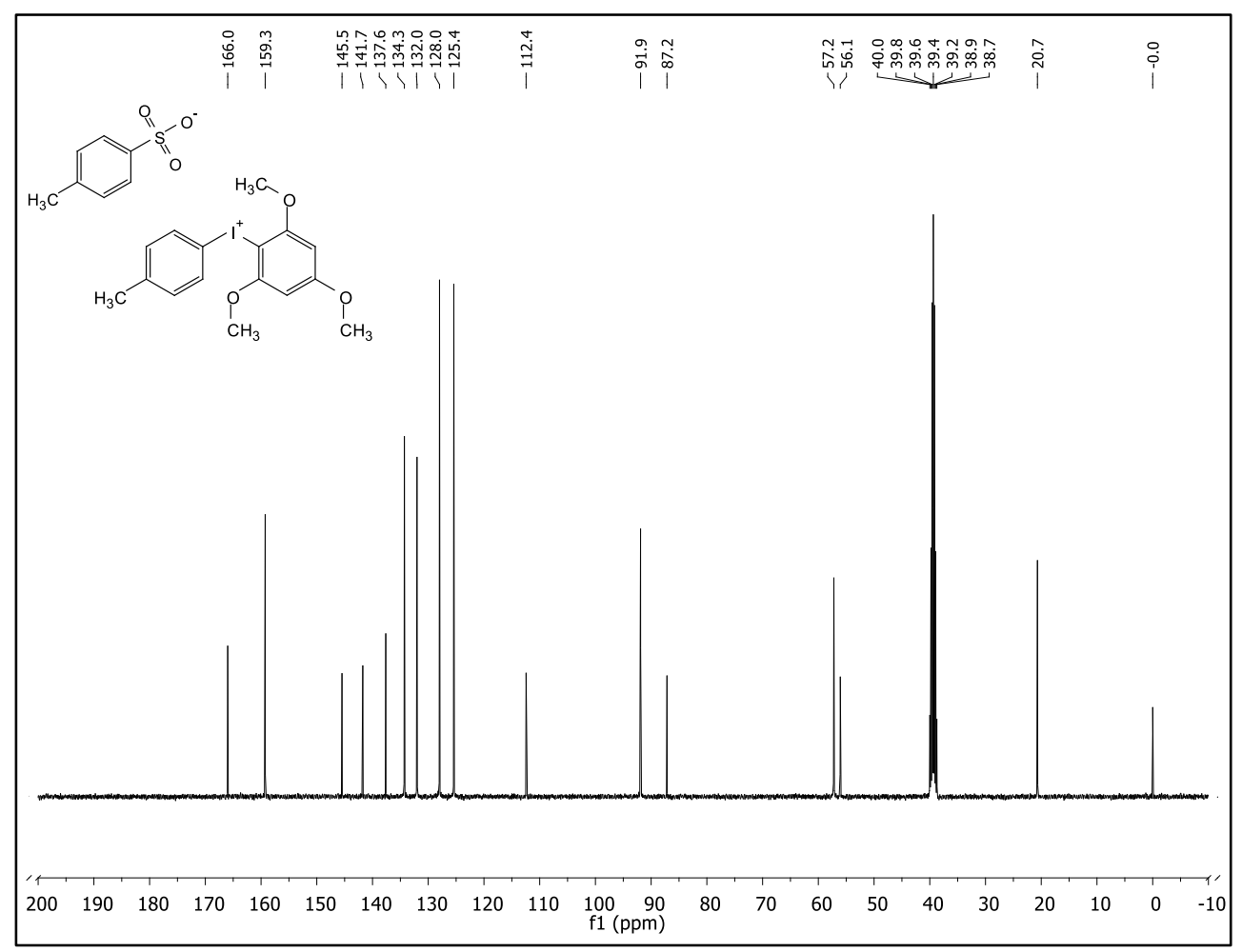

Figure $71 .{ }^{13} \mathrm{C}$ NMR spectrum of 11 at $101 \mathrm{MHz}$ in DMSO- $d_{6}$ at $298 \mathrm{~K}$ 


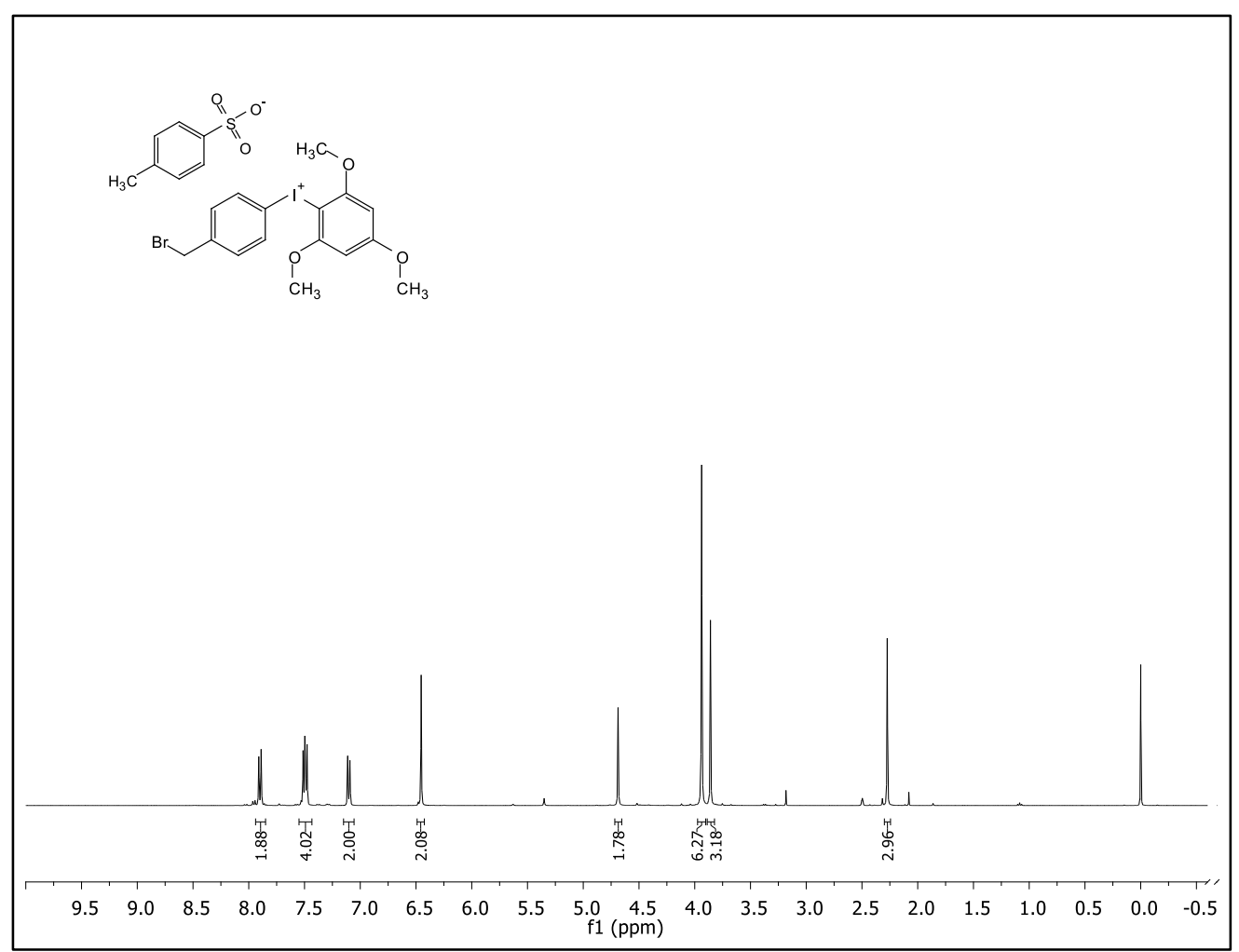

Figure 72. ${ }^{1} \mathrm{H}$ NMR spectrum of 12 at $400 \mathrm{MHz}$ in DMSO- $d_{6}$ at $298 \mathrm{~K}$

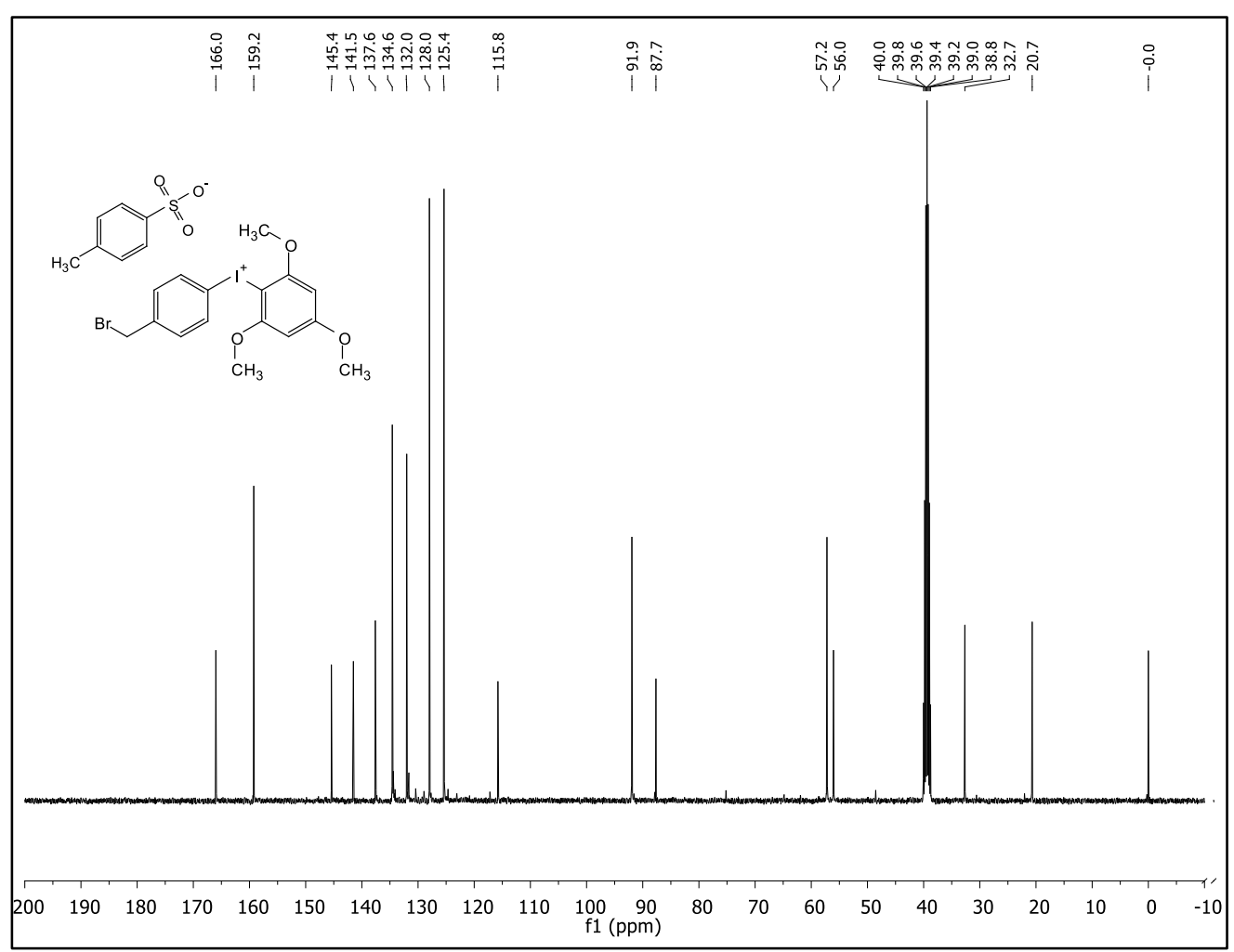

Figure $73 .{ }^{13} \mathrm{C}$ NMR spectrum of 12 at $101 \mathrm{MHz}$ in DMSO-d6 at 298K 


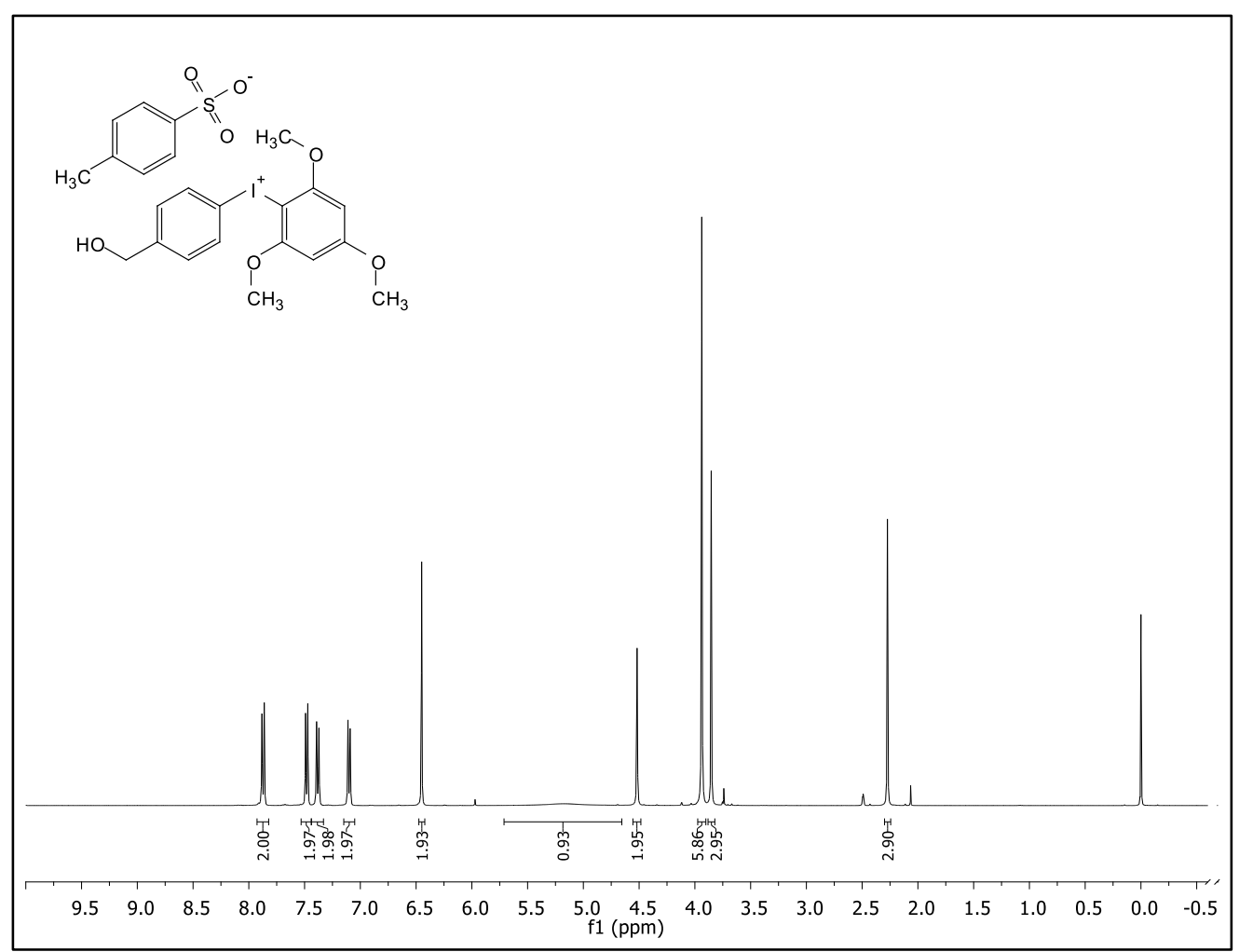

Figure 74. ${ }^{1} \mathrm{H}$ NMR spectrum of 13 at $400 \mathrm{MHz}$ in DMSO- $d_{6}$ at $298 \mathrm{~K}$

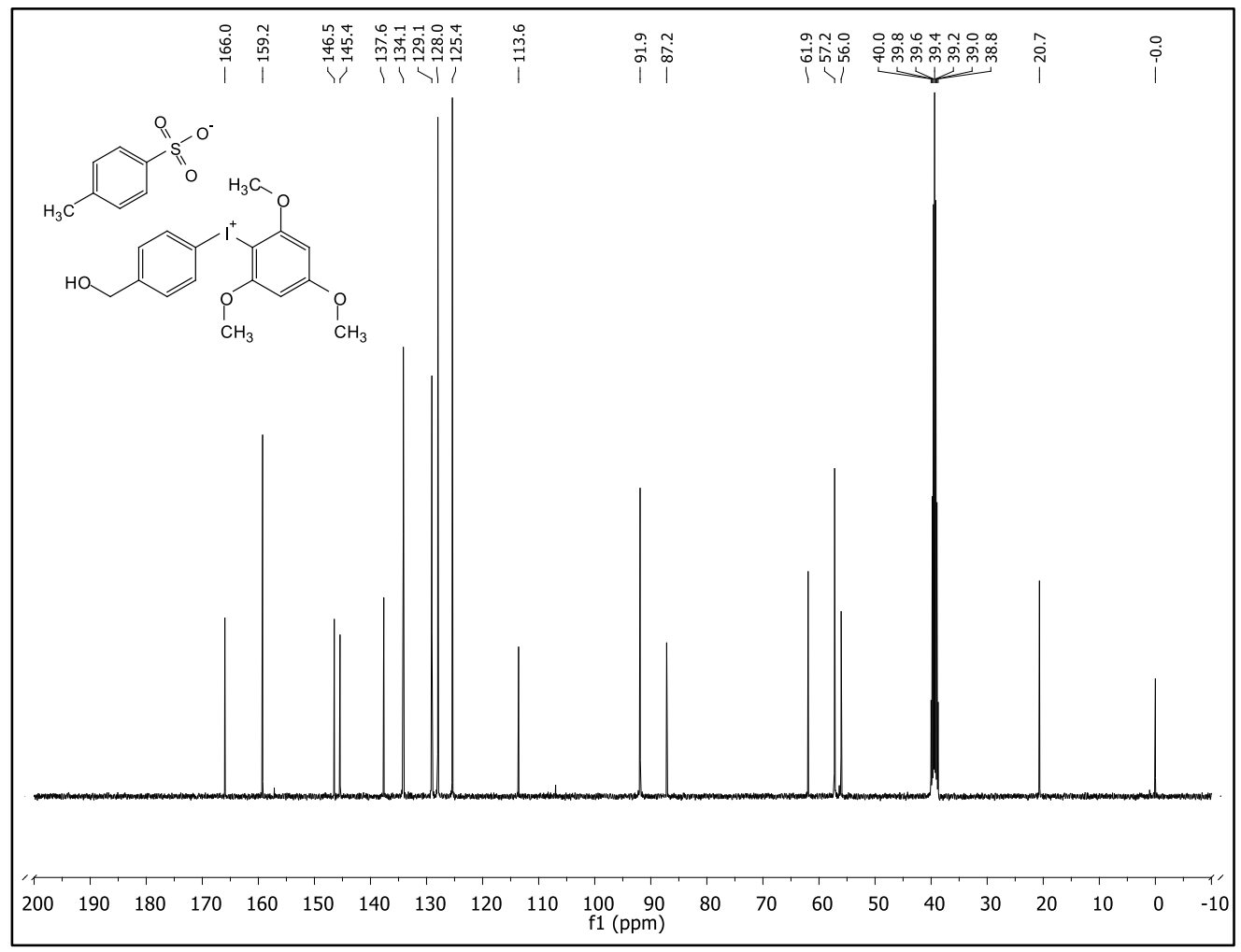

Figure $75 .{ }^{13} \mathrm{C}$ NMR spectrum of 13 at $101 \mathrm{MHz}$ in DMSO- $d_{6}$ at $298 \mathrm{~K}$ 


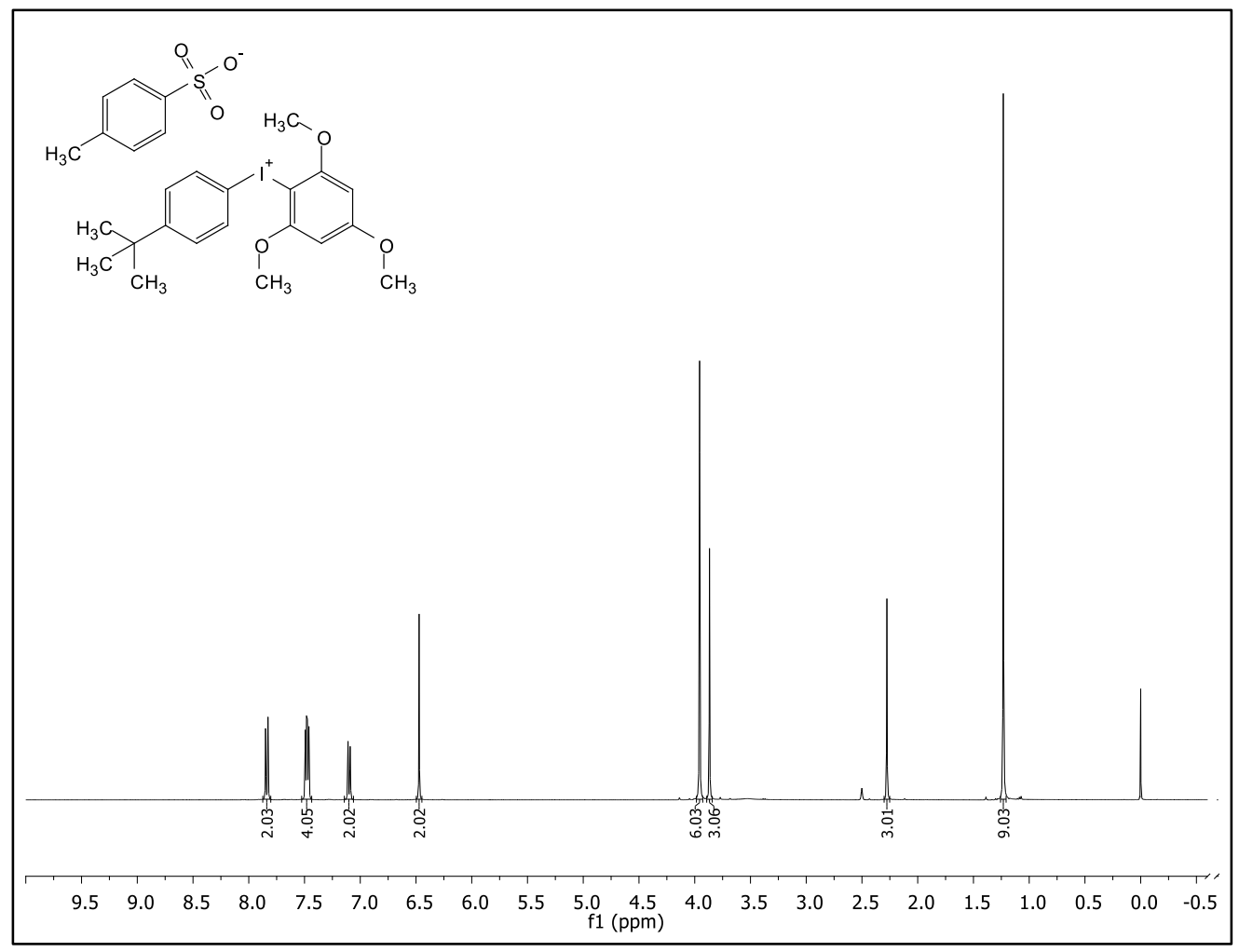

Figure $76 .{ }^{1} \mathrm{H}$ NMR spectrum of 14 at $400 \mathrm{MHz}$ in DMSO-d $d_{6}$ at $298 \mathrm{~K}$

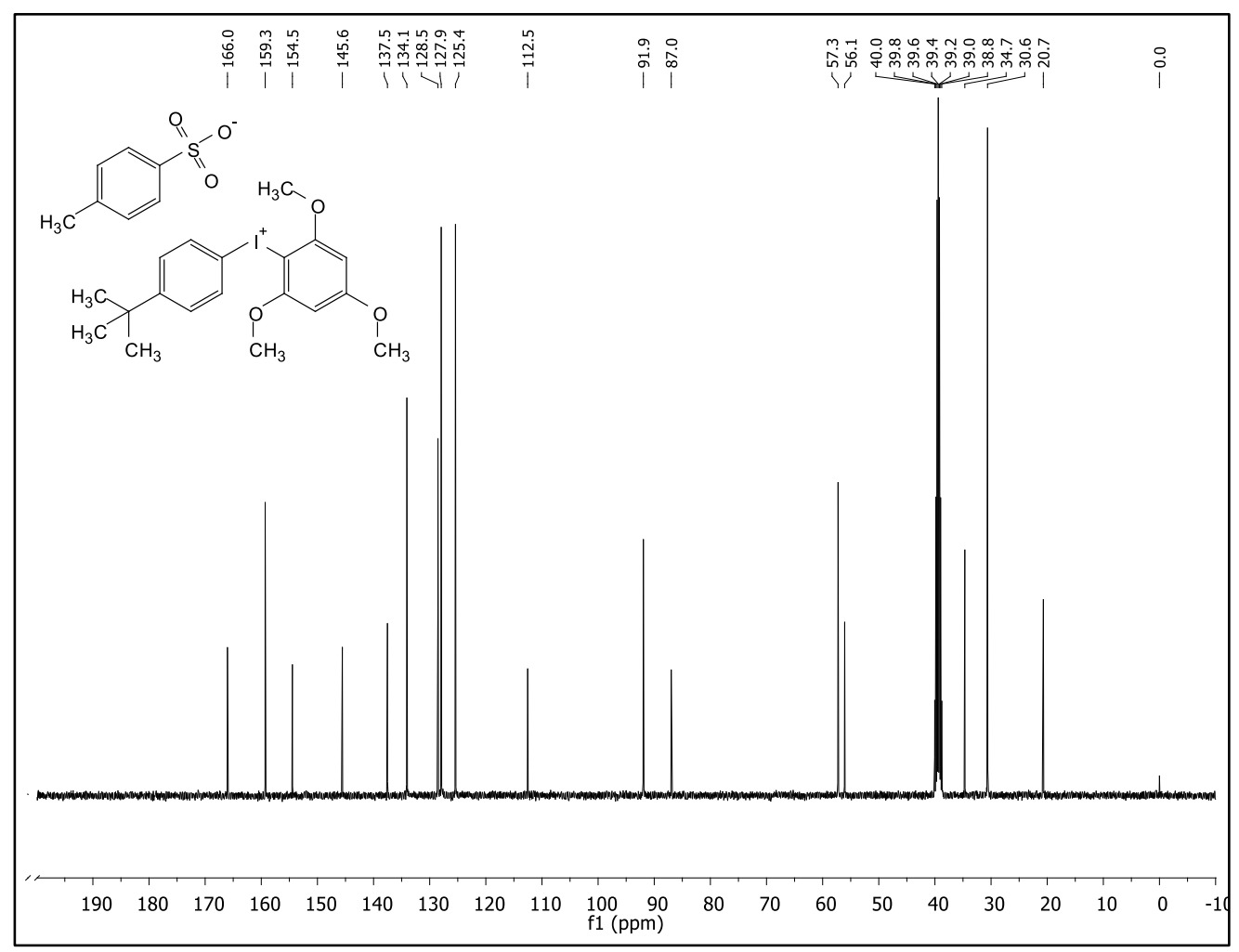

Figure $77 .{ }^{13} \mathrm{C}$ NMR spectrum of 14 at $101 \mathrm{MHz}$ in DMSO- $d_{6}$ at $298 \mathrm{~K}$ 


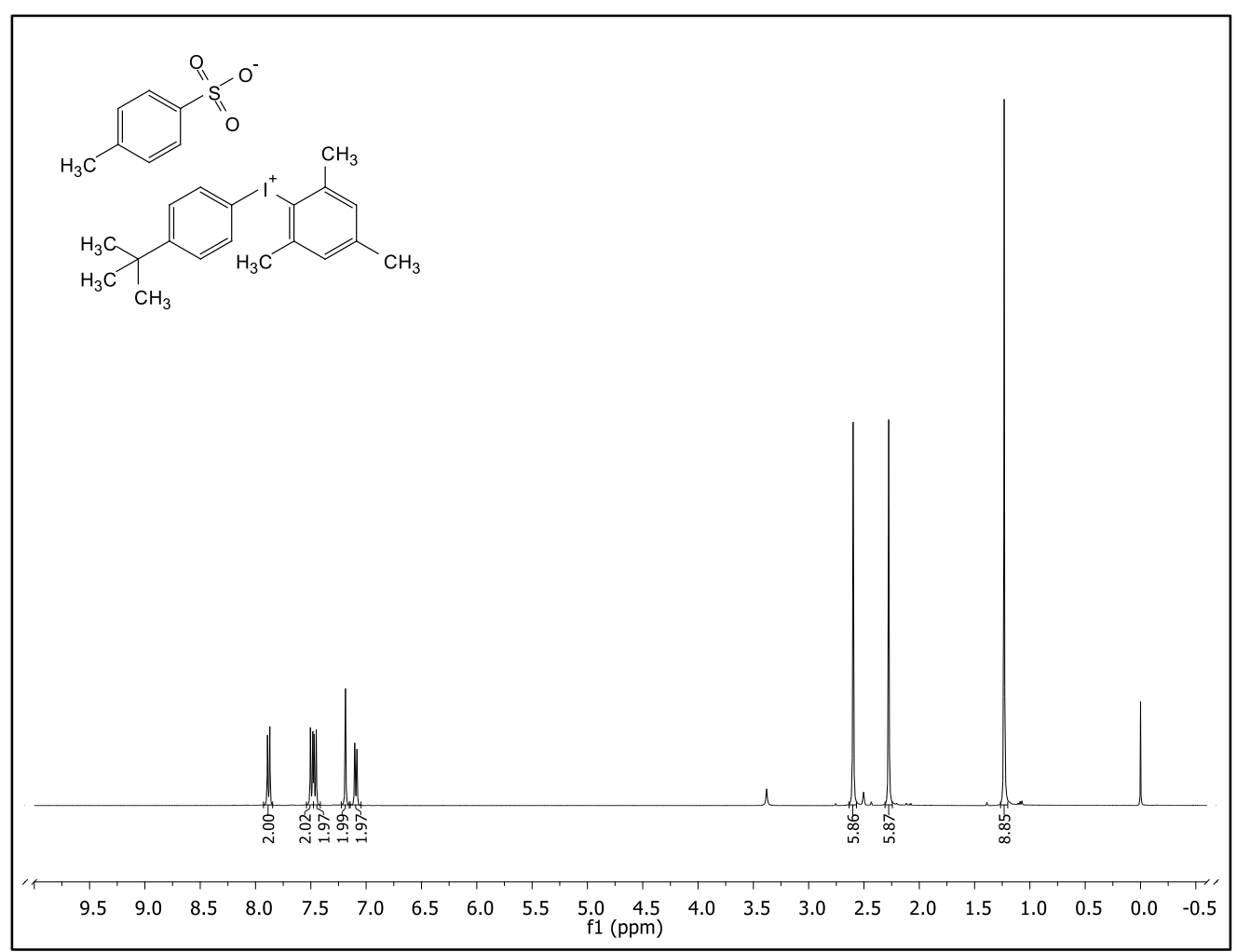

Figure 78. ${ }^{1} \mathrm{H}$ NMR spectrum of 15 at $400 \mathrm{MHz}$ in DMSO- $d_{6}$ at $298 \mathrm{~K}$

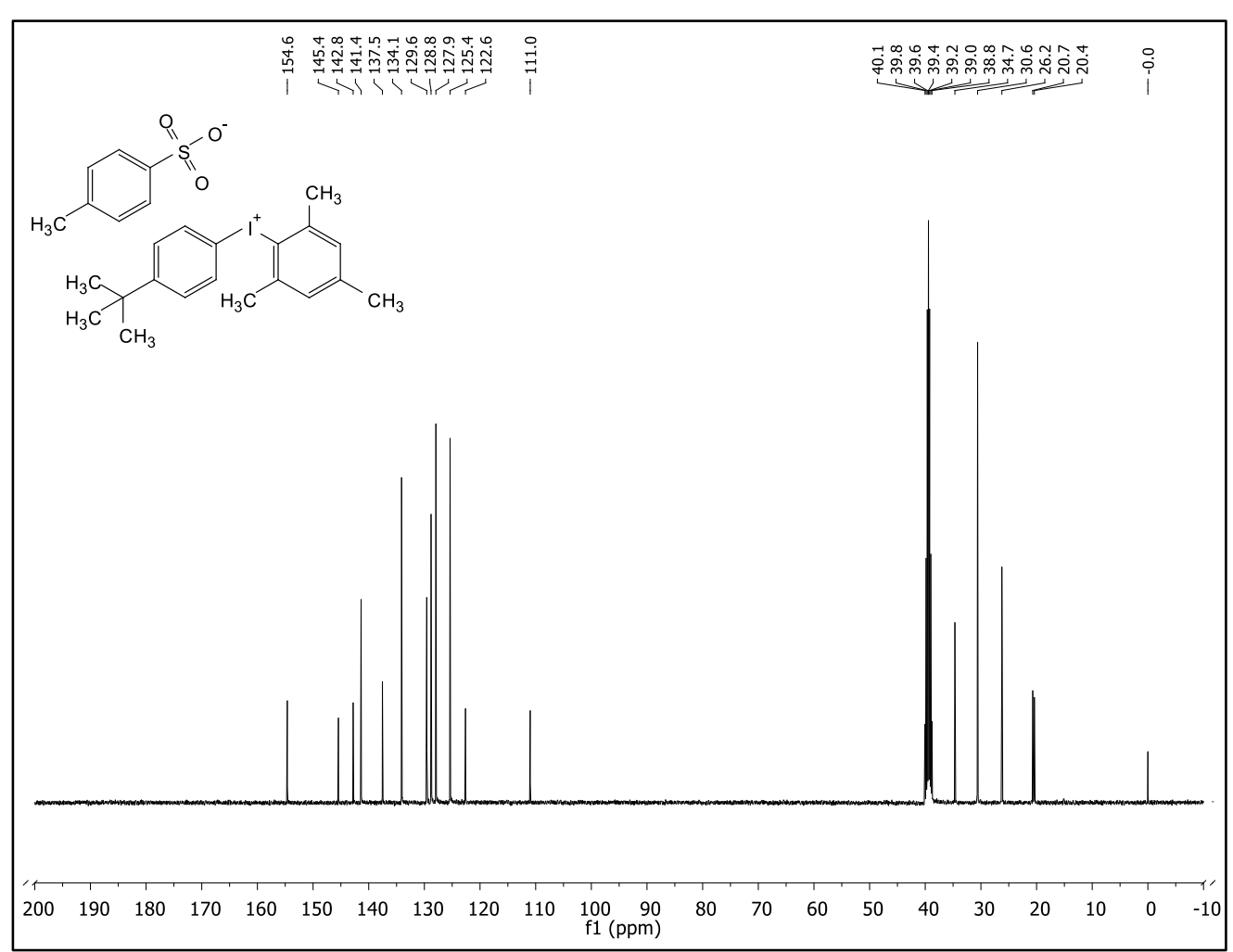

Figure $79 .{ }^{13} \mathrm{C}$ NMR spectrum of 15 at $101 \mathrm{MHz}$ in DMSO- $d_{6}$ at $298 \mathrm{~K}$ 


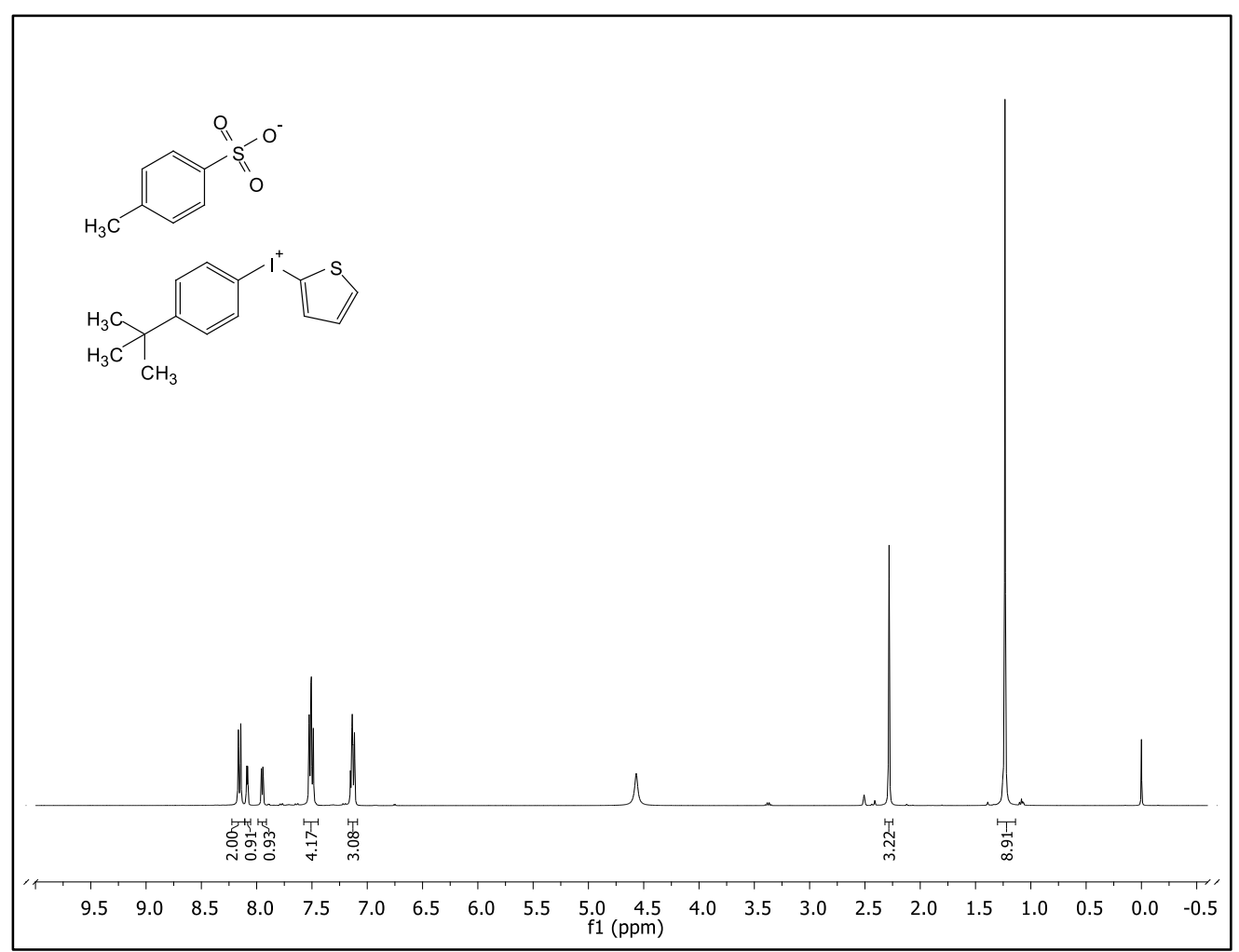

Figure 80. ${ }^{1} \mathrm{H}$ NMR spectrum of 16 at $400 \mathrm{MHz}$ in DMSO- $d_{6}$ at $298 \mathrm{~K}$

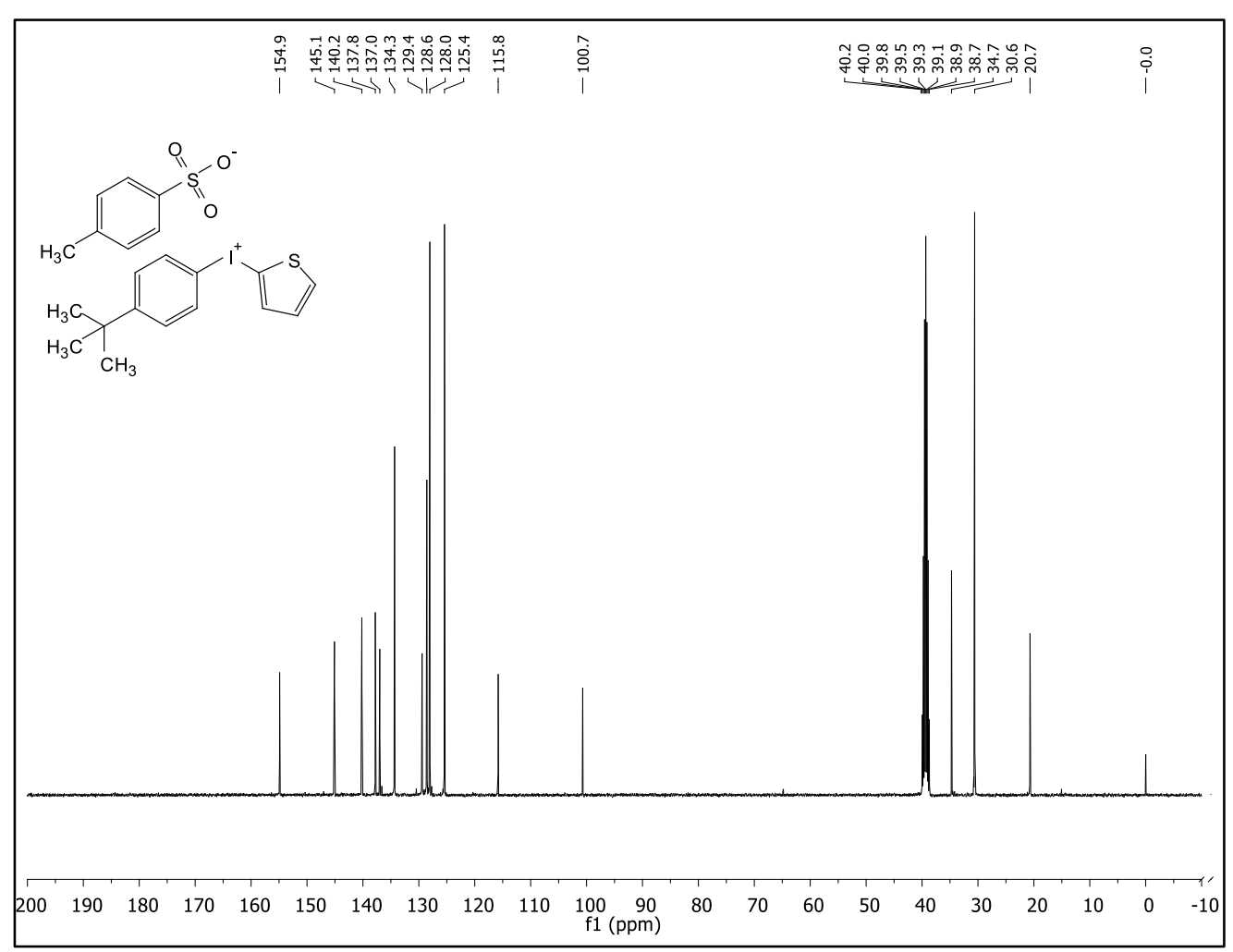

Figure $81 .{ }^{13} \mathrm{C}$ NMR spectrum of 16 at $101 \mathrm{MHz}$ in DMSO- $d_{6}$ at $298 \mathrm{~K}$ 


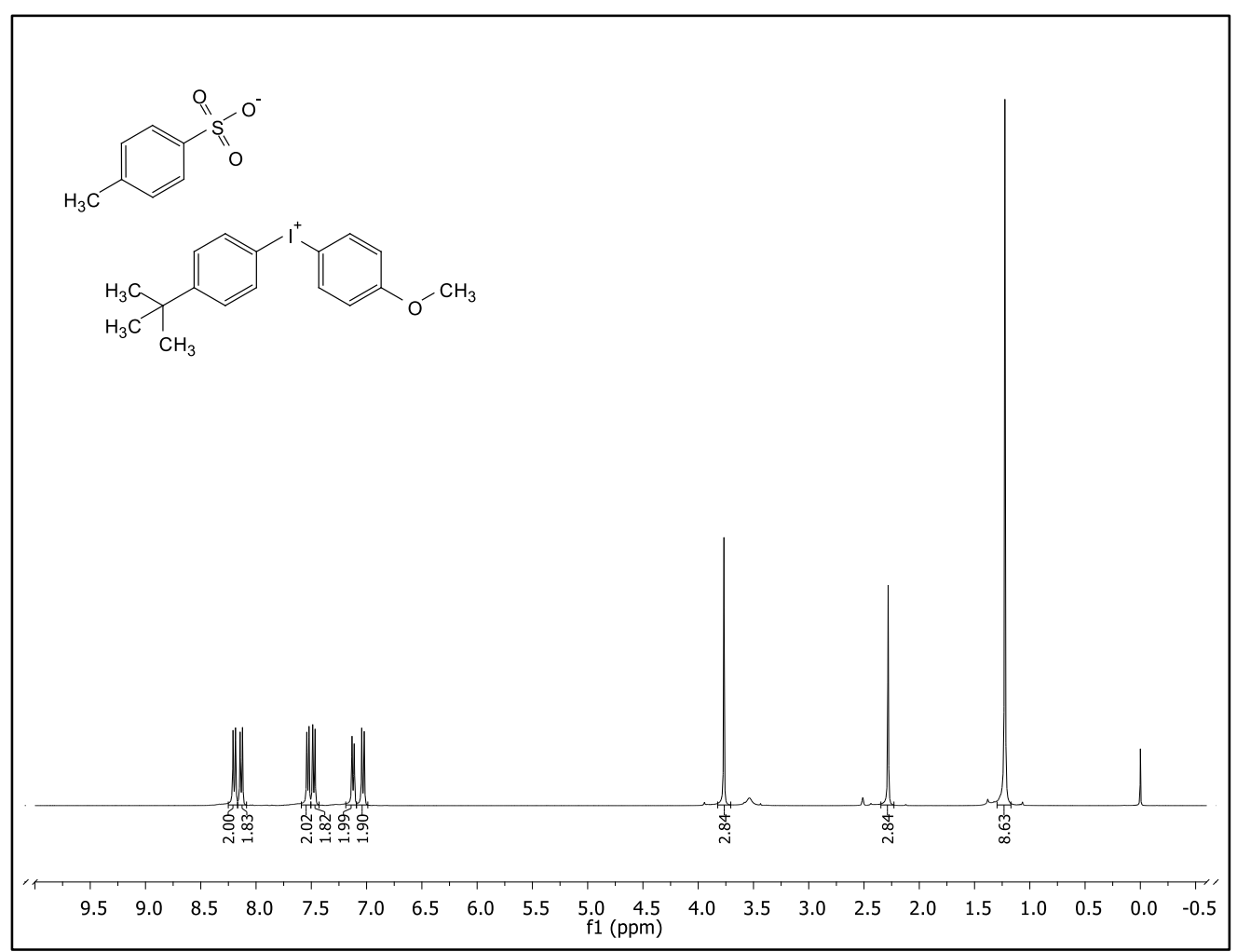

Figure 82. ${ }^{1} \mathrm{H}$ NMR spectrum of 17 at $400 \mathrm{MHz}$ in DMSO- $d_{6}$ at $298 \mathrm{~K}$

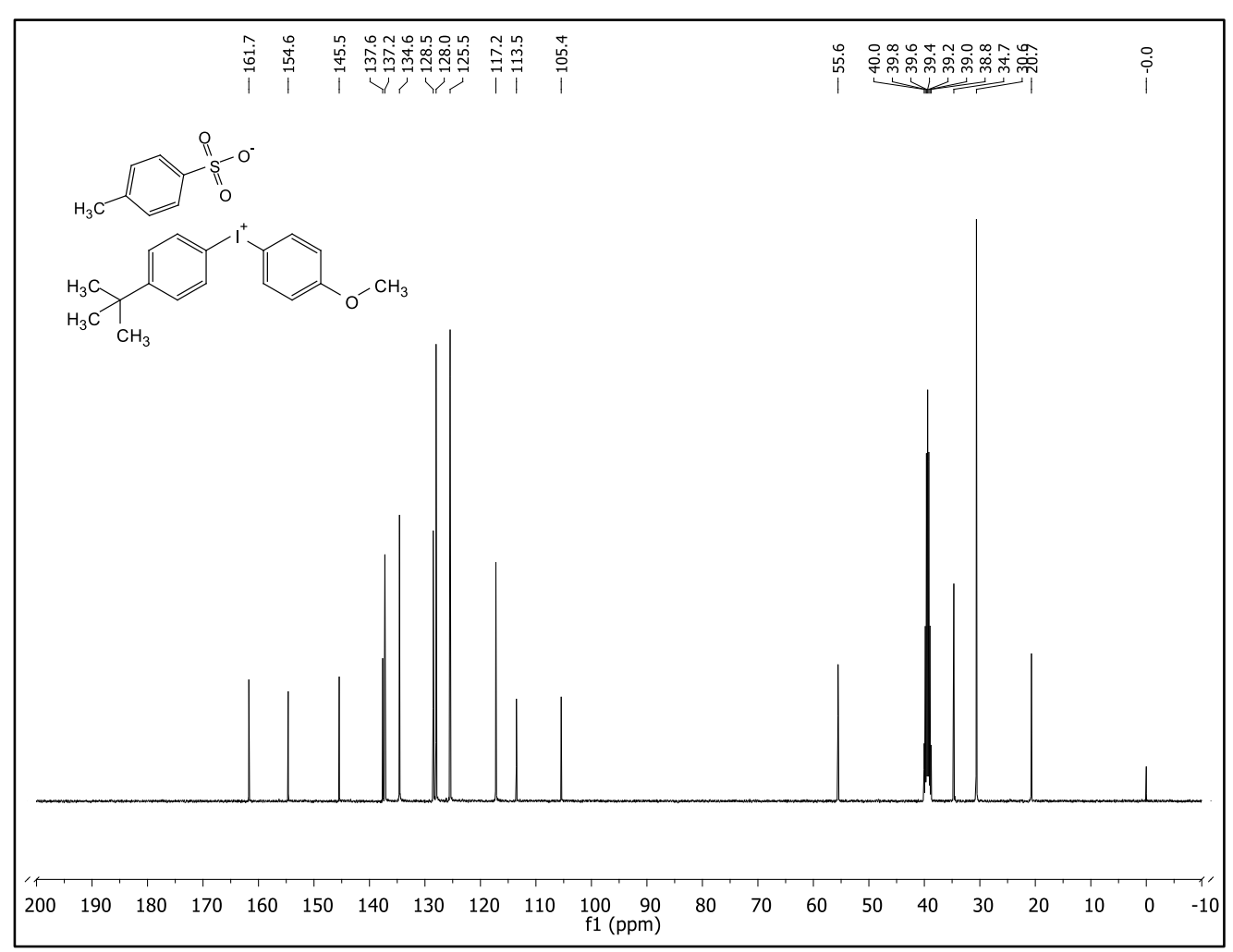

Figure $83 .{ }^{13} \mathrm{C}$ NMR spectrum of 17 at $101 \mathrm{MHz}$ in DMSO- $d_{6}$ at $298 \mathrm{~K}$ 


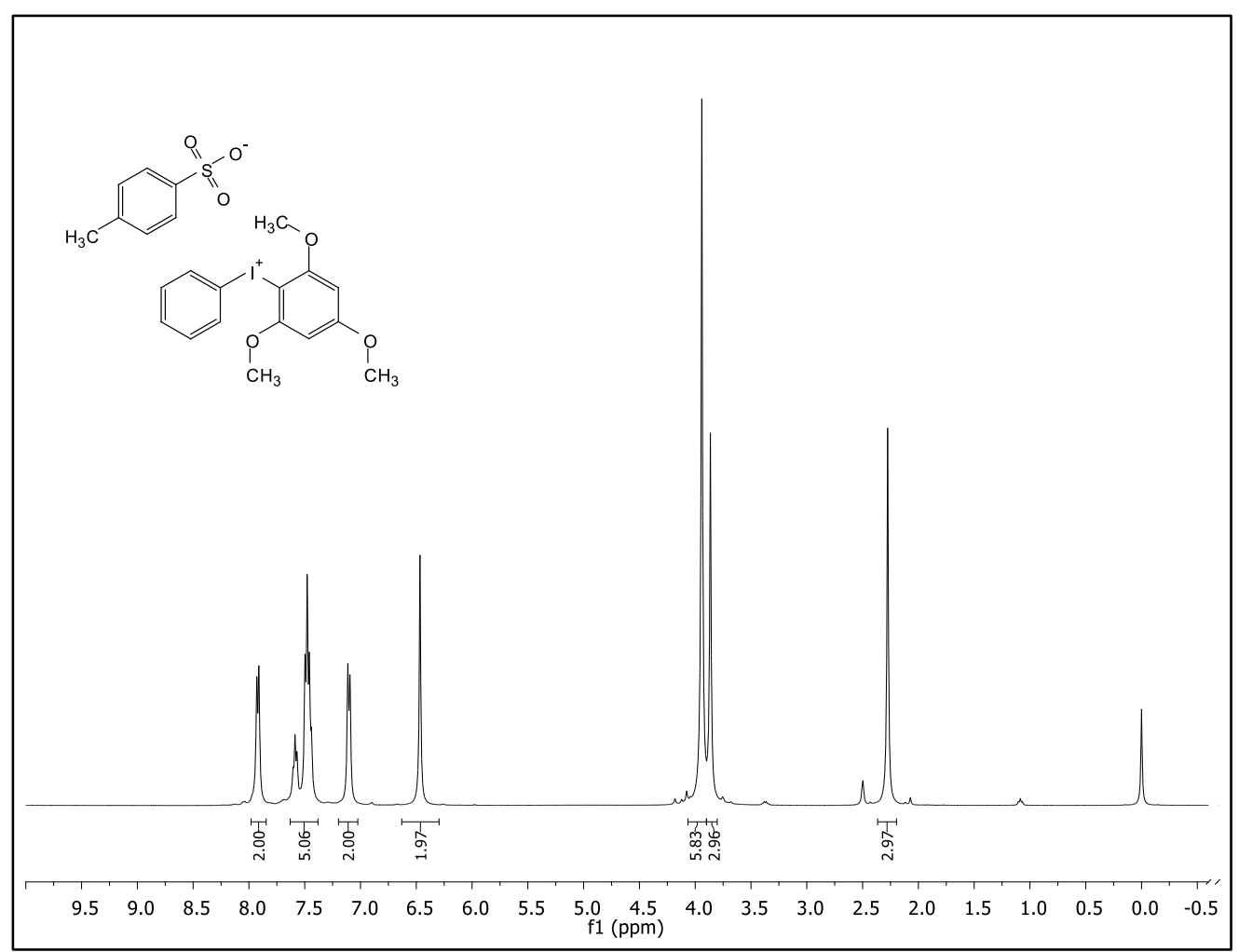

Figure 84. ${ }^{1} \mathrm{H}$ NMR spectrum of 18 at $400 \mathrm{MHz}$ in DMSO- $d_{6}$ at $298 \mathrm{~K}$

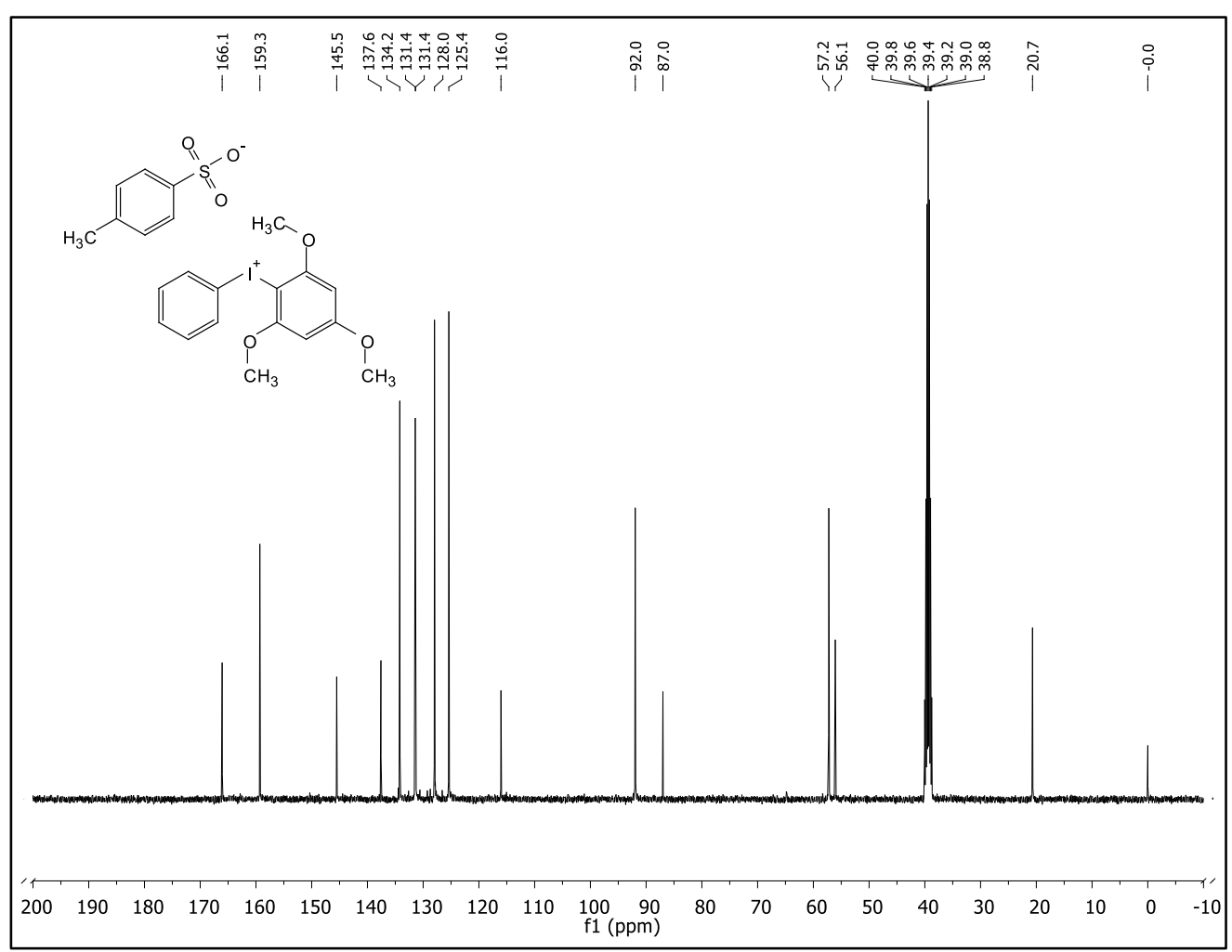

Figure $85 .{ }^{13} \mathrm{C}$ NMR spectrum of 18 at $101 \mathrm{MHz}$ in DMSO- $d_{6}$ at $298 \mathrm{~K}$ 


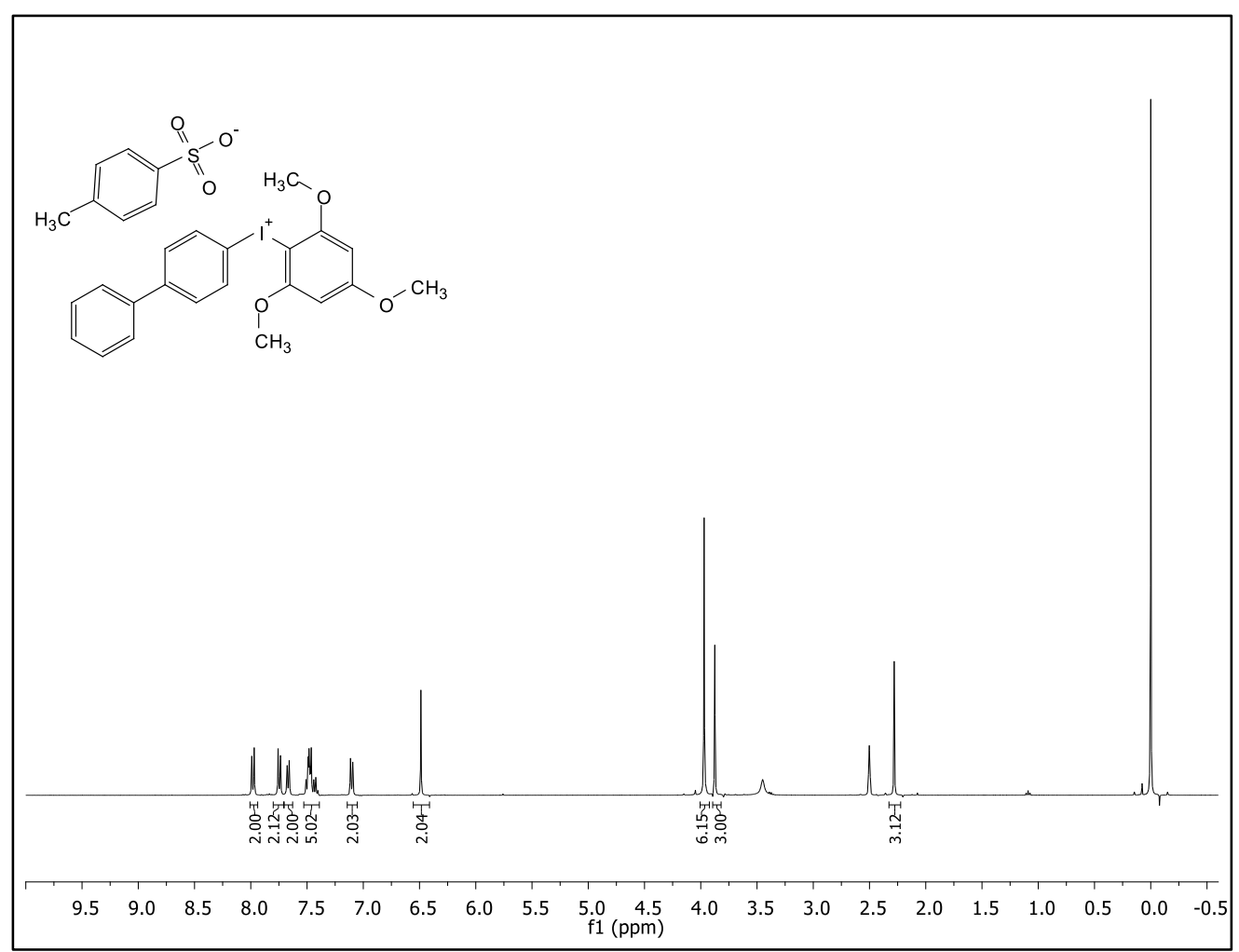

Figure 86. ${ }^{1} \mathrm{H}$ NMR spectrum of 19 at $400 \mathrm{MHz}$ in DMSO- $d_{6}$ at $298 \mathrm{~K}$

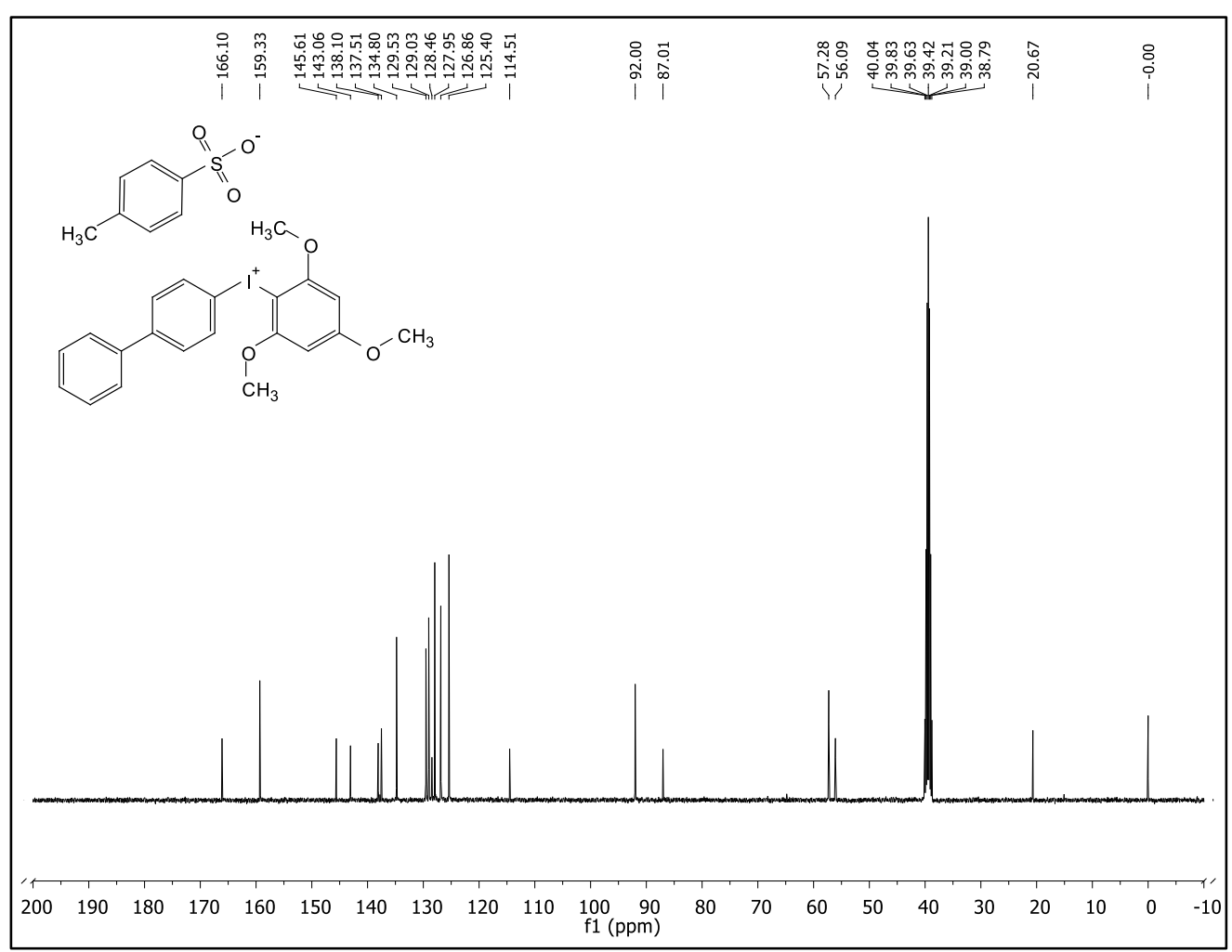

Figure $87 .{ }^{13} \mathrm{C}$ NMR spectrum of 19 at $101 \mathrm{MHz}$ in DMSO- $d_{6}$ at $298 \mathrm{~K}$ 


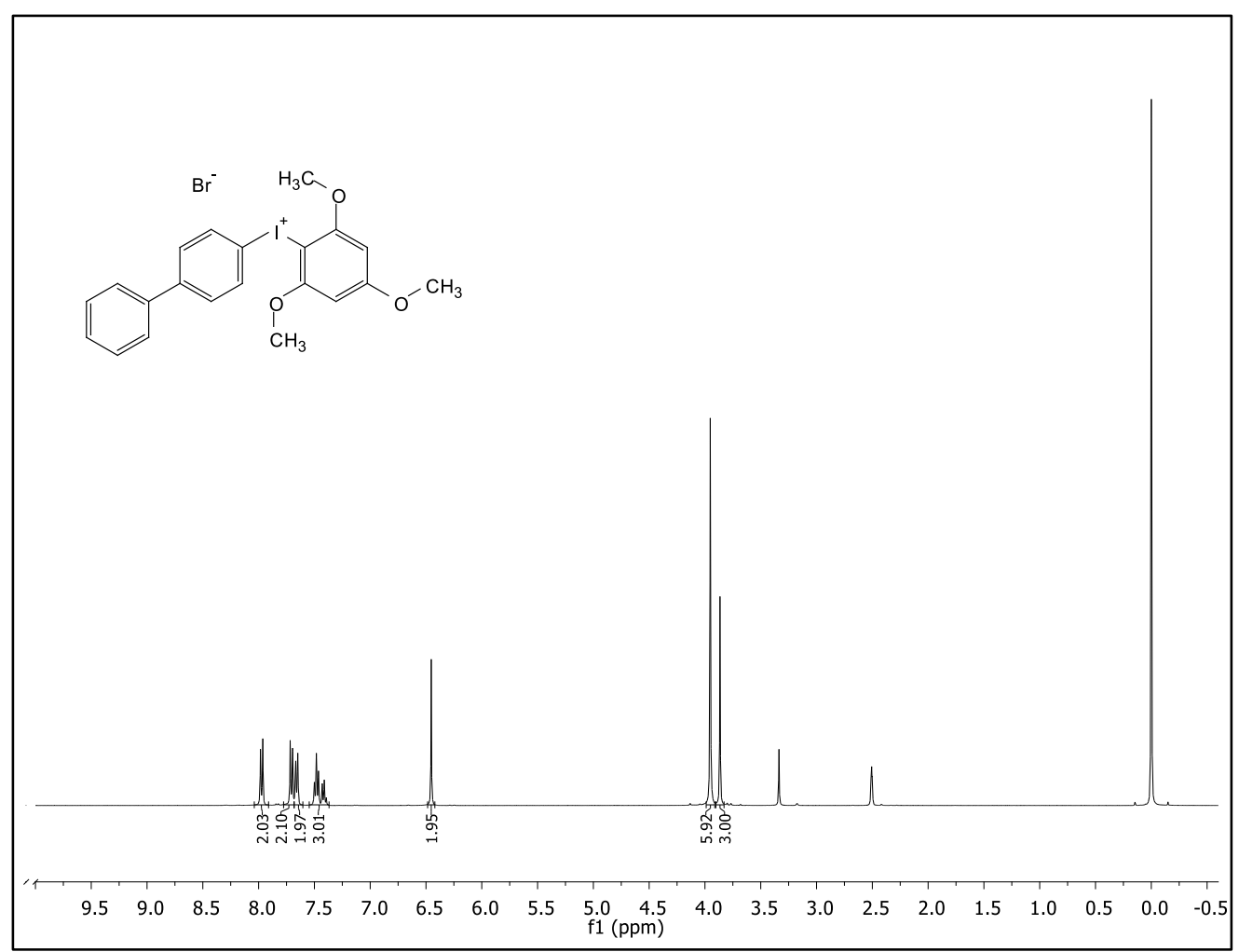

Figure 88. ${ }^{1} \mathrm{H}$ NMR spectrum of $19-\mathrm{Br}$ at $400 \mathrm{MHz}$ in DMSO- $d_{6}$ at $298 \mathrm{~K}$

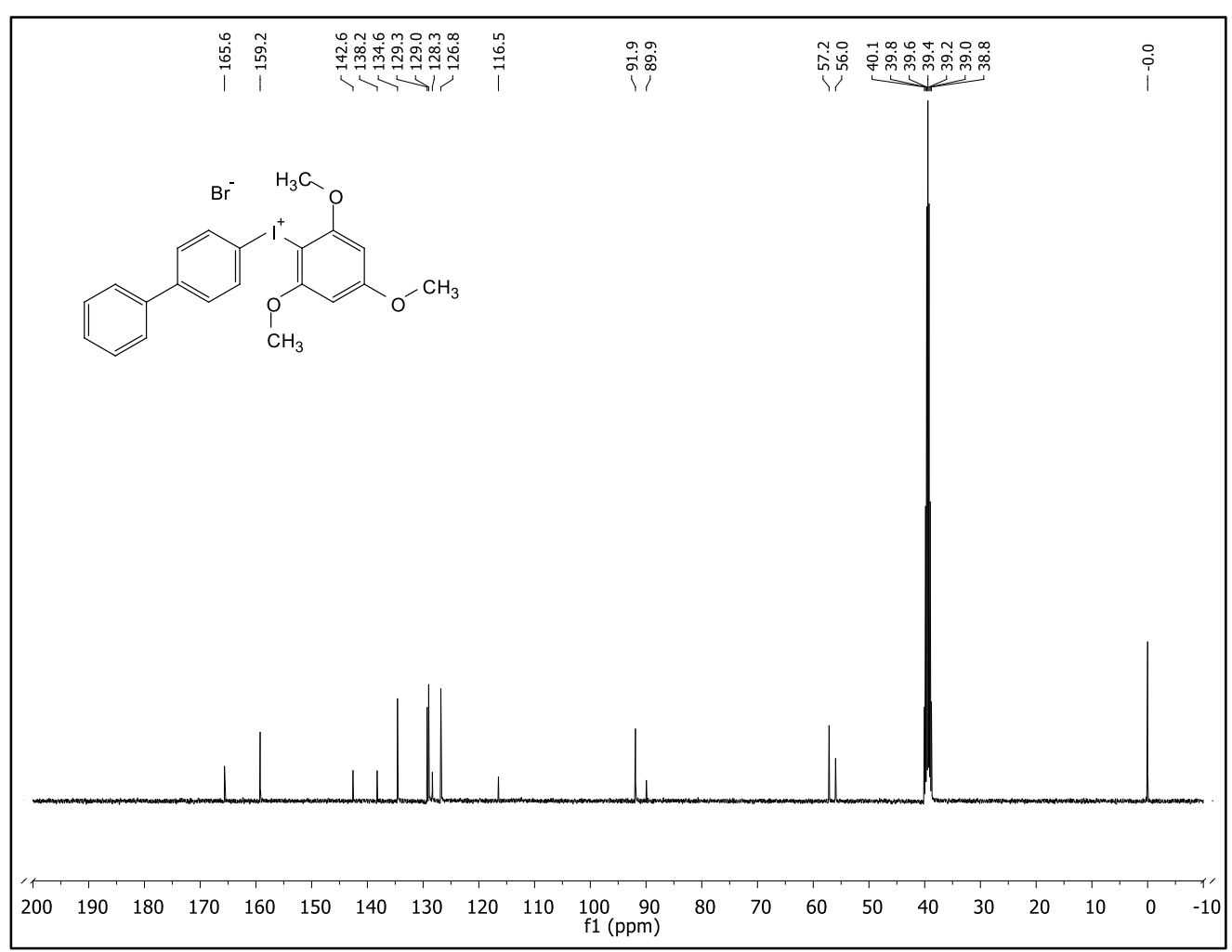

Figure 89. ${ }^{13} \mathrm{C}$ NMR spectrum of $19-\mathrm{Br}$ at $101 \mathrm{MHz}$ in DMSO- $d_{6}$ at $298 \mathrm{~K}$ 


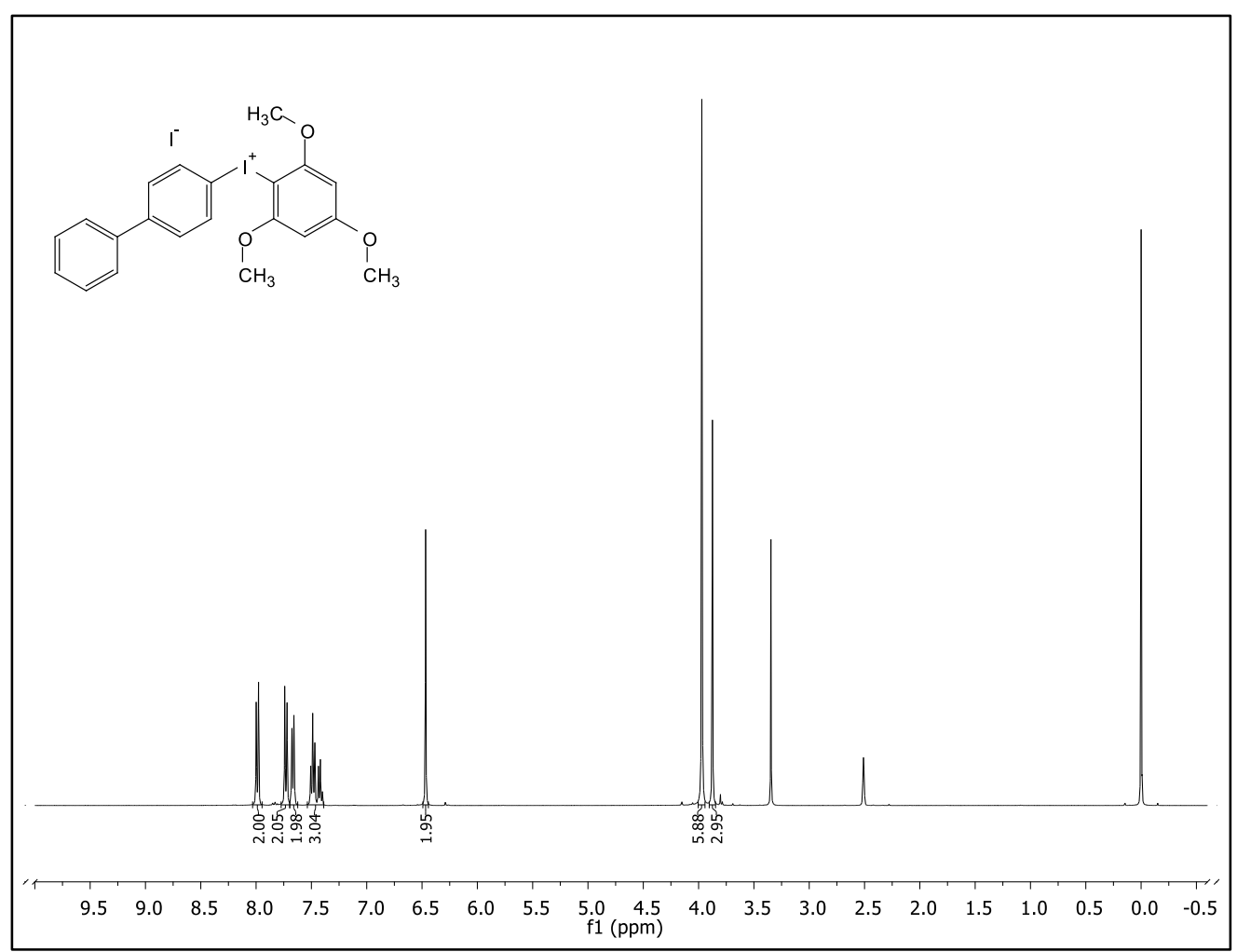

Figure 90. ${ }^{1} \mathrm{H}$ NMR spectrum of 19-I at $400 \mathrm{MHz}$ in DMSO- $d_{6}$ at $298 \mathrm{~K}$

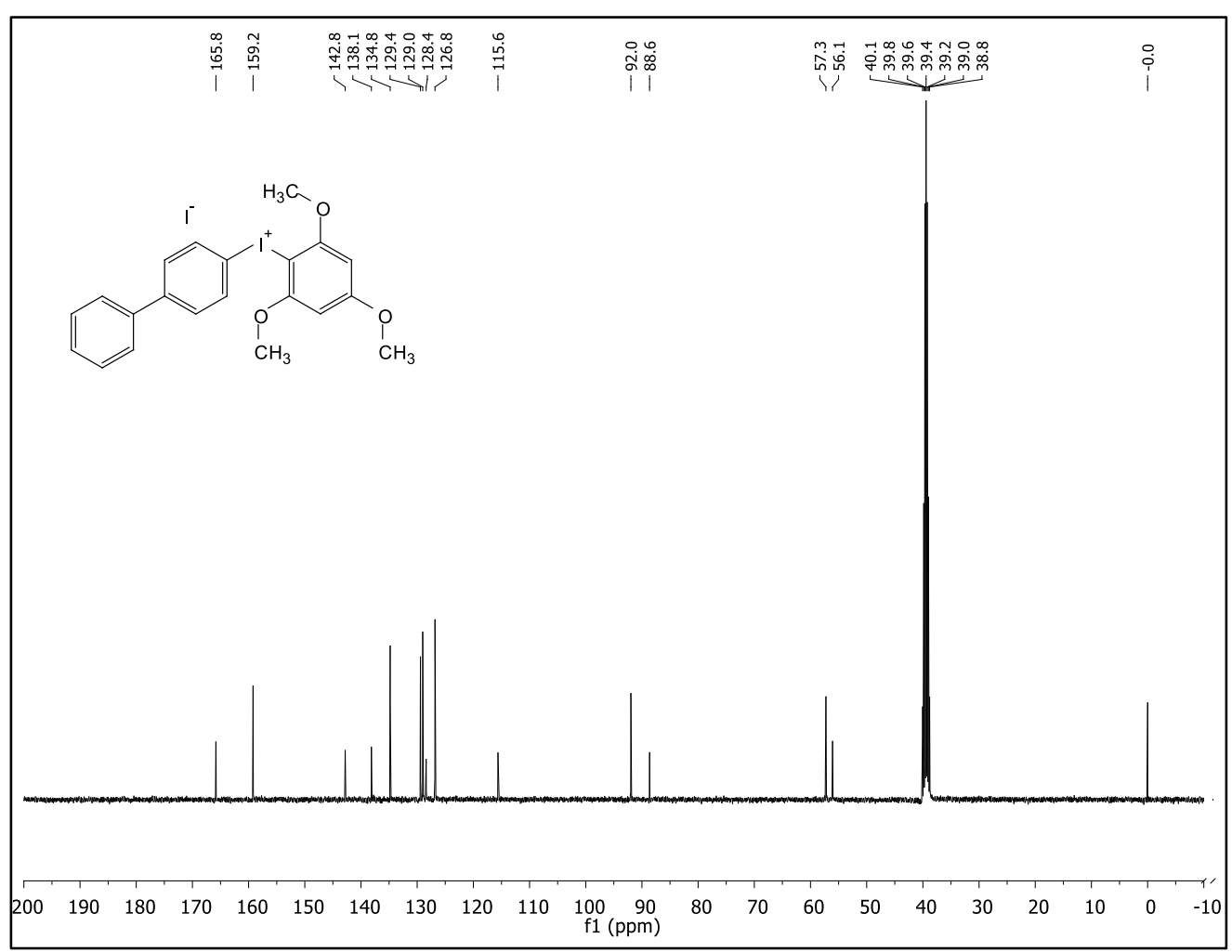

Figure $91 .{ }^{13} \mathrm{C}$ NMR spectrum of 19-I at $101 \mathrm{MHz}$ in DMSO- $d_{6}$ at $298 \mathrm{~K}$ 


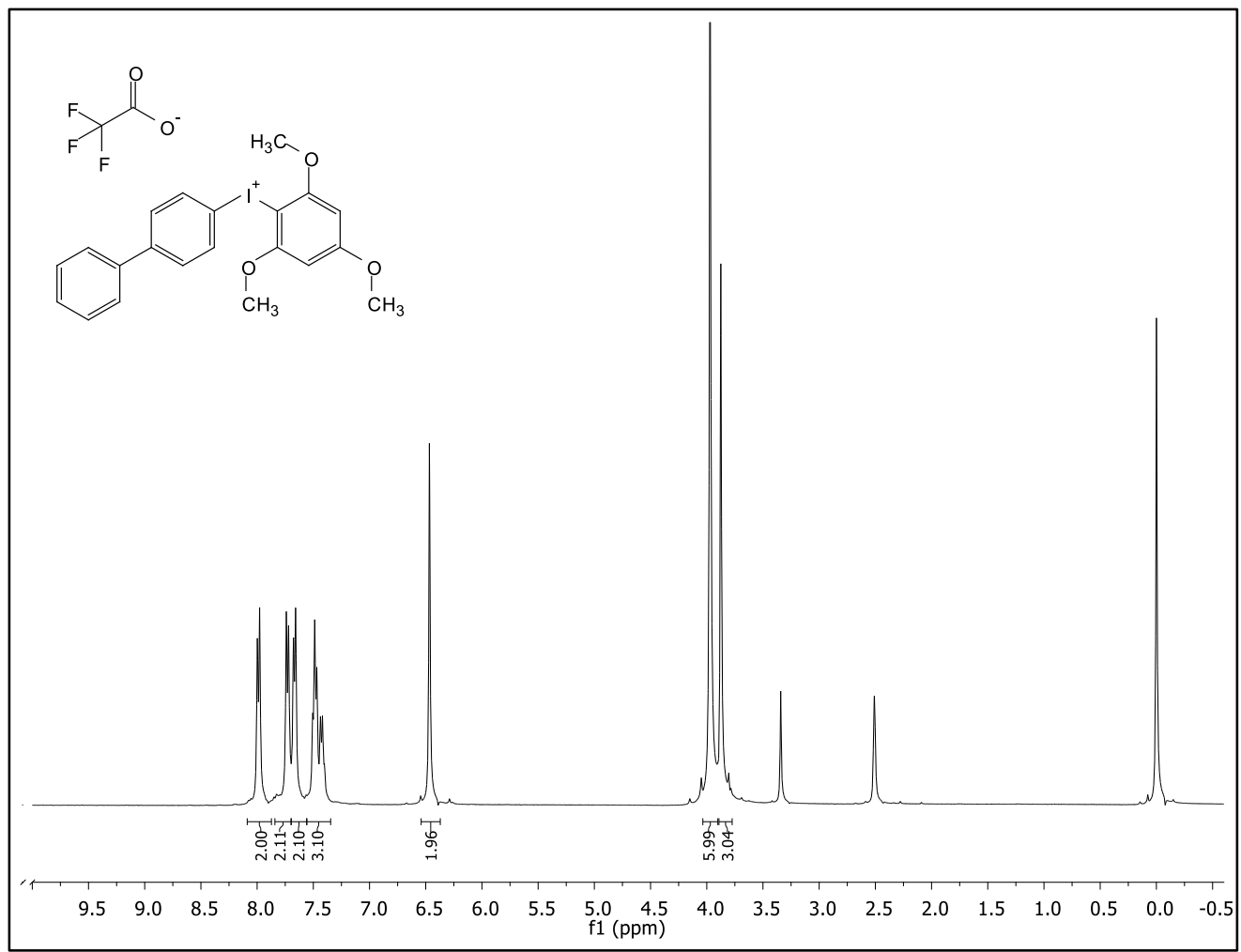

Figure 92. ${ }^{1} \mathrm{H}$ NMR spectrum of 19-CF 3 COO at $400 \mathrm{MHz}$ in DMSO-d ${ }_{6}$ at $298 \mathrm{~K}$

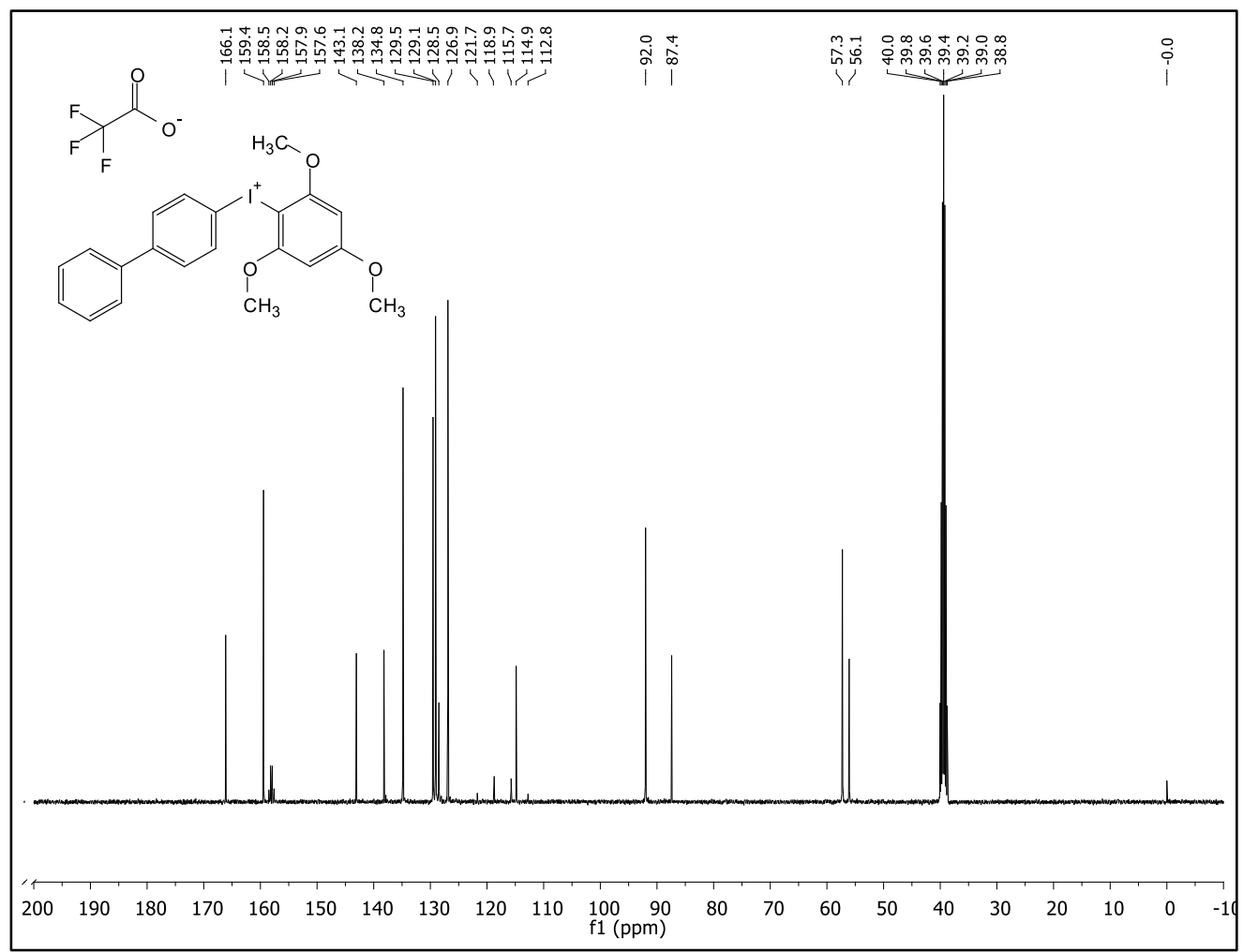

Figure 93. ${ }^{13} \mathrm{C}$ NMR spectrum of $19-\mathrm{CF}_{3} \mathrm{COO}$ at $101 \mathrm{MHz}$ in DMSO- $d_{6}$ at $298 \mathrm{~K}$ 


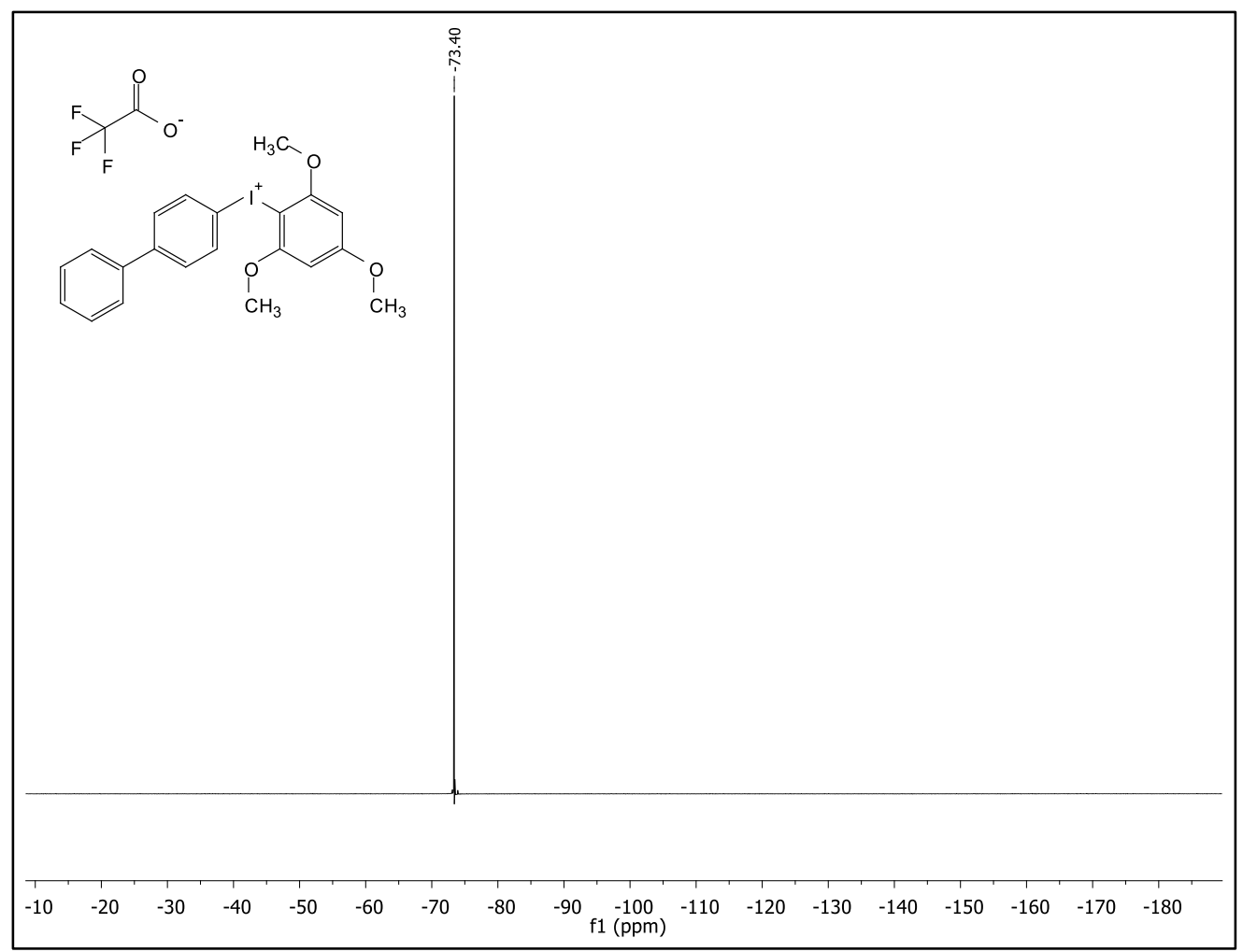

Figure 94. ${ }^{19} \mathrm{~F}$ NMR spectrum of $19-\mathrm{CF}_{3} \mathrm{COO}$ at $376 \mathrm{MHz}$ in DMSO- $d_{6}$ at $298 \mathrm{~K}$

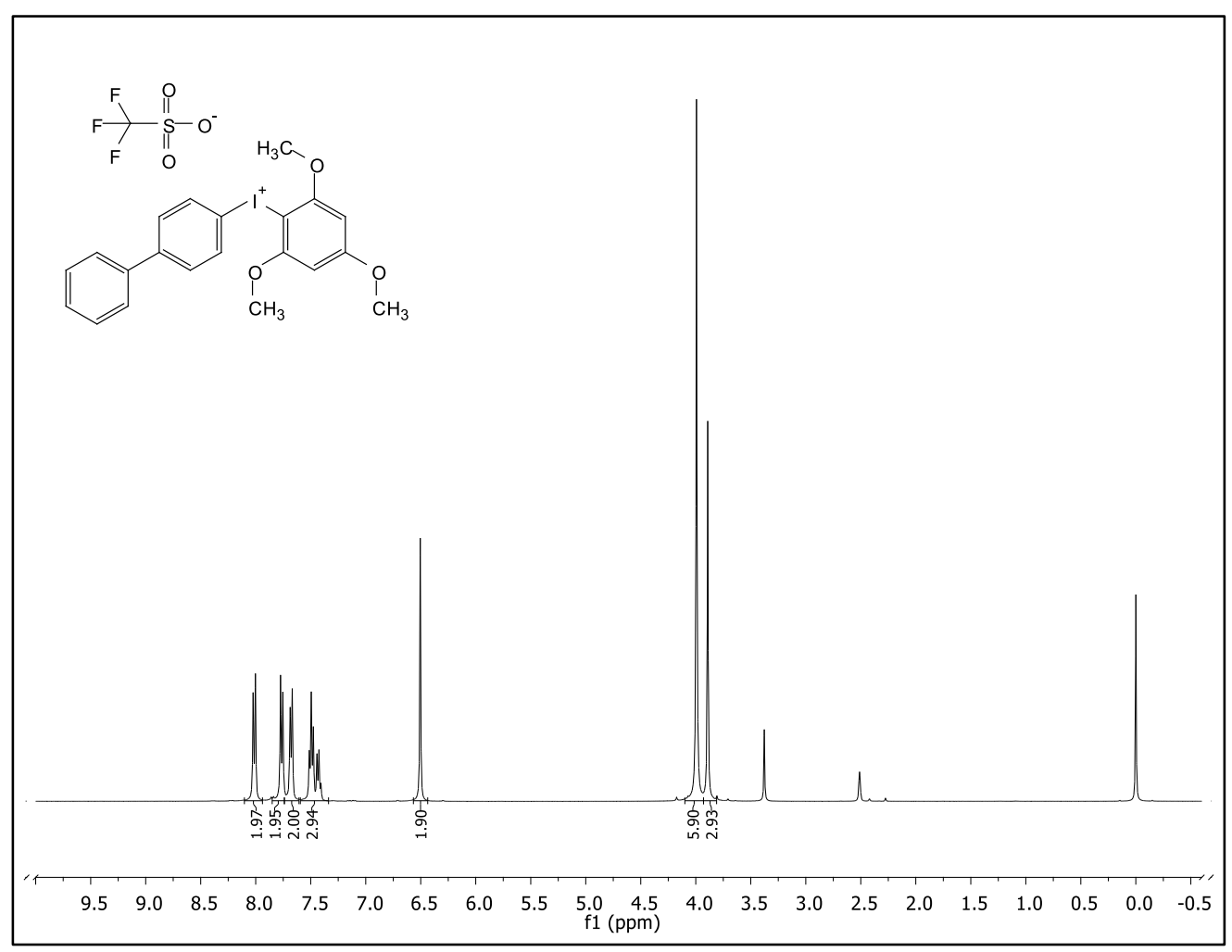

Figure 95. ${ }^{1} \mathrm{H}$ NMR spectrum of 19-OTf at $400 \mathrm{MHz}$ in DMSO- $d_{6}$ at $298 \mathrm{~K}$ 


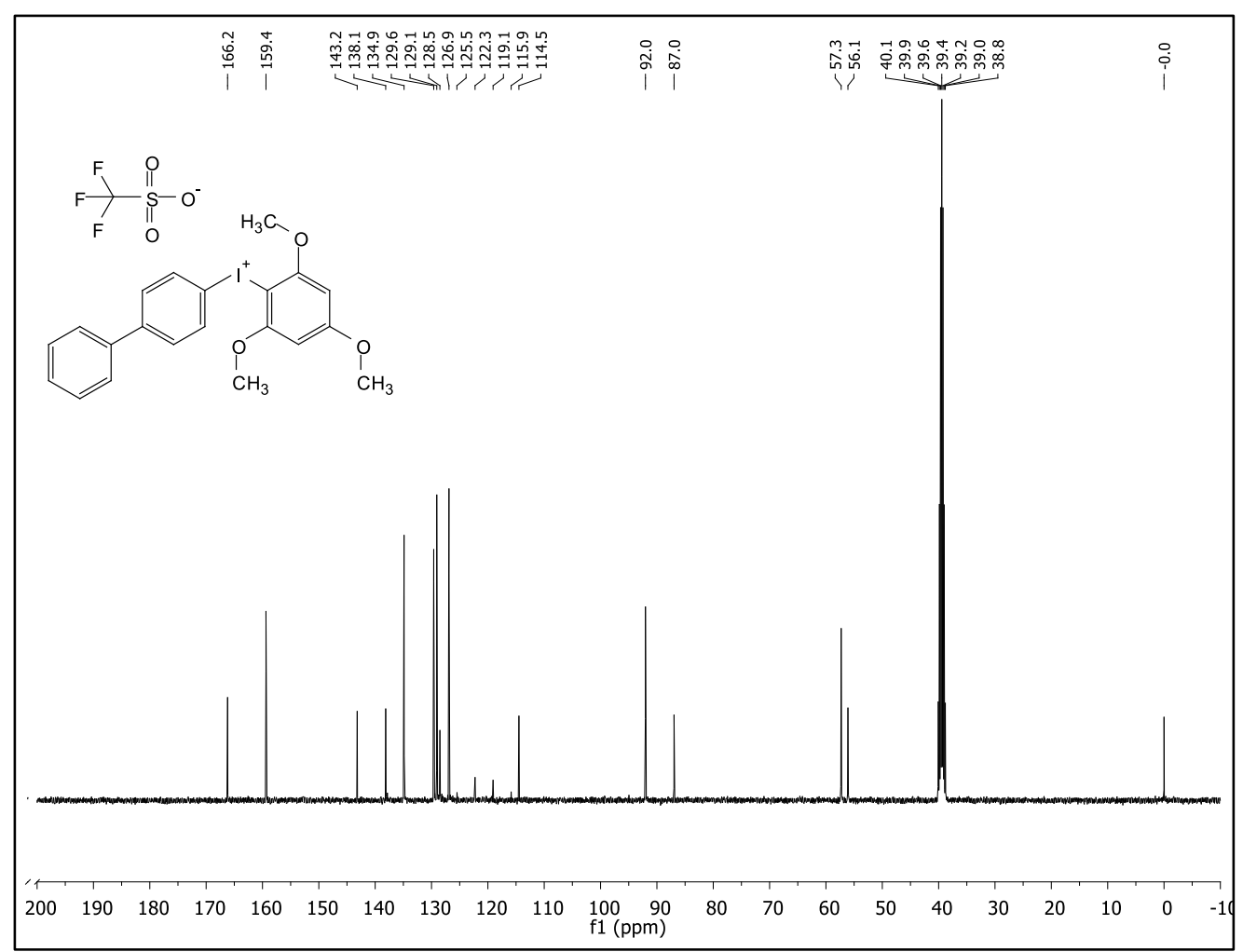

Figure 96. ${ }^{13} \mathrm{C}$ NMR spectrum of 19-OTf at $101 \mathrm{MHz}$ in DMSO- $d_{6}$ at $298 \mathrm{~K}$

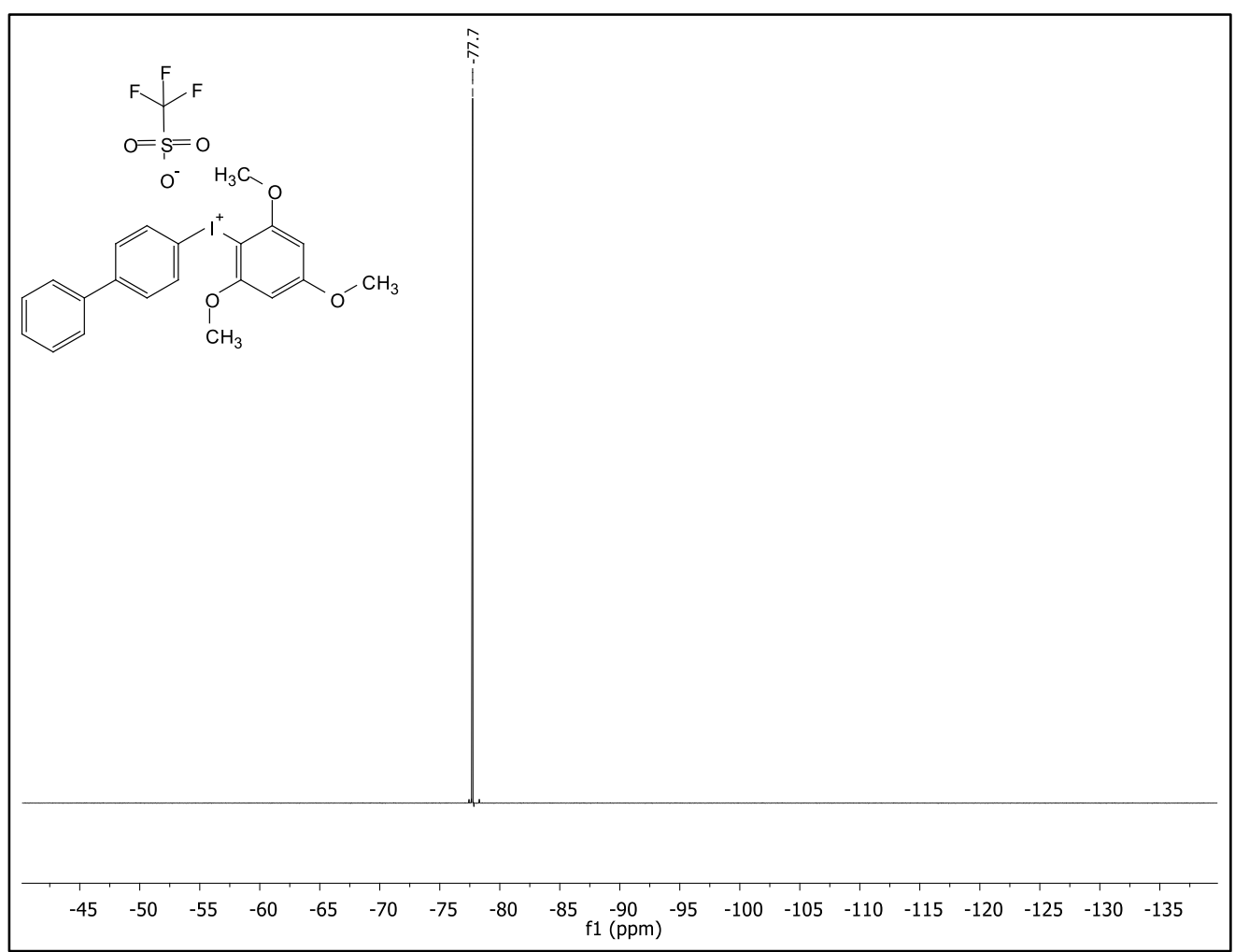

Figure 97. ${ }^{19} \mathrm{~F}$ NMR spectrum of 19-OTf at $376 \mathrm{MHz}$ in DMSO- $d_{6}$ at $298 \mathrm{~K}$ 


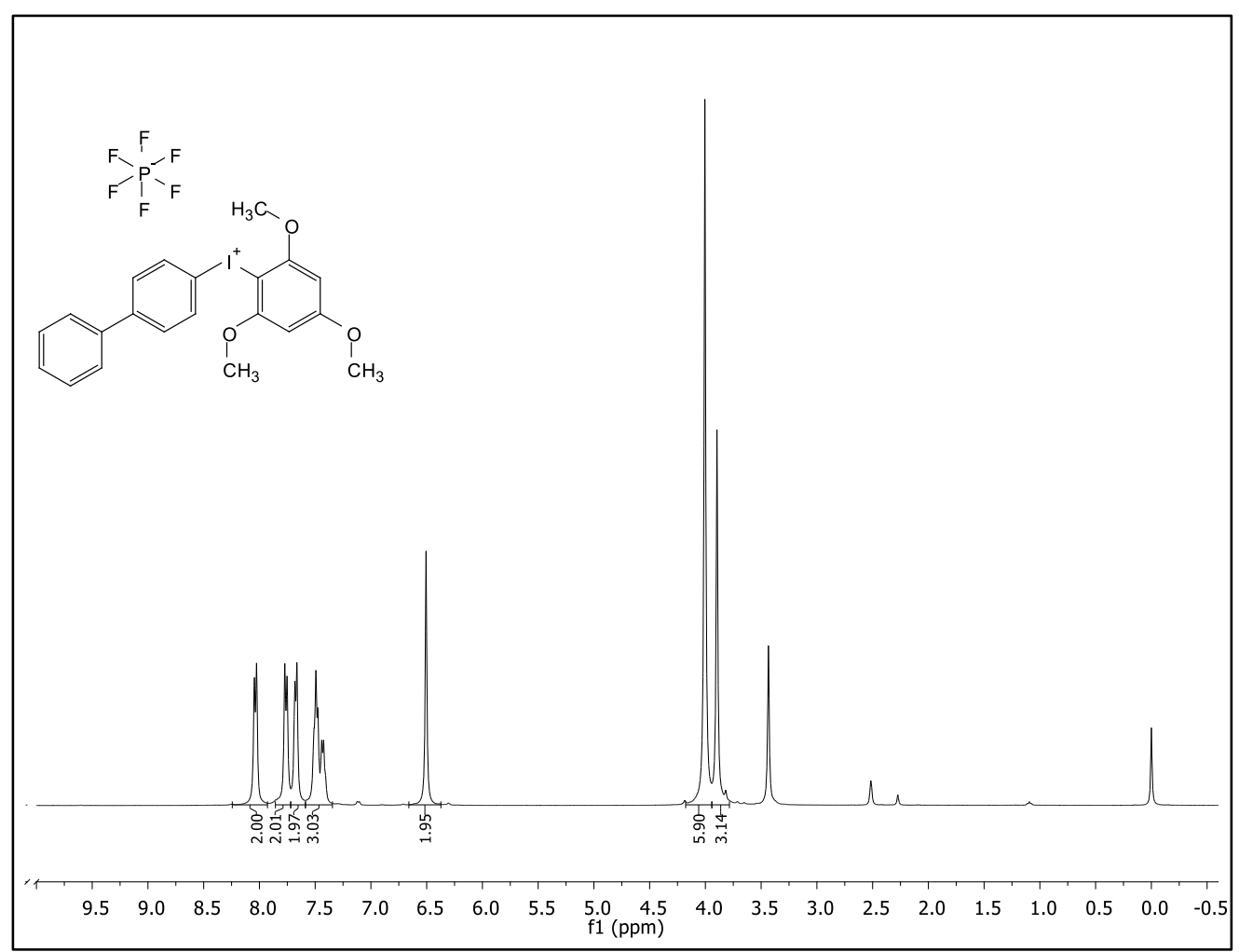

Figure 98. ${ }^{1} \mathrm{H}$ NMR spectrum of $19-\mathrm{PF}_{6}$ at $400 \mathrm{MHz}$ in DMSO- $d_{6}$ at $298 \mathrm{~K}$

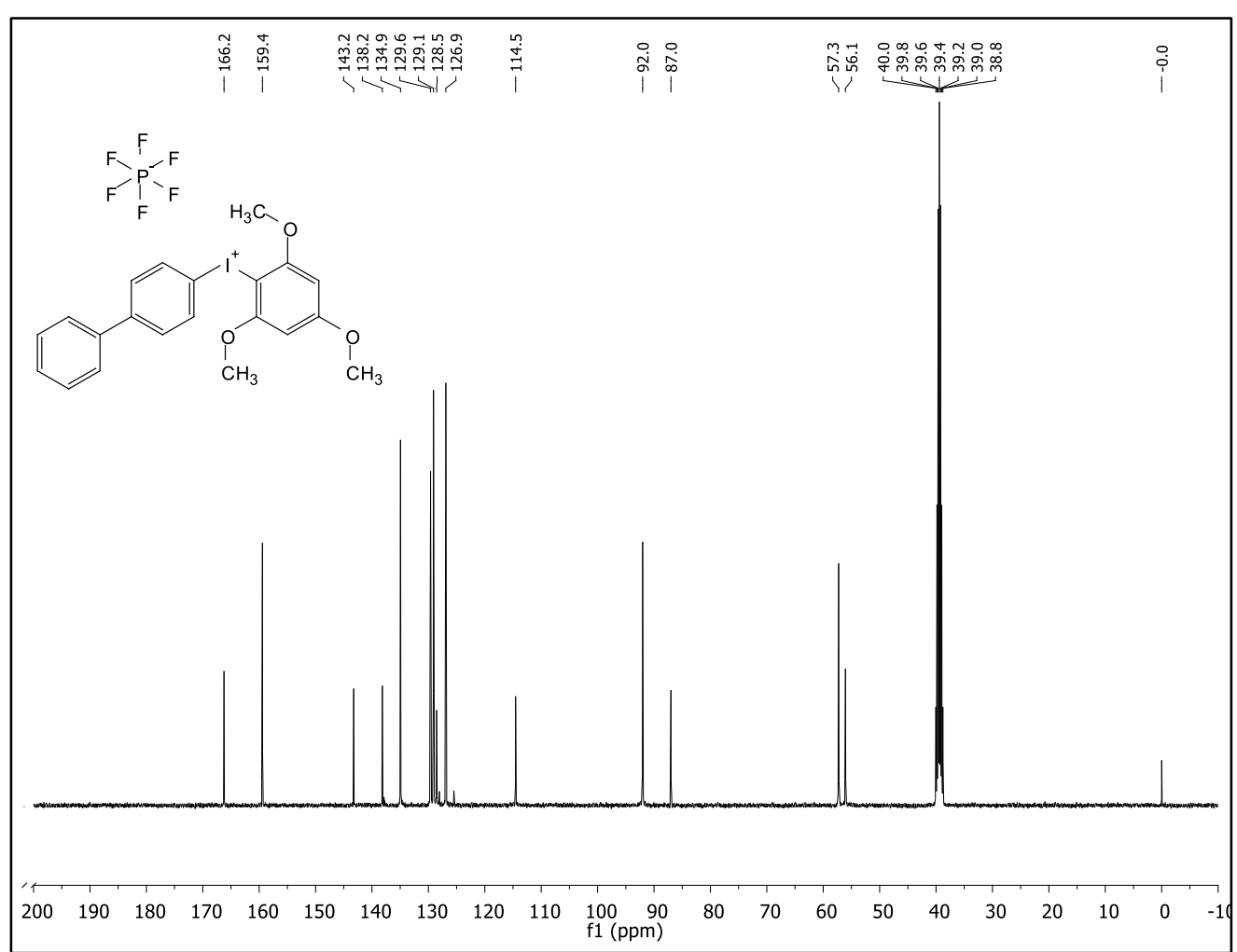

Figure 99. ${ }^{13} \mathrm{C}$ NMR spectrum of $19-\mathrm{PF}_{6}$ at $101 \mathrm{MHz}$ in DMSO- $d_{6}$ at $298 \mathrm{~K}$ 


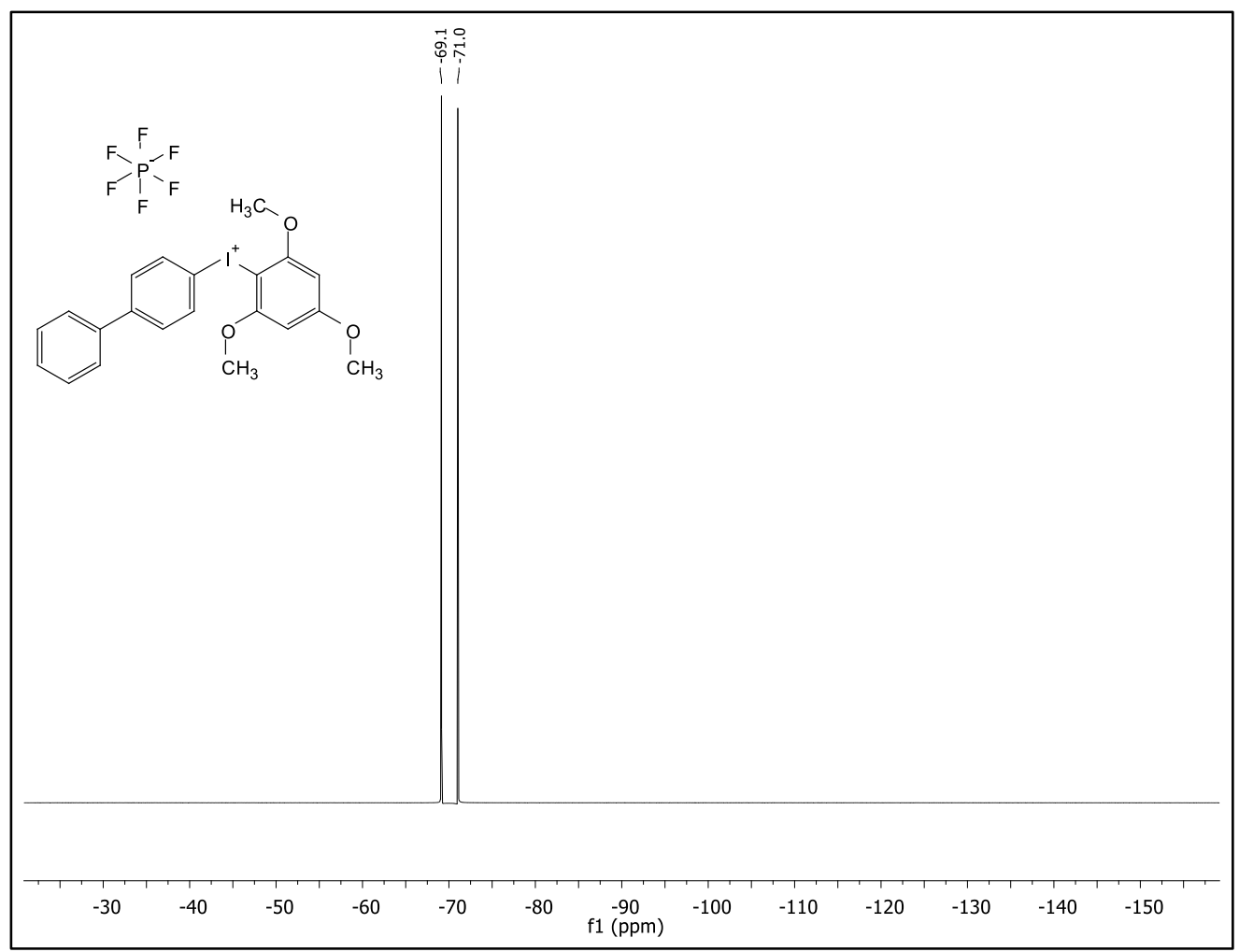

Figure 100. ${ }^{19} \mathrm{~F}$ NMR spectrum of $19-\mathrm{PF}_{6}$ at $376 \mathrm{MHz}$ in DMSO- $d_{6}$ at $298 \mathrm{~K}$

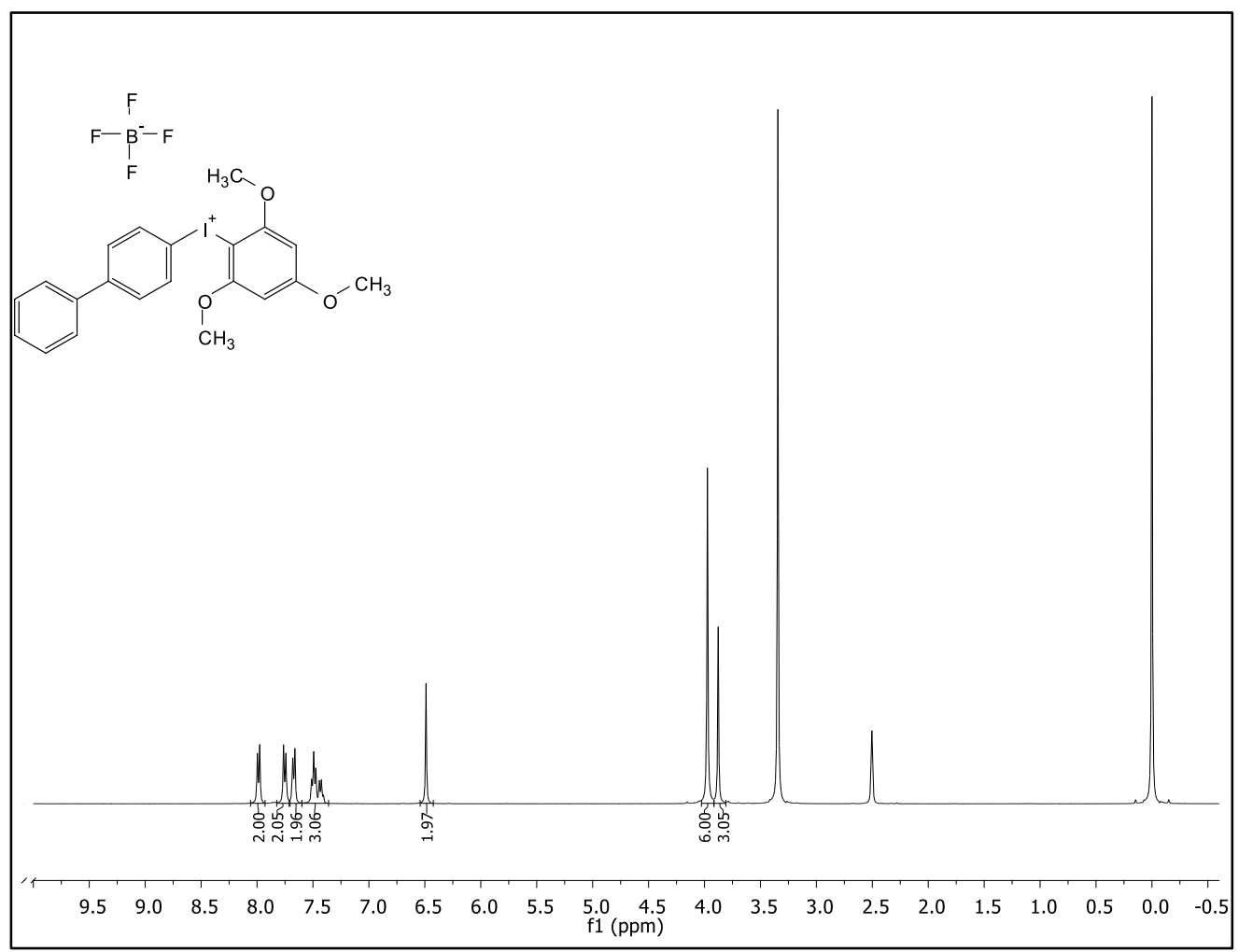

Figure 101. ${ }^{1} \mathrm{H}$ NMR spectrum of $19-\mathrm{BF}_{4}$ at $400 \mathrm{MHz}$ in DMSO- $d_{6}$ at $298 \mathrm{~K}$ 


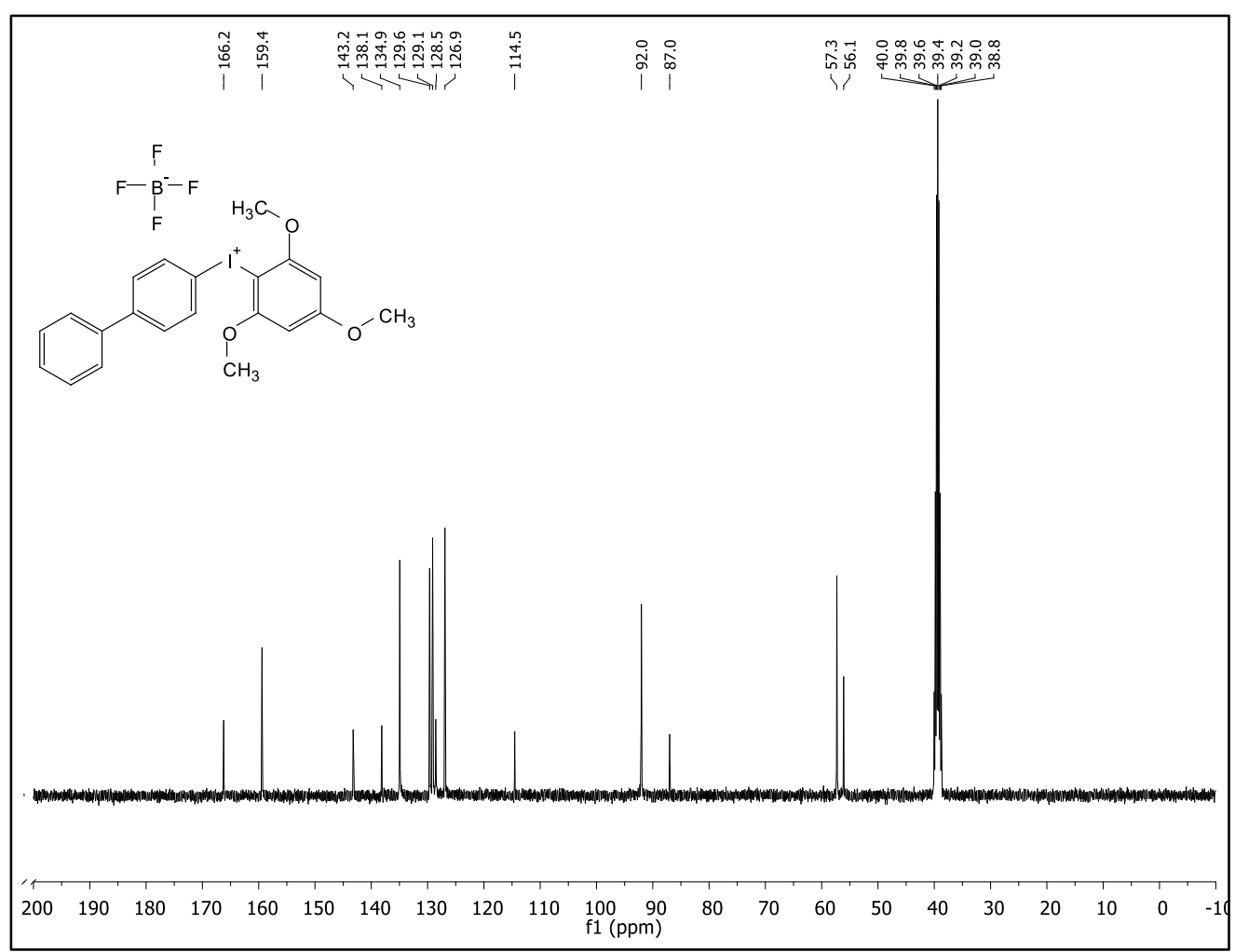

Figure $102 .{ }^{13} \mathrm{C}$ NMR spectrum of $19-\mathrm{BF}_{4}$ at $101 \mathrm{MHz}$ in DMSO- $d_{6}$ at $298 \mathrm{~K}$

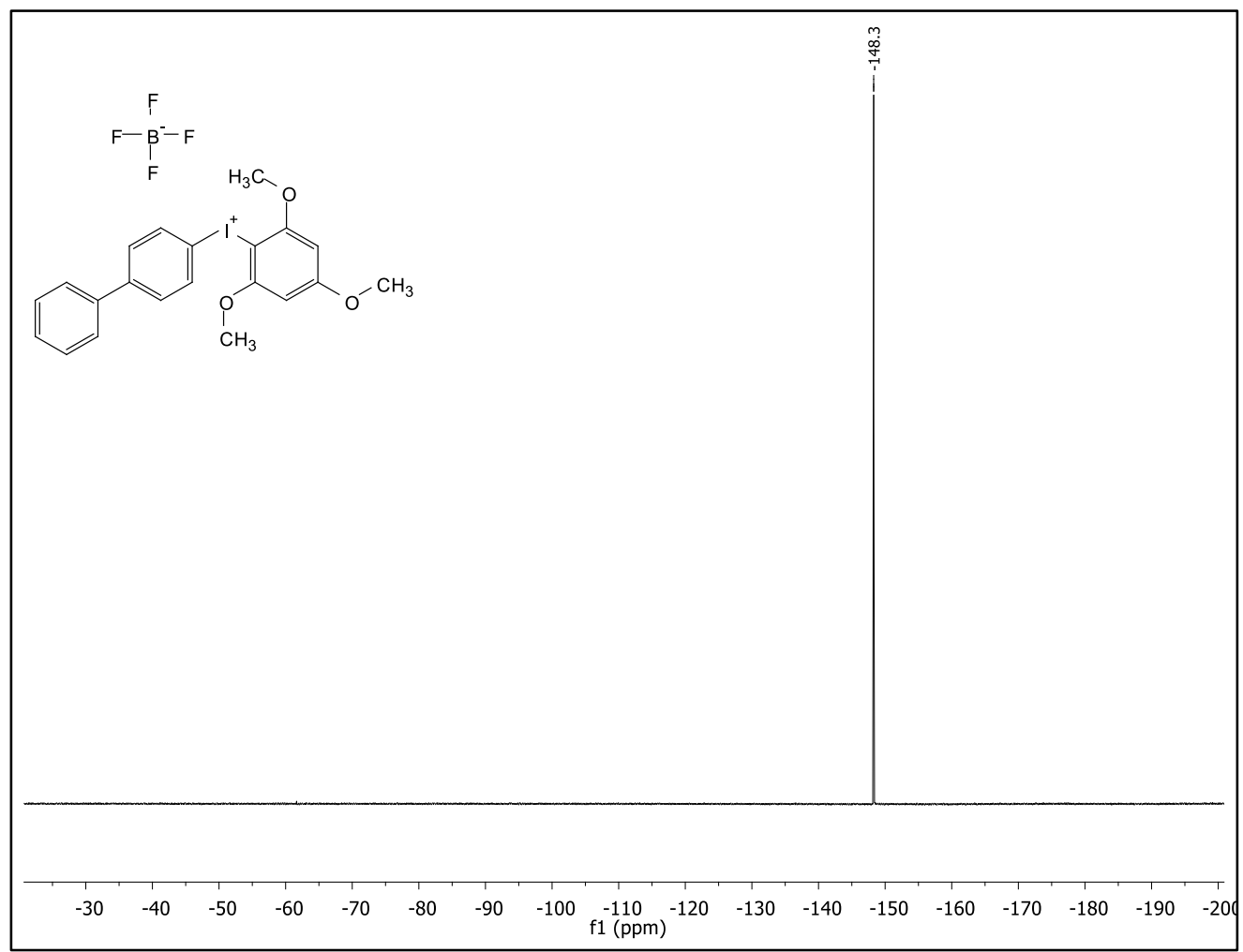

Figure 103. ${ }^{19} \mathrm{~F}$ NMR spectrum of $19-\mathrm{BF}_{4}$ at $376 \mathrm{MHz}$ in DMSO-d 6 at $298 \mathrm{~K}$ 


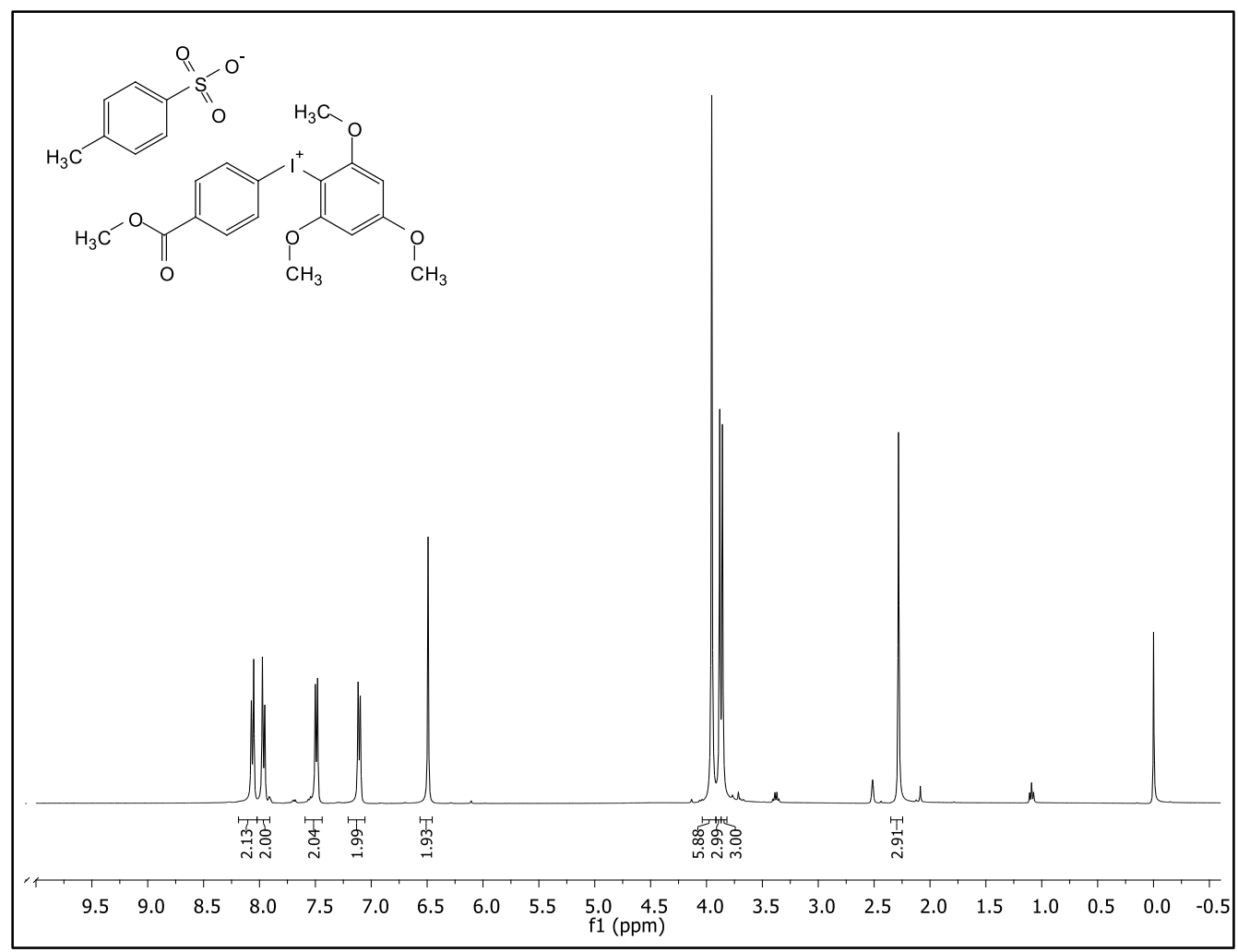

Figure 104. ${ }^{1} \mathrm{H}$ NMR spectrum of 20 at $400 \mathrm{MHz}$ in DMSO- $d_{6}$ at $298 \mathrm{~K}$

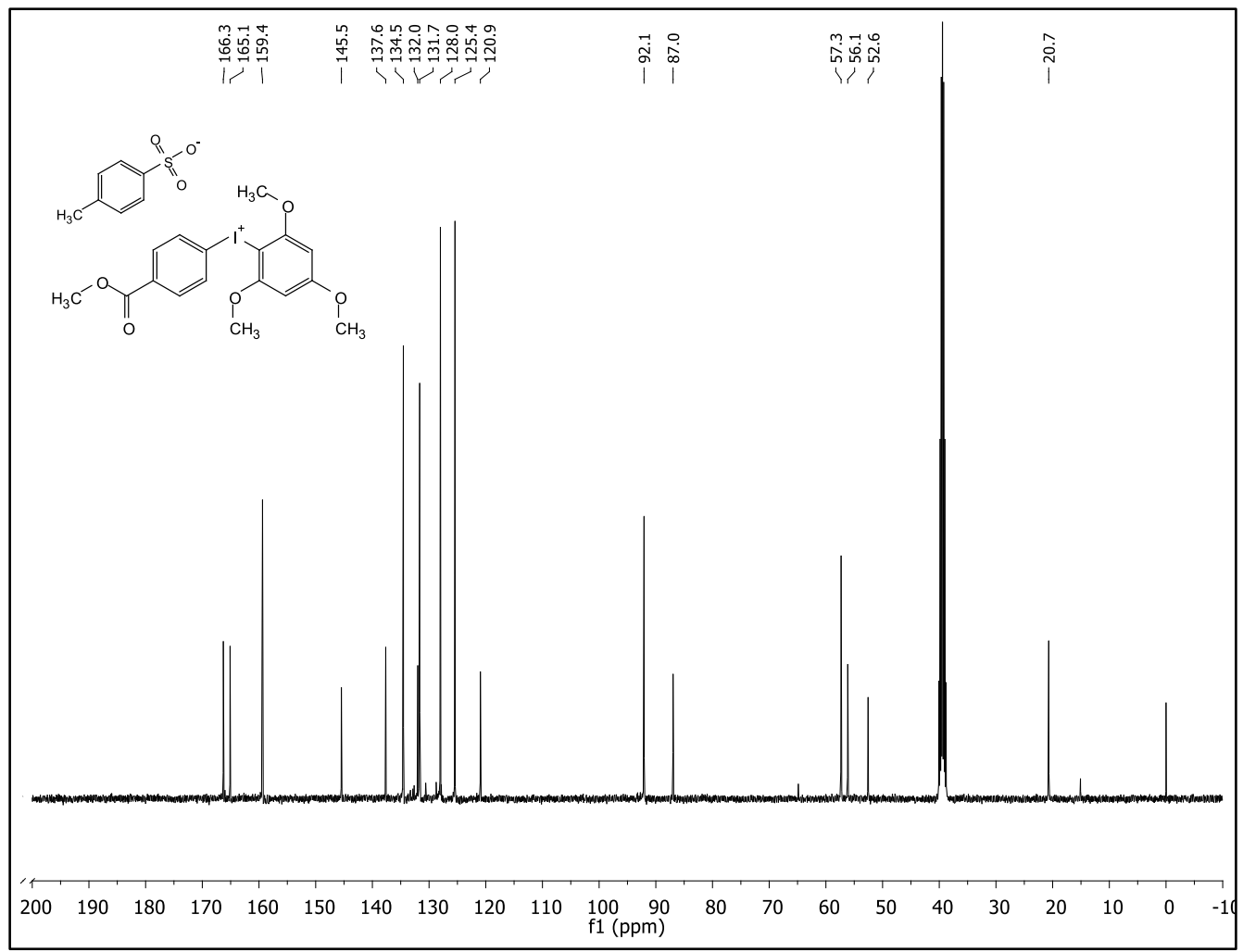

Figure $105 .{ }^{13} \mathrm{C}$ NMR spectrum of 20 at $101 \mathrm{MHz}$ in DMSO- $d_{6}$ at $298 \mathrm{~K}$ 


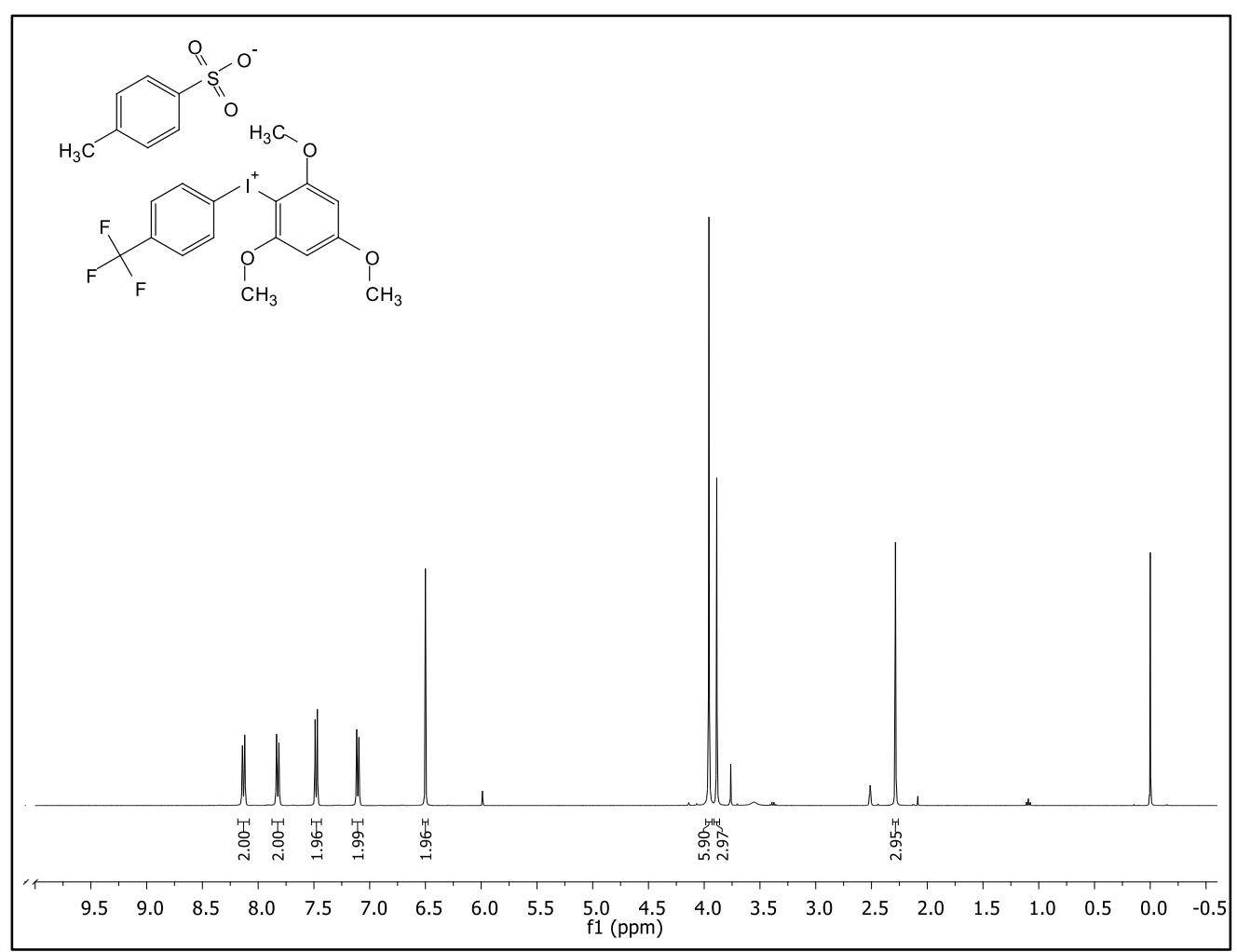

Figure 106. ${ }^{1} \mathrm{H}$ NMR spectrum of 21 at $400 \mathrm{MHz}$ in DMSO- $d_{6}$ at $298 \mathrm{~K}$

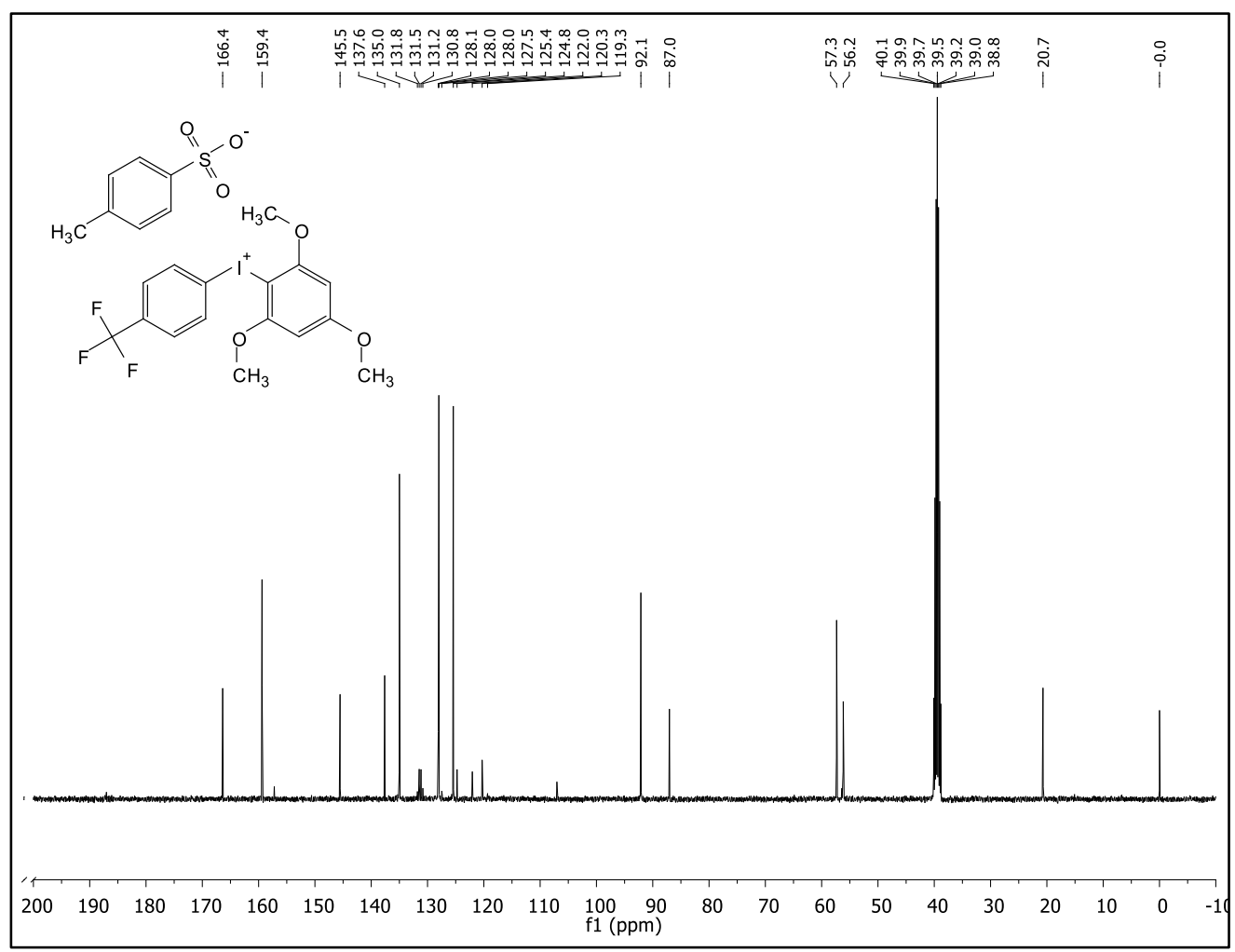

Figure 107. ${ }^{13} \mathrm{C}$ NMR spectrum of 21 at $101 \mathrm{MHz}$ in DMSO-d $d_{6}$ at $298 \mathrm{~K}$ 


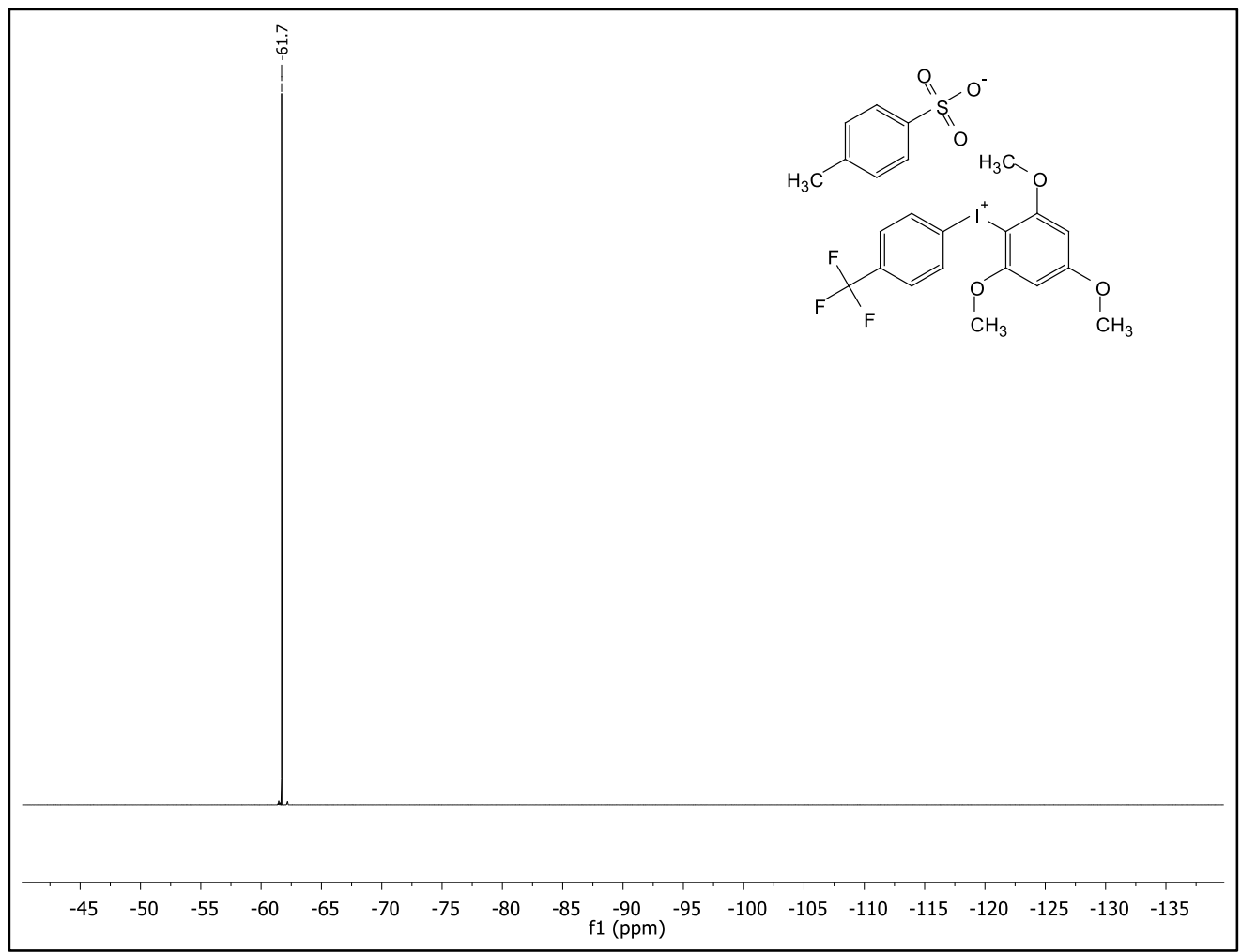

Figure 108. ${ }^{19} \mathrm{~F}$ NMR spectrum of 21 at $376 \mathrm{MHz}$ in DMSO-d $d_{6}$ at $298 \mathrm{~K}$

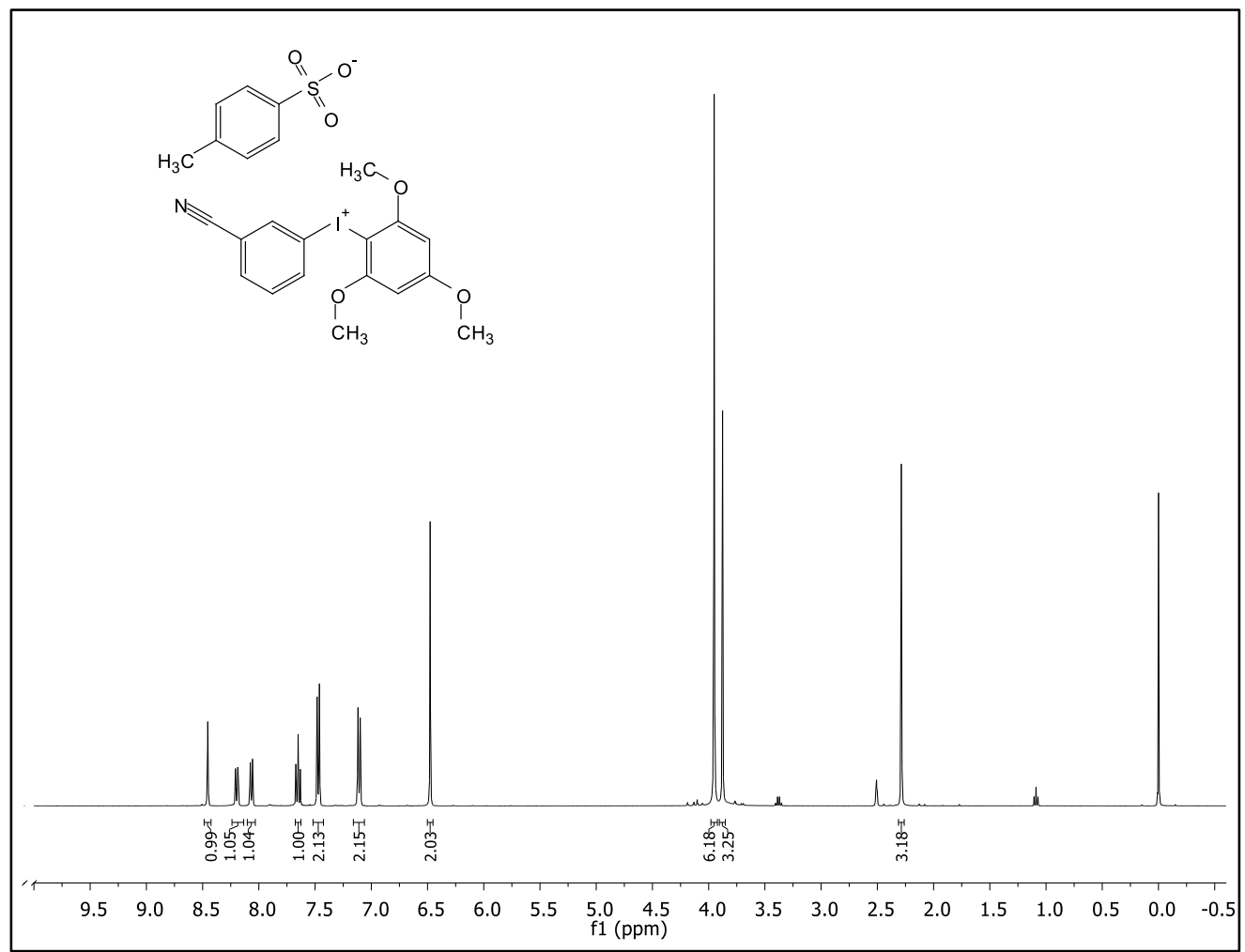

Figure 109. ${ }^{1} \mathrm{H}$ NMR spectrum of 22 at $400 \mathrm{MHz}$ in DMSO- $d_{6}$ at $298 \mathrm{~K}$ 


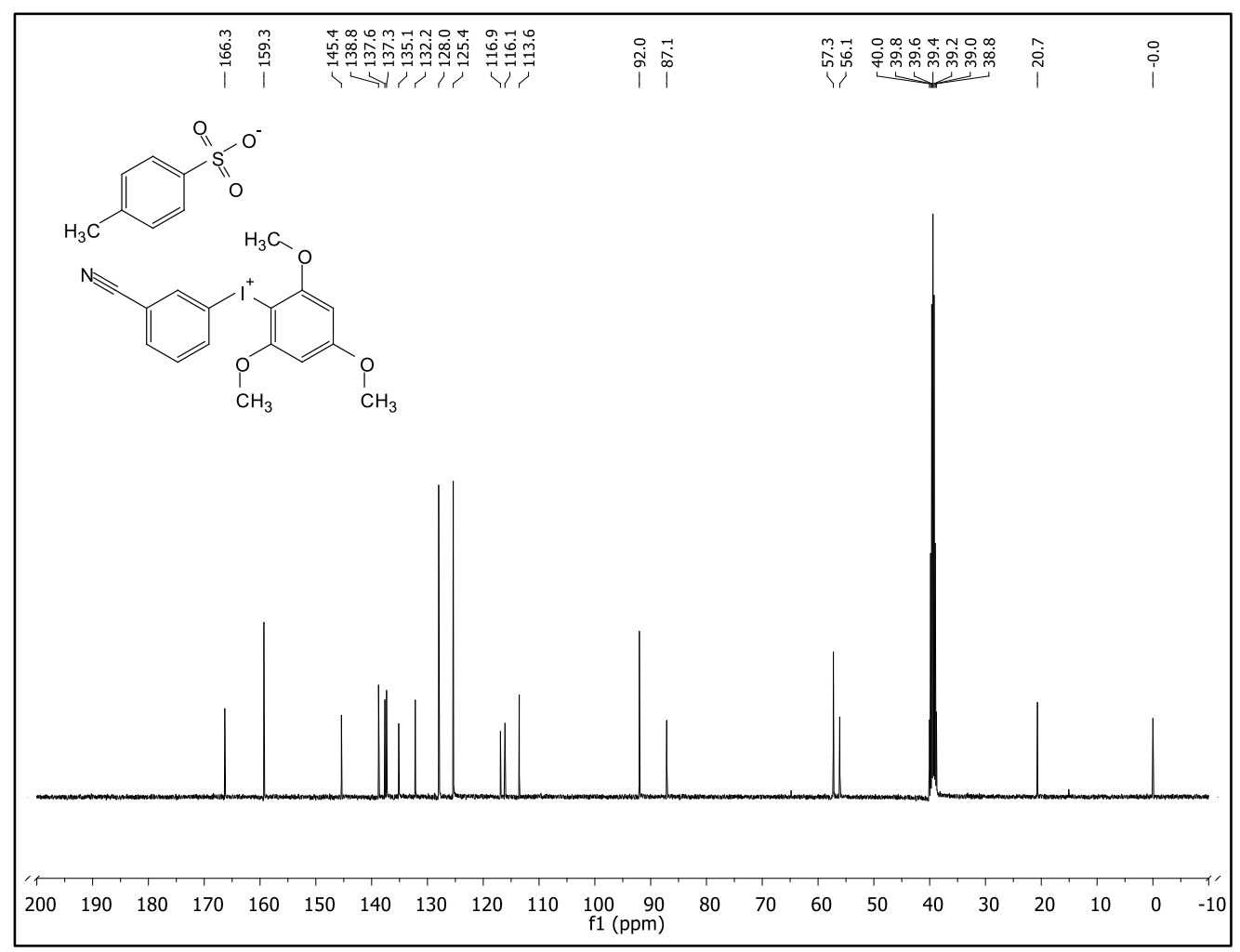

Figure $110 .{ }^{13} \mathrm{C}$ NMR spectrum of 22 at $101 \mathrm{MHz}$ in DMSO- $d_{6}$ at $298 \mathrm{~K}$

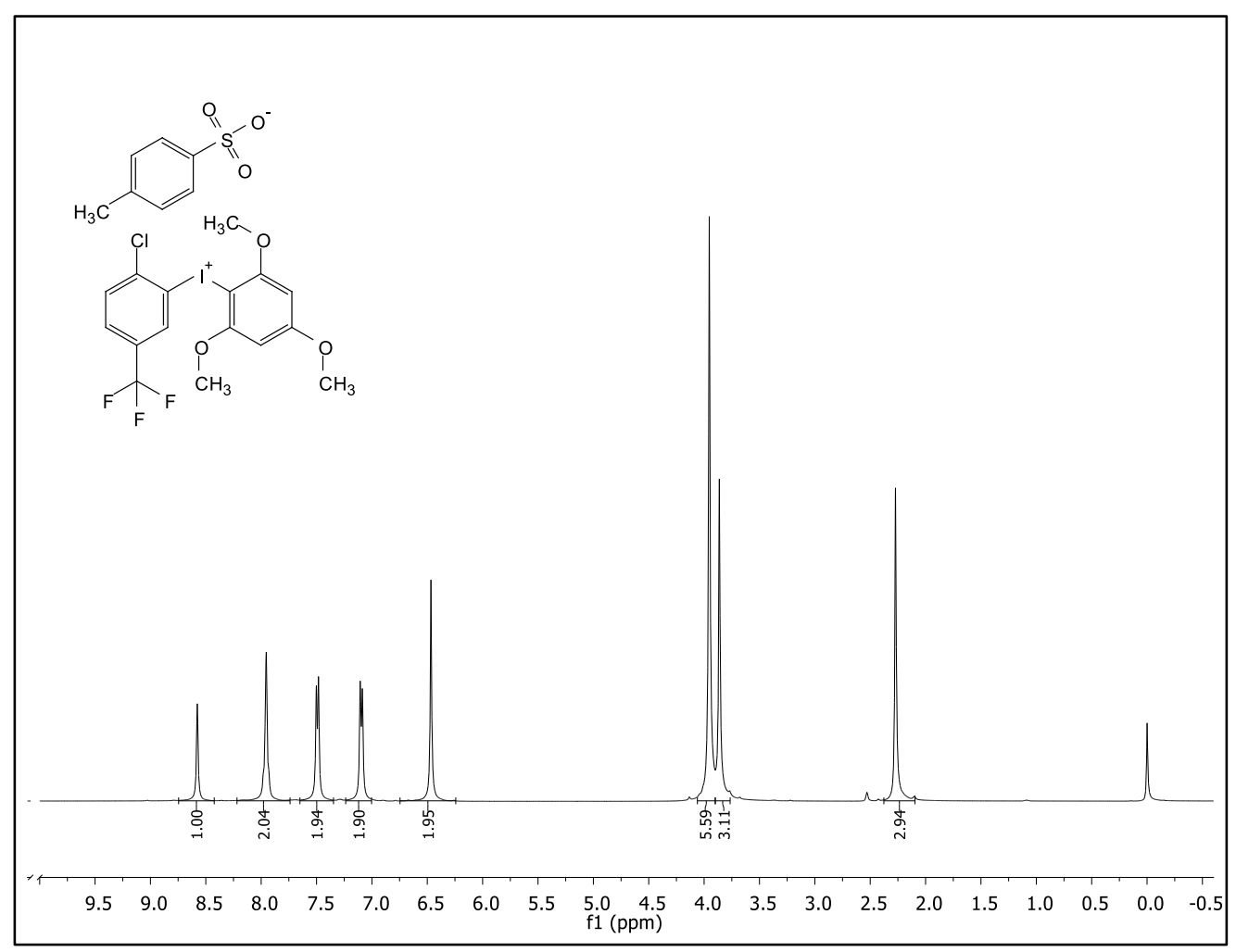

Figure 111. ${ }^{1} \mathrm{H}$ NMR spectrum of 24 at $400 \mathrm{MHz}$ in DMSO- $d_{6}$ at $298 \mathrm{~K}$ 


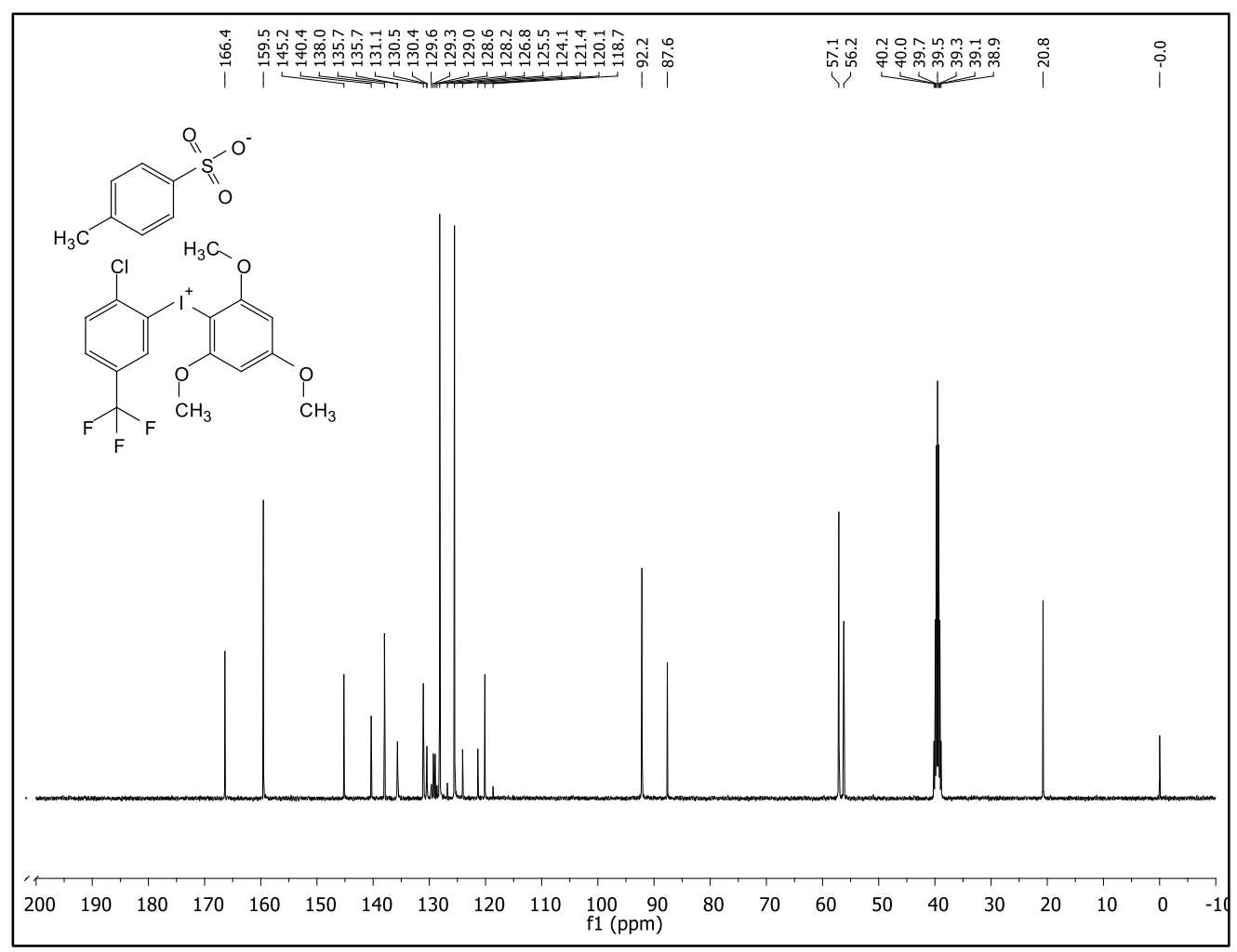

Figure $112 .{ }^{13} \mathrm{C}$ NMR spectrum of 24 at $101 \mathrm{MHz}$ in DMSO- $d_{6}$ at $298 \mathrm{~K}$

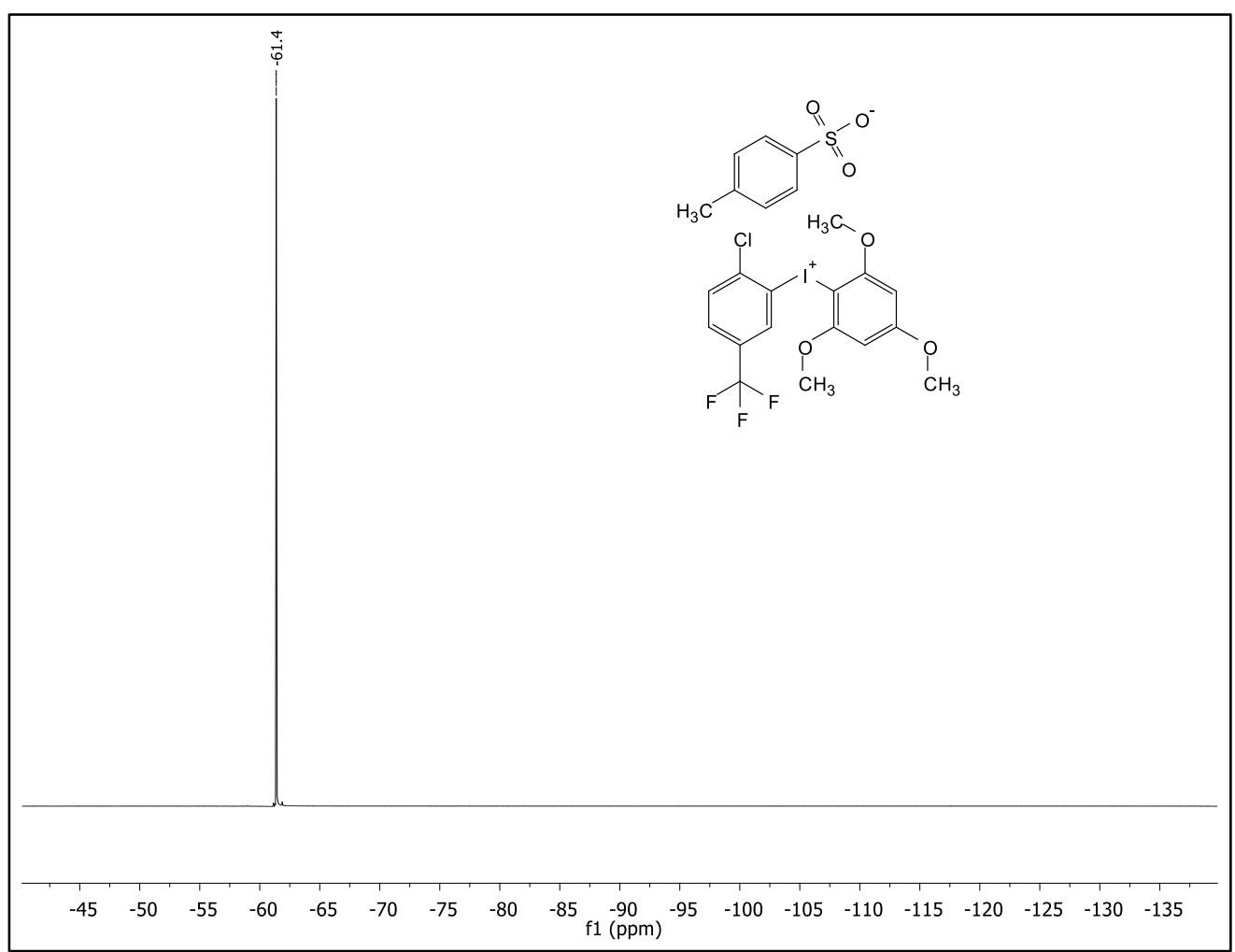

Figure 113. ${ }^{19} \mathrm{~F}$ NMR spectrum of 24 at $376 \mathrm{MHz}$ in DMSO-d 6 at $298 \mathrm{~K}$ 


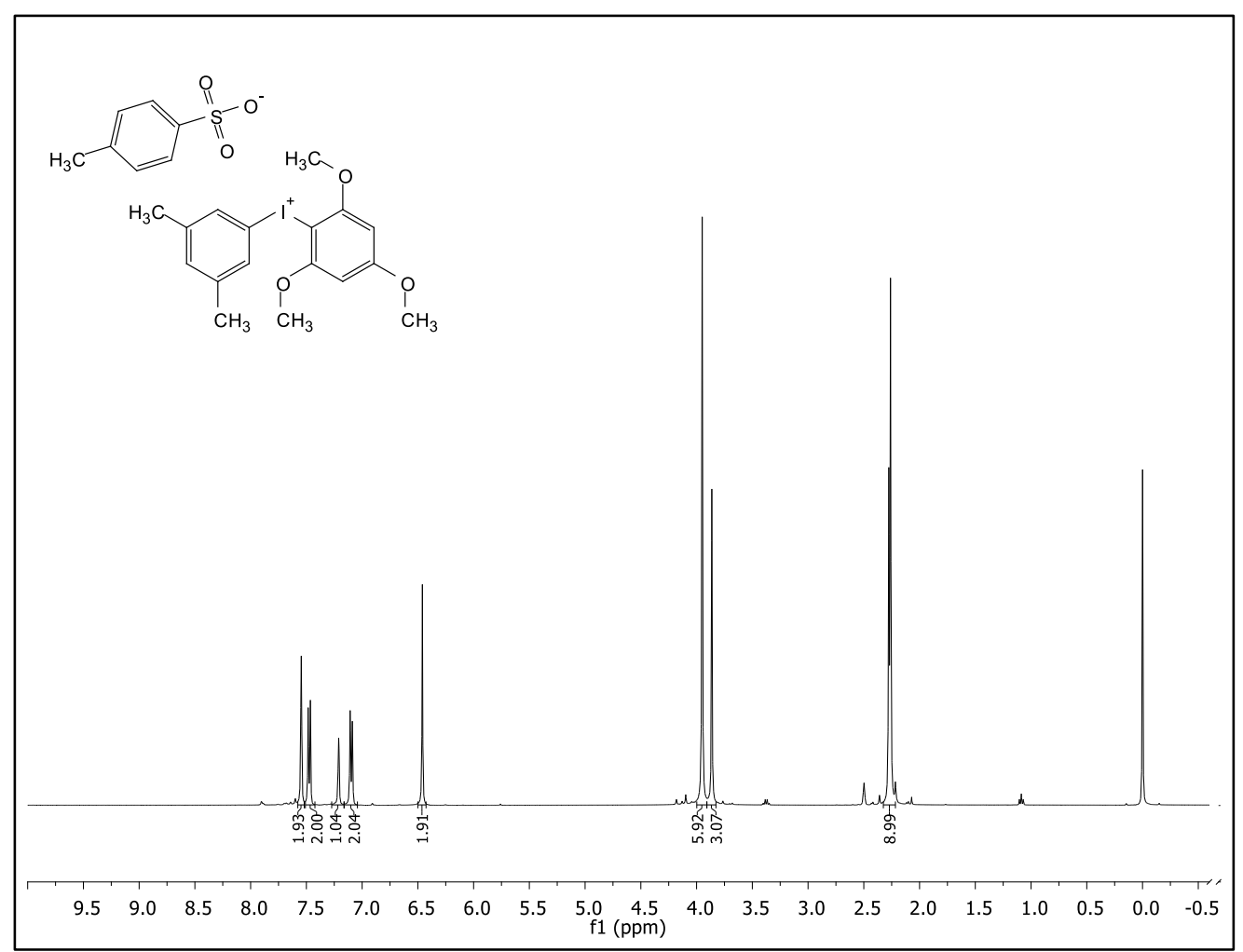

Figure 114. ${ }^{1} \mathrm{H}$ NMR spectrum of 25 at $400 \mathrm{MHz}$ in DMSO- $d_{6}$ at $298 \mathrm{~K}$

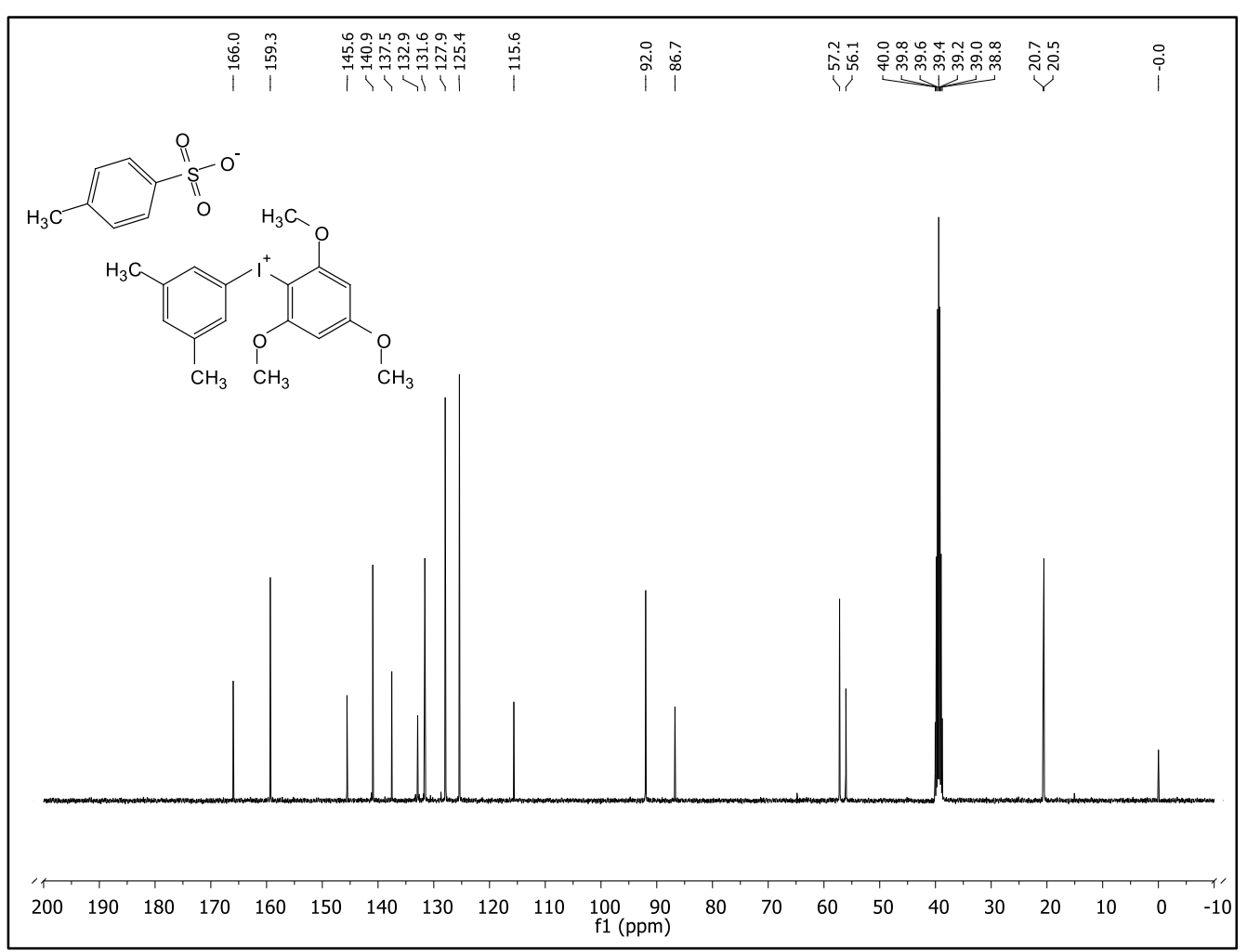

Figure 115. ${ }^{13} \mathrm{C}$ NMR spectrum of 25 at $101 \mathrm{MHz}$ in DMSO-d $d_{6}$ at $298 \mathrm{~K}$ 


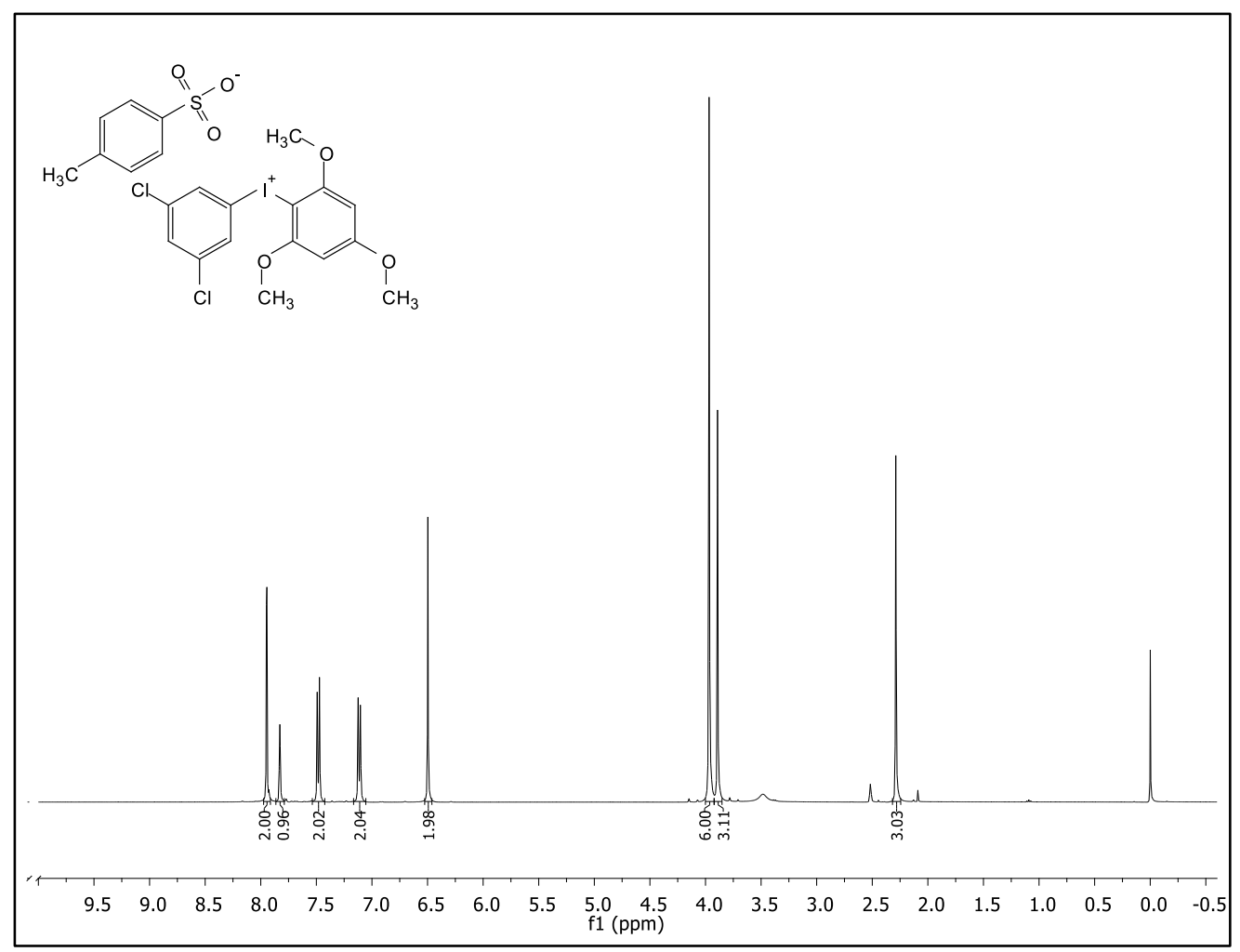

Figure 116. ${ }^{1} \mathrm{H}$ NMR spectrum of 26 at $400 \mathrm{MHz}$ in DMSO-d $d_{6}$ at $298 \mathrm{~K}$

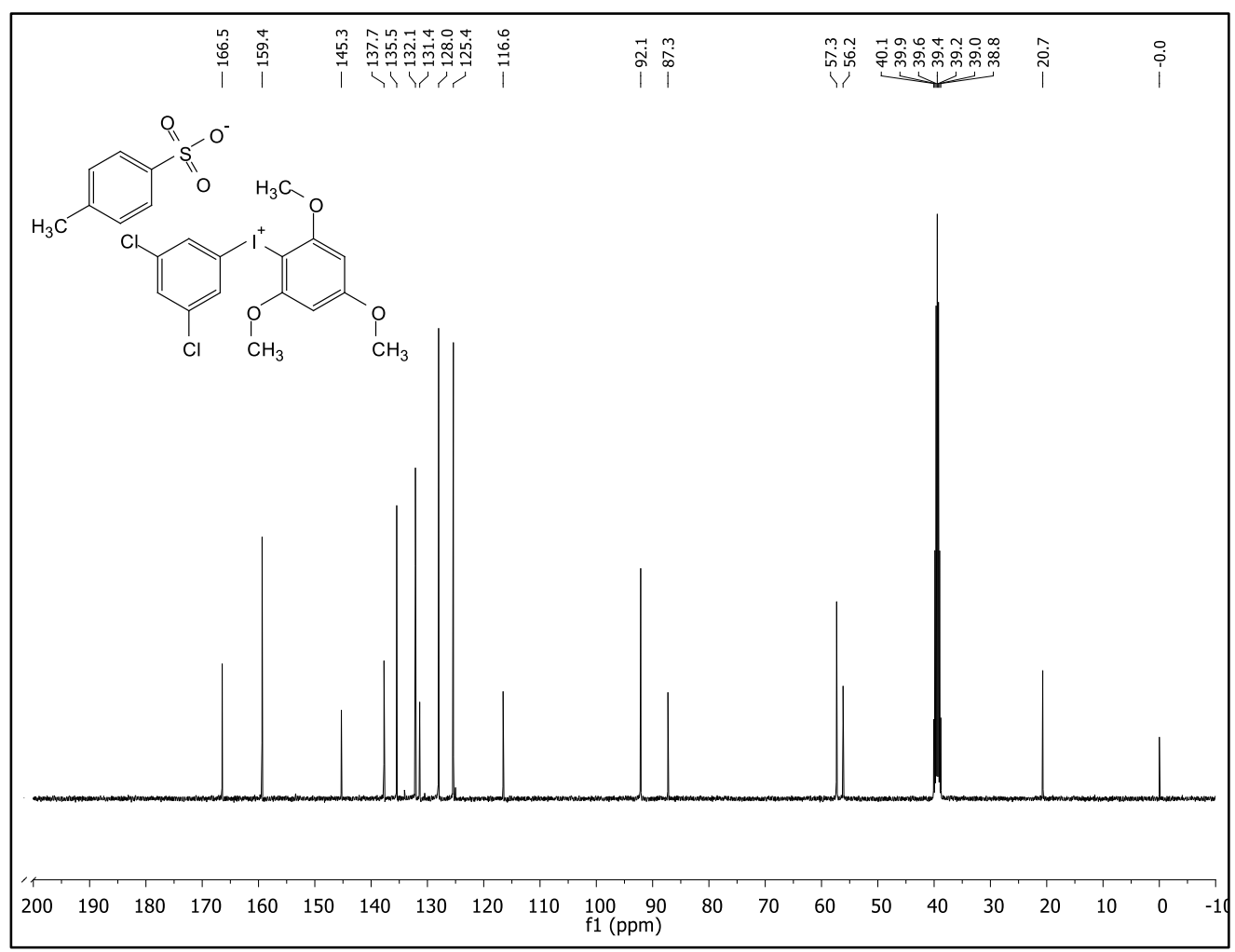

Figure 117. ${ }^{13} \mathrm{C}$ NMR spectrum of 26 at $101 \mathrm{MHz}$ in DMSO- $d_{6}$ at $298 \mathrm{~K}$ 


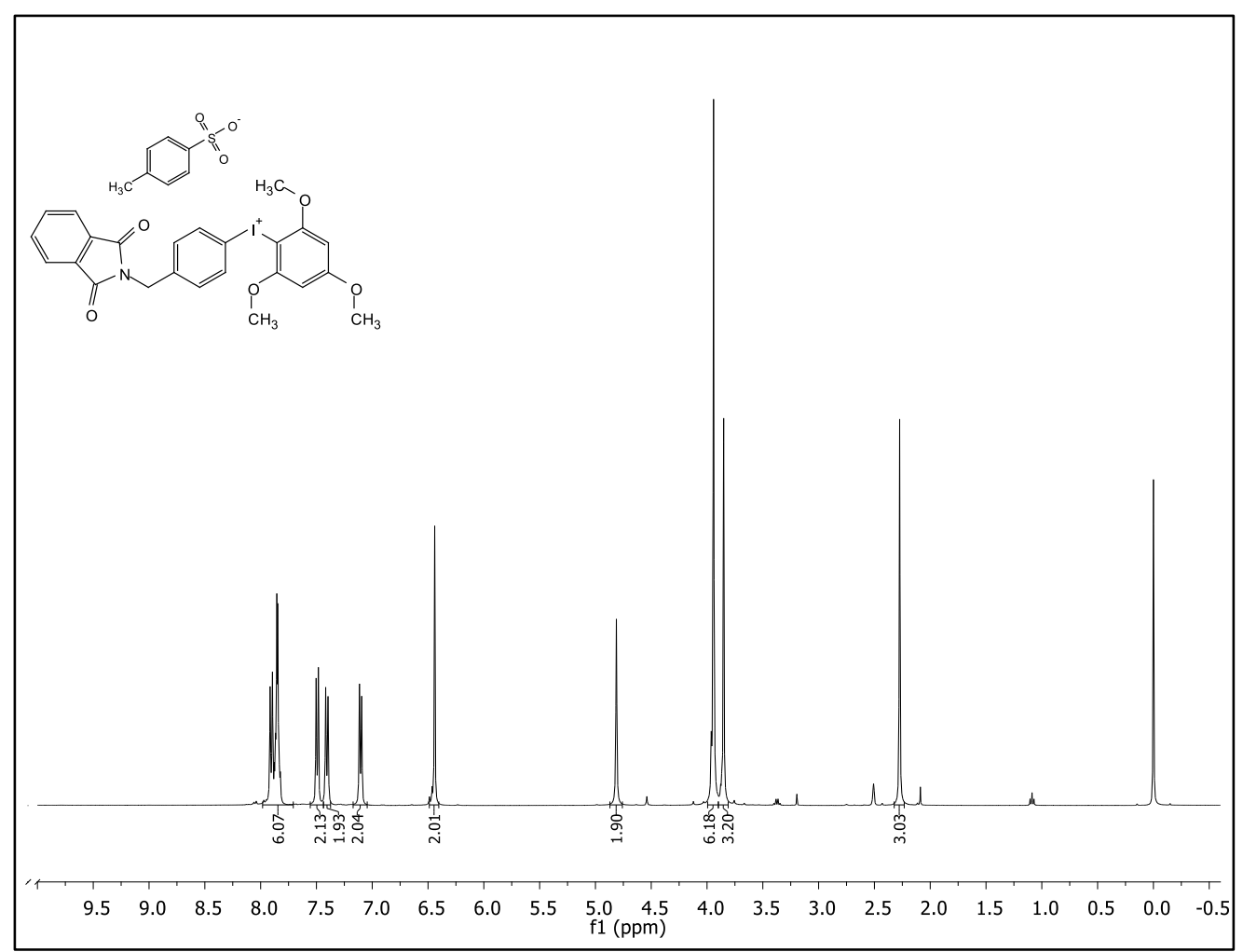

Figure 118. ${ }^{1} \mathrm{H}$ NMR spectrum of 27 at $400 \mathrm{MHz}$ in DMSO- $d_{6}$ at $298 \mathrm{~K}$

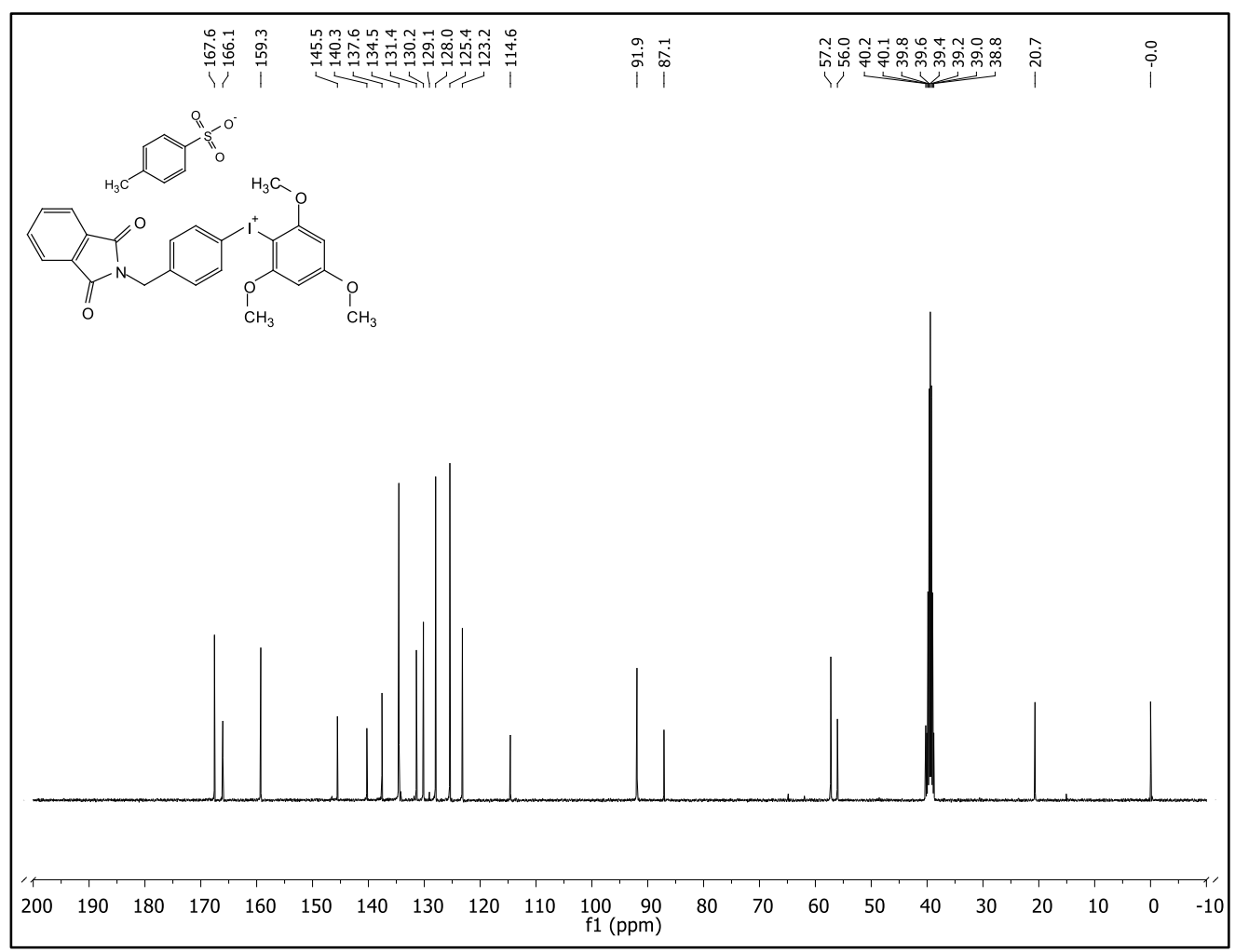

Figure 119. ${ }^{13} \mathrm{C}$ NMR spectrum of 27 at $101 \mathrm{MHz}$ in DMSO- $d_{6}$ at $298 \mathrm{~K}$ 


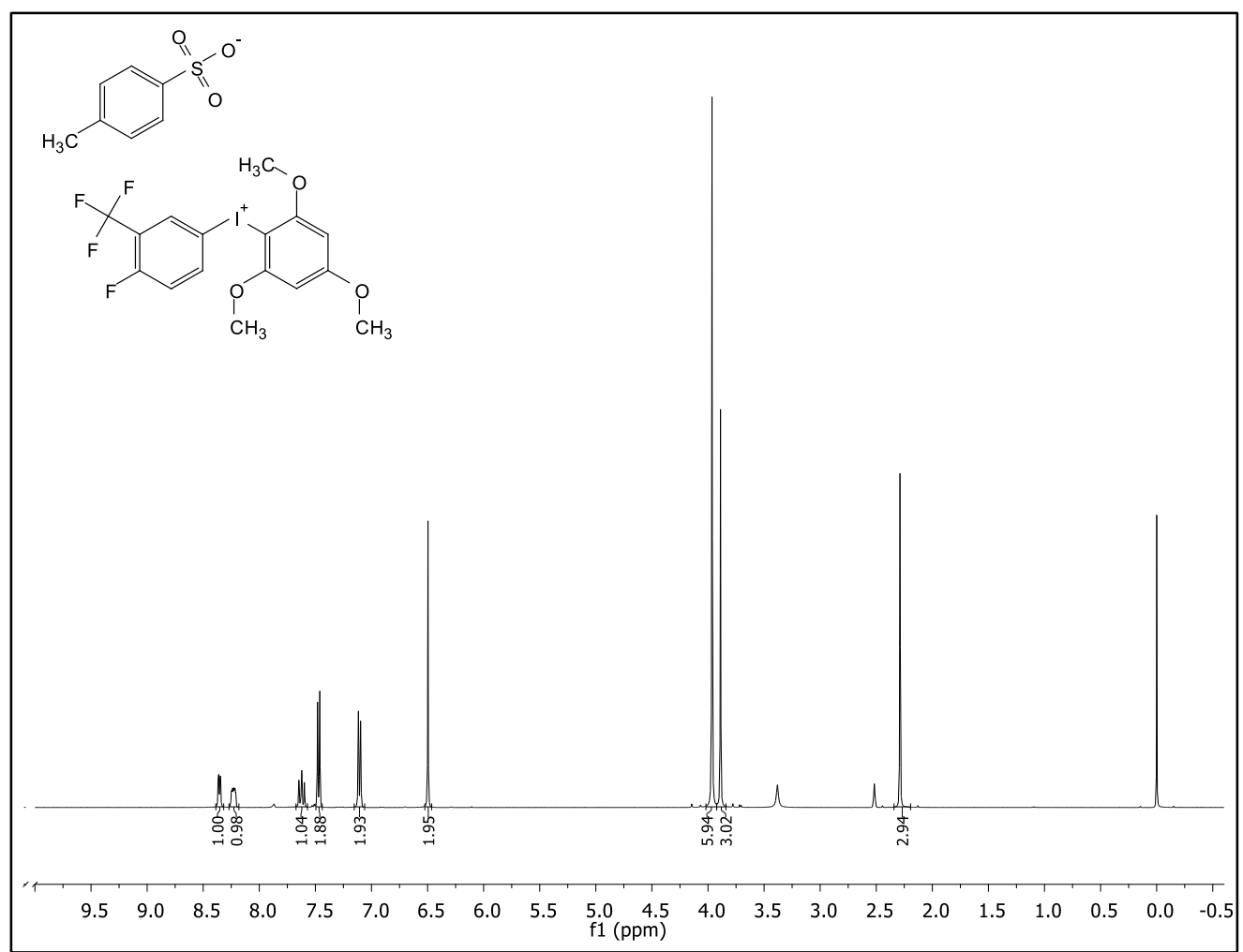

Figure 120. ${ }^{1} \mathrm{H}$ NMR spectrum of 28 at $400 \mathrm{MHz}$ in DMSO-d $d_{6}$ at $298 \mathrm{~K}$

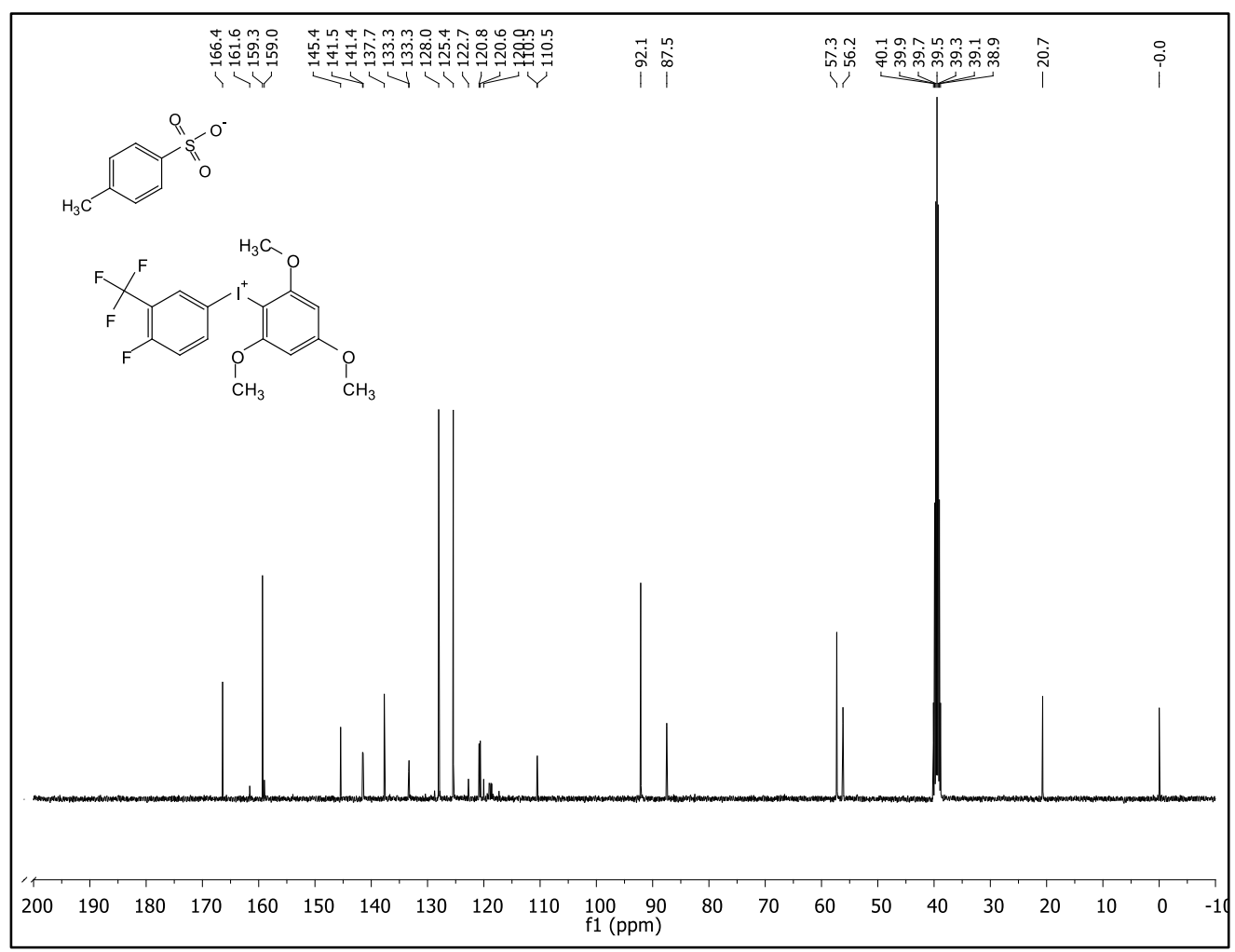

Figure $121 .{ }^{13} \mathrm{C}$ NMR spectrum of 28 at $101 \mathrm{MHz}$ in DMSO- $d_{6}$ at $298 \mathrm{~K}$ 


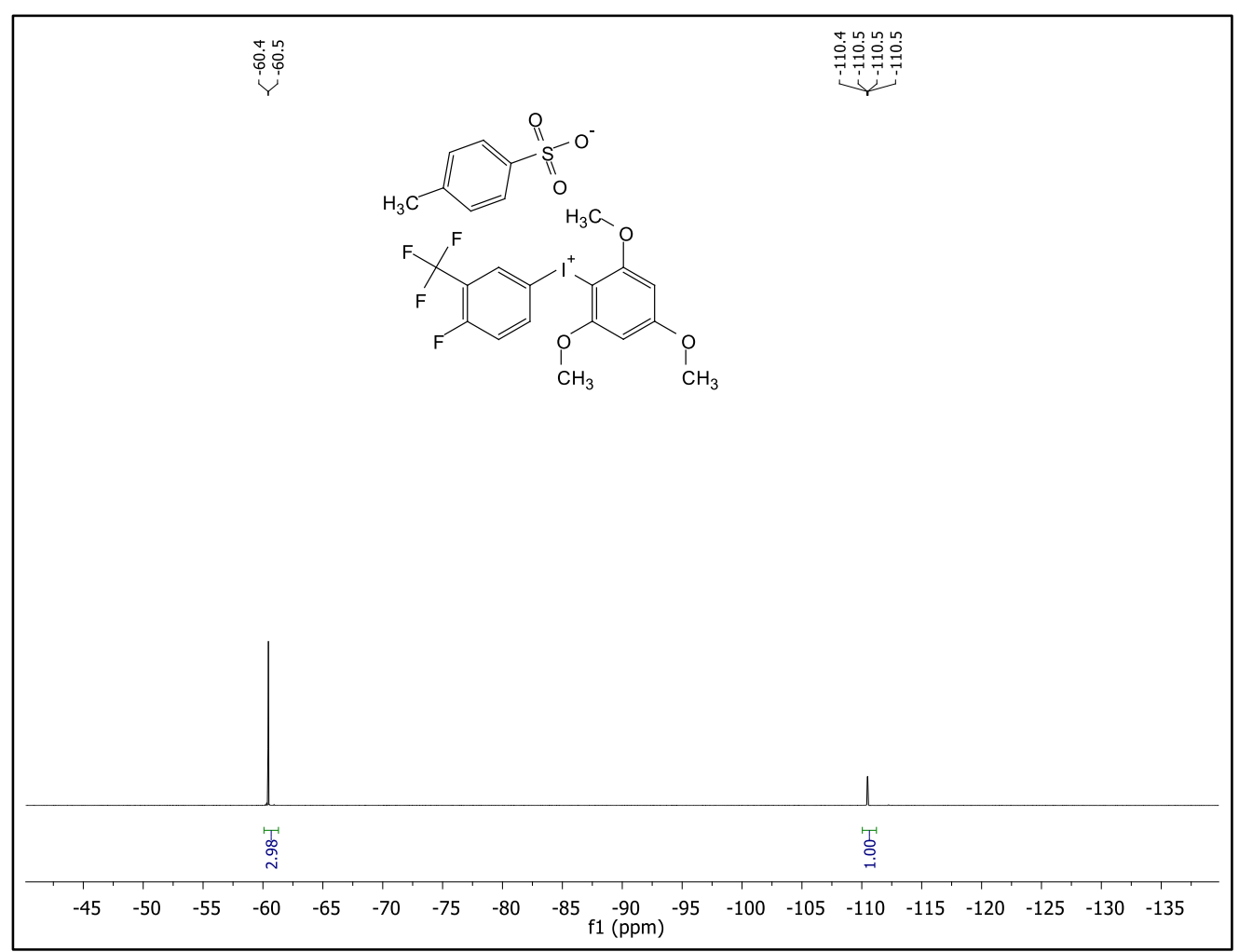

Figure 122. ${ }^{19} \mathrm{~F}$ NMR spectrum of 28 at $376 \mathrm{MHz}$ in DMSO- $d_{6}$ at $298 \mathrm{~K}$

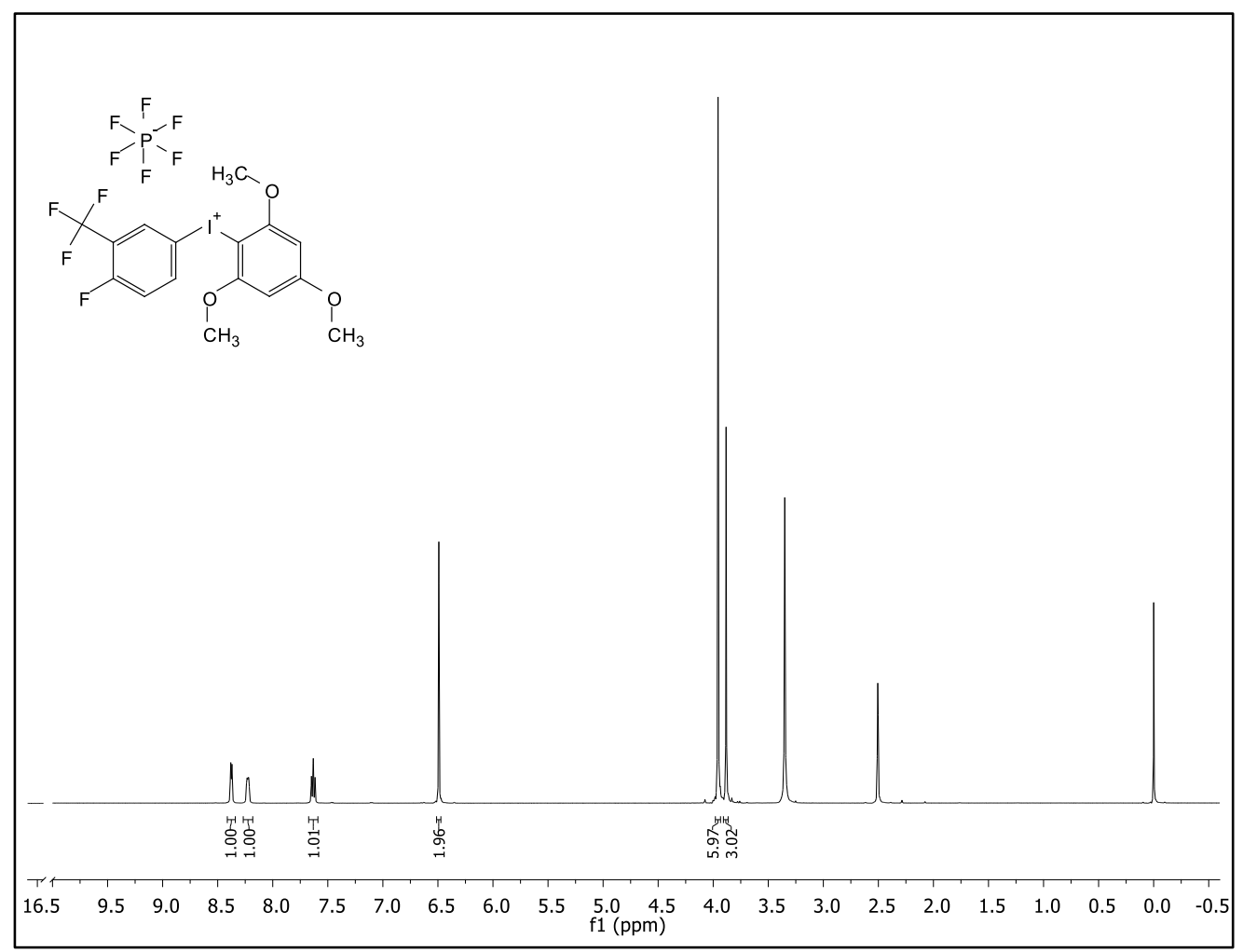

Figure 123. ${ }^{1} \mathrm{H}$ NMR spectrum of $28-\mathrm{PF}_{6}$ at $600 \mathrm{MHz}$ in DMSO- $d_{6}$ at $298 \mathrm{~K}$ 


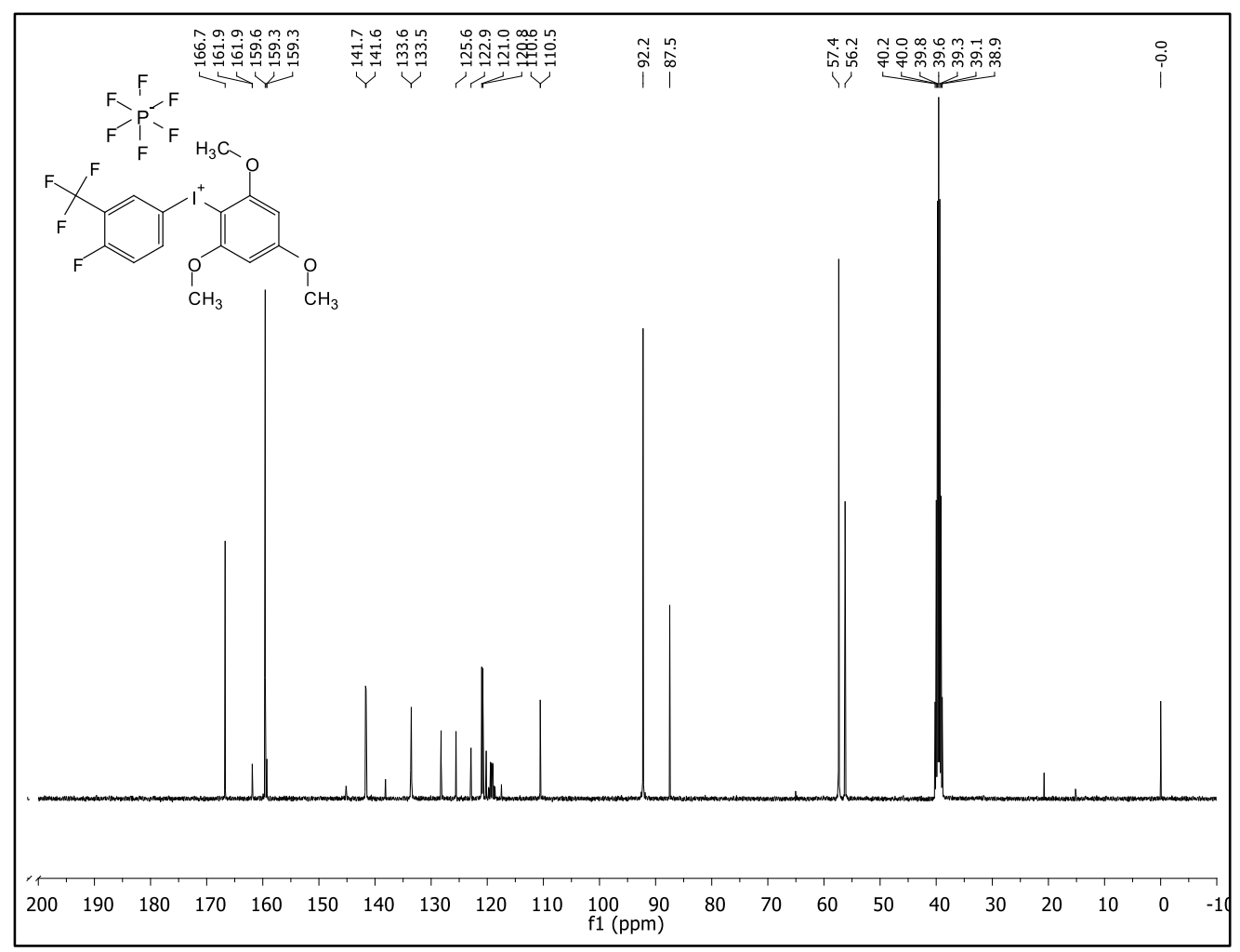

Figure 124. ${ }^{13} \mathrm{C}$ NMR spectrum of $28-\mathrm{PF}_{6}$ at $101 \mathrm{MHz}$ in DMSO- $d_{6}$ at $298 \mathrm{~K}$

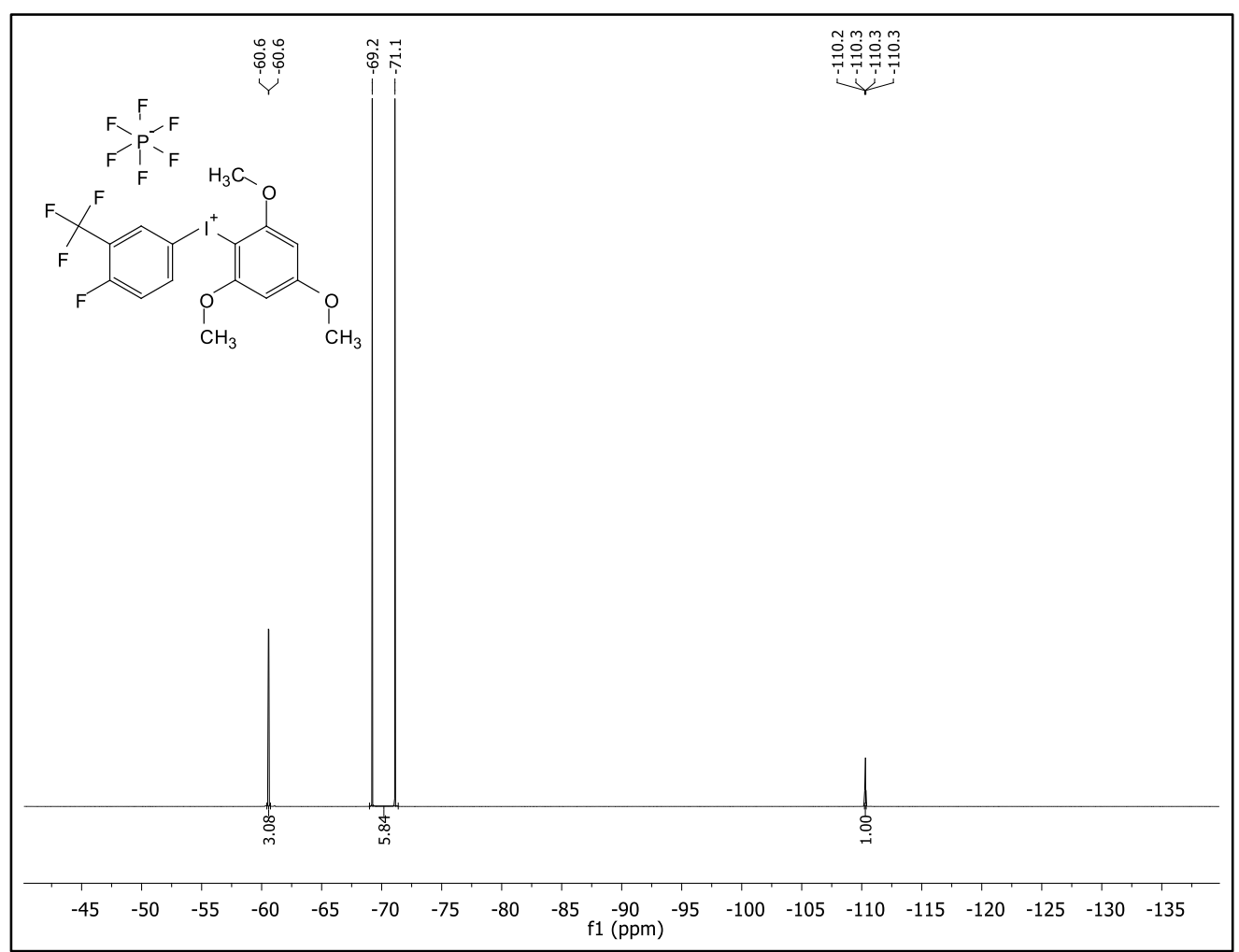

Figure 125. ${ }^{19} \mathrm{~F}$ NMR spectrum of $28-\mathrm{PF}_{6}$ at $376 \mathrm{MHz}$ in DMSO- $d_{6}$ at $298 \mathrm{~K}$ 


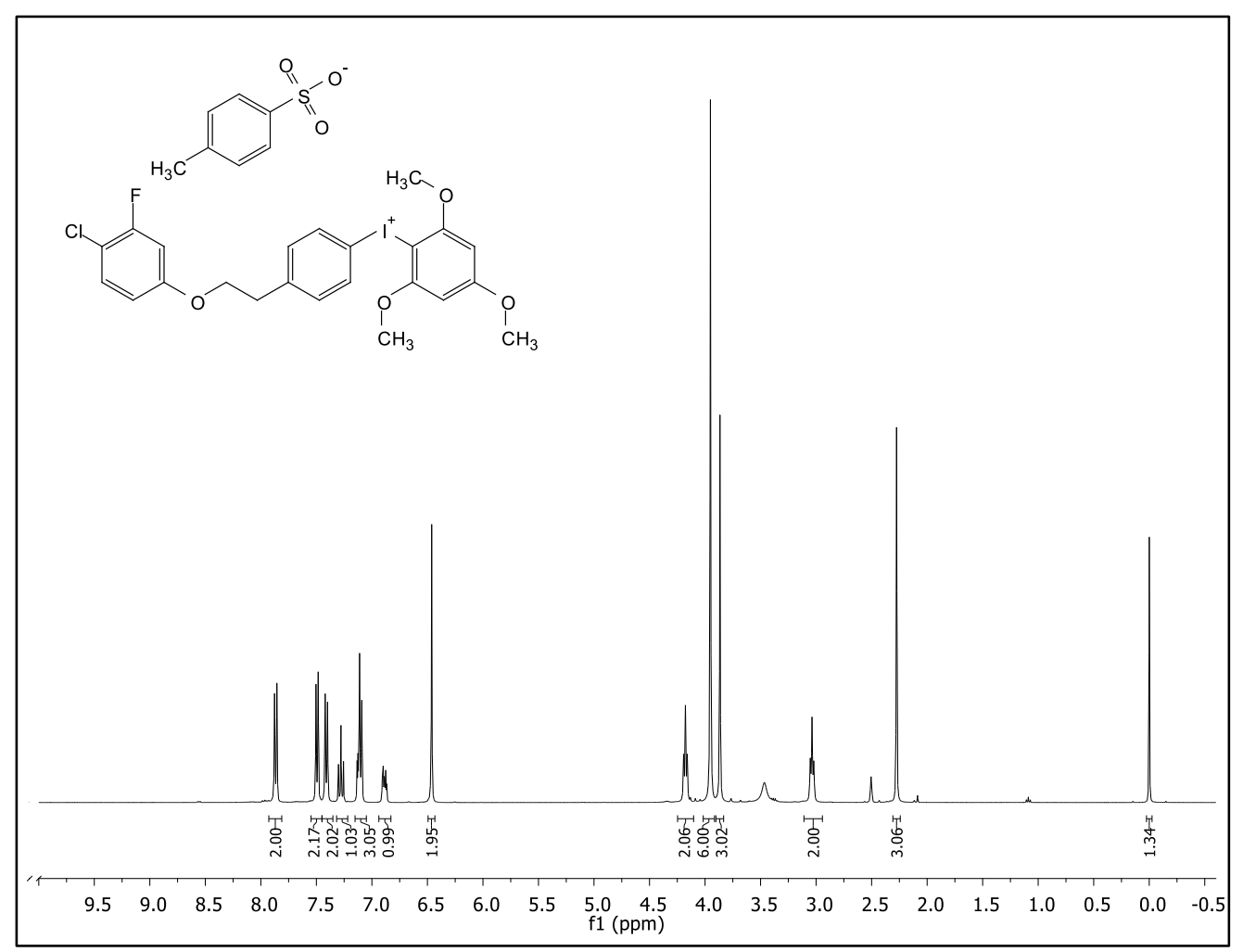

Figure 126. ${ }^{1} \mathrm{H}$ NMR spectrum of 29 at $400 \mathrm{MHz}$ in DMSO- $d_{6}$ at $298 \mathrm{~K}$

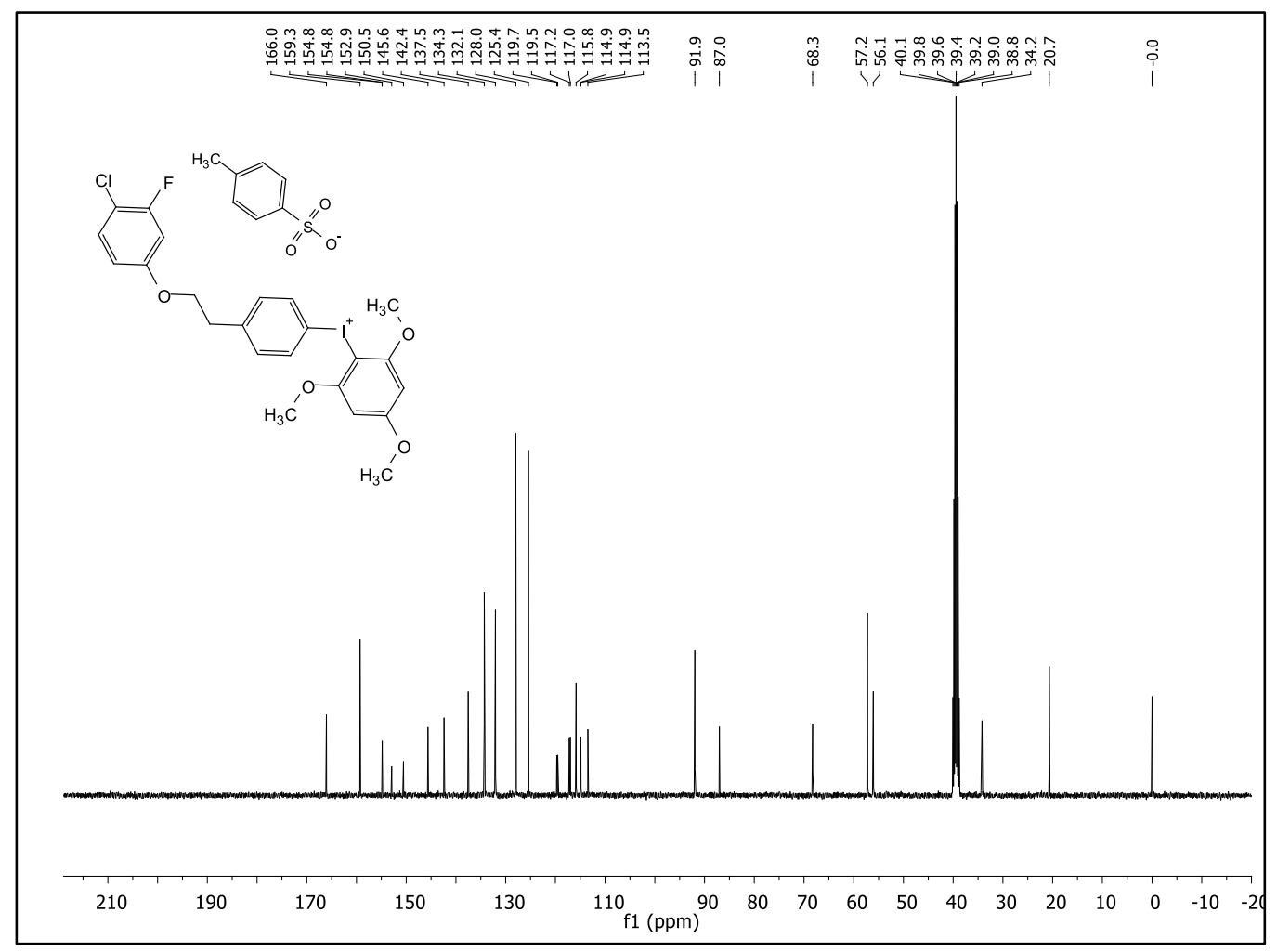

Figure 127. ${ }^{13} \mathrm{C}$ NMR spectrum of 29 at $101 \mathrm{MHz}$ in DMSO- $d_{6}$ at $298 \mathrm{~K}$

142 


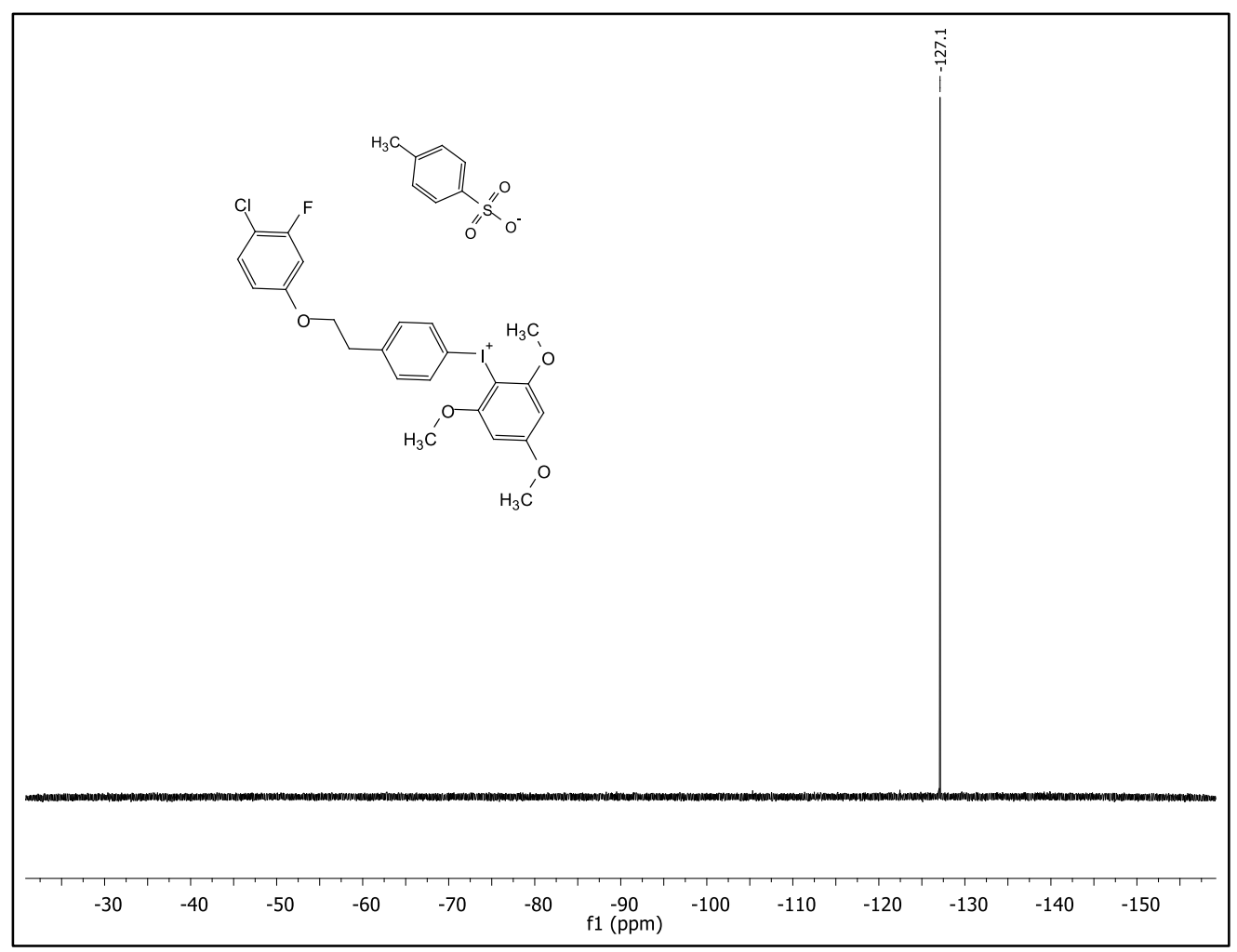

Figure $128 .{ }^{19} \mathrm{~F}$ NMR spectrum of 29 at $376 \mathrm{MHz}$ in DMSO-d $d_{6}$ at $298 \mathrm{~K}$

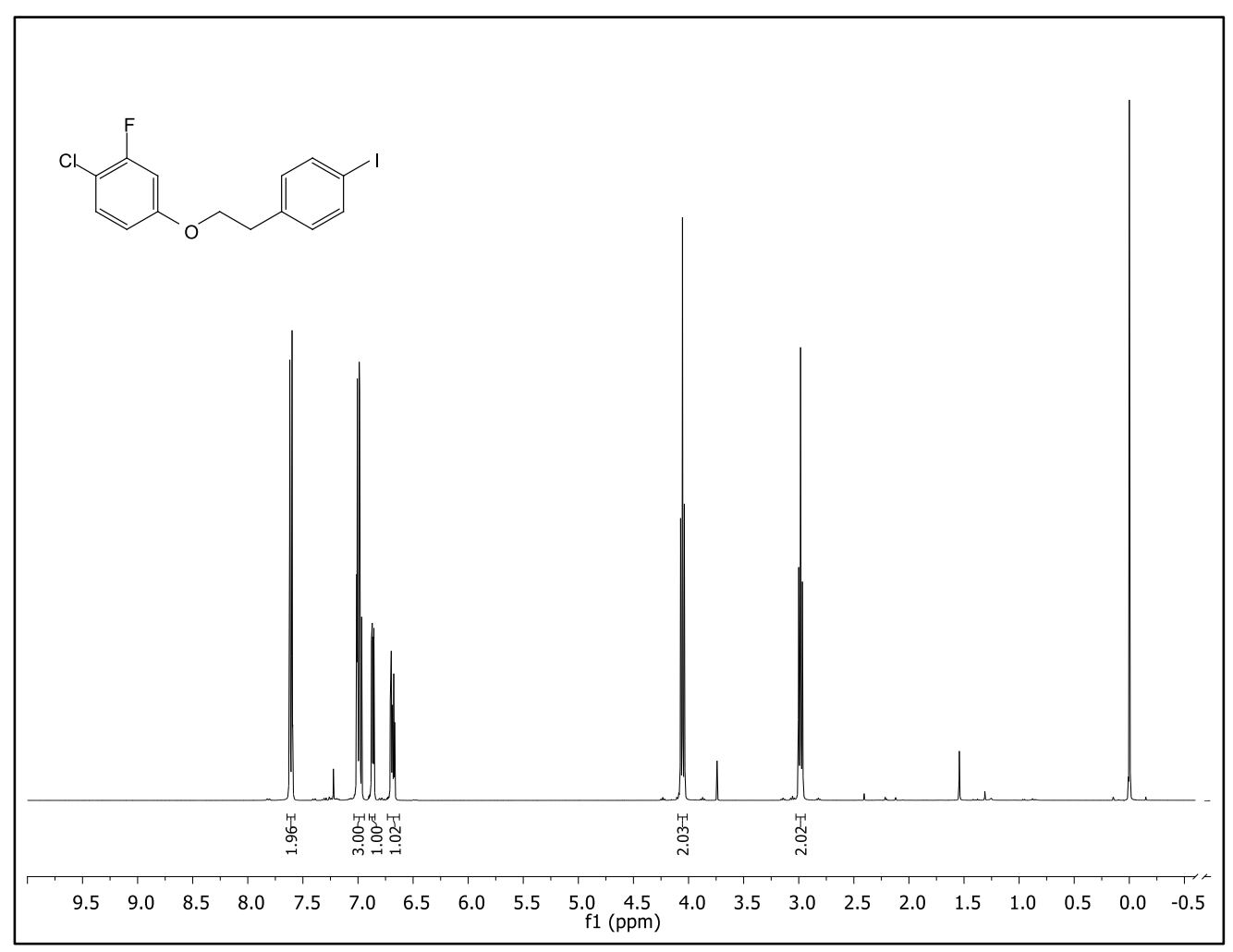

Figure 129. ${ }^{1} \mathrm{H}$ NMR spectrum of precursor for 29 at $400 \mathrm{MHz}$ in $\mathrm{CDCl}_{3}$ at $298 \mathrm{~K}$ 


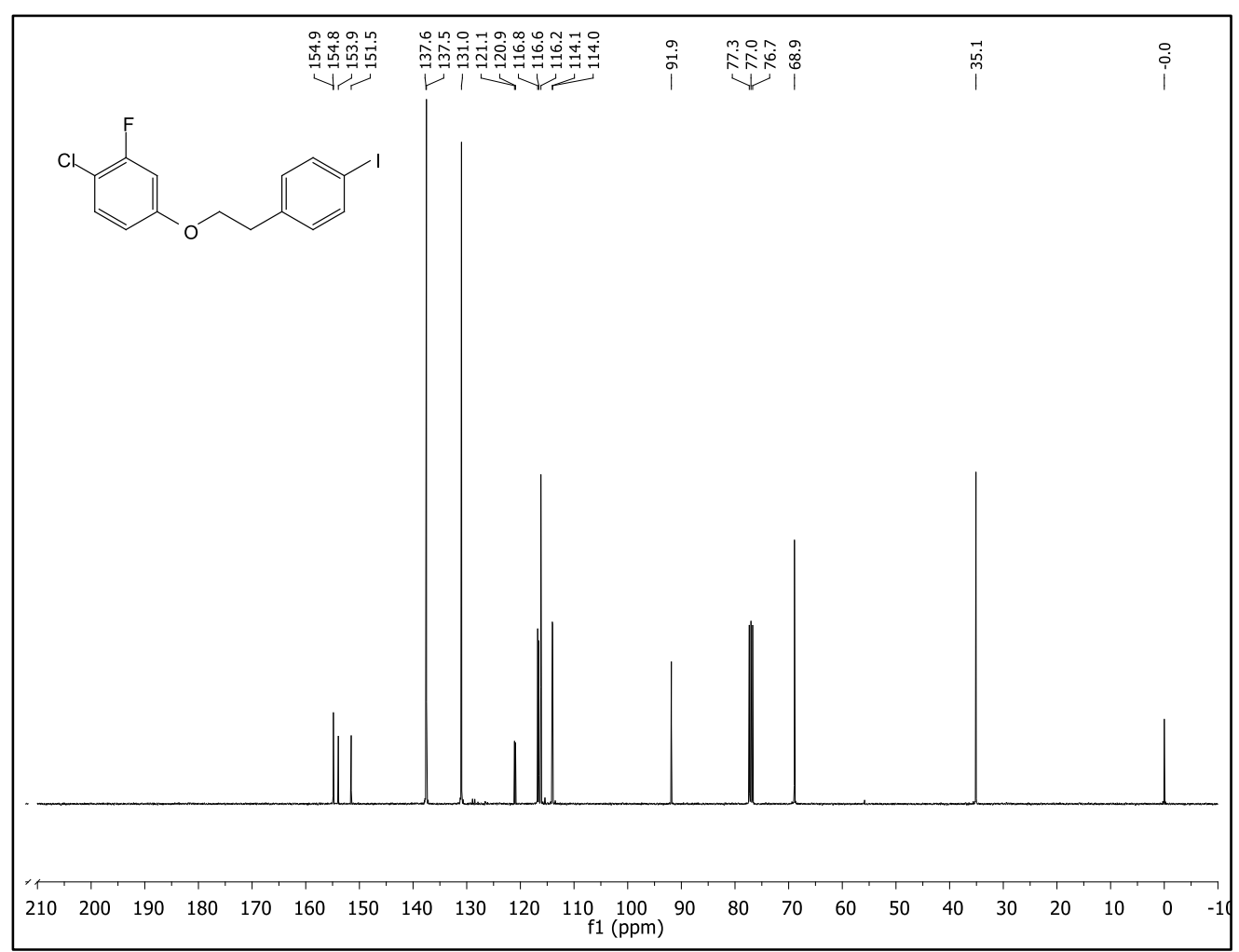

Figure 130. ${ }^{13} \mathrm{C}$ NMR spectrum of precursor for 29 at $101 \mathrm{MHz}$ in $\mathrm{CDCl}_{3}$ at $298 \mathrm{~K}$

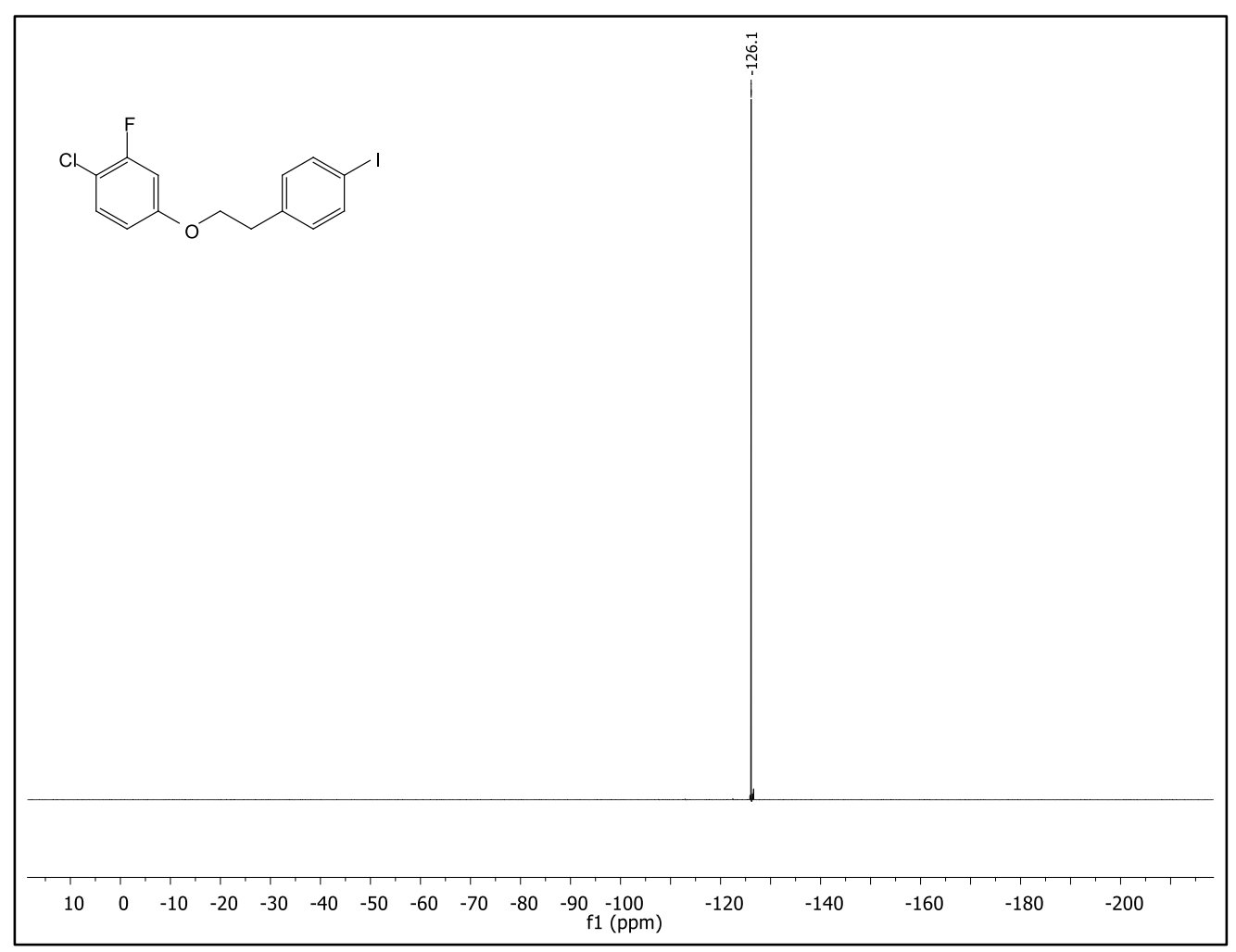

Figure 131. ${ }^{19} \mathrm{~F}$ NMR spectrum of precursor for 29 at $376 \mathrm{MHz}$ in $\mathrm{CDCl}_{3}$ at $298 \mathrm{~K}$ 


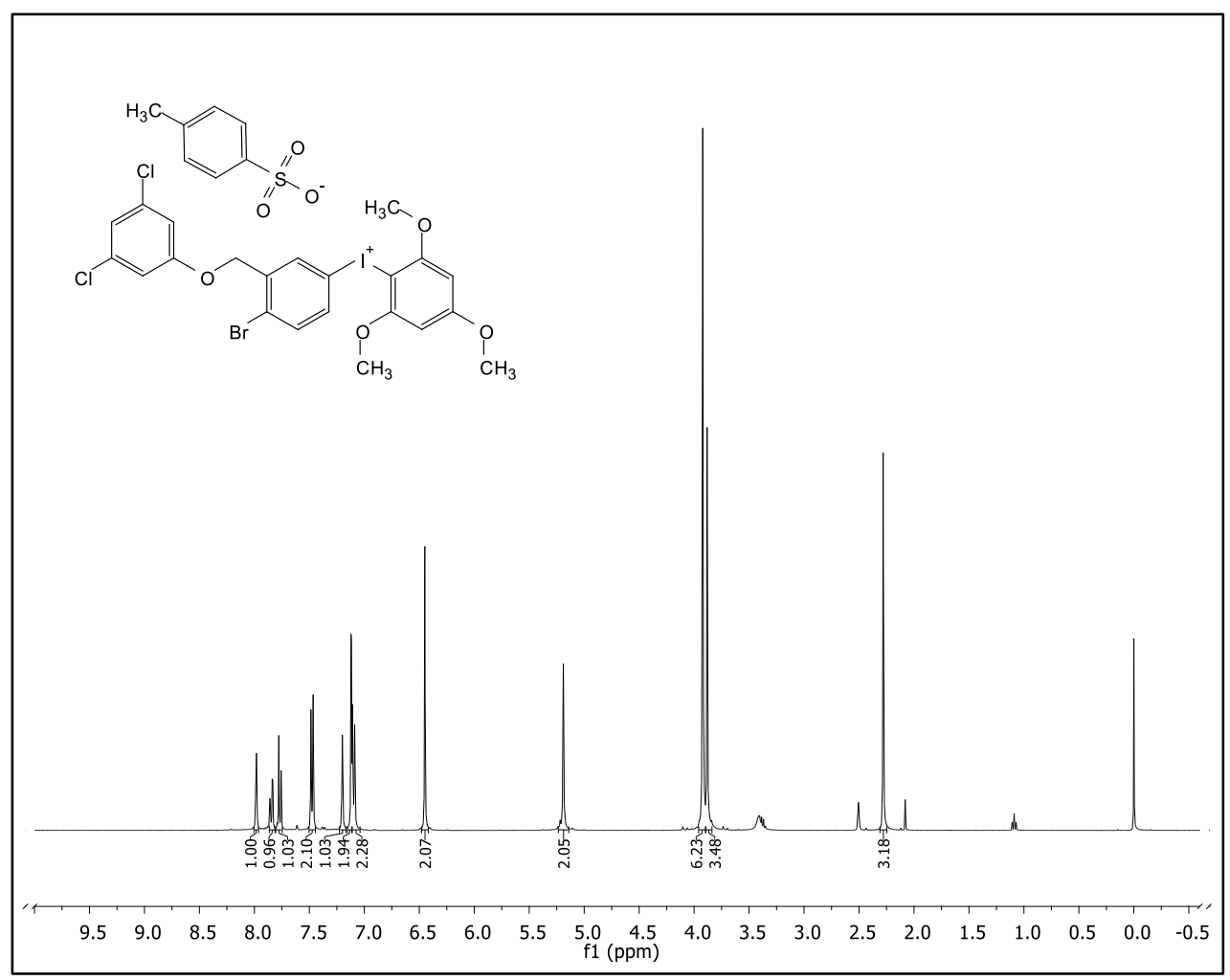

Figure 132. ${ }^{1} \mathrm{H}$ NMR spectrum of 30 at $400 \mathrm{MHz}$ in DMSO- $d_{6}$ at $298 \mathrm{~K}$

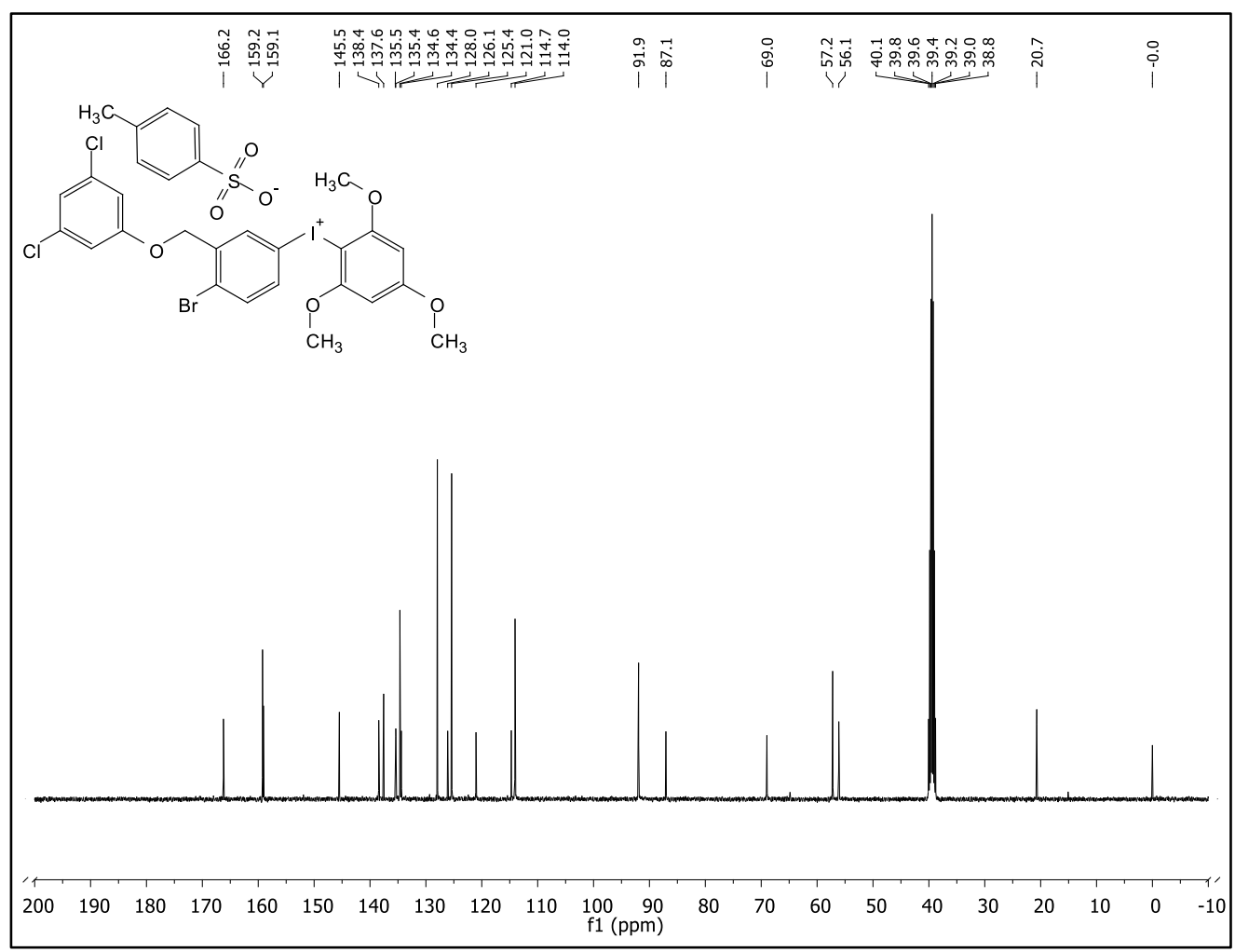

Figure $133 .{ }^{13} \mathrm{C}$ NMR spectrum of 30 at $101 \mathrm{MHz}$ in DMSO- $d_{6}$ at $298 \mathrm{~K}$ 


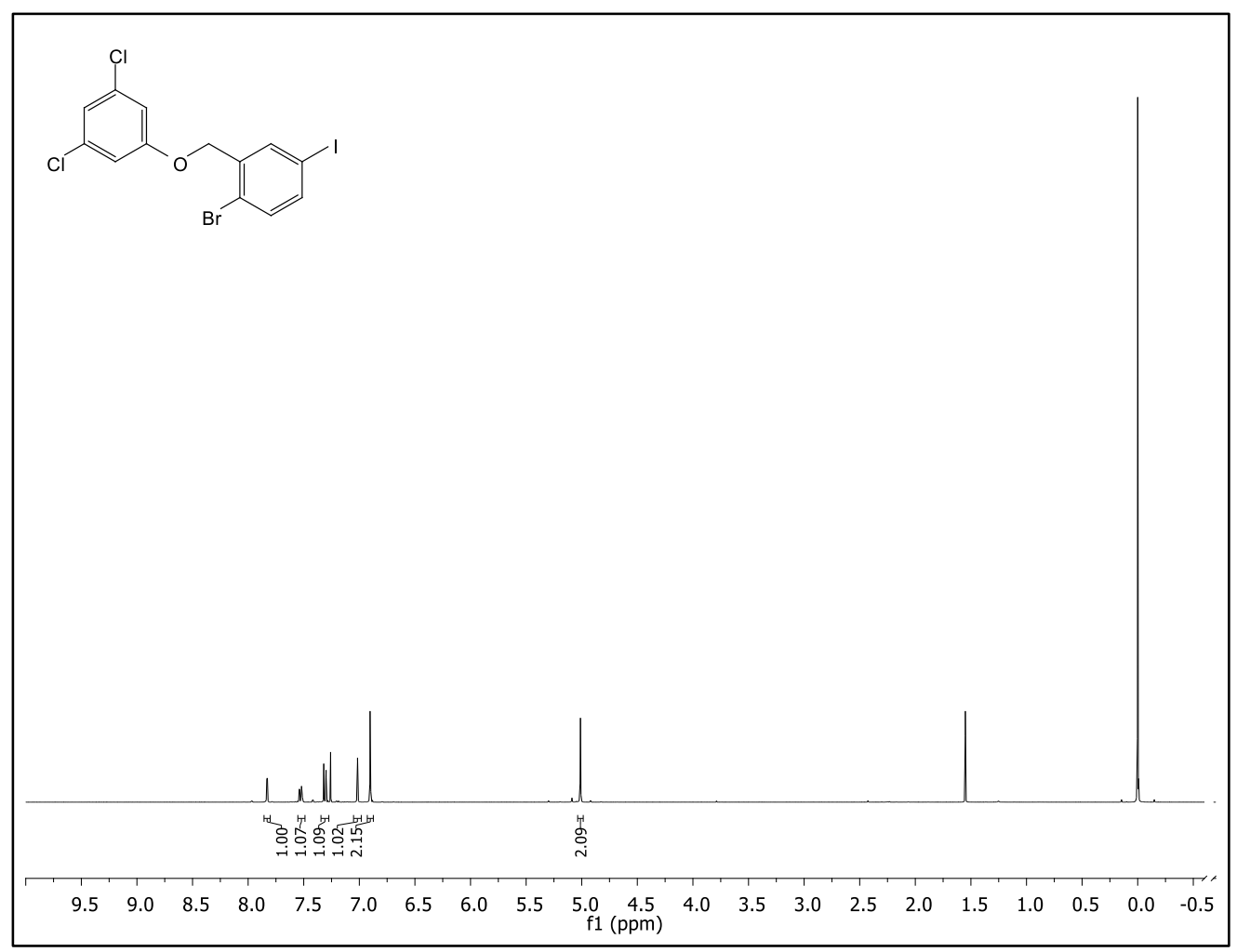

Figure 134. ${ }^{1} \mathrm{H}$ NMR spectrum of precursor for 30 at $400 \mathrm{MHz}$ in $\mathrm{CDCl}_{3}$ at $298 \mathrm{~K}$

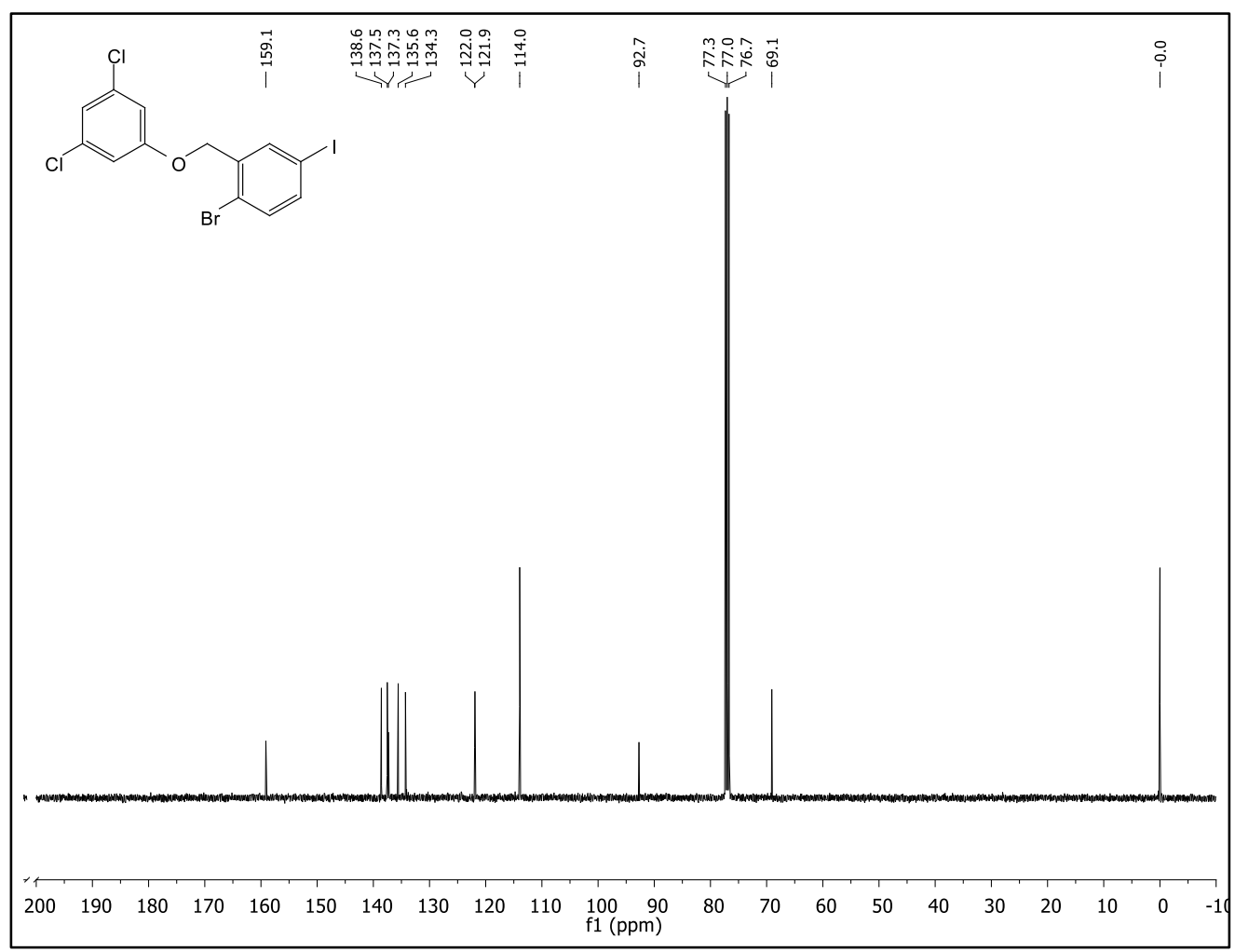

Figure 135. ${ }^{13} \mathrm{C}$ NMR spectrum of precursor for 30 at $101 \mathrm{MHz}$ in $\mathrm{CDCl}_{3}$ at $298 \mathrm{~K}$ 


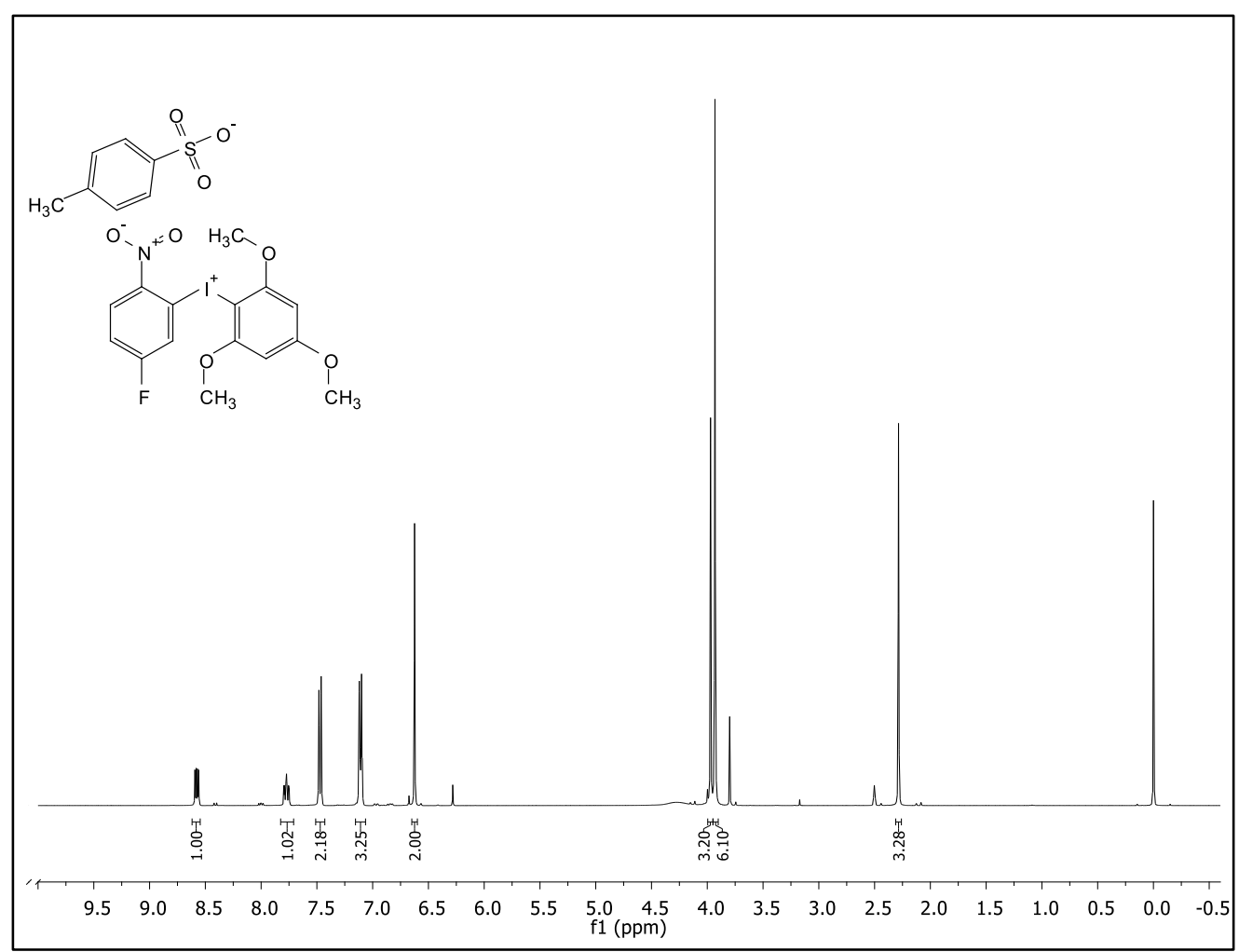

Figure 136. ${ }^{1} \mathrm{H}$ NMR spectrum of 31 at $400 \mathrm{MHz}$ in DMSO-d $d_{6}$ at $298 \mathrm{~K}$

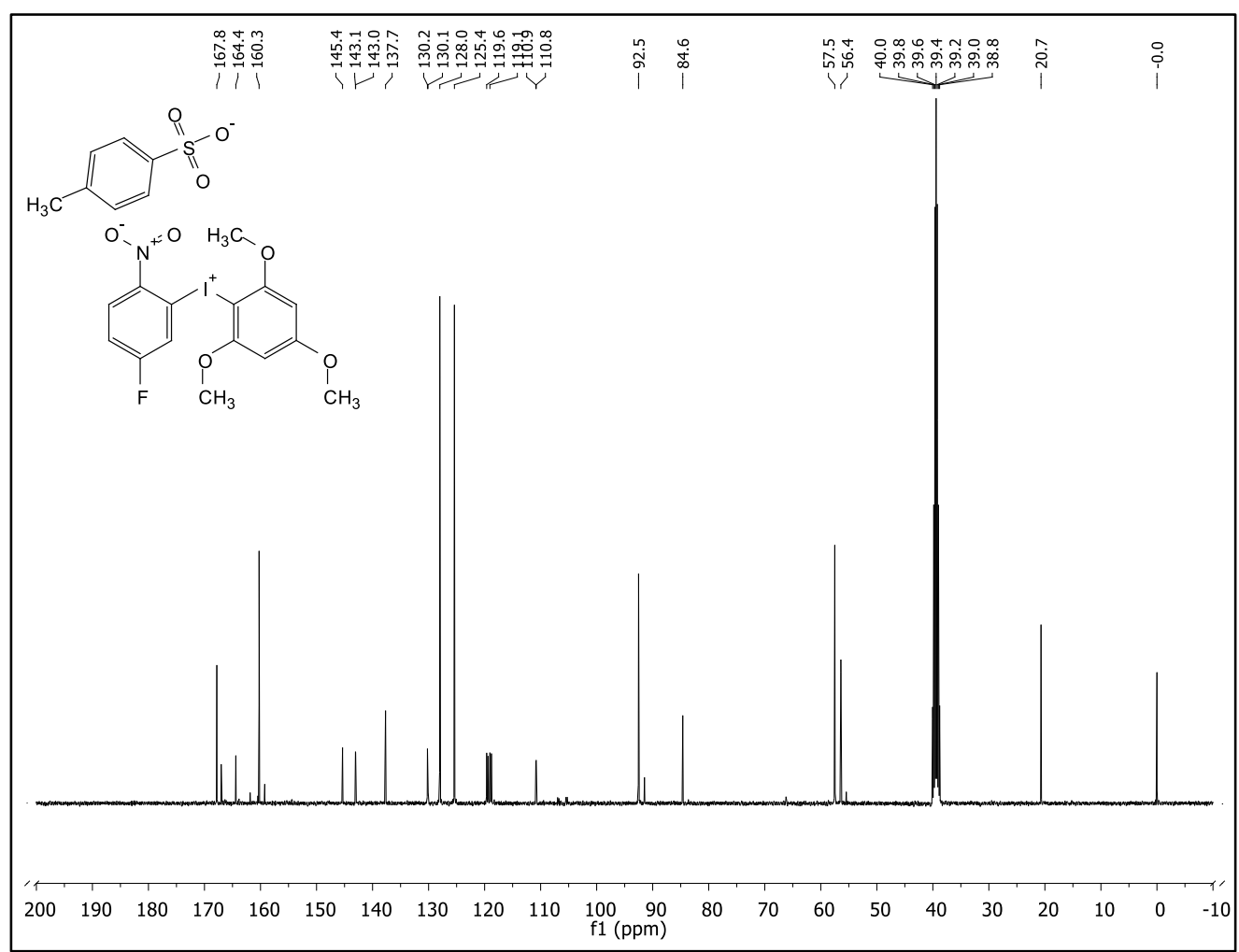

Figure 137. ${ }^{13} \mathrm{C}$ NMR spectrum of 31 at $101 \mathrm{MHz}$ in DMSO-d 6 at $298 \mathrm{~K}$ 


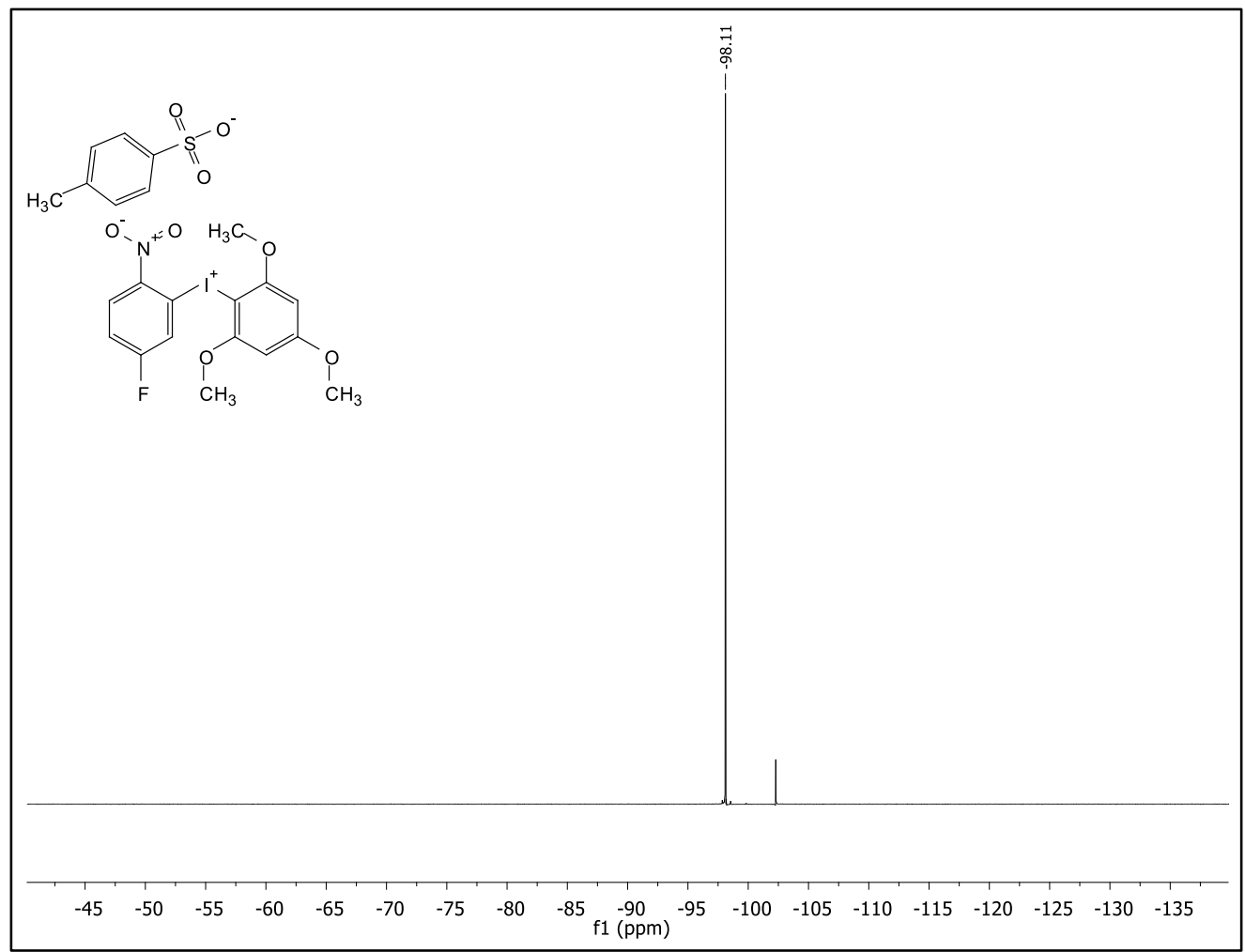

Figure 138. ${ }^{19} \mathrm{~F}$ NMR spectrum of 31 at $376 \mathrm{MHz}$ in DMSO-d $d_{6}$ at $298 \mathrm{~K}$

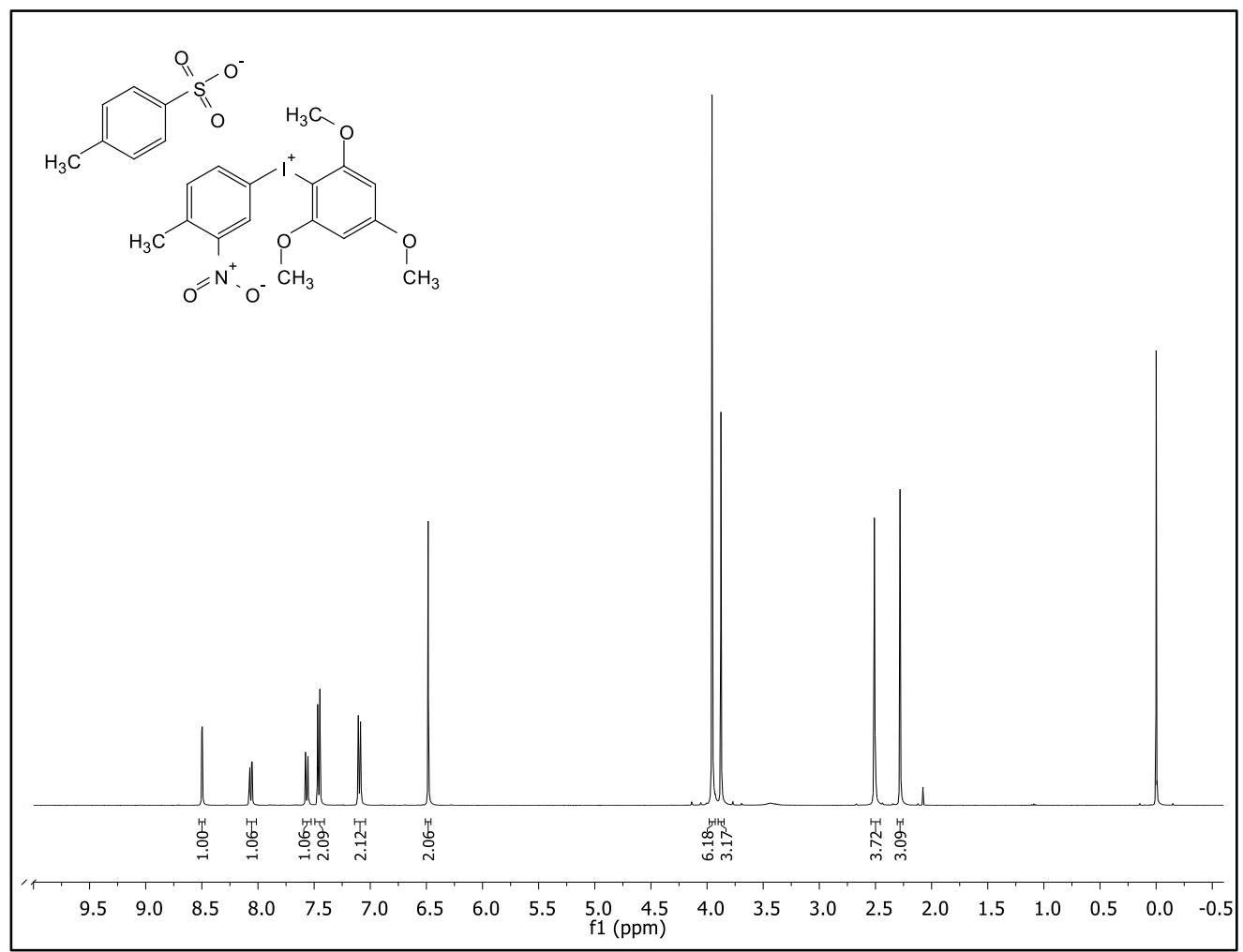

Figure 139. ${ }^{1} \mathrm{H}$ NMR spectrum of 32 at $400 \mathrm{MHz}$ in DMSO- $d_{6}$ at $298 \mathrm{~K}$ 


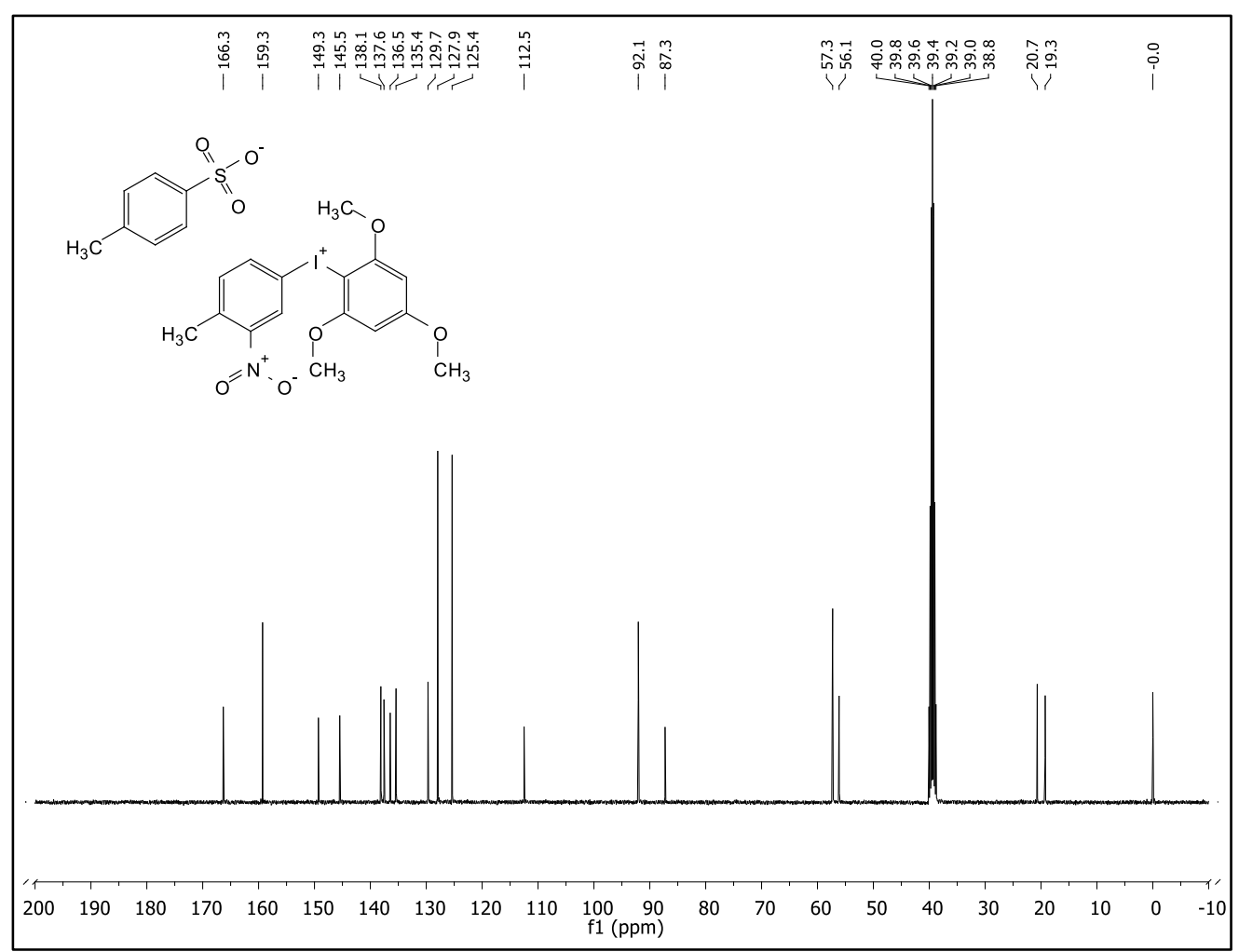

Figure $140 .{ }^{13} \mathrm{C}$ NMR spectrum of 32 at $101 \mathrm{MHz}$ in DMSO- $d_{6}$ at $298 \mathrm{~K}$

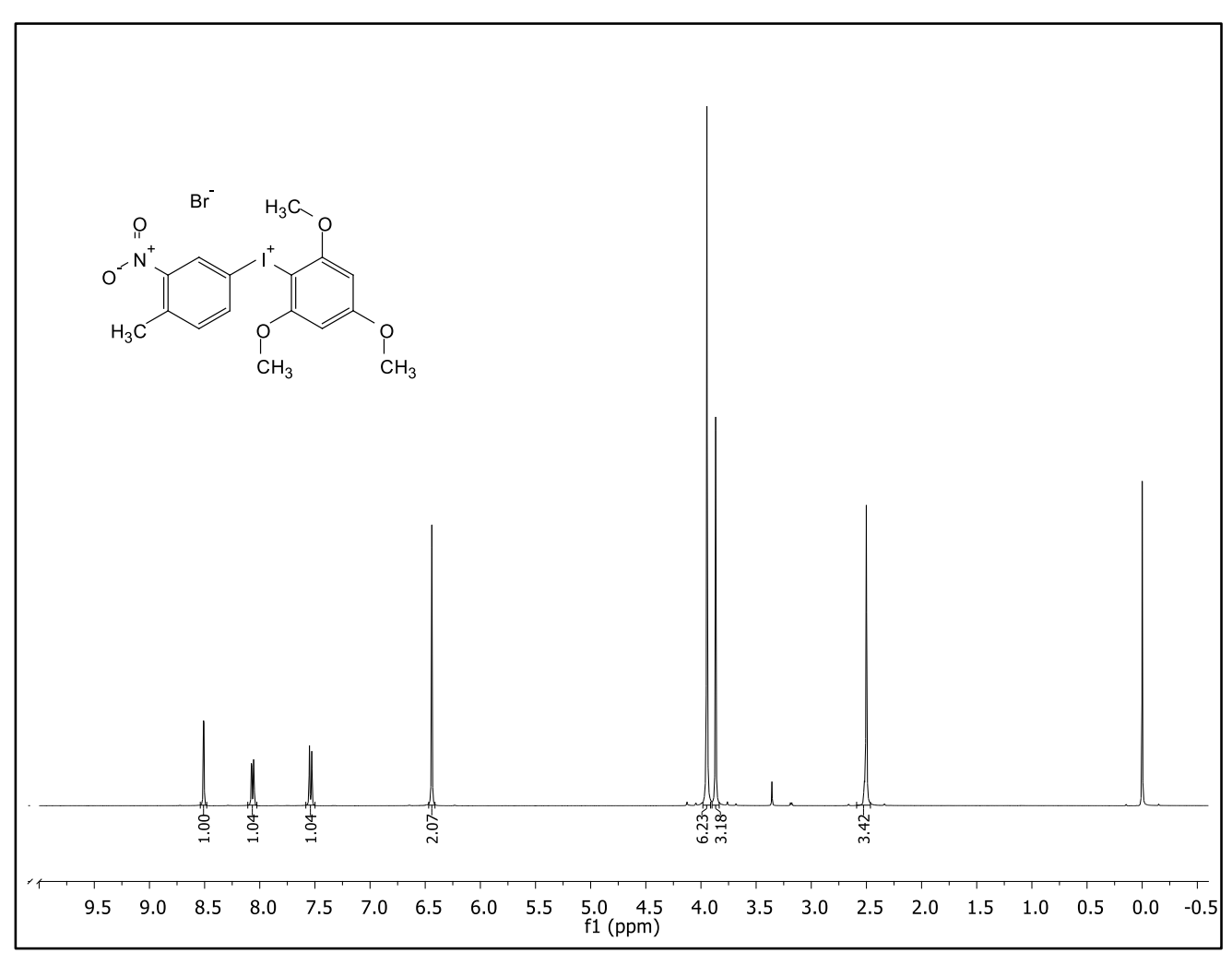

Figure 141. ${ }^{1} \mathrm{H}$ NMR spectrum of $32-\mathrm{Br}$ at $400 \mathrm{MHz}$ in DMSO-d $d_{6}$ at $298 \mathrm{~K}$ 


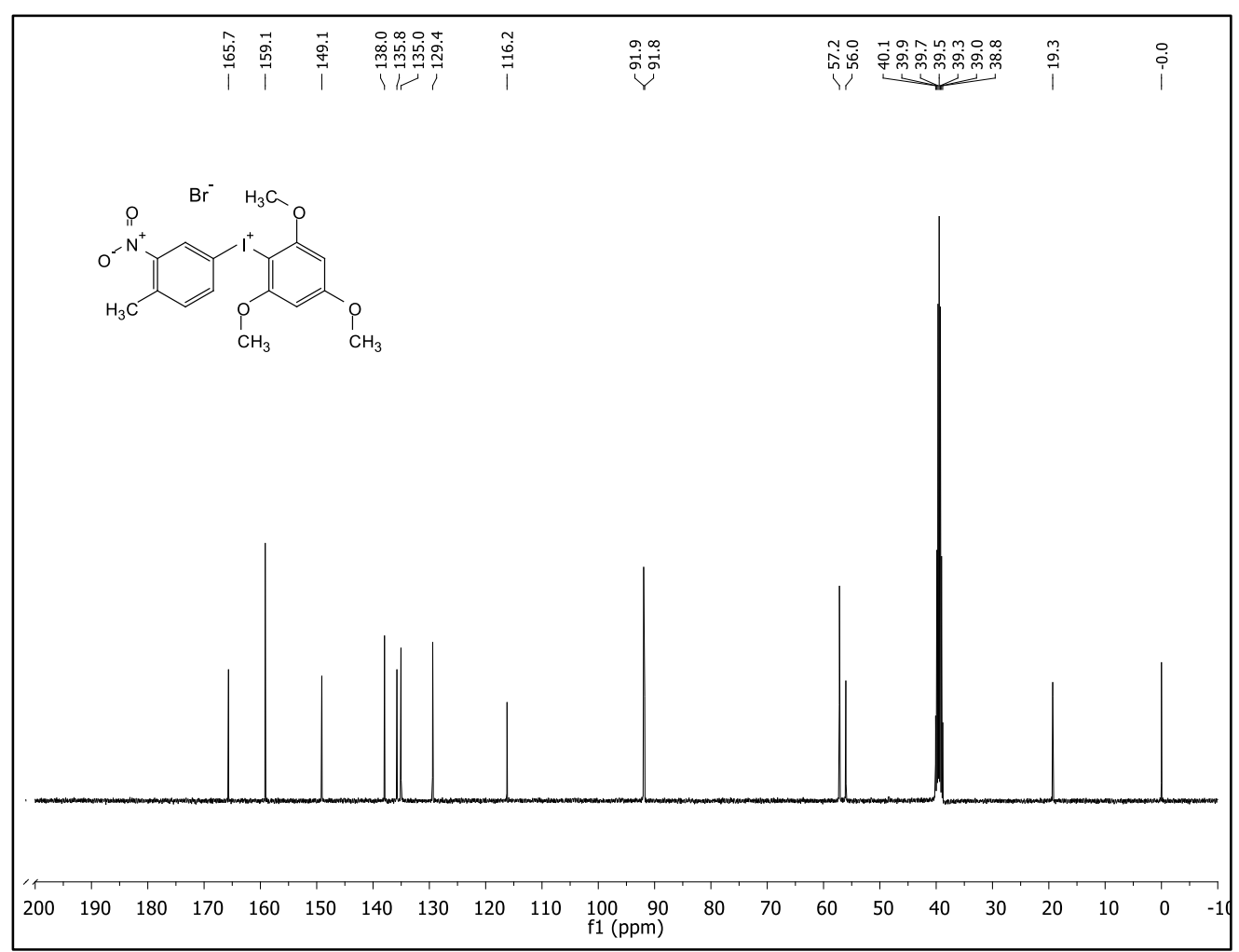

Figure $142 .{ }^{13} \mathrm{C}$ NMR spectrum of $32-\mathrm{Br}$ at $101 \mathrm{MHz}$ in DMSO-d $d_{6}$ at $298 \mathrm{~K}$

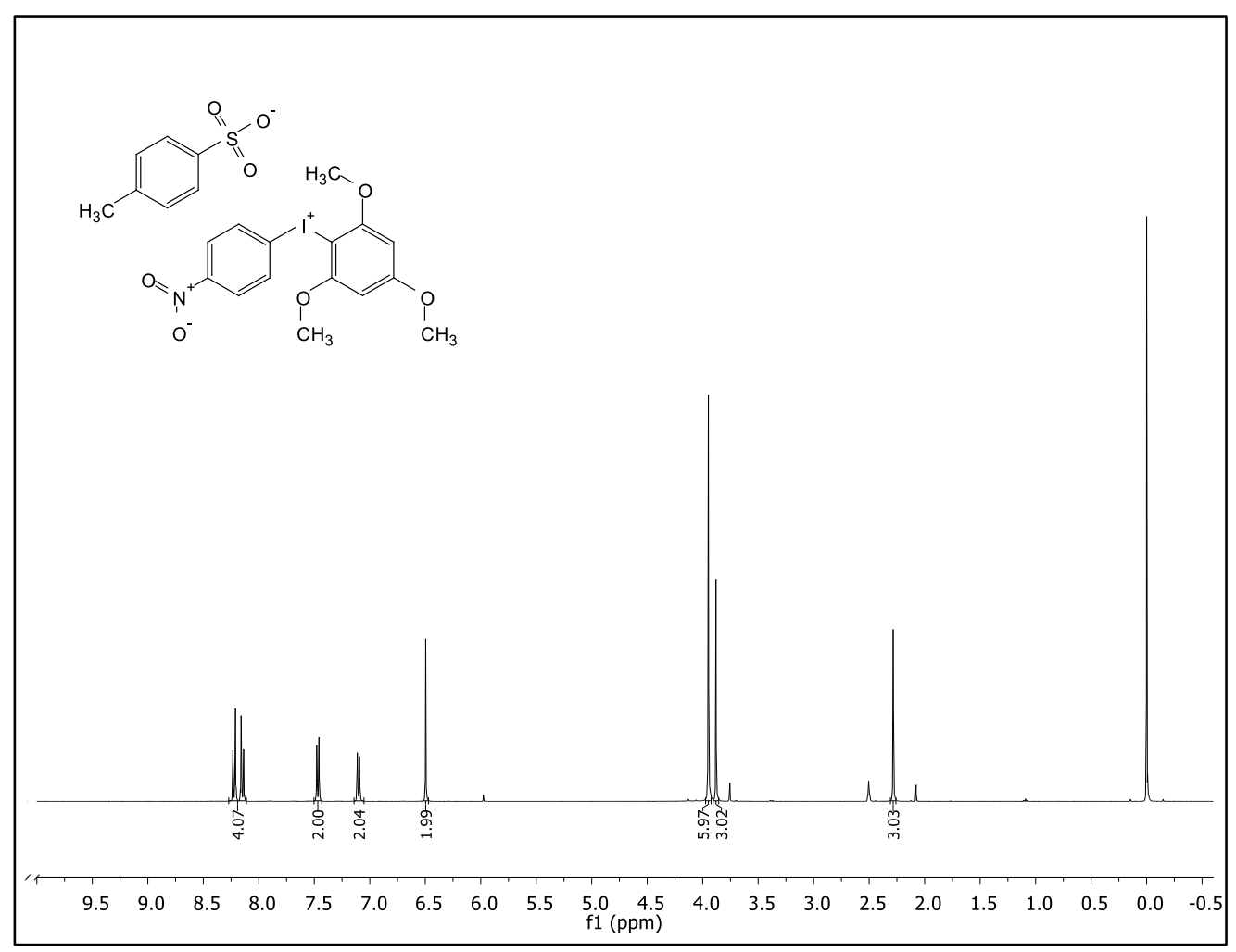

Figure $143 .{ }^{1} \mathrm{H}$ NMR spectrum of 33 at $400 \mathrm{MHz}$ in DMSO- $d_{6}$ at $298 \mathrm{~K}$ 


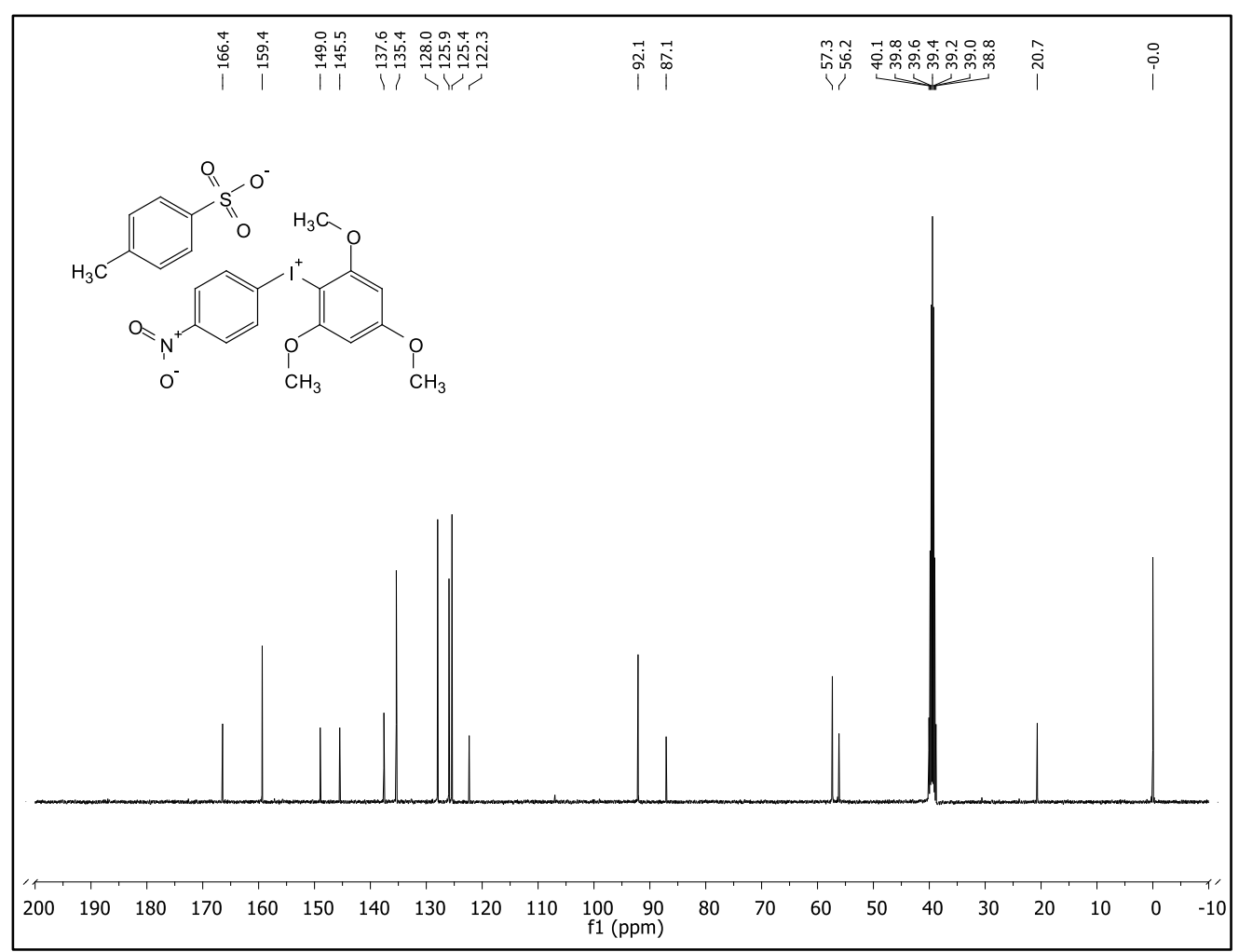

Figure $144 .{ }^{13} \mathrm{C}$ NMR spectrum of 33 at $101 \mathrm{MHz}$ in DMSO- $d_{6}$ at $298 \mathrm{~K}$

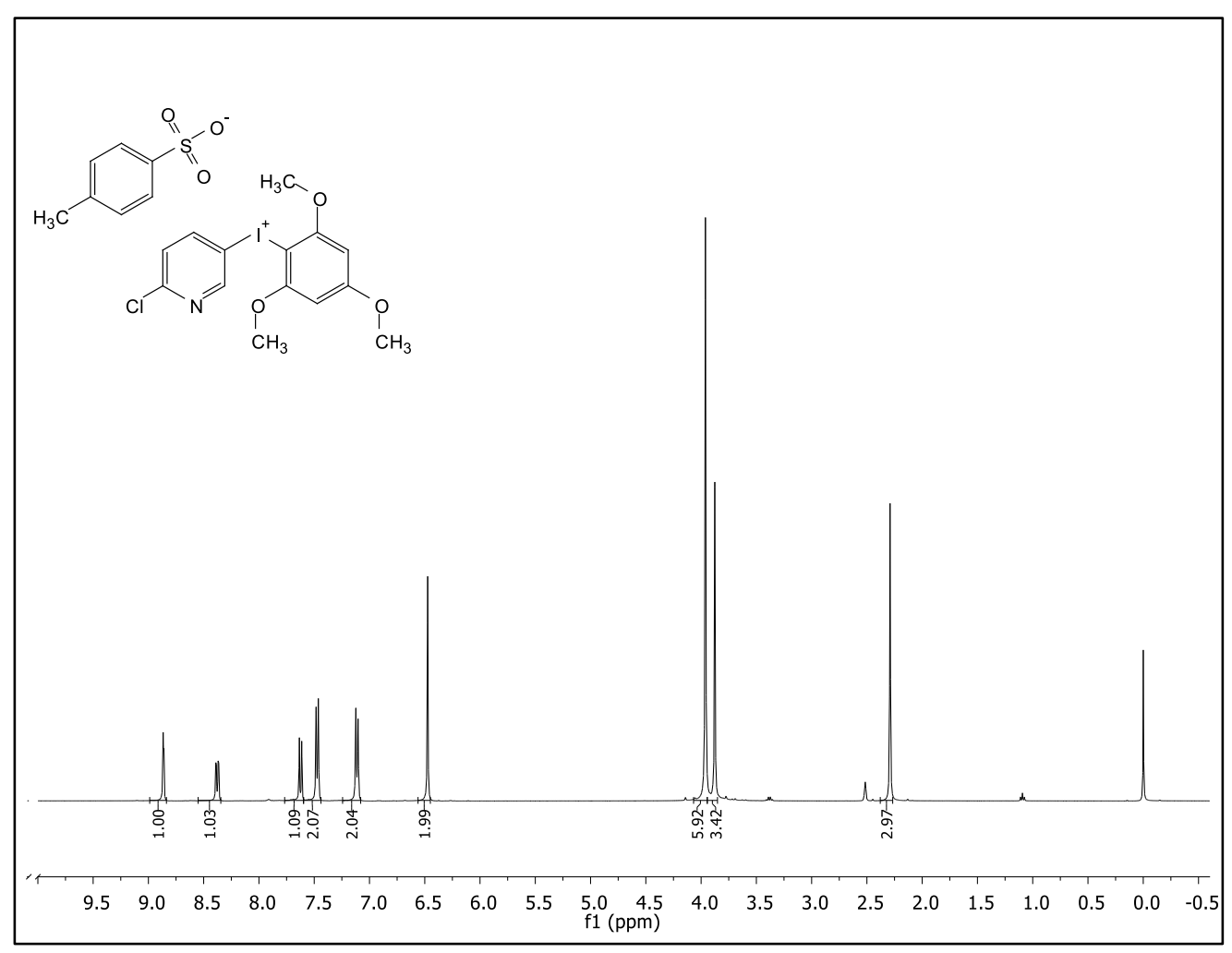

Figure $145 .{ }^{1} \mathrm{H}$ NMR spectrum of 34 at $400 \mathrm{MHz}$ in DMSO- $d_{6}$ at $298 \mathrm{~K}$ 


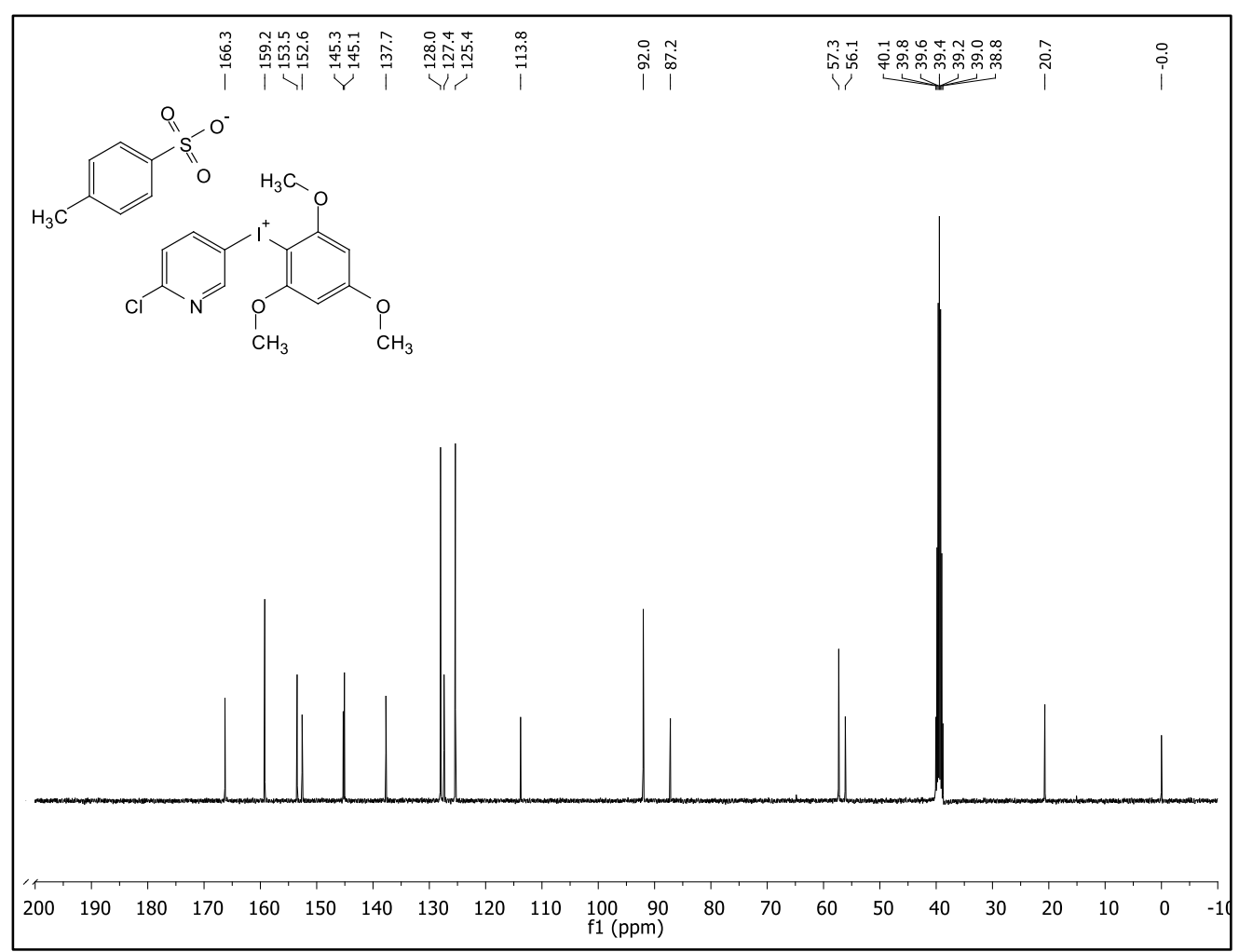

Figure $146 .{ }^{13} \mathrm{C}$ NMR spectrum of 34 at $101 \mathrm{MHz}$ in DMSO- $d_{6}$ at $298 \mathrm{~K}$

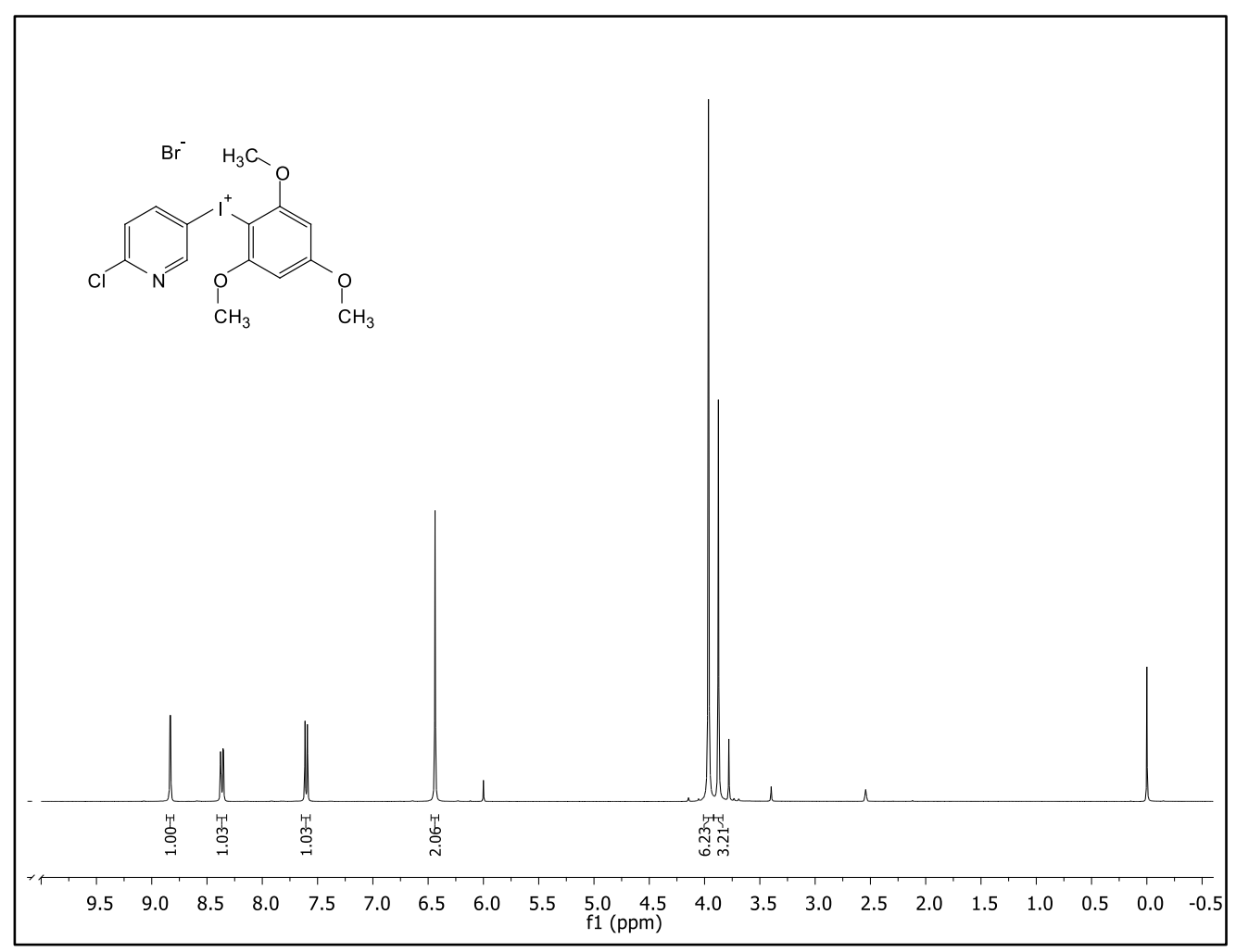

Figure 147. ${ }^{1} \mathrm{H}$ NMR spectrum of $34-\mathrm{Br}$ at $400 \mathrm{MHz}$ in DMSO-d $d_{6}$ at $298 \mathrm{~K}$ 


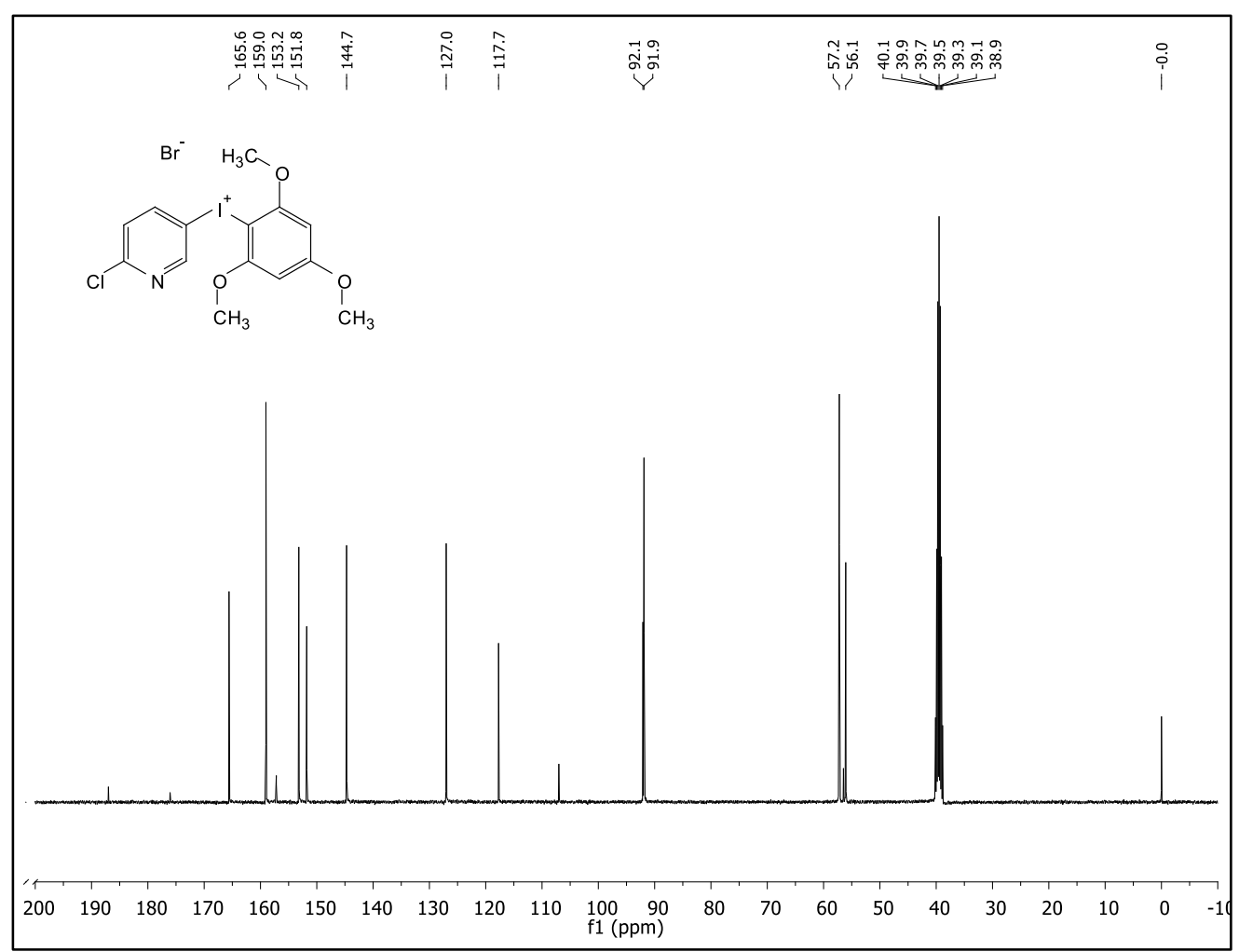

Figure $148 .{ }^{13} \mathrm{C}$ NMR spectrum of $34-\mathrm{Br}$ at $101 \mathrm{MHz}$ in DMSO-d $d_{6}$ at $298 \mathrm{~K}$

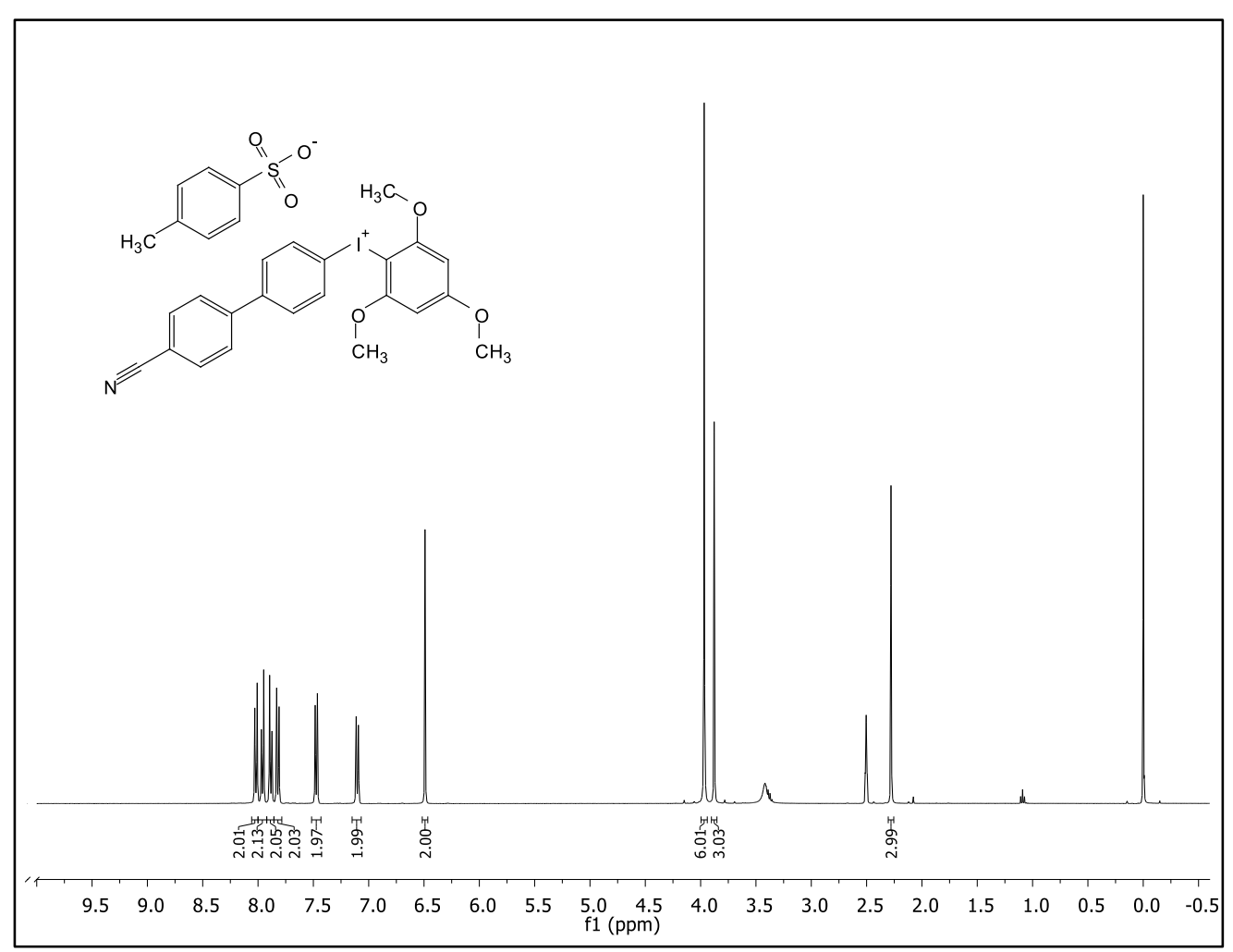

Figure 149. ${ }^{1} \mathrm{H}$ NMR spectrum of 35 at $101 \mathrm{MHz}$ in DMSO- $d_{6}$ at $298 \mathrm{~K}$ 


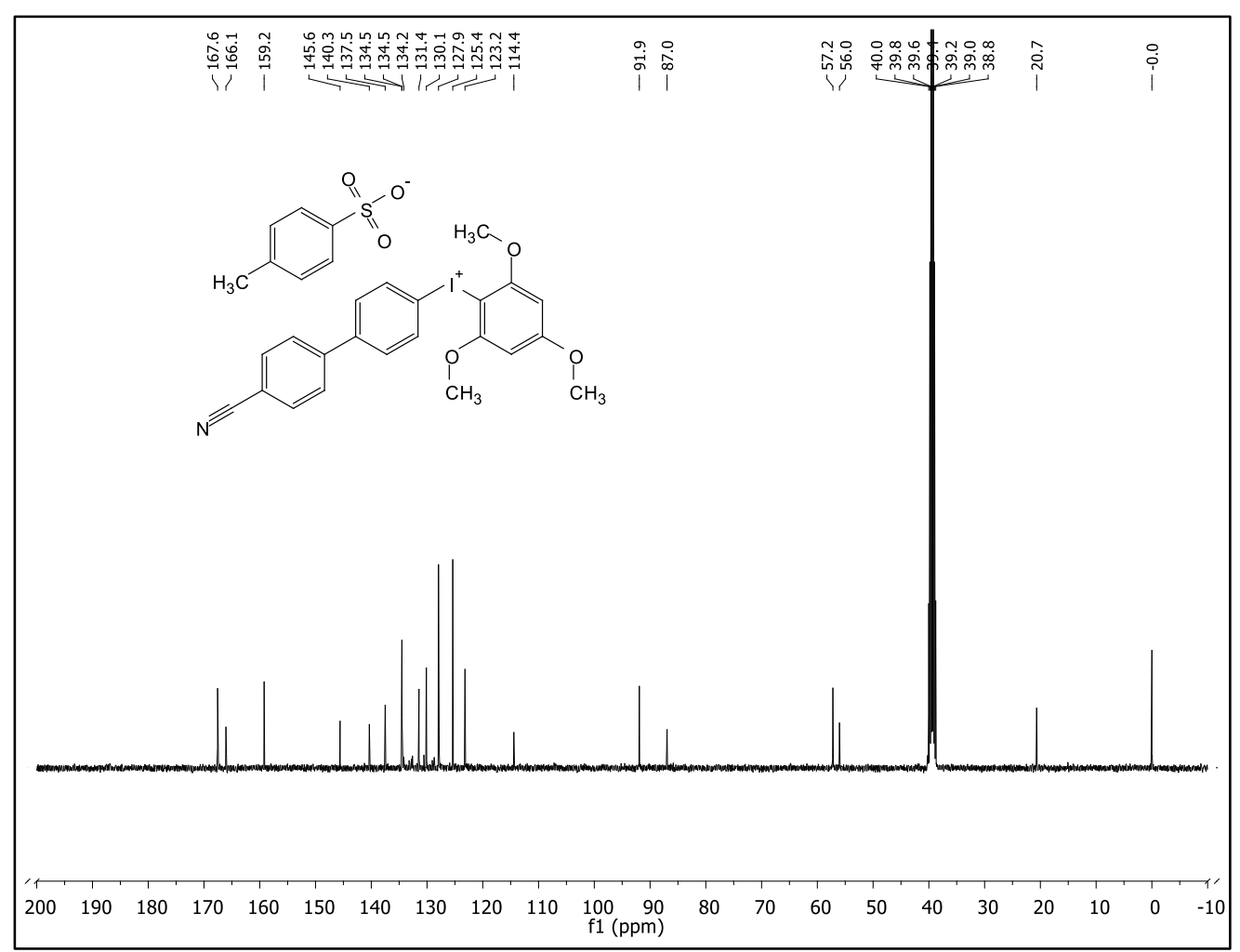

Figure $150 .{ }^{13} \mathrm{C}$ NMR spectrum of 35 at $101 \mathrm{MHz}$ in DMSO- $d_{6}$ at $298 \mathrm{~K}$

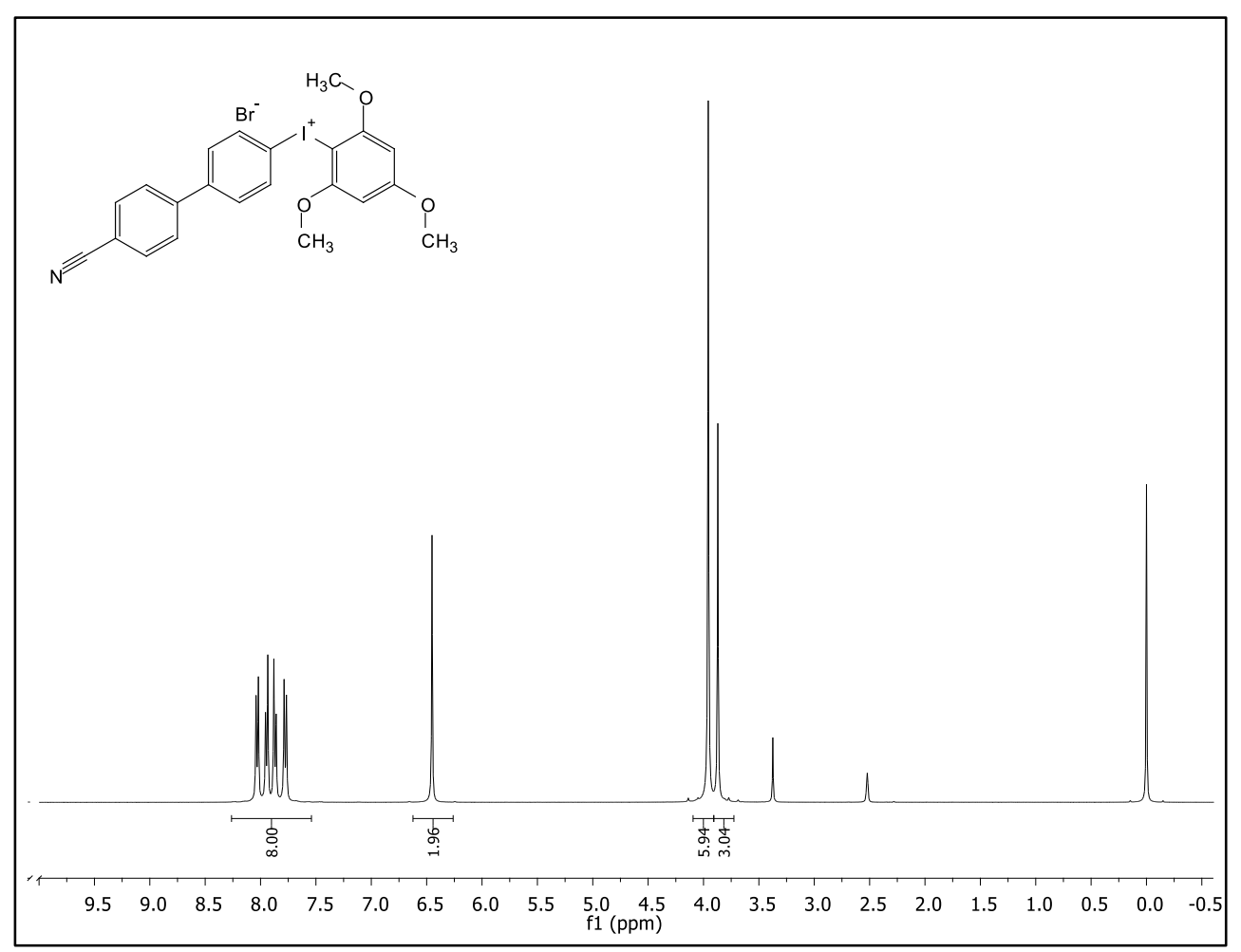

Figure 151. ${ }^{1} \mathrm{H}$ NMR spectrum of $35-\mathrm{Br}$ at $400 \mathrm{MHz}$ in DMSO-d $d_{6}$ at $298 \mathrm{~K}$ 


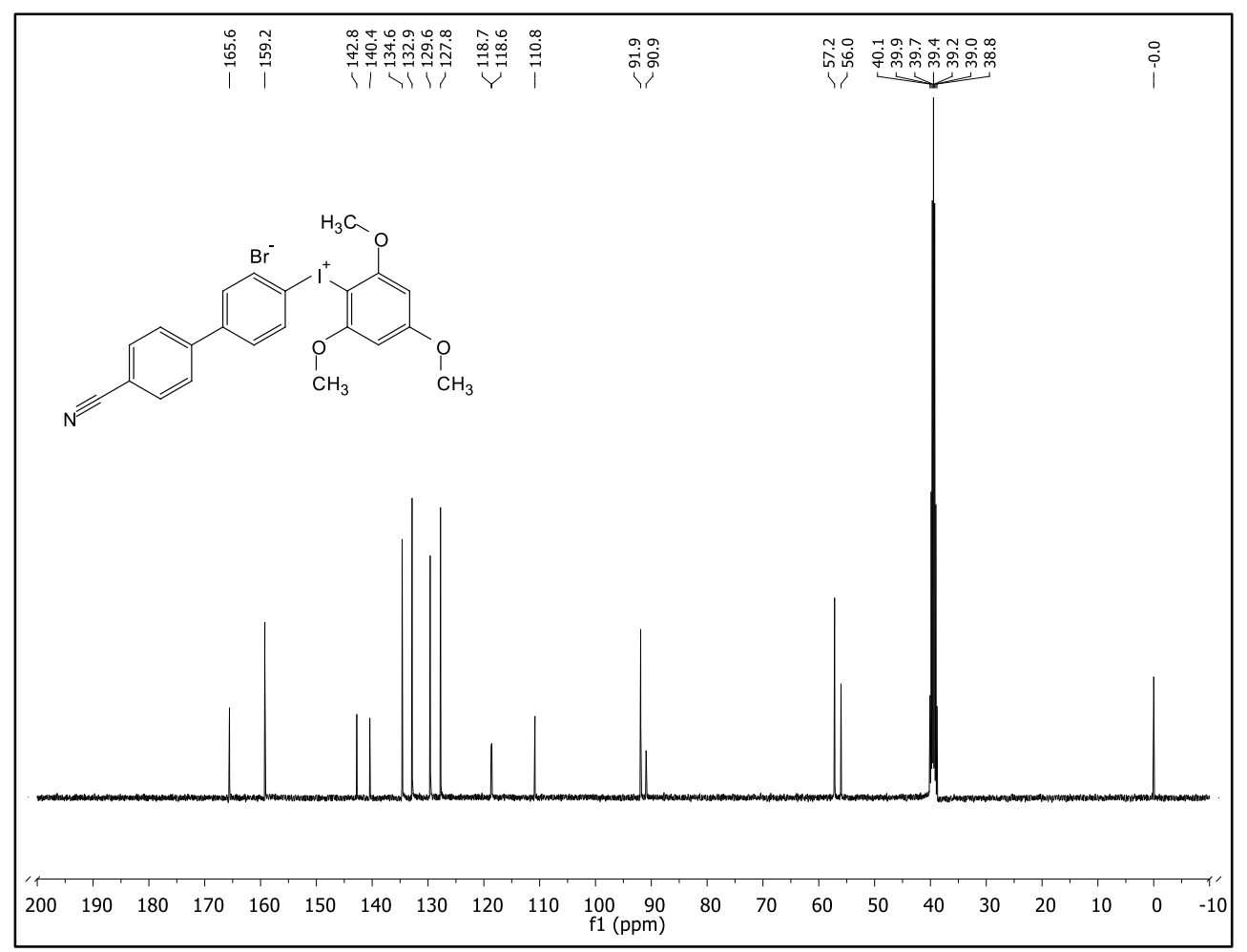

Figure $152 .{ }^{13} \mathrm{C}$ NMR spectrum of $35-\mathrm{Br}$ at $101 \mathrm{MHz}$ in DMSO- $d_{6}$ at $298 \mathrm{~K}$

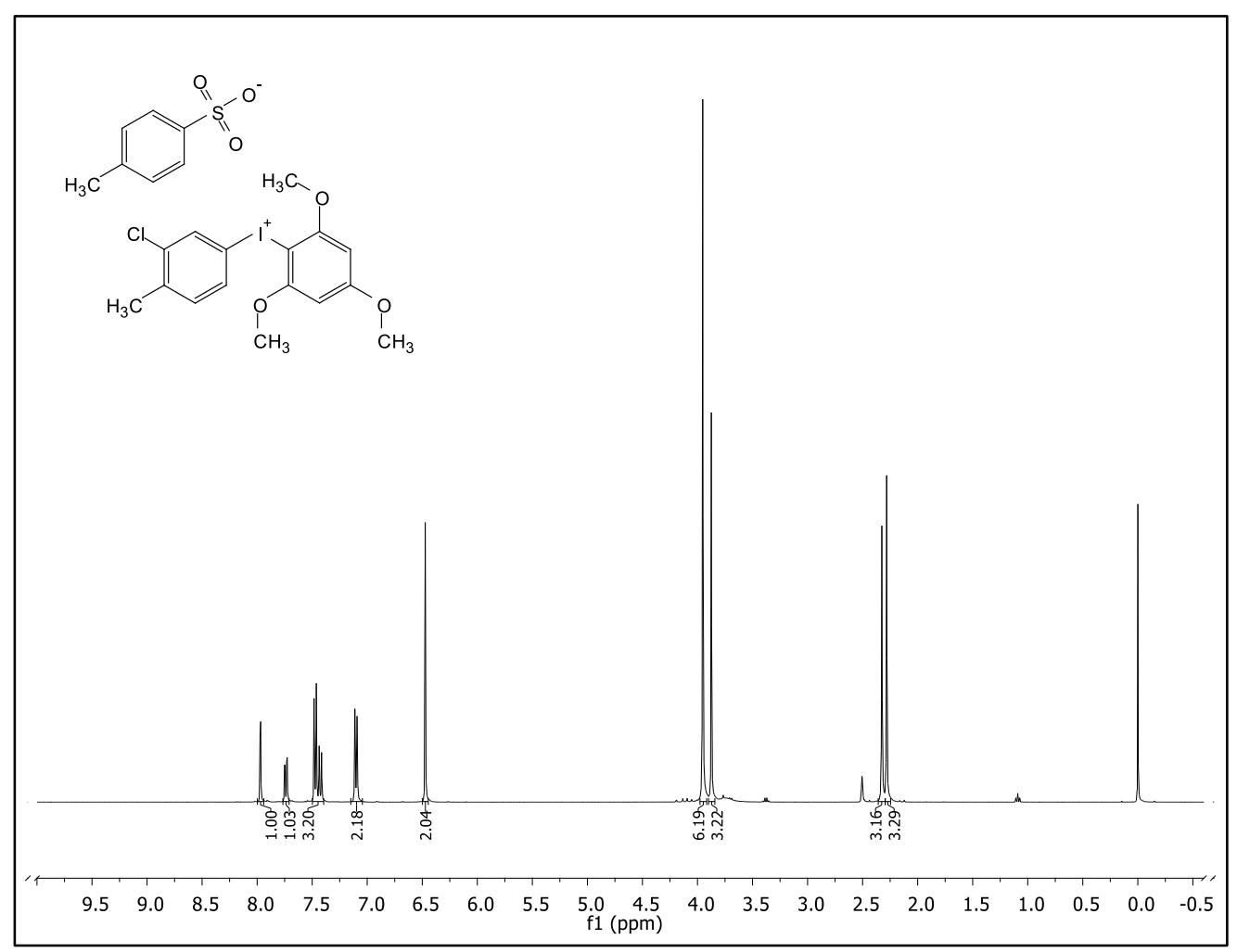

Figure 153. ${ }^{1} \mathrm{H}$ NMR spectrum of 36 at $400 \mathrm{MHz}$ in DMSO- $d_{6}$ at $298 \mathrm{~K}$ 


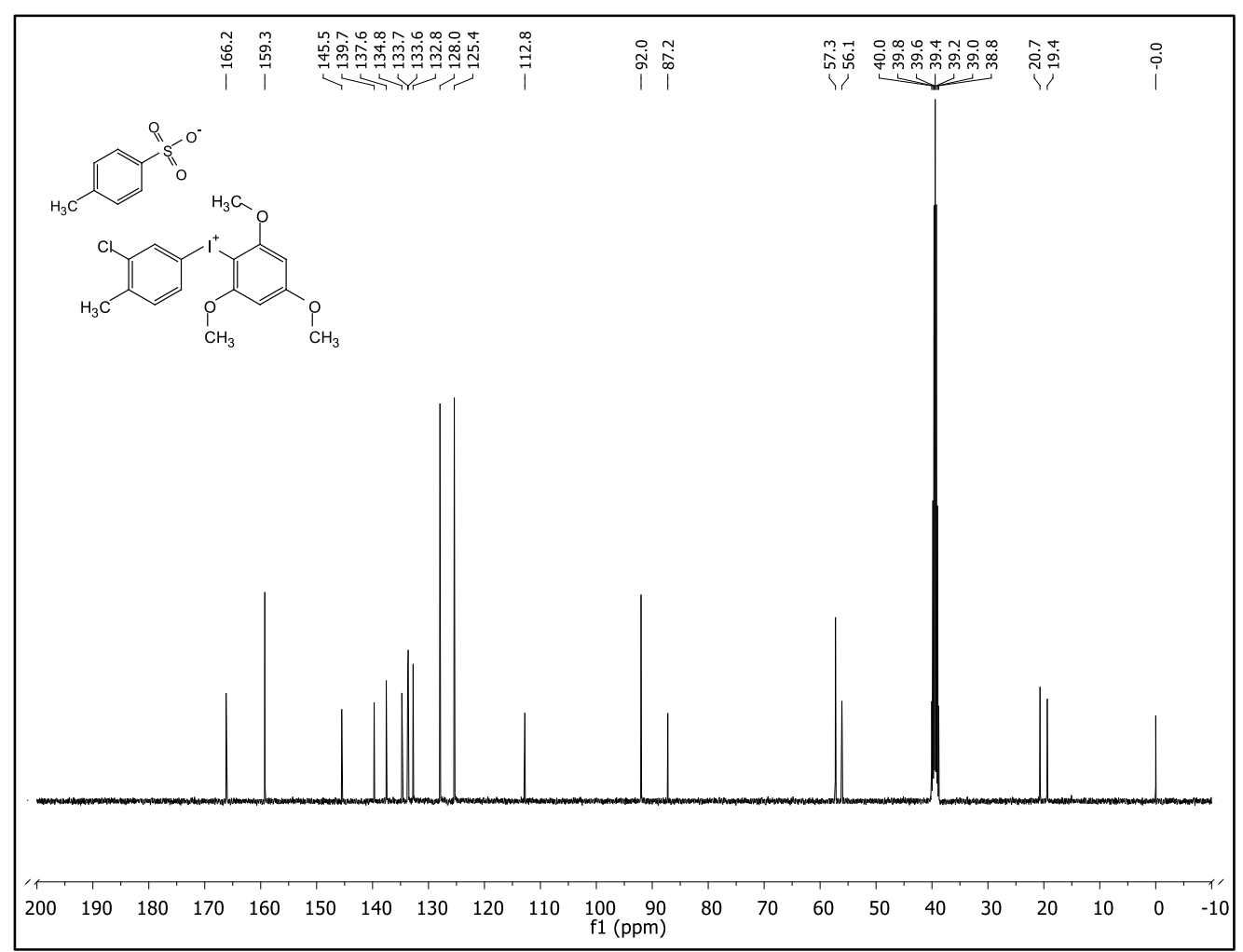

Figure $154 .{ }^{13} \mathrm{C}$ NMR spectrum of 36 at $101 \mathrm{MHz}$ in DMSO- $d_{6}$ at $298 \mathrm{~K}$

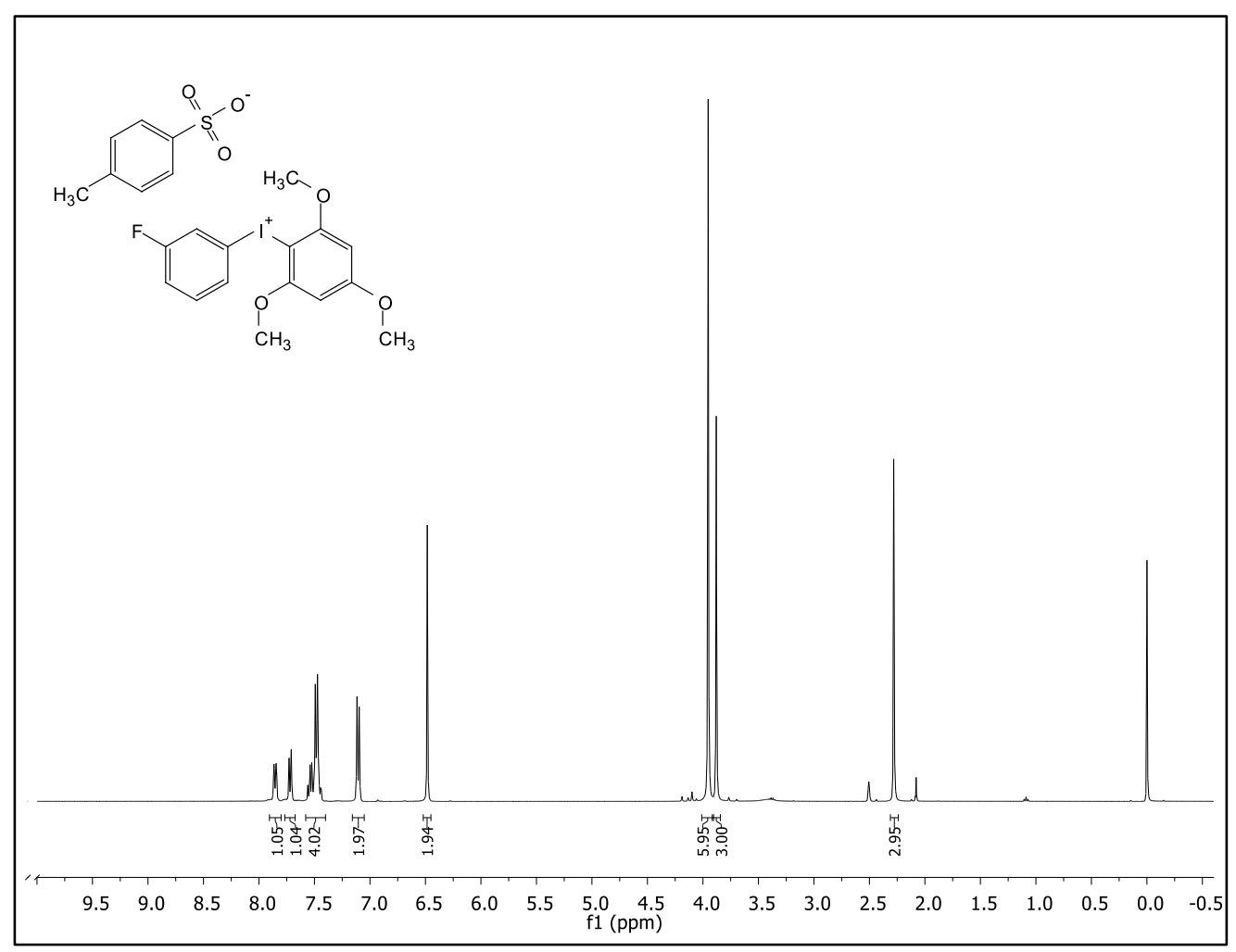

Figure $155 .{ }^{1} \mathrm{H}$ NMR spectrum of 37 at $400 \mathrm{MHz}$ in DMSO- $d_{6}$ at $298 \mathrm{~K}$ 


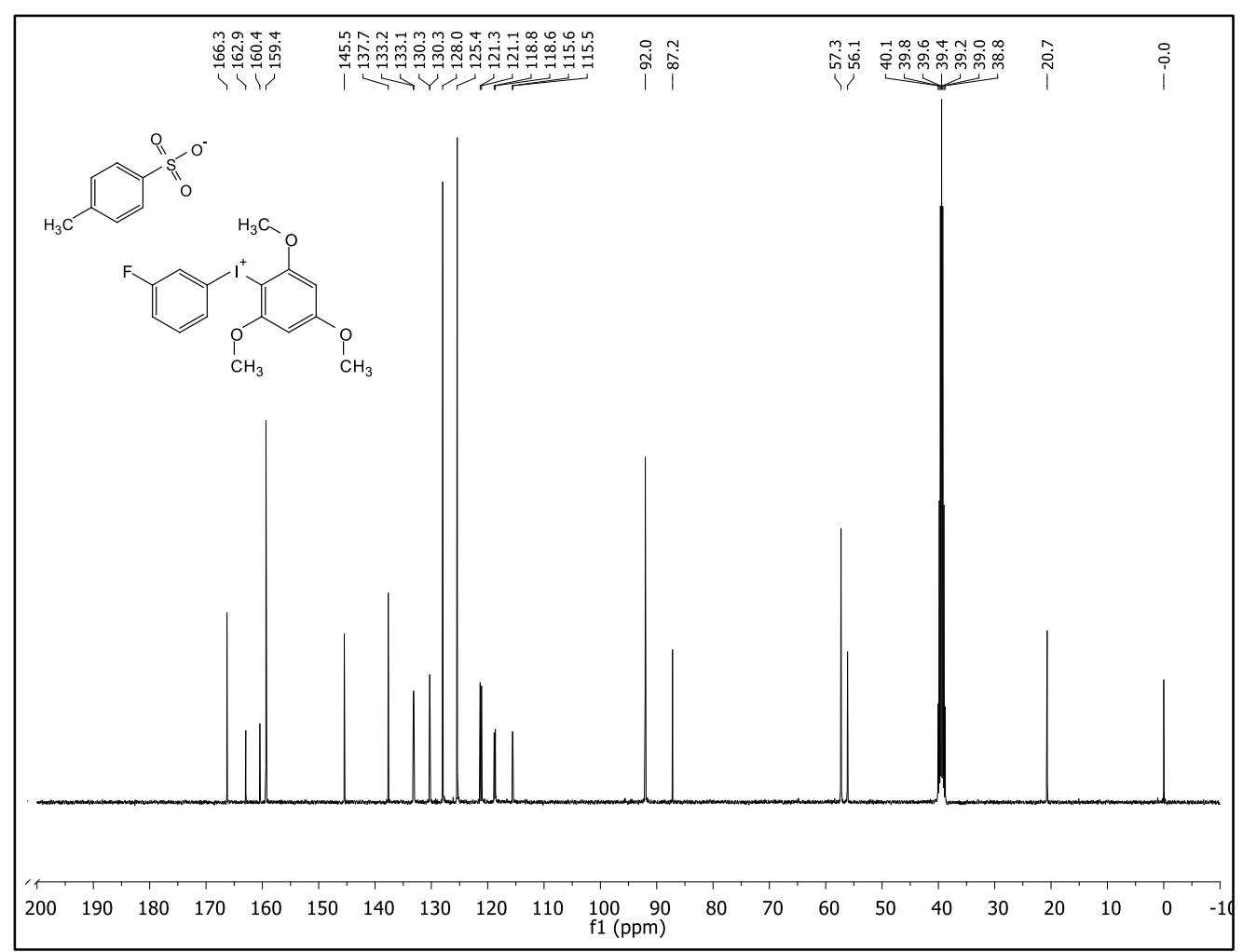

Figure 156. ${ }^{13} \mathrm{C}$ NMR spectrum of 37 at $101 \mathrm{MHz}$ in DMSO- $d_{6}$ at $298 \mathrm{~K}$

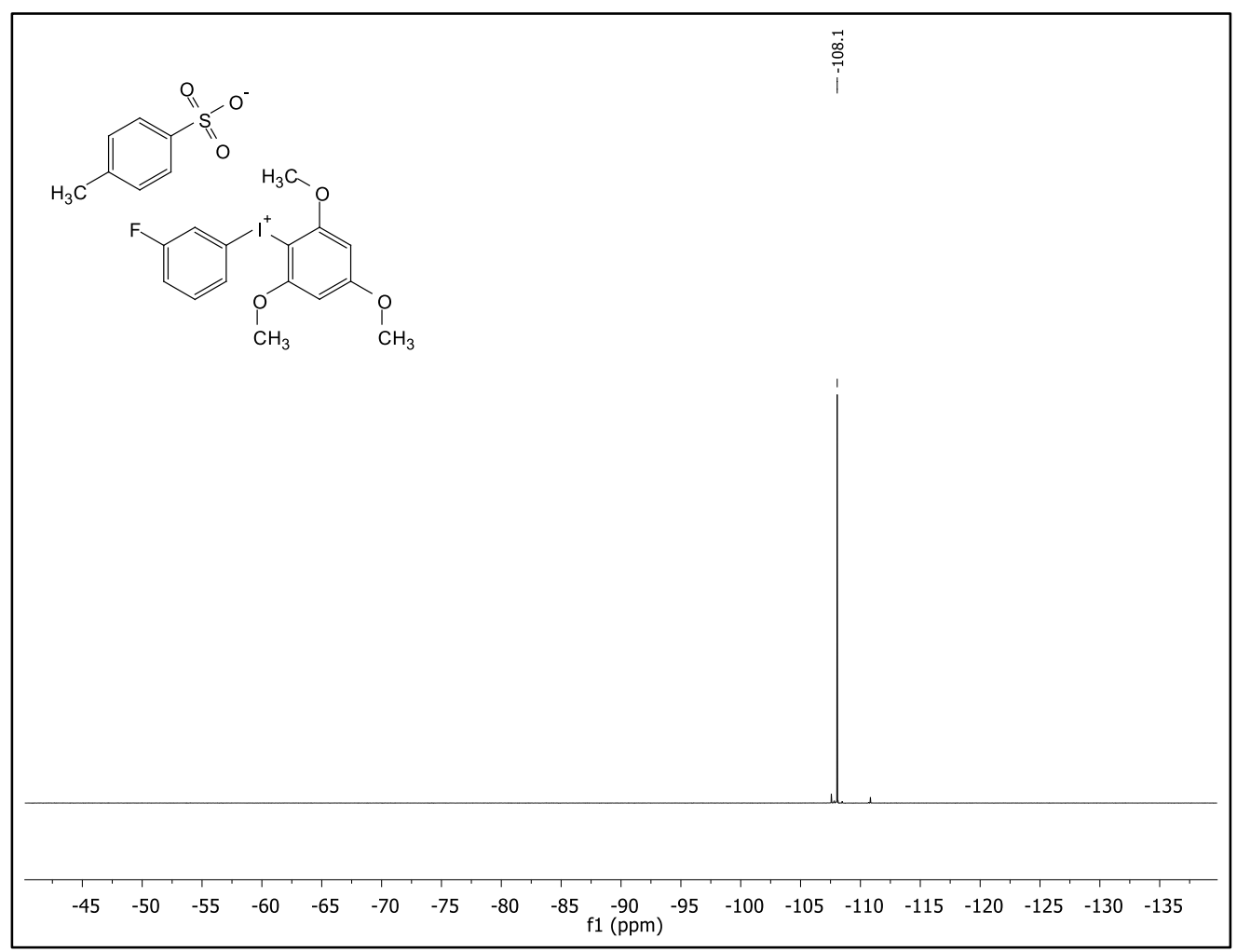

Figure $157 .{ }^{19} \mathrm{~F}$ NMR spectrum of 37 at $376 \mathrm{MHz}$ in DMSO- $d_{6}$ at $298 \mathrm{~K}$ 


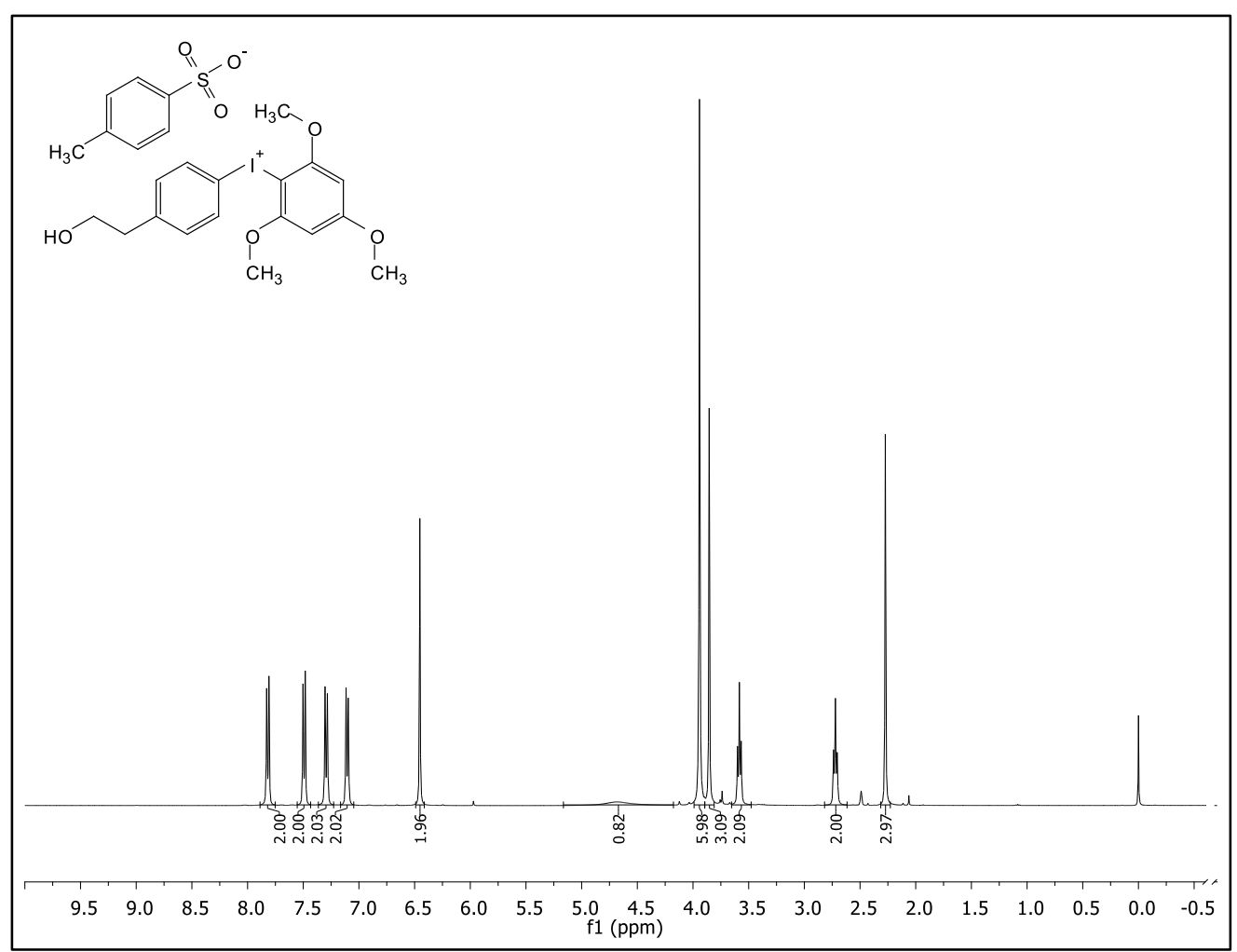

Figure $158 .{ }^{1} \mathrm{H}$ NMR spectrum of 38 at $400 \mathrm{MHz}$ in DMSO- $d_{6}$ at $298 \mathrm{~K}$

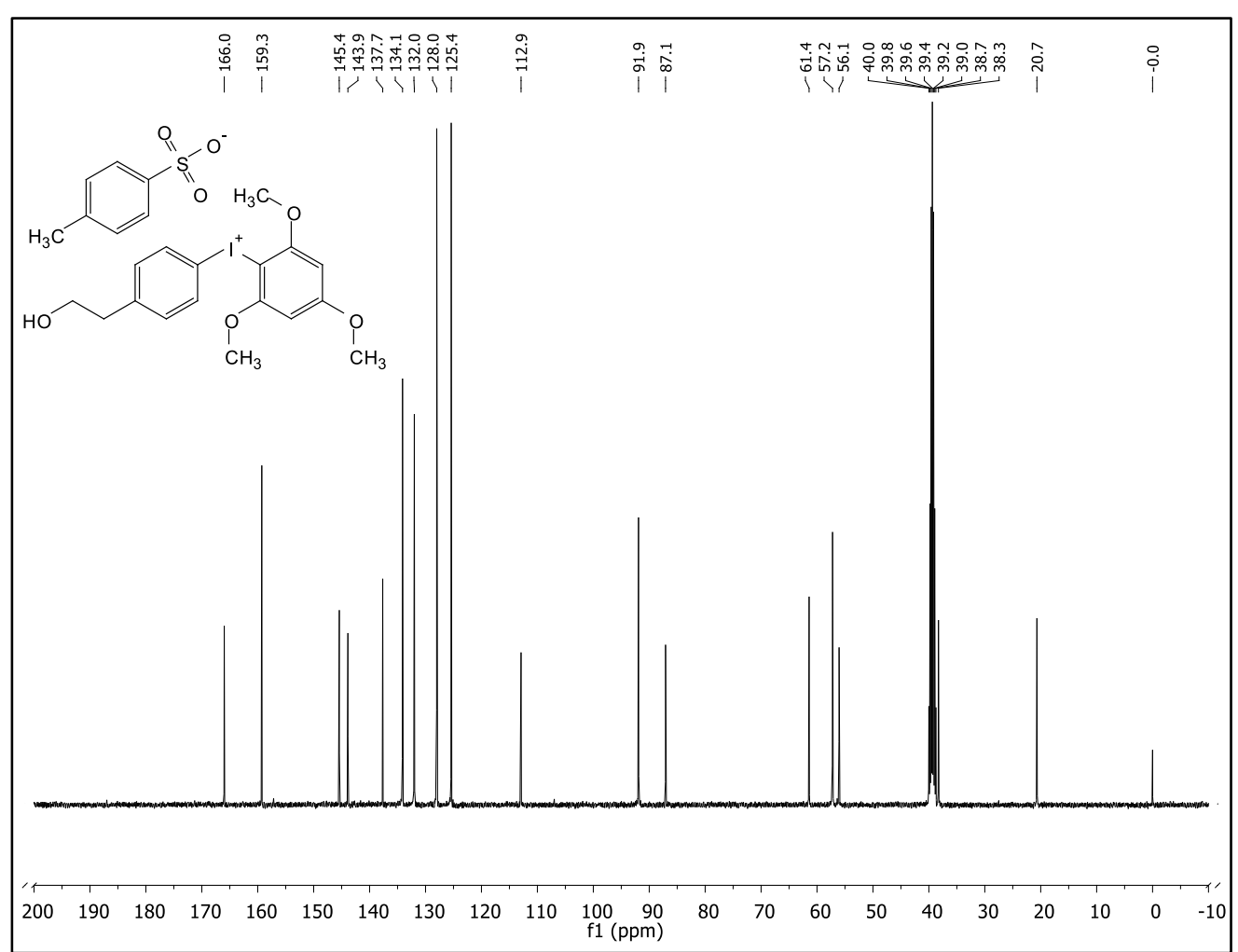

Figure $159 .{ }^{13} \mathrm{C}$ NMR spectrum of 38 at $101 \mathrm{MHz}$ in DMSO- $d_{6}$ at $298 \mathrm{~K}$ 


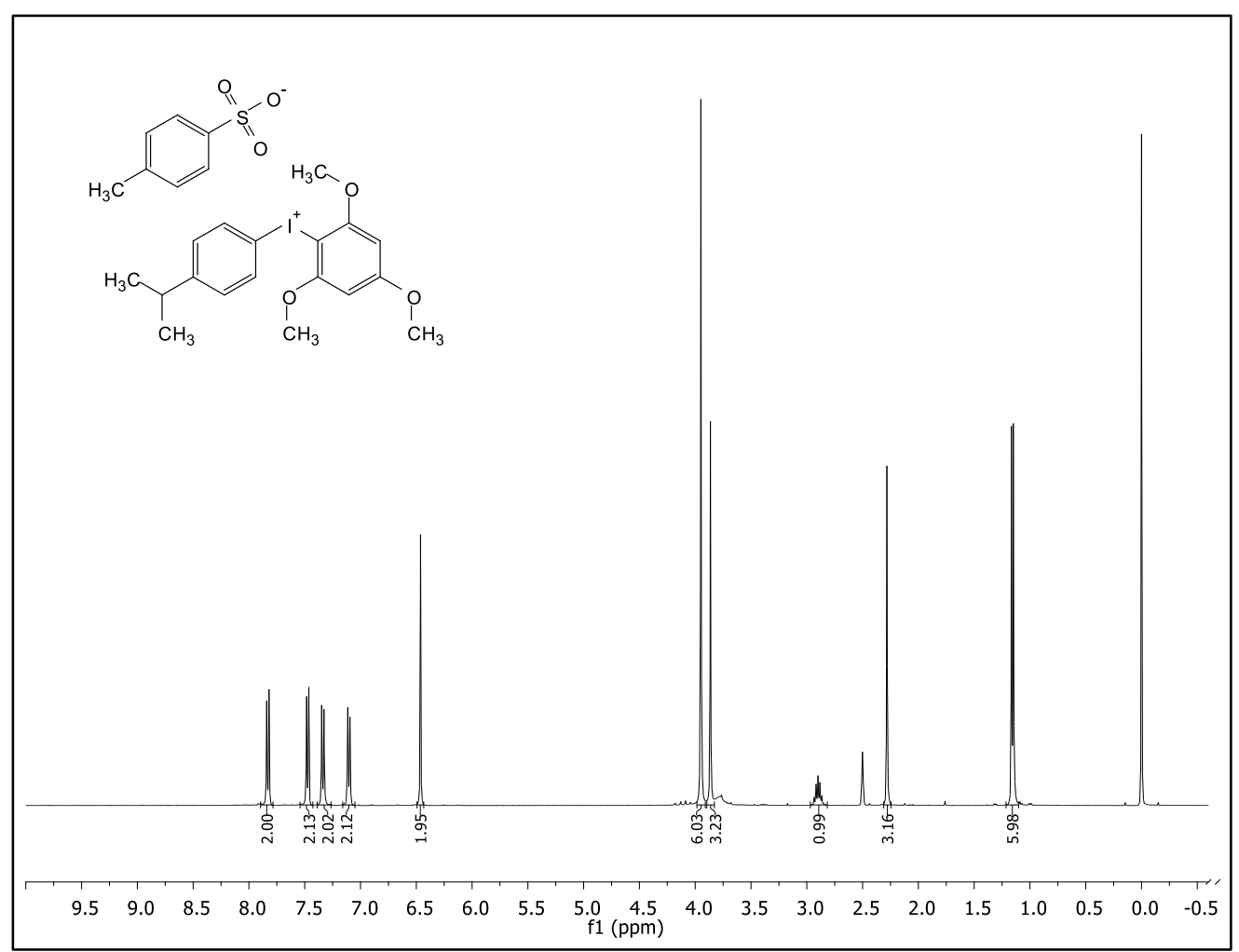

Figure $160 .{ }^{1} \mathrm{H}$ NMR spectrum of 39 at $400 \mathrm{MHz}$ in DMSO- $d_{6}$ at $298 \mathrm{~K}$

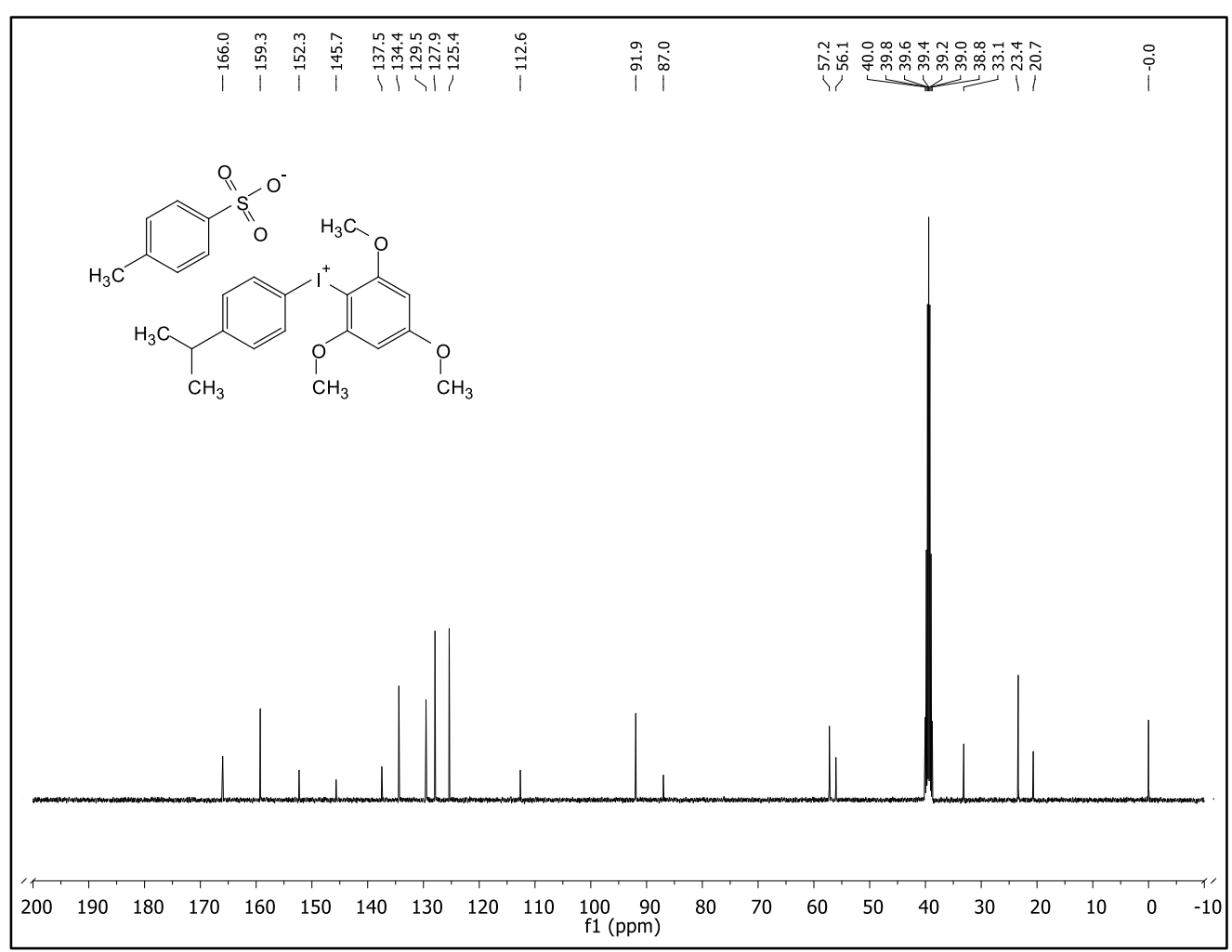

Figure $161 .{ }^{13} \mathrm{C}$ NMR spectrum of 39 at $101 \mathrm{MHz}$ in DMSO- $d_{6}$ at $298 \mathrm{~K}$ 


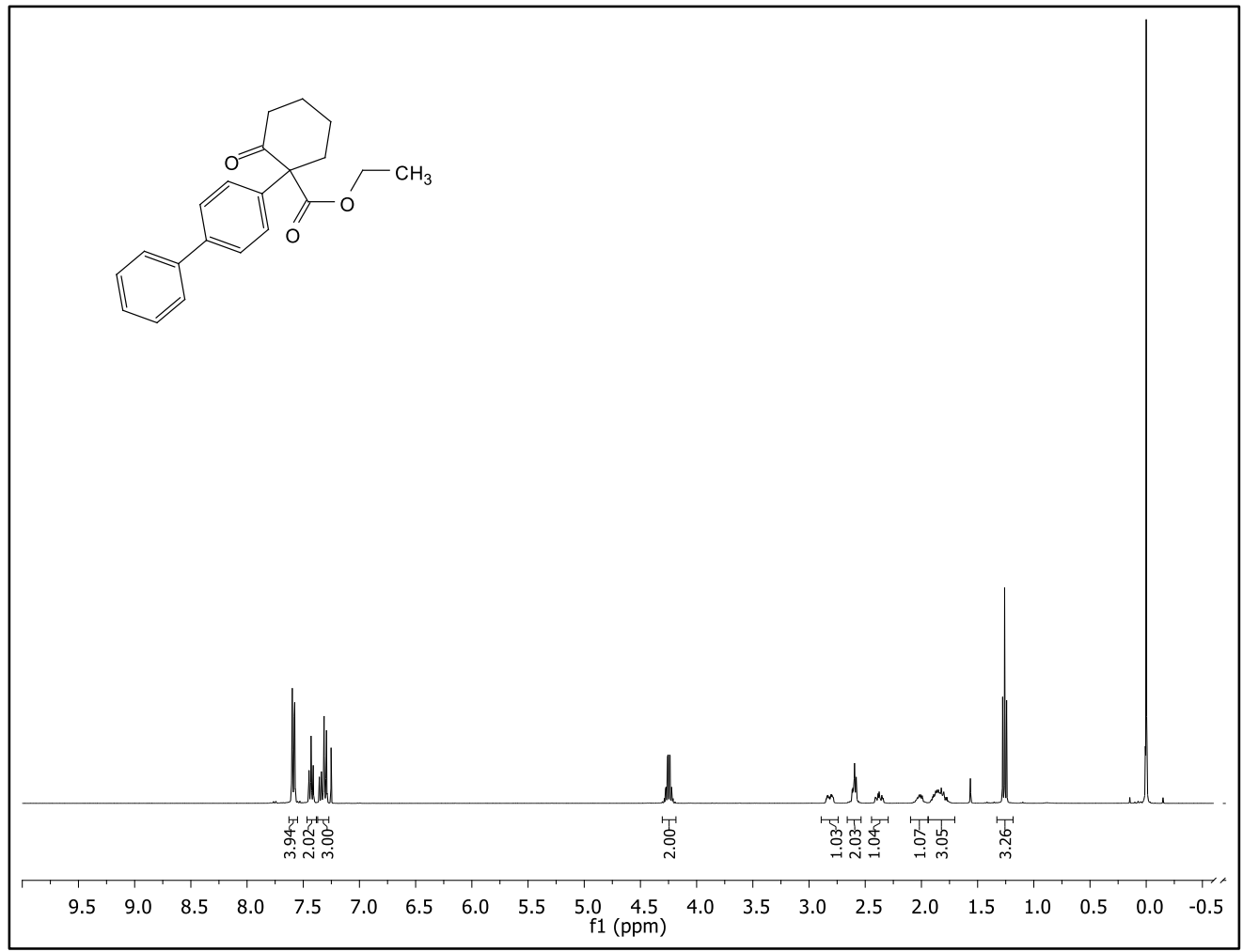

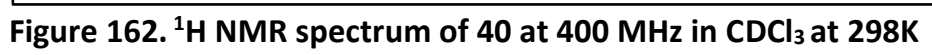

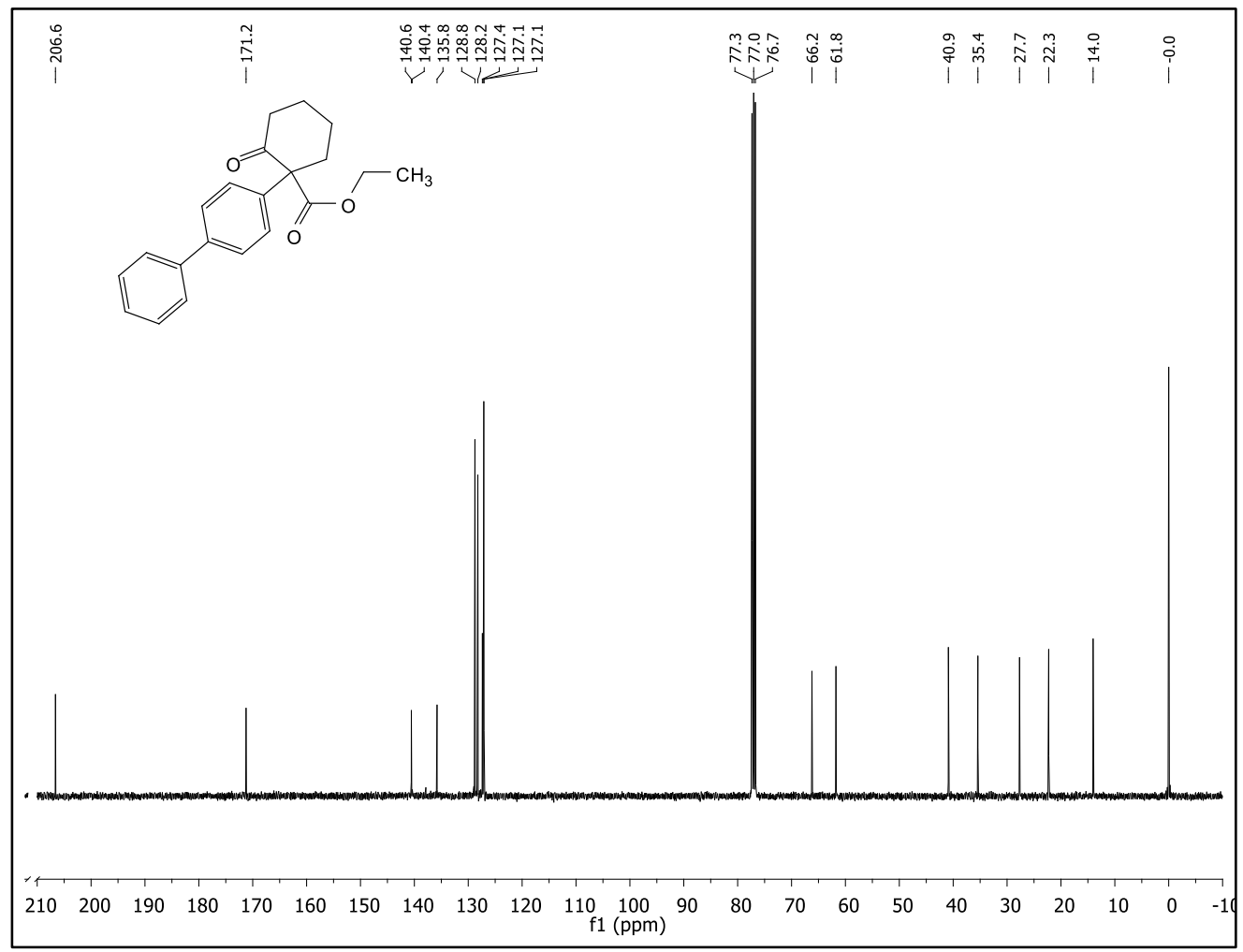

Figure $163 .{ }^{13} \mathrm{C}$ NMR spectrum of 40 at $101 \mathrm{MHz}$ in $\mathrm{CDCl}_{3}$ at $298 \mathrm{~K}$ 


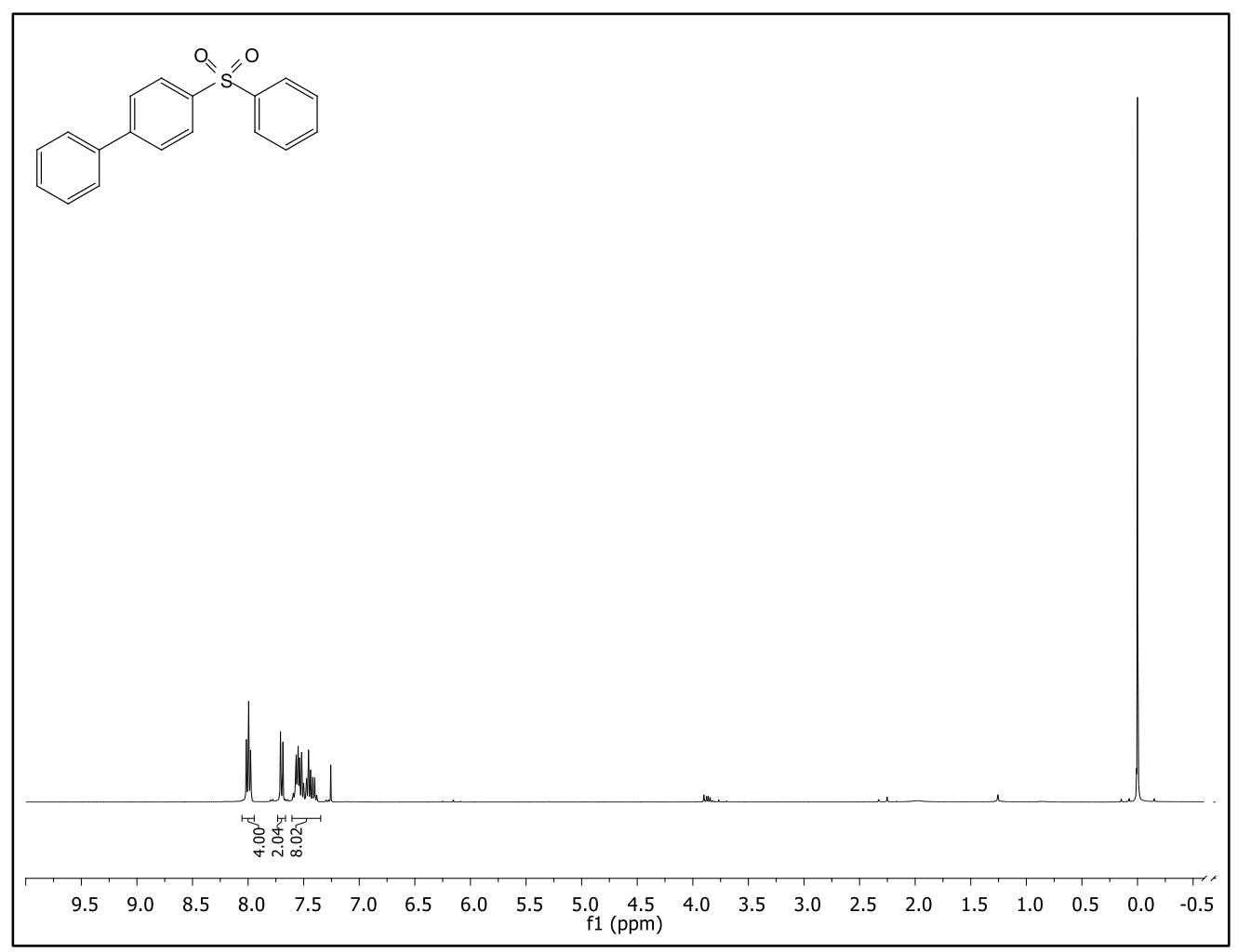

Figure 164. ${ }^{1} \mathrm{H}$ NMR spectrum of 43 at $400 \mathrm{MHz}$ in $\mathrm{CDCl}_{3}$ at $298 \mathrm{~K}$

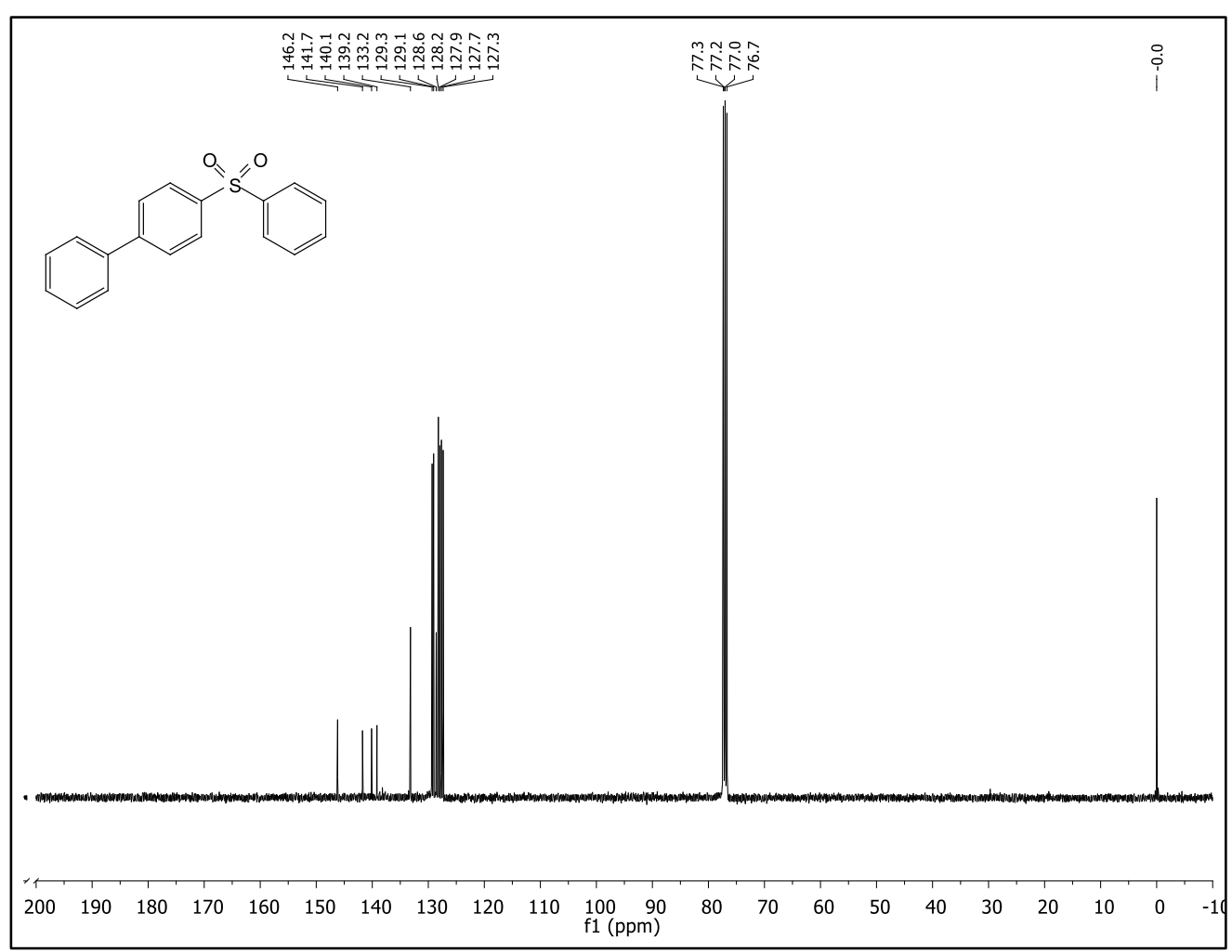

Figure $165 .{ }^{13} \mathrm{C}$ NMR spectrum of 43 at $101 \mathrm{MHz}$ in $\mathrm{CDCl}_{3}$ at $298 \mathrm{~K}$ 


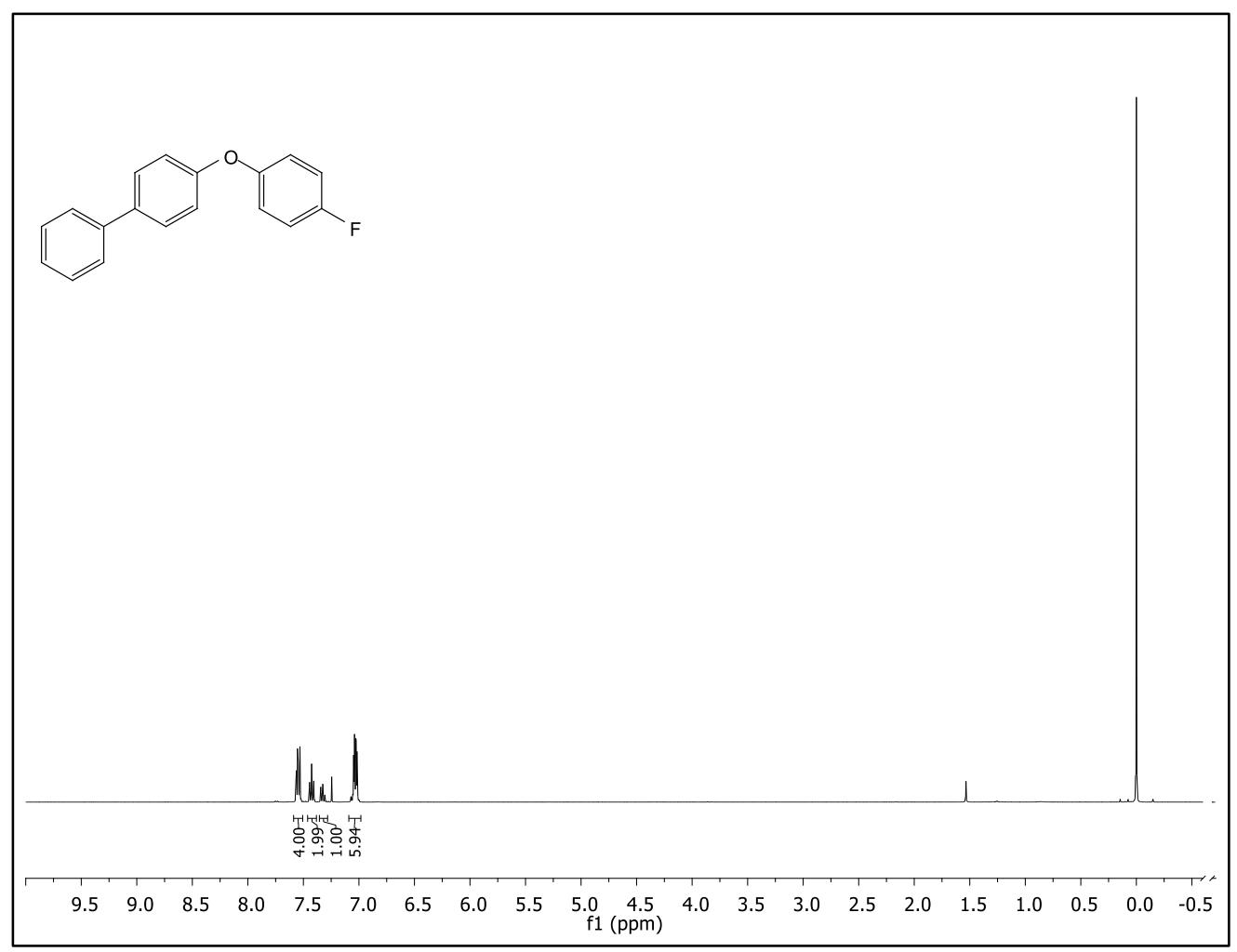

Figure 166. ${ }^{1} \mathrm{H}$ NMR spectrum of 45 at $400 \mathrm{MHz}$ in $\mathrm{CDCl}_{3}$ at $298 \mathrm{~K}$

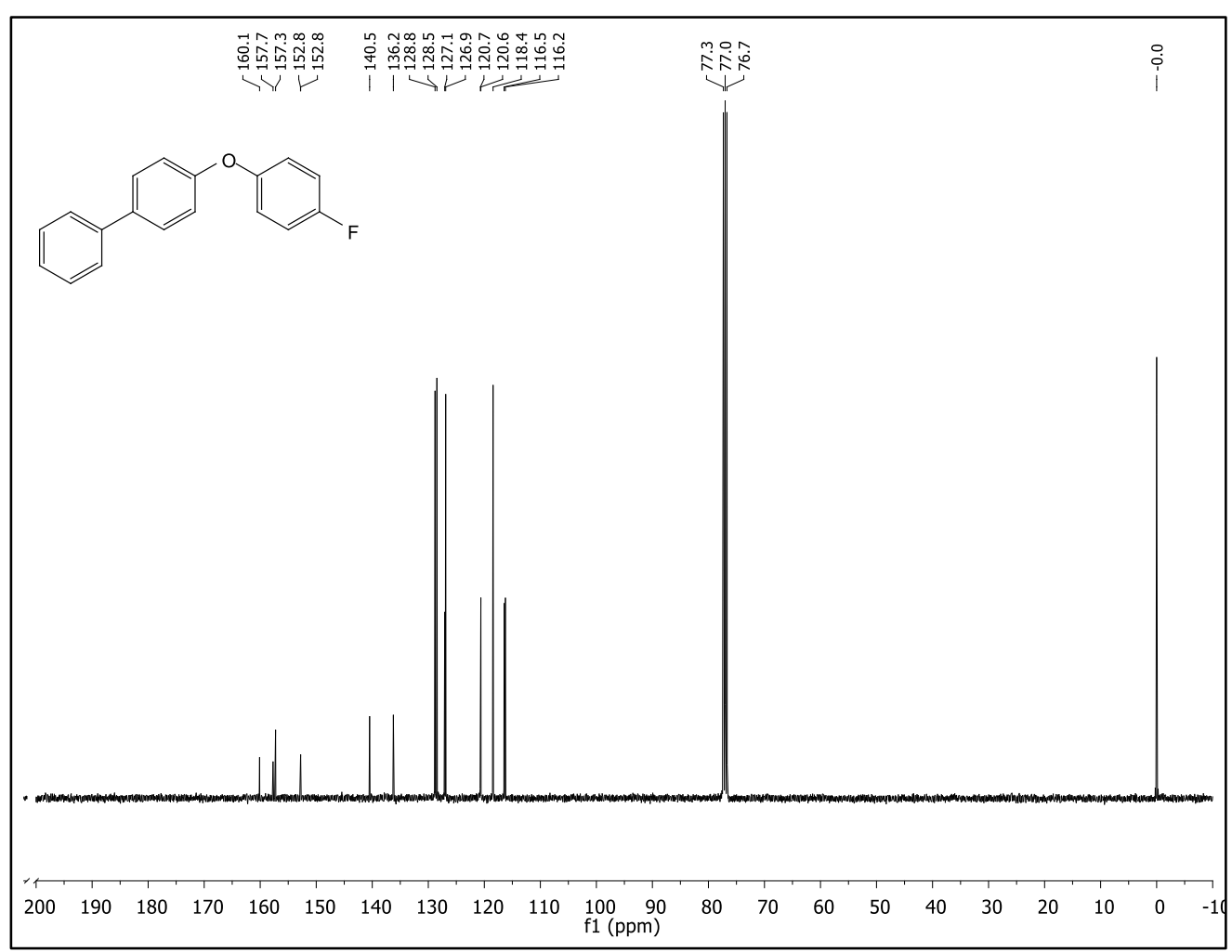

Figure 167. ${ }^{13} \mathrm{C}$ NMR spectrum of 45 at $101 \mathrm{MHz}$ in $\mathrm{CDCl}_{3}$ at $298 \mathrm{~K}$ 


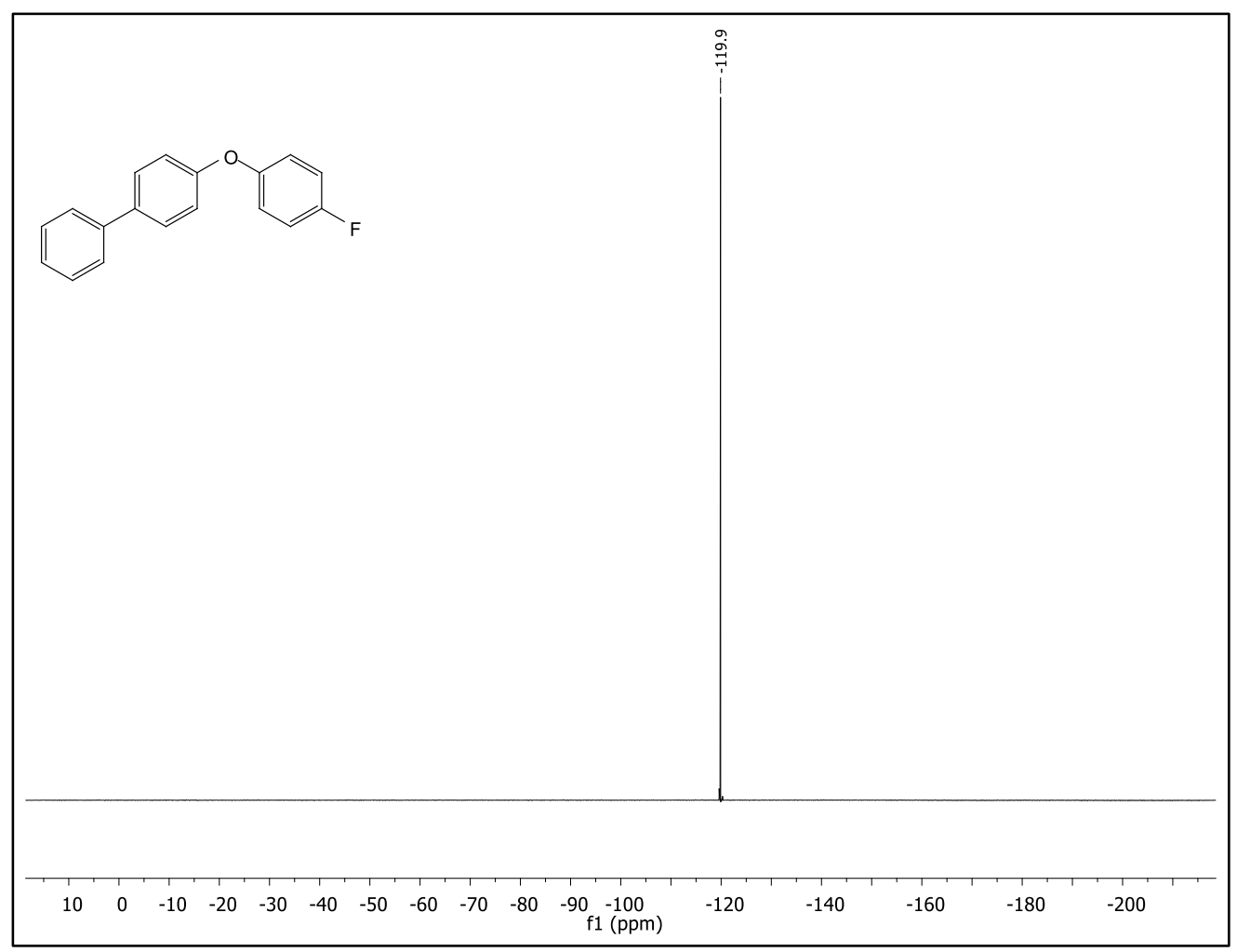

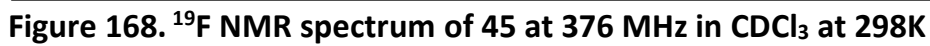




\subsection{Supporting Information for Chapter 3}

\subsubsection{Procedure A: Synthesis of aryl(TMP)iodonium tosylates ${ }^{2}$}

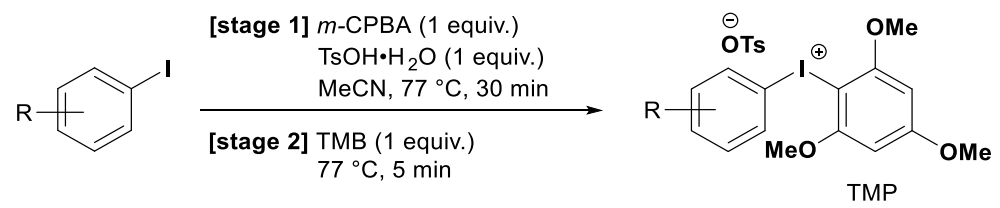

Figure 169. Synthesis of aryl(TMP)iodonium tosylates

Aryl iodide (5 mmol, 1 equiv.) and acetonitrile $(5 \mathrm{~mL})$ were added to a $50 \mathrm{~mL}$ roundbottom flask, equipped with a magnetic stir bar. Toluenesulfonic acid (5.05 mmol, 1.01 equiv.) was added in one portion, followed by one portion of $m$-CPBA (5.05 mmol, 1.01 equiv.) at room temperature. After attaching a reflux condenser, the reaction was lowered into an oil bath set to $77^{\circ} \mathrm{C}$ and stirred vigorously. After 30 minutes, the reflux condenser was removed in order to add (5.05 mmol, 1.01 equiv.) 1,3,5trimethoxybenzene $(\mathrm{TMB})$ in one portion and stirring was continued at $77^{\circ} \mathrm{C}$ for 5 minutes. The reaction was removed from heat and concentrated under reduced pressure. The crude residue was triturated with diethyl ether. The precipitate was isolated by vacuum filtration and washed by slurry filtration with diethyl ether $(3 \times 20$ $\mathrm{mL}$ ). After drying under high vacuum the diaryliodonium salt was obtained in analytically pure form. 


\subsubsection{Procedure B: Anion exchange of aryl(TMP)iodonium tosylates ${ }^{2}$}

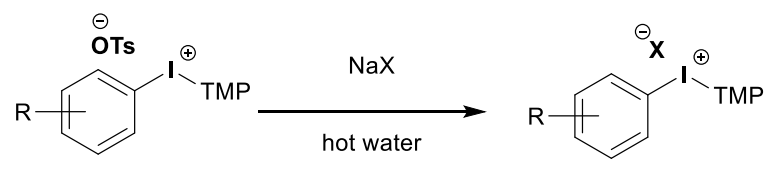

Figure 170. Anion exchange of aryl(TMP)iodonium tosylates

Aryl(TMP)iodonium tosylate ( $1 \mathrm{~g}, 1$ equiv) is added to $50 \mathrm{~mL}$ boiling water. If the iodonium salt does not dissolve after boiling for 1-2 minutes, then methanol is added in small portions until the material is dissolved or the solution has homogenous appearance. While still hot, a salt containing the target anion is added in excess. The exact amount required depends on the exchange salt and the iodonium salt and an excess of 10 or more equivalents is recommended. The resulting solution is allowed to naturally cool to ambient temperature, before chilling further in an ice-bath. The precipitate is isolated by suction filtration and the filter cake washed by slurry filtration with water $(3 \times 30 \mathrm{~mL})$. The cake is dried under suction for $10-20 \mathrm{~min}$ and then washed by slurry filtration with ethyl ether $(3 \times 30 \mathrm{~mL})$. The sample is finally dried under high vacuum to remove residual solvent. If product is suspected in the aqueous wash then it may be recovered by extraction with dichloromethane or ethyl acetate. 


\subsubsection{Procedure C: Aryl(TMP)iodonium bromides to acetate exchange}

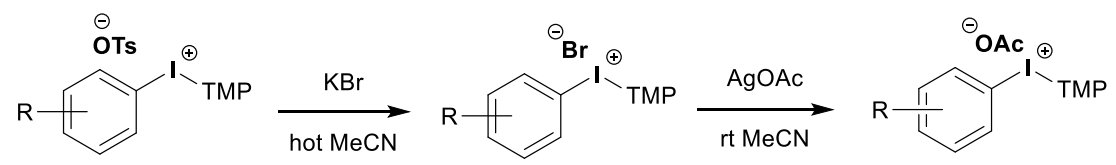

Figure 171. Aryl(TMP)iodonium bromides to acetate exchange

Aryl(TMP)iodonium bromide, $(2 \mathrm{mmol})$ is added to an Erlenmeyer flask with a Teflon coated magnetic stirbar and dissolved in $50 \mathrm{~mL}$ of hot acetonitrile. Silver acetate $(2 \mathrm{~g}$, $12 \mathrm{mmol}$ ) is added to the stirred solution and a yellow precipitate immediately forms. The flask is removed from heat, allowed to cool naturally and the precipitate gradually turns grey. When cool, the solution is repeatedly filtered through a fine fritted funnel containing packed Celite ${ }^{\circledR}$ until grey color is not observed. The solvent is evaporated under reduced pressure and the product triturated with ethyl ether to yield a white or off-white powder. 


\subsubsection{Determination of GC response factors for $2 a$ and $2 b$}

\begin{tabular}{|c|c|c|c|c|c|}
\hline \multicolumn{4}{|c|}{$\begin{array}{l}\text { Response factor } \mathbf{1 a}=1.51 \\
\text { Response factor } \mathbf{2 0}=1.77\end{array}$} & \multirow{2}{*}{$\begin{array}{c}\text { Area } \\
\text { MesBr/azide } \\
0.002\end{array}$} & \multirow{2}{*}{$\begin{array}{c}\text { mol } \\
\text { MesBr/azide } \\
0.000\end{array}$} \\
\hline mes-Br & 0.0099 & 0.0000 & 0.0100 & & \\
\hline \multirow[t]{4}{*}{ tBuPhN3 } & 0.0101 & 0.0020 & 0.0080 & 0.441 & 0.246 \\
\hline & & 0.0040 & 0.0060 & 1.108 & 0.656 \\
\hline & & 0.0060 & 0.0040 & 2.171 & 1.476 \\
\hline & conc (M) & vol MesBr & vol azide & $\begin{array}{c}\text { Area } \\
\text { MesBr/azide }\end{array}$ & $\begin{array}{c}\text { mol } \\
\text { MesBr/azide }\end{array}$ \\
\hline mes-Br & 0.0080 & 0.001 & 0.009 & 0.22 & 0.11 \\
\hline \multirow[t]{4}{*}{ COOMePh } & 0.0072 & 0.002 & 0.008 & 0.42 & 0.25 \\
\hline & & 0.003 & 0.007 & 0.76 & 0.43 \\
\hline & & 0.004 & 0.006 & 1.15 & 0.67 \\
\hline & & 0.005 & 0.005 & 1.74 & 1.00 \\
\hline
\end{tabular}

Table 13. Determination of GC response factors for $2 a$ and $2 b$.

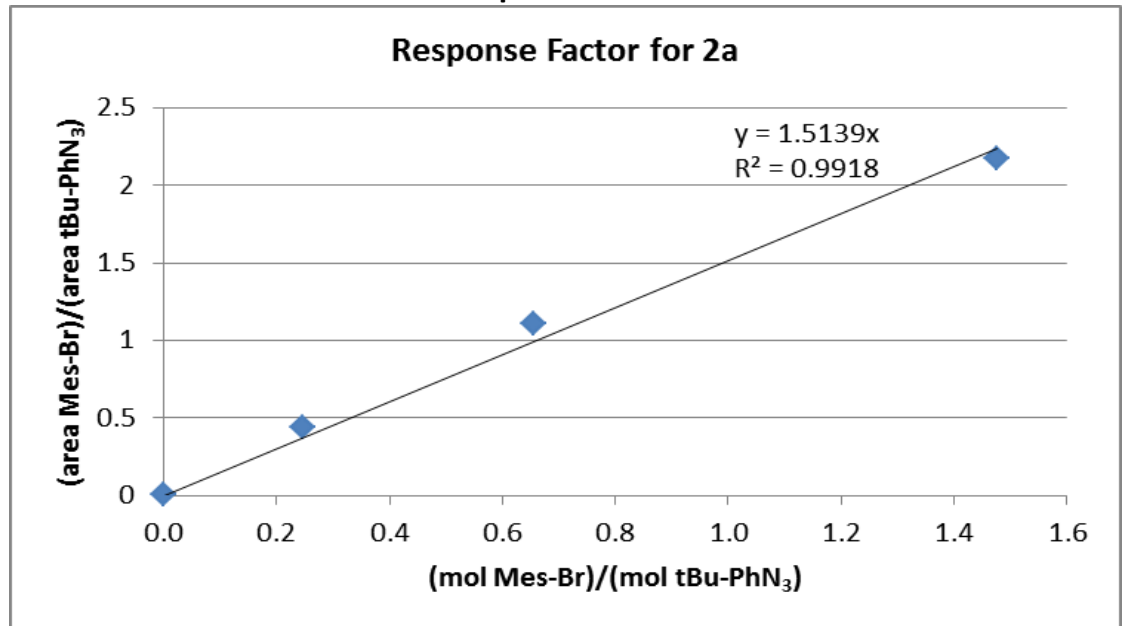

Figure 172. Determination of GC response factors for $2 a$

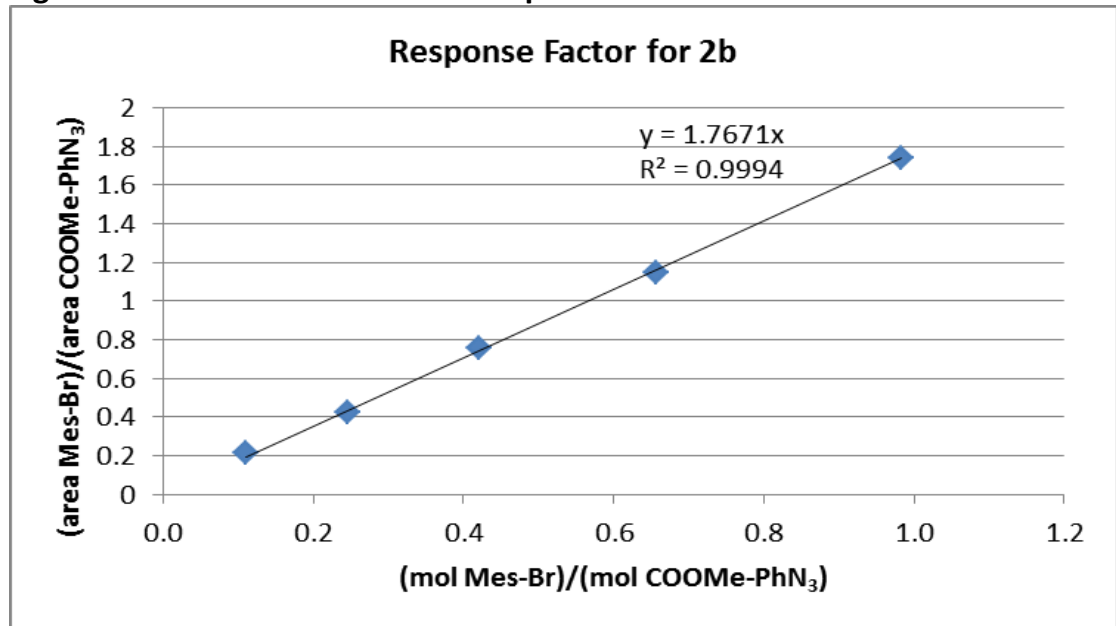

Figure 173. Determination of GC response factors for $2 \mathrm{~b}$ 


\subsubsection{Procedure D: Aryl azidation with pre-exchanged diaryliodonium salts}
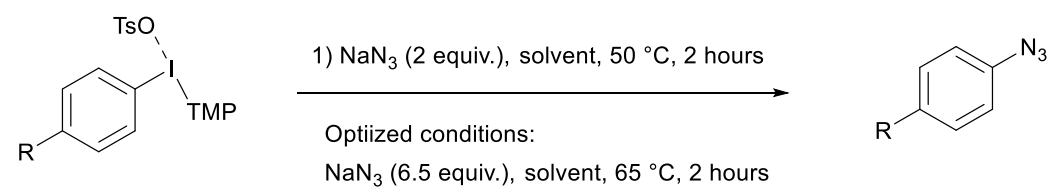

Figure 174. Aryl azidation with pre-exchanged diaryliodonium salts

Aryl(TMP)iodonium salt $(0.1 \mathrm{mmol}, 1 \mathrm{eq})$ is added to a vial with a magnetic stirbar.

Sodium azide ( $0.2 \mathrm{mmol}, 2$ equiv.) is added, followed by $1 \mathrm{~mL}$ anhydrous diglyme. The solution is stirred at $50^{\circ} \mathrm{C}$ for two hours, removed from heat and diluted with $1 \mathrm{~mL}$ of aqueous bicarbonate solution. Upon addition of $10 \mu \mathrm{L}$ of internal standard (bromomesitylene), the reaction is extracted with ethyl acetate, filtered through a Celite $^{\circledR}$ plug and analyzed by GC/MS.

\subsubsection{Procedure E: Aryl azidation of aryl(TMP)iodonium tosylates with a dope} salt.

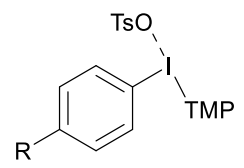

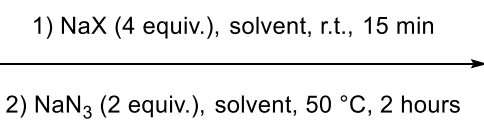<smiles>[R]c1ccc([N+]#N)cc1</smiles>

Figure 175. Aryl azidation of aryl(TMP)iodonium tosylates with a dope salt

Aryl(TMP)iodonium tosylate $(0.1 \mathrm{mmol}, 1 \mathrm{eq})$ and is added to a vial with a magnetic stirbar. A sodium salt with the desired anion is added $(0.4 \mathrm{mmol}, 4 \mathrm{equ})$, followed by 1 $\mathrm{mL}$ of anhydrous diglyme. The mixture is vigorously stirred at room temperature for 15 min. Sodium azide ( $2 \mathrm{mmol}, 2$ equiv) is added and the mixture is stirred at $50^{\circ} \mathrm{C}$ for two hours and then removed from heat and diluted with $1 \mathrm{~mL}$ of aqueous sodium 
bicarbonate solution. Upon addition of $(10 \mu \mathrm{L}, \sim 1 \mathrm{eq})$ of internal standard (bromomesytilene), the reaction is extracted with ethyl acetate, filtered through a celite plug and analyzed by GC/MS.

\subsubsection{Screening Table: Corrected GC-MS yields ( 2 equiv. $\mathrm{NaN}_{3}, 50{ }^{\circ} \mathrm{C}, 2$ hours)}

\begin{tabular}{|c|c|c|c|c|c|c|c|c|c|c|c|c|c|}
\hline $\begin{array}{l}\text { salt additive } \\
\text { solvent } \\
\vee\end{array}$ & 莺 & $\begin{array}{l}\overline{\tilde{Z}} \\
\bar{z}\end{array}$ & $\begin{array}{l}\overrightarrow{0} \\
\bar{n}\end{array}$ & 崖 & 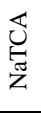 & 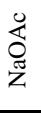 & 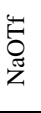 & 壱 & $\sum_{\tilde{Z}}^{\infty}$ & $\begin{array}{l}\text { 丕 } \\
\text { בै }\end{array}$ & $\begin{array}{l}\frac{L^{0}}{L^{0}} \\
\tilde{J}^{\pi}\end{array}$ & 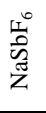 & 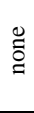 \\
\hline 1a-diglyme & 60 & 34 & 0 & 11 & 0 & 54 & 10 & 17 & 59 & 18 & 6 & 6 & 64 \\
\hline 1b-diglyme & 64 & 58 & 16 & 61 & 25 & 60 & 59 & 51 & 44 & 63 & 60 & 44 & 53 \\
\hline 1a-MeCN & 39 & 35 & 0 & 5 & 3 & 42 & 0 & 0 & 38 & 0 & 0 & 0 & 38 \\
\hline 1b-MeCN & 44 & 65 & 30 & 64 & 50 & 60 & 35 & 34 & 46 & 55 & 48 & 18 & 63 \\
\hline
\end{tabular}

Table 14. Screening Table: Corrected GC-MS yields ( 2 equiv. $\mathrm{NaN}_{3}, 50{ }^{\circ} \mathrm{C}, 2$ hours).

\subsubsection{Raw (uncorrected) GC-MS data for recapitulation of literature screening}

Each of the three examples below were adapted from the indicated literature preparation. The literature preparations were modified only as follows: i)

diphenyliodonium tosylate was used in each case, ii) diphenyliodonium tosylate, solvent and the sodium salt of the indicated $\mathrm{x}$-group were stirred for fifteen minutes at ambient temperature before adding other reactants. Product formation was confirmed by spiking a GC/MS sample with the authentic compound. 


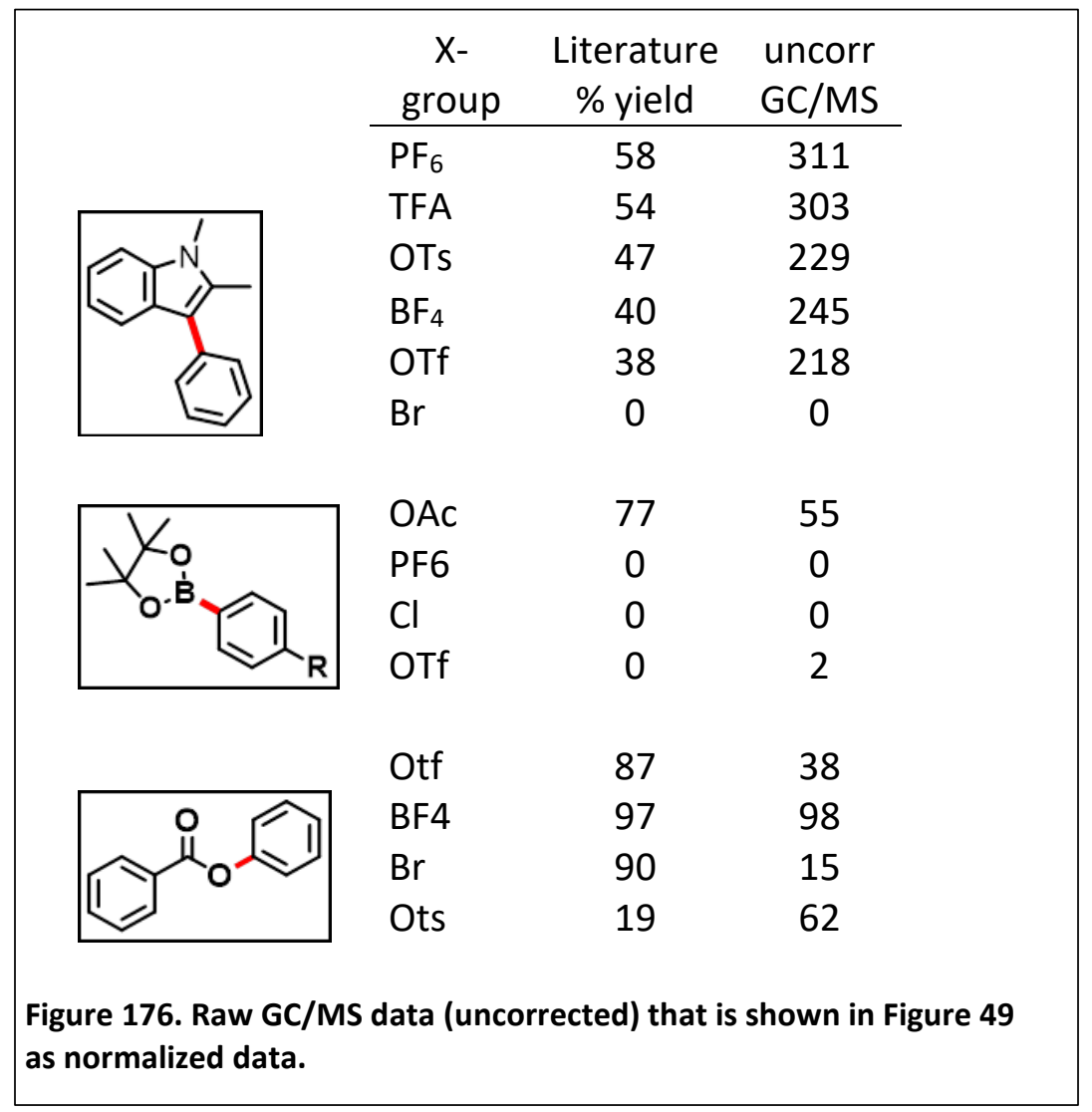

\subsubsection{Characterization data}

Compound 14- $\mathrm{Br}$ - Prepared from 14 according to Procedure B on 2 mmol scale, using<smiles>CN(O)c1ccc(C2(C3CC3)CC2CBr)cc1</smiles>
potassium bromide (12 g, 10 equiv.) and obtained in 95\% yield $(1.138 \mathrm{~g})$ as a white powder. ${ }^{1} \mathrm{H}$ NMR $\left(600 \mathrm{MHz}, \mathrm{DMSO}-d_{6} \&\right.$ $\left.\mathrm{CD}_{3} \mathrm{OD}\right) \delta 7.81(\mathrm{~d}, J=7.0 \mathrm{~Hz}, 2 \mathrm{H}), 7.43(\mathrm{~d}, J=7.0 \mathrm{~Hz}, 2 \mathrm{H}), 6.39(\mathrm{~s}$, $2 \mathrm{H}), 3.92(\mathrm{~s}, 6 \mathrm{H}), 3.83(\mathrm{~s}, 3 \mathrm{H}), 1.24(\mathrm{~s}, 9 \mathrm{H}) .{ }^{13} \mathrm{C}$ NMR $(151 \mathrm{MHz}$, DMSO- $\left.d_{6} \& \mathrm{CD}_{3} \mathrm{OD}\right) \delta 165.58,159.27,153.86,133.89,128.31$, 114.65 , 91.92 , $90.28,57.20$, 56.06 , 34.70 , 30.73. FTIR: 3051, 2953, 2868, 2841, 1576, 1458, 1409, 1207, 1121, $814 \mathrm{~cm}^{-1}$. HRMS (ESI ${ }^{+}$): Calculated for $\mathrm{C}_{19} \mathrm{H}_{24} \mathrm{IO}_{3}{ }^{+}[\mathrm{M}-\mathrm{Br}]^{+}:$427.0765; Observed: 427.0768. Mp $194{ }^{\circ} \mathrm{C}$.

Compound 14- $\mathrm{Cl}$ - Prepared from 14 according to Procedure B on $2 \mathrm{mmol}$ scale, using<smiles>COc1ccc(C2(C)CC2)cc1</smiles>
sodium chloride (12.6 g, 100 equiv.) and obtained in 94\% (0.873 g) yield as a white powder. ${ }^{1} \mathrm{H}$ NMR $\left(600 \mathrm{MHz}, \mathrm{DMSO}-d_{6} \& \mathrm{CD}_{3} \mathrm{OD}\right) \delta$ $7.81(\mathrm{~d}, \mathrm{~J}=7.6 \mathrm{~Hz}, 2 \mathrm{H}), 7.43(\mathrm{~d}, \mathrm{~J}=7.6 \mathrm{~Hz}, 2 \mathrm{H}), 6.40(\mathrm{~s}, 2 \mathrm{H}), 3.92$ (s, $6 \mathrm{H}), 3.84(\mathrm{~s}, 3 \mathrm{H}), 1.23(\mathrm{~s}, 9 \mathrm{H}) .{ }^{13} \mathrm{C}$ NMR (151 MHz, DMSO- $d_{6}$ \& $\left.\mathrm{CD}_{3} \mathrm{OD}\right) \delta 166.6,159.9,155.0,134.4,128.7,113.4,92.0,88.0,57.1$, 56.0, 34.9, 30.7. FT-IR: 3068, 3004, 2955, 2901, 2868, 1586, 1410, 1231, 1119, 1059, 
810, $670 \mathrm{~cm}^{-1}$. HRMS $\left(\mathrm{ESI}^{+}\right)$: Calculated for $\mathrm{C}_{19} \mathrm{H}_{24} \mathrm{IO}_{3}{ }^{+}[\mathrm{M}-\mathrm{Cl}]^{+}:$427.0765, Observed: 427.0759. $\mathrm{Mp} 207^{\circ} \mathrm{C}$.

Compound 14-OAc - Prepared to Procedure C by stirring 14- $\mathrm{Br}(3.8 \mathrm{~g}, 7.5 \mathrm{mmol})$ into

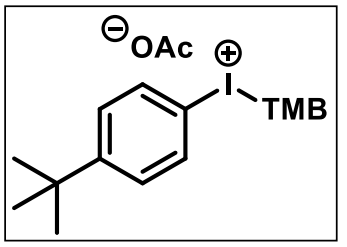
hot acetonitrile until completely dissolved. Silver acetate $(1.704 \mathrm{~g}$, $10.3 \mathrm{mmol}$ ) was added and a yellow powder immediately precipitated and gradually turned grey. The product was obtained as a white powder in $70 \%$ yield. ${ }^{1} \mathrm{H} N M R\left(400 \mathrm{MHz}, \mathrm{CD}_{3} \mathrm{OD}\right) \delta 7.90$ $(\mathrm{d}, J=8.6 \mathrm{~Hz}, 2 \mathrm{H}), 7.52(\mathrm{~d}, J=8.6 \mathrm{~Hz}, 2 \mathrm{H}), 6.43(\mathrm{~s}, 2 \mathrm{H}), 4.01(\mathrm{~s}, 6 \mathrm{H})$, $3.91(\mathrm{~s}, 3 \mathrm{H}), 1.88(\mathrm{~s}, 3 \mathrm{H}), 1.32(\mathrm{~s}, 9 \mathrm{H}) .{ }^{13} \mathrm{C}$ NMR (101 MHz, MeOD) $\delta$ 178.7, 167.2, 160.1, 155.7, 134.3, 128.6, 111.3, 91.5, 85.3, 56.3, 55.3, 34.6, 30.0, 22.9. FT-IR: 3101, 3068, 3023, 2960, 2911, 2869, 2845, 1581, 1552, 1382, 1338, 1235, 1117, $1069,824,637 \mathrm{~cm}^{-1}$. HRMS $\left(\mathrm{ESI}^{+}\right)$: Calculated for $\mathrm{C}_{19} \mathrm{H}_{24} \mathrm{IO}_{3}{ }^{+}[\mathrm{M}-\mathrm{OAc}]^{+}:$: 27.0765 , Observed: 427.0747 . Mp $149-151^{\circ} \mathrm{C}$.

Compound 14-OTf - Prepared from 14 according to Procedure B on $2 \mathrm{mmol}$ scale,

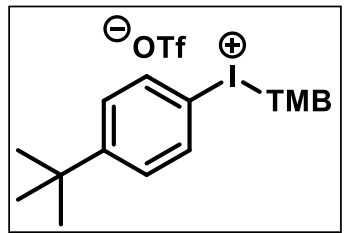
using sodium triflate $(5.0 \mathrm{~g}, 29$ equiv.) and obtained in $92 \%$ (1.06 g, $1.8 \mathrm{mmol}$ ) yield as a white powder. ${ }^{1} \mathrm{H} \mathrm{NMR}\left(400 \mathrm{MHz}, \mathrm{DMSO}-d_{6}\right)$ $\delta 7.84(\mathrm{~d}, \mathrm{~J}=8.7 \mathrm{~Hz}, 2 \mathrm{H}), 7.50(\mathrm{~d}, \mathrm{~J}=8.7 \mathrm{~Hz}, 2 \mathrm{H}), 6.48(\mathrm{~s}, 2 \mathrm{H}), 3.96$ $(\mathrm{d}, \mathrm{J}=5.8 \mathrm{~Hz}, 6 \mathrm{H}), 3.87(\mathrm{~d}, \mathrm{~J}=4.7 \mathrm{~Hz}, 3 \mathrm{H}), 1.25(\mathrm{~s}, 9 \mathrm{H}) .{ }^{13} \mathrm{C} N M R$ $\left(101 \mathrm{MHz}, \mathrm{DMSO}-d_{6}\right) \delta 166.1,159.3,154.7,134.2,128.7,120.7$

$\left(q, J_{C-F}=322.5 \mathrm{~Hz}\right), 112.5,92.0,86.9,57.3,56.1,34.8,30.7 .{ }^{19} \mathrm{~F} \mathrm{NMR}(376 \mathrm{MHz}$, DMSO-d $) \delta(\mathrm{ppm}):-77.7$. FT-IR: 3070, 2955, 2870, 2847, 1580, 1471, 1415, 1243, 1210, $1125,1026,814,635 \mathrm{~cm}^{-1}$. HRMS $\left(\mathrm{ESI}^{+}\right)$: Calculated for $\mathrm{C}_{19} \mathrm{H}_{24} \mathrm{IO}_{3}{ }^{+}[\mathrm{M}-\mathrm{OTf}]^{+}: 427.0765$, Observed: 427.0765 . $\mathrm{Mp} 78-79^{\circ} \mathrm{C}$.

Compound 14-BF 4 - Prepared from 14 according to Procedure B on $2 \mathrm{mmol}$ scale, using

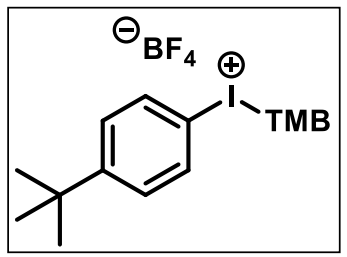
sodium tetrafluoroborate ( $22 \mathrm{~g}, 95$ equiv.) and obtained in $91 \%$ yield $(0.930 \mathrm{~g}, 1.81 \mathrm{mmol})$ as a white powder. ${ }^{1} \mathrm{H} \mathrm{NMR}(400 \mathrm{MHz}$, DMSO- $\left.d_{6}\right) \delta 7.85(\mathrm{~d}, J=8.6 \mathrm{~Hz}, 2 \mathrm{H}), 7.50(\mathrm{~d}, J=8.6 \mathrm{~Hz}, 2 \mathrm{H}), 6.48(\mathrm{~s}$, $2 \mathrm{H}), 3.97(\mathrm{~s}, 6 \mathrm{H}), 3.88(\mathrm{~s}, 3 \mathrm{H}), 1.25(\mathrm{~s}, 9 \mathrm{H}) .{ }^{13} \mathrm{C}$ NMR $(101 \mathrm{MHz}$, DMSO- $\left.d_{6}\right) \delta 166.6,159.9,155.2,134.7,129.2,113.0,92.5,87.4$, $57.8,56.6,35.3,31.2 .{ }^{19} \mathrm{~F} \mathrm{NMR}\left(376 \mathrm{MHz}, \mathrm{DMSO}-d_{6}\right) \delta(\mathrm{ppm})$ : -148.3. FT-IR: 3022, 2903, 2870, 1579, 1462, 1347, 1232, 1126, 1050, 995, 808, 665 $\mathrm{cm}^{-}$ 1. HRMS $\left(\mathrm{ESI}^{+}\right)$: Calculated for $\mathrm{C}_{19} \mathrm{H}_{24} \mathrm{IO}_{3}{ }^{+}\left[\mathrm{M}-\mathrm{BF}_{4}\right]^{+}$: 427.0765, Observed: 427.0747. Mp $162{ }^{\circ} \mathrm{C}$.

Compound 20-Br - Prepared from 20 according to Procedure B on $2 \mathrm{mmol}$ scale, using

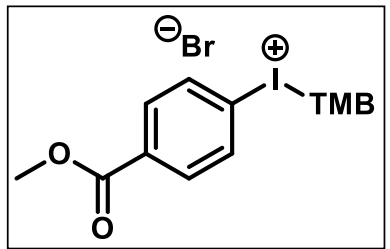
potassium bromide (12 g, 100 equiv.) and obtained in $85 \%$ yield (0.930 g, $1.81 \mathrm{mmol})$ as a white powder. ${ }^{1} \mathrm{H}$ NMR $(600 \mathrm{MHz}$, DMSO- $\left.d_{6}\right) \delta 8.27-7.79(\mathrm{~m}, 4 \mathrm{H}), 6.49(\mathrm{~s}, 2 \mathrm{H}), 3.97(\mathrm{~s}, 6 \mathrm{H}), 3.89-$ $3.52(\mathrm{~m}, 6 \mathrm{H}) .{ }^{13} \mathrm{C}$ NMR $\left(151 \mathrm{MHz}\right.$, DMSO- $\left.d_{6}\right) \delta$ 166.9, 165.6, $159.9,135.1,132.7,132.3,121.4,92.6,87.3,57.8,56.6,53.1$. FT-IR: 3086, 2988, 2972, 2901, 1721, 1579, 1279, $1121 \mathrm{~cm}^{-1}$. 
HRMS (ESI $)$ : Calculated for $\mathrm{C}_{17} \mathrm{H}_{18} \mathrm{IO}_{5}{ }^{+}[\mathrm{M}-\mathrm{Br}]^{+}:$429.0193; Observed 429.0167. Mp 152 ${ }^{\circ} \mathrm{C}$.

Compound $\mathbf{2 0}-\mathrm{Cl}$ - Prepared from 20 according to Procedure B on $3.25 \mathrm{mmol}$ scale,

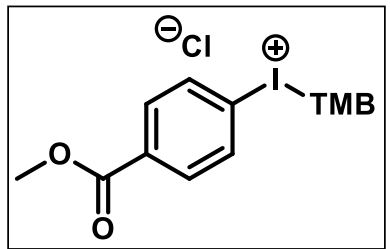
using sodium chloride (14 g, 74 equiv.) and obtained in $94 \%$ yield $(1.42 \mathrm{~g})$ as a white powder. ${ }^{1} \mathrm{H}$ NMR $\left(400 \mathrm{MHz}\right.$, DMSO- $d_{6}$ and $\left.\mathrm{CD}_{3} \mathrm{OD}\right) \delta 8.03-7.83(\mathrm{~m}, 4 \mathrm{H}), 6.37(\mathrm{~s}, 2 \mathrm{H}), 3.90(\mathrm{~s}, 6 \mathrm{H}), 3.82$ (s, 3H), 3.82 (s, 3H). ${ }^{13} \mathrm{C}$ NMR (101 MHz, DMSO- $\left.d_{6} \& \mathrm{CD}_{3} \mathrm{OD}\right) \delta$ $166.4,165.0,159.4,134.0,132.1,131.2,121.1,91.4,87.3,56.4$, 55.3, 51.7. FT-IR: 3071, 2988, 2971, 2944, 2901, 1733, 1577, $1280,1116,748 \mathrm{~cm}^{-1}$. HRMS $\left(\mathrm{ESI}^{+}\right)$: Calculated for $\mathrm{C}_{17} \mathrm{H}_{18} \mathrm{IO}_{5}{ }^{+}[\mathrm{M}-\mathrm{Cl}]^{+}:$429.0193; Observed 429.0170. $\mathrm{Mp} 167^{\circ} \mathrm{C}$.

Compound 20-TFA - Prepared from 20 according to Procedure B on $2 \mathrm{mmol}$ scale,<smiles>COC(=O)c1ccc(I(O)OC(=O)[O-])cc1</smiles>
using sodium trifluoroacetate ( $14 \mathrm{~g}, 50$ equiv.) and obtained in $33 \%$ yield $(1.42 \mathrm{~g})$ as a white powder. The filtrate in the final wash step was not extracted. ${ }^{1} \mathrm{H}$ NMR $\left(400 \mathrm{MHz}, \mathrm{DMSO}-d_{6}\right) \delta$ $8.06(\mathrm{~d}, J=7.8 \mathrm{~Hz}, 2 \mathrm{H}), 7.96(\mathrm{~d}, J=7.9 \mathrm{~Hz}, 2 \mathrm{H}), 6.48(\mathrm{~s}, 2 \mathrm{H}), 3.95$ $(\mathrm{s}, 6 \mathrm{H}), 3.88(\mathrm{~s}, 3 \mathrm{H}), 3.84(\mathrm{~s}, 3 \mathrm{H}) .{ }^{13} \mathrm{C}$ NMR $\left(151 \mathrm{MHz}, \mathrm{DMSO}-d_{6}\right)$ $\delta 166.7,165.7,160.0,15 j 8.6\left(q, J_{C-F}=31.1 \mathrm{~Hz}\right), 134.9,132.4$, $132.1,117.7\left(q, J_{C-F}=300.1 \mathrm{~Hz}\right), 92.5,88.1,57.7,56.6,53.0 .{ }^{19} \mathrm{~F}$ NMR (376 MHz, DMSO-d $\left.d_{6}\right) \delta-73.4$ (ppm): FT-IR: 3092, 3070, 2988, 2972, 2956, 2901, 1723, 1662, 1581, 1273, 1108, $763 \mathrm{~cm}^{-1}$. HRMS $\left(\mathrm{ESI}^{+}\right)$: Calculated for $\mathrm{C}_{17} \mathrm{H}_{18} \mathrm{IO}_{5}{ }^{+}\left[\mathrm{M}-\mathrm{CF}_{3} \mathrm{COO}\right]^{+}:$: 429.0193; Observed 429.0200. Mp $168{ }^{\circ} \mathrm{C}$. Compound 20-OAc - Prepared to Procedure C by stirring 20-Br (2.314 g, $4.55 \mathrm{mmol})$<smiles>COC(=O)c1ccc(I(O)OC(=O)[O-])cc1</smiles>
into hot acetonitrile until completely dissolved. Silver acetate ( $2.3 \mathrm{~g}, 3$ equiv) was added and a yellow powder immediately precipitated and gradually turned grey. The product was obtained as a white powder in $47 \%$ yield $(1.033 \mathrm{~g}, 2.12 \mathrm{mmol})$. ${ }^{1} \mathrm{H}$ NMR $\left(400 \mathrm{MHz}, \mathrm{CD}_{3} \mathrm{OD}\right) \delta 8.12-8.00(\mathrm{~m}, 4 \mathrm{H}), 6.45(\mathrm{~s}, 2 \mathrm{H})$, $4.00(\mathrm{~s}, 6 \mathrm{H}), 3.95-3.91(\mathrm{~m}, 6 \mathrm{H}), 1.89(\mathrm{~s}, 3 \mathrm{H}) .{ }^{13} \mathrm{C}$ NMR $(101$ $\left.\mathrm{MHz}, \mathrm{CD}_{3} \mathrm{OD}\right) \delta$ 178.4, 167.5, 165.4, 160.1, 134.3, 133.1, 131.8, 119.5, 91.6, 85.1, 56.4, 55.3, 51.8, 22.6. FTIR: 3079, 3053, 3028, 2947, 2907, 2834, 1716, 1579, 1549, 1388, $1339,1277,1225,1158,1116,1066,807,761,643 \mathrm{~cm}^{-1}$. HRMS $\left(E S I^{+}\right)$: Calculated for $\mathrm{C}_{17} \mathrm{H}_{18} \mathrm{IO}_{5}{ }^{+}[\mathrm{M}-\mathrm{OAC}]^{+}:$429.0193; Observed 429.0191. Mp $111^{\circ} \mathrm{C}$.

Compound 20-OTf - Prepared from 20 according to Procedure B on $1 \mathrm{mmol}$ scale,

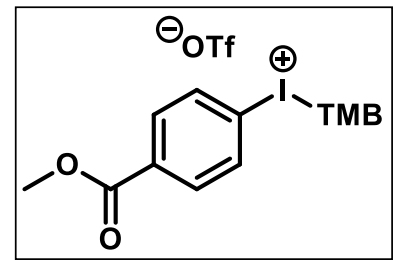
using sodium triflate ( $3 \mathrm{~g}, 17.5$ equiv) and obtained in $84 \%$ yield as a white powder. ${ }^{1} \mathrm{H}$ NMR $\left(400 \mathrm{MHz}, \mathrm{DMSO}-d_{6}\right) \delta 8.05$ (d, J = 8.6 Hz, 2H), $7.98(\mathrm{~d}, J=8.6 \mathrm{~Hz}, 2 \mathrm{H}), 6.49(\mathrm{~s}, 2 \mathrm{H}), 3.95$ (s, $6 \mathrm{H}), 3.88(\mathrm{~s}, 3 \mathrm{H}), 3.86(\mathrm{~s}, 3 \mathrm{H}) .{ }^{13} \mathrm{C}$ NMR $\left(101 \mathrm{MHz}, \mathrm{DMSO}-d_{6}\right) \delta$ $166.4,165.1,159.4,134.6,132.2,131.8,120.8,120.7$ (q, J J $\mathrm{C}_{-F}$ $=322.4 \mathrm{~Hz}), 92.1$, $86.8,57.3$, 56.2 , 52.6. ${ }^{19} \mathrm{~F} \mathrm{NMR}(376 \mathrm{MHz}$, 
DMSO-d6) $\delta$-77.7 (s). FTIR: 3107, 2950, 2849, 1732, 1576, 1464, 1352, 1275, 1229, $1159,1029,816,665 \mathrm{~cm}^{-1}$. HRMS $\left(\mathrm{ESI}^{+}\right)$: Calculated for $\mathrm{C}_{17} \mathrm{H}_{18} \mathrm{IO}_{5}{ }^{+}[\mathrm{M}-\mathrm{OTf}]^{+}: 429.0193$; Observed 429.0191. Mp $104^{\circ} \mathrm{C}$.

Compound 20-BF 4 - Prepared from 20 according to Procedure B on $2 \mathrm{mmol}$ scale, using<smiles></smiles>
sodium tetrafluoroborate ( $11 \mathrm{~g}, 50$ equiv) and obtained in $77 \%$ yield $(0.8079 \mathrm{~g})$ as a white powder. The filtrate was not extracted to recover more product. ${ }^{1} \mathrm{H}$ NMR $(400 \mathrm{MHz}$, DMSO$d_{6}$ and $\left.\mathrm{CD}_{3} \mathrm{OD}\right) \delta 8.61-7.78(\mathrm{~m}, 4 \mathrm{H}), 6.49(\mathrm{~s}, 2 \mathrm{H}), 4.01(\mathrm{~s}, 6 \mathrm{H})$, $3.92-3.78(\mathrm{~m}, 6 \mathrm{H}) .{ }^{13} \mathrm{C}$ NMR $\left(101 \mathrm{MHz}, \mathrm{DMSO}-d_{6}\right.$ and $\left.\mathrm{CD}_{3} \mathrm{OD}\right) \delta$ $166.9,165.6,159.9,135.1,132.7,132.3,121.4,92.6,87.3,57.8$, 56.6, 53.1. ${ }^{19} \mathrm{~F}$ NMR (376 MHz, DMSO- $d_{6}$ and $\left.\mathrm{CD}_{3} \mathrm{OD}\right) \delta-148.30$ (s). FT-IR: 3089,2988 , 2971, 2901, 1716, 1578, 1549, 1277, 1159, 1115, 1066, $642 \mathrm{~cm}^{-1}$. HRMS (ESI'): Calculated for $\mathrm{C}_{17} \mathrm{H}_{18} \mathrm{IO}_{5}{ }^{+}\left[\mathrm{M}-\mathrm{BF}_{4}\right]^{+}:$429.0193; Observed 429.0186. Mp $168{ }^{\circ} \mathrm{C}$ (decomposed).

Compound 50 - Prepared according to Procedure D on $0.5 \mathrm{mmol}$ scale and obtained in

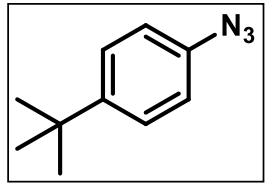
$94 \%$ ( $0.0818 \mathrm{~g}, 0.47 \mathrm{mmol}$ ) yield as a pale yellow oil. The crude product was adsorbed onto silica and purified by column chromatography using hexanes as the eluent. The characterization data agree with previously reported values. ${ }^{55}{ }^{1} \mathrm{H} \mathrm{NMR}\left(400 \mathrm{MHz}, \mathrm{CDCl}_{3}\right) \delta 7.31(\mathrm{~d}, J=8.6 \mathrm{~Hz}, 2 \mathrm{H})$, $6.90(\mathrm{~d}, J=8.6 \mathrm{~Hz}, 2 \mathrm{H}), 1.27(\mathrm{~s}, 9 \mathrm{H}) .{ }^{13} \mathrm{C} \mathrm{NMR}\left(101 \mathrm{MHz}, \mathrm{CDCl}_{3}\right) \delta$ 147.9, $137.2,126.6,119.0,34.5,31.3$.

Compound 51 - Prepared according to Procedure D on $0.1 \mathrm{mmol}$ scale with the

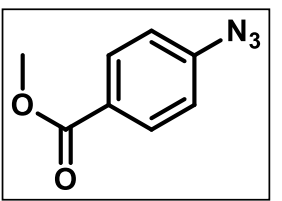
following deviations: i) the crude reaction was extracted with pentane and purified by column chromatography on silica using $5 \%$ ethyl ether followed by $10 \%$ ethyl ether in pentane. The product was obtained in $95 \%(0.0167 \mathrm{~g}, 0.095 \mathrm{mmol})$ yield as a pale yellow solid. The characterization data agree with previously reported values. ${ }^{56}{ }^{1} \mathrm{H}$ NMR $\left(600 \mathrm{MHz}, \mathrm{CDCl}_{3}\right) \delta 8.03(\mathrm{~d}, J=8.1 \mathrm{~Hz}, 1 \mathrm{H}), 7.07(\mathrm{~d}, J=8.1 \mathrm{~Hz}, 1 \mathrm{H}), 3.91(\mathrm{~s}, 1 \mathrm{H}) .{ }^{13} \mathrm{C} \mathrm{NMR}$ $\left(151 \mathrm{MHz} \mathrm{CDCl}_{3}\right) \delta 166.3,144.8,131.4,126.7,118.8,52.2$.

Compound 56 - Prepared according to Procedure D on $0.1 \mathrm{mmol}$ scale with the following deviations: i) acetonitrile was used as the solvent, ii) the  crude reaction was extracted with ethyl ether and purified by column chromatography on silica using ethyl ether in hexanes $(1: 1)$ to followed by neat ethyl ether. The product was obtained in $86 \%(0.014 \mathrm{~g}, 0.086 \mathrm{mmol})$ yield as a colorless oil. The characterization data agree with previously reported values. ${ }^{57}{ }^{1} \mathrm{H} \mathrm{NMR}\left(600 \mathrm{MHz}, \mathrm{CDCl}_{3}\right) \delta 7.21(\mathrm{~d}, J=7.6 \mathrm{~Hz}, 2 \mathrm{H}), 6.98(\mathrm{~d}$, $J=7.4 \mathrm{~Hz}, 2 \mathrm{H}), 3.84(\mathrm{t}, J=6.4 \mathrm{~Hz}, 2 \mathrm{H}), 2.84(\mathrm{t}, J=6.4 \mathrm{~Hz}, 2 \mathrm{H}), 1.70(\mathrm{~s}, 1 \mathrm{H}) .{ }^{13} \mathrm{C}$ NMR (101 $\left.\mathrm{MHz}_{2} \mathrm{CDCl}_{3}\right) \delta 138.3,135.5,130.5,119.2,65.9,38.6$. 
Compound 57 - Prepared according to Procedure D on $0.5 \mathrm{mmol}$ scale and obtained in ${ }_{\mathrm{Me}}^{\mathrm{O} N} \mathrm{~N}^{\mathrm{N}_{3}}$ $93 \%(0.0828 \mathrm{~g}, 0.465 \mathrm{mmol})$ yield as a yellow solid. ${ }^{1} \mathrm{H}$ NMR $(400 \mathrm{MHz}$, $\left.\mathrm{CDCl}_{3}\right) \delta 7.64(\mathrm{~d}, J=2.4 \mathrm{~Hz}, 1 \mathrm{H}), 7.33(\mathrm{~d}, J=8.3 \mathrm{~Hz}, 1 \mathrm{H}), 7.17$ (dd, $J=$ 8.3, 2.4 Hz, $1 \mathrm{H}), 2.57(\mathrm{~s}, 3 \mathrm{H}) .{ }^{13} \mathrm{C} \mathrm{NMR}\left(101 \mathrm{MHz}, \mathrm{CDCl}_{3}\right) \delta 149.7,139.3$, 134.1, 130.0, 123.4, 115.2, 20.0. FT-IR: 3081, 2988, 2938, 2901, 2110, $1527,1303,1338,1066,907,872,729 \mathrm{~cm}^{-1}$. HRMS (ESI ${ }^{+}$) Calculated for $\mathrm{C}_{7} \mathrm{H}_{6} \mathrm{~N}_{4} \mathrm{O}_{2}{ }^{+}[\mathrm{M}$ $\mathrm{H}^{+}:$178.0491; Observed 178.0507. Mp $67-68^{\circ} \mathrm{C}$

Compound 58 - Prepared according to Procedure D on $0.5 \mathrm{mmol}$ scale and obtained in<smiles>Nc1ccc(Br)c(COc2cc(Cl)cc(Cl)c2)c1</smiles>
$92 \%(0.172 \mathrm{~g}, 0.462 \mathrm{mmol})$ yield. ${ }^{1} \mathrm{H} \mathrm{NMR}\left(400 \mathrm{MHz}, \mathrm{CDCl}_{3}\right)$ $\delta 7.55(\mathrm{~d}, J=8.5 \mathrm{~Hz}, 1 \mathrm{H}), 7.17(\mathrm{~d}, J=2.7 \mathrm{~Hz}, 1 \mathrm{H}), 7.01(\mathrm{t}, J=$ $1.8 \mathrm{~Hz}, 1 \mathrm{H}), 6.91-6.85(\mathrm{~m}, 3 \mathrm{H}), 5.04(\mathrm{~s}, 2 \mathrm{H}) .{ }^{13} \mathrm{C}$ NMR (101 $\left.\mathrm{MHz}, \mathrm{CDCl}_{3}\right) \delta 159.1,140.0,137.0,135.6,133.9,121.9$, 120.0, 119.2, 117.2, 114.0, 69.4. FT-IR: 3095, 3055, 2920, $2842,2115,2075,1590,1572,1299,1057,804,662 \mathrm{~cm}^{-1}$. HRMS (ESI+) Calculated for $\mathrm{C}_{13} \mathrm{H}_{8} \mathrm{BrCl}_{2} \mathrm{~N}_{3} \mathrm{O}[\mathrm{M}-\mathrm{H}]^{+}: 370.9228$; Observed 370.9250. Mp $98-99^{\circ} \mathrm{C}$

Compound 59 - Prepared according Procedure D on $0.1 \mathrm{mmol}$ scale with the following $\overbrace{N}^{N_{3}}$ deviations: i) acetonitrile was used as the solvent. The crude product was purified by column chromatography on silica using $10 \%$ ethyl ether in hexanes. The product was obtained in $74 \%(0.0114 \mathrm{~g}, 0.074$ mmol) yield as a yellow solid. ${ }^{1} \mathrm{H} \mathrm{NMR}\left(400 \mathrm{MHz}, \mathrm{CDCl}_{3}\right) \delta 8.14$ (dd, $\mathrm{J}=$ 2.1, $1.5 \mathrm{~Hz}, 1 \mathrm{H}), 7.45-7.25(\mathrm{~m}, 2 \mathrm{H}) .{ }^{13} \mathrm{C}$ NMR $\left(101 \mathrm{MHz}, \mathrm{CDCl}_{3}\right) \delta 147.1,140.7,136.4$, 128.9, 125.0. FT-IR: 3086, 3055, 2131, 2099, 1455, 1299, 824, $565 \mathrm{~cm}^{-1}$. HRMS (ESI+) Calculated for $\mathrm{C}_{5} \mathrm{H}_{3} \mathrm{ClN}_{4}[\mathrm{M}-\mathrm{H}]^{+}: 154.0046$ Observed 154.0066. Mp $39{ }^{\circ} \mathrm{C}$. 
5.3.10. NMR spectra for aryl(TMP)iodonium tosylates

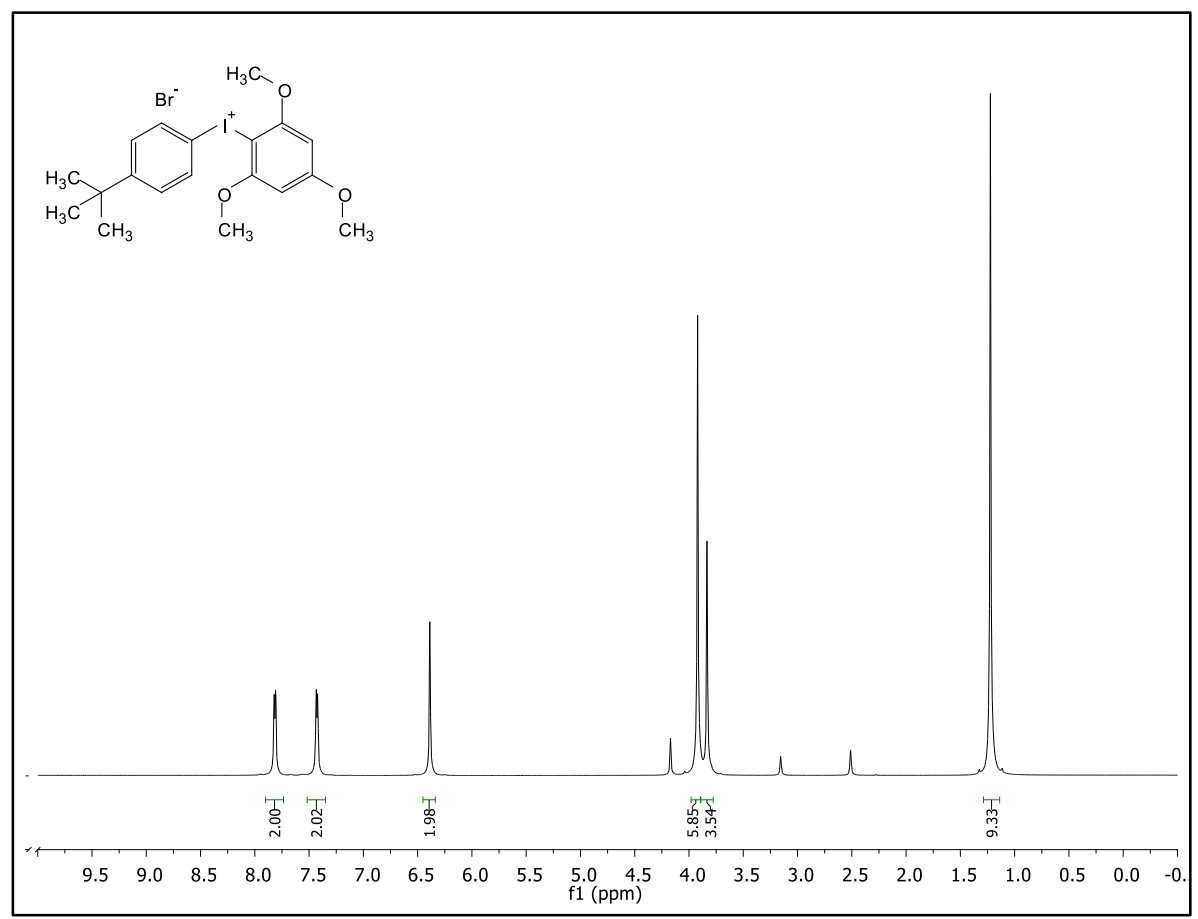

Figure $177 .{ }^{1} \mathrm{H}$ NMR spectrum of $14-\mathrm{Br}$ at $600 \mathrm{MHz}$ in $\mathrm{DMSO}-d_{6}$ and $\mathrm{CD}_{3} \mathrm{OD}$ at $298 \mathrm{~K}$

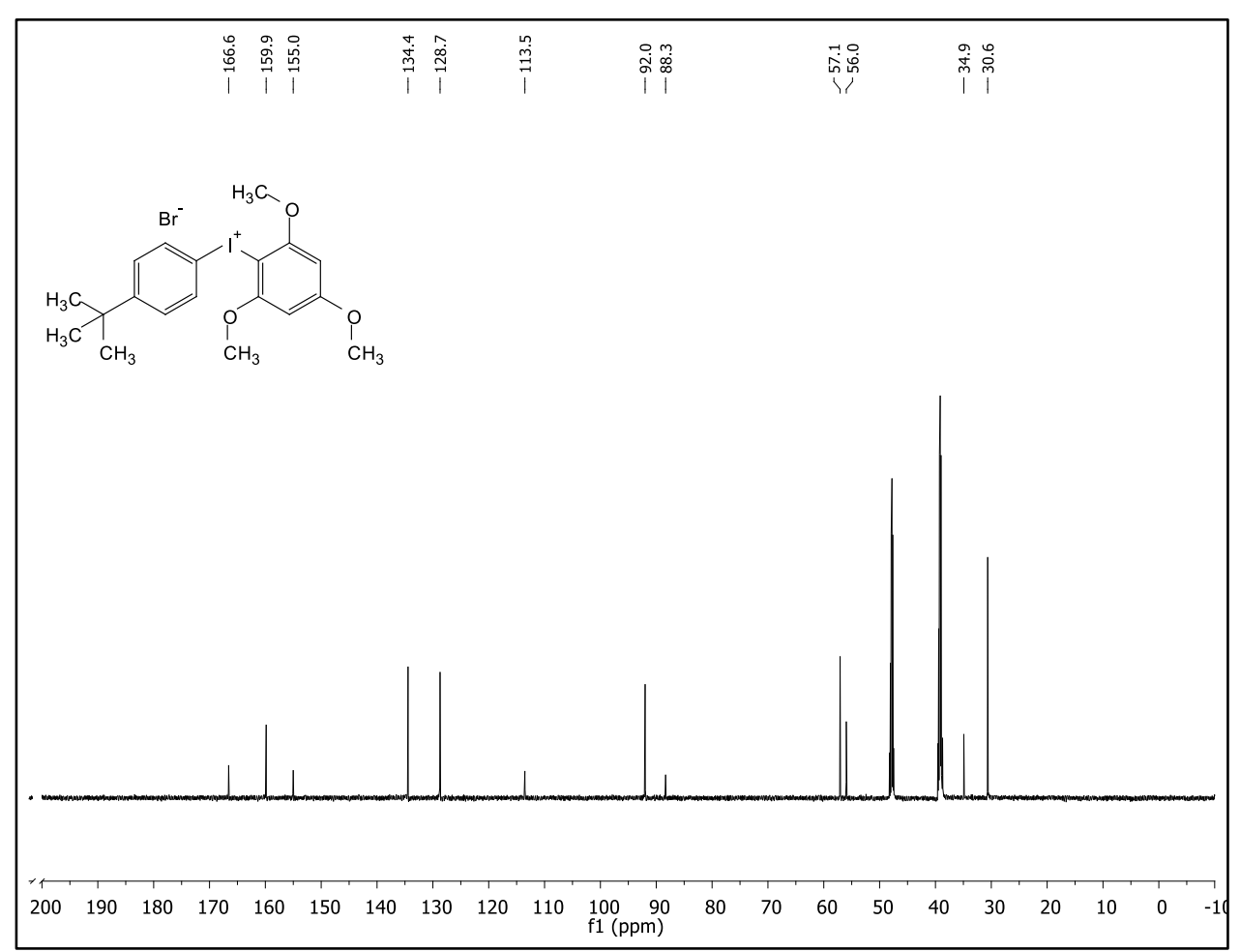

Figure $178 .{ }^{13} \mathrm{C}$ NMR spectrum of $14-\mathrm{Br}$ at $101 \mathrm{MHz}$ in DMSO-d $\mathrm{d}_{6}$ and $\mathrm{CD}_{3} \mathrm{OD}$ at $298 \mathrm{~K}$ 


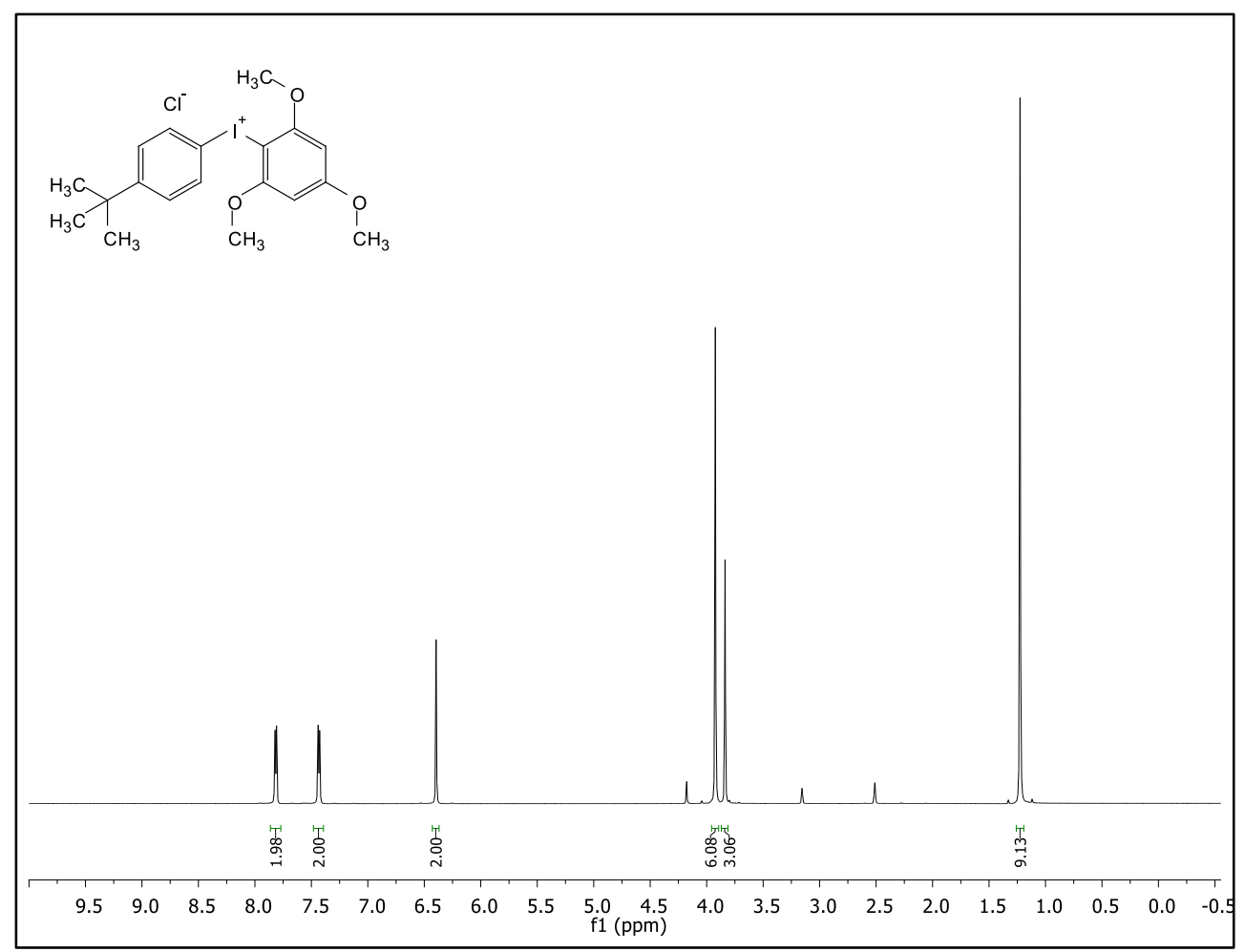

Figure 179. ${ }^{1} \mathrm{H}$ NMR spectrum of $14-\mathrm{Cl}$ at $400 \mathrm{MHz}$ in DMSO- $d_{6}$ and $\mathrm{CD}_{3} \mathrm{OD}$ at $298 \mathrm{~K}$

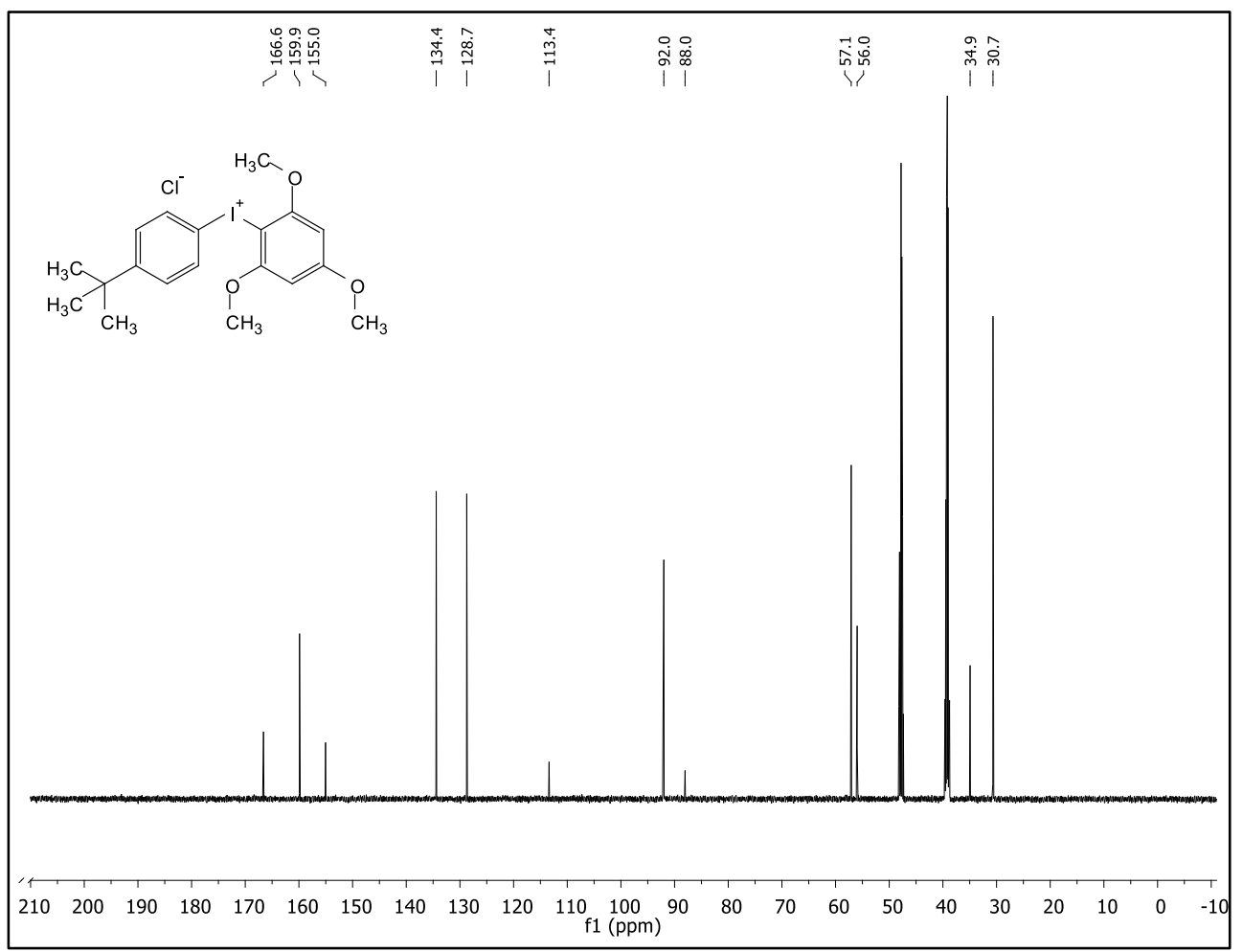

Figure $180 .{ }^{13} \mathrm{C}$ NMR spectrum of $14-\mathrm{Cl}$ at $101 \mathrm{MHz}$ in DMSO- $d_{6}$ and $\mathrm{CD}_{3} \mathrm{OD}$ at $298 \mathrm{~K}$ 


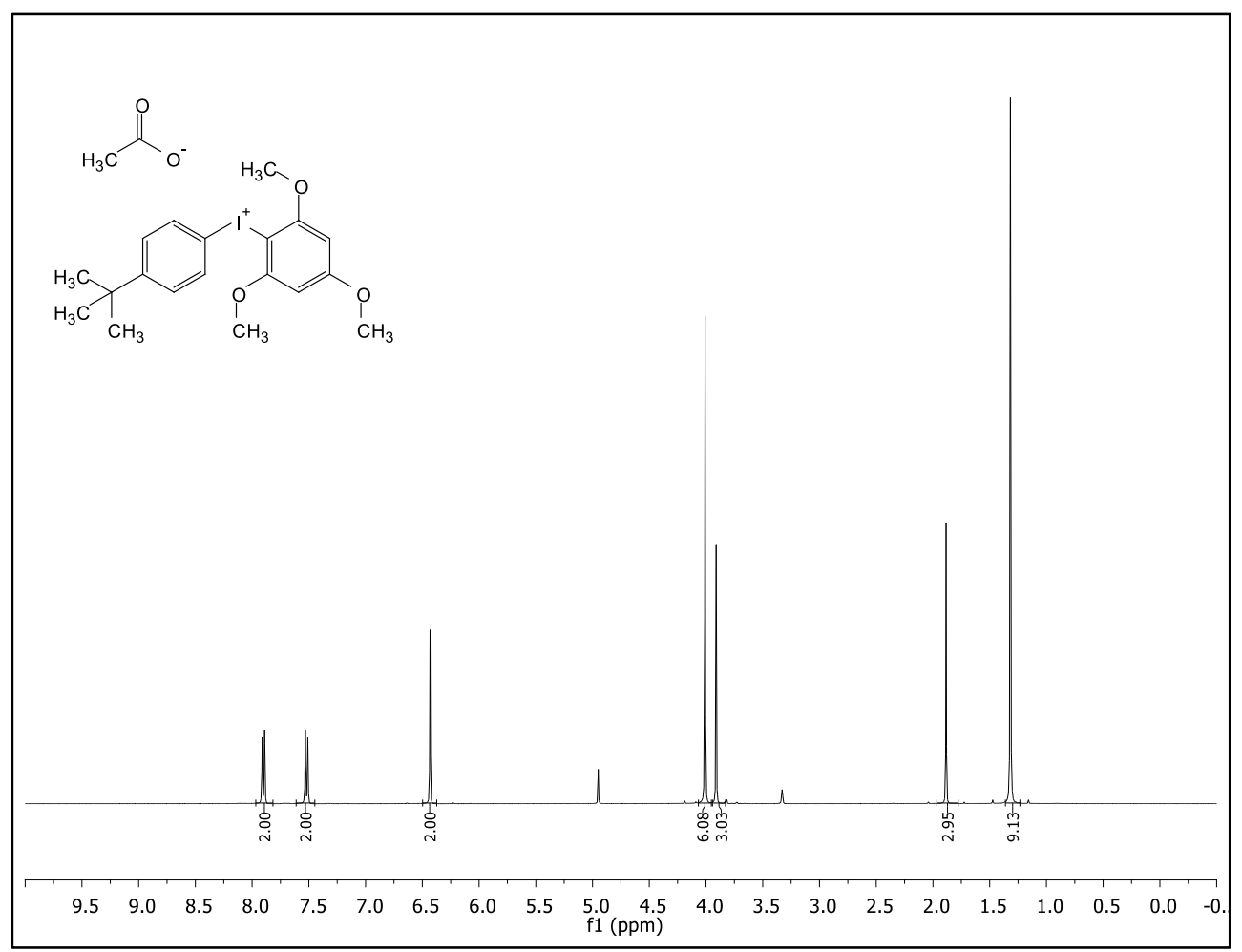

Figure 181. ${ }^{1} \mathrm{H}$ NMR spectrum of $14-\mathrm{OAC}$ at $400 \mathrm{MHz}$ in $\mathrm{CD}_{3} \mathrm{OD}$ at $298 \mathrm{~K}$

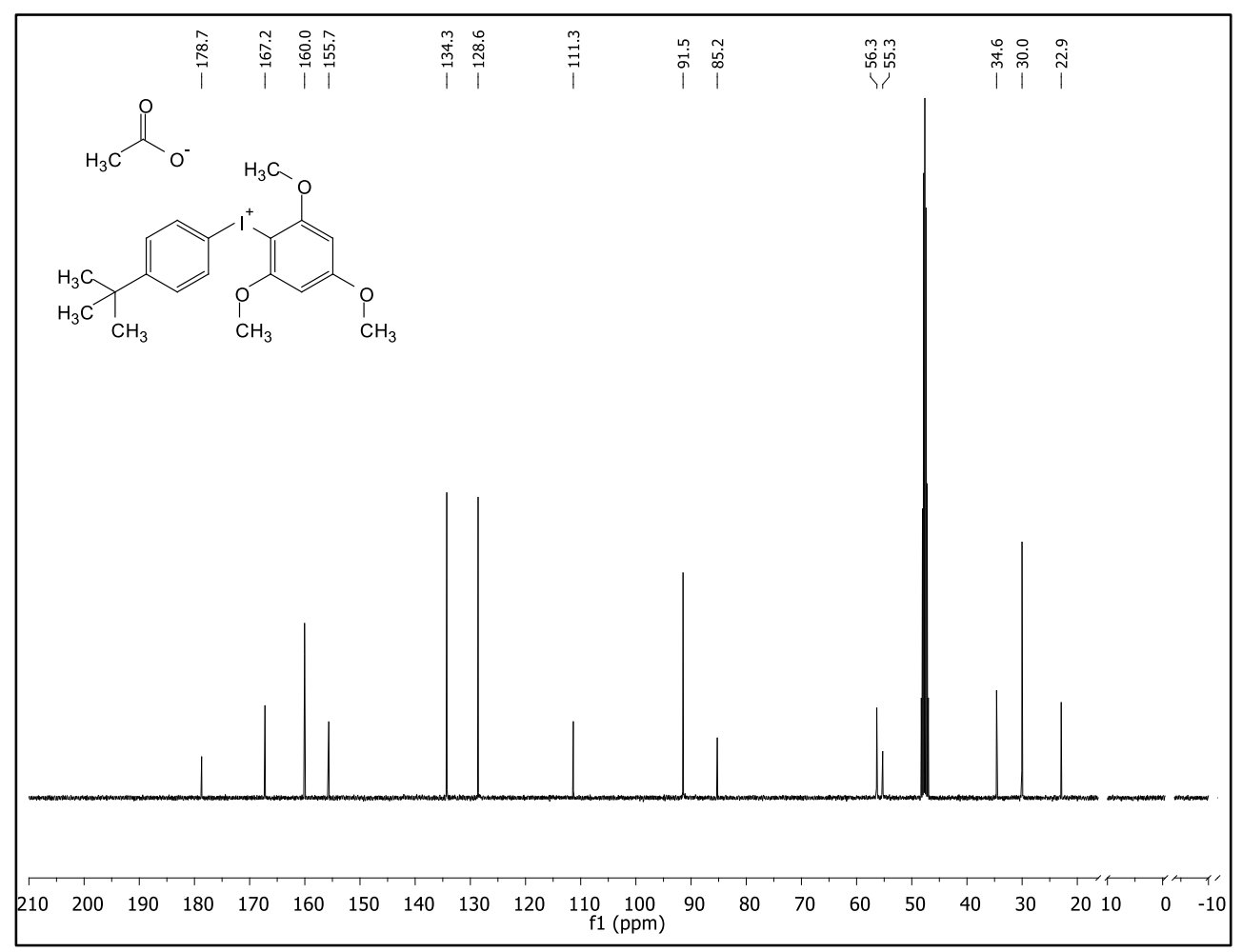

Figure $182 .{ }^{13} \mathrm{C}$ NMR spectrum of $14-\mathrm{OAC}$ at $101 \mathrm{MHz}$ in $\mathrm{CD}_{3} \mathrm{OD}$ at $298 \mathrm{~K}$ 


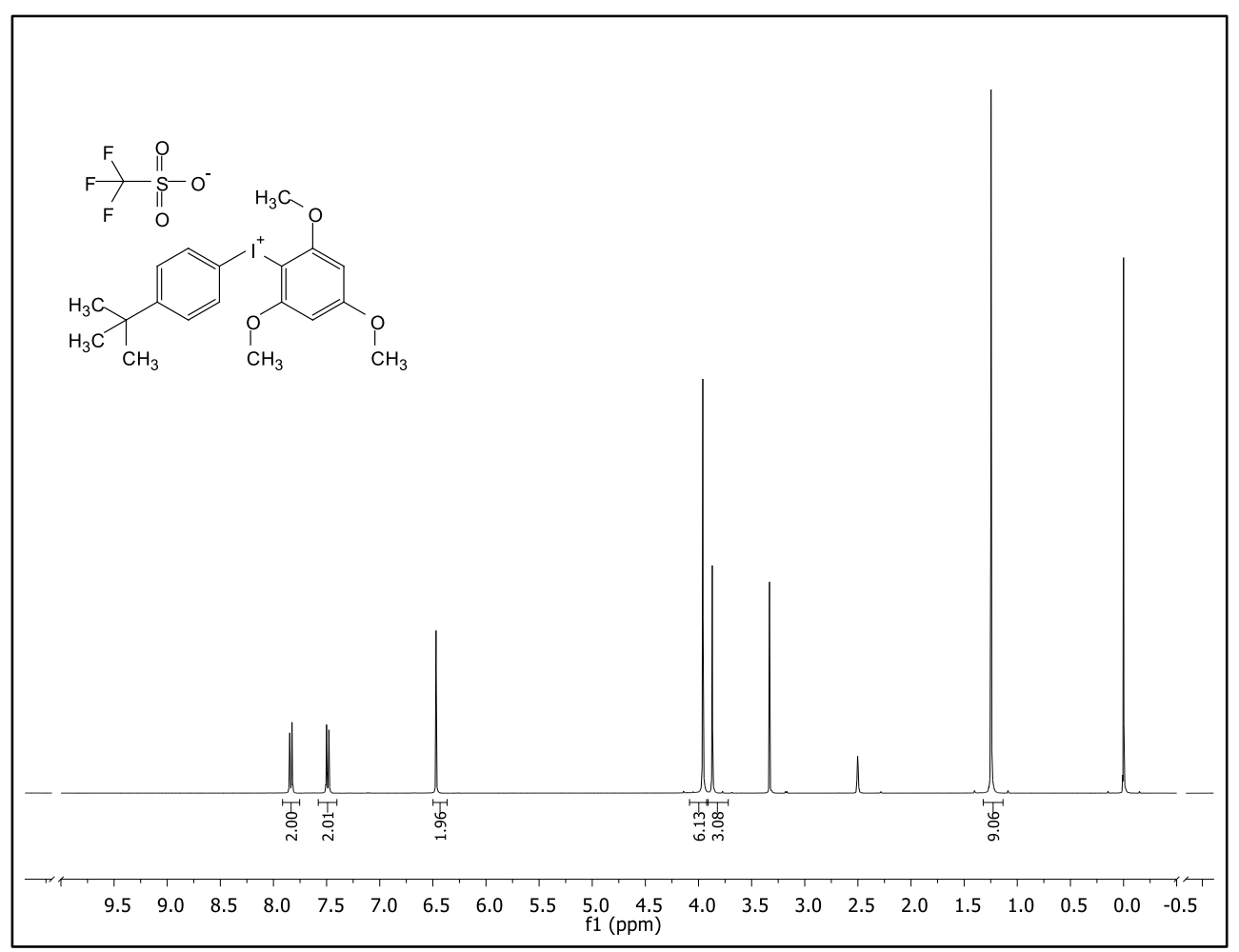

Figure $183 .{ }^{1} \mathrm{H}$ NMR spectrum of $14-0 \mathrm{Tf}$ at $400 \mathrm{MHz}$ in DMSO-d ${ }_{6}$ at $298 \mathrm{~K}$

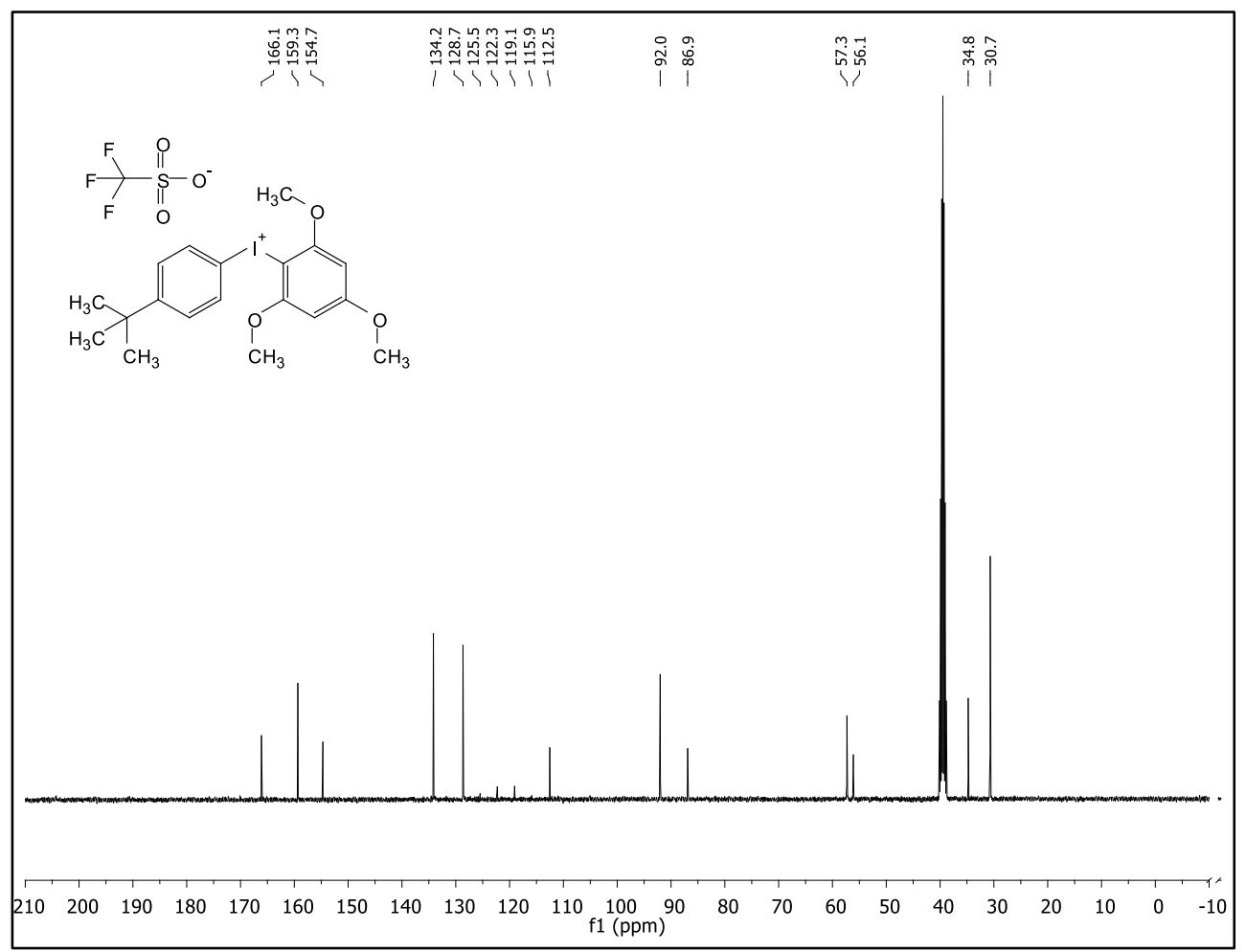

Figure $184 .{ }^{13} \mathrm{C}$ NMR spectrum of $14-0 \mathrm{Tf}$ at $101 \mathrm{MHz}$ in DMSO-d $d_{6}$ at $298 \mathrm{~K}$ 


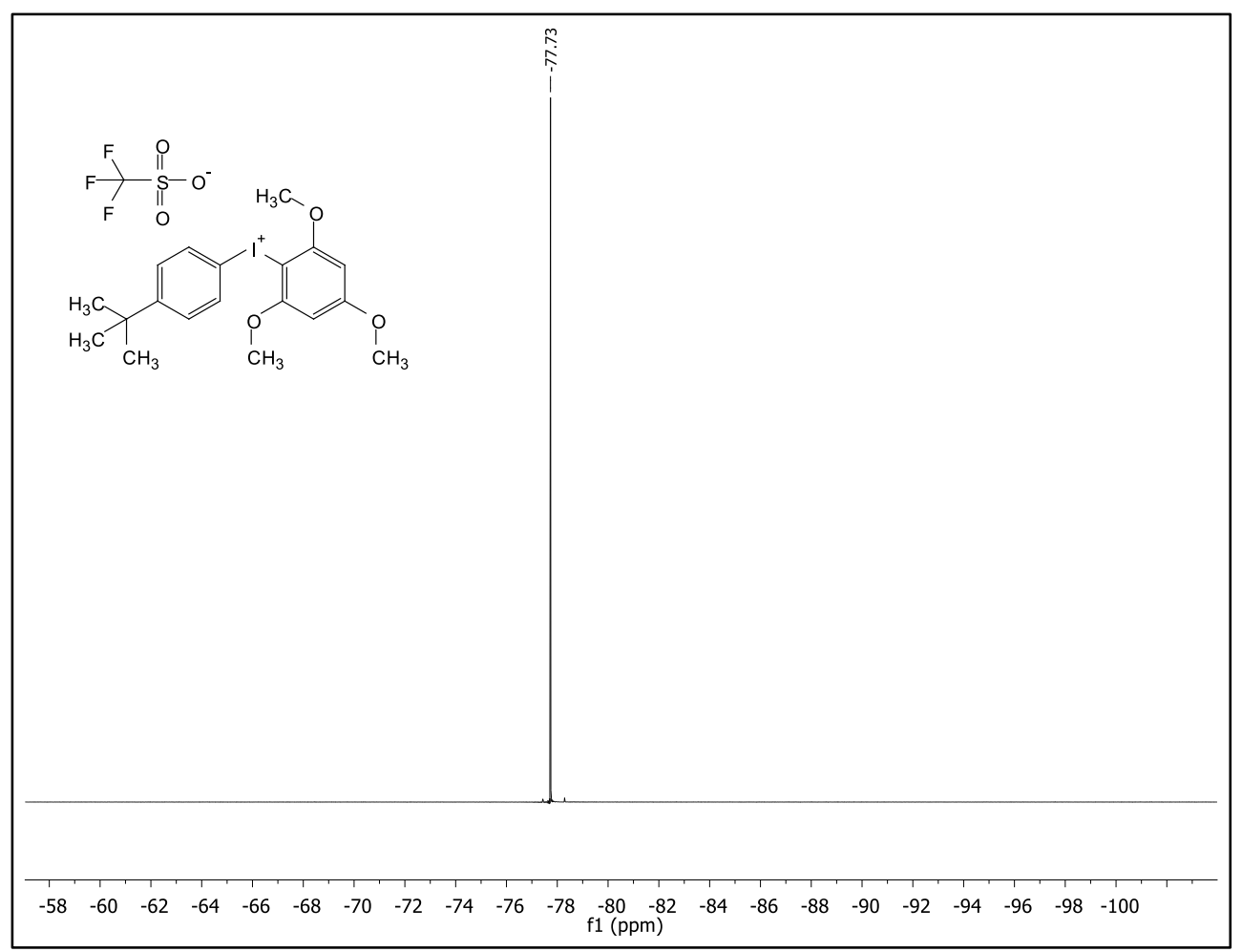

Figure $185 .{ }^{19} \mathrm{~F}$ NMR spectrum of $14-\mathrm{OTf}$ at $376 \mathrm{MHz}$ in DMSO- $d_{6}$ at $298 \mathrm{~K}$

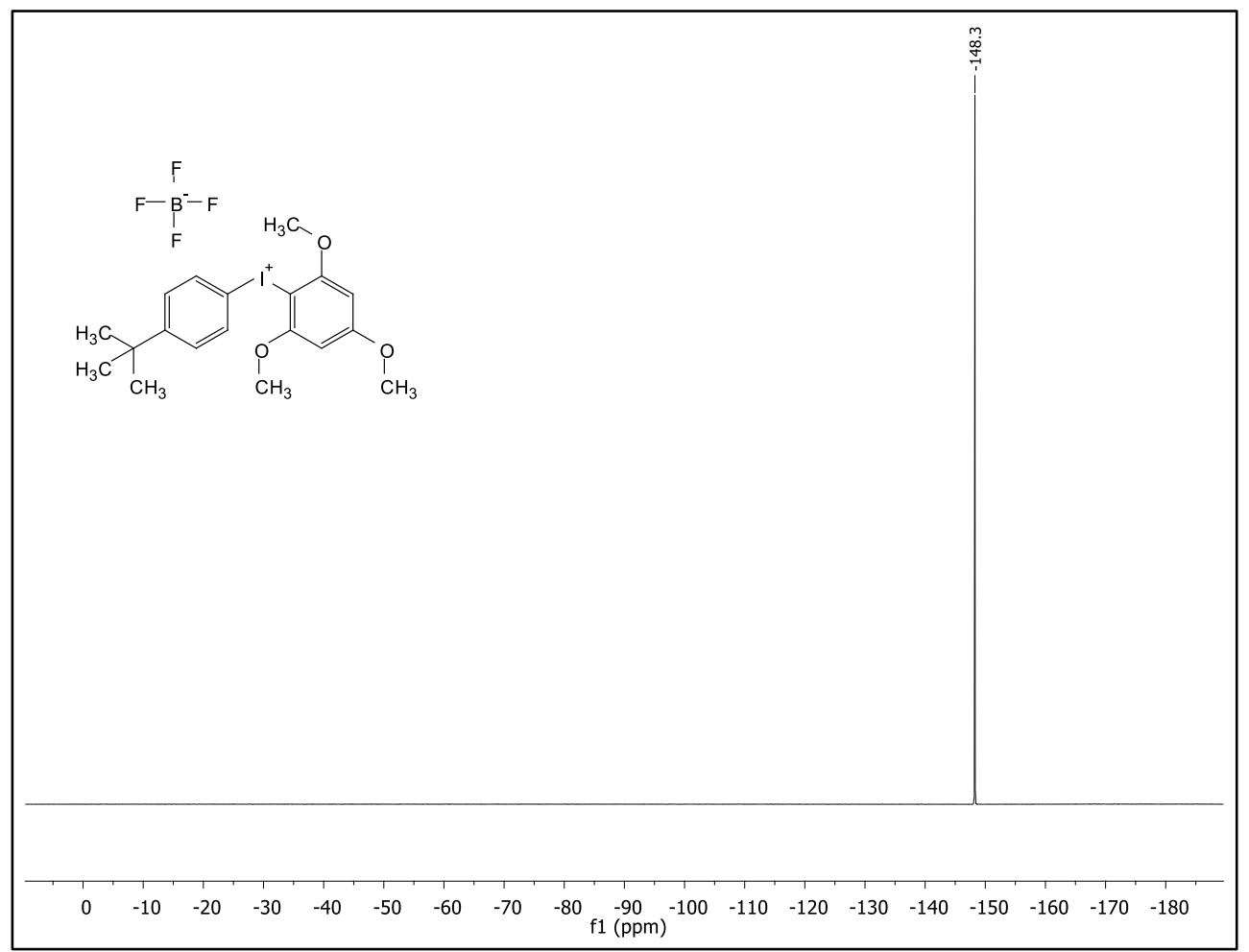

Figure $186 .{ }^{1} \mathrm{H}$ NMR spectrum of $14-\mathrm{BF}_{4}$ at $400 \mathrm{MHz}$ in DMSO- $d_{6}$ at $298 \mathrm{~K}$ 


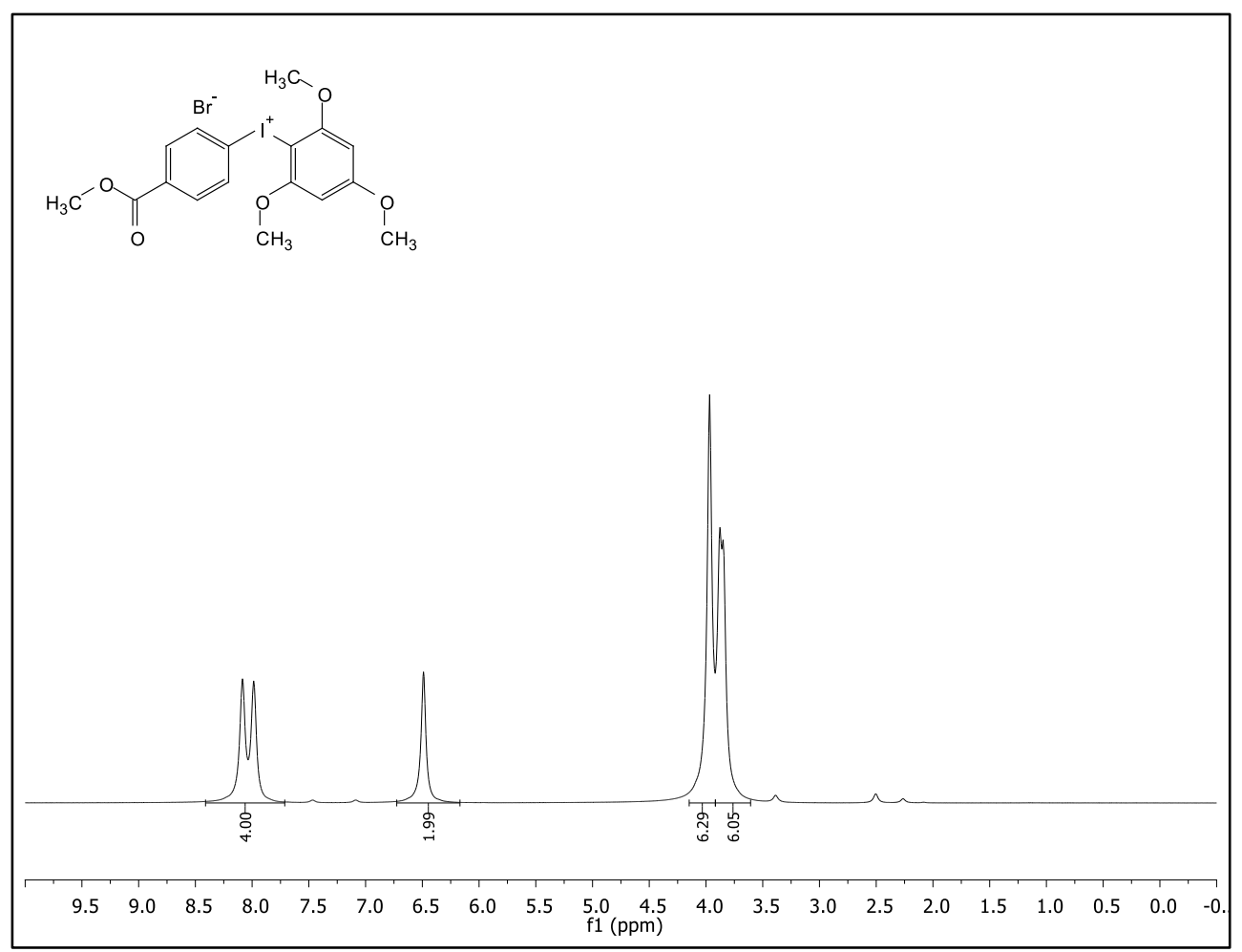

Figure 187. ${ }^{1} \mathrm{H}$ NMR spectrum of $20-\mathrm{Br}$ at $600 \mathrm{MHz}$ in DMSO-d $d_{6}$ at $298 \mathrm{~K}$

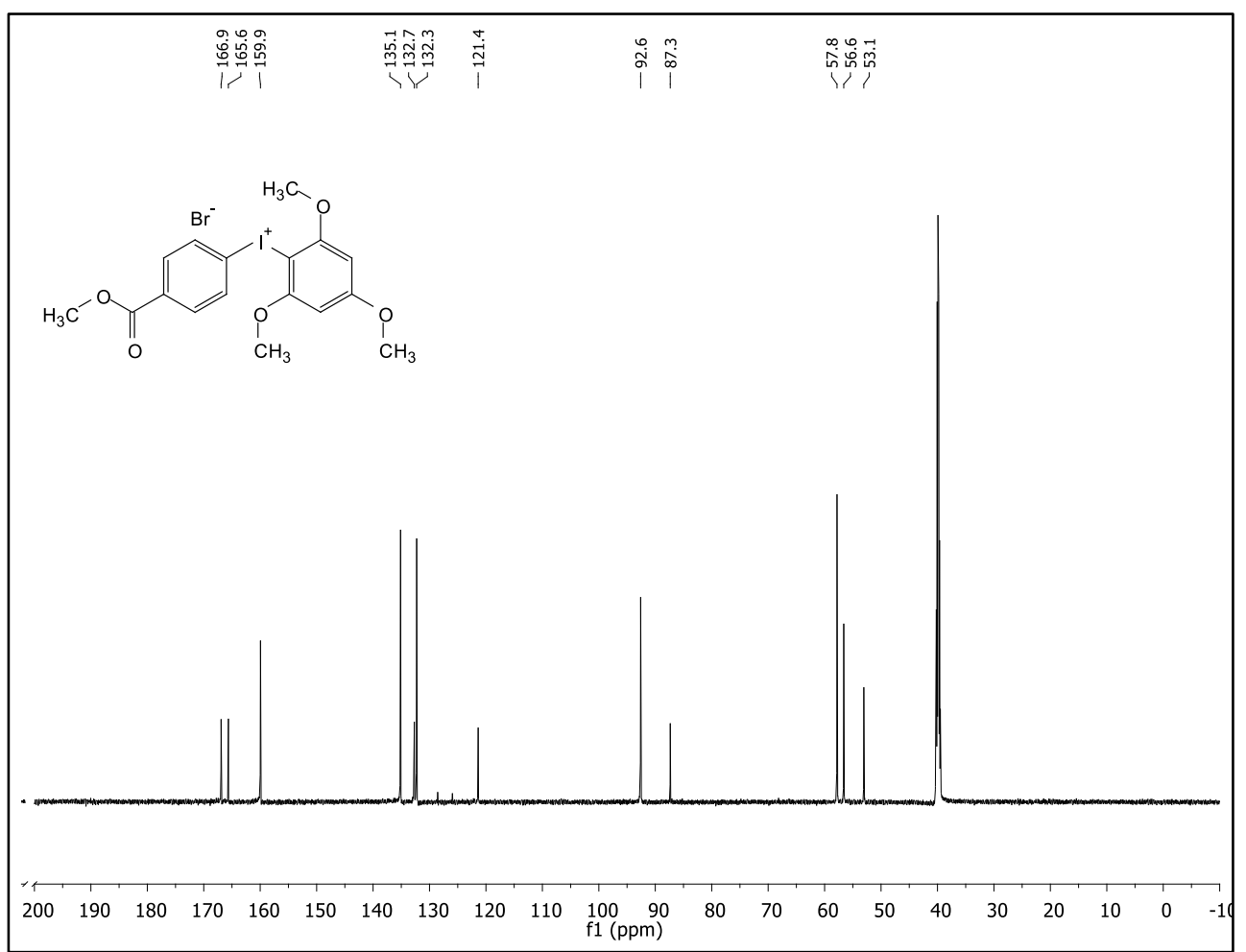

Figure 188. ${ }^{13} \mathrm{C}$ NMR spectrum of $20-\mathrm{Br}$ at $151 \mathrm{MHz}$ in DMSO- $d_{6}$ and $\mathrm{CD}_{3} \mathrm{OD}$ at $298 \mathrm{~K}$ 


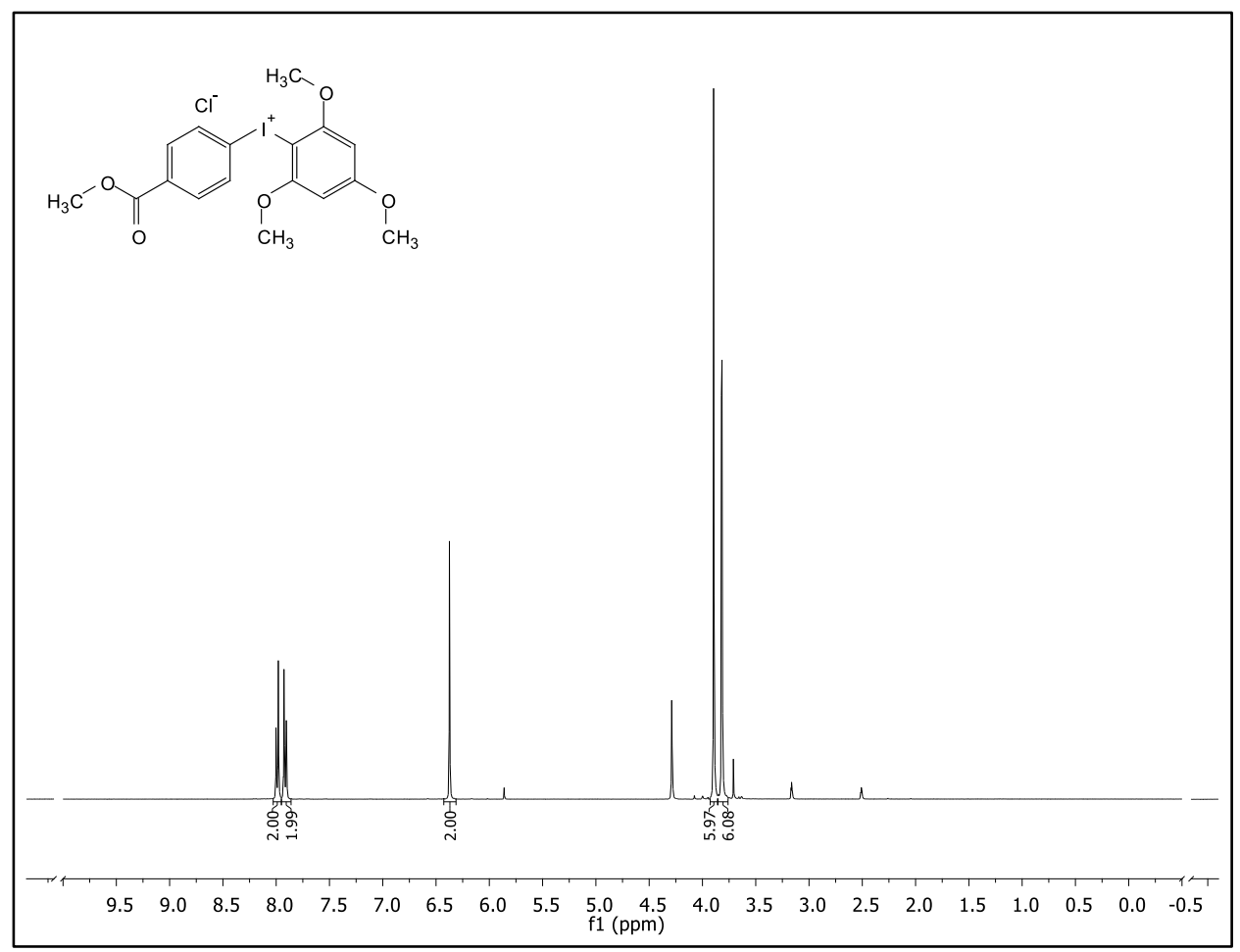

Figure $189 .{ }^{1} \mathrm{H} \mathrm{NMR}$ spectrum of $20-\mathrm{Cl}$ at $400 \mathrm{MHz}$ in DMSO- $d_{6}$ and $\mathrm{CD}_{3} \mathrm{OD}$ at $298 \mathrm{~K}$

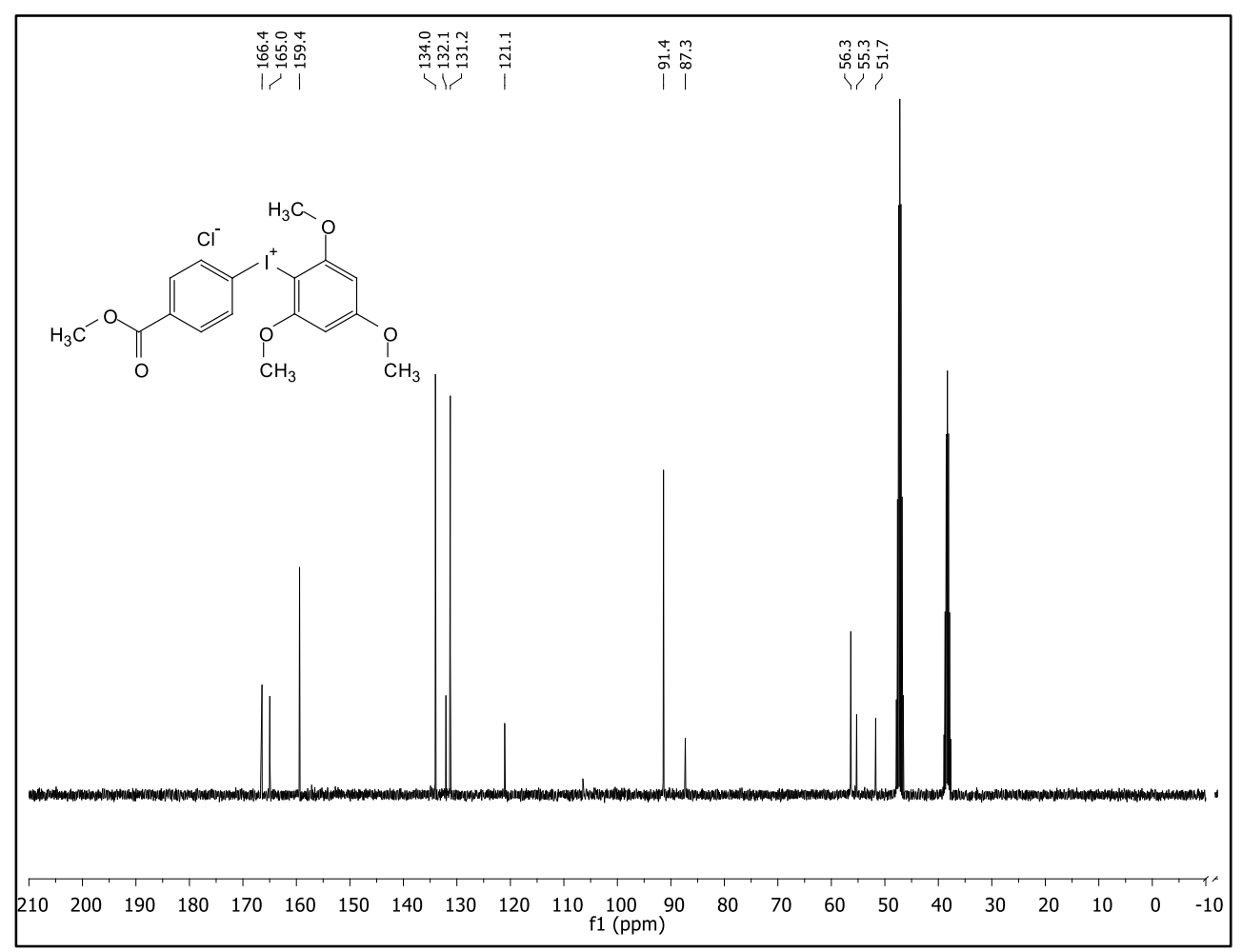

Figure $190 .{ }^{13} \mathrm{C} \mathrm{NMR}$ spectrum of $20-\mathrm{Cl}$ at $101 \mathrm{MHz}$ in DMSO- $d_{6}$ and $\mathrm{CD}_{3} \mathrm{OD}$ at $298 \mathrm{~K}$ 


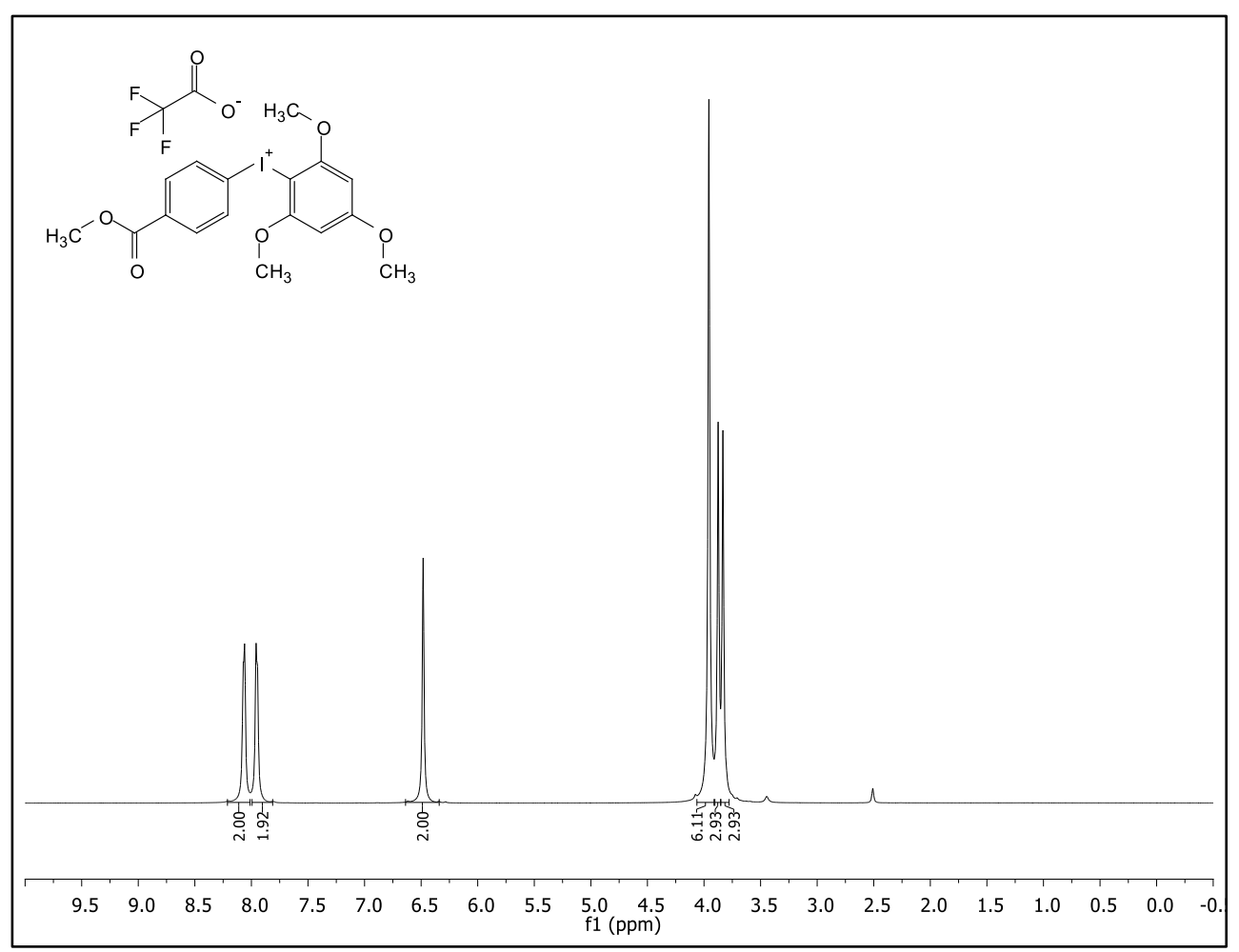

Figure $191 .{ }^{1} \mathrm{H}$ NMR spectrum of 20 -TFA at $600 \mathrm{MHz}$ in DMSO- $d_{6}$ at $298 \mathrm{~K}$

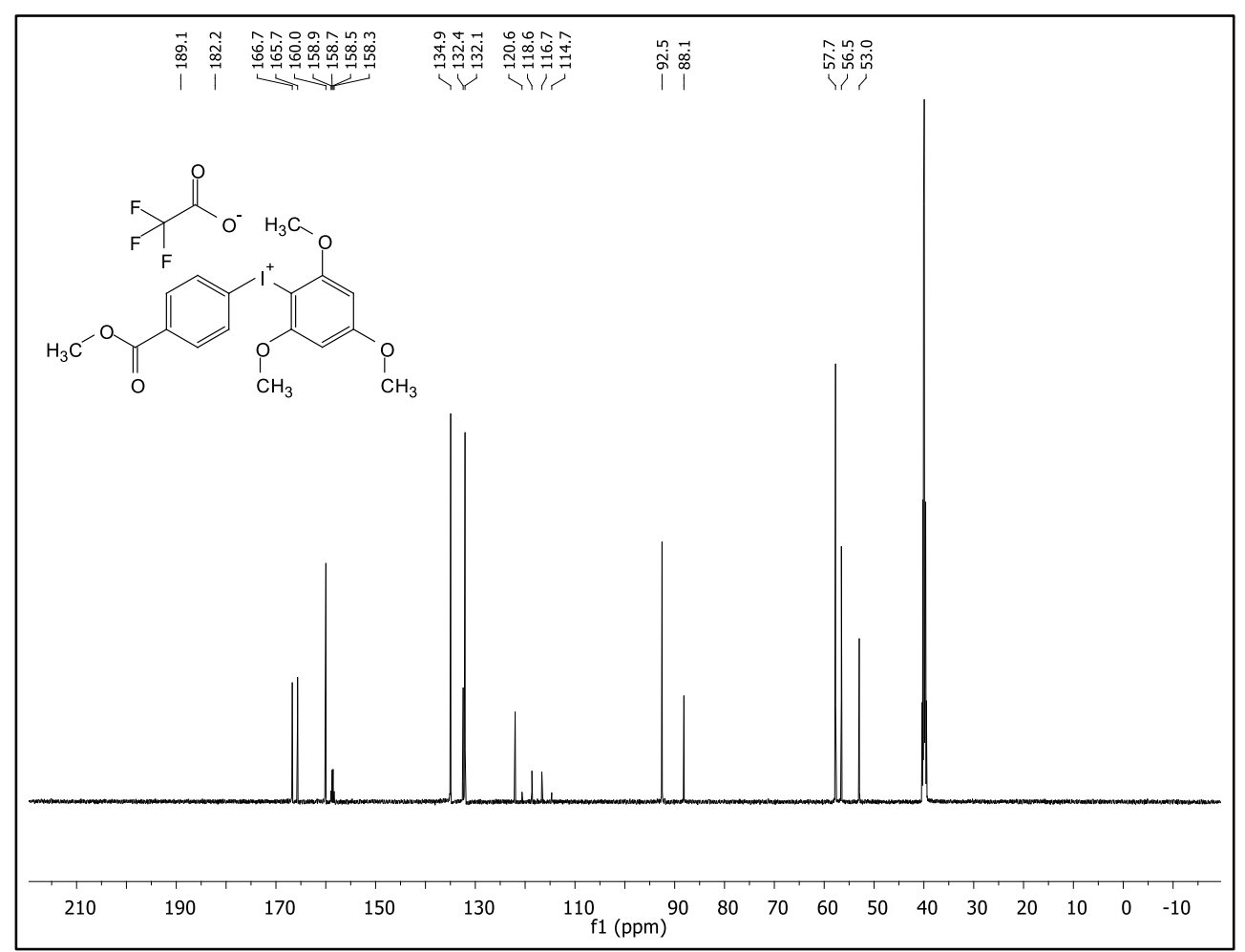

Figure $192 .{ }^{13} \mathrm{C}$ NMR spectrum of 20-TFA at $151 \mathrm{MHz}$ in DMSO- $d_{6} 298 \mathrm{~K}$ 


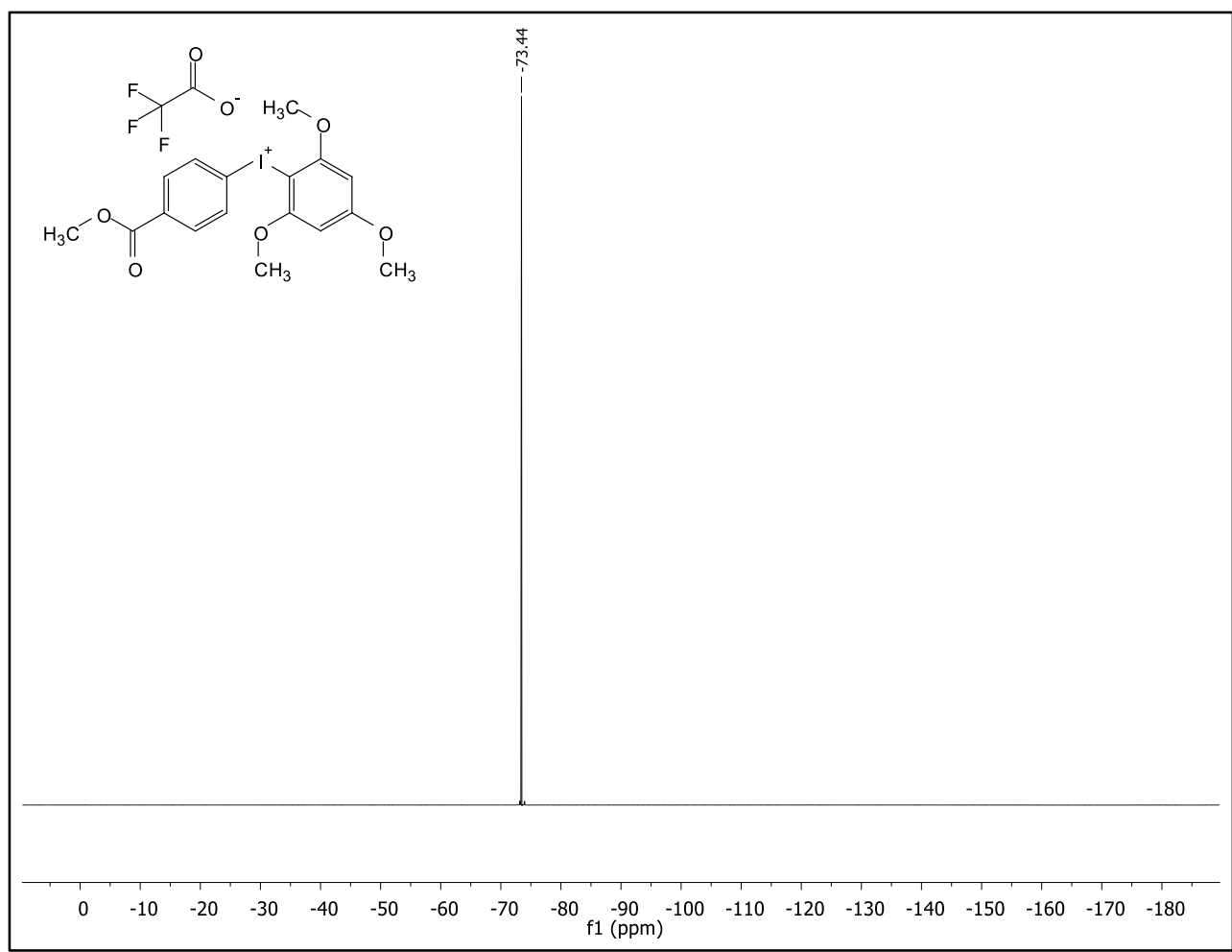

Figure $193 .{ }^{19} \mathrm{~F}$ NMR spectrum of 20 -TFA at $376 \mathrm{MHz}$ in DMSO-d 6 298K

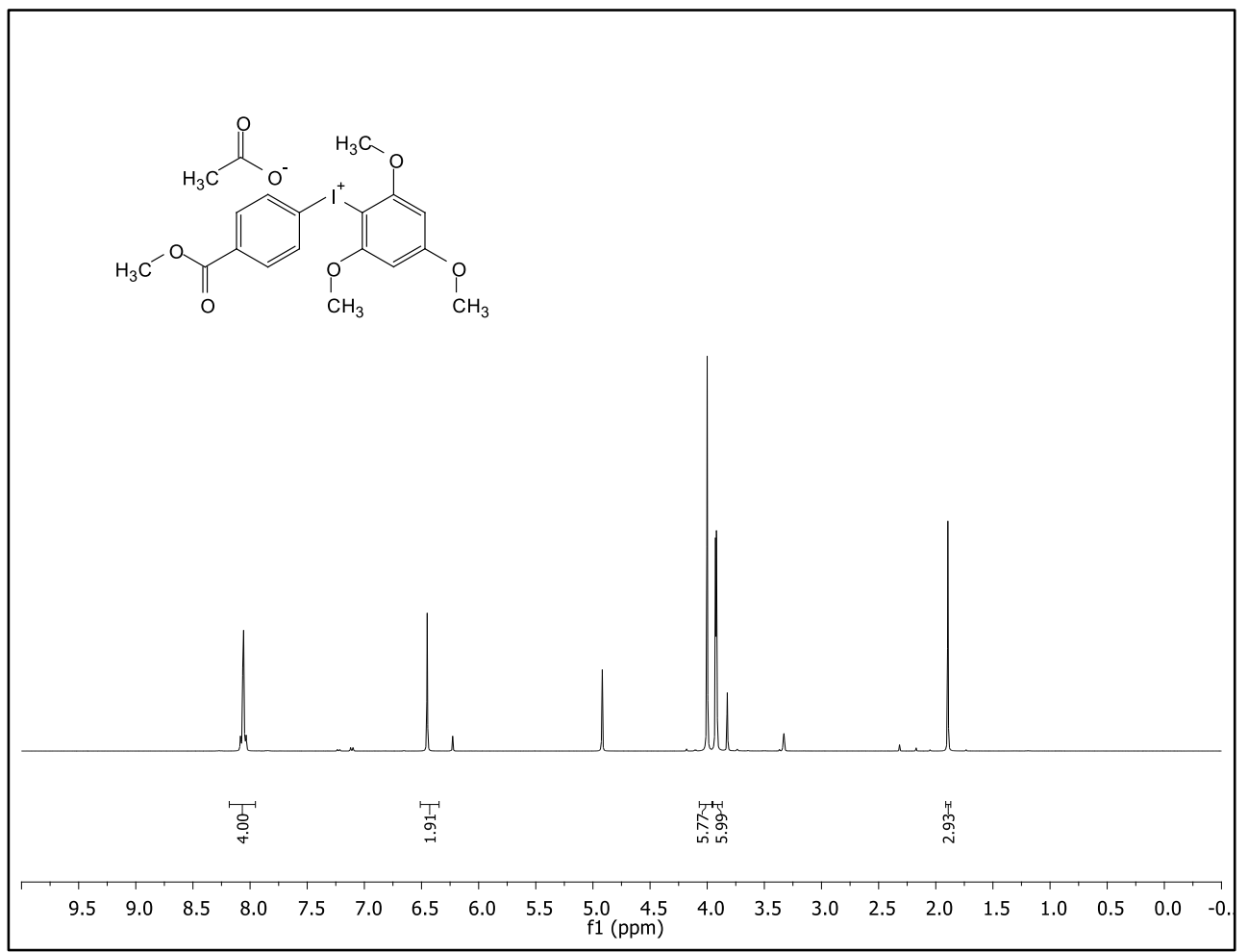

Figure 194. ${ }^{1} \mathrm{H}$ NMR spectrum of $20-\mathrm{OAC}$ at $600 \mathrm{MHz}$ in $\mathrm{CD}_{3} \mathrm{OD}$ at $298 \mathrm{~K}$ 


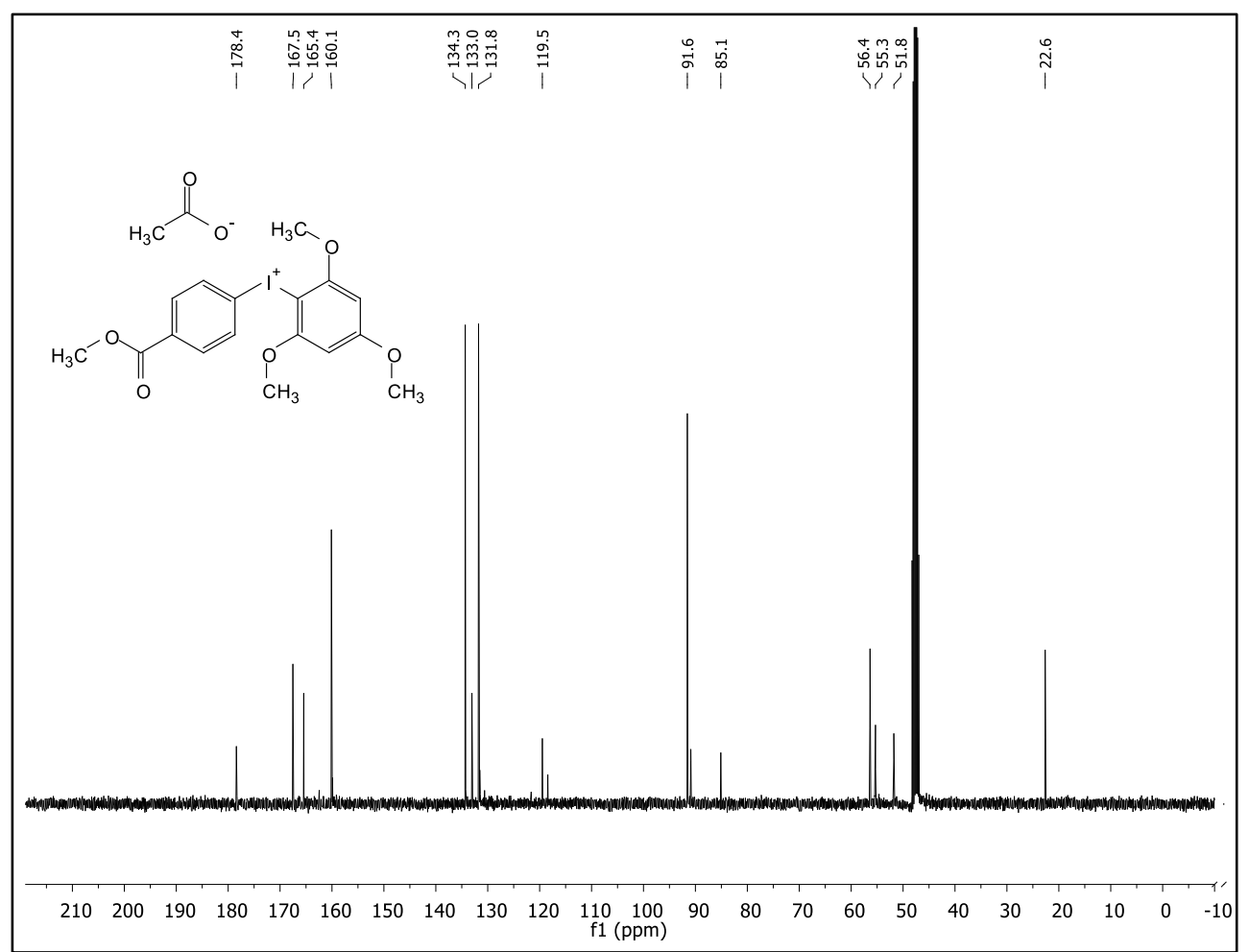

Figure $195 .{ }^{13} \mathrm{C}$ NMR spectrum of $20-\mathrm{OAC}$ at $151 \mathrm{MHz}$ in $\mathrm{CD}_{3} \mathrm{OD}$ at $298 \mathrm{~K}$

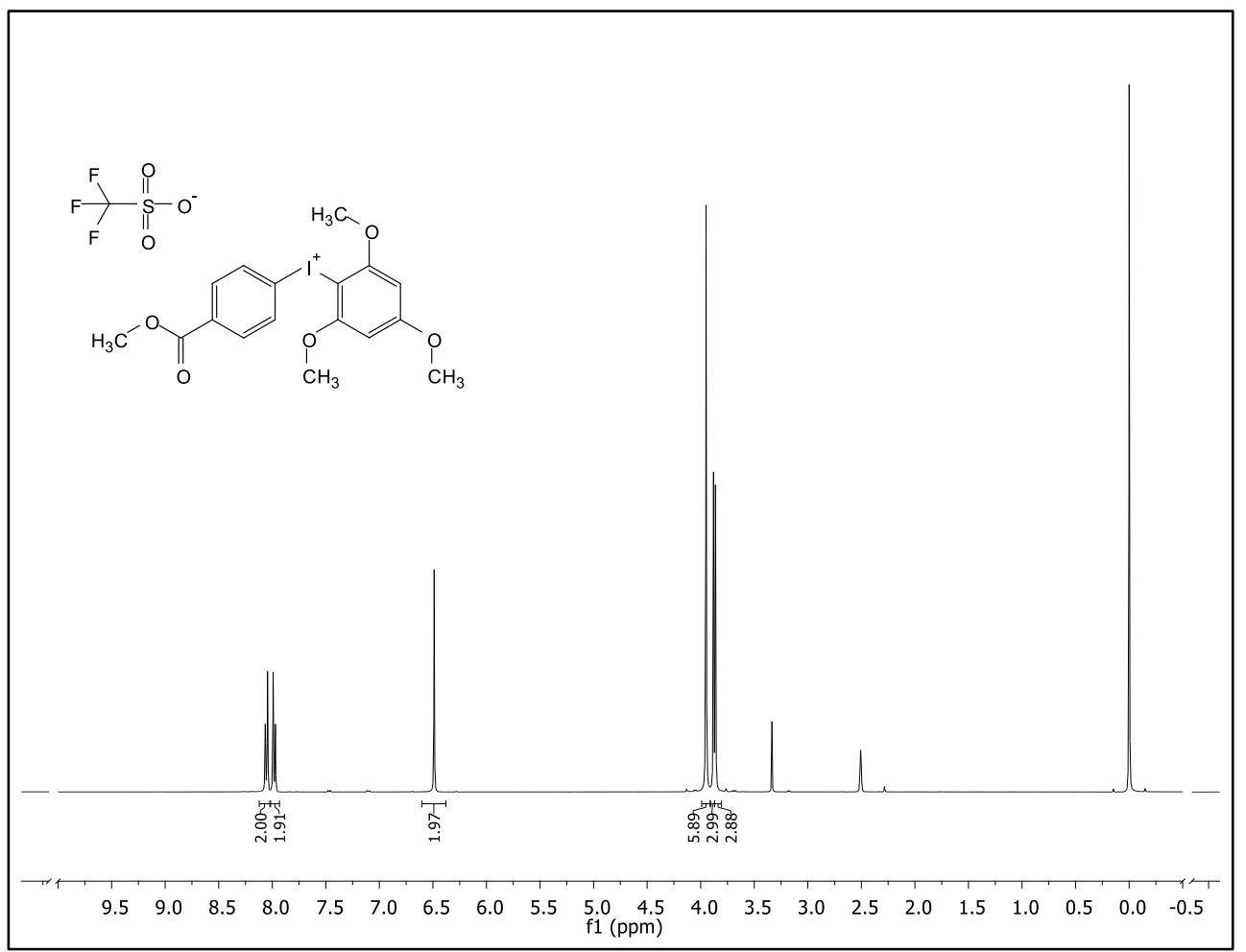

Figure 196. ${ }^{1} \mathrm{H}$ NMR spectrum of $20-0 \mathrm{Tf}$ at $400 \mathrm{MHz}$ in DMSO- $d_{6}$ at $298 \mathrm{~K}$ 


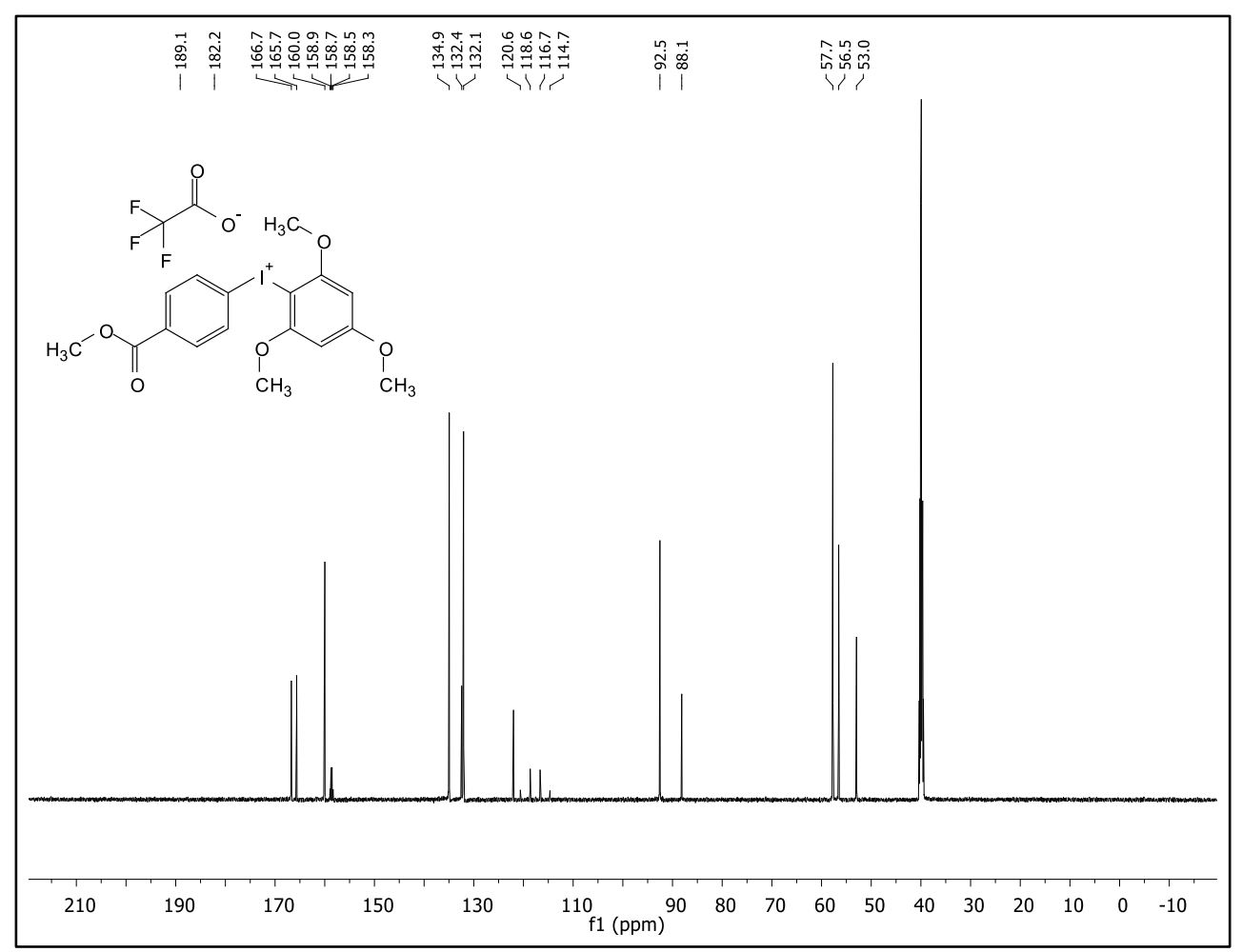

Figure $197 .{ }^{13} \mathrm{C}$ NMR spectrum of $20-0 \mathrm{Tf}$ at $101 \mathrm{MHz}$ in DMSO- $d_{6}$ at $298 \mathrm{~K}$

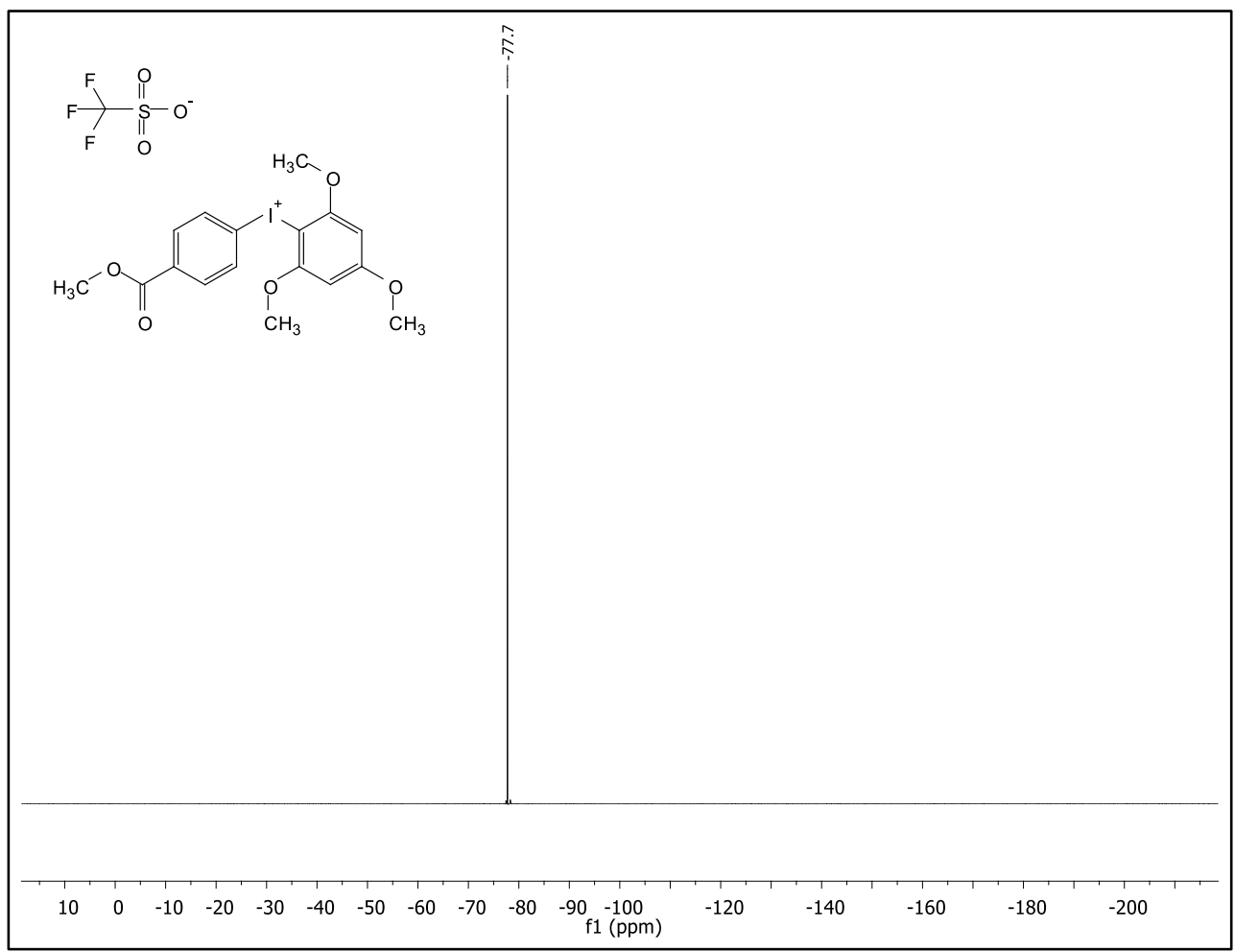

Figure $198 .{ }^{19} \mathrm{~F}$ NMR spectrum of 20-OTf at $376 \mathrm{MHz}$ in DMSO- $d_{6}$ at $298 \mathrm{~K}$ 


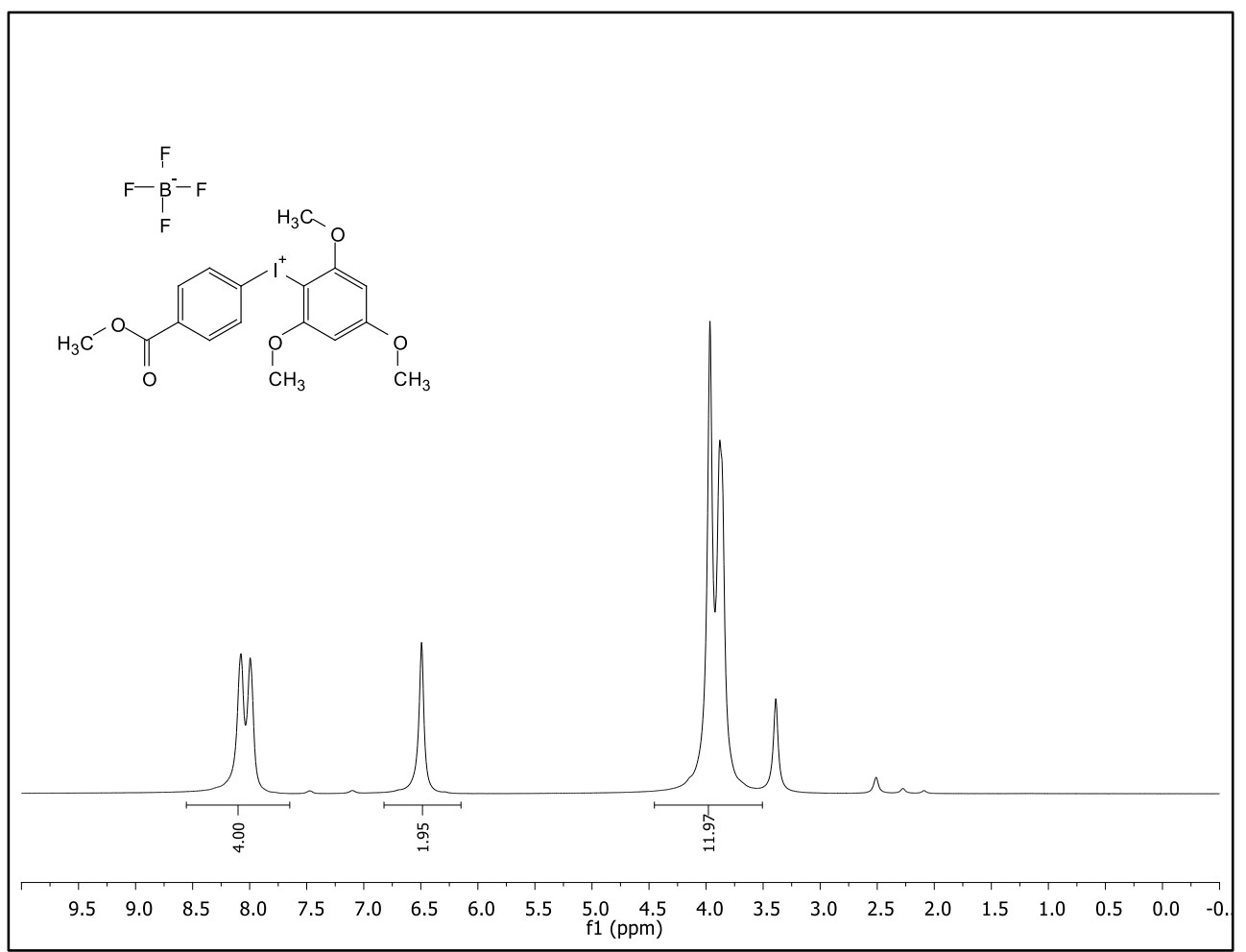

Figure $199 .{ }^{1} \mathrm{H}$ NMR spectrum of $20-\mathrm{BF}_{4}$ at $400 \mathrm{MHz}$ in DMSO- $d_{6}$ at $298 \mathrm{~K}$

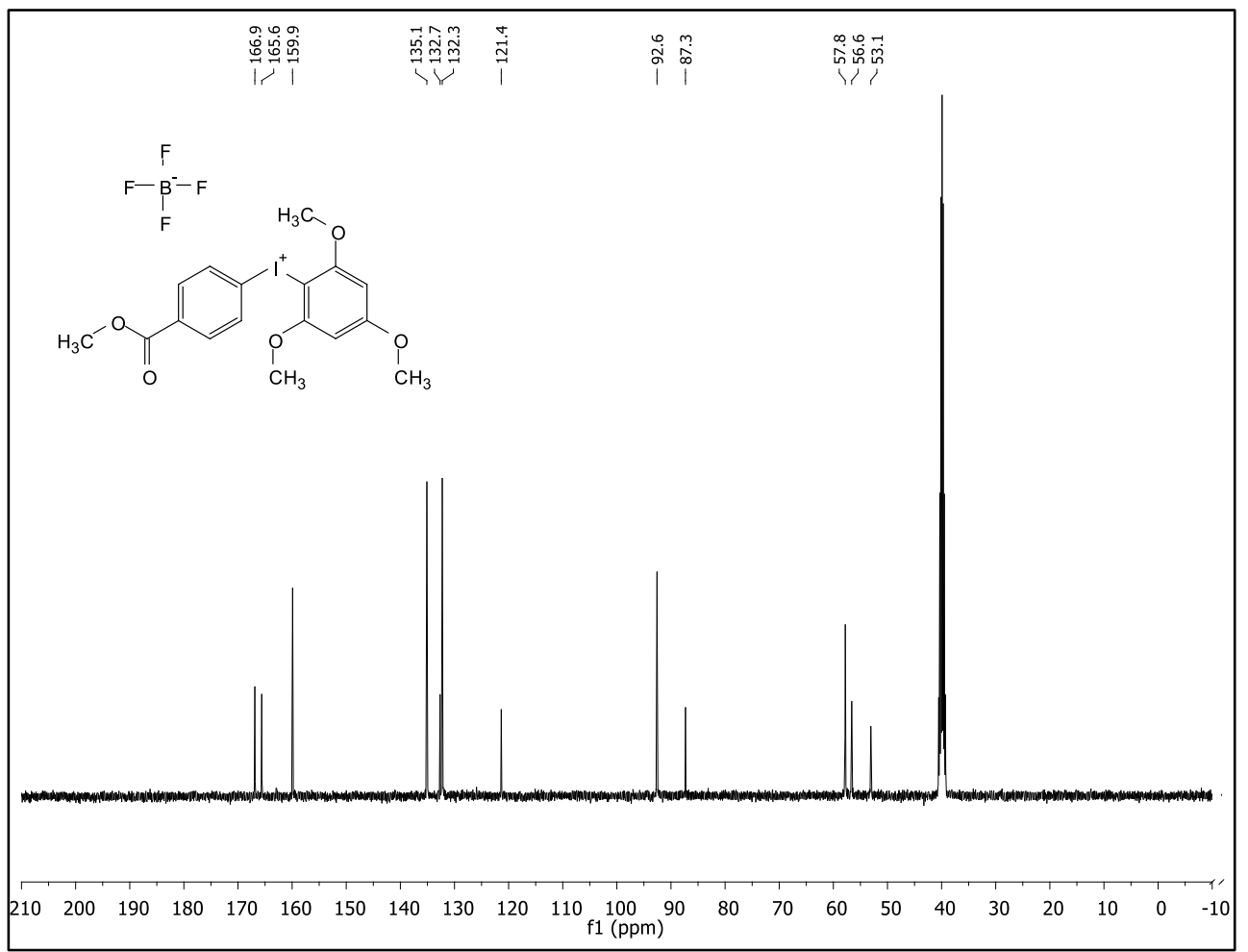

Figure 200. ${ }^{13} \mathrm{C}$ NMR spectrum of $20-\mathrm{BF}_{4}$ at $101 \mathrm{MHz}$ in DMSO- $d_{6}$ at $298 \mathrm{~K}$ 


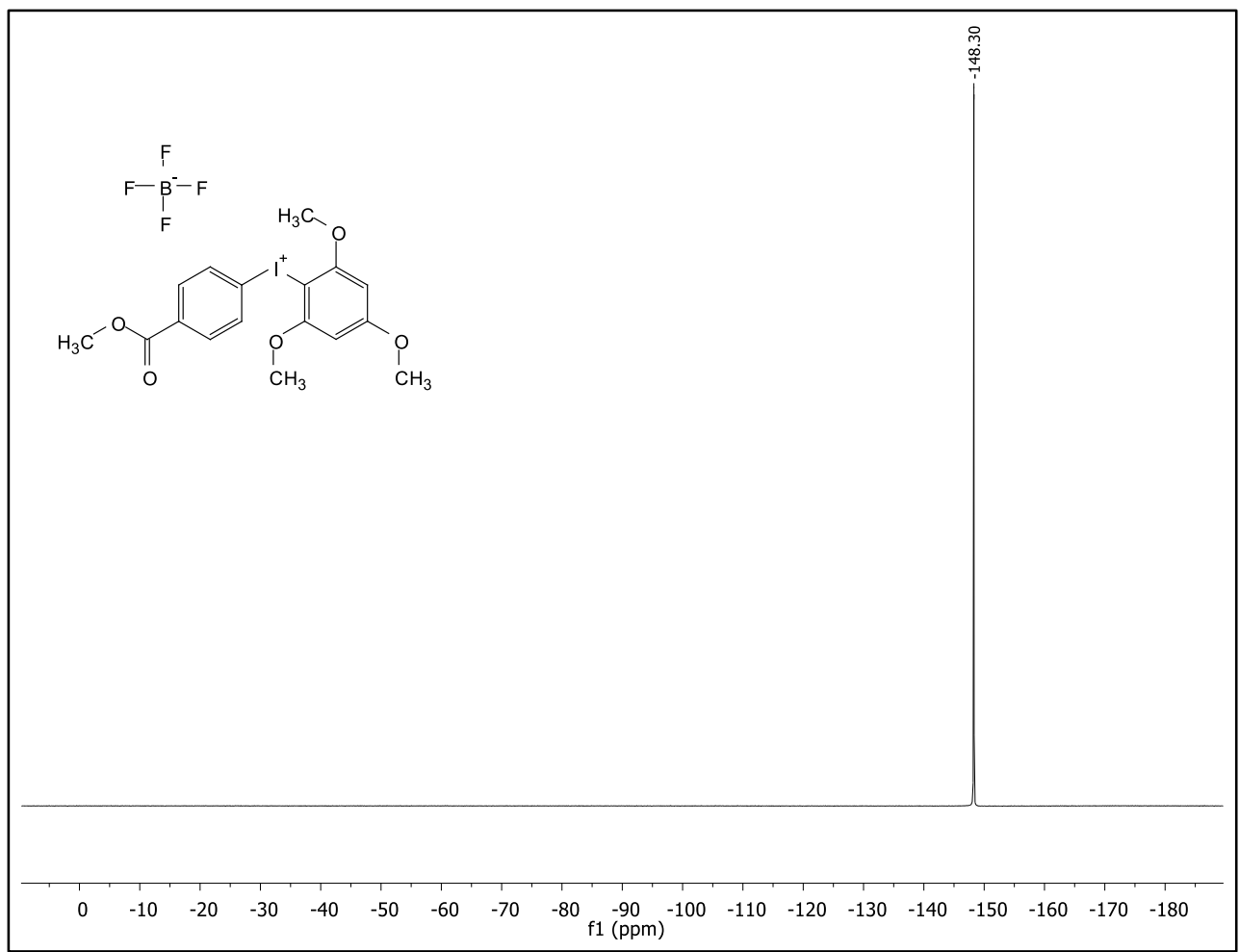

Figure 201. ${ }^{19} \mathrm{~F}$ NMR spectrum of $20-\mathrm{BF}_{4}$ at $376 \mathrm{MHz}$ in DMSO-d 6 at $298 \mathrm{~K}$

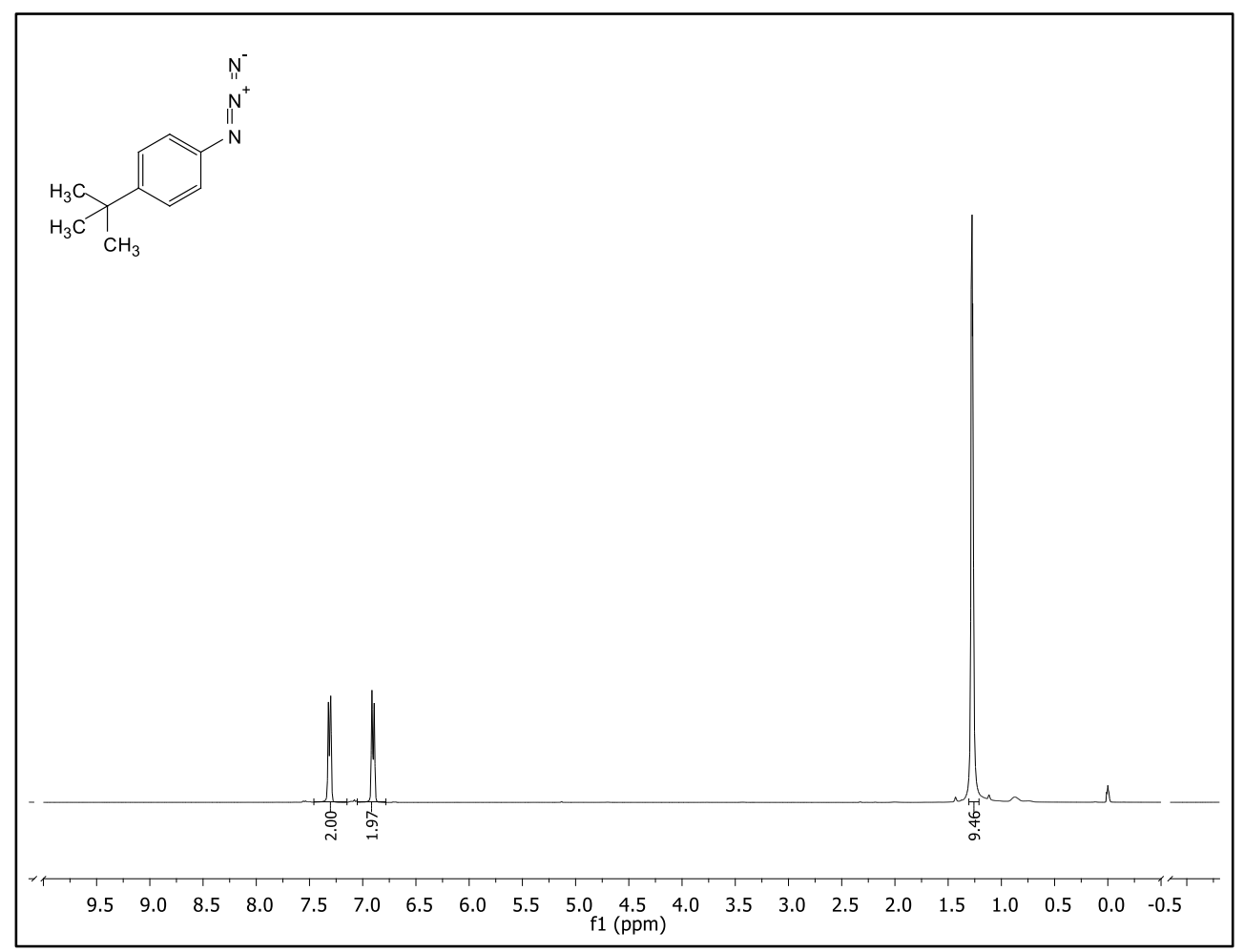

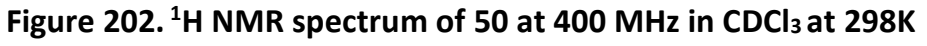




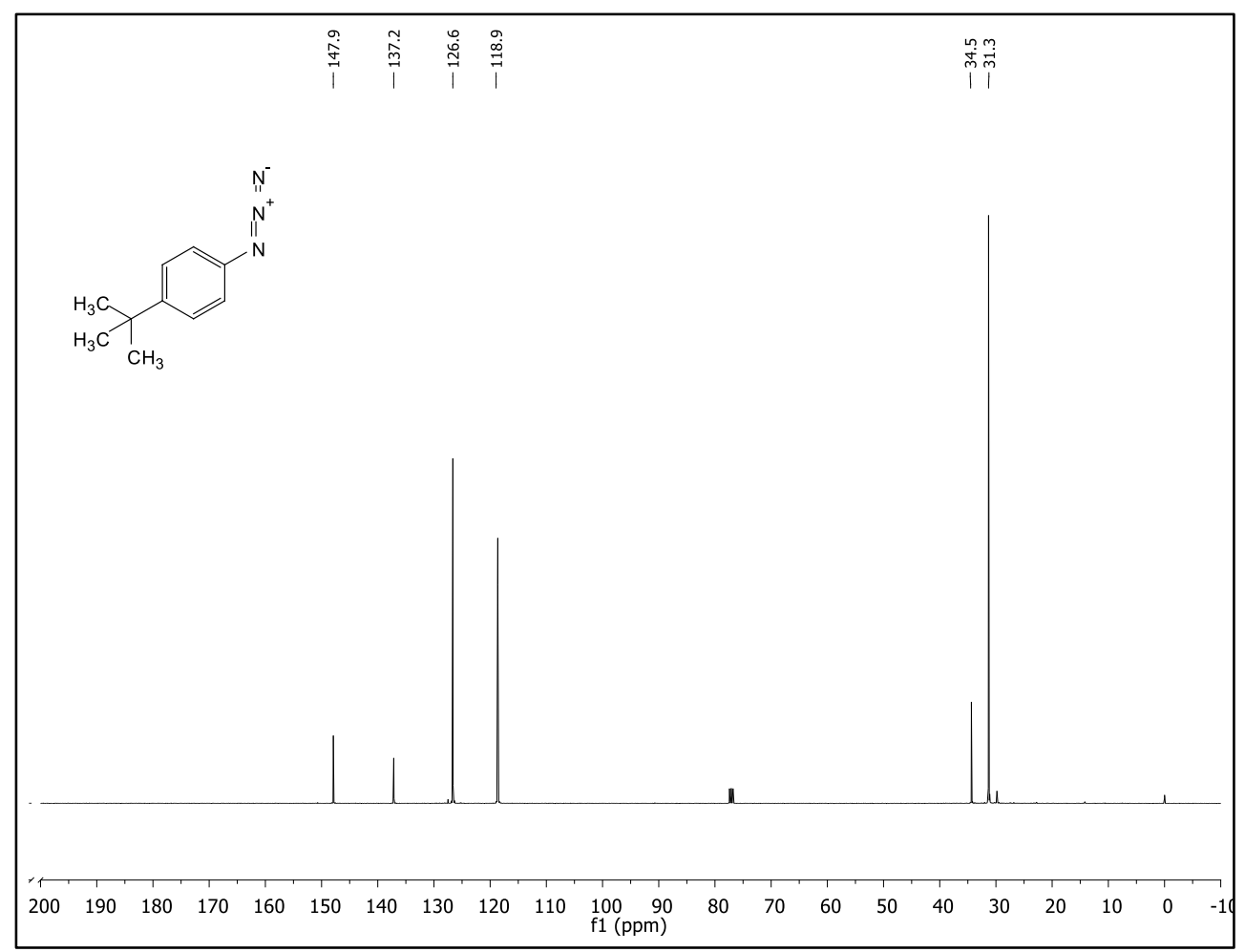

Figure 203. ${ }^{13} \mathrm{C}$ NMR spectrum of 50 at $101 \mathrm{MHz}$ in $\mathrm{CDCl}_{3}$ at $298 \mathrm{~K}$

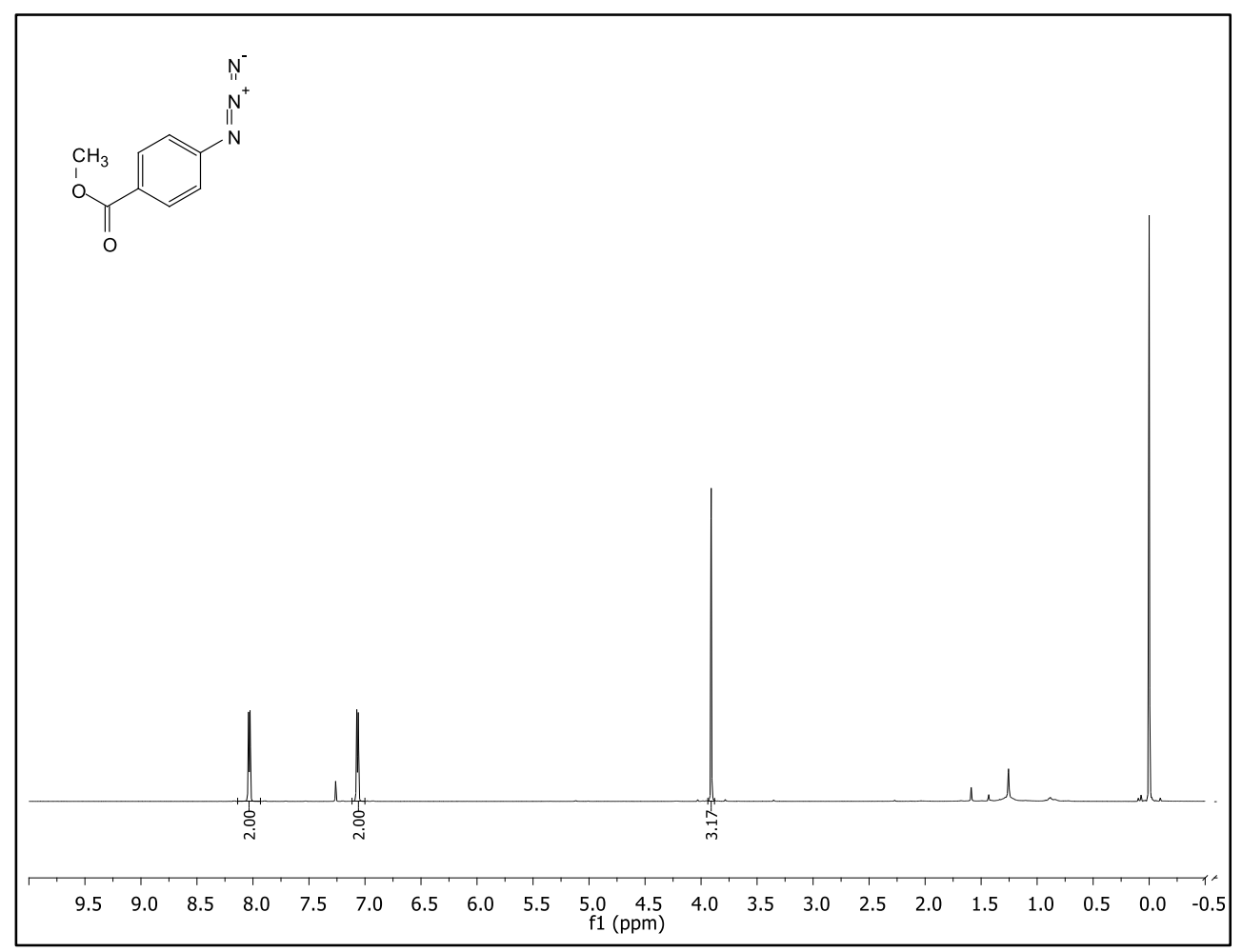

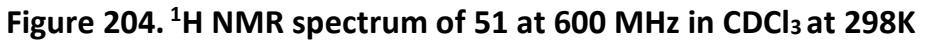




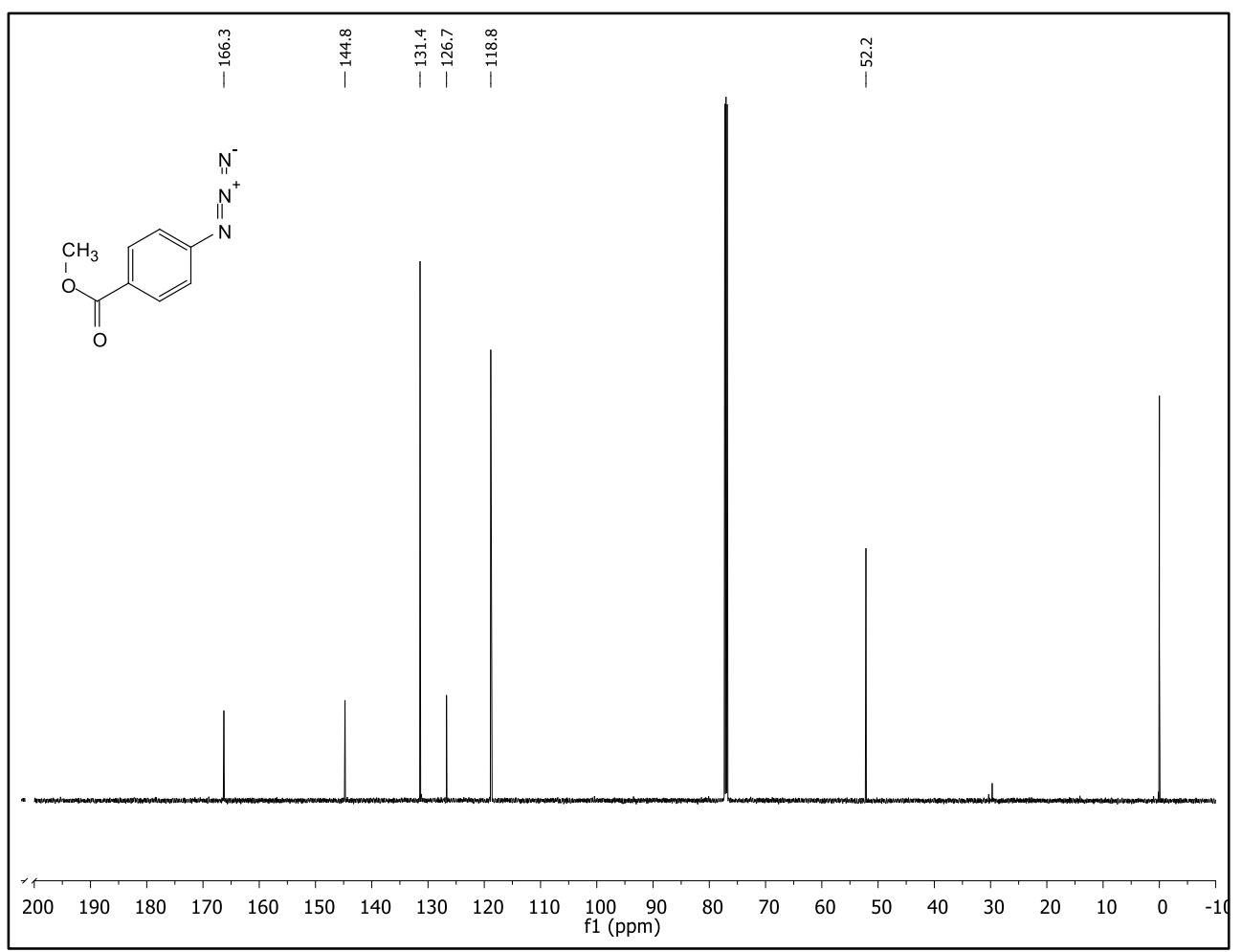

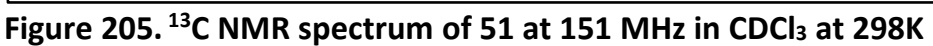

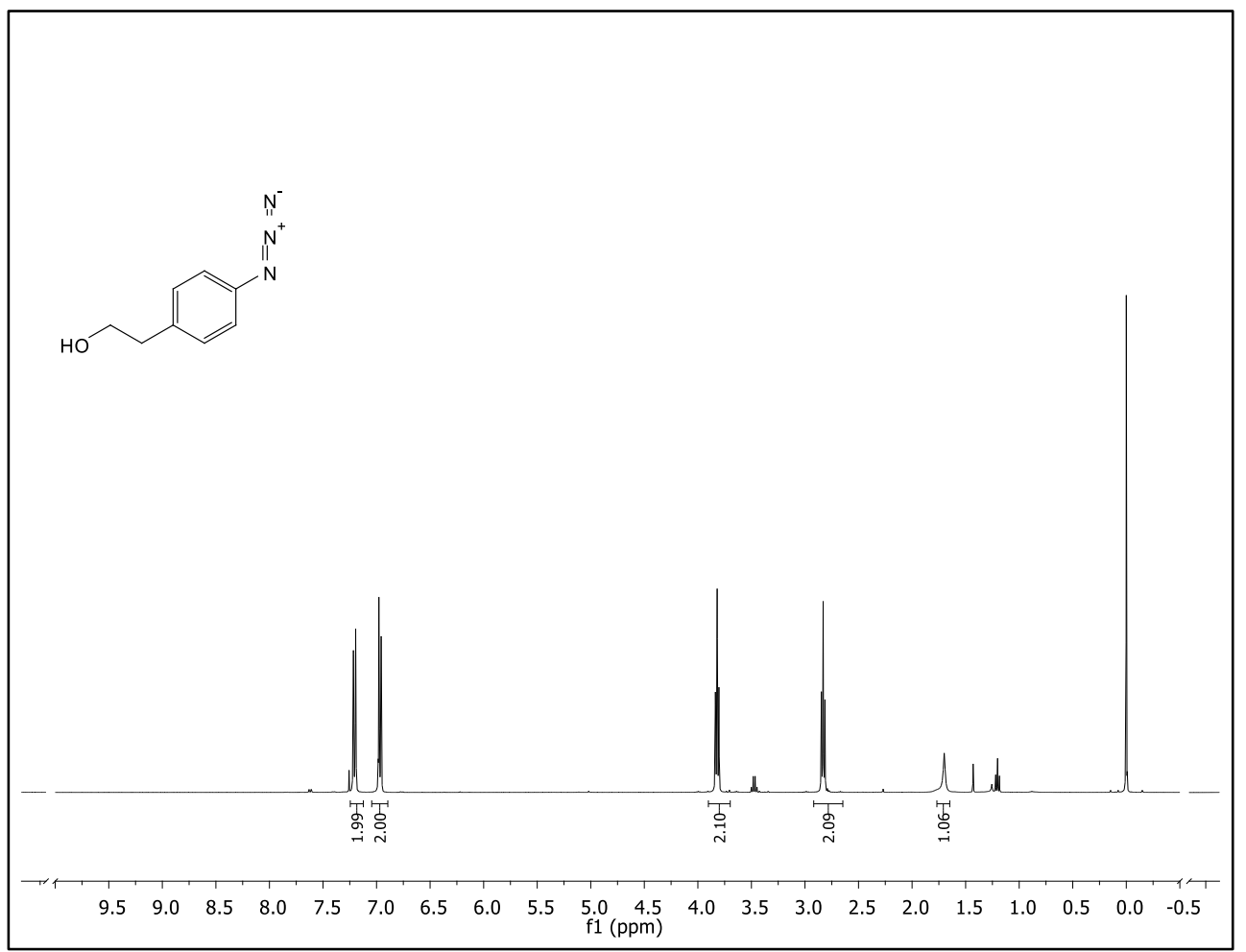

Figure 206. ${ }^{1} \mathrm{H}$ NMR spectrum of 56 at $101 \mathrm{MHz}$ in $\mathrm{CDCl}_{3}$ at $298 \mathrm{~K}$ 


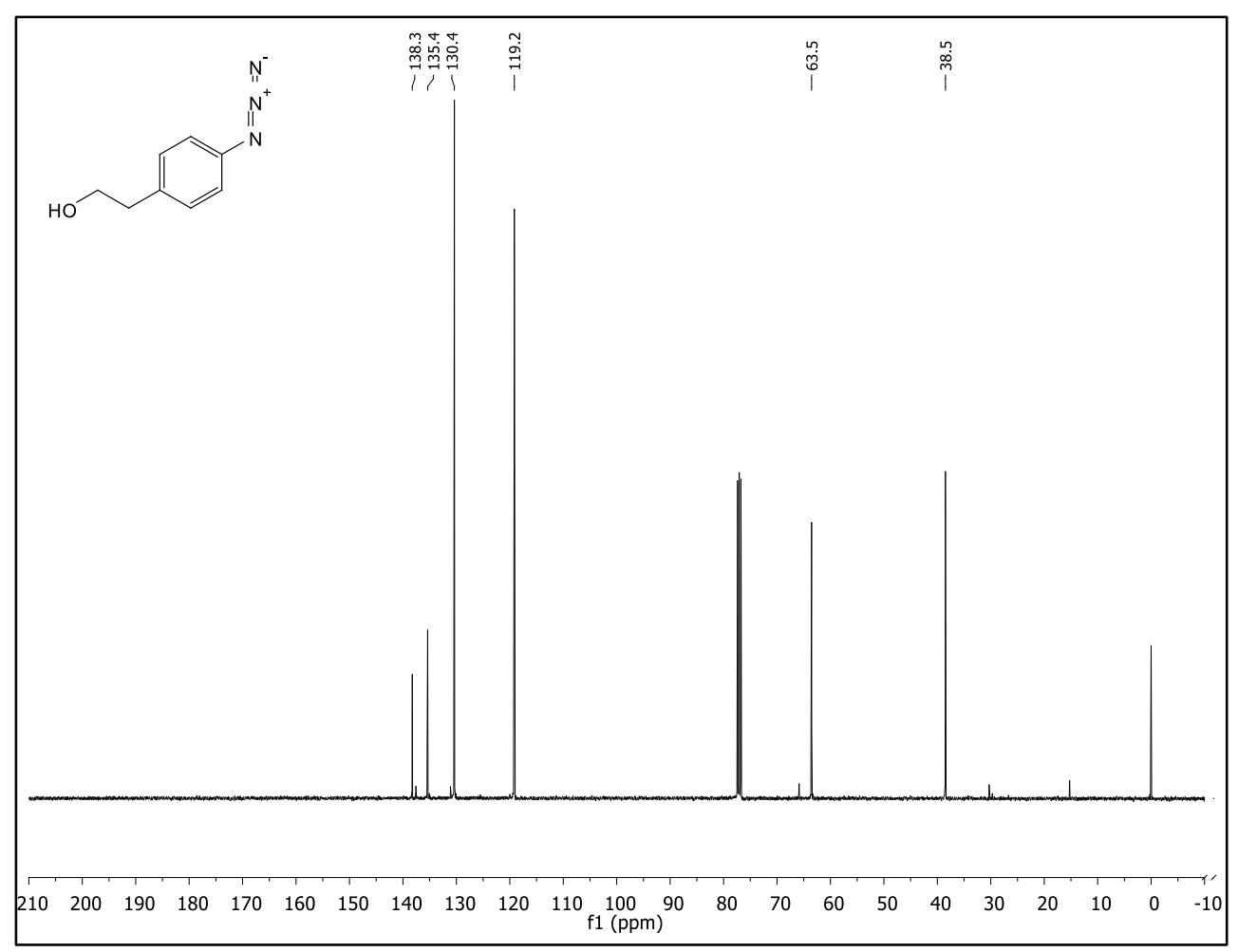

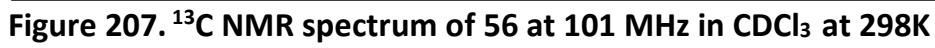

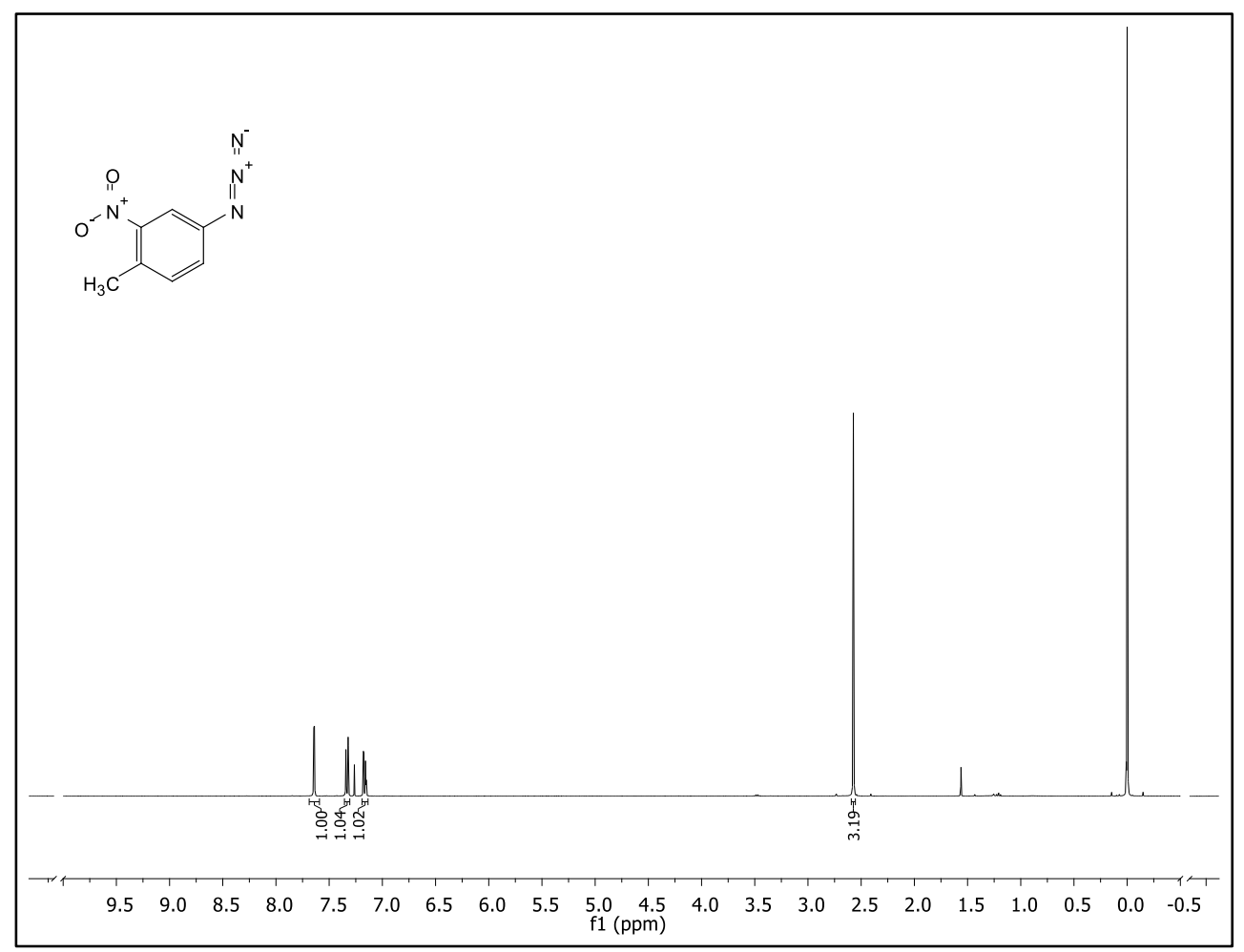

Figure 208. ${ }^{1} \mathrm{H}$ NMR spectrum of 57 at $400 \mathrm{MHz}$ in $\mathrm{CDCl}_{3}$ at $298 \mathrm{~K}$ 


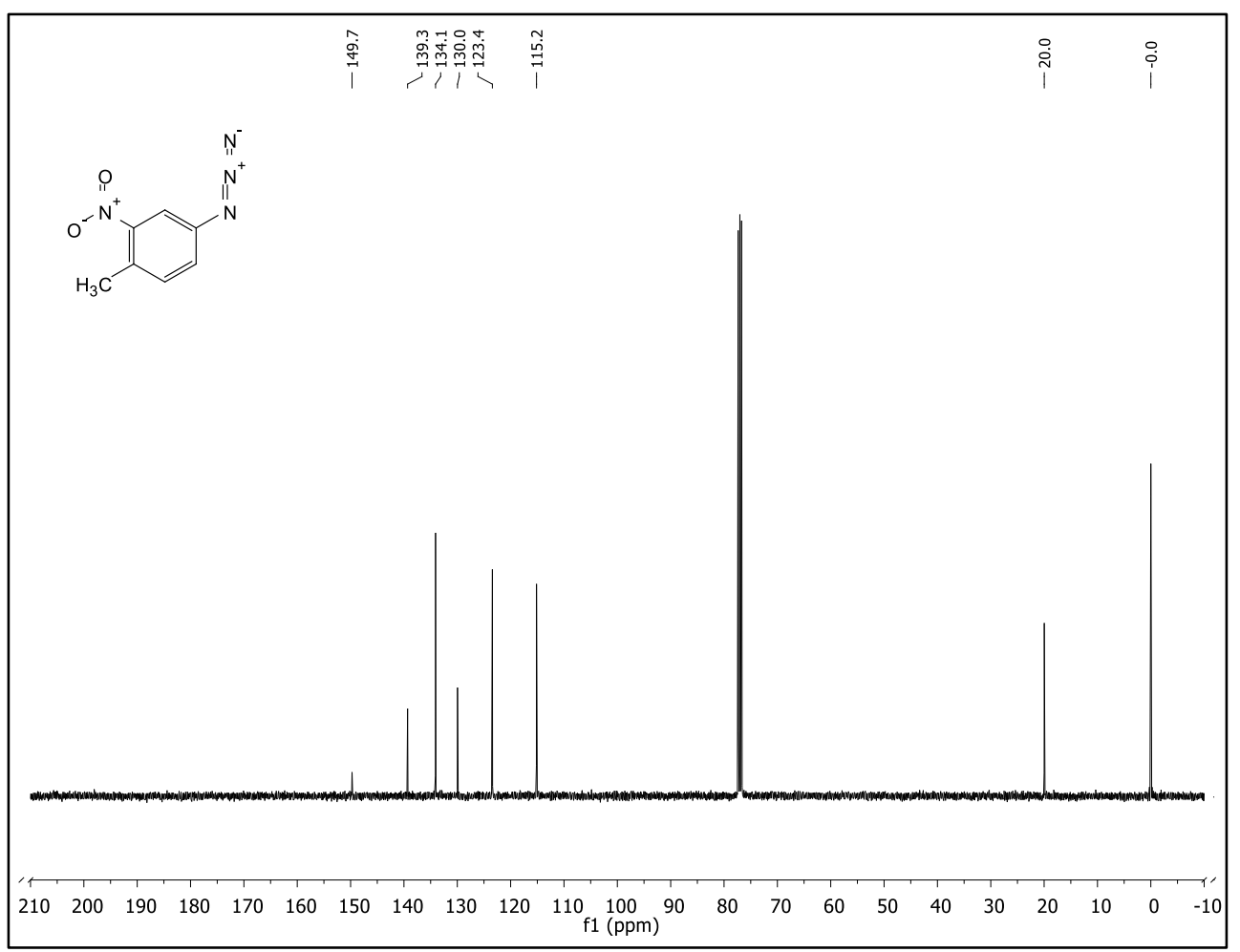

Figure 209. ${ }^{13} \mathrm{C}$ NMR spectrum of 57 at $101 \mathrm{MHz}$ in $\mathrm{CDCl}_{3}$ at $298 \mathrm{~K}$

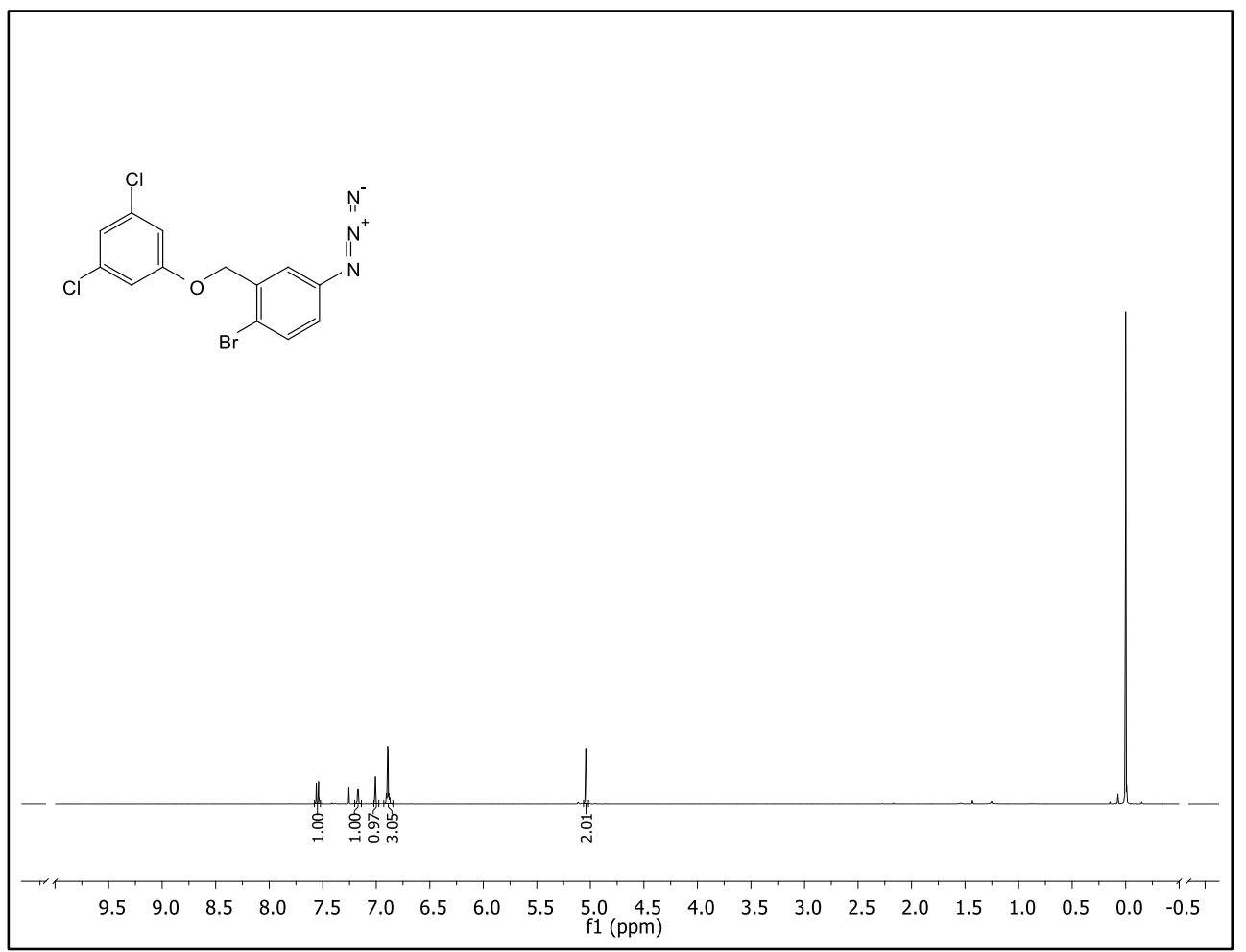

Figure 210. ${ }^{1} \mathrm{H} \mathrm{NMR}$ spectrum of 58 at $400 \mathrm{MHz}$ in $\mathrm{CDCl}_{3}$ at $298 \mathrm{~K}$ 


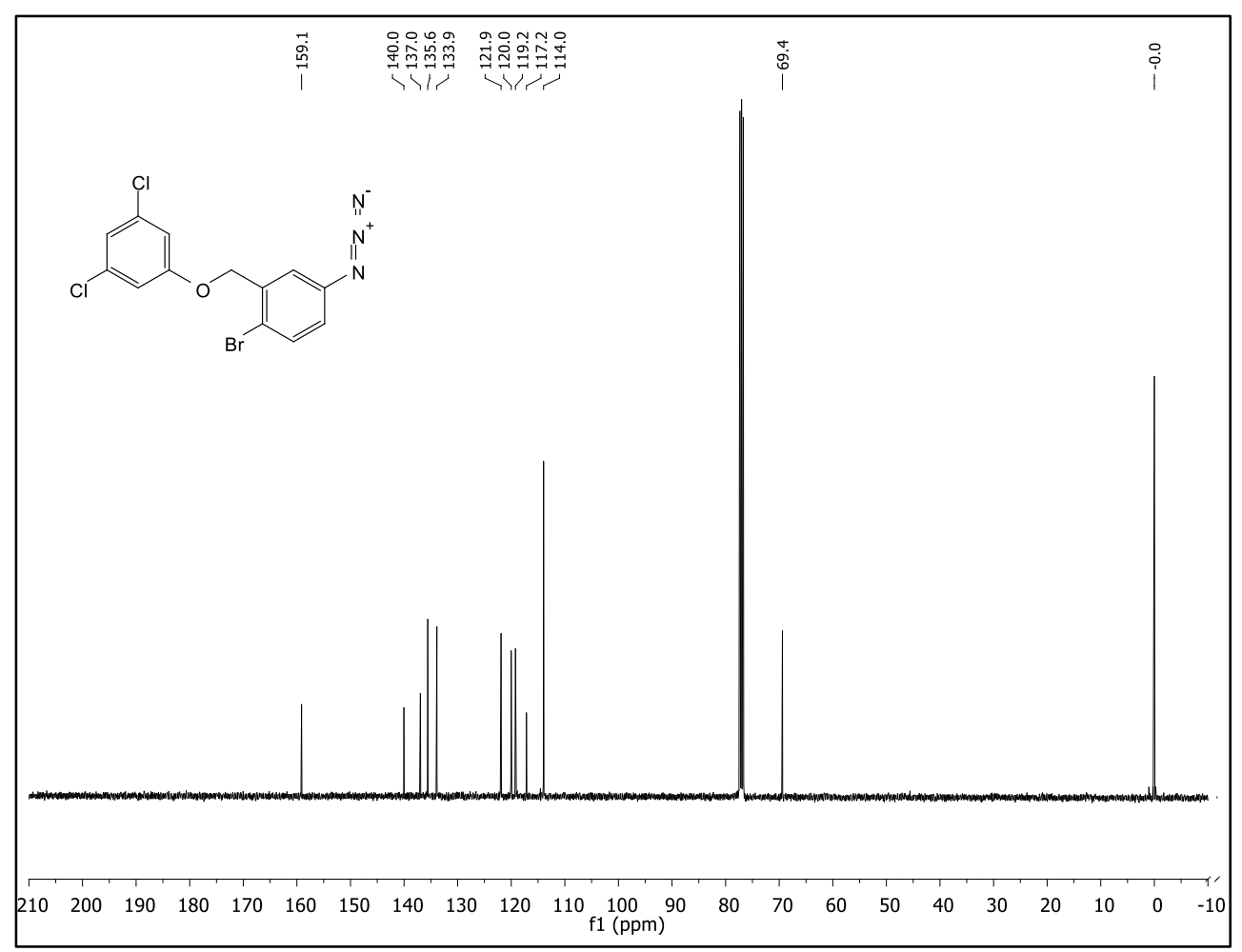

Figure 211. ${ }^{13} \mathrm{C}$ NMR spectrum of 58 at $101 \mathrm{MHz}$ in $\mathrm{CDCl}_{3}$ at $298 \mathrm{~K}$

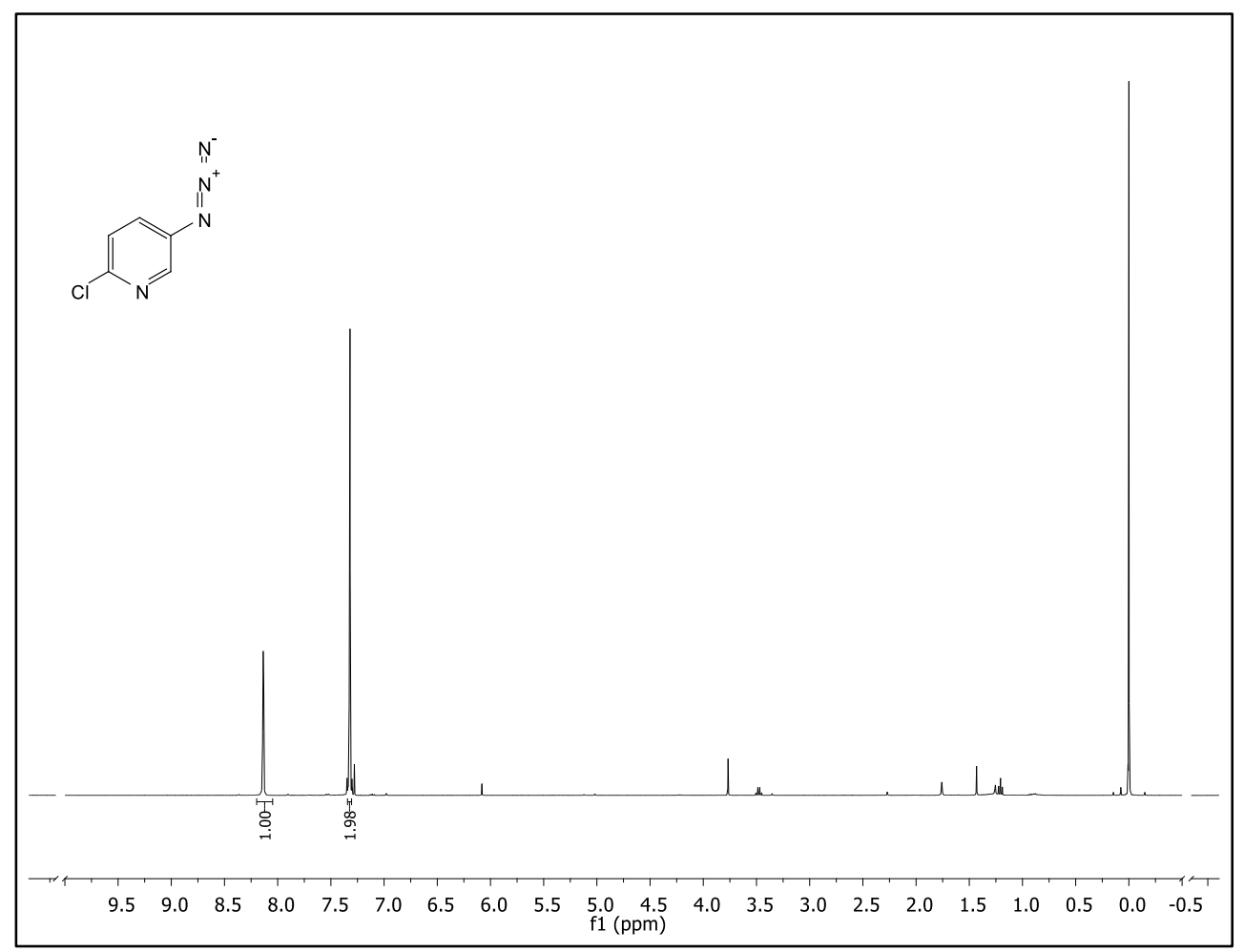

Figure 212. ${ }^{1} \mathrm{H}$ NMR spectrum of 59 at $400 \mathrm{MHz}$ in $\mathrm{CDCl}_{3}$ at $298 \mathrm{~K}$ 


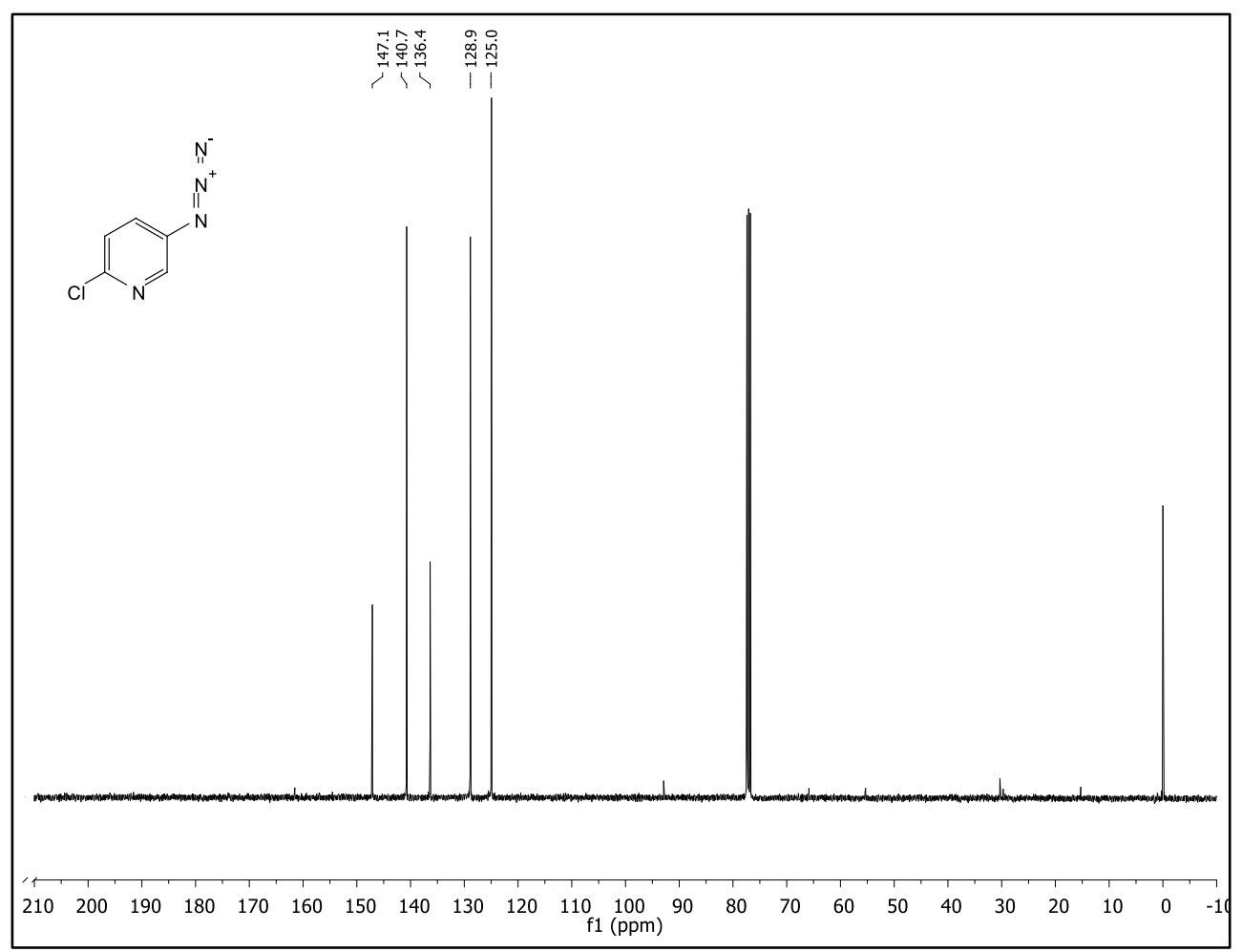

Figure $213 .{ }^{13} \mathrm{C}$ NMR spectrum of 59 at $101 \mathrm{MHz}$ in $\mathrm{CDCl}_{3}$ at $298 \mathrm{~K}$

\subsubsection{References for Chapter 3}

\subsubsection{References for counteranion review (Figure 44, Chapter 3, also}

\section{listed in final references section)}

- L. Ackermann, M. Dell'Acqua, S. Fenner, R. Vicente, R. Sandmann, Metal-Free Direct Arylations of Indoles and Pyrroles with Diaryliodonium Salts. Org. Lett., 2011, 13, 2358

- T. Petersen, R. Khan, B. Olofsson, Metal-Free Synthesis of Aryl Esters from Carboxylic Acids and Diaryliodonium Salts. Org. Lett., 2011, 13, 3462

- N. Jalalian, E. Ishikawa, L. F. Silva Jr., B. Olofsson, Room Temperature, MetalFree Synthesis of Diaryl Ethers with Use of Diaryliodonium Salts. Org. Lett., 2011, 13, 1552

- F. Guo, L. Wang, P. Wang, J. Yu, J. Han, Transition-Metal-Free N-Arylation of Carbazoles and C-Arylation of Tetrahydrocarbazoles by using Diaryliodonium Salts. Asian J. Org. Chem. 2012, 1, 218

- N. Jalalian, T. B. Petersen, B. Olofsson, Metal-Free Arylation of Oxygen Nucleophiles with Diaryliodonium Salts. Chem. Eur. J. 2012, 18, 14140 
- N. Yamaoka, K. Sumida, I. Itani, J. Kubo, Y. Ohnishi, S. Sekiguchi, T. Dohi, Y. Kita, Metal-Free C-H Cross-Coupling toward Oxygenated NaphthaleneBenzene Linked Biaryls. Chem. Eur. J. 2013, 19, 15004

- D. Kumar, V. Arun, M. Pilania, K. P. Chandra Shekar, A Metal-Free and Microwave-Assisted Efficient Synthesis of Diaryl Sulfones. Synlett, 2013, 24, 831

- N. Umierski, G. Manolikakes, Arylation of Lithium Sulfinates with Diaryliodonium Salts: A Direct and Versatile Access to Arylsulfones. Org. Lett., 2013, 15, 4972

- $\quad$ N. Umierski, G. Manolikakes, Metal-Free Synthesis of Diaryl Sulfones from Arylsulfinic Acid Salts and Diaryliodonium Salts. Org. Lett., 2013, 15, 188

- E. Lindstedt, R. Ghosh, B. Olofsson, Metal-Free Synthesis of Aryl Ethers in Water. Org. Lett., 2013, 15, 6070

- D. Wang, X. Yu, K. Zhao, L. Li, Y. Ding, Rapid synthesis of aryl sulfides through metal-free $\mathrm{C}-\mathrm{S}$ coupling of thioalcohols with diaryliodonium salts.

Tetrahedron Letters, 2014, 55, 5739

- P. Thorat, N. Waghmode, N. Karade, Direct metal-free O-arylation of Biginelli 4-aryl-6-methyl-pyrimidine-2(1H)-one derivatives using diaryliodonium salts. Tetrahedron Letters, 2014, 55, 5718

- H. Gao, Q. Xu, C. Keene, L. Kurti, Scalable, Transition-Metal-Free Direct Oxime O-Arylation: Rapid Access to O-Arylhydroxylamines and Substituted Benzo[b]furans. Chem. Eur. J., 2014, 20, 8883

- $\quad$ R. Ghosh, E. Stridfeldt, B. Olofsson, Metal-Free One-Pot Synthesis of Benzofurans. Chem. Eur. J. 2014, 20, 8888

- $\quad$ R. Ghosh, E. Lindstedt, N. Jalalian, B. Olofsson, Room Temperature, MetalFree Arylation of Aliphatic Alcohols. Chemistry Open 2014, 3, 54

- $\quad$ R. Ghosh, B. Olofsson, Metal-Free Synthesis of N-Aryloxyimides and Aryloxyamines. Org. Lett. 2014, 16, 1830

- A. M. Wagner, M. S. Sanford, Transition-Metal-Free Acid-Mediated Synthesis of Aryl Sulfides from Thiols and Thioethers. J. Org. Chem., 2014, 79, 2263

- $\quad$ K. Miyagi, K. Moriyama, H. Togo, One-Pot Preparation of 2-Arylbenzofurans from Oximes with Diaryliodonium Triflate. Heterocycles, 2014, 89

- Y. Yang, X. Wu, J. Han, S. Mao, X. Qian, L. Wang. Cesium Carbonate Promoted Direct Arylation of Hydroxylamines and Oximes with Diaryliodonium Salts. Eur. J. Org. Chem., 2014, 6854

- T. Huang, X. Ji, W. Wu, F. Liang, S. Cao, Metal-free one-pot sequential direct diarylation of pyrazolin-5-ones with diaryliodonium salts. RSC Adv., 2015, 5, 66598

- W. Xiong, C. Qi, Y. Peng, T. Guo, M. Zhang, H. Jiang, Base-Promoted Coupling of Carbon Dioxide, Amines, and Diaryliodonium Salts: A Phosgene- and Metal-Free Route to O-Aryl Carbamates. Chem. Eur. J., 2015, 21, 14314

- F. Liu, H. Yang, X. Hu, G. Jiang, Metal-Free Synthesis of ortho-CHO Diaryl Ethers by a Three-Component Sequential Coupling. Org. Lett., 2014, 16, 6408 
- $\quad$ X. Ma, W. Shi, X. Mo, X. Li, L. Li, C. Pan, B. Chen, Synthesis of $\alpha, \beta-$ Unsaturated N-Aryl Ketonitrones from Oximes and Diaryliodonium Salts: Observation of a Metal-Free N-Arylation Process. J. Org. Chem., 2015, 80, 10098

- A. Monastyrskyi, N. Namelikonda, R. Manetsch, Metal-Free Arylation of Ethyl Acetoacetate with Hypervalent Diaryliodonium Salts: An Immediate Access to Diverse 3-Aryl-4(1H)-Quinolones. J. Org. Chem., 2015, 80, 2513

- $\quad$ N. Margraf, G. Manolikakes, One-Pot Synthesis of Aryl Sulfones from Organometallic Reagents and lodonium Salts. J. Org. Chem., 2015, 80, 2582

- W. Shi, X. Ma, C. Pan, G. Su, D. Mo, Tandem C-O and C-N Bonds Formation Through O-Arylation and [3,3]-Rearrangement by Diaryliodonium Salts: Synthesis of N-Aryl Benzo[1,2,3]triazin-4(1H)-one Derivatives. J. Org. Chem., 2015, 80, 11175

- $\quad$ N. Miralles, R. M. Romero, E. Fernandez, K. Muniz, A mild carbon-boron bond formation from diaryliodonium salts. Chem. Commun., 2015, 51, 14068

- $\quad$ Z. Gonda, Z. Novak, Transition-Metal-Free N-Arylation of Pyrazoles with Diaryliodonium Salts. Chem. Eur. J., 2015, 21, 16801

- C. Dey, E. Lindstedt, B. Olofsson, Metal-Free C-Arylation of Nitro Compounds with Diaryliodonium Salts. Org. Lett., 2015, 17, 4554

- $\quad$ F. Tinnis, E. Stridfeldt, H. Lundberg, H. Adolfsson, B. Olofsson, Metal-Free NArylation of Secondary Amides at Room Temperature. Org. Lett., 2015, 17, 2688

- $\quad$ S. K. Sundalam, D. R. Stuart, Base Mediated Synthesis of Alkyl-aryl Ethers from the Reaction of Aliphatic Alcohols and Unsymmetric Diaryliodonium Salts. J. Org. Chem., 2015, 80, 6456

- S. Mao, X. Geng, Y. Yang, X. Qian, S. Wu, J. Han, L. Wang, Base promoted direct C4-arylation of 4-substituted-pyrazolin-5-ones with diaryliodonium salts. RSC Adv. , 2015, 5, 36390

- $\quad$ P. Li, Y. Weng, X. Xu, X. Cui, Access to Indole Derivatives from Diaryliodonium Salts and 2-Alkynylanilines. J. Org. Chem., 2016, 81, 3994

- X. Zhou, Q. Wu, Y. Yu, C. Yu, E. Hao, Y. Wei, X. Mu, L. Jiao, Metal-Free Direct $\alpha$-Selective Arylation of Boron Dipyrromethenes via Base-Mediated $\mathrm{C}-\mathrm{H}$ Functionalization. Org. Lett., 2016, 18, 736

- M. K. Mehra, M. P. Tantak, I. Kumar, D. Kumar, Microwave-Assisted Metaland Ligand-Free O-Arylation of Quinolones Using Diaryliodonium Salts: An Easy and Rapid Synthesis of Aryloxyquinolines. Synlett, 2016, 27, 604

- $\quad$ X. Li, W. Ni, F. Mao, W. Wang, J. Li, A Metal-free Approach to 3-Aryl-3hydroxy-2-oxindoles by Treatment of 3-Acyloxy-2-oxindoles with Diaryliodonium Salts. Chem. Asian J., 2016, 11, 226

- Z. Wang, W. Shi, H. Bi, X. Li, G. Su, D. Mo, Synthesis of N-(2Hydroxyaryl)benzotriazoles via Metal-Free O-Arylation and $\mathrm{N}-\mathrm{O}$ Bond Cleavage. J. Org. Chem., 2016, 81, 8014 
- E. Lindstedt, E. Stridfelt, B. Olofsson, Mild Synthesis of Sterically Congested Alkyl Aryl Ethers. Org. Lett., 2016, 18, 4234

- T. Sasaki, K. Miyagi, K. Moriyama, H. Togo, Direct Preparation of 3lodochromenes from 3-Aryl- and 3-Alkyl-2-propyn-1-ols with Diaryliodonium Salts and NIS. Org. Lett., 2016, 18, 944

- X. Qian, J. Han, L. Wang, tert-Butoxide-Mediated Arylation of 2-Substituted Cyanoacetates with Diaryliodonium Salts. Adv. Synth. Catal., 2016, 358, 940

- D. Wang, C. Ge, X. Yu, H. Wan, X. Xu, Highly Site-Selective Metal-Free C-H Acyloxylation of Stable Enamines. Synlett, 2016, 27, A-E

- J. Li, X. Zheng, W. Li, W. Zhou, W. Zhu, Y. Zhang, Transition-metal free Narylation of cyanamides by diaryliodonium triflates in aqueous media. New $\mathrm{J}$. Chem., 2016, 40, 77 


\section{References}

1 E. Negishi, Angew. Magical Power of Transition Metals: Past, Present, and Future (Nobel Lecture). Chem. Int. Ed. 2011, 50, 6738.

2 Cole, E. L.; Stewart, M. L.; Littich, R.; Hoareau, R.; Scott, P. J. H.; Radiosyntheses using Fluorine-18: the Art and Science of Late Stage Fluorination. Curr. Top. Med. Chem. $2014 ; 14(7): 875$

3 Q3D Elemental Impurities: Guidance for Industry; US Department of Health and Human Services, FDA, September 2015

4 Larsen et al; Efficient Synthesis of Losartan, A Nonpeptide Angiotensin II Receptor Antagonist. J. Org. Chem, 59 (21), 6391

${ }^{5}$ For general reviews, see: Suzuki, A.; Cross-Coupling Reactions of Organoboranes: An Easy Way to Construct C-C Bonds (Novel Lecture). Angew. Chem. Int. Ed. 2011; Surry, D.; Buchwald, S.L. Dialkylbiaryl Phosphines in Pd-Catalyzed Amination: a User's Guide. Chem. Sci., 2011, 2, 27

6 Garrett, C.E.; Prasad, K. The Art of Meeting Palladium Specifications in Active Pharmaceutical Ingredients Produced by Pd-Catalyzed Reactions. Adv. Synth. \& Catal. 2004, 346, 889

7 Monex Precious Metals, http://www.monex.com/prods/palladium chart.html, December $28^{\text {th }}, 2015$

8 Zhdankin, V. V.; Yoshimura, A. Advances in Synthetic Applications of Hypervalent lodine Compounds. Chem. Rev. 2016, 116, 3328-3435

9 Yusubov, M., S.; Zhdankin, V. V. , Iodine Catalysis : A Green Alternative to Transition Metals in Organic Chemistry and Technology. Resource-Efficient Technologies, 2015 (1) 49-67

${ }^{10}$ Tremblay, J-F. Facts \& Figures of the Chemical Industry. Chem. Eng. News, 2011, 89 (49), pp 22-24

11 Willgerodt, C.; Einwirkung des Phenyljodidchlorides auf Quecksilberdiphenyl: Darstellung des Diphenylchlorjodes und anderer Korper. Berichte Der Deutschen Chemischen Gesellschaft, 1897, 30, 56-58

12 Beringer, M.; Activation of Manganese Dioxide by Azeotropic Removal of Water. Journal of Organic Chemistry, 1969, 34, 1981

13 a) Mekhman, S.; Yusubov, A; Maskaev, V.; Zhdankin, V.; lodonium Salts in Organic Synthesis. ARKIVOC, 2011, (i), 370-409 b)also see ref. 1

${ }^{14}$ Crivello; Lam. Diaryliodonium Salts: A New Class of Photoinitiators for Cationic Polymerization. Macromolecules, 1977, 10 (6), 1307- 1315.

${ }^{15}$ Kaiho, T., Ed. Iodine Chemistry And Applications; John Wiley \& Sons, Inc.: New York, 2015. 
${ }^{16}$ Moon, B.; Park, J.; Lee, H.; Lee, B.; Kim, S. Routine Production of [(18)f]flumazenil from Iodonium Tosylate Using a Sample Pretreatment Method: a 2.5-year Production Report. Mol. Imaging Biol., 2014, 16 (5), 619.

17 Ochiai, M.; Trans-Influences on Hypervalent Bonding of Aryl $\lambda^{3}$-lodanes: Their Stabilities and Isodesmic Reactions of Benziodoxolones and Benziodazolones. Angewandte Chemie International Edition, 2006, 45 (48), 8203-8206.

${ }^{18}$ Shustorovich, E. Perturbation Theory, 3-Orbital-4-Electron and 4-Orbital-4-Electron Bonding, and the Inductive Effect in Tetrahedral Compounds. J. Am. Chem. Soc., 1978, 100,7513

${ }^{19}$ Barton, D. H. R.; Jaszberenyi J.C.; Lessmann K.; Timar T, Hypervalent lodine in C-C Bond Forming Reactions: A New Reaction of Hypervalent lodine Compounds and Organolithium Reagents. Tetrahedron, 1992, 48,8881.

20 a) Okuyama T.; Takino T.; Sueda T.; Ochiai M.; Solvolysis of Cyclohexenyliodonium Salt, a New Precursor for the Vinyl Cation: Remarkable Nucleofugality of the Phenyliodonio Group and Evidence for Internal Return from an Intimate Ion-Molecule Pair. J. Am.

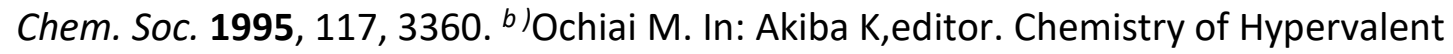
Compounds: Organic Synthesis Using Hypervalent Organiiodines. NewYork: WileyVCH; 1999. p 359.

21 a)Shi, W.-M.; Ma, X.-P.; Pan, C.-X.; Su, G.-F.; Mo, D.-L. Tandem C-O and C-N Bonds Formation Through O-Arylation and [3,3]-Rearrangement by Diaryliodonium Salts: Synthesis of N-Aryl Benzo[1,2,3]triazin-4(1H)-one Derivatives. J. Org. Chem. 2015, 80, $11175-11183 .{ }^{b)}$ Gonda, Z.; Novák, Z. Transition-Metal-Free N-Arylation of Pyrazoles with Diaryliodonium Salts. Chem. Eur. J. 2015, 21, $16801-16806 .{ }^{c)}$ Ma, X.-P.; Shi, W.M.; Mo, X.-L.; Li, X.-H.; Li, L.-G.; Pan, C.-X.; Chen, B.; Su, G.-F.; Mo, D.-L. Synthesis of $\alpha, \beta$-Unsaturated $\mathrm{N}$-Aryl Ketonitrones from Oximes and Diaryliodonium Salts: Observation of a Metal-Free N-Arylation Process. J. Org. Chem. 2015, 80, 10098 10107. ${ }^{\text {d) }}$ Dey, C.; Lindstedt, E.; Olofsson, B. Metal-Free C-Arylation of Nitro Compounds with Diaryliodonium Salts. Org. Lett. 2015, 17, 4554 - 4557.e) Xiong, W.; Qi, C.; Peng, Y.; Guo, T.; Zhang, M.; Jiang, H. Base-Promoted Coupling of Carbon Dioxide, Amines, and Diaryliodonium Salts: A Phosgene- and Metal-Free Route to O-Aryl Carbamates. Chem. Eur. J. 2015, 21, 14314 - 14318. f) Miralles, N.; Romero, R. M.; ernández, E.; Muñiz, K. A Mild Carbon-Boron Bond Formation from Diaryliodonium Salts. Chem. Commun. 2015, 51, 14068 - 14071. g) Matsuzaki, K.; Okuyama, K.; Tokunaga, E.; Saito, N.; Shiro, M.; Shibata, N. Synthesis of Diaryliodonium Salts Having Pentafluorosulfanylarenes and Their Application to Electrophilic Pentafluorosulfanylarylation of C-, O-, N-, and S-Nucleophiles. Org. Lett. 2015, 17, 3038 - 3041. h) Sundalam, S. K.; Stuart, D. R. Base Mediated Synthesis of Alkyl-aryl Ethers from the Reaction of Aliphatic Alcohols and Unsymmetric Diaryliodonium Salts. J. Org. Chem. 2015, 80, 6456-6466. 
i) Tinnis, F.; Stridfeldt, E.; Lundberg, H.; Adolfsson, H.; Olofsson, B. Metal-Free NArylation of Secondary Amides at Room Temperature. Org. Lett. 2015, 17, $2688-$ 2691. j) Hu, B.; Miller, W. H.; Neumann, K. D.; Linstad, E. J.; DiMagno, S. G. An Alternative to the Sandmeyer Approach to Aryl lodides. Chem. Eur. J. 2015, 21, 6394 6398. ${ }^{k}$ ) Margraf, N.; Manolikakes, G. One-Pot Synthesis of Aryl Sulfones from Organometallic Reagents and lodonium Salts. J. Org. Chem. 2015, 80, 2582 - 2600. ') Monastryrski, A.; Namelikonda, N. K.; Manetsch, R. Metal-Free Arylation of Ethyl Acetoacetate with Hypervalent Diaryliodonium Salts: An Immediate Access to Diverse 3-Aryl-4(1H)-Quinolones. J. Org. Chem. 2015, 80, 2513-2520. k) For an example where the TMB group is the transferring aryl group through a proposed radical mechanism, see: Yamaoka, N.; Sumida, K.; Itani, I.; Kubo, H.; Ohnishi, Y.; Sekiguchi, S.; Dohi, T.; Kita, Y. Metal-Free C-H Cross-Coupling toward Oxygenated NaphthaleneBenzene Linked Biaryls. Chem. Eur. J. 2013, 19, $15004-15011$.

22 Magalhaes, H.; Luthi, H. P.; Togni, A. Reductive Eliminations from $\lambda^{3}$-lodanes: Understanding Selectivity and the Crucial Role of the Hypervalent Bond. Org. Lett., 2012,14,3830

${ }^{23}$ Lancer, K. M., Wiegand, G. H.; The Ortho Effect in the Pyrolysis of Iodonium Halides. A Case for a. Sterically Controlled Nucleophilic Aromatic (SN) Substitution Reaction. J. Org. Chem. 1076, 41, 3360

${ }^{24}$ Malmgren, J.; Santoro, S.; Jalalian, N.; Himo, F.; Olofsson, B. Arylation with Unsymmetrical Diaryliodonium Salts: A Chemoselectivity Study. Chem. Eur. J. 2013, 19, $10334-10342$

25 a) Chun, J. H.; Lu, S.; Lee, Y. S.; Pike, V. W. Fast and High-yield Micro-reactor Syntheses of Ortho-substituted [ $\left.{ }^{18} \mathrm{~F}\right]$ Fluoroarenes from Reactions of $\left[{ }^{18} \mathrm{~F}\right] \mathrm{Fluoride}$ Ion with Diaryliodonium Salts. J. Org. Chem. 2010, 75, 3332 - 3338; b) Shah, A.; Pike, V. W.; Widdowson, D. A. The synthesis of $\left[{ }^{18} \mathrm{~F}\right]$ fluoroarenes from the reaction of cyclotronproduced $\left[{ }^{18} \mathrm{~F}\right]$ fluoride ion with diaryliodonium salts. J. Chem. Soc. Perkin Trans. 1 1998, $2043-2046$.

${ }^{26}$ Bromme, T.; Oprych, D.; Horst, J.; Pinto, P. S.; Strehmel, B.; New iodonium salts in NIR sensitized radical photopolymerization of multifunctional monomers. RSC Adv., 2015, 5,69915

27 a Tohma, H.; Morioka, H.; Harayama, Y.; Hashizume, M.; Kita, Y. Novel and Efficient Synthesis of $p$-Quinones in Water via Oxidative Demethylation of Phenol Ethers using

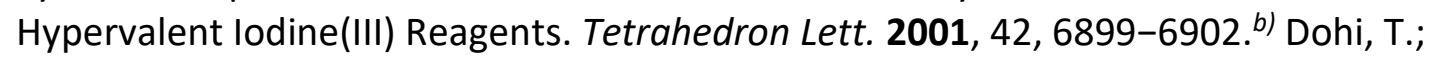
Yamaoka, N.; Kita, Y. Hypervalent lodine in Organic Synthesis. Tetrahedron 2010, 66,

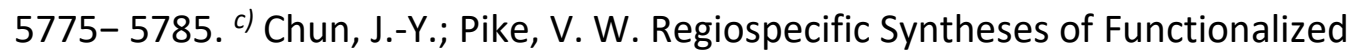
Diaryliodonium Tosylates via [Hydroxy(tosyloxy)iodo] arenes Generated in Situ from (Diacetoxyiodo)arenes. J. Org. Chem. 2012, 77, 1931-1938. 
d) Malmgren, J.; Santoro, S.; Jalalian, N.; Himo, F.; Olofsson, B. C-2 Selective Arylation of Indoles with Heterogeneous Nanopalladium and Diaryliodonium Salts. Chem. - Eur. J. 2013, 19, 10334-10342. e) Chun, J.-H.; Pike, V. W. Single-step syntheses of nocarrier-added functionalized $\left[{ }^{18} \mathrm{~F}\right]$ fluoroarenes as labeling synthons from diaryliodonium salts. Org. Biomol. Chem. 2013, 11, 6300-6306.

${ }^{28}$ Merritt, E. A.; Carneiro, V. M. T.; Silva, L. F. Jr.; Olofsson, B. Facile Synthesis of Koser's Reagent and Derivatives from lodine or Aryl lodides. J. Org. Chem. 2010, 75, 7416.

${ }^{29}$ Chun, J.-H.; Pike, V. W. Regiospecific Syntheses of Functionalized Diaryliodonium Tosylates via [Hydroxy(tosyloxy)iodo]arenes Generated in Situ from (Diacetoxyiodo)arenes. J. Org. Chem. 2012, 77, 1931.

30 Jalalian, N.; Olofsson, B. Synthesis of Koser's Reagent and Derivatives. Org Synth. 2013, 90, 1.

${ }^{31}$ Analytical Methods Committee, AMCTB No 55 Anal. Methods, 2013, 5, 1901

32 Box, G., Hunter, William Gordon, \& Hunter, J. Stuart. (1978). Statistics for experimenters : An introduction to design, data analysis, and model building (Wiley series in probability and mathematical statistics). New York: Wiley.

${ }^{33}$ Mizar, P.; Laverny, A.; El-Sherbini, M.; Farid, U.; Brown, M.; Malmedy, F.; Wirth, T. Enantioselective Diamination with Novel Chiral Hypervalent lodine Catalysts. Chem. Eur. J. 2014, 20, $9910-9913$

${ }^{34}$ Francke, R.; Little, D. Redox catalysis in organic electrosynthesis: basic principles and recent developments. Chem. Soc. Rev., 2014,43, 2492

${ }^{35}$ Kajiyama, D.; Saitoh, T.; Nishiyama, S. Application of Electrochemically Generated Hypervalent lodine Oxidant to Natural Products Synthesis. Electrochemistry, 2013, 81, 319 - 324

${ }^{36}$ See references section of Supporting Information for Chapter 3: Section 5.3.11.1

37 Hoefler, D.; van Gemmeren, M.; Wedemann, P.; Kaupmees, K.; Leito, I.; Leutzsch, M.; Lingnau, J. B.; List, B. 1,1,3,3-Tetratriflylpropene (TTP): A Strong, Allylic C-H Acid for Brønsted and Lewis Acid Catalysis. Angew. Chem. Int. Ed. 2017, 56, 1411

38 Org. Lett., 2013, Vol. 15, No. 1,

39 a) Mao, S.; Geng, X.; Yang, Y.; Qian, X.; Wu, S.; Han, J.; Wang, L. Base promoted direct C4-arylation of 4-substituted-pyrazolin-5-ones with diaryliodonium salts. RSC Adv., 2015, 5, $36390^{\text {b) }}$ Ghosh, R.; Stridfeldt, E.; Olofsson, B. Metal-Free One-Pot Synthesis of Benzofurans. Chem. Eur. J. 2014, 20, 8888

${ }^{40}$ For early work of aryl-azide coupling with diaryliodonium salts, see: J. J. Lubinkowski, M. Gomez, J. L. Calderon, W. E. McEwen Reactions of Diaryliodonium Fluoroborates with Inorganic Anions. J. Org. Chem. 1978, 43, 2432

${ }^{41}$ For other recent methods to aryl azides, see: (a) L. G. Prieto, M. J. L. Fiego, A. B. Chopa, M. T. Lockhart A reliable one-pot synthesis of aryl azides from aryl amines using organotin azides as effective and recoverable reagents. J. Organomet. Chem. 2017, 830, 26. 
(b) F. Zhao, Z. Chen, P. Lei, L. Kong, Y. Jiang. Facile one-pot synthesis of aryl azides from nitrobenzenes. Tetrahedron Lett. 2015, 56, 2197. (c) Y. Li, L.-X. Gao, F.-S. Han Reliable and Diverse Synthesis of Aryl Azides through Copper-Catalyzed Coupling of Boronic Acids or Esters with $\mathrm{TMSN}_{3}$. Chem. Eur. J. 2010, 16, 7969.

42 (a) F. M. Beringer, S. A. Galton, S. J. Huang Diaryliodonium Salts. XVII. The Phenylation of 1,3-Indandiones. J. Am. Chem. Soc. 1962, 84, 2819. (b) N. Miralles, R. M. Romero, E. Fernandez, K. Muñiz. A Mild Carbon-Boron Bond Formation from Diaryliodonium Salts. Chem. Commun. 2015, 51, 14068. (c) T. B. Petersen, R. Khan, B. Olofsson. Metal-Free Synthesis of Aryl Esters from Carboxylic Acids and Diaryliodonium Salts. Org. Lett. 2011, 13, 3462. (d) N. Jalalian, T. B. Petersen, B. Olofsson. Metal-Free Arylation of Oxygen Nucleophiles with Diaryliodonium Salts. Chem. Eur. J. 2012, 18, 14140.

${ }^{43}$ Carlson, R.; Lundstedt, T.; Albano, C. Screening of Suitable Solvents in Organic Synthesis: Strategies for Solvent Selection. Acta Chem. Scand. B, 1985, 39, 79

${ }^{44}$ N. Jalalian, B. Olofsson, Synthesis of Koser's Reagent and Derivatives. Org. Syn. 2013, 90, 1 - 9 .

${ }^{45}$ T. Seidl, S. Sundalam, B. McCullough, D. Stuart, Unsymmetrical Aryl(2,4,6trimethoxyphenyl)iodonium Salts: One-Pot Synthesis, Scope, Stability, and Synthetic Studies. J. Org. Chem., 2016, 81, 1998-2009

${ }^{46}$ V. Carreras, A. H. Sandtorv, D. R. Stuart, Synthesis of Aryl(2,4,6trimethoxyphenyl)iodonium Trifluoroacetate Salts. J. Org. Chem., 2017, 82, 1279

${ }^{47}$ T. Dohi, M. Ito, K. Morimoto, Y. Minamitsuji, N. Takenaga, Y. Kita, Versatile direct dehydrative approach for diaryliodonium(III) salts in fluoroalcohol media. Chem. Commun., 2007, 4152

48 Uldry, A.-C.; Griffin, J. M.; Yates, J. R.; Pérez-Torralba, M.; Santa Maria, M. D.; Webber, A. L.; Beaumont, M. L. L.; Samoson, A.; Claramunt, R. M.; Pickard, C. J.; Brown, S. P. Quantifying Weak Hydrogen Bonding in Uracil and 4-Cyano-4'-ethynylbiphenyl: A Combined Computational and Experimental Investigation of NMR Chemical Shifts in the Solid State. J. Am. Chem. Soc. 2008, 130, 945

${ }^{49}$ Park, K. D.; Morieux, P.; Solomé, C.; Cotton, S. W.; Reamtong, O.; Eyers, C.; Gaskell, S. J.; Stables, J. P.; Liu, R.; Kohn, H. Lacosamide Isothiocyanate-Based Agents: Novel Agents to Target and Identify Lacosamide Receptors. J. Med. Chem. 2009, 52, 68976911.

${ }^{50}$ Sundalam, S.; Stuart, D. R. Base Mediated Synthesis of Alkyl-aryl Ethers from the Reaction of Aliphatic Alcohols and Unsymmetric Diaryliodonium Salts. J. Org. Chem. 2015, 80, 6456-6466.

51 Mert, H.; Dinçer, H.; Çaliş̧an, E.; Şen, B. N.; Gürsel, Y. H. Preparation of a New Polymer-Dispersed Liquid Crystal Film by Using Phthalocyanine-Functional Photocurable Copolymer. J. Appl. Polym. Sci. 2015 
${ }^{52}$ Oh, C. H.; Kim, J. S.; Jung, H. H. Highly Efficient Arylation of Malonates with Diaryliodonium Salts. J. Org. Chem. 1999, 64, 1338- 1340.

53 Umierski, N.; Manolikakes, G. Metal-Free Synthesis of Diaryl Sulfones from Arylsulfinic Acid Salts and Diaryliodonium Salts. Org. Lett. 2013, 15, 188 - 191.

54 Jalalian, N.; Ishikawa, E. E.; Silva, L. F. Jr.; Olofsson, B. Room Temperature, Metal-Free Synthesis of Diaryl Ethers with Use of Diaryliodonium Salts. Org. Lett. 2011, 13, 1552 1555.

55 L. Barr, S. Lincoln, C. Easton, A Cyclodextrin Molecular Reactor for the Regioselective Synthesis of 1,5-disubstituted-1,2,3-triazoles. Supramolec. Chem., 2005, 17, 547-555

${ }^{56}$ H. Yang, Y. Li, M. Jiang, J. Wang, H. Fu. General Copper-Catalyzed Transformations of Functional Groups from Arylboronic Acids in Water. Chem. Eur. J. 2011, 17, 5652-5660

${ }^{57}$ D. Brems, H. Rilling. Photoaffinity Labeling of the Catalytic Site of Prenyltransferase. Biochemistry, 1979, 18, 860-864

${ }^{58}$ L. Ackermann, M. Dell'Acqua, S. Fenner, R. Vicente, R. Sandmann, Metal-Free Direct Arylations of Indoles and Pyrroles with Diaryliodonium Salts. Org. Lett., 2011, 13, 2358

${ }^{59}$ F. Guo, L. Wang, P. Wang, J. Yu, J. Han, Transition-Metal-Free N-Arylation of Carbazoles and C-Arylation of Tetrahydrocarbazoles by using Diaryliodonium Salts. Asian J. Org. Chem. 2012, 1, 218

60 D. Kumar, V. Arun, M. Pilania, K. P. Chandra Shekar, A Metal-Free and MicrowaveAssisted Efficient Synthesis of Diaryl Sulfones. Synlett, 2013, 24, 831

${ }^{61}$ N. Umierski, G. Manolikakes, Arylation of Lithium Sulfinates with Diaryliodonium Salts: A Direct and Versatile Access to Arylsulfones. Org. Lett., 2013, 15, 4972

${ }^{62}$ E. Lindstedt, R. Ghosh, B. Olofsson, Metal-Free Synthesis of Aryl Ethers in Water. Org. Lett., 2013, 15, 6070

${ }^{63}$ D. Wang, X. Yu, K. Zhao, L. Li, Y. Ding, Rapid synthesis of aryl sulfides through metalfree C-S coupling of thioalcohols with diaryliodonium salts. Tetrahedron Letters, 2014, 55,5739

${ }^{64}$ P. Thorat, N. Waghmode, N. Karade, Direct metal-free O-arylation of Biginelli 4-aryl-6methyl-pyrimidine-2(1H)-one derivatives using diaryliodonium salts. Tetrahedron Letters, 2014, 55, 5718

${ }^{65}$ H. Gao, Q. Xu, C. Keene, L. Kurti, Scalable, Transition-Metal-Free Direct Oxime OArylation: Rapid Access to O-Arylhydroxylamines and Substituted Benzo[b]furans. Chem. Eur. J., 2014, 20, 8883

${ }^{66}$ R. Ghosh, E. Lindstedt, N. Jalalian, B. Olofsson, Room Temperature, Metal-Free Arylation of Aliphatic Alcohols. Chemistry Open 2014, 3, 54

${ }^{67}$ R. Ghosh, B. Olofsson, Metal-Free Synthesis of N-Aryloxyimides and Aryloxyamines. Org. Lett. 2014, 16, 1830

${ }^{68}$ A. M. Wagner, M. S. Sanford, Transition-Metal-Free Acid-Mediated Synthesis of Aryl Sulfides from Thiols and Thioethers. J. Org. Chem., 2014, 79, 2263 
${ }^{69}$ K. Miyagi, K. Moriyama, H. Togo, One-Pot Preparation of 2-Arylbenzofurans from Oximes with Diaryliodonium Triflate. Heterocycles, 2014, 89

${ }^{70}$ Y. Yang, X. Wu, J. Han, S. Mao, X. Qian, L. Wang. Cesium Carbonate Promoted Direct Arylation of Hydroxylamines and Oximes with Diaryliodonium Salts. Eur. J. Org. Chem., 2014, 6854

${ }^{71}$ T. Huang, X. Ji, W. Wu, F. Liang, S. Cao, Metal-free one-pot sequential direct diarylation of pyrazolin-5-ones with diaryliodonium salts. RSC Adv., 2015, 5, 66598

${ }^{72}$ F. Liu, H. Yang, X. Hu, G. Jiang, Metal-Free Synthesis of ortho-CHO Diaryl Ethers by a Three-Component Sequential Coupling. Org. Lett., 2014, 16, 6408

${ }^{73}$ P. Li, Y. Weng, X. Xu, X. Cui, Access to Indole Derivatives from Diaryliodonium Salts and 2-Alkynylanilines. J. Org. Chem., 2016, 81, 3994

${ }^{74}$ X. Zhou, Q. Wu, Y. Yu, C. Yu, E. Hao, Y. Wei, X. Mu, L. Jiao, Metal-Free Direct $\alpha-$ Selective Arylation of Boron Dipyrromethenes via Base-Mediated $\mathrm{C}-\mathrm{H}$ Functionalization. Org. Lett., 2016, 18, 736

${ }^{75}$ M. K. Mehra, M. P. Tantak, I. Kumar, D. Kumar, Microwave-Assisted Metal- and Ligand-Free O-Arylation of Quinolones Using Diaryliodonium Salts: An Easy and Rapid Synthesis of Aryloxyquinolines. Synlett, 2016, 27, 604

${ }^{76}$ X. Li, W. Ni, F. Mao, W. Wang, J. Li, A Metal-free Approach to 3-Aryl-3-hydroxy-2oxindoles by Treatment of 3-Acyloxy-2-oxindoles with Diaryliodonium Salts. Chem. Asian J., 2016, 11, 226

77 Z. Wang, W. Shi, H. Bi, X. Li, G. Su, D. Mo, Synthesis of N-(2-Hydroxyaryl)benzotriazoles via Metal-Free O-Arylation and N-O Bond Cleavage. J. Org. Chem., 2016, 81, 8014

${ }^{78}$ E. Lindstedt, E. Stridfelt, B. Olofsson, Mild Synthesis of Sterically Congested Alkyl Aryl Ethers. Org. Lett., 2016, 18, 4234

79 T. Sasaki, K. Miyagi, K. Moriyama, H. Togo, Direct Preparation of 3-lodochromenes from 3-Aryl- and 3-Alkyl-2-propyn-1-ols with Diaryliodonium Salts and NIS. Org. Lett., 2016, 18, 944

${ }^{80}$ X. Qian, J. Han, L. Wang, tert-Butoxide-Mediated Arylation of 2-Substituted Cyanoacetates with Diaryliodonium Salts. Adv. Synth. Catal., 2016, 358, 940

${ }^{81}$ D. Wang, C. Ge, X. Yu, H. Wan, X. Xu, Highly Site-Selective Metal-Free C-H Acyloxylation of Stable Enamines. Synlett, 2016, 27, A-E

$82 \mathrm{~J}$. Li, X. Zheng, W. Li, W. Zhou, W. Zhu, Y. Zhang, Transition-metal free N-arylation of cyanamides by diaryliodonium triflates in aqueous media. New J. Chem., 2016, 40, 77 